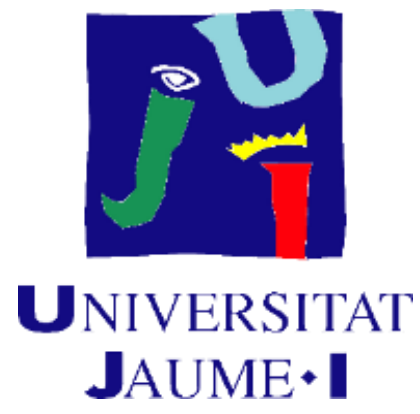

Programa de Doctorat en Ciències

Escola de Doctorat de la Universitat Jaume I

\title{
NANOMATERIALES BASADOS EN HIDROXIAPATITA PARA LA CONSERVACIÓN DEL PATRIMONIO CULTURAL EN SOPORTE PÉTREO Y PINTURA MURAL
}

Memòria presentada per Livio Ferrazza per optar al grau de doctor per la Universitat Jaume I.

Doctorando

Livio Ferrazza
Directors de la tesi

Dra. Eloisa Cordoncillo Cordoncillo 



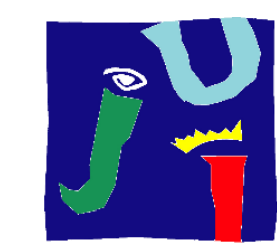

UNIVERSITAT

JAUME•I

Programa de Doctorat en Ciències

Escola de Doctorat de la Universitat Jaume I

Eloisa Cordoncillo Cordoncillo, Catedrática de Química Inorgánica de la Universitat Jaume I y Héctor Beltrán Mir, Profesor titular de Química Inorgánica de la Universitat Jaume I

Certifican: Que D. Livio Ferrazza ha realizado bajo su dirección en los laboratorios de Química Inorgánica del Departamento de Química Inorgánica y Orgánica de la Escuela Superior de Tecnología y Ciencias Experimentales de la Universitat Jaume I de Castellón, el trabajo que bajo el título "NANOMATERIALES BASADOS EN HIDROXIAPATITA PARA LA CONSERVACIÓN DEL PATRIMONIO CULTURAL EN SOPORTE PÉTREO Y PINTURA MURAL” presenta esta memoria que constituye su tesis para optar al grado de Doctor.

Y para que conste a los efectos oportunos, firmamos el presente certificado en Castellón de la Plana a 22 de diciembre de 2017.

Fdo. Eloisa Cordoncillo Cordoncillo

Fdo. Héctor Beltrán Mir 



\section{Agradecimientos}

Que estas palabras valgan para expresar mi agradecimiento a todas las personas que en estos últimos años me han dado su apoyo y colaboración en este proceso de aprendizaje.

En primer lugar a la Dra. Eloisa Cordoncillo Cordoncillo y al Dr. Héctor Beltrán Mir, directores de esta tesis, por su guía, consejos y dedicación a lo largo de estos años. Sin duda sus sugerencias y comentarios han hecho mejorar mi formación tanto académica como investigadora.

Agradecer a la Dra. Gemma $\mathrm{M}^{\mathrm{a}}$ Contreras Zamorano, Subdirectora del Instituto Valenciano de Conservación, Restauración e Investigación (IVCR+i), el haberme dado la oportunidad de integrarme desde muchos años en su grupo de trabajo y poder disponer de los equipos e instalaciones del Laboratorio de Materiales del IVCR+i. Asimismo, agradecer a los Dres. David Juanes Barber y $\mathrm{M}^{\mathrm{a}}$ Teresa Pastor Vall, por su apoyo y consejos. Y agradecer especialmente al Dr. Thales Rafael Machado por su imprescindible colaboración y consejos en la parte del trabajo experimental de esta tesis.

También me gustaría agradecer su apoyo a todos los compañeros actuales y pasados del Grupo de Química del Estado Sólido de la UJI, en especial a Iván, Olga, Michelle, Marc, Ricardo, Ester.

Quiero mostrar igualmente mi agradecimiento a Luis Solano Fernández-Clemente, por confiar en mí en el

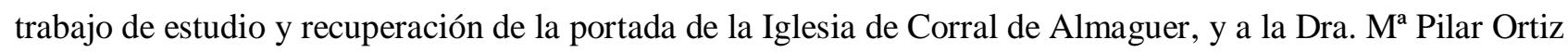
Calderón de la Universidad Pablo de Olavide por sus valiosos consejos.

Finalmente, y no por estos menos importantes, quiero agradecer de forma muy especial por la paciencia y comprensión mostrada en estos años, a Andrés y a mi familia, porque si no fuese por ellos, a buen seguro no estaría escribiendo estas palabras.

A todos gracias de corazón. 



\section{ABREVIATURAS Y SÍMBOLOS}

\section{Abreviaturas y símbolos (Mayúsculo)}

A

AENOR

ATR

BSE

CA

CIE

$D$

DAP

DCP

DCPD

EBSD

EDX

XRD

FTIR

HA

HCT

K

HR

HR-SEM

HR-TEM

ICDD

IR

JCPDS

$\mathrm{L}^{*}$

$\mathrm{M}$

MCPM

ME

MO

OCP

$P 2 / b$

$\mathrm{PC}_{3} / \mathrm{m}$
Área superficial

Asociación Española de Normalización y Certificación

Reflectancia total atenuada

Electrones retrodispersados

Coeficiente de absorción capilar

Comisión internacional de la iluminación

Coeficiente de difusión del vapor de agua

Hidrogenofosfato amónico

Hidrogenofosfato cálcico

Hidrogenofosfato cálcico dihidratado

Difracción de electrones por retrodispersión

Espectrometría por dispersión de energías de rayos $\mathrm{X}$

Difracción de rayos $\mathrm{X}$

Espectroscopía infrarroja por transformada de Fourier

Hidroxiapatita

Hidrocarburos totales

Constante de solubilidad

Humedad relativa

Microscopia electrónica de barrido de alta resolución

Microscopia electrónica de transmisión de alta resolución

The International Centre for Diffraction Data

Infrarrojo

Joint Committee on Powder Diffraction Standards

Valor de luminosidad

Línea media

Fosfato monocálcico monohidratado

Microscopia estereoscópica

Microscopia óptica

Fosfato octacálcico

Grupo espacial de la hidroxiapatita monoclínica

Grupo espacial de la hidroxiapatita hexagonal 


$\begin{array}{cl}\mathrm{Q}_{\mathrm{i}} & \text { Cantidad de agua absorbida por unidad de superficie por tiempo } \\ \mathrm{R}_{A} & \text { Resistencia a la difusión del vapor de agua } \\ \mathrm{Ra} & \text { Valor promedio de rugosidad } \\ \mathrm{Rp} & \text { Pico máximo del perfil de rugosidad } \\ \mathrm{R}_{D} & \text { Constante de gas del vapor de agua } \\ \mathrm{Rv} & \text { Pico máximo más profundo del perfil de rugosidad } \\ \mathrm{Rz} & \text { Altura máxima del perfil de rugosidad } \\ \mathrm{SAED} & \text { Difracción de electrones de área seleccionada } \\ \mathrm{SEM} & \text { Microscopia electronica de barrido } \\ \mathrm{TCP} & \text { Fosfato tricálcico } \\ \text { TEOS } & \text { Tetraetilortosilicato } \\ \text { TTCP } & \text { Fosfato tetracálcico } \\ \text { UNE } & \text { Asociación Española de Normalización } \\ \text { UNI } & \text { Ente Nacional italiano de Unificación } \\ \mathrm{UV} & \text { Ultravioleta } \\ \text { VP-SEM } & \text { Microscopia electronica de barrido a pressión variable } \\ \text { WDD } & \text { Grado de transmisión del vapor de agua }\end{array}$

\section{Símbolos alfabeto griego}

$2 \theta$

$\Delta \mathrm{a}^{*}$

$\Delta \mathrm{b}^{*}$

$\Delta \mathrm{E}^{*}$

$\Delta G / \Delta t$

$\Delta \mathrm{L}^{*}$

$\Delta M$

$\Delta_{p}$

$\Lambda$

$\delta_{L}$

$\mu$

$\lambda$

$v_{\mathrm{n}}$
Angulo de Bragg

Diferencia en rojo/verde

Diferencia en amarillo/azul

Diferencia de color

Flujo del vapor de agua

Diferencia de los valores de luminosidad

Valor medio de la variación de peso

Diferencia de tensión del vapor de agua

Permanencia al vapor de agua

Coeficiente de difusión del vapor de agua en el aire

Factor de resistencia al vapor de agua

Longitud de onda

Modo vibracional 


\section{RESUMEN}

Los nanomateriales están adquiriendo, en la última década, una importante repercusión en el sector de la conservación y restauración del Patrimonio Cultural debido a las nuevas posibilidades que ofrecen estos materiales en los tratamientos de consolidación y protección de superficies pétreas o decoraciones parietales. Los nanomateriales, basados en compuestos inorgánicos tales como hidróxido de calcio e silicio coloidal, son los más estudiados y destacan por sus potenciales aplicaciones, y es por ello que muchas investigaciones se centran en el estudio y desarrollo de estos materiales. La presente tesis doctoral tiene como objetivo la preparación de nanopartículas con estequiometría de hidroxiapatita pura $\mathrm{Ca}_{10}\left(\mathrm{PO}_{4}\right)_{6}(\mathrm{OH})_{2}$ y la evaluación de las mismas en los tratamientos de consolidación y protección en soporte pétreo y pintura mural. Este trabajo multidisciplinar se desarrolla en dos campos de investigación complementarios: los nanomateriales, al centrarse en la preparación y caracterización de partículas de hidroxiapatita con un tamaño del orden de nanómetros, cuyas características estructurales y morfológicas vienen modificadas químicamente, y la otra parte relativa a la conservación de bienes culturales al focalizar la aplicación de estos materiales en los tratamiento de restauración tales como la consolidación y protección de obras en soporte pétreo y pintura mural.

La hidroxiapatita presenta una elevada compatibilidad química con la naturaleza mineralógica de los constituyentes presentes en los sustratos pétreos y la pintura mural compuestos básicamente por carbonato de calcio o carbonato de calcio y magnesio. Con el fin de introducir esta nueva clase de materiales en los tratamientos de restauración, la presente tesis doctoral se encamina a preparar una serie de materiales a base de hidroxiapatita caracterizados por nanopartículas de diferente morfología y cristalinidad, y el estudio de como influyen estos parámetros en la acción consolidante y protectora en piedra y pintura mural, incluyendo además un estudio inicial sobre la aplicabilidad de las partículas en materiales de origen paleontológico como marfil y hueso.

En los primeros capítulos de la presente tesis se revisan conceptos generales relacionados con la conservación de bienes culturales en soporte pétreo y decoraciones parietales, donde se describe esta tipología de bienes tales como los materiales constitutivos, técnicas de ejecución y los mecanismos de alteración que los afectan. También se ofrece una revisión de los tratamientos de restauración existentes tales como la consolidación y la protección necesarios para restablecer las propiedades físicas y mecánicas de los materiales alterados, así como de los productos consolidantes y protectores utilizados en los tratamientos de restauración y sus limitaciones. Asimismo se detalla la síntesis de la hidroxiapatita y se describen las diferentes propiedades de estos materiales, objeto de una intensa investigación científica por la amplia variedad de aplicaciones potenciales en diferentes campos donde destaca la aplicación biomédica. 
En los capítulos de la parte experimental se describe el procedimiento de síntesis utilizado, la caracterización estructural y microestructural de las muestras obtenidas y la adecuación y caracterización de las probetas de soporte pétreo y de los fragmentos de pintura mural. Las etapas anteriores son necesarias para llevar a cabo el estudio de evaluación de aplicabilidad así como de la acción consolidante y protectora de los materiales preparados. En cuanto a la respuesta de la hidroxiapatita en los tratamientos de restauración, aquellas que presentan una mayor cristalinidad alcanzan una buena acción de consolidación y protección en piedra y pintura mural, con un excelente grado de penetración en los poros de los materiales tratados. En resumen los trabajos descritos en la presente tesis demuestran que las nanopartículas de hidroxiapatita de alta cristalinidad, tienen aplicabilidad y acción consolidante y protectora para piedra y pintura mural. Por otra parte, estas mismas partículas ofrecen una respuesta menos prometedora en otros soportes de menor porosidad tales como marfil o hueso.

Esta investigación ha ido dirigida también a desarrollar una metodología accesible para instituciones, profesionales, etc., mediante un trabajo normalizado donde es posible mediante la microscopia electrónica de barrido a presión variable (VP-SEM), microanálisis EDX, espectroscopia infrarroja por transformada de Fourier (FTIR), medida de las coordenadas colorimétricas o de absorción de agua por capilaridad, determinar los cambios químicos, físicos y ópticos que se producen en los materiales con los tratamientos de consolidación y protección. 


\section{ABSTRACT}

In the last decade, nanomaterials are acquiring an important impact in the sector of conservation and restoration of Cultural Heritage due to the new possibilities offered by these materials in the consolidation and protection treatments of stone surfaces or wall painting. Nanomaterials, based on inorganic compounds such as calcium hydroxide and colloidal silicon, are the most studied and stand out for their potential applications, and that is why many investigations focus on the study and development of these materials. The objective of this doctoral thesis is the preparation of nanoparticles with pure hydroxyapatite stoichiometry $\mathrm{Ca}_{10}\left(\mathrm{PO}_{4}\right)_{6}(\mathrm{OH})_{2}$ and the evaluation of these materials in consolidation and protection treatments in stone support and wall painting. This multidisciplinary work is developed in two complementary areas of research: nanomaterials, focusing on the preparation and characterization of hydroxyapatite particles with a size of the order of nanometers, whose structural and morphological characteristics are chemically modified. The second part is related to the conservation of cultural assets by focusing the application of these materials on restoration treatments such as the consolidation and protection in stone support and mural painting.

Hydroxyapatite has a high chemical compatibility with the mineralogical nature of the constituents present in stony substrates and wall painting, basically composed of calcium carbonate or calcium and magnesium carbonate. In order to introduce this new class of materials in restoration treatments, this doctoral thesis is aimed at preparing a series of materials based on hydroxyapatite characterized by nanoparticles of different morphology and crystallinity, and the study of how these parameters influence the consolidating and protective action in stone and wall painting, including an initial study on the applicability of particles in materials of paleontological origin such as ivory and bone.

In the first chapters of this thesis, general concepts related to the conservation of cultural assets in stone support and parietal decorations are reviewed. The constituent materials, the execution techniques and the alteration mechanisms that affect these cultural heritages are described. It also offers a review of the existing restoration treatments such as the consolidation and protection needed to restore the physical and mechanical properties of the altered materials, as well as the consolidating and protective products used in the restoration treatments and their limitations. Also, the synthesis of hydroxyapatite is detailed and the different properties of these materials are described, the subject of an intense scientific investigation due to the wide variety of potential applications in different fields where biomedical application stands out.

In the experimental section, the synthesis procedure used, the structural and microstructural characterization of the samples obtained and the adequacy and characterization of stone support samples and fragments of wall painting are described. The previous stages are necessary to carry out the applicability evaluation study as well as the consolidating and protective action of the prepared materials. Regarding the response of 
hydroxyapatite in restoration treatments, the samples with a higher crystallinity achieve a good consolidation and protection action in stone and wall painting, with an excellent penetration in the pores of the treated materials. In summary, the works described in this thesis show that hydroxyapatite nanoparticles of high crystallinity have applicability and consolidating and protective action for stone and wall painting. These same particles offer a less promising response in other substrates of lower porosity such as ivory or bone.

This research has also been aimed at developing an accessible methodology for institutions, professionals, etc., through standardized work where it is possible through variable-pressure scanning electron microscopy (VP-SEM), EDX microanalysis, Fourier transform infrared spectroscopy (FTIR), measurement of the colorimetric coordinates or water absorption by capillarity, determine the chemical, physical and optical changes that occur in the materials with consolidation and protection treatments. 


\section{ÍNDICE}

Organización de los contenidos

$\begin{array}{lr}\text { 1.1. Bienes culturales en soporte pétreo y decoraciones parietales } & 8\end{array}$

$\begin{array}{ll}\text { 1.2. Mecanismos de alteración } & 15\end{array}$

1.3. Los tratamientos de consolidación y protección 26

1.3.1. Propiedades del consolidante 29

1.3.2. Productos consolidantes tradicionales $\quad 31$

1.3.2.1. Consolidantes inorgánicos 32

$\begin{array}{ll}\text { 1.3.2.2. Consolidantes orgánicos } & 34\end{array}$

1.4. Consolidantes nanométricos comerciales 35

1.5. Limitaciones en los tratamientos de consolidación con productos comerciales 39

1.6. Estudios preliminares de tratamientos de consolidación con disoluciones acuosas de 45 hidrogenofosfato amónico sobre piedra

Capítulo 2. Objetivos de la tesis

Capítulo 3. La aplicación científica aplicada al estudio de bienes culturales: 55 Caracterización de materiales, diagnosis del estado de conservación y evaluación de los tratamientos de restauración 

restauración en bienes culturales

Capítulo 4. Aspectos generales de la hidroxiapatita. Estructura y preparación

4.2. Estructura de la hidroxiapatita

4.3.1. Rutas de síntesis por métodos vía seca

4.3.2. Rutas de síntesis por métodos vía húmeda

Capítulo 5. Técnicas instrumentales de caracterización de materiales y de evaluación de los tratamientos de consolidación y protección

5.1. Caracterización de los materiales constituyentes los bienes culturales en soporte pétreo y pintura mural

5.2. Caracterización de las muestras sintetizadas con estequiometría de hidroxiapatita

5.3. Caracterización de probetas y evaluación de los tratamientos de consolidación y protección

5.3.1. Colorimetría

5.3.2. Perfilometría

5.3.2.1. Parámetros de rugosidad

5.3.3. Absorción de agua por capilaridad 
Capítulo 6. Caracterización del soporte pétreo de la portada de la Iglesia de Nuestra

Señora de la Asunción de Corral de Almaguer y de los fragmentos de pintura mural de la Casa de Ariadna en Pompeya

$\begin{array}{ll}\text { 6.1. Introducción } & 94\end{array}$

6.2. Portada de la Iglesia de Nuestra Señora de la Asunción de Corral de Almaguer (Toledo) 96

6.2.1. Caracterización del soporte pétreo sin alteración: muestra EP19.2P 100

6.2.2. Caracterización del soporte pétreo alterado: muestras EP19.4P - EP19.5P $\quad 108$

6.3. Las pinturas murales de la Casa de Ariadna en Pompeya (Italia) 113

$\begin{array}{ll}\text { 6.3.1. Caracterización de los materiales constituyentes } & 114\end{array}$

6.3.2. Evaluación del estado de conservación 130

$\begin{array}{lr}\text { 6.4. Conclusiones } & 134\end{array}$

$\begin{array}{ll}\text { Capítulo 7. Procedimiento experimental } & 137\end{array}$

$\begin{array}{ll}\text { 7.1. Síntesis de las muestras con estequiometría de hidroxiapatita } & 138\end{array}$

7.2. Caracterización estructural y microestructural de las muestras preparadas 141

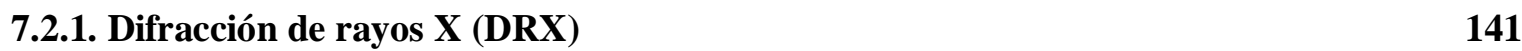

7.2.2. Espectroscopia infrarroja por transformada de Fourier (FTIR) 143

7.2.3. Caracterización microestructural por microscopia electrónica de barrido de $\mathbf{1 4 5}$ alta resolución (HR-SEM)

7.2.4. Caracterización microestructural por microscopia electrónica de transmisión de alta resolución (HR-TEM)

7.3. Caracterización de las probetas de soporte pétreo y pintura mural

7.3.1. Selección de soportes y adecuación

7.3.2. Caracterización de probetas, aplicación de las muestras preparadas y metodología de evaluación de los tratamientos de consolidación y protección 
7.3.2.2. Evaluación de la acción consolidante y de protección de las muestras preparadas

7.4. Conclusiones

Capítulo 8. Evaluación de los tratamientos de consolidación y protección en soporte pétreo

8.1. Introducción

8.2. Evaluación en probetas de soporte pétreo sin alteración

8.2.1. Evaluación del tratamiento con la muestra ACP

8.2.1.1. Evaluación del tratamiento en superficie

8.2.1.2. Evaluación del tratamiento en corte transversal

8.2.1.3. Estudio de espectroscopia infrarroja por transformada de Fourier (FTIR)

8.2.2. Evaluación del tratamiento con hidroxiapatita cristalina: muestra HA1

8.2.2.1. Evaluación del tratamiento en superficie

8.2.2.2. Evaluación del tratamiento en corte transversal

8.2.2.3. Estudio de espectroscopia infrarroja (FTIR)

8.2.3. Evaluación del tratamiento con hidroxiapatita con alta cristalinidad: muestra HA2

8.2.3.1. Evaluación del tratamiento en superficie

8.2.3.2. Evaluación del tratamiento en corte transversal

8.2.3.3. Estudio de espectroscopia infrarroja por transformada de Fourier (FTIR)

8.2.4. Colorimetría 

con microanálisis EDX

8.3.2. Estudio de espectroscopia infrarroja por transformada de Fourier (FTIR)

9.3.1. Evaluación en superficie y en corte transversal de la muestra ACP 
10.3.1. Evaluación de la muestra ACP sobre fragmentos de marfil y hueso

10.3.2. Evaluación de la muestra HA1 sobre fragmentos de marfil y hueso

10.3.3. Evaluación de la muestra HA2 sobre fragmentos de marfil y hueso

10.3.4. Espectroscopia infrarroja por transformada de Fourier (FTIR)

10.3.5. Colorimetría

10.4. Comparación del producto consolidante en uso a base de hidróxido de calcio respecto a 250 las muestras ACP, HA1 y HA2 en fragmentos de marfil y hueso

10.4.1. Evaluación del producto consolidante de hidróxido de calcio en marfil

10.4.2. Evaluación del producto consolidante de hidróxido de calcio en hueso 


\section{Organización de los contenidos}





\section{Organización de los contenidos}

La presente tesis doctoral se estructura en dos secciones, la primera relativa a los fundamentos teóricos, en la que se introducen toda una serie de conceptos básicos necesarios para poder realizar una correcta lectura e interpretación de los resultados expuestos en los capítulos de la segunda parte, referente a la sección experimental y resultados. La tesis se compone de 13 capítulos bien diferenciados donde se exponen los resultados conseguidos durante la realización de la investigación. En Capítulo 1, Fundamentos, se introducen conceptos relativos a la conservación y restauración de bienes de interés cultural en soporte pétreo y decoraciones parietales. Se revisan conceptos generales relacionados con la conservación de bienes culturales en soporte pétreo y decoraciones parietales, donde se describe esta tipología de bienes tales como materiales constitutivos, técnica de ejecución y los mecanismos de alteración que los afectan. También se ofrece una revisión del estado de la cuestión, sobre tratamientos de restauración tales como la consolidación y la protección necesarios para restablecer las propiedades físicas y mecánicas de los materiales alterados, así como de los productos consolidantes y protectores utilizados en los tratamientos de restauración de bienes culturales en piedra y pintura mural y sus limitaciones. Por último, se detallan los antecedentes en el desarrollo de los nuevos nanomateriales y sus aplicaciones en el sector de la restauración de los bienes de interés cultural. El objetivo especifico de la presenta tesis doctoral, así como los objetivos específicos, se detallan en el segundo capítulo. En el Capítulo 3, titulado La aplicación científica aplicada al estudio de bienes culturales: Caracterización de materiales, diagnosis del estado de conservación y evaluación de los tratamientos de restauración, se exponen una serie de conceptos básicos relativos a la importancia de los estudios científicos aplicados al sector de los bienes culturales como herramientas de conocimiento de los materiales constitutivos, de las técnicas de ejecución o de los mecanismos de alteración y degradación que comprometen la futura conservación de la obra. En el Capítulo 4 se presenta, brevemente, una revisión sobre los fosfatos de calcio en general, en la que se describe la estructura cristalina, así como las propiedades y las rutas de síntesis por vía seca y por vía húmeda utilizadas hasta hora para la obtención de estos materiales. Se hace especial hincapié en la descripción de la hidroxiapatita, sus propiedades y aplicaciones, de las metodologías de síntesis para la preparación de polvos amorfos o cristalinos, y los procedimientos utilizados para los tratamientos de consolidación y protección sobre los que versa la tesis. Los aspectos relacionados con los procedimientos de caracterización de los materiales que constituyen los bienes culturales en soporte pétreo y pintura mural, y las técnicas analíticas para el estudio de caracterización química y estructural de las muestras de hidroxiapatita preparadas se describen en el Capítulo 5. En éste se detalla la metodología para la 
preparación tanto de las probetas de soporte pétreo y de pintura mural como de las condiciones experimentales con las que se han aplicado las diferentes técnicas utilizadas para la caracterización y evaluación de la acción consolidante y protectora de los compuestos preparados. Finalmente, la primera parte de la tesis doctoral se concluye con el Capítulo 6 titulado Caracterización del soporte pétreo de la Portada de la Iglesia de Nuestra Señora de la Asunción de Corral de Almaguer y de fragmentos de pintura mural de la Casa de Ariadna en Pompeya, donde se exponen los resultados sobre la caracterización de los materiales constituyentes de los bienes culturales seleccionados para el desarrollo de la investigación de la presente tesis doctoral. Se describe en primer lugar, el estudio de los fragmentos pétreos extraídos de la portada principal de la Iglesia de Nuestra Señora de la Asunción de Corral de Almaguer (Toledo) del siglo XV; y a continuación los resultados obtenidos con diferentes fragmentos de pintura mural del siglo I d.C., procedentes del yacimiento arqueológico de la Casa de Ariadna en Pompeya (Italia).

Los capítulos de la parte experimental recogen los resultados de manera secuencial. Así, en el Capítulo 7 se detalla la preparación de las nanopartículas con estequiometría de hidroxiapatita para obtener diferente grado de cristalinidad, tamaño y morfología. La caracterización estructural y microestructural de las muestras obtenidas, la adecuación y caracterización de las probetas de soporte pétreo y de los fragmentos de pintura mural necesarios para llevar a cabo el estudio de evaluación de aplicabilidad así como de la acción consolidante y protectora por parte de los polvos preparados se describen en el mismo capítulo. Los resultados de la aplicabilidad y de la acción consolidante de las muestras de hidroxiapatita sobre probetas de soporte pétreo se describen en el Capítulo 8: Evaluación de los tratamientos de consolidación y protección en soporte pétreo. En este apartado se muestran los resultados referentes a la valoración de la acción de consolidación y protección en soporte pétreo sin alteración por parte de las muestras de hidroxiapatita con diferente grado de cristalinidad. Seguidamente, se muestran los resultados donde se ha incorporado en una probeta de soporte pétreo alterado por sulfatación; la muestra de hidroxiapatita de calcio que mejor resultado ha proporcionado en la primera fase de evaluación. En cuanto a los resultados alcanzados con el estudio de la valoración de la acción consolidante y protectora de las muestras preparadas sobre un fragmento de pintura mural procedente de Pompeya (Italia), se explican en el Capítulo 9. La posibilidad de utilizar la hidroxiapatita como producto consolidante y protector en fragmentos de origen paleontológicos tales como marfil y hueso, se plantea en el Capítulo 10, titulado Estudio de la aplicabilidad en material paleontológico. Se muestran los resultados de un primer estudio, que se ha centrado en comparar la acción consolidante y protectora de las muestras preparadas con un producto consolidante en uso a base de nanopartículas de hidróxido de calcio. La experimentación se ha fundamentado en la aplicación sobre los fragmentos, de las mismas técnicas analíticas antes y después de la aplicación de los consolidantes para poder realizar estudios comparativos a nivel superficial y composicional referidos principalmente a posibles cambios de color, penetración e interacción con el sustrato. 


\section{Fundamentos}




\section{Capítulo 1. Fundamentos}

1.1. Bienes culturales en soporte pétreo y decoraciones parietales

1.2. Mecanismos de alteración

1.3. Los tratamientos de consolidación y protección

1.3.1. Propiedades del consolidante

1.3.2. Productos consolidantes tradicionales

1.3.2.1. Consolidantes inorgánicos

1.3.2.2. Consolidantes orgánicos

1.4. Consolidantes nanométricos comerciales

1.5. Limitaciones en los tratamientos de consolidación con productos comerciales

1.6. Estudios preliminares de tratamientos de consolidación con disoluciones acuosas de hidrogenofosfato amónico sobre piedra 


\section{Capítulo 1. Fundamentos}

En este capítulo se expone brevemente una revisión de conceptos generales relacionados con la conservación de bienes culturales en soporte pétreo y decoraciones parietales. Se describen estas tipologías de bienes tales como materiales constitutivos, técnica de ejecución y los mecanismos de alteración que los afectan. A continuación se detallan los tratamientos de restauración tales como la consolidación y la protección necesarios para restablecer las propiedades físicas y mecánicas de los materiales alterados. Seguidamente se presenta una revisión de los productos consolidantes y protectores utilizados en los tratamientos de restauración de bienes culturales en piedra y pintura mural, y sus limitaciones. Por último, se detallan los antecedentes en el desarrollo de los nuevos nanomateriales y sus aplicaciones en el sector de la restauración de bienes de interés cultural. 


\subsection{Bienes culturales en soporte pétreo y decoraciones parietales}

La piedra y los morteros -estos últimos compuestos procedentes de rocas trituradas- constituyen materiales de gran interés en la conservación y restauración de bienes culturales. El material pétreo y sus derivados deben ser considerados bien de interés cultural mueble ${ }^{1}$ como son las esculturas y elementos ornamentales y, como bienes inmuebles ${ }^{2}$ tales como monumentos arquitectónicos, artísticos o históricos, lugares arqueológicos, edificios de interés histórico o artístico, elementos ornamentales y decoraciones parietales. En este último caso, nos referimos especialmente a las pinturas murales -policromía sobre mortero- y a las pinturas rupestres -policromía sobre piedra-.

Considerar un objeto como un bien de interés cultural es otorgarle una protección y como define la Ley de Patrimonio Histórico de España: "en el seno del Patrimonio Histórico Español, y al objeto de otorgar una mayor protección y tutela, adquiere un valor singular la categoría de bienes de interés cultural, que se extiende a los muebles e inmuebles de aquel Patrimonio que, de forma más palmaria, requieran tal protección. Semejante categoría implica medidas asimismo singulares que la Ley establece según la naturaleza de los bienes sobre los cuales recae"3.

La protección y tutela de los bienes culturales constituye, por tanto, un aspecto prioritario para garantizar su conservación futura. Asimismo la preservación de los soportes pétreos y de las decoraciones parietales expuestas a la intemperie o desintegradas es otro aspecto no menos importante a considerar.

Entre las intervenciones aceptadas en bienes protegidos figuran el mantenimiento, la reparación y la restauración:

- El mantenimiento de una obra constituye todas las acciones cuyo fin es evitar el deterioro del bien. Estas acciones, como primer paso hacia la conservación, contemplan, por ejemplo, la limpieza de las superficies y el control de los parámetros termo-higrométricos.

\footnotetext{
${ }^{1}$ Según el artículo 335 del Código Civil, se consideran bienes muebles los susceptibles de apropiación que no sean considerados inmuebles, y en general todos los que se puedan transportar de un punto a otro sin menoscabo de la cosa inmueble a que estén unidos (fuente: Ministerio de Educación, Cultura y Deporte).

${ }^{2}$ Son considerados bienes inmuebles los que recoge el artículo 334 del Código Civil, y cuantos elementos puedan considerarse consustanciales con los edificios y formen parte de los mismos o de su entorno o lo hayan formado, aunque en el caso de poder ser separados constituyan un todo perfecto de fácil aplicación a otras construcciones o a usos distintos del suyo original (fuente: Ministerio de Educación, Cultura y Deporte).

${ }^{3}$ Ley 16/1985 de 25 de junio de Patrimonio Histórico Español.
} 
- Por el contrario, la reparación es la actuación en elementos concretos que se encuentran dañados, y tienen como finalidad recuperar o mejorar la integridad y funcionalidad constructiva de un bien o parte de él.

- La restauración es una operación especial de la conservación y es la actividad que se realiza físicamente y de forma global sobre el bien de interés cultural, destinada a salvaguardarlo, mantenerlo y prolongar su permanencia para transmitirlo al futuro. Como grado de intervención, la restauración está constituida por todos aquellos procedimientos técnicos que buscan restablecer el valor histórico o artístico del bien patrimonial, respetando sus cualidades de documento histórico, considerando su estética y recuperando en lo posible, sus valores formales y compositivos ${ }^{4}$.

Por todo ello, las actividades de conservación y restauración de bienes de interés cultural representan una serie de actuaciones que permiten garantizar la permanencia de todas aquellas manifestaciones culturales y artísticas, protegerlas y rescatarlas de manera profesional y responsable de manera que se logren transmitir a generaciones futuras al asegurar su uso actual y al respetar su significado histórico, artístico y social ${ }^{5,6}$. Puesto que estas intervenciones dependen no sólo de la naturaleza química y física de los materiales a intervenir, sino también de la composición y la estructura de los productos de la alteración, es indispensable realizar antes de los tratamientos de conservación y restauración, una caracterización de los componentes que constituyen el soporte del bien; que, por otra parte, permita la identificación de las alteraciones y textura y las causas de alteración.

El Patrimonio Cultural, de hecho, es un testigo clave y de gran valor para la historia y la evolución del país. Tanto la estética como la importancia histórica de los monumentos no resultan inmunes a la inevitable alteración, deterioro y degradación de los constituyentes debidos, fundamentalmente, a la continua adaptación de los materiales al medio ambiente -este último cada vez más agresivo en las últimas décadas ${ }^{7}$. Las transformaciones que se verifican en los materiales rocosos se traducen en un cambio más o menos evidente y rápido de las características originales del material. Puesto que cada material sufre un proceso de cambio de acuerdo con sus características intrínsecas y las del medio ambiente circundante, la restauración

\footnotetext{
${ }^{4}$ C. Brandi, Teoría de la restauración, Alianza Editorial, 2002.

${ }^{5}$ I. González-Vara, Conservación de bienes culturales. Teoría, principios y normas. Ediciones Cátedra. 539, 2008; C. Chanflón Olmos, Fundamentos teóricos de la restauración. 303-304.

${ }^{6}$ M.J. Martínez Justicia, Historia y teoría de la conservación y restauración artística. Techos. 24, 2008.

7 Jornada técnica sobre tratamientos de Conservación aplicados a materiales pétreos en construcciones históricas. Instituto Tecnológico de Rocas Ornamentales y Materiales de Construcción - INTROMAC, Badajoz 2007.
} 
debe efectuarse necesariamente a través de un conocimiento de las técnicas y de los materiales que constituyen el patrimonio cultural, así como un diagnóstico para estudiar los mecanismos de deterioro.

En la presente tesis doctoral nos centraremos en los materiales pétreos, exactamente en las rocas calizas y sus derivados -árido y cal- para la elaboración de morteros. El carbonato de calcio $\mathrm{CaCO}_{3}$ y el carbonato de calcio y magnesio, este ultimo constituido por el sistema $\mathrm{CaCO}_{3}-\mathrm{MgCO}_{3}$, son los componentes mineralógicos más abundantes en el sector artístico y arquitectónico; se puede encontrar en los morteros que componen las pinturas murales, o en las diferentes tipologías de piedras como mármoles, travertinos y dolomías, utilizadas en la ejecución de monumentos, edificios, estatuarias, etc.

El carbonato cálcico es el más común y presenta una variedad casi infinita de estructura, coloración y dureza. Las rocas calizas se clasifican en base a la naturaleza de sus componentes minerales o a la del cemento que mantiene los granos unidos de una manera compacta. El nombre genérico de caliza puede ir acompañado de adjetivos tales como arenosa, arcillosa, dolomítica, silícea, ferruginosa, etc., y cuando la roca deriva de estructuras orgánicas puede denominarse conchífera, de crinoideos, etc., según los casos. Además, las calizas pueden ser compactas, granulares u oolíticas ${ }^{8}$. Por último, estas características pueden combinarse y existir, por ejemplo una caliza silícea de crinoideos. El grado de cementación y la forma, la naturaleza y el porcentaje de los granos influyen en la resistencia de la roca a la alteración, y determinan sus propiedades.

Estas rocas se han utilizado desde la Antigüedad como materia prima para la edificación de monumentos, edificios y estatuaria, así como materia prima para la elaboración de morteros necesarios, por ejemplo, para la ejecución de las pinturas murales. Igual que el patrimonio histórico artístico en piedra monumental, la pintura mural ocupa un lugar relevante como expresión artística y medio de comunicación visual, dentro de las manifestaciones plásticas de las grandes civilizaciones del pasado. La gran parte de las construcciones arquitectónicas antiguas estaban pintadas en su exterior, y las superficies parietales del interior eran pintadas por diferentes escenas e imágenes ${ }^{9}$.

Con el desarrollo de las civilizaciones antiguas, se localizan los primeros testigos de pinturas murales realizadas al secco -técnicas del temple donde los pigmentos vienen mezclados con aglutinantes inorgánicos como agua de cal, o con aglutinantes de naturaleza orgánica aplicados sobre la superficie del mortero ya carbonatado-, o al fresco -en este ultimo caso los pigmentos disueltos en agua se aplican sobre el mortero húmedo.

\footnotetext{
${ }^{8}$ Los oolitos son pequeñas estructuras carbonatadas de origen sedimentario, de forma generalmente esferoidal, con un diámetro de entre 0,5 y $2 \mathrm{~mm}$.

${ }^{9}$ AA.VV., Le tecniche artistiche. Mursia Editrice, 2007.
} 
La pintura mural se compone de tres elementos principales: soporte, mortero y capa pictórica. Sobre el soporte, generalmente de piedra o de ladrillos, se aplican las distintas capas de morteros, que resulta ser una mezcla compuesta habitualmente por cal, arena, polvo de mármol y agua ${ }^{10}$. Estas capas son necesarias para obtener una superficie lisa y de coloración blanca, dando así lugar a una superficie idónea para recibir la capa de policromía.

El mortero, en sentido amplio, es cualquier mezcla natural o artificial de conglomerantes inorgánicos, agregados finos, agua y posibles aditivos. Entre las características principales figuran su plasticidad inicial que permite trabajarla y moldearla según la necesidad, y su posterior endurecimiento o aumento de la resistencia mecánica que lo hacen útil como material de construcción u ornamentación.

Las mezclas de los morteros constan generalmente de:

- Un material inerte o árido, prevalentemente arena o polvo de mármol de diferente granulometría.

- Un material aglutinante, ligante, conglomerante o aglomerante, que imparte plasticidad, cohesión y resistencia mecánica a la mezcla. Habitualmente este último componente es la cal ${ }^{11}$.

- Posibles aditivos.

El óxido de calcio $\mathrm{CaO}$ o cal viva, es un óxido alcalino, que al contacto con el agua reacciona desprendiendo calor $(15.500 \mathrm{cal} / \mathrm{mol})$, denominándose cal apagada y que corresponde con el $\mathrm{Ca}(\mathrm{OH})_{2}$ :

$\mathrm{CaO}+\mathrm{H}_{2} \mathrm{O} \leftrightarrow \mathrm{Ca}(\mathrm{OH})_{2}$

Es decir, en este caso, el $\mathrm{CaO}$ mezclado con agua y expuesto a la acción del aire, tiene una primera fase de fraguado por cristalización del hidróxido cálcico (ec. 1.1) y, a continuación, una segunda fase de endurecimiento a través de la carbonatación por la acción del $\mathrm{CO}_{2}$ atmosférico, transformándose en carbonato de calcio $\mathrm{CaCO}_{3}$ (ec. 1.2):

\footnotetext{
${ }^{10}$ Los morteros de yeso realizados con un aglomerante a base de sulfato de calcio dihidratado $\mathrm{CaSO}_{4} \cdot 2 \mathrm{H}_{2} \mathrm{O}$, no han sido incluidos en nuestro estudio focalizado en sustratos inorgánicos a base de carbonato de calcio $\mathrm{CaCO}_{3}$ y carbonato de magnesio $\mathrm{MgCO}_{3}$.

${ }^{11}$ Según la Norma UNE ENV459-1, con el término cal se incluyen formas físicas y químicas de diferentes variedades en las que puede presentarse el óxido y el hidróxido de calcio y de magnesio.
} 
$\mathrm{Ca}(\mathrm{OH})_{2}+\mathrm{CO}_{2} \leftrightarrow \mathrm{CaCO}_{3}+\mathrm{H}_{2} \mathrm{O}$

(ec.1.2)

En la Figura 1.1 se muestra el ciclo del $\mathrm{CaO}$ donde se resume la reactividad de la cal o del hidróxido de calcio, con el dióxido de carbono atmosférico para formar carbonato cálcico en una reacción de carbonatación $^{12,13}$.

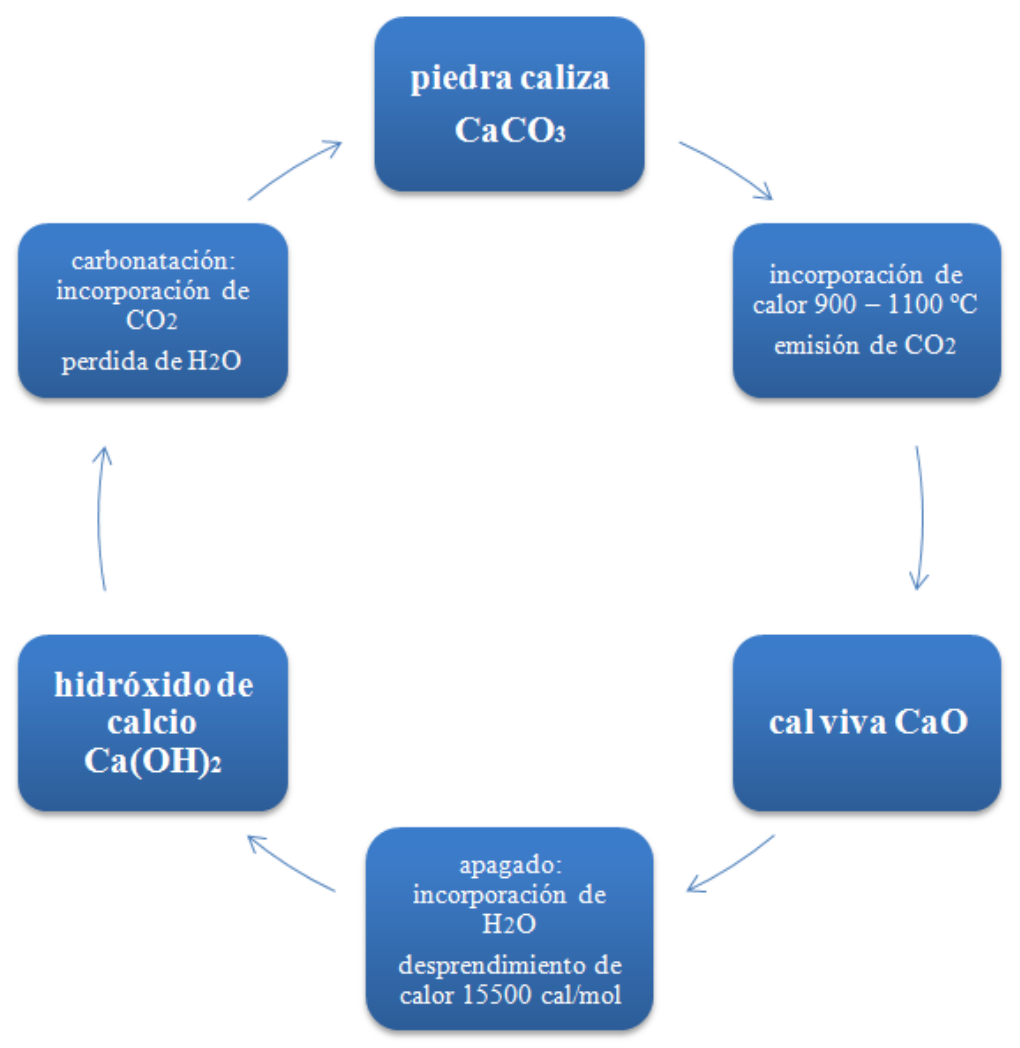

Figura 1.1. Ciclo de la cal aérea. Cocción, apagado y endurecimiento de la cal.

\footnotetext{
${ }^{12}$ V. Daniele, G. Taglieri, R. Quaresima, The nanolimes in Cultural Heritage conservation: Characterisation and analysis of the carbonatation process. J. Cult. Herit., Vol. 9, no. 3, 294-301, 2008.

${ }^{13}$ P. Santana, Uso de la Cal en Morteros Calerías e Industrias S.A. 2015. http://slideplayer.es/slide/2861668/.
} 
Las pinturas murales podían ser realizadas con la técnica al temple con la mezcla de los pigmentos con aglutinantes orgánicos (cola animal, huevo, caseína, aceite secante, gomas vegetales), o con la técnica del al fresco que se realiza pintando con pigmentos generalmente de orígenes minerales mezclados en agua y aplicados sobre la superficie de un mortero de cal fresco (Figura 1.2 A). De esta manera, a través del proceso de carbonatación que se realiza por la presencia del hidróxido de calcio que constituye el soporte, con el dióxido de carbono presente en la atmosfera, el pigmento viene englobado en una matriz de carbonato cálcico, adquiriendo gran resistencia al agua y al proceso de envejecimiento como se describe en el esquema de la Figura $1.2 \mathrm{~B}^{14}$. En el esquema se observa una última capa que se presenta como una película transparente (calcina), que resulta formarse por la carbonatación de la cal del mortero, y crea una capa protectora que engloba las partículas de pigmento efectuando un acción adhesiva y cohesiva.

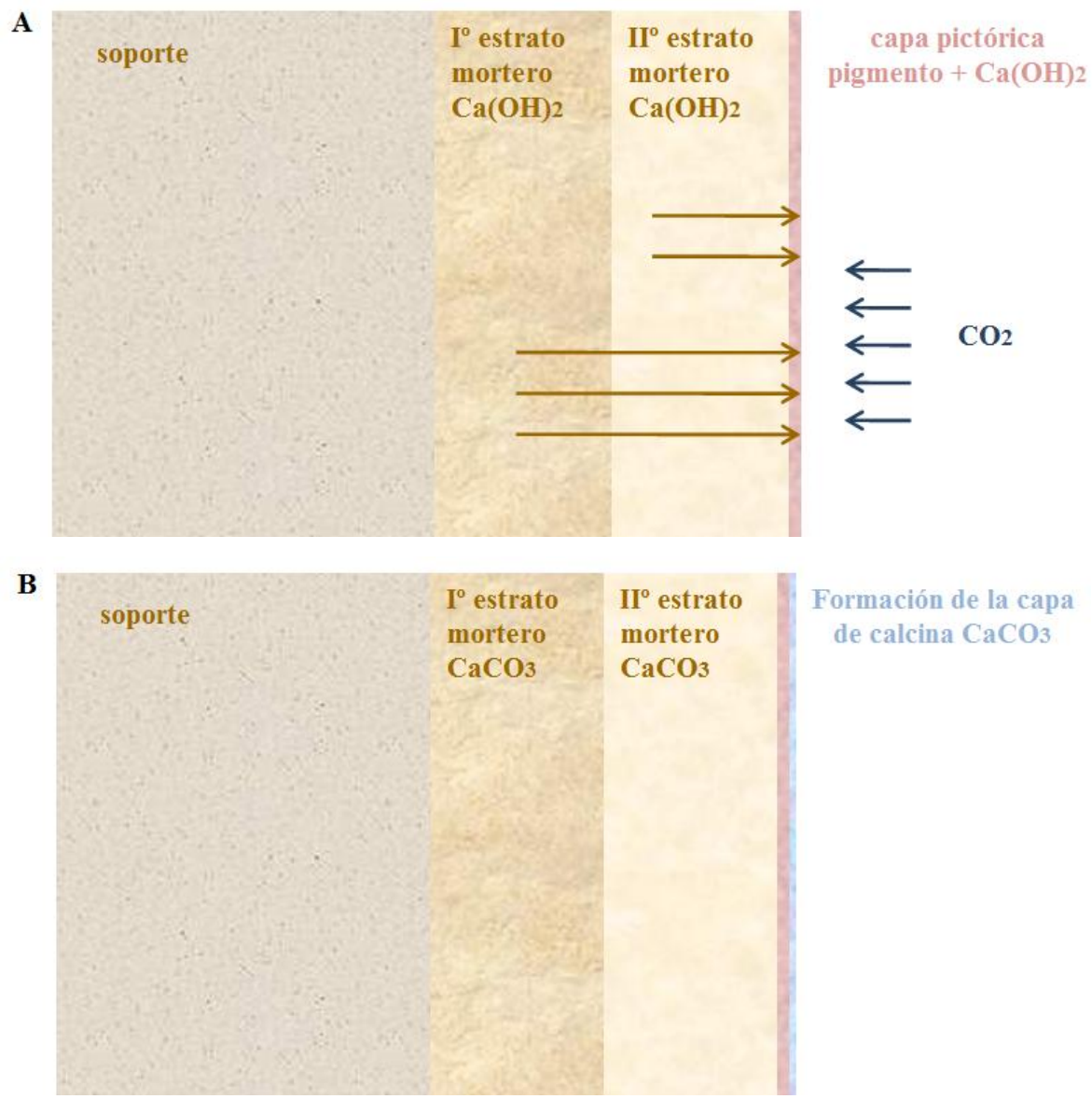

Figura 1.2. Esquema del proceso de carbonatación de una pintura mural realizada con la técnica al fresco, visto en sección transversal. A) El hidróxido de calcio presente en los estratos del mortero, reacciona con el dióxido de carbono atmosférico. B) Formación del carbonato de calcio englobando el pigmento.

\footnotetext{
${ }^{14}$ AA.VV., Le tecniche artistiche. Mursia Editrice, 2007; http://it.wikipedia.org/wiki/Affresco.
} 
El color, que es aplicado sobre el mortero aun húmedo, se elabora con pigmentos minerales de origen natural o sintético, ya que deben resistir a la alcalinidad producida por el mortero de cal. Entre los pigmentos utilizados en la Antigüedad, en la técnica del al fresco figuran el blanco a base de carbonato cálcico o de harina fósil, el ocre amarillo y rojo constituidos por óxidos e hidróxidos de hierro, el Caeruleum, pigmento azul de silicato de cobre y calcio, la tierra verde a base de arcilla y el negro de manganeso y hierro calcinados entre otros ${ }^{15}$. Las correcciones eventuales son posibles con la técnica al mezzo fresco o al secco, donde los pigmentos vienen mezclados, en el primer lugar con aglutinantes inorgánicos como agua de cal, y en el segundo lugar con aglutinantes de naturaleza orgánica aplicados sobre la superficie del mortero ya carbonatado. En este caso las policromías resultan ser menos resistentes a la acción de los diferentes mecanismos de deterioro.

En las pinturas parietales del Imperio Romano, y en particular con los significativos ejemplos pictóricos de las ciudades de Pompeya y Herculano, como se puede observar en la imágenes de la Figura 1.3, encontramos principalmente la técnica de al fresco realizados con morteros húmedos, junto con la técnica al mezzo fresco (pigmentos mezclados con agua de cal, y aplicado sobre un mortero ligeramente húmedo), y la técnica al secco. Esta última modalidad empleada sobre todo para efectuar acabados de las policromías ya realizadas con las otras técnicas artísticas descritas.
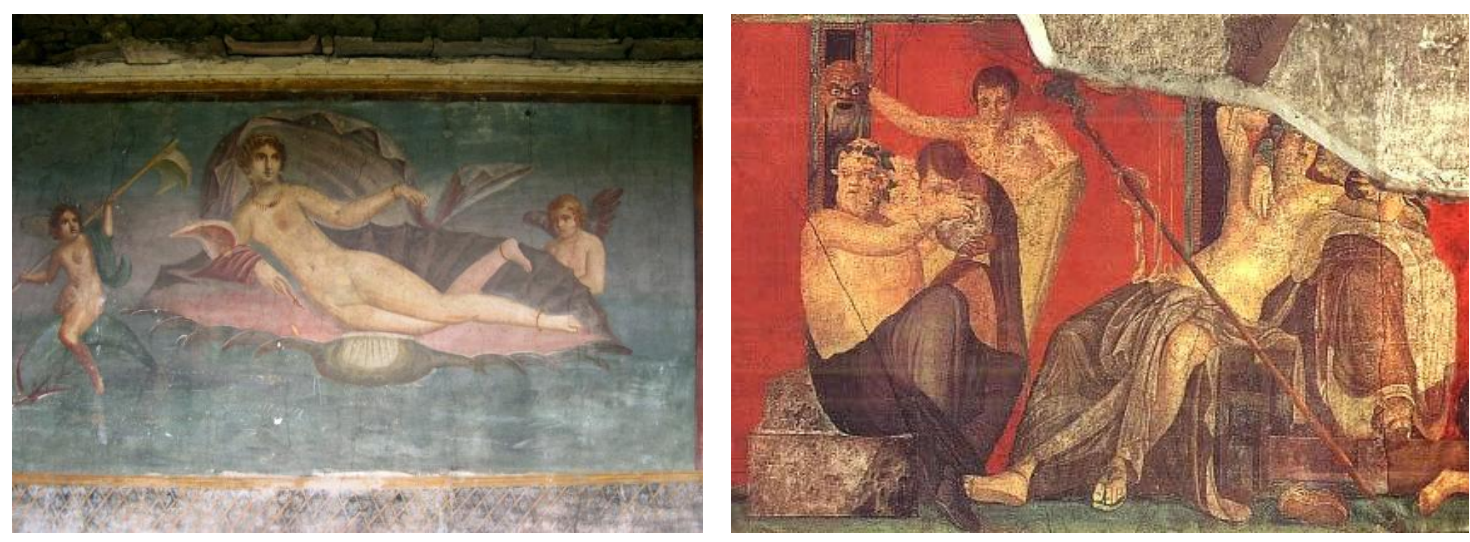

Figura 1.3. Ejemplos de pinturas murales conservadas en Pompeya (Italia), del siglo I d.C.

\footnotetext{
${ }^{15}$ U. Alesi, Il restauro dei materiali in architettura. Tecnoservizi s.c.r.l., Ascoli Piceno,Tipografia Fast Edist, Acquaviva Picena (AP). www.umbertoalesi.it.
} 


\subsection{Mecanismos de alteración}

Con el término de alteración nos referimos al cambio de las propiedades que se aprecian en la piedra o mortero cuando, ante variaciones del medio que la rodea, evoluciona hacia situaciones de nuevo equilibrio. Cuando estos cambios producen la pérdida de las propiedades del sustrato rocoso y sus derivados, hablamos de degradación. Tanto la alteración como la degradación son procesos físico-químicos que afectan a los soportes rocosos en su emplazamiento original. Actualmente se manifiesta de forma más acusada en los materiales utilizados en los monumentos y otras expresiones artísticas, ya que el deterioro ha aumentado de manera exponencial durante los últimos años como respuesta a la creciente contaminación ambiental ${ }^{16}$. Los procesos de alteración y degradación se producen por un proceso natural de envejecimiento de los materiales bien por sus características intrínsecas como la composición mineralógica y textura, o bien inducido por agentes externos como agua, eflorescencias salinas, contaminantes medioambientales, ciclos de hielo-deshielo, variaciones de los parámetros termo-higrométricos (alteración atmosférica y meteorización) o factores de naturaleza biológica (bioalteración). A estos factores se pueden añadir el deterioro causado por agentes de origen antrópico (alteración antropogénica) como por el uso inapropiado de productos de restauración como algunos consolidantes o protectores, que pueden presentan la gran desventaja de no tener una buena compatibilidad químico-física y mecánica con el substrato de la obra ${ }^{17}$.

Alcalde Moreno M. ${ }^{18,19}$ y colaboradores establecen una relación entre factores medioambientales o del soporte pétreo con los mecanismos de alteración y sintomatología de las alteraciones (ver Tabla 1.1).

\footnotetext{
${ }^{16}$ R. Fort, La contaminación atmosférica en el deterioro del patrimonio monumental: medidas de prevención. En el libro: Ciencia, Tecnología y Sociedad para una conservación sostenible del patrimonio pétreo. 57-71, 2007.

${ }^{17} \mathrm{R}$. Villegas, Efecto de la contaminación atmosférica sobre los materiales pétreos. La alteración de la piedra de la Catedral de Sevilla. Estudio de tratamientos de conservación. Proyecto Fin de Carrera. Escuela Superior de Ingenieros Industriales. Univ. Sevilla, 1985.

${ }^{18}$ Indicadores de alteración de los materiales pétreos: Propuesta de una terminología. M. Alcalde Moreno, A. martín Pérez. PH: Boletín del Instituto Andaluz del Patrimonio Histórico, Año nº4, № 15, 68-74, 1996.

${ }^{19}$ Guía para el estudio de la alteración de la piedra de los monumentos y de medidas de conservación. Manuel Alcalde Moreno, Rosario Villegas Sánchez. PH: Boletín del Instituto Andaluz del Patrimonio Histórico, Año nº 4, No 15, 62-67, 1996.
} 
Tabla 1.1. Relación entre factores medioambientales o del soporte con los mecanismos de alteración y sintomatología de las alteraciones.

\begin{tabular}{|c|c|c|}
\hline Factores alteración & Mecanismos alteración & Indicadores alteración \\
\hline $\begin{array}{l}\text { Humedad con presencia de sales y } \\
\text { viento }\end{array}$ & $\begin{array}{l}\text { Incremento de volumen en poros e } \\
\text { intersticios }\end{array}$ & Picados y alveolizaciones \\
\hline $\begin{array}{l}\text { Humedad ascendente con sales } \\
\text { disueltas, sin viento }\end{array}$ & Cristalización de sales & Eflorescencias y subflorescencias \\
\hline $\begin{array}{c}\text { Dióxido de carbono atmosférico y } \\
\text { lluvia }\end{array}$ & Solubilización de los carbonatos & Costra calcín y concreciones \\
\hline $\begin{array}{c}\text { Contaminación atmosférica con } \\
\text { óxidos de azufre }\end{array}$ & Ataque químico & $\begin{array}{c}\text { Costra sulfín, disyunción de placas, } \\
\text { arenizaciones }\end{array}$ \\
\hline $\begin{array}{c}\text { Naturaleza esquistosa/laminar de la } \\
\text { piedra }\end{array}$ & $\begin{array}{l}\text { Tensiones por diferencias de } \\
\text { temperatura o presión }\end{array}$ & Exfoliaciones \\
\hline
\end{tabular}

Las principales causas de deterioro de las pinturas murales son las mismas que afectan a las estructuras arquitectónicas y pueden tener dos orígenes diferentes: natural (lluvia, cristalización salina, ciclos de hielodeshielo, microclima y cambios térmicos), y un origen antrópico, originado principalmente por la contaminación atmosférica o por inadecuadas intervenciones de restauración realizadas en el pasado ${ }^{20,21}$. Los cambios continuos de los parámetros medioambientales, las condiciones termo-higrométricas, los ciclos de cristalización interna y/o superficial de soluciones salinas acuosas, la lluvia, etc., asociados a la porosidad y a la estructura del material, generan ciclos de estrés mecánicos causando un cambio en las propiedades de adhesión, cohesión y resistencia mecánica del carbonato de calcio ${ }^{22}$. Esto se traduce, generalmente, en un aspecto pulverulento de las policromías, con fenómenos de exfoliación y pérdida de los materiales que constituyen las pinturas.

\footnotetext{
${ }^{20}$ W. T. Lipfert, Atmospheric damage to calcareous stones: Comparison and reconciliation of recent experimental findings. Atmos. Environ., 23, 415-429, 1989.

${ }^{21}$ M. Alcalde, R. Villegas, Guía para el estudio de la alteración de la piedra de los monumentos y medidas de conservación. $\mathrm{PH}$, Boletín Instituto Andaluz del Patrimonio Histórico, IV (15). 62-67, 1996.

${ }^{22}$ F. De Beacourt, C. Jaton, Les types d'alteration des roches calcaires.- Les monuments historiques de la France. 65, rue St. Antoine, Paris, Numéro special hors série, 14-32, 1975.
} 
En las imágenes de la Figura 1.4 y de la Figura 1.5, se muestran dos ejemplos del deterioro producido por los mecanismos anteriormente descritos en el soporte pétreo de la portada principal de la Iglesia de Nuestra Señora de la Asunción de Corral de Almaguer (Toledo) del siglo XV y en una pintura mural pompeyana del siglo I d.C. En la Figura 1.4 se observan los mecanismos de alteración y degrado del soporte pétreo con formación de pátinas biológicas, sulfatación y pérdida de material. En la Figura 1.5 A se aprecian fenómenos de cristalización de sales en la pintura mural con exfoliación y pulverización de la capa de policromía, mientras que en la imagen B se muestra la alteración generalizada de la pintura mural por cristalizaciones de sales.
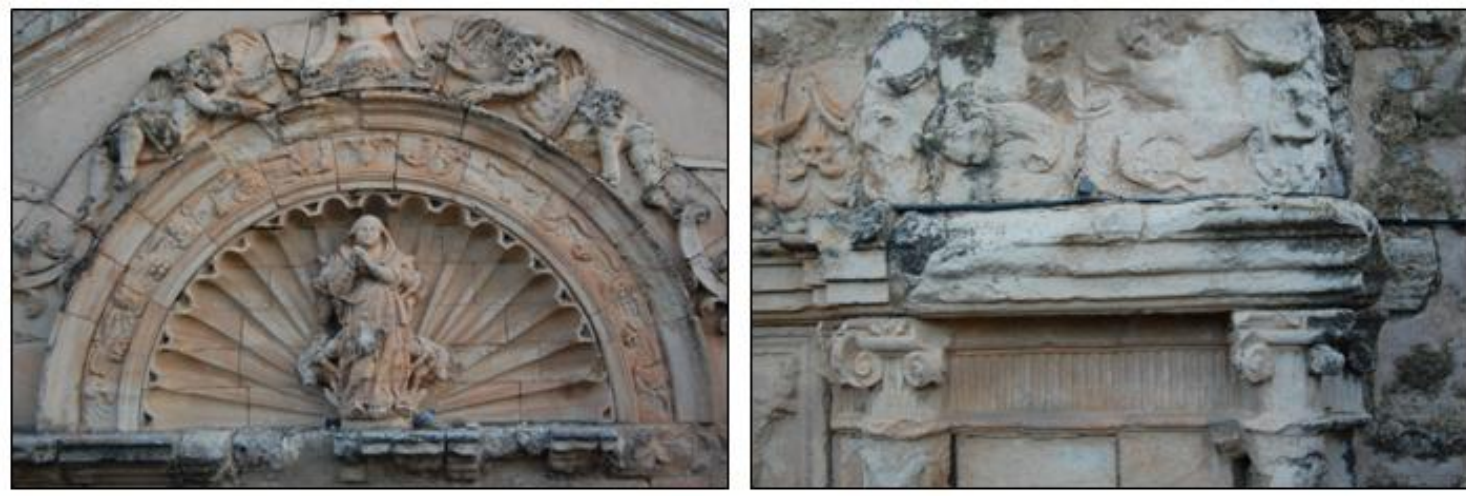

Figura 1.4. Detalles de la portada principal de la Iglesia de Nuestra Señora de la Asunción de Corral de Almaguer (Toledo) del siglo XV.
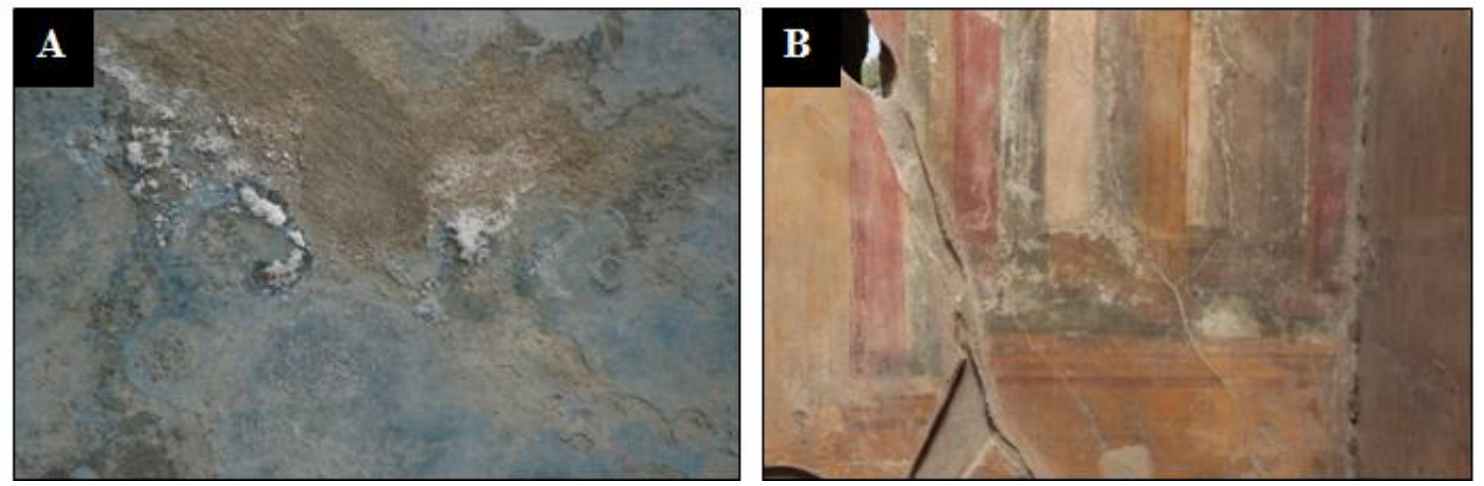

Figura 1.5. Deterioro de la pintura mural pompeyana del siglo I d.C.

Entre los factores externos, el principal y más importante factor de alteración de las obras en soporte pétreo y morteros es, sin duda, el agua. El agua penetra en los poros del material no solo en estado líquido por 
capilaridad, sino también en estado gaseoso para luego condensar en el sistema poroso del sustrato. El efecto negativo del agua se traduce en la presencia constante de humedad en el material, lo que lleva a la formación de manchas de humedad que aumentan de tamaño durante el periodo invernal, sobretodo por la presencia de sales minerales dentro de la composición del soporte, así como de sales procedentes del suelo, originando depósitos superficiales denominadas eflorescencias ${ }^{23}$.

Las eflorescencias, por lo general, aparecen en forma de depósitos cristalinos, blancos, poco coherentes, de aspecto pulverulento o filamentoso. Dependiendo de la presencia o ausencia de corrientes de aire, a la misma temperatura, la evaporación del agua se produce con diferentes mecanismos: si los flujos de aire son lentos, las sales solubles cristalizan en la superficie creando la propiamente llamada eflorescencias; en presencia de baja humedad y ventilación fuerte, debido a que hay rápida evaporación del agua, las sales no se depositan en la superficie sino que permanecen en la parte interior del soporte, generando el fenómeno de las subflorescencias $^{24}$ o criptoflorescencias ${ }^{25}$ salinas. Estas cristalizaciones internas producen efectos más perjudiciales tales como la exfoliación y el desprendimiento ${ }^{26,27}$. Debido a la solubilización, a la migración y a la recristalización de las sales solubles, con la generación de fuertes presiones internas se puede producir hasta la desintegración total de la estructura interna.

Los procesos determinados por el agua que causan la desintegración de la materia, se pueden resumir de la siguiente manera:

- Acción mecánica debido a las tensiones que se generan a los ciclos de hielo-deshielo del agua.

- Erosión causada por la precipitación de lluvia.

- Acción físico-mecánico en relación con el transporte de sales solubles en el material y su cristalización, generando tensiones dentro de la estructura capilar.

- Acción de tipo químico en la estructura porosa del material, debido a la presencia de ácidos contaminantes presentes en el medio ambiente.

\footnotetext{
${ }^{23}$ R. Esbert, R. Marcos, La deterioración de las piedras de la Catedral de Oviedo. $2^{a}$ parte: formas y fenómenos de alteración, Materiales de la Construcción 186, 79-88, 1982.

${ }^{24}$ Las sales que se mueven hacia la superficie de la piedra cristalizan inmediatamente debajo de la superficie original de la mi sma, la cual queda como una delgada y endurecida costra de material alterado.

${ }^{25}$ Es el resultado de la cristalización de sales en el interior de la piedra, en materiales pétreos con grandes poros.

${ }^{26}$ M. Alcalde, A. Martín, Indicadores de alteración de los materiales pétreos. Propuesta de una terminología. PH, Boletín Instituto Andaluz del Patrimonio Histórico, IV (15), 68-74, 1996.

${ }^{27}$ NORMAL (Normativa Manufatti Lapidei, CNR-ICR, Italia) 1/80: Alterazioni mactroscopiche de material lipidei: Lessico.
} 
Por otro lado, la contaminación atmosférica modifica las propiedades químicas, físicas y biológicas del aire y genera alteraciones de distinta gravedad en los materiales a base de carbonato de calcio ${ }^{28}$. Las sustancias contaminantes agresivas para las piedras calizas y las pinturas murales son muy variadas. Entre las más importantes figuran los compuestos de azufre $\mathrm{SO}_{x}, \mathrm{H}_{2} \mathrm{~S}_{\text {y H}} \mathrm{SO}_{4}$, los compuestos del carbono $\mathrm{CO}, \mathrm{CO}_{2}, \mathrm{CH}_{4}$ y $\mathrm{HCT}^{29}$, los compuestos de nitrógeno $\mathrm{N}_{\mathrm{x}} \mathrm{O}_{\mathrm{y}}$ y $\mathrm{NH}_{3}$, las partículas sólidas presentes en atmósfera, los oxidantes fotoquímicos tales como $\mathrm{O}_{3}$, peróxidos y aldehídos, y los halógenos y los compuestos halogenados $\mathrm{Cl}_{2}, \mathrm{HCl}$, HF. Todos estos compuestos gaseosos o sólidos, son considerados contaminantes que en los últimos años han aumentado su concentración de manera constante a causa de la intensificación del uso de combustibles fósiles como el petróleo o carbón, o la emisión por sistemas de calefacción doméstico. Las superficies de los monumentos, pinturas murales y esculturas de tipo calcáreo, resultan ser sensibles a la presencia de agua acidificada por la presencia de estos contaminantes.

En el caso del dióxido de carbono como contaminante, con una solubilidad de $1,45 \mathrm{~g} / \mathrm{L}$ a $25^{\circ} \mathrm{C}$ genera un cambio de pH del agua de neutro a ácido como se refleja en la ecuación 1.3:

$\mathrm{H}_{2} \mathrm{O}(\mathrm{ac})+\mathrm{CO}_{2}(\mathrm{~g}) \leftrightarrow \mathrm{HCO}_{3}^{-}(\mathrm{ac})+\mathrm{H}^{+}(\mathrm{ac})$

Este cambio en el pH del agua hace que cuando esta incide sobre las piedras calizas o dolomíticas pueden generar iones de hidrogenocarbonato como se muestra en la ecuación $1.4^{30}$ :

$\mathrm{CaCO}_{3}-\mathrm{MgCO}_{3}+2 \mathrm{CO}_{2}+2 \mathrm{H}_{2} \mathrm{O} \leftrightarrow \mathrm{Ca}^{2+}(\mathrm{ac})+\mathrm{Mg}^{2+}(\mathrm{ac})+4 \mathrm{HCO}_{3}^{-}(\mathrm{ac})$

El hidrogenocarbonato de calcio es disuelto en agua y lixiviado por las aguas de escorrentía, pero puede penetrar en el interior de la piedra y precipitar en los poros, generando presiones internas que desmenuzan y

\footnotetext{
${ }^{28}$ P. Bonanni, C. Cacace, A. Giovagnoli, R. Gaddi, Gli effetti dell'inquinamento atmosferico sui beni di interesse storico-artistico esposti all'aperto. APAT - Dipartimento Stato dell'Ambiente e Metrologia ambientale, Servizio Inquinamento Atmosferico e Ambiente Urbano.

${ }^{29}$ Familia de compuestos formados por hidrógeno y carbono que intervienen en la formación del smog fotoquímico.

${ }^{30}$ P. Bonanni, C. Cacace, A. Giovagnoli, R. Gaddi, Gli effetti dell'inquinamento atmosferico sui beni di interesse storico-artistico esposti all'aperto. APAT - Dipartimento Stato dell'Ambiente e Metrologia ambientale, Servizio Inquinamento Atmosferico e Ambiente Urbano.
} 
degradan el material. Una segunda fase comporta la deshidratación del bicarbonato de calcio con formación de carbonato de calcio, con aspecto pulverulento y soluble como se describe en la siguiente ecuación:

$\mathrm{Ca}\left(\mathrm{HCO}_{3}\right)_{2} \rightarrow \mathrm{CaCO}_{3} \downarrow+\mathrm{CO}_{2}+\mathrm{H}_{2} \mathrm{O}$

De manera análoga, la presencia de los compuestos de azufre causan la acidificación del ambiente que afecta a los soportes a base de calcita y dolomita, causando el proceso de sulfatación del carbonato cálcico con formación otra fase mineral menos estable y más soluble como el sulfato de calcio dihidratado $\mathrm{CaSO}_{4} \cdot 2 \mathrm{H}_{2} \mathrm{O}$. Los mecanismos de esta transformación se describen en las ecuaciones $1.6-1.8$ :

$2 \mathrm{SO}_{2}(\mathrm{~g})+\mathrm{O}_{2}(\mathrm{~g}) \rightarrow 2 \mathrm{SO}_{3}(\mathrm{~g})$

$\mathrm{SO}_{3}(\mathrm{~g})+\mathrm{H}_{2} \mathrm{O}(\mathrm{ac}) \rightarrow \mathrm{H}_{2} \mathrm{SO}_{4}(\mathrm{ac}) \leftrightarrow \mathrm{H}^{+}+\mathrm{HSO}_{4}^{-}$

$\mathrm{H}_{2} \mathrm{SO}_{4}(\mathrm{ac})+\mathrm{CaCO}_{3}(\mathrm{~s})+\mathrm{H}_{2} \mathrm{O}(\mathrm{ac}) \rightarrow \mathrm{CaSO}_{4} \cdot 2 \mathrm{H}_{2} \mathrm{O} \downarrow+\mathrm{CO}_{2}(\mathrm{~g})$

La formación del sulfato de calcio dihidratado conlleva una pérdida del material en la superficie de la obra ya que puede ser fácilmente lavado por la lluvia. Este deterioro también puede determinar, como ya se ha descrito anteriormente, fenómenos de alteración de tipo mecánico por la cristalización de $\mathrm{CaSO}_{4} \cdot 2 \mathrm{H}_{2} \mathrm{O}$ en áreas internas o superficiales de la obra. Los sulfatos pueden cristalizar de forma distinta, presentando diferentes cantidades de agua en su estructura, la cual aumenta el volumen de los cristales. En este caso se crean tensiones mecánicas debido a que el sulfato de calcio presenta un volumen del $20 \%$ mayor respecto al carbonato de calcio, creando exfoliación, descamación, arenización (estado muy avanzado de decohesión interna caracterizado por la caída, generalmente inducida, de materia de la piedra en forma de granos de tamaño de arena) y pulverización (estado último de decohesión interna que se manifiesta en la caída de material de la piedra, mortero o pintura en forma de polvo, simplemente al tocarla e incluso de manera espontánea) del material como se aprecia en las imágenes A y B de la Figura 1.6, referentes a un sustrato pétreo afectado por sulfatación.

Las imágenes son detalle del friso de la portada principal de la Iglesia de Nuestra Señora de la Asunción de Corral de Almaguer (Toledo), donde se produce la sulfatación del soporte pétreo con cromatización y pérdida superficial de material. La sulfatación produce en este caso la descamación del soporte pétreo, una 
alteración por disyunción que se manifiesta por despegamiento total o parcial de escamas de la superficie de la piedra, independientemente de su estructura. Las escamas están formadas generalmente de material en apariencia inalterado. En la imagen de la Figura 1.7 se muestra la cristalización de sales solubles por debajo del estrato de pintura (subflorescencia salinas), provocando la pulverización y descamación de la policromía en la pintura mural pompeyana.
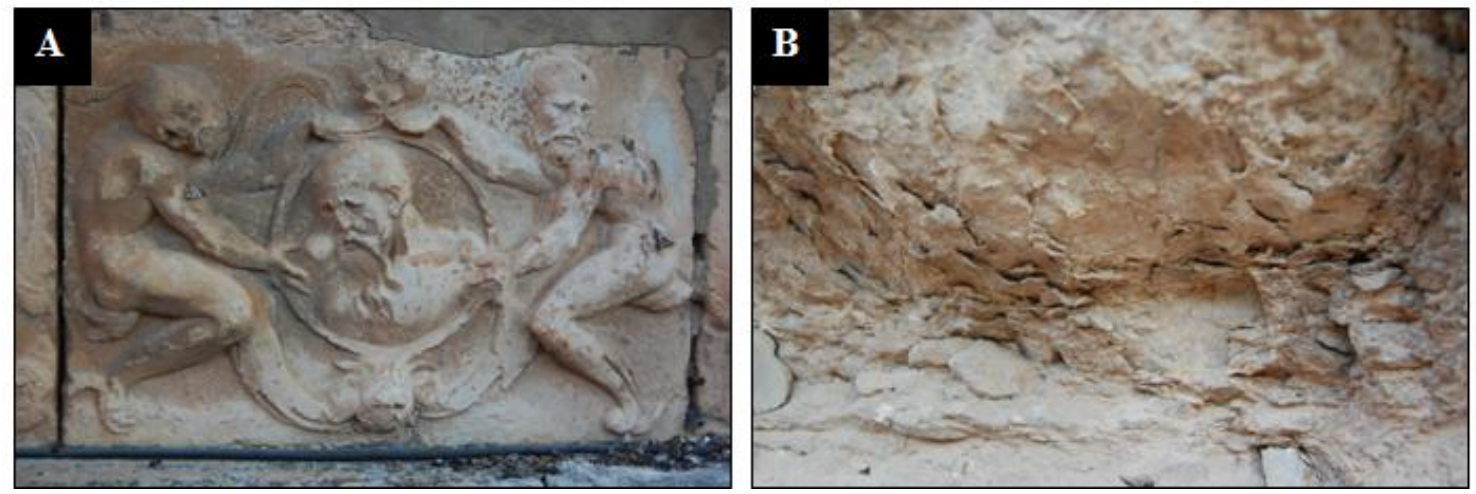

Figura 1.6. A y B) Detalles del friso de la portada principal de la Iglesia de Nuestra Señora de la Asunción de Corral de Almaguer (Toledo), donde se produce la sulfatación del soporte pétreo.

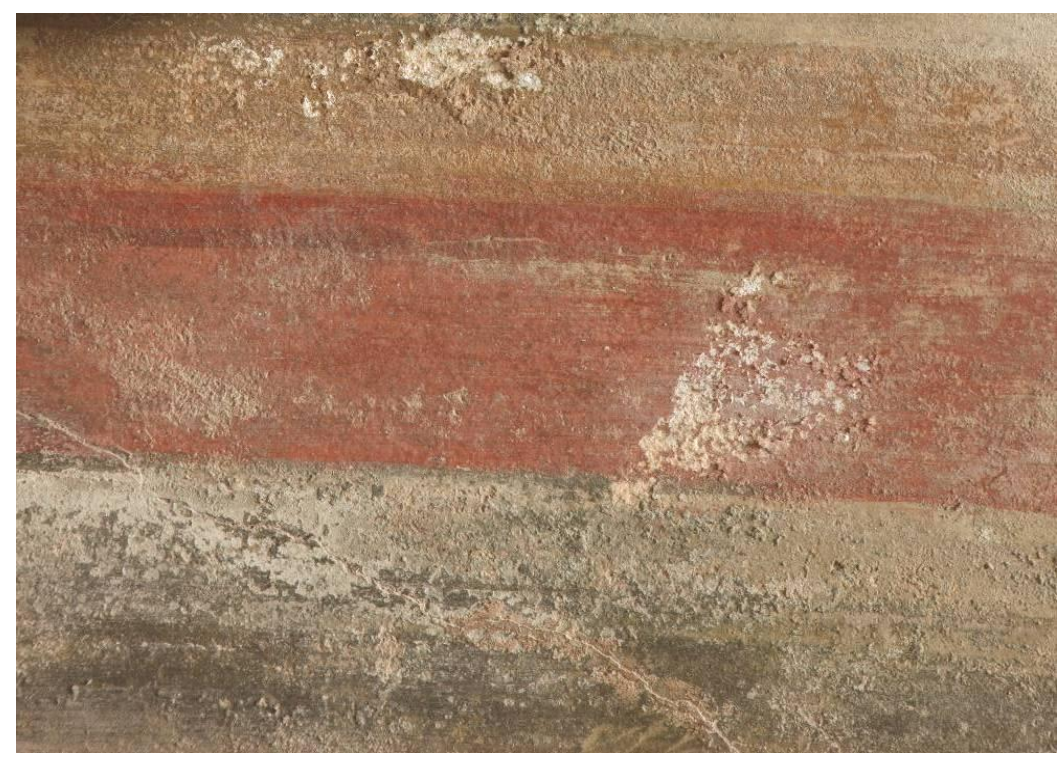

Figura 1.7. Detalle de la pintura mural de la case de Ariadna en Pompeya (Italia) del siglo I d.C. 
La Figura 1.8 nos muestras la cristalización de sulfato de calcio entre los cristales mineralógicos de un sustrato pétreo, provocando con los ciclos de solubilización y cristalización, la disgregación del material.

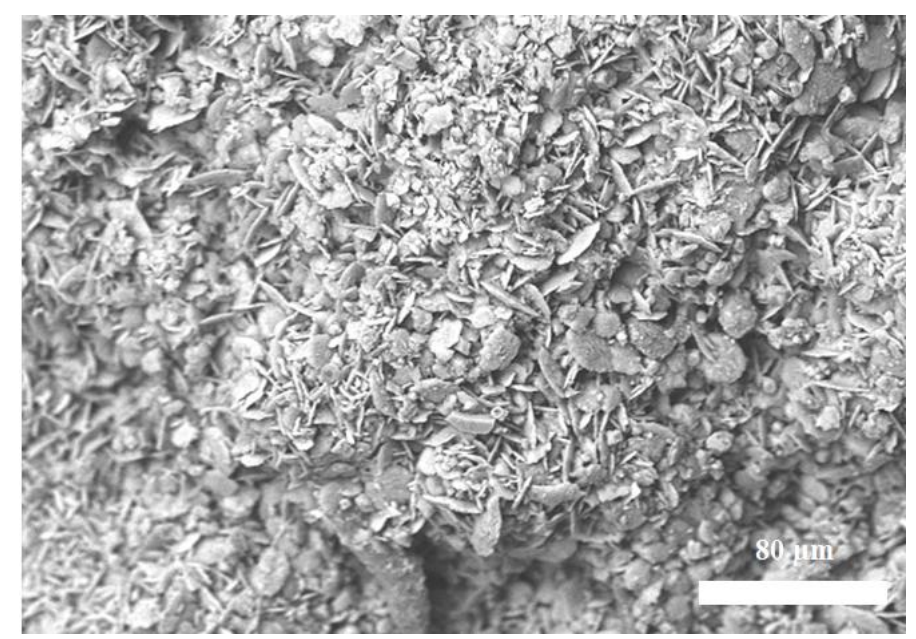

Figura 1.8. Imagen por SEM en modalidad electrones retrodispersados donde se observa la disgregación del material pétreo por acción de la cristalización interna y superficial de sulfato de calcio.

Los cloruros también constituyen unas tipologías de sales dañinas para los materiales pétreos debido a su alta higroscopicidad y capacidad de penetrar en los poros de los materiales ${ }^{31}$. En la imagen SEM de la Figura 1.9 se observa la alteración en la superficie del material pétreo por cristalización de cloruro de sodio.

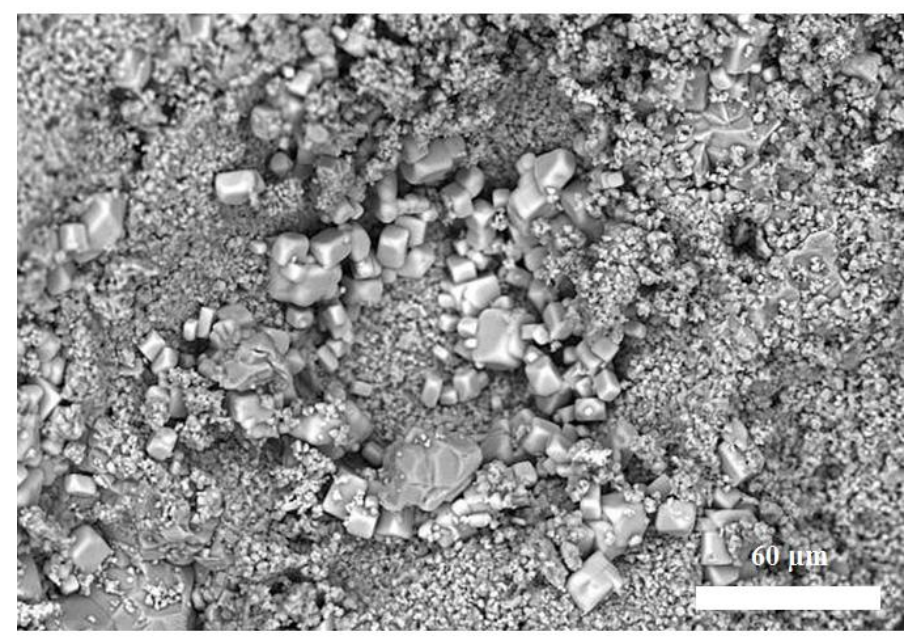

Figura 1.9. Imagen por SEM de la superficie de un sustrato pétreo con cristales de $\mathrm{NaCl}$. El cloruro de sodio se presenta en fase sólida con una estructura cristalina cúbica.

\footnotetext{
${ }^{31}$ K. Zehnder, Weathering of molasse sandstones on monuments and natural outcrops. Proc. 3rd Int. Cong. Deterioration and Preservation of Stones, Venice, 2427/X/1979.
} 
Otro factor considerado crítico para la conservación de los bienes culturales en soporte pétreo o pintura mural, son los agentes biológicos como hongos, líquenes y musgos que colonizan las superficies que constituyen el monumento o la pintura mural. En este caso se habla de biodeterioro, que se refiere a acciones físicas, mecánicas, químicas y estéticas producidas por la actividad vital de organismos que conducen a las alteraciones del sustrato sobre el que se desarrollan ${ }^{32}$. El biodeterioro ${ }^{33}$, por lo general, se manifiesta con capas superficiales de color diferentes que crean alteración estética con la formación de las costras biológicas o biopátina (la pátina representa el estado envejecido o alterado de un material, que se manifiesta con alteración cromática y una modificación superficial más significativa de tipo mecánico, químico, biológico, etc.).

La alteración con acción mecánica se produce, en gran parte, por los cambios volumétricos y las presiones ejercidas sobre la estructura de la piedra o mortero por parte de raíces, rizinas e hifas que penetran en la porosidad y grietas del material. A este primer mecanismo de deterioro se añade el mecanismo de degradación de tipo químico-corrosivo, y que es atribuible a las sustancias ácidas emitidas durante el metabolismo de estos agentes biológicos y que pueden solubilizar o transformar el material de carbonato de calcio.

En Figura 1.10 se muestran ejemplos de biopátina en soporte pétreo y en pintura mural (imágenes A y B). En las imágenes $\mathrm{C}$ y D se evidencia el deterioro causado por la presencia de líquenes de tipo crustosos sobre soporte pétreo originando cromatización y disgregación del sustrato. La imagen SEM de la Figura 1.11, es un claro ejemplo del crecimiento de agentes biológicos como los líquenes crustosos de tipo calcífilo sobre la superficie del sustrato pétreo. En este último caso, los líquenes se encuentran entre los principales agentes de alteración bioquímica implicados en la transformación de la roca por la facilidad de producir $\mathrm{CO}_{2}$ y ácido oxálico, con la sucesiva formación de las pátinas de oxalatos. Además, su carácter esponjoso hace que retengan la humedad en la piedra subyacente lo que contribuye a un daño posterior, ya que mantienen un contenido de agua en la roca casi continuamente por encima del valor crítico y, dado que uno de los principales mecanismos de alteración se debe al número de ciclos mojado-secado de la piedra, tales áreas están preservadas frente a la acción de las sales porque el número de ciclos es pequeño, pero peligran respecto a posible acción de heladas. Otro aspecto crítico, como se observa en la Figura 1.11, es la alteración mecánica producida por el crecimiento de los rizomas de los líquenes en el sustrato pétreo. Este crecimiento provoca tensiones mecánicas con sucesiva formación de micro-rupturas y disgregación del material.

\footnotetext{
${ }^{32}$ G. Amoroso, Trattato di scienza della conservazione dei monumenti. ALINEA editrice, Firenze 2002.

${ }^{33}$ U. Alesi, Il restauro dei materiali in architettura. Tecnoservizi s.c.r.l., Ascoli Piceno,Tipografia Fast Edist, Acquaviva Picena (AP). www.umbertoalesi.it.
} 

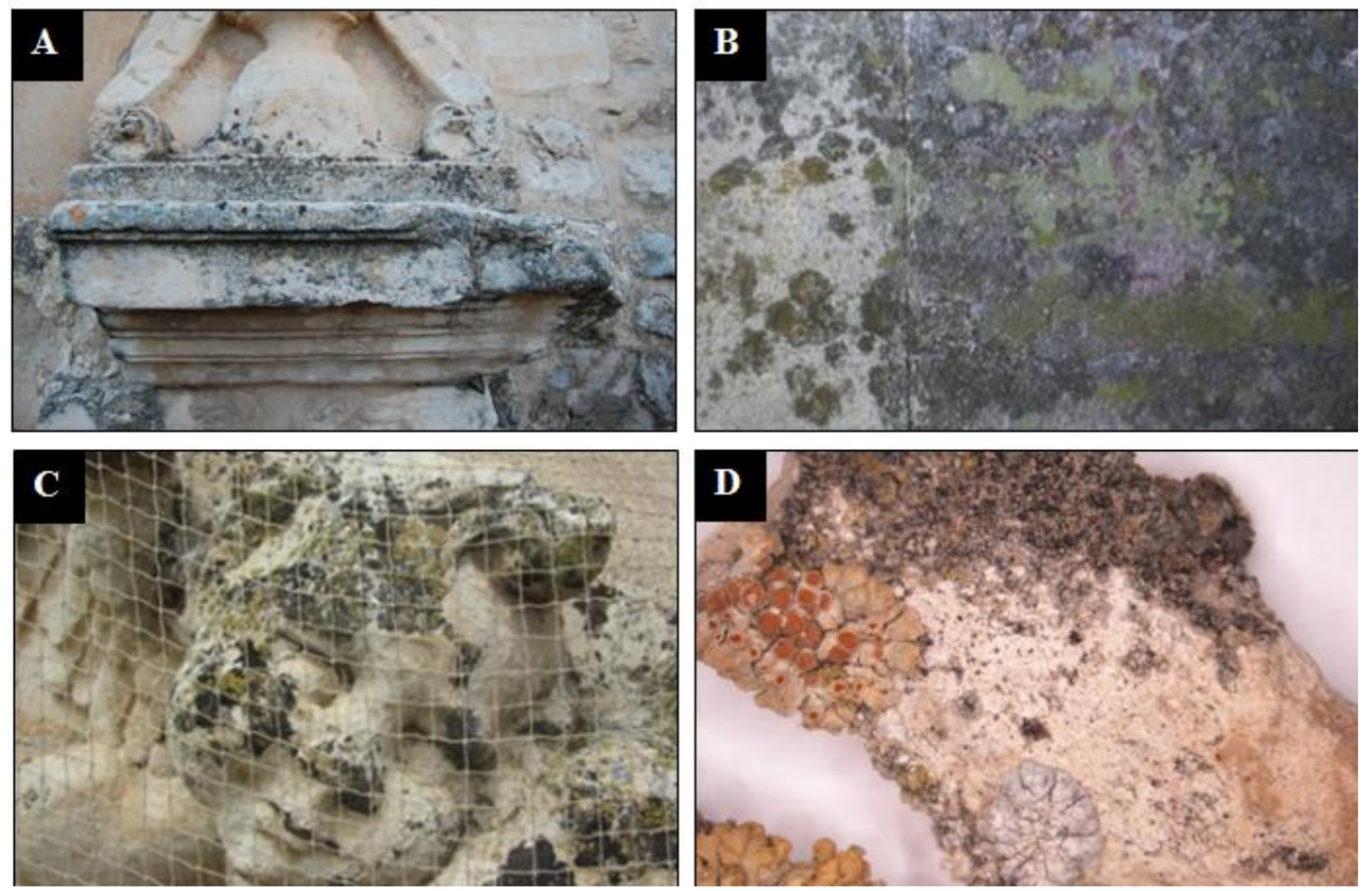

Figura 1.10. A y B) Ejemplos de formación de la biopátina sobre la superficie pétrea y en pintura mural. C y D)

Presencia de líquenes de tipo crustosos sobre soporte pétreo causando cromatización y disgregación del sustrato.

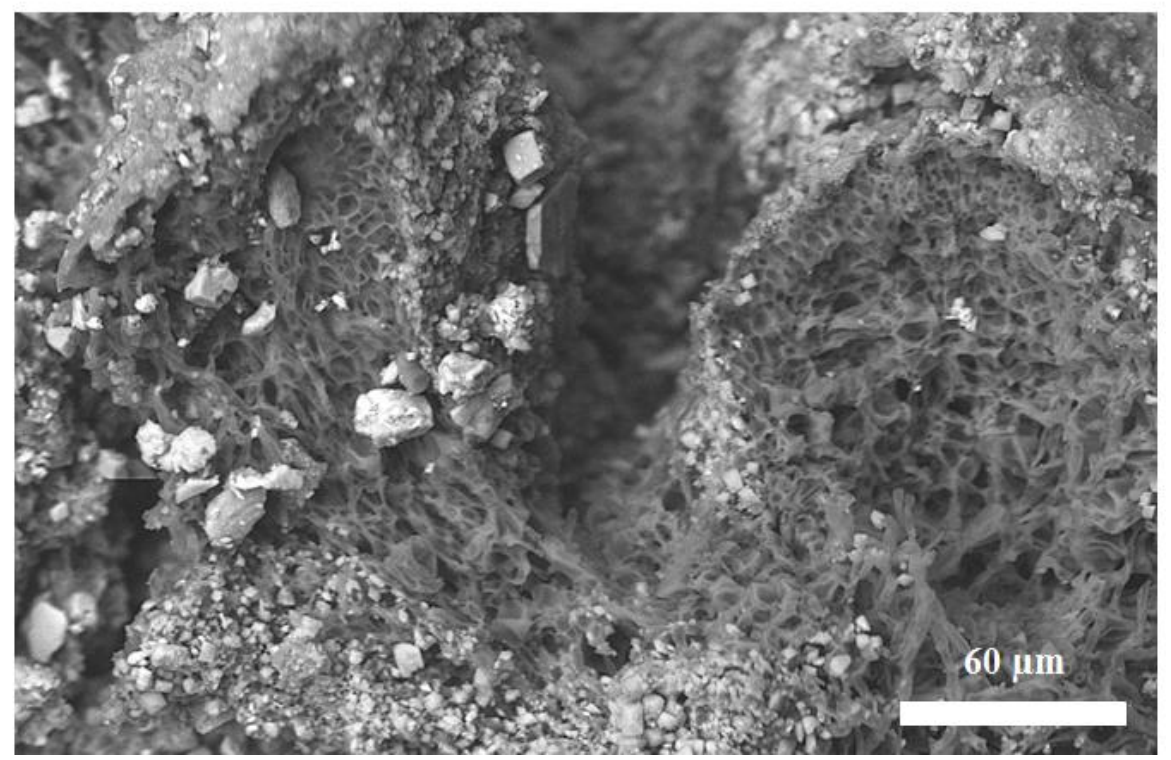

Figura 1.11. Imagen por SEM en modalidad electrones retrodispersados. Se observa la disgregación del material pétreo por acción del crecimiento de la estructura del liquen. 
Por último, el resultado del deterioro de las superficies artísticas también ha sido provocado en numerosos casos por antiguas intervenciones de restauración donde se han utilizado productos que presentan la gran desventaja de no tener compatibilidad químico-física con el sustrato de la obra.

En las últimas tres décadas, han sido numerosos los productos utilizados para los tratamientos de consolidación y protección para materiales pétreos y pinturas murales. Destacan los fijadores de naturaleza orgánica, las resinas acrílicas y los polímeros de vinilo comúnmente empleados en la consolidación de la piedra o de paredes pintadas, así como los compuestos a base de alcóxidos de silicio tales como el tetraetilortosilicato (TEOS) o de silicatos de etilo $\left(\mathrm{C}_{2} \mathrm{H}_{5}\right)_{4} \mathrm{SiO}_{4}{ }^{34,35}$.

La mayoría de estos productos utilizados en la consolidación y protección del patrimonio cultural en piedra y sus derivados, no presentan una excelente compatibilidad con las características intrínsecas del sustrato tratado (composición química, características petrográficas y propiedades físicas), o con los factores ambientales tales como agua, temperatura, contaminación atmosférica, etc. La existencia de estos factores de incompatibilidad ha determinado la aparición de toda una serie de mecanismos de alteración que se observan como modificaciones superficiales (cromatización, pátinas), eliminación o pérdida de materia, deformaciones, rupturas, etc.

\footnotetext{
${ }^{34}$ R. Villegas, M. Alcalde, J.F. Vale, A. Martín, Diagnosis y tratamiento de la piedra. I. La alteración de la piedra en monumentos. II. Consolidantes e hidrófugos. Productos para el tratamiento de materiales pétreos. I. C. Construcción Eduardo Torroja. CSIC. Monografía no 400. Madrid, 1990.

${ }^{35}$ J. López, Utilización de consolidantes e hidrofugantes en la conservación de la piedra natural. Características técnicas de algunos de los productos más utilizados actualmente. V Congreso de Geoquímica de España, 1993.
} 


\subsection{Los tratamientos de consolidación y protección}

En los materiales pétreos, morteros y decoraciones parietales que presentan mecanismos de alteración y deterioro, se evidencian generalmente fenómenos de disgregación y pulverización de las superficies, con la pérdida de adhesión y cohesión entre los constituyentes mineralógicos del soporte o entre los constituyentes de los estratos pictóricos. Estos mecanismos comportan una progresiva pérdida de la resistencia mecánica y de material por lo que es necesario intervenir mediante tratamientos de restauración, de consolidación y protección $^{36,37}$.

La consolidación y protección superficial es un tratamiento casi siempre imprescindible en los procesos de intervención de materiales inorgánicos en bienes culturales tales como los soportes pétreos, decoraciones parietales y a otros soportes de interés como pueden ser los materiales óseos de procedencia arqueológica y paleontológica $^{38}$. Estos tratamientos persiguen, mediante la aplicación de un material consolidante o protector, la restitución -en la medida de lo posible- de la cohesión mecánica superficial perdida, buscando la máxima penetración del producto, la adhesión entre la zona alterada y sana del sustrato, evitando así la formación de películas superficiales. La aplicación de estos productos permite aumentar la cohesión y adhesión interna de los constituyentes y disminuir la porosidad del soporte alterado, evitando la entrada de humedad en el sistema poroso del soporte al ser el agua el agente fundamental en la mayor parte de los procesos de deterioro químico, físico y biológico. Por tanto, los productos aplicados permiten aumentar la resistencia mecánica de los materiales alterados frente a futuros agentes de deterioro. La finalidad principal es conseguir la introducción de estas sustancias disueltas o dispersas en el interior de poros y grietas de manera que, una vez se produzca la evaporación del disolvente, las partes de materia anteriormente descohesionadas se mantengan unidas por el componente sólido de la solución. Así, para asegurar la efectividad del tratamiento, se debe perseguir una alta penetración de estas soluciones líquidas para que se pueda depositar la mayor cantidad posible de consolidante en el interior del material.

\footnotetext{
${ }^{36}$ R. Villegas, M. Alcalde, J.F. Vale, A. Martín, Diagnosis y tratamiento de la piedra. I. La alteración de la piedra en monumentos. II. Consolidantes e hidrófugos. Productos para el tratamiento de materiales pétreos. I. C. Construcción Eduardo Torroja. CSIC. Monografía no 400. Madrid, 1990.

${ }^{37}$ L. Lazzarini, M. Laurenzi-Tabasso, Il restauro della pietra, CEDAN. Ed. Dott. Antonio Milani, 1986.

${ }^{38}$ A. E. Rixon, Fossil Animal Remains: Their Preparation and Conservation. London: Athlone Press, 1976.
} 
Los productos para la consolidación, tanto de naturaleza orgánica como inorgánica, en general se presentan en fase liquida y son capaces, una vez han penetrado en los poros del sustrato, de pasar al estado sólido generando estructuras reticuladas que se adhieren a la superficie de los poros y restableciendo parcialmente las propiedades mecánicas al sustrato. Las características mecánicas de un material rocoso o de un mortero, dependen de su homogeneidad y de la composición mineralógica, por lo que resulta importante la elección del producto consolidante a utilizar y del conjunto de las propiedades mecánicas que la pieza tenía en origen, añadiendo durabilidad y fiabilidad ${ }^{39}$. Además de la posibilidad de recuperar la cohesión y adhesión, la continuidad de la materia, etc., la consolidación también permite mejorar algunas características inherentes del material para que sea más resistente a los procesos de alteración. Un ejemplo, como ya se ha descrito anteriormente, es la disminución y la uniformidad de la porosidad de sustrato, ya que la falta de homogeneidad estructural es un factor que acelera los mecanismos de alteración. De esta manera, los materiales resultan menos accesibles a disoluciones acuosas salinas y ácidas ${ }^{40}$.

Por lo que respecta a los tratamientos de consolidación y protección superficial en pinturas murales, las intervenciones proporcionan una nueva adhesión de la capa pictórica al soporte cuando se presentan fenómenos de alteración como la exfoliación. Asimismo, permite una nueva cohesión interna a la capa pictórica, entre las partículas del pigmento, cuando se presentan fenómenos de pulverización por pérdida del aglutinante. El tratamiento permite realizar una acción de adhesión y cohesión más interna, que involucra las diferentes capas de morteros o la capa de pintura con el mortero.

En la intervención de consolidación y protección, una vez evaluados los diferentes aspectos relacionados con la elección del producto, estos pueden ser aplicados sobre la superficie del sustrato en varias formas: en disolución, en emulsión o en suspensión ${ }^{41}$.

1. Disolución: El uso de disoluciones resulta ser la metodología de intervención más común para la consolidación y protección de materiales pétreos, pinturas murales, etc. Generalmente, el disolvente utilizado es de tipo orgánico -alcoholes, acetona- aunque la tendencia es la sustitución de estos disolventes por agua con el fin de reducir los costes, facilitar el manejo y evitar la contaminación de los operadores y del medio ambiente. La formación del depósito sólido del producto aplicado en el soporte alterado se produce por evaporación del disolvente. Inicialmente la velocidad de evaporación depende de la naturaleza del disolvente, posteriormente, puesto que la viscosidad del depósito se

\footnotetext{
${ }^{39}$ M. Matteini, A. Moles, La chimica nel restauro. I materiali dell'arte pittorica. Nardini Editore, 2007.

${ }^{40}$ A. Campanella, A. Casoli, M. P. Colombini, R. Marini Bettolo, M. Matteini, L. M. Migneco, A. Montenero, L, Nodari, C. Picciol i, M. Plossi Zappalà, G. Portalone, U. Russo, M. P. Sammartino, Chimica per l'arte. Zanichelli Editore, 2007.

${ }^{41}$ G. Amoroso, Trattato di scienza della conservazione dei monumenti. ALINEA editrice, Firenze 2002.
} 
vuelve cada vez más alta, la evaporación dependerá de la velocidad de difusión de las moléculas del disolvente dentro de la estructura del depósito. La posible retención del disolvente actúa como un plastificante, reduciendo la rigidez del depósito. Después del secado sigue un período de estabilización en que el depósito del producto aplicado adquiere forma y consistencia. La viscosidad de una disolución dependerá tanto de la concentración del polímero como del tamaño de sus moléculas.

2. Emulsión: Las emulsiones son mezclas heterogéneas que constan de al menos dos líquidos inmiscibles, uno de los cuales está disperso en el otro en forma de gotas, cuyo diámetro es generalmente mayor de $0,1 \mu \mathrm{m}$. Se obtienen a través de una fuerte agitación y homogeneización y su estabilidad, en general, se mantiene por la inclusión de aditivos, tales como tensioactivos, que actúan como emulsionantes y agentes dispersantes. La película sólida, generalmente un retículo más o menos continuo, se forma en el sustrato a través de la evaporación de la fase dispersante, típicamente agua, a través de un proceso de coalescencia de la fase dispersa. La viscosidad de las emulsiones resulta ser baja también con altas concentraciones de la fase dispersa y es casi independiente del tamaño molecular del polímero. La tensión superficial generalmente alta de estos sistemas suele reducir la penetración en la porosidad del material mostrando la tendencia de concentrarse en la superficie del soporte ${ }^{42}$.

3. Suspensión: Las suspensiones son mezclas de un material sólido (fase dispersa) en polvo finamente dividido, o por pequeñas partículas no solubles con diámetros entre 1 y $100 \mathrm{~nm}$ (coloides), disperso en un segundo material líquido (fase dispersante). A diferencia de las disoluciones, las suspensiones coloidales generalmente aparecen opacas debido al efecto Tyndall.

\footnotetext{
${ }^{42}$ A. Cadorin, Studio e valutazione delle proprietà consolidanti di sistemi inorganici nanofasici applicati su supporti porosi. Tesi di Laurea specialistica in Scienze e Tecnologie dei Materiali, Relatore prof.ssa E. Zendri, Università Ca’ Foscari di Venezia, Facoltà di Scienze MM. FF. NN., A.A 2007-2008.
} 


\subsubsection{Propiedades del consolidante}

Para que un tratamiento de consolidación o de protección sea eficiente y que, además, resulte adecuado, fiable y estable en el tiempo, es fundamental que los productos que se apliquen muestren una serie de criterios y propiedades específicas ${ }^{43}$ relacionados tanto con la fase de aplicación como a su estabilidad en el tiempo e interacción con el sustrato. En primer lugar es importante que los productos aplicados tengan una buena compatibilidad químico-física con los materiales del sustrato.

- Compatibilidad química: Los productos aplicados tienen que presentar inercia química respecto a los materiales constituyentes del sustrato tratado. No mostrar ninguna acción disolvente o reactiva sobre los materiales constitutivos y tener buena resistencia a las distintos parámetros del medio ambiente y a los procesos de alteración y degradación de tipo químico, físico y biológico de manera que no induzcan a una cinética de alteración más rápida del soporte tratado. Además, no deberán dejar residuos que puedan dañar el soporte y no debería desarrollar productos secundarios que puedan resultar nocivos.

- Compatibilidad física: Los productos consolidantes y protectores tienen que presentar un comportamiento similar en cuanto a coeficiente de dilatación térmica, sensibilidad a la humedad, modulo elástico, permeabilidad, transpirabilidad y absorción por capilaridad. La permeabilidad es una característica que, tras el tratamiento, no tiene que variar demasiado ya que los procedimientos aplicados no deben obstaculizar la libre circulación del agua en el sistema poroso del soporte, evitando de esta manera fenómenos de retención y condensación interna.

- Buena capacidad de penetrar en profundidad, evitando la formación de películas espesas superficiales. Un consolidante debe restablecer la cohesión entre la zona externa alterada y el sustrato interno sin alterar. La interfase entre las dos zonas marca un cambio de las propiedades físico-mecánicas tales como el coeficiente de dilatación térmica, porosidad o permeabilidad al agua líquida y vapor; si este cambio es muy brusco, puede llevar al desprendimiento de la capa tratada. La profundidad de penetración es inversamente proporcional a la viscosidad del producto y al ángulo de contacto con la piedra. Los productos existentes para los tratamientos de consolidación y protección de la piedra cumplen, en general, las prestaciones para las que han sido diseñados, sin embargo, la mayoría están concebidos para ser aplicados a materiales homogéneos, con una composición, textura y porosidad uniformes. Por el contrario, la piedra es un material generalmente heterogéneo en

\footnotetext{
${ }^{43}$ M. Matteini, A. Moles, La chimica nel restauro. I materiali dell'arte pittorica. Nardini Editore, 2007.
} 
textura, porosidad, etc., lo que condiciona un distinto grado de penetración y distribución de los productos de tratamiento en el seno de la piedra y, por tanto, una diferente durabilidad.

- Los disolventes deben tener tensión superficial y viscosidad baja. Estos factores, junto con un bajo peso molecular y una baja reactividad en las primeras horas del tratamiento, favorecen la penetración del consolidante en la estructura porosa del material.

- No tóxicos para el restaurador y el medioambiente.

- Tienen que presentar poca coloración o ser preferiblemente transparentes, deben mejorar la adherencia del color al soporte y no tienen que alterar el aspecto cromático de la superficie (aspecto, brillo, color) $)^{44}$.

Como última propiedad que se exige a los productos para la consolidación y protección, es la reversibilidad, o sea la posibilidad de eliminación del producto aplicado cuando se considere oportuno. El término de reversibilidad se entiende como un criterio fundamental que tiene que existir en todas las intervenciones y con todos los productos en la restauración de bienes de interés cultural en las distintas tipologías de soportes ${ }^{45,46}$. Como se ha indicado con anterioridad, a través del tratamiento de consolidación se persigue una homogénea y buena penetración del producto en el sistema poroso del sustrato, por tal razón, prácticamente no existen métodos para la eliminación del producto introducido. En este caso, conseguir una total reversibilidad es difícil. Es posible, únicamente, una eliminación parcial y superficial del consolidante con los posibles daños mecánicos y estéticos que se pueden generar. Por este motivo es importante el desarrollo y la utilización de productos lo más compatibles químicamente y físicamente con el soporte, que tengan buena durabilidad y resistencia frente a los mecanismos de alteración y degradación de tipo químico, físico y biológico.

\footnotetext{
${ }^{44}$ G. Biscontin, B. Driussi, Colour changes in resin-treated stone materials, scientific methodologies applied to works art. Firenze. $101,1984$.

${ }^{45}$ M. Matteini, A. Moles, Aspetti critici del trattamento fondato sull'impiego di idrato di bario. in: C. Danti, M. Matteini, A. Moles, (Editor), Florence: Centro Di della Edifimi s.r.1. 297-302, 1990.

${ }^{46}$ G. Biscontin, E. Zendri, G. Driussi, Reversibilità e prestazioni delle operazioni e dei prodotti per il restauro. in La reversibità nel restauro. Atti del convegno di studi di Bressanone. Scienza e Beni Culturali XIX”, Bressanone, Ed. Arcadia Ricerche, 2003.
} 


\subsubsection{Productos consolidantes tradicionales}

Los tratamientos de consolidación y de protección de superficies pétreas, morteros y pinturas murales se han aplicado desde la Antigüedad hasta nuestros días con productos y resultados muy diversos. En las intervenciones más antiguas, donde se empleaban materiales similares a las obras a tratar como el agua de cal, se aseguraba una total compatibilidad entre los materiales añadidos y los materiales originales, pero con una limitada acción del tratamiento, generalmente poca penetración en el sustrato tratado, alteraciones estéticas superficiales con la formación de patinas blancas que alteraban el aspecto de la obra.

A partir de la Revolución Industrial y el desarrollo de la química moderna, la oferta de productos disponibles en el mercado ha aumentado considerablemente. Se han sintetizado nuevos compuestos y materiales que actualmente se están empleando en la conservación y la restauración del patrimonio cultural, pero no siempre con los resultados esperados. En base a la naturaleza química, los productos consolidantes utilizados principalmente en la conservación de los sustratos inorgánicos, se pueden dividir en diferentes clases: productos inorgánicos y productos de naturaleza orgánica de composiciones heterogéneas como silicatos y alquil-alcoxi-silanos que conducen a la formación de polímeros de silicio ${ }^{47}$. En la actualidad, se están desarrollando cada vez más nuevas formulaciones de productos de consolidación y protección a base de micro polímeros orgánicos, dispersiones acuosas de nanomateriales o de sílice coloidal ${ }^{48}$. Más recientemente, también se han desarrollado materiales híbridos orgánico-inorgánicos ${ }^{49}, 50$, incluso de carácter nanofásico, con un gran número de posibles aplicaciones en los tratamientos de restauración de bienes culturales.

A continuación se describen los antecedentes en cuanto a los diferentes tipos de materiales utilizados como consolidantes y protectores para sustratos inorgánicos hasta el momento utilizados.

\footnotetext{
${ }^{47}$ L. Falchi, Studio chimico-fisico di consolidanti a base di resine acriliche e silici colloidali in dispersione acquosa per malte storiche. Tesi specialistica in Scienze chimiche per la conservazione e il restauro, Relatore prof. G. Biscontin, Università Ca' Foscari di Venezia, Facoltà di Scienze MM. FF. NN., A.A 2008-2009.

${ }^{48}$ R. Giorgi, L. Dei, P. Baglioni, A new Method for consolidating wall paintings based on dispersions of lime in alcohol. Stud. Cons. 45. 154-161, 2000.

${ }^{49}$ R. Kasemann, H. Schmidt, New J. Chem. 18, 1117, 1994.

${ }^{50}$ L. Ruiz-Villar, Criterios y problemática de la selección y uso de consolidantes e hidrofugantes. V Congreso de Geoquímica de España, 1993.
} 


\subsubsection{Consolidantes inorgánicos}

Por la semejanza de los productos inorgánicos con acción consolidante y protectora respecto a los sustratos pétreos y sus derivados, tanto en composición como en las propiedades químicas y físicas, han hecho que estos compuestos inorgánicos hayan sido ampliamente utilizados en la restauración desde varios siglos hasta la actualidad.

Los materiales inorgánicos se aplican generalmente en disolución acuosa y, a través de las reacciones químicas que tienen lugar con el agua o con algunos componentes del aire, precipitan dentro de los poros del material como sales insolubles. Presentan un pequeño tamaño de partícula que favorece la penetración en el sistema poroso de los materiales pétreos y morteros. Además, por su naturaleza inorgánica, resultan compatibles químicamente con el soporte, así como estables en el tiempo. Por otro lado, estos materiales inorgánicos presentan las desventajas de tener una limitada capacidad de adhesión, de hecho, no forman enlaces fuertes con las paredes de los poros, tienden casi únicamente a rellenar los poros determinando un acción de consolidación más escasa respecto a otros tipos de productos de naturaleza diferente. El relleno y la oclusión de los poros en el material tratado también pueden crear estructuras poco homogéneas con la generación de tensiones en la interfaz entre el material tratado y no tratado. Finalmente, la aplicación de estos compuestos inorgánicos puede ser fuente de subproductos dañinos para el material tratado, con la formación de sales solubles como $\mathrm{CaSO}_{4}$, generando los mecanismos de cristalización con aparición de eflorescencias, subeflorescencias y criptoflorescencias ${ }^{51}$.

Los productos elaborados con elementos inorgánicos, generalmente disoluciones acuosas de hidróxido de calcio $\mathrm{Ca}(\mathrm{OH})_{2}$ o de hidróxido de bario $\mathrm{Ba}(\mathrm{OH})_{2}$, presentan la ventaja de tener una elevada compatibilidad físico-mecánica y química con la matriz de la piedra, morteros y de las pinturas murales, presentando también alta durabilidad y resistencia en el tiempo. Estos productos a través específicas reacciones químicas precipitan formando compuestos en el interior de la estructura del material, aglutinando las partículas o los diferentes componentes del soporte con acción cementante. En general, la consolidación de las superficies con estos productos resultan ser irreversibles; esto es una desventaja si se observa bajo los principios de reversibilidad que deben tener los métodos y los productos utilizados en la conservación y restauración de los Bienes Culturales, sin embargo, presentan la ventaja de conservar la hidrofilía y la permeabilidad a los líquidos de las superficies tratadas, y de proporcionar nuevamente una adecuada porosidad dentro del material que puede ser generalmente alterada por los diferentes fenómenos de alteración. En el caso del $\mathrm{Ca}(\mathrm{OH})_{2}$, el mayor inconveniente al utilizarlo como consolidante, es su baja solubilidad en agua, 1,7 $\mathrm{gl}^{-1}$ a 20

\footnotetext{
${ }^{51}$ A. Laurenzi, M. L. Tabasso, La conservazione dei materiali lapidei: aspetti scientifici e tecnici. Venezia, 1988.
} 
${ }^{\circ} \mathrm{C}$, además hay que tener en cuenta la inestabilidad de las dispersiones acuosa con cal viva, presentando una alta velocidad de sedimentación.

En cuanto al hidróxido de bario utilizado como consolidante, este compuesto presenta la ventaja de la gran compatibilidad química física del carbonato de bario que se genera, con los componentes constitutivos de los morteros, pinturas murales y soportes pétreos, que resultan ser, en la mayoría de los casos, de tipo mineral. Destaca en la conservación de las pinturas murales y de los soportes a base de carbonato de calcio y magnesio, ya que permite minimizar la acción de degradación determinada por los mecanismos de sulfatación $^{52}$. Este tratamiento permite eliminar el sulfato de calcio formado por los mecanismos de alteración química de la piedra por acción de los compuestos del azufre como explicado anteriormente (ec. 1.6 - 1.8). En una primera fase de intervención hay una reacción de intercambio entre el sulfato de calcio del sustrato alterado y el carbonato de amonio introducido con el tratamiento, y de eliminar sucesivamente el sulfato de amonio que se ha formado (sal soluble), haciéndolo reaccionar con el hidróxido de bario que genera la formación del sulfato de bario, una sal inerte, poco soluble y poco hidratable. Los mecanismos de las reacciones se indican en las ecuaciones 1.9 y 1.10 :

$$
\begin{aligned}
& \left(\mathrm{NH}_{4}\right)_{2} \mathrm{CO}_{3}(\mathrm{ac})+\mathrm{CaSO}_{4} \cdot 2 \mathrm{H}_{2} \mathrm{O}(\mathrm{s}) \rightarrow\left(\mathrm{NH}_{4}\right)_{2} \mathrm{SO}_{4}(\mathrm{~s})+\mathrm{CaCO}_{3}(\mathrm{~s})+2 \mathrm{H}_{2} \mathrm{O}(\mathrm{ac}) \\
& \left(\mathrm{NH}_{4}\right)_{2} \mathrm{SO}_{4}(\mathrm{~s})+\mathrm{Ba}(\mathrm{OH})_{2}(\mathrm{~s}) \rightarrow \mathrm{BaSO}_{4}(\mathrm{~s})+2 \mathrm{NH}_{3} \uparrow+2 \mathrm{H}_{2} \mathrm{O}(\mathrm{ac})
\end{aligned}
$$

A través de la aplicación del hidróxido de bario sobre la superficie del sustrato sulfatado, se forma de manera gradual y natural también el carbonato de bario (los tiempos de carbonatación pueden variar de una semana hasta unos meses) dentro de los poros del soporte, que determina una acción cohesiva. El carbonato de bario que se forma puede considerarse cristalográficamente y químicamente similar a la del carbonato cálcico presente en los materiales pétreos y morteros. El mecanismo de reacción del hidróxido de bario con el dióxido de carbono atmosférico que precipita como carbonato de bario en la estructura cristalina del soporte se detalla en la ecuación 1.11:

$$
\mathrm{Ba}(\mathrm{OH})_{2}(\mathrm{~s})+\mathrm{CO}_{2}(\mathrm{~g}) \rightarrow \mathrm{BaCO}_{3}(\mathrm{~s})+\mathrm{H}_{2} \mathrm{O}(\mathrm{ac})
$$

\footnotetext{
${ }^{52}$ Il metodo del bario, Approfondimento, P.Torsello, Corso di Chimica del restauro, R.Giorgi, P.Baglioni, Università di Firenze A.A. 2001-2002
} 


\subsubsection{Consolidantes orgánicos}

Los consolidantes y protectores orgánicos están constituidos, principalmente, por polímeros de resinas sintéticas en fase de disolución o como dispersiones. Destacan las resinas epoxi, resinas de poliéster y polímeros vinílicos en disolución con disolventes orgánicos o en dispersión acuosa ${ }^{53,54}$.

El uso de estos polímeros en los tratamientos de restauración de soportes inorgánicos está favorecido por una mayor elasticidad que permite solucionar los problemas relacionados con los diferentes coeficientes de dilatación térmica del soporte respecto a los consolidantes de naturaleza inorgánica. Estos productos poliméricos de síntesis generan dentro de la porosidad del sustrato tratado una película coherente y continua, o forman retículos tridimensionales que consolidan y mejoran la capacidad mecánica del material. También tienen buenas propiedades de adherencia, resistencia mecánica y un cierto carácter hidrófobo. Son, generalmente, reversibles porque son solubles en disolventes orgánicos, incluso después de la polimerización. Sin embargo, los aspectos negativos que poseen son las incompatibilidades físico-químicas y la rápida degradación de la estructura polimérica causada por el natural envejecimiento o por la interacción con agentes del medioambiente, sobre todo de la radiación solar UV donde se generan reacciones de fotoxidación de las moléculas del polímero con amarillamiento de la película y pérdida de las propiedades de adhesión con un aumento de la fragilidad del sistema ${ }^{55}$.

\footnotetext{
53 T. J. S. Learner, Analysis of Modern Paints. The Getty Conservation Institute, 2004; C. V. Horie, Materials for Conservation, Organic consolidants, adesive and coatings. ELSEVIER, 1987.

${ }^{54}$ L. Borgioli, P. Cremonesi, Le resine sintetiche usate nel trattamento delle opere policrome. collana I talenti, editore Il Prato, 2005.

${ }^{55}$ L. Lazzarini, M. L. Tabasso, Il restauro della pietra. Ed. Cedam, 1986.
} 


\subsection{Consolidantes nanométricos comerciales}

La expresión nanotecnología se refiere un sector de la ciencia aplicada interesada en el estudio, diseño, síntesis y aplicación de materiales a escala nanométrica. El desarrollo de esta disciplina se produce a partir de las propuestas de Richard Feynman, Premio Nóbel de Física en $1965^{56}$. A esta escala, la materia presenta características y propiedades totalmente nuevas, que permiten desarrollar nuevos materiales, sistemas, etc., con propiedades únicas. Los nanomateriales representan materiales cuyas partículas que lo forman poseen propiedades morfológicas más pequeñas que una décima de micrómetro en al menos una dimensión. La bibliografía nos muestra que existen estudios relacionados con la nanotecnología para la conservación de los materiales de obras de bienes de interés cultural, donde se ofrecen innovadores productos nanoestructurados. Los primeros estudios que fueron desarrollados en la pasada década, se basan en la síntesis y aplicación de nanopartículas a base de hidróxido de calcio, $\mathrm{Ca}(\mathrm{OH})_{2}$, hidróxido de magnesio, $\mathrm{Mg}(\mathrm{OH})_{2}$, y hidróxido de bario $\mathrm{Ba}(\mathrm{OH})_{2}$, y que tienen importantes aplicaciones hoy en día en la consolidación de pinturas murales o piedra, y en la neutralización de la acidez de los papeles o de maderas, garantizando la durabilidad en el tiempo de estos materiales. Por tanto, resulta evidente que obtener materiales tradicionales a escala nanométrica permite disponer de nuevos productos con prestaciones distintas y mejoradas, entre ellas la posibilidad de disponer de dispersiones estables y mejorar, por ejemplo, la penetración de los consolidantes en la estructura porosa del material que constituye el soporte pétreo, mortero o de la pintura mural. Sin embargo, la eficacia de consolidación y la estabilidad en el tiempo de estos nuevos productos están hoy en día aún en fase de estudio y evaluación.

Sobre la investigación referente a la síntesis de nanopartículas de hidróxido de calcio y de hidróxido de bario, cabe resaltar los estudios realizados por el grupo CSGI (Center for Colloid and Surface Science) de Florencia (Italia), cuyo objetivo principal es evaluar los mecanismos de síntesis más adecuados en la producción de las nanopartículas variando las condiciones de síntesis ${ }^{57,58}$. La síntesis de estas nanopartículas de hidróxido de calcio se realiza por precipitación de disoluciones de cloruro de calcio $\mathrm{CaCl}_{2}$ e hidróxido sódico $\mathrm{NaOH}$ en una atmosfera controlada de nitrógeno para evitar la carbonatación por reacción con el $\mathrm{CO}_{2}$ del aire. La disolución acuosa de precipitación obtenida se sustituye por otra a base de alcoholes alifáticos de cadena corta (etanol, propanol o isopropanol) con el fin de evitar la aglomeración en la dispersión de las

\footnotetext{
${ }^{56}$ http://es.wikipedia.org/wiki/Richard_Feynman; http://www.euroresidentes.com/futuro/nanotecnologia/historia_nanotecnologia.

${ }^{57}$ R. Giorgi, L. Dei, P. Baglioni, A New Method for Consolidating Wall Paintings Based on Dispersions of Lime in Alcohol. Stud. Conserv., Vol. 45, no. 3. 154-161, 2000.

${ }^{58}$ R. Giorgi, L. Dei, M. Ceccato, C. Schettino, P. Baglioni, Nanotechnologies for conservation of cultural heritage: Paper and canvas deacidification. Langmuir, Vol. 18, no. 21. 8198-8203, 2002.
} 
nanopartículas formadas y ralentizar su velocidad de sedimentación. El principio de efectividad de las nanopartículas se basa en el hecho de que la superficie específica de un sólido aumenta exponencialmente con la disminución de su volumen por lo que, además de su mayor capacidad de penetración por los poros de materiales como la piedra por su pequeño tamaño, hay que añadir su mayor reactividad gracias a este aumento de la superficie específica ${ }^{59}$. Las nanopartículas de hidróxido de calcio en dispersión alcohólica representan teóricamente una significativa mejora técnica respecto a los productos de consolidación tradicionales. Los métodos de síntesis modernos desarrollados por los equipos de investigación permiten obtener partículas de tamaño uniforme del orden de 20 a $500 \mathrm{~nm}$, de composición química y formas bien definidas, generalmente planas y hexagonales ${ }^{60,61}$ (ver imágenes de la Figura 1.12 ${ }^{62}$ ). Estas modificaciones permiten optimizar los procesos de carbonatación en las zonas tratadas gracias a una mayor reactividad, propiciada por el aumento de la superficie específica y por la pureza química del producto ${ }^{63}$.
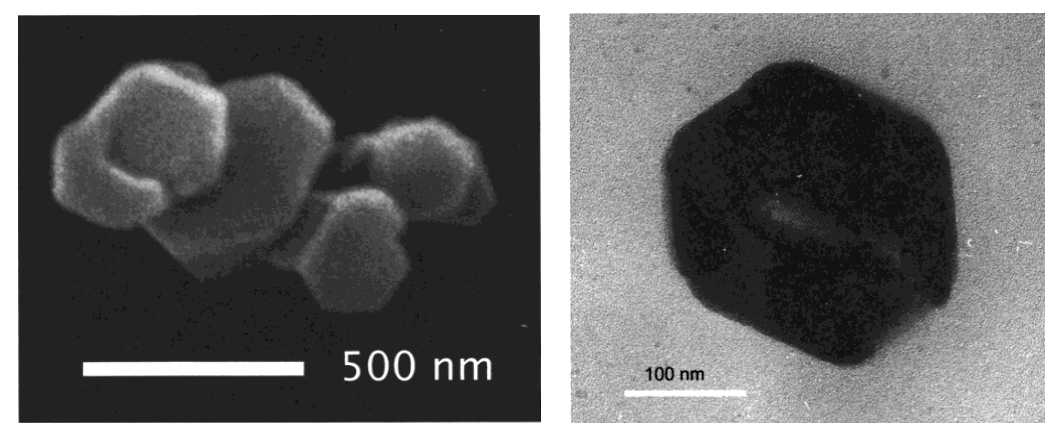

Figura 1.12. Nanopartículas de $\mathrm{Ca}(\mathrm{OH})_{2}$.

\footnotetext{
${ }^{59}$ P. López-Arce, L. S. Gómez Villalba, S. Martínez-Ramírez, M. Álvarez de Buergo, R. Fort, Influence of relative humidity on the carbonation of calcium hydroxide nanoparticles and the formation of calcium carbonate polymorphs. Powder Technol., vol. 205, no. 1-3. 263-269, 2011.

${ }^{60}$ I. Natali, M. L. Saladino, F. Andriulo, D. Chillura Martino, E. Caponetti, E. Carretti, L. Dei, Consolidation and protection by nanolime: Recent advances for the conservation of the graffiti, Carceri dello Steri Palermo and of the 18th century lunettes, SS. Giuda e Simone Cloister, Corniola (Empoli). J. Cult. Herit., Vol. 15, no. 2. 151-158, 2014.

${ }^{61}$ P. López-Arce, L. S. Gómez Villalba, S. Martínez-Ramírez, M. Álvarez de Buergo, R. Fort, Influence of relative humidity on the carbonation of calcium hydroxide nanoparticles and the formation of calcium carbonate polymorphs. Powder Technol., Vol. 205, no. 1-3. 263-269, 2011.

${ }^{62}$ M. Ambrosi, L. Dei, R. Giorgi, C. Neto, P. Baglioni, Colloidal Particles of $\mathrm{Ca}(\mathrm{OH})_{2}$ : Properties and Applications to Restoration of Frescoes, Langmuir 2001, 17.

${ }^{63}$ H. Quelart Gavaldà, V. Vergès Belmin, Nanopartícules de calç. Un nou mètode per a la consolidació de la pedra calcària. UNICUM, no. 13. 113-121, 2014.
} 
El tratamiento con nanopartículas de $\mathrm{Ca}(\mathrm{OH})_{2}$, especialmente recomendado para la consolidación y preconsolidación de soportes calizos que han sufrido una pérdida de sus propiedades mecánicas actúa del siguiente modo según Carretti y col. ${ }^{64}$ : las nanopartículas de hidróxido de calcio penetran en la matriz porosa del sustrato a base de carbonato de calcio y llevan a cabo su función consolidante formando capas de prismas hexagonales que se orientan en un empaquetado lineal que favorece la absorción de moléculas de agua interlaminares entre las sucesivas capas de hidróxido cálcico. La absorción del agua retenida favorece la correcta carbonatación al provocar la disolución del hidróxido de calcio $\mathrm{Ca}(\mathrm{OH})_{2}$ y del dióxido de carbono ambiental $\mathrm{CO}_{2}$ que en este medio básico se disocia en iones hidrogenocarbonato $\mathrm{HCO}_{3}{ }^{-}$y carbonato $\mathrm{CO}_{3}{ }^{2-}$, pasos que contribuyen a la reacción de precipitación del carbonato de calcio $\mathrm{CaCO}_{3}$. La reacción global se puede resumir mediante la siguiente reacción química ${ }^{65,66}$ :

$\mathrm{Ca}(\mathrm{OH})_{2}+\mathrm{CO}_{2}(\mathrm{~g}) \rightarrow \mathrm{CaCO}_{3}(\mathrm{~s})+\mathrm{H}_{2} \mathrm{O}(\mathrm{ac})$

De este modo se forma una red cristalina de carbonato cálcico de neoformación que se incrusta entre las partículas descohesionadas del material ejerciendo como elemento cementante de alta compatibilidad fisicoquímica $^{67}$, pero sin afectar a la porosidad y a la capacidad de intercambio de humedad, es decir, manteniendo la transpiración, tal y como se espera de un consolidante óptimo. Sin embargo, la presencia de grandes cantidades de sulfatos solubles (sulfatos de sodio o magnesio), puede limitar la acción de consolidación con nanopartículas de hidróxido de calcio. En este caso, los iones sulfato pueden reaccionar con el hidróxido de calcio y dar lugar a una reacción de doble intercambio, produciendo un yeso ligeramente soluble (sulfato de calcio dihidratado).

\footnotetext{
${ }^{64}$ E. Carretti, D. Chelazzi, G. Rocchigiani, P. Baglioni, G. Poggi, L. Dei, Interactions between Nanostructured Calcium Hydroxide and Acrylate Copolymers: Implications in Cultural Heritage Conservation. Langmuir, Vol. 29, no. 31. 9881-9890, 2013.

${ }^{65}$ H. Quelart Gavaldà, V. Vergès Belmin, Nanopartícules de calç. Un nou mètode per a la consolidació de la pedra calcària. UNICUM, no. 13. 113-121, 2014.

${ }^{66}$ P. López Arce, L. S. Gómez-Villalba, S. Martínez-Ramírez, M. Álvarez de Buergo, R. Fort, Influence of relative humidity on the carbonation of calcium hydroxide nanoparticles and the formation of calcium carbonate polymorphs. Powder Technol., Vol. 205, no. 1-3. 263-269, 2011.

${ }^{67}$ E. Carretti, D. Chelazzi, G. Rocchigiani, P. Baglioni, G. Poggi, L. Dei, Interactions between Nanostructured Calcium Hydroxide and Acrylate Copolymers: Implications in Cultural Heritage Conservation. Langmuir, Vol. 29, no. 31. 9881-9890, 2013.
} 
Las nanopartículas de hidróxido de bario pueden representar en este caso una alternativa muy útil y una herramienta complementaria para dificultar este proceso, ya que permite consolidar la estructura de la pintura mural con la formación de carbonato de bario, y convirtiendo los sulfatos en $\mathrm{BaSO}_{4}$. En la Figura $1.13^{68}$, se muestra un ejemplo de tratamiento de consolidación y protección de una pintura mural con nanopartículas de hidróxido de calcio e hidróxido de bario. El tratamiento permite reducir los daños provocado por las cristalizaciones de sales solubles. En la imagen de la izquierda se observa la presencia de sulfatos en la superficie y los fenómenos de descamación que dañan la capa de pintura. En la imagen de la derecha se observa el mismo después de la aplicación del producto consolidante a base de una mezcla de nanopartículas de hidróxido de calcio/hidróxido de bario.
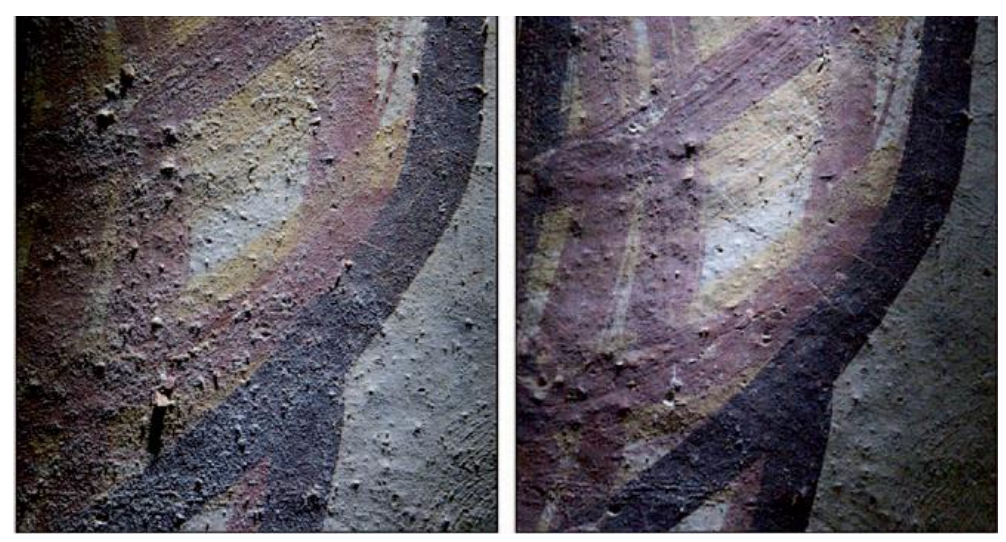

Figura 1.13. Detalles de la pintura mural de la Acrópolis de Chik Naab en Calakmul (México).

Otro importante grupo de nanomateriales que en los últimos años han experimentados un importante uso en los tratamientos de restauración de soporte pétreo, morteros, ladrillos, etc., está constituido por dispersiones acuosas de sílice coloidal. Las partículas presentan un tamaño de 10-20 nm, inferiores respecto al tamaño de partícula de las microemulsiones acrílicas $(40-50 \mathrm{~nm}$ ) o de las nanopartículas de hidróxido de calcio (200 $\mathrm{nm})$. Respecto a otros productos similares tal como los silicatos alcalinos, las nanopartículas de sílice, no forman subproductos dañinos en el soporte tratado, permitiendo una reducción mínima a la permeabilidad al vapor de agua.

\footnotetext{
${ }^{68}$ Imagen tomada de R. Giorgi et al., Nanopaticles for Cultural Heritage Conservation: Calcium and Barium Hydroxide Nanoparticles for Wall Painting Consolidation, Chem. Eur. J. 16, 9374-9382, 2010.
} 


\subsection{Limitaciones en los tratamientos de consolidación con productos comerciales}

En general, algunos de los inconvenientes o limitaciones más comunes de los consolidantes comerciales son la penetrabilidad, compatibilidad y reversibilidad. Existen casos de estudio donde se ha observado que los consolidantes y protecores poliméricos (resinas acrilicas, siliconicas, vinílicas, etc.), en sustratos inorgánicos crean importantes problemas como la limitada penetración, amarillamento de la superficie tratada por fotoxidación provocado por UV, e incremento del biodeterioro por acción de bacterias y hongos. Numerosas experiencias a lo largo de estos años han demostrado que una gran mayoría de los polímeros pueden producir daños adicionales a medio y largo plazo acelerando el deterioro. Por otro lado, los resultados obtenidos de los estudios con productos tales como el oxalato amónico, nanopartículas de hidróxido de calcio, nanopartículas de dióxido de silicio, pusieron en evidencia que estos productos presentan limitaciones en cuanto a la eficacia del tratamiento de consolidación en soportes pétreos o morteros. Algunas de estas limitaciones son:

- Insuficiente penetración del producto en los poros del sustrato tratado. Esta problemática se debe, fundamentalmente, al medio de disolución del producto (ejemplo disolventes orgánicos), al tamaño de las partículas y a la aglomeración del producto consolidante durante el periodo de almacenamiento.

- El tratamiento se localiza únicamente la zona superficial del soporte tratado, generando tensiones internas, fracturas, descamación o pulverización del soporte.

- Acumulación del producto en la superficie tratada dando lugar a variación de las coordenadas colorimetricas de las superficies, donde se observa generalmente la saturación del color, un aumento del brillo, un aspecto vidriado o formación de pátinas opacas.

- Cambios importantes en la morfología de las superficie tratadas, pudiendo crear con el tiempo subprodutos dañinos a la futura conservación de la obra.

Como ejemplos de estas limitaciones se muestran tres estudios previos realizados en este trabajo donde se pueden observar los problemas que presentan los tratamientos con los productos consolidantes hasta hora existentes. Se muestra un estudio de evaluación de un primer tratamiento realizado sobre probeta de piedra con el silicato de etilo ${ }^{69}$. Por otro lado se muestra un segundo tratamiento con hidróxido de calcio de tamaño nanométrico en dispersión en alcohol isopropílico (nanocal) y un tercer tratamiento con el hidróxido de bario en dispersión acuosa.

\footnotetext{
${ }^{69}$ A través del proceso de hidrólisis y polimerización hay la formación de un agregado amorfo de gel de sílice $\mathrm{SiO}_{2}$.
} 
1. Silicato de etilo: En la imágenes de la Figura 1.14 se muestra la misma superficie pétrea antes y después del tratamiento con silicato de etilo. Se observa cómo después del tratamiento se forma sobre la superficie de la probeta, una película del producto aplicado. Esta capa superficial provoca una saturación del color, determinando a la piedra un tenue aspecto vidriado, incrementando la saturación del color y del brillo. Este resultado indicaría la escasa penetración del producto consolidante en la estructura de la piedra, depositándose principalmente en la superficie.
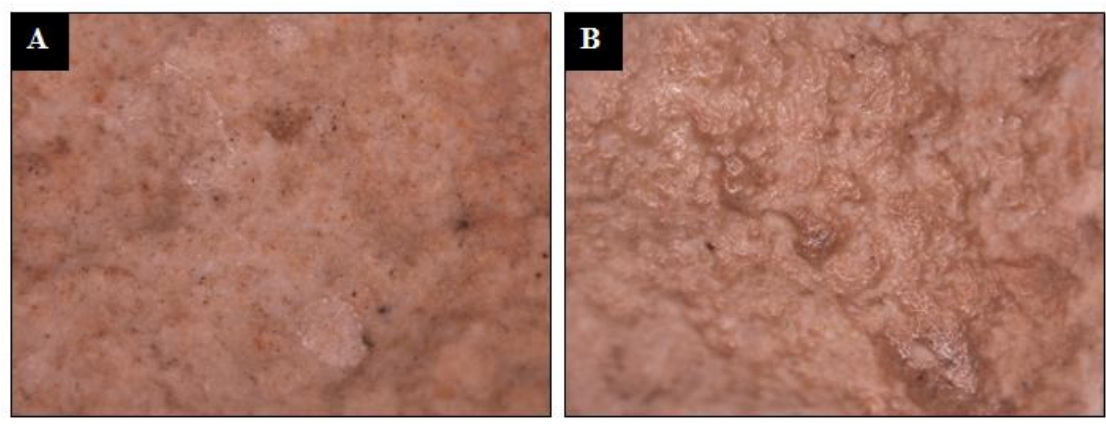

Figura 1.14. Imágenes de microscopia estereoscópica. A) Superficie del soporte pétreo sin tratamiento. B) Superficie del soporte pétreo después del tratamiento con silicato de etilo.

Las imágenes de microscopía electrónica de barrido SEM de la Figura 1.15 confirman la formación de una película sobre la superficie de la probeta de soporte pétreo después del tratamiento con el silicato de etilo. Como se muestra en detalle en las imágenes C y D de la Figura 1.15, la pelicula superficial se presenta con un extenso craquelado con descamación y pérdida de la película.
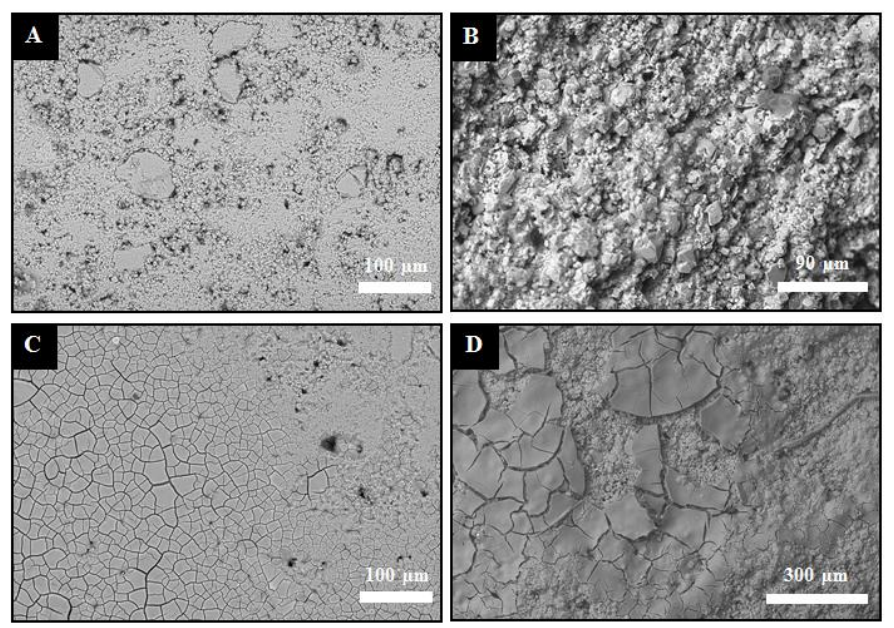

Figura 1.15. Imágenes por SEM. A y B) Se observa la superficie del soporte pétreo sin tratamiento a distintos aumentos. C y D) Se muestra la superficie después del tratamiento con silicato de etilo. 
El estudio de un corte transversal obtenido de la probeta de soporte pétreo después del mismo tratamiento, permite valorar el grado de penetración del producto aplicado en la estructura porosa del soporte pétreo. En el mapping de la Figura 1.16 se observa la acumulación del producto aplicado a nivel superficial, detectando bajas concentraciones de silicio hasta una profundidad de $200 \mu \mathrm{m}$ aproximadamente dentro de los poros de la piedra.
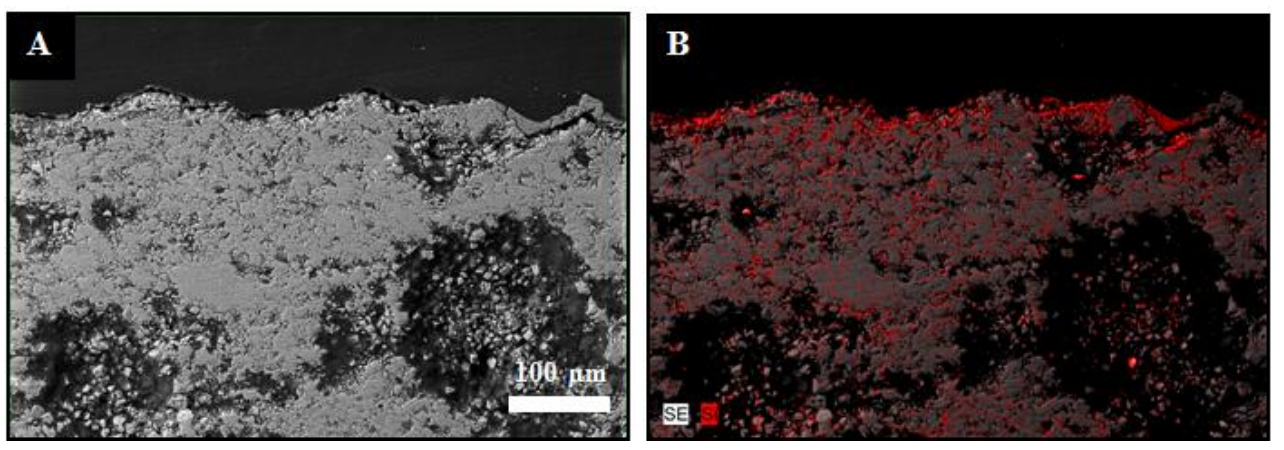

Figura 1.16. A) Imágenes por SEM de la sección transversal del fragmento de soporte pétreo tratado con silicato de etilo. B) Se observa la alta concentración del silicio (Si) a nivel superficial y su distribución dentro de la piedra.

2. Hidróxido de calcio: Con el estudio de evaluación del tratamiento de consolidación se observó que el producto aplicado sobre la probeta de soporte pétreo tiene una acción superficial. Como se observa en las micrografías SEM de la Figura 1.17, después del tratamiento con la nanocal (imagen B), la superficie del soporte pétreo presenta pequeños agregados del producto aplicado. No se observa una acción cementante por parte de las nanopartículas aplicadas y, en general, hay una distribución poco homogénea del producto sobre la superficie.
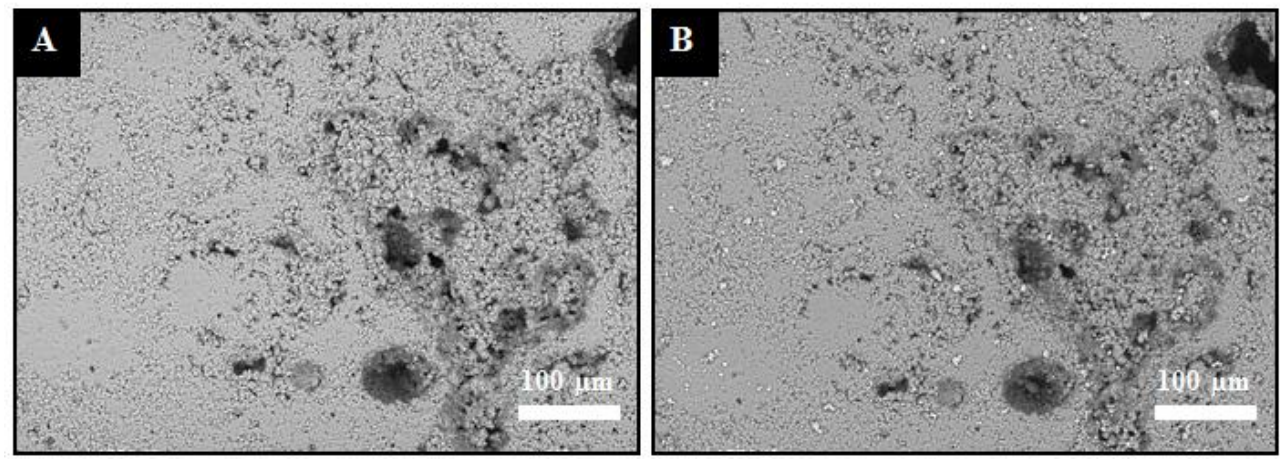

Figura 1.17. Imágenes SEM de la superficie del soporte pétreo. Se observa la misma superficie pétrea antes (A) y después (B) del tratamiento con nanopartículas de hidróxido de calcio. Después del tratamiento se observan las partículas del consolidante aplicado sin ejercer una acción consolidante o protectora suficiente respecto al sustrato. 
3. Hidróxido de bario: En el caso del hidroxido de bario comercial, los estudios previos realizados en la presente tesis doctoral detectaron que, posiblemente, el tamaño de las partículas limita la penetración del producto en los poros del sustrato pétreo, ejerciendo una acción consolidante y de conversión de los sulfatos solo a nivel superficial. Generalmente los restauradores descartan su uso en piedra por su bajo poder de penetración ya que ha generado muchos problemas de exfoliación y desplacación de la superficie tratada, como consecuencia de la rápida formación de carbonato de bario que rellena los poros sin ningún efecto consolidante. Además la evaluación realizada con hidróxido de bario sobre piedra muestra un cambio de color de la superficie significativo. En las micrografías SEM de la Figura 1.18, se observa la superficie del soporte pétreo después del tratamiento donde hay la formación de depósitos superficiales que cambian la morfología de la piedra. En base a los microanálisis EDX realizados, estos depósitos son ricos en bario.
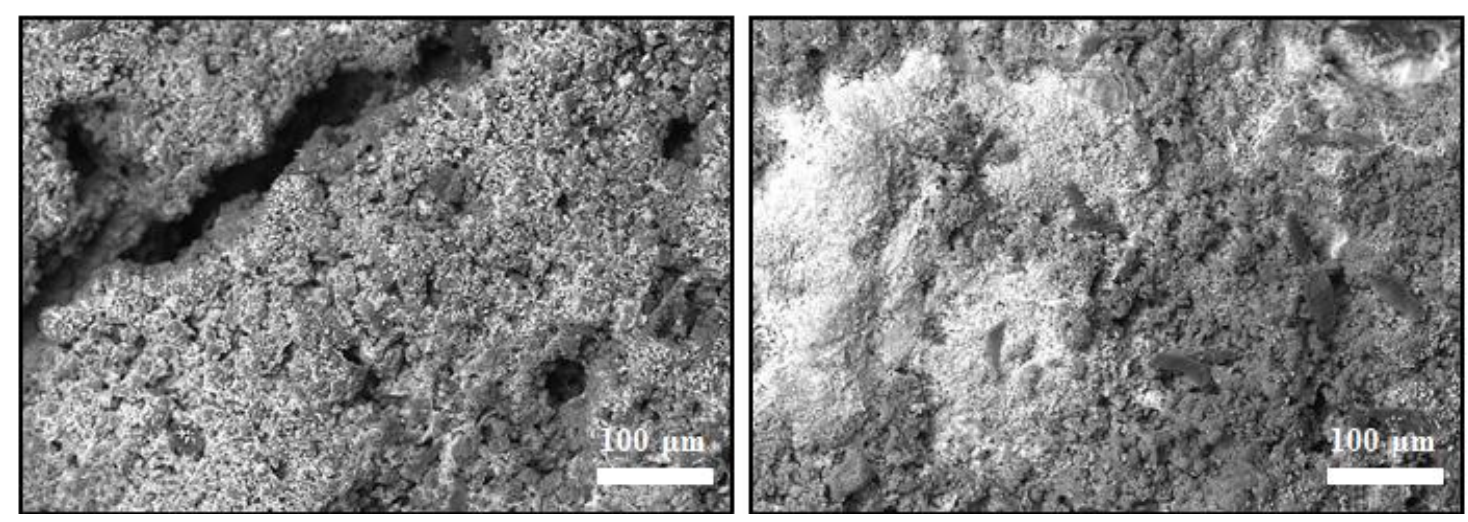

Figura 1.18. Imágenes por SEM en modalidad electrones retrodispersados de la superficie del soporte pétreo después del tratamiento con hidróxido de bario. Se observa la distribución del bario sobre la superficie (áreas blancas).

Con la evaluación del tratamiento en un corte transversal, se observó la acción únicamente superficial ejercitada por parte del hidróxido de bario. Como se muestra en la imagen del mapping de la Figura 1.19, el bario se deposita en superficie, penetrando en los poros de la piedra hasta una profundidad aproximada de 50-150 $\mu \mathrm{m}$, dependiendo del estado de conservación, porosidad, etc. del sustrato pétreo. 


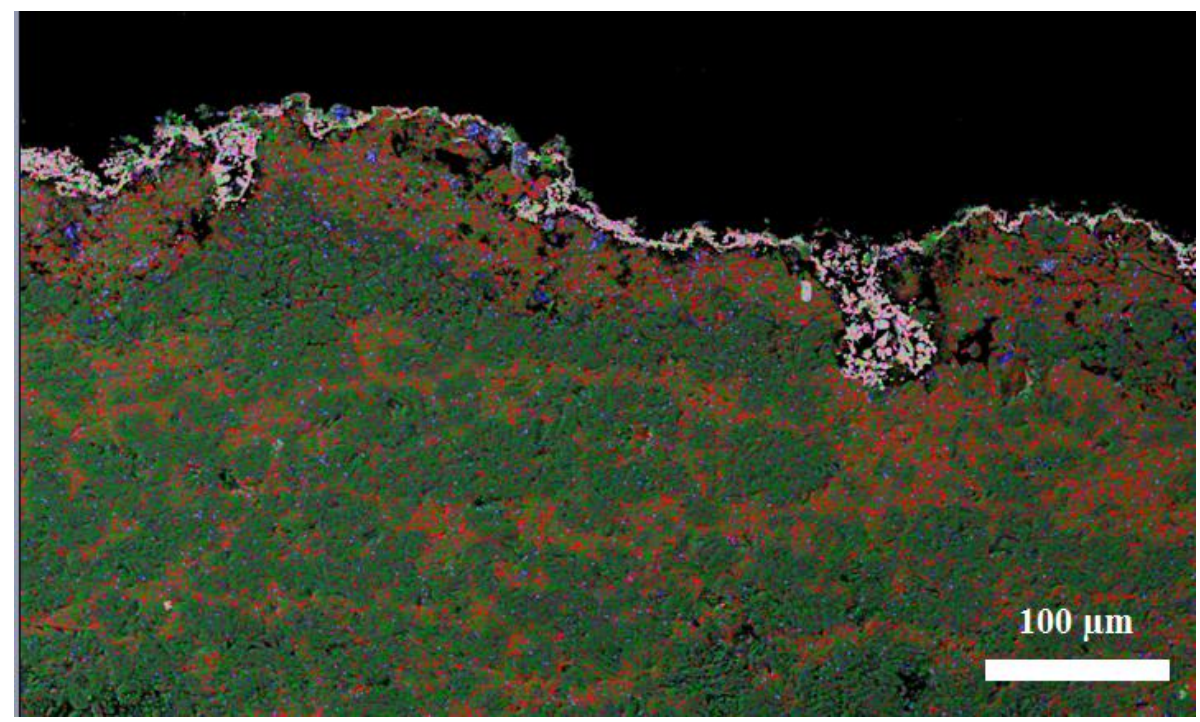

Figura 1.19. Imagen por SEM de un corte transversal de la probeta de soporte pétreo tratada con hidróxido de bario. Se observa en superficie la formación del fino estrato de bario.

En cuanto al uso de los nuevos nanomateriales, estos han experimentado una importante aplicación en los últimos años en la conservación del Patrimonio Cultural pero, por el momento, sigue siendo principalmente un sector de carácter experimental. Las dispersiones de nanopartículas, soluciones coloidales, las micro y nanoemulsiones se convierten en nuevas herramientas del futuro para restaurar y conservar las obras de arte, donde los sistemas de síntesis permiten el desarrollo de nuevos materiales específicos para aliviar los mecanismos de alteración y deterioro que amenazan la conservación del Patrimonio Cultural. Las nanopartículas que actualmente se utilizan para la restauración de piedra, pinturas murales ${ }^{70,71}$; o las de hidróxido de calcio y magnesio utilizados también para la recuperación de papel, madera y tela ${ }^{72,73}$, presentan importantes limitaciones en cuanto a penetración. Aunque se podría pensar que una dispersión de nanopartículas penetran más en un material poroso debido al tamaño más pequeño que las partículas

\footnotetext{
${ }^{70}$ P. Baglioni, E. Carretti, L. Dei, R. Giorgi, in: B.H. Robinson (Ed.), Nanotechnology in Wall Painting Conservation. Selfassembly, IOS Press. 32, 2003.

${ }^{71}$ R. Giorgi, L. Dei, P. Baglioni, Studies in Conservation 45. 154, 2000; M. Ambrosi, L. Dei, R. Giorgi, C. Neto, P. Baglioni, Langmuir 17. 4251, 2001.

${ }^{72}$ B. Salvadori, L. Dei, Langmuir 17. 2371, 2001.

${ }^{73}$ R. Giorgi, L. Dei, C.V. Schettino, P. Baglioni, A New Method for Paper Deacidification Based on Calcium Hydroxide Dispersed in Nonaqueous Media. in: V. Daniels, A. Donnithorne, P. Smith (Eds.), Preprint of the IIC Congress 2002 e Works of Art on Paper, Books, Documents and Photographs: Techniques and Conservation, IIC, London. 69, 2002.
} 
micrométricas, los estudios han demostrado que estas dispersiones en realidad no penetran profundamente, y la acción de consolidación se limita únicamente a las capas más superficiales. En el caso de las intervenciones en monumentos, fachadas de piedra o morteros, donde se requieren una buena profundidad de penetración, esto puede ser un problema.

Sin embargo, en el caso de las intervenciones en pinturas murales, donde el tratamiento que se requiere es generalmente de consolidación y de protección limitado a la superficie, el uso de nanodispersiones puede ser beneficioso, como muestran algunos casos de estudio ${ }^{74}$. Ante estas limitaciones de los nanomateriales, los principales objetivos se centran actualmente en la síntesis de estos compuestos: la morfología cristalina o amorfa, una baja polidipersión, alta pureza y estabilidad del producto final. Aunque existen numerosos procedimientos de síntesis para obtener altos rendimientos de las nanopartículas y controlar su tamaño, forma y polidispersión, estas metodologías tienen la difícil tarea de solucionar el problema relacionado a la tendencia termodinámica de los nanomateriales en agregarse para formar estructuras masivas a baja energía superficial. Este problema representa la principal limitación para el gran potencial de utilización de estos materiales en diferentes campos, entre ellos el de la conservación de los bienes de interés cultural.

\footnotetext{
${ }^{74}$ R. Giorgi, D. Chelazzi, P. Baglioni, Applied Physics A: Materials Science and Processing 83, 2006. 567; R. Giorgi, D. Chelazzi, P. Baglioni, Langmuir 21. 10743, 2005.
} 


\subsection{Estudios preliminares de tratamientos de consolidación con disoluciones acuosas de hidrogenofosfato amónico sobre piedra}

Desde 2011 se han empezado nuevas líneas de investigación donde se estudia la posibilidad de realizar tratamientos de consolidación de soporte pétreo con la introducción de compuestos a base de fosfatos de calcio $^{75}, 76$. El tratamiento consiste en la aplicación en probetas de piedra de una disolución de hidrogenofosfato amónico (DAP) en condiciones suaves de temperatura. En estos primeros estudios publicados, las probetas utilizadas, a base de piedra caliza, fueron tratadas con una disolución de DAP 1 molar por inmersión parcial durante 48 horas o aplicando la disolución de hidrogenofosfato mediante brocha hasta saturación. Los autores afirmaron la formación de la fase de hidroxiapatita a partir de las observaciones por microscopia electrónica de barrido (SEM) y la caracterización de fase realizada por espectroscopia de dispersión de energía de rayos X (EDX) y difracción de electrones (EBSD). Sin embargo, no pudieron confirmar dicha fase por difracción de rayos X (DRX) lo que conduce a ciertas dudas sobre la fase presente. Los resultados mostraron que las probetas tratadas tenían valores mayores en el modulo elástico dinámico y en la resistencia a la tracción como consecuencia del relleno de los poros del sustrato. La absorción de las probetas tratadas se reduce en un $26-44 \%$ mientras que los cambios de color que se registran presentan un valor de $\Delta \mathrm{E}^{*}$ mayor de 6 , indicando un leve cambio en la coloración de la superficie.

En estudios posteriores ${ }^{77,78}$ realizados por los mismos autores, se comparan los resultados de los tratamientos con DAP a diferentes concentraciones y tiempos de reacción. Asimismo se compara los cambios producidos en base a la modalidad de aplicación (inmersión, brocha, etc.) o el tipo de sustrato pétreo tratado (caliza, mármol), observando resultados semejantes a los anteriormente mencionados. Por otro lado, en otros estudios publicados ${ }^{79,80}$ se compara el tratamiento con DAP aplicado sobre probetas de arenisca o mármol

\footnotetext{
${ }^{75}$ E. Sassoni, S. Naidu, G. W. Scherer, Preliminary Results of the Use of Hydroxyapatite as a Consolidant for Carbonate Stones, Conference: Materials Research Society Fall Meeting 2010, At Boston (USA), Volume: Materials Issues in Art and Archaeology IX, Vol. 1319, 189-195, 2011.

${ }^{76}$ E. Sassoni, S. Naidu, G. W. Scherer, The use of hydroxyapatite as a new inorganic consolidant for damaged carbonate stones. J. Cult. Herit., Vol. 12, no. 4. 346-355, 2011.

${ }^{77}$ E. Franzoni, E. Sassoni, G. Graziani, Brushing, poultice or immersion? The role of the application technique on the performance of a novel hydroxyapatite-based consolidating treatment for limestone, Article in Journal of Cultural Heritage 16(2), 2014.

${ }^{78}$ E. Sassoni, E. Franzoni, Sugaring Marble in the Monumental Cemetery in Bologna (Italy): Characterization of Naturally and Artificially Weathered Samples and First Results of Consolidation by Hydroxyapatite, Article in Applied Physics A 117(4), 2014.

79 E. Sassoni, E. Franzoni, B. Pigino, G.W. Scherer, S. Naidu, Consolidation of calcareous and siliceous sandstones by hydroxyapatite: comparison with a TEOS-based consolidant, Journal of Cultural Heritage 14S, e103-e108, 2013.
} 
con los tratamientos realizados con TEOS y oxalato de amonio. Los autores indican la formación de la fase de la hidroxiapatita únicamente por SEM-EDX, comparando los efectos de los tratamientos de consolidación, estudiando los cambios estructurales y las propiedades físicas y mecánicas de las probetas tratadas y no tratadas. En general se muestra que la piedra consolidada con el tratamiento con DAP experimentan un aumento en el modulo elástico dinámico y resistencia a la tracción. Respecto a los estudios de absorción de agua por capilaridad, se observó cambios poco significativos con las probetas que presentan la fase de fosfato cálcico, mientras se registró una reducción más alta en la absorción en las probetas con TEOS. En la Figura 1.20 se muestra la variación de absorción de agua detectada por parte de los autores en probetas no tratadas (en gris), respecto a probetas tratadas con DAP (en verde) y TEOS (en rojo).
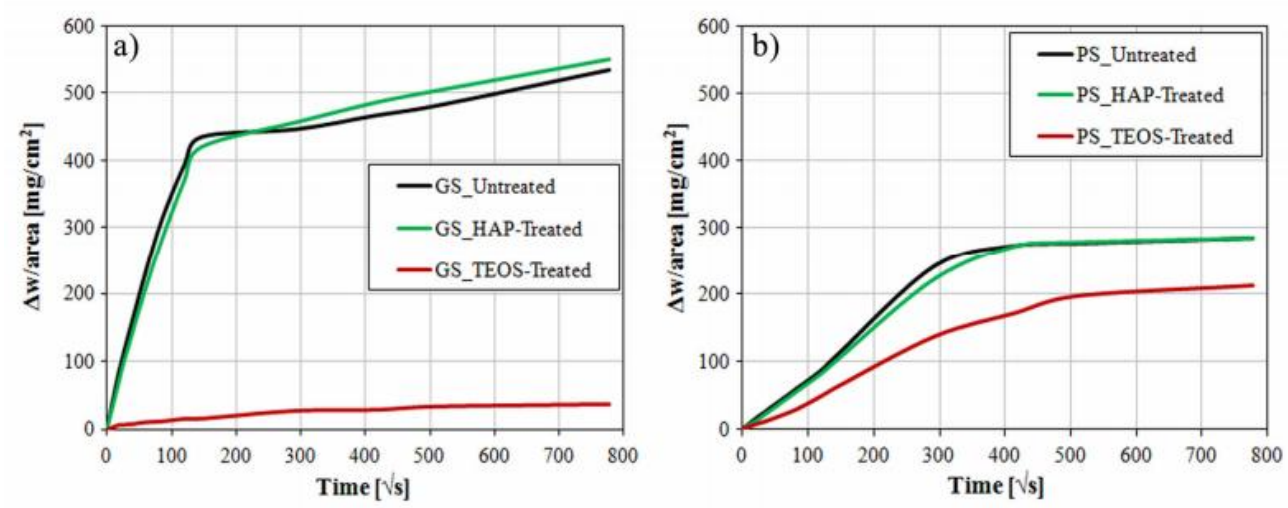

Figura 1.20. Absorción de agua por capilaridad en diferentes probetas de piedra no tratadas respectos a probetas con HA y TEOS.

Tras estos estudios se observa que el tratamiento de consolidación con hidrogenofosfato amónico es prometedor, ya que no altera sustancialmente las propriedades de la piedra.

A partir de los estudios realizados por Sassoni y col. ${ }^{79-84}$, en los ultimos años se han ido publicado otros trabajos relativos al tratamiento de consolidación en piedra con disolución de hidrogenofosfato amónico $(\mathrm{DAP})^{81},{ }^{82}$. En este sentido los trabajos publicados no presentan novedades destacadas respectos a los

\footnotetext{
${ }^{80}$ E. Sassoni, G. Graziani, E. Franzoni, Repair of sugaring marble by ammonium phosphate: comparison with ethyl silicate and ammonium oxalate and pilot application to historic artifact, Materials and Design 88, 1145-1157, 2015.

${ }^{81}$ X. Ma, M. Balonis, H. Pasco, M. Toumazou, D. Counts, I. Kakoulli, Evaluation of hydroxyapatite effects for the consolidation of a Hellenistic-Roman rock-cut chamber tomb at Athienou-Malloura in Cyprus, Article in Construction and Building Materials 150, 333-344, 2017.
} 
anteriormente descritos, ya que se sigue utilizando la disolución de DAP a diferentes concentraciones, verificando la formación de la fase de fosfatos de calcio en la piedra. Destaca el trabajo de Xia Ma y col. ${ }^{85}$ del 2017 donde la evaluación del tratamiento se realiza una vez aplicada la disolución de DAP directamente sobre la superficie de la piedra de una estructura funeraria de Chipre, monitoreando la formación de la fase hidroxiapatita durante un año mediante las técnicas de DRX, FTIR y SEM-EDX, si bien dicha fase siempre va acompañada de otras fases cristalinas presentes en el sustrato pétreo.

Análogo a los casos anteriores, Cano Barriuso y col. presentan el tratamiento de la piedra con la disolución de DAP, evaluando los inconvenientes que generan los residuos de la propia síntesis. En este artículo ${ }^{86}$ los residuos de compuestos de nitrógeno y fósforo de la disolución del hidrogenofosfato amónico podrían favorecer, en contextos húmedos, el deterioro por ataque biológico de la piedra por crecimiento de bacterias, hongos, etc. Con el fin de contrarrestar este fenómeno, se ha estudiado la combinación de un biocida, el cloruro de benzalconio con la disolución de DAP. Los resultados obtenidos muestran efectivamente a una disminución de la actividad biológica mediante el uso del bactericida.

En general, las investigaciones llevadas a cabo hasta la fecha muestran como algunas de las propiedades del tratamiento de consolidación sobre soporte pétreo alterado con la disolución de hidrogenofosfato amónico son parecidas a las obtenidas con otros productos. En cuanto a las desventajas en utilizar el DAP respecto a los consolidantes convencionales se podrían resumir en:

- El procedimiento experimental propuesto se presenta como una metodología bastante limitada para ser aplicada en tratamientos de obras reales. A través de las buenas prácticas en las intervenciones de restauración de un bien cultural en piedra se consideraría poco coherente la acción de calar enteramente piezas en una disolución de DAP, siendo este ultimo un reactivo líquido, donde el mecanismo de reacción con el carbonato de calcio de la piedra para la formación de la supuesta hidroxiapatita no puede ser controlado. Esta metodología puede comprometer la integridad de los materiales constituyentes de la obra, donde no existe, de manera exacta, la posibilidad de controlar la cinética del tratamiento y los cambios de composición de fase, morfología, color, etc., que se pueden producir en el material tratado.

- Permanencia de residuos de compuetsos de nitrógeno y fósforo después del tartamiento con DAP que pueden favorecer el crecimiento biologico de bacterias, hongos, etc.. El biocida propuesto, el

\footnotetext{
${ }^{82}$ B. Cano Barriuso, G. Botticelli, O. Adriana Cuzman, I. Osticioli, P. Tiano, M. Matteini, Conservation of calcareous stone monuments: Screening different diammonium phosphate based formulations for countering phototrophic colonization, Journal of Cultural Heritage, Vol. 27, 97-106, 2017.
} 
cloruro de benzalconio, es un bactericida e inhibidor de la actividad viral en dosis altas, activo únicamente contra las bacterias Gram-positivas. Tiene propiedades fungicidas, específicamente sobre los géneros Trichophyton, Epidermophton y Candida ${ }^{83}$. Para los tratamientos en piedra u otras obras como la pintura mural, este biocida presenta las desventajas de ser corrosivo y tóxico según la ficha MSDS de referencia BE0155 conforme a la directiva 2001/58/CE, así como de una gran toxicidad en ambientes acuáticos. En algunos casos de estudios, el producto aplicado en el tratamiento de restauración, puede dejar residuos a base de cloro, responsable de reaccionar con algunos materiales pictóricos (pigmentos) o favorecer la formación de sales ${ }^{84}$. Otra desventaja es la acción de corta duración y con un poder fungicida limitado, necesitando en este caso intervenciones de mantenimiento de la obra a corto plazo.

- El tratamiento tampoco sería aplicable en otras obras como pueden ser la pintura mural. La disolución aplicada podría reaccionar con pigmentos o componentes orgánicos tales como los aglutinantes a base de proteínas y aceites que generalmente coexisten en la obra. Estas reacciones podrían provocar cambios en el color de los pigmentos, disoluciones o alteraciones de las proteínas y aceites con mecanismos de desnaturación o lixiviación.

\footnotetext{
${ }^{83}$ J. Sarkar, S. Chaudhary, A. Namavari, O. Ozturk, J.H. Chang, L. Yco, S. Sonawane, S. Jain, Corneal neurotoxicity due to topical benzalkonium chloride, Invest Ophthalmol Vis Sci, 6, 53 (4), 1792-1802, 2012.

${ }^{84}$ P. Pablo Pérez, M. ${ }^{a}$ A. García, L. Ferrazza, Aportación de los estudios científicos a la restauración del Pórtico de la Gloria en la Catedral de Santiago de Compostela: análisis de las alteraciones, en La Ciencia y el Arte VI - Ciencias experimentales y conservación del patrimonio, Ministerio de Educación, Cultura y Deporte, 2017.
} 


\section{Objetivos de la tesis}


Capítulo 2. Objetivos de la tesis 


\section{Capítulo 2. Objetivos de la tesis}

El objetivo principal de la presente tesis doctoral es la preparación de nanomateriales con estequiometría de hidroxiapatita y la evaluación de los mismos en los tratamientos de consolidación y protección en soporte pétreo y decoraciones parietales en bienes culturales.

Los objetivos específicos planteados son:

1. Caracterización de materiales y estudio de los mecanismos de alteración y degradación químico, físico y biológico mediante extracción de muestras en la portada principal de la Iglesia de Nuestra Señora de la Asunción de Corral de Almaguer (Toledo) del siglo XV, y de diferentes fragmentos de pintura mural sobre mortero procedentes de la Casa de Ariadna en Pompeya (Italia) del siglo I d.C.

2. Estudio de la síntesis y la caracterización de nanopartículas con estequiometría de hidroxiapatita obtenidas por el método de precipitación. El trabajo experimental se base en la síntesis y caracterización de nanopartículas con diferente grado de cristalinidad, tamaño y morfología. Con el desarrollo de estas muestras se pretende determinar la posible aplicabilidad y viabilidad como nuevos materiales inorgánicos para los tratamientos de consolidación y protección. El objetivo ha sido el diseño, preparación y caracterización de muestras de hidroxiapatita con una elevada superficie específica y con diferente grado de cristalinidad, tamaño y morfología, con vistas a obtener materiales óptimamente activos con aplicaciones añadidas en el campo de la conservación del Patrimonio Cultural. Estudio de síntesis primando la preparación de suspensiones acuosas que puedan mejorar la penetración de éstas en los soportes y que no sean nocivas para la salud humana y el medioambiente, como puede ser con otros tipos de disolventes diferentes del agua.

3. Estudio de evaluación sobre la aplicabilidad, efectividad e idoneidad en los tratamientos de consolidación y protección superficial por parte de las muestras preparadas en soporte pétreo y pintura mural. Un aspecto importante de este estudio ha sido el determinar como influyen las características de cristalinidad, tamaño y morfología de partícula de las muestras sintetizadas en los tratamientos de consolidación y protección. Evaluación de los nuevos productos en laboratorio, donde se ha estudiado su eficacia con distintas metodologías de análisis y en diferentes probetas de soporte pétreo y pintura mural según los protocolos de trabajo establecidos por las normativas 
italianas sobre bienes culturales UNI y Raccomandazioni NorMal, las normativas españolas UNE AENOR y las indicaciones dictadas por publicaciones científicas editadas por instituciones que operan en el sector de la conservación de bienes culturales.

4. Estudio sobre aplicación y de evaluación de la acción consolidante y protectora por parte de los nanomateriales preparados en fragmentos paleontológicos tales como huesos y marfiles de origen fósil y sub-fósil.

5. Estudio de la eficacia del tratamiento del tratamiento de consolidación y protección por parte de las productos preparados, al restablecer las propiedades mecánicas del sustrato tratado que han sido modificadas por diferentes factores de alteración y degradación de tipo químico, físico o biológico.

6. Estudio de evaluación de distintos productos consolidantes y protectores en uso (hidróxido de calcio, hidróxido de bario, silicato de etilo). Esta etapa es necesaria para determinar la eficacia del tratamiento alcanzado con los productos tradicionalmente utilizados y de las limitaciones que cada producto presenta como la penetrabilidad, la permanencia de residuos o los posibles cambios de color, morfología y compacidad que se puedan producir. De esta manera se ha obtenido una evaluación objetiva y científica sobre la acción de consolidación y protección de cada producto aplicado, permitiendo proponer de manera objetiva y fiable los cambios a introducir en el desarrollo de nuevos materiales con posibilidad de ser aplicados en los tratamientos de restauración.

A partir de las fases descritas, el objetivo es disponer de nuevos productos consolidantes y protectores que resulten ser más efectivos en los tratamientos de restauración de soportes pétreos, morteros y decoraciones parietales. El Patrimonio Histórico, como es conocido, es un valor añadido para un país, así como un generador de riqueza. Los resultados de este proyecto pueden tener una aplicación directa y una gran repercusión dentro de la conservación del Patrimonio Cultural, ya que van a permitir disponer de un nuevo producto para los tratamientos de consolidación, pre-consolidación y protección de numerosos bienes. 


\section{La aplicación científica aplicada al}

estudio de bienes culturales:

Caracterización de materiales, diagnosis del estado de conservación y evaluación de los

tratamientos de restauración 
Capítulo 3. La aplicación científica aplicada al estudio de bienes culturales: Caracterización de materiales, diagnosis del estado de conservación y evaluación de los tratamientos de restauración

\subsection{Introducción}

3.2. Protocolización de la metodología científica en la evaluación de los tratamientos de restauración en bienes culturales 


\section{Capítulo 3. La aplicación científica aplicada al estudio de bienes culturales:} Caracterización de materiales, diagnosis del estado de conservación y evaluación de los tratamientos de restauración

\footnotetext{
En este capítulo se muestra la importancia de los estudios científicos aplicados al sector de los bienes culturales como herramientas de conocimiento de los materiales constitutivos, de las técnicas de ejecución o de los mecanismos de alteración y degradación que comprometen la futura conservación de la obra. Es preciso que todas las actuaciones que se cometen sobre bienes de interés cultural se sustenten de una base científica, con la necesidad de definir una metodología de trabajo normalizada que contemple los sistemas de control de calidad que se consideren más adecuados para cada caso de estudio, tanto en los procesos como en los tratamientos y materiales de restauración utilizados.
} 


\subsection{Introducción}

La caracterización de materiales, la diagnosis del estado de conservación de los bienes culturales así como el estudio preliminar de productos necesarios para los tratamientos de limpieza, consolidación, protección, etc., representan unas herramientas indispensables en las intervenciones de restauración y conservación o en la documentación de las obras de interés artístico e histórico. En el sector científico, y especialmente en la química y la física, los nuevos avances que se vienen desarrollando en la instrumentación asociada a las técnicas de caracterización, encuentran en el análisis y en el diagnóstico del Patrimonio Cultural un área de utilización cada vez más importante. En el pasado, la identificación de los materiales constituyentes de las obras de arte, su diagnóstico y las metodologías de conservación y restauración, han sido realizados y establecidos fundamentalmente por eruditos basándose en la aspecto visual de la obra, como en el diseño, el decorado, la técnica artística y el envejecimiento de los materiales, quedándose como métodos instantáneos, utilizados por historiadores, arqueólogos y expertos en arte. En las Cartas del Restauro ${ }^{85}$ de Roma, se definen los términos de conservación, prevención, salvaguarda y mantenimiento de los bienes culturales, donde se confiere la importancia al contexto de la obra, a la planificación de las actuaciones de conservación y restauración, y a la necesidad de que se sustenten en una base científica.

Es a partir del siglo XX, donde se observa el nacimiento de una nueva visión entre los materiales del Patrimonio Cultural y las técnicas científicas de caracterización, se logra establecer una conexión entre el arte, la ciencia, la historia y la arqueología, hablando en este contexto de restauración científica que resulta ser hoy éticamente correcta y necesaria. El estudio científico de los bienes de interés cultural y la restauración científica comienza en España en la década de los años 60 del pasado siglo, a partir de los análisis químico-físicos aplicados a las obras de interés artístico e histórico, con la creación del Instituto de Conservación y Restauración de Obras de Arte, Arqueología y Etnología, sucesivamente denominado Instituto de Conservación y Restauración de Bienes Culturales (ICRBC), y actualmente Instituto del Patrimonio Cultural de España (IPCE) ${ }^{86}$.

La aplicación de la ciencia en los estudios del Patrimonio Cultural ha generado una importante investigación multidisciplinar entre investigadores, museos, y universidades, permitiendo descifrar y entender los

\footnotetext{
${ }^{85}$ Carta del Restauro de 1932, Carta Italiana del Restauro de 1972, Carta de Conservación y Restauración de Objetos de Arte y Cultura de 1987.

${ }^{86}$ J.M. Cabrera, J.M., Inicios de la restauración moderna en España, Ciencia y Arte III, 17-18. Museo de Bellas Artes, Valencia, 2010.
} 
conocimientos de las sociedades de nuestro pasado. A través de las diferentes técnicas analíticas aplicadas a obras de arte es posible alcanzar una serie de objetivos ${ }^{87}$ entre los cuales destacan:

- Desarrollar una completa caracterización físico-química de los compuestos orgánicos e inorgánicos presentes en las diferentes obras de arte (pintura mural, pintura sobre lienzo o tabla, esculturas policromadas, obras metálicas, objetos de interés arqueológicos, etc.).

- Conocer la composición, morfología, degradación y las propiedades físico-químicas de los componentes orgánicos e inorgánicos que contribuyen a la planificación de la conservación preventiva $^{88}$, ya que de estos estudios se derivan los tratamientos a realizar durante las intervenciones de restauración y las condiciones más adecuadas para la conservación.

- Obtener una completa caracterización de los materiales inorgánicos (pigmentos minerales, metales, soportes pétreos, etc.), usando diversas técnicas de laboratorio tales como la microscopia óptica, microscopia electrónica de barrido equipado con sistema de microanálisis, técnicas de espectroscopia infrarroja y difracción de rayos X.

- Obtener una completa caracterización de los materiales orgánicos (colorantes, aglutinantes, barnices, adhesivos, etc.), usando técnicas de laboratorio como las de cromatografías, técnicas espectroscópicas o de espectrometría de masas.

- Caracterización de las tecnologías de fabricación y la identificación de las materias primas, con el fin de definir de manera exacta, el nivel tecnológico alcanzado por las sociedades antiguas y la complejidad de su economía.

- Caracterización para determinar la procedencia del objeto y sus materias primas con el fin de reconstruir los circuitos comerciales antiguos y, a través de ellos, los contactos culturales y las relaciones entre las comunidades antiguas.

- Datación de los objetos antiguos y pruebas útiles para el reconocimiento de objetos falsos.

Por último, el campo de la síntesis química, permite investigar y desarrollar nuevos productos que puedan ser aplicados en los tratamientos de restauración de bienes culturales y donde el uso de diversas técnicas de

\footnotetext{
${ }^{87}$ S. Volpin, L. Appolonia, Le analisi di laboratorio applicate ai beni artistici policromi, Collana i Talenti, Il Prato, 1999; D. Creagh, D. Bradley, Radiation in Art and Archeometry, Elsevier, Amsterdam, 2000.

${ }^{88}$ Puede definirse la conservación preventiva como estrategia de identificación, detección y control de los factores de deteri oro de los bienes culturales, con el fin de minimizar sus efectos en los mismos. Consiste en una actuación continuada en el entorno de los bienes para evitar, en la medida de lo posible, la intervención directa sobre los mismos (Plan Nacional de Conservación Preventiva).
} 
análisis permite realizar un control de las intervenciones de restauración a través de la evaluación de los productos y tratamientos, como pueden ser los consolidantes, productos para la protección de superficies, inhibidores de corrosión y adhesivos.

\subsection{Protocolización de la metodología científica en la evaluación de los tratamientos de restauración en bienes culturales}

En gran parte de los trabajos de restauración de bienes culturales, la valoración de la idoneidad de cualquier tipo de metodología de intervención y productos de tratamiento, tal como la limpieza, la consolidación y la protección, se realiza por parte de los técnicos restauradores a través de una atenta observación de las propiedades organolépticas de los materiales tratados. Contando generalmente con instrumentos y herramientas básicas tales como una lupa binocular, se realiza esta valoración necesaria para poder tomar decisiones a pie de obra sin intervención de análisis de laboratorio más complejos. Fijándonos en aspectos como pueden ser la textura, morfología, color, homogeneidad, etc., se puede diagnosticar si un determinado producto o metodología de intervención es apto o no para la restauración de la obra.

En este contexto se considera necesario sistematizar los procesos de estudio y seguimiento de las intervenciones de restauración, elaborando un protocolo de trabajo que permita, de manera rápida y con criterio científico, obtener resultados de valoración de las metodologías así como de los productos utilizados ${ }^{89,90,91}$. Este seguimiento de las intervenciones de restauración tiene que realizarse con métodos de ensayos y técnicas de análisis que pueden ser fácilmente accesibles en centros de investigación y universidades tales como las técnicas cromatográficas, espectrométricas y las microscópicas. A través de un número reducido de técnicas de análisis es posible dilucidar la eficacia y el riesgo de los sistemas y productos de restauración propuestos, contribuyendo de esta manera a la planificación y ejecución de las

\footnotetext{
${ }^{89}$ E. Ontiveros, R. Villegas, M. Alcalde, E. Sebastián, Programa de Normalización de estudios previos y control de calidad en las intervenciones, PH Boletín del Instituto Andaluz del Patrimonio Histórico, 15, 60-61.

${ }^{90}$ E. Ontiveros, R. Villegas, Programa de normalización de estudios previos y control de calidad en las intervenciones: Propiedades Hídricas. $1^{a}$ Parte, PH Boletín del Instituto Andaluz del Patrimonio Histórico, 22, 45-49.

${ }^{91}$ E. Ontiveros, R. Villegas, Programa de normalización de estudios previos y control de calidad en las intervenciones: Propiedades Hídricas. $2^{a}$ Parte, PH Boletín del Instituto Andaluz del Patrimonio Histórico, 23, 40-45.
} 
distintas fases de restauración, de acuerdo con las diferentes casuísticas que se presenten y el diagnóstico de las alteraciones determinadas en los estudios previos.

Con la metodología científica desarrollada en este trabajo, proyectada para evaluar la acción consolidante y protectora de las muestras de hidroxiapatita preparadas en diferentes soportes, se pretende aportar un sistema normalizado simplificado y accesible a cualquier empresa o institución que trabaje en el sector de la conservación y restauración de bienes culturales. La metodología propuesta se completa con las normas existentes de aplicación nacional e internacional (UNI, UNE - AENOR), que tienen sus antecedentes en los trabajos de la Comisión 25-PEM y en las normas Raccomandazioni NorMal, elaboradas durante los años '80 y '90 del siglo pasado por el Consiglio Nazionale delle Ricerche - Istituto Centrale del Restauro de Roma (CNR-ICR). Muchas de ellas son normas de ensayo, propias de análisis de laboratorio (petrográficos, químicos, físicos, etc.), pero también hay normas relacionadas con la toma y características de las muestras, con el ambiente, glosarios y, en general, recomendaciones de utilidad para la comunidad científica, docente y técnica. 

Aspectos generales de la hidroxiapatita. Estructura y preparación 
Capítulo 4. Aspectos generales de la hidroxiapatita. Estructura y preparación

\subsection{Introducción}

4.2. Estructura de la hidroxiapatita

4.3. Síntesis de la hidroxiapatita

4.3.1. Rutas de síntesis por métodos vía seca

4.3.2. Rutas de síntesis por métodos vía húmeda

4.3.2.1. Método por precipitación 


\section{Capítulo 4. Aspectos generales de la hidroxiapatita. Estructura y preparación}

En este capítulo se presenta de manera breve, una revisión sobre la hidroxiapatita, describiendo la estructura cristalina, propiedades y las rutas de síntesis por vía seca y por vía húmeda para la obtención de estos materiales. Además, se describe de forma particular y con más detalle las propiedades y aplicaciones, así como de las metodologías de síntesis para la preparación de polvos amorfos o cristalinos de unos de los fosfatos de calcio más importantes, objeto de estudio en esta tesis, la hidroxiapatita. 


\subsection{Introducción}

El principal componente mineral del hueso humano, aproximadamente más del $95 \%$, es un compuesto de calcio (fósforo, oxigeno e hidrógeno) denominado hidroxiapatita Ha. La hidroxiapatita está formada por el fosfato de calcio cristalino $\mathrm{Ca}_{5}\left(\mathrm{PO}_{4}\right)_{3}(\mathrm{OH})$, que en la mayoría de las veces es expresada de acuerdo con la fórmula $\mathrm{Ca}_{10}\left(\mathrm{PO}_{4}\right)_{6}(\mathrm{OH})_{2}$ para denotar que la unidad cristalina esta formada por dos entidades.

La hidroxiapatita constituye alrededor del $60-70 \%$ del peso seco del tejido óseo, haciéndolo muy resistente a la compresión. Hasta el $50 \%$ en volumen y el $70 \%$ en peso del tejido óseo humano es una forma modificada de hidroxiapatita (conocida como mineral óseo) ${ }^{92}$. La hidroxiapatita deficitaria en calcio es el principal mineral del que se componen el esmalte dental y la dentina.

La hidroxiapatita es un biomaterial que pertenece a la familia de las apatitas, un grupo de minerales de las familias de los fosfatos de calcio, compuestos que contienen los grupos fosfatos $\mathrm{PO}_{4}{ }^{3-}, \mathrm{HPO}_{4}{ }^{2-}$ y $\mathrm{H}_{2} \mathrm{PO}_{4}$. Generalmente con los fosfatos de calcio se hace referencia a los minerales de la hidroxiapatita, cloropatitas y fluorapatitas, caracterizadas por altas concentraciones de los iones $\mathrm{OH}^{-}, \mathrm{Cl}^{-}$y $\mathrm{F}^{-}$respectivamente ${ }^{93,94}$. En la naturaleza las apatitas se pueden encontrar formando parte de las rocas sedimentarias y metamórficas ${ }^{95}$.

La hidroxiapatita cristaliza en su forma pura en el grupo espacial monoclínico $P 2_{1} / b$, mientras que a temperaturas superiores a $207{ }^{\circ} \mathrm{C}$ cristaliza de manera reversible en la estructura hexagonal, con el grupo espacial $P 6_{3} / \mathrm{m}^{96}$. Generalmente, la hidroxiapatita presenta vacantes iónicas o impurezas en su red cristalinas, que estabilizan el compuesto en la fase hexagonal a temperatura ambiente. Tanto la hidroxiapatita de origen geológico presente en naturaleza, así como la hidroxiapatita de origen biológico o de laboratorio, presentan una estabilización de las vacantes iónicas por impurezas, como los grupos $\mathrm{CO}_{3}{ }^{2-}$, cristalizando en la estructura hexagonal ${ }^{97,98}$.

\footnotetext{
${ }^{92}$ J. Foltin, Janet, H. Lebowitz, P. J. Boyle, eds. Basic Histology, Text \& Atlas, (10th ed.) McGraw-Hill Companies. $144,2003$.

${ }^{93}$ R. Zapanta Legeros, Biological and synthetic apatites, In Hydroxyapatite and related materials (eds. Browns, P.W. \& Constantz, B., 1995), CRC Press, London, 3-28, 2000.

${ }^{94}$ W.F. De Jong, La substance minerale dans le os, Rev. Tam. Chim. 4, 45, 448, 1926.

${ }^{95}$ K. Smith Deanne, Calcium phosphate apatites in nature, In Hydroxyapatite and related materials (eds. Browns, P.W. \& Constantz, B., 1995), CRC Press, London, 46-52, 2000.

${ }^{96}$ J.B. Kendall, Biomaterials Research Advances, 1a ed. Nova Iorque, Nova Science Publisher, 2008.

${ }^{97} \mathrm{~V}$. Uskokovic, The role of hydroxyl channel in defining selected physicochemical peculiarities exhibited by hydroxyapatite, RSC Adv. 5, $36614-36633,2015$.

${ }^{98}$ M. Fleet, Carbonated Hydroxyapatite: Materials, Synthesis, and Applications, Nova Iorque, Pan Stanford Publishing, 2015.
} 
Muchos investigadores han demostrado las propiedades biocompatibles y bioactivas de la hidroxiapatita, lo que la hace que hoy sea uno de los biomateriales más estudiados y deseados para aplicaciones biomédicas ${ }^{99}$ 100, 101. Las investigaciones realizadas sobre este mineral y de su asociación con algunos elementos traza, tanto en las estructuras de las apatitas biológicas como en las estructuras sintetizadas, han sido de enorme relevancia para la investigación de estos compuestos como biomateriales que pueden ser utilizados en

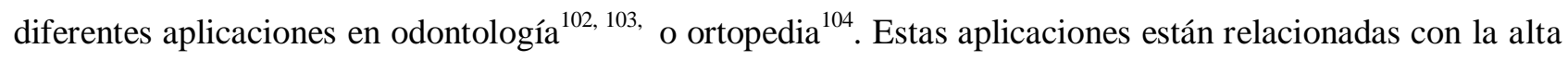
biocompatibilidad de las apatitas respecto al organismo por su composición mineral similar a la de los huesos o dientes, sin efectos de toxicidad, alergia o inflamación. Otras características importantes de algunos fosfatos de calcio sintéticos para sus aplicaciones biomédicas son la bioactividad y la reabsorción en sistemas fisiológicos, además de la capacidad de estimular el proceso de formación de nuevas células dentro del tejido óseo ${ }^{105,106}$.

En lo referente a la hidroxiapatita, su utilización en los tratamientos de consolidación y protección en soporte pétreo y decoraciones parietales en bienes culturales puede ser una opción interesante por su compatibilidad química y física con los soportes a base de carbonato de calcio. Si bien su uso en conservación no está desarrollado, la síntesis de nanopartículas de hidroxiapatita es un tema ampliamente documentado en disciplinas como la odontología y la ingeniería biomédica principalmente para la reconstrucción de tejidos óseos y dentarios. Para este fin se han desarrollado nanopartículas de hidroxiapatita crudas, es decir, sin la fase de calcinación a la que se someten normalmente las muestras de hidroxiapatita sintetizadas con fines

\footnotetext{
${ }^{99}$ S. Ramakrishna, M. Ramalingam, T.S.S. Kumar, W.O. Soboyejo, Biomaterials: A Nano Approach. Ed.: Hardcover, CRC Press, 2010 .

${ }^{100}$ J. Chen, Y. Wang, X. Chen, L. Ren, Ch. Lai, W. He, Q. Zhang, Mater Lett 65, 1923-1926, 2011.

${ }^{101}$ M.N. Salimi, R.H. Bridson, L.M. Grover, G.A. Leeke, Powder Technology, 218, 109-118, 2012.

${ }^{102}$ A. Chandrasekar, S. Sagadevan, A. Dakshnamoorthy, Synthesis and characterization of nano-hydroxyapatite (n-HAP) using the wet chemical technique. Int. J. Phys. Sci., Vol. 8, no. 32. 1639-1645, 2013.

${ }^{103}$ M. P. Ferraz, F. J. Monteiro, C. M. Manuel, Hydroxyapatite nanoparticles: A review of preparation methodologies. J. Appl. Biomater., Vol. 2, no. 2, 2004. 74-80.

${ }^{104}$ D. Ratner, J.A. Buddy, An introduction to materials in medicine, Academic Press, USA, 1996.

${ }^{105}$ M. Vallet Regí, J.M. González Balbet, Calcium phosphates as substitution of bone tissues, Prog. Solid State Chem. 32, 1-31, 2004.

106 J. Huang, S.M. Best, W. Bonfield, R.A. Brooks, N. Rushton, S.N. Jayasinghe, M.J. Edirisighe, In vitro assessment of the biological response to nano-sized hydroxyapatite, J. Mater. Sci. Mater. Med. 15, 441-445, 2004.
} 
biomédicos ${ }^{107,} 108$, lo que en teoría les conferirá una mayor reactividad y permitirá aprovechar mejor su morfología, solubilidad, estabilidad y gran compatibilidad con el sustrato pétreo, morteros y posiblemente con otras clases de materiales inorgánicos tal como el paleontológico.

Respecto a los estudios descritos sobre el uso de la disolución de hidrogenofosfato amónico (DAP) para el tratamiento de consolidación de piedra, las nanopartículas con estequiometría de hidroxiapatita sintetizadas pueden constituir un importante avance respecto a los materiales consolidantes y protectores actualmente en uso, donde existe la posibilidad de incrementar la acción y la eficacia de los tratamientos de protección y consolidación superficial en sustratos inorgánicos. Se dispondría de polvos cristalinos nanoestructurados en dispersión acuosa, que ofrecer una alta compatibilidad química, física y mecánica con el material intervenido, además de una efectiva acción consolidante y una alta durabilidad en el tiempo. Del mismo modo se demuestra que son materiales más respectuosos con la salud humana y el medioambiente.

En cuanto a compatibilidad de la hidroxiapatita con sustratos a base de carbonato de calcio, está justificada por distintos factores. El mineral de la hidroxiapatita presenta una estructura cristalina bastante similar a la estructura de la calcita, resulta ser menos soluble que la calcita ${ }^{109,110}$ y tiene una estructura cristalina con celda unitaria hexagonal similar a la calcita ${ }^{111}$, que resulta ser romboédrica que pero se describe como hexagonal ${ }^{112}$. La hidroxiapatita tiene parámetros de red similares la calcita considerando dos moléculas por unidad de celda, respectivamente, $\mathrm{a}=\mathrm{b}=9,43 \AA \mathrm{y} \mathrm{c}=6,88 \AA$ mientras para la calcita son $\mathrm{a}=\mathrm{b}=9,96 \AA$ y c $=17,07 \AA^{113,114}$.

\footnotetext{
${ }^{107}$ J. Quispe, M. Moreno, J. Montano, A. Guzman, A. Cavero, M. Pillaca, Estudio Comparativo Entre Bioapatita E Hidroxiapatita Sintética Obtenida Por Precipitación Química Y Síntesis Mecano- Química. Rev. Investig. Fis., Vol. 12. 21-24. 2009.

${ }^{108}$ N. M. Pareja, D. M. Escobar, C. P. Ossa, A. Echavarría, Síntesis y caracterización de hidroxiapatita microporosa, comparación con un producto comercial. Rev. Fac. Ing., no. 43. 67-76, 2008.

${ }^{109}$ S.V. Dorozhkin, Calcium orthophosphates in nature, biology and medicine. Materials 2, 399-498, 2009.

${ }^{110}$ G. Bonel, Apatitic calcium orthophosphates and related biomaterial preparation, Annals of the New York Academy of Sciences. 253, 115-130, 1988.

${ }^{111}$ G. Boivin, The hydroxyapatite crystal: a closer look. Medicographia 29. 126-132, 2007.

${ }^{112}$ A.J. Skinner, J.P. LaFemina, H.J.F.Hansen, Structure and bonding of calcite: a theoretical study. Am Mineral 79. $205-214,1994$.

${ }^{113}$ M. Mathew, S. Takagi, Structures of biological minerals in dental research. J Res Natl Inst Stand Technol 106. 1035-1044, 2001.

${ }^{114}$ E.N. Maslen, V.A.Streltsov, N.R. Streltsova, N. Ishizawa, Electron density and optical anisotropy in rhombohedral carbonates. III. Synchroton X-ray studies of $\mathrm{CaCO}_{3}, \mathrm{MgCO}_{3}$ and $\mathrm{MnCO}_{3}$. Acta Crystallogr B51. 929-939, 1995.
} 


\subsection{Estructura de la hidroxiapatita}

Los fosfatos de calcio, sintéticos y biológicos, poseen variada composición química, estructura cristalográfica y solubilidad en agua. La relación molar $\mathrm{Ca} / \mathrm{P}$ influye en las características del material, en base a la variación de esta relación pueden crearse numerosos compuestos de fosfatos de calcio, que poseen diferente composición química, estructura cristalográfica y solubilidad en agua.

En la Tabla 4.1 se muestran algunos de los fosfatos de calcio existentes con diferente relación $\mathrm{Ca} / \mathrm{P}^{115,116}$.

Tabla 4.1. Fosfatos de calcio: composición química, relación molar Ca/P y solubilidad.

\begin{tabular}{|c|c|c|c|c|}
\hline Nombre & Abreviación & Formula Química & $\begin{array}{l}\text { Relación molar } \\
\qquad \mathrm{Ca} / \mathbf{P}\end{array}$ & $\begin{array}{c}\text { Solubilidad } \\
-\log \left(K_{s}\right)\end{array}$ \\
\hline Fosfato de calcio amorfo & $\mathrm{ACP}$ & $\begin{array}{c}\mathrm{Ca}_{\mathrm{x}}\left(\mathrm{HPO}_{4}\right)_{\mathrm{y}}\left(\mathrm{PO}_{4}\right)_{\mathrm{z}} \cdot \mathrm{n}\left(\mathrm{H}_{2} \mathrm{O}\right) \\
\mathrm{n}=3,0-4,5 \\
15-20 \mathrm{wt} \% \mathrm{H}_{2} \mathrm{O}\end{array}$ & $1,2-2,2$ & $25,7-32,7$ \\
\hline Fosfato tetracálcico & TTCP & $\mathrm{Ca}_{4} \mathrm{O}\left(\mathrm{PO}_{4}\right)_{2}$ & 2,00 & $38-44$ \\
\hline Hidroxiapatita & $\mathrm{HA}$ & $\mathrm{Ca}_{10}\left(\mathrm{PO}_{4}\right)_{6}(\mathrm{OH})_{2}$ & 1,67 & 116,8 \\
\hline Fosfato tricálcico & TCP & $\mathrm{Ca}_{3}\left(\mathrm{PO}_{4}\right)_{2}(\alpha, \beta, \gamma)$ & 1,50 & $25,5-28,9$ \\
\hline Fosfato octacálcico & $\mathrm{OCP}$ & $\mathrm{Ca}_{8} \mathrm{H}_{2}\left(\mathrm{PO}_{4}\right)_{6} \cdot 5 \mathrm{H}_{2} \mathrm{O}$ & 1,33 & 96,6 \\
\hline Hidrogenofosfato de calcio (Brushita) & DCPD & $\mathrm{CaHPO}_{4} \cdot 2 \mathrm{H}_{2} \mathrm{O}$ & 1,00 & 6,59 \\
\hline $\begin{array}{l}\text { Hidrogenofosfato de calcio anhidro } \\
\text { (Monetita) }\end{array}$ & $\mathrm{DCP}$ & $\mathrm{CaHPO}_{4}$ & 1,00 & 6,9 \\
\hline $\begin{array}{c}\text { Dihidrogenofosfao de calcio } \\
\text { dihidratado }\end{array}$ & MCPM & $\mathrm{Ca}\left(\mathrm{H}_{2} \mathrm{PO}_{4}\right)_{2} \cdot 2 \mathrm{H}_{2} \mathrm{O}$ & 0,50 & 1,14 \\
\hline
\end{tabular}

De entre todos estos fosfatos de calcio, se detallaran únicamente las características de dos de ellas, el fosfato de calcio amorfo (ACP) y la hidroxiapatita (HA).

\footnotetext{
115 B. León, J.A. Jansen, Thin Calcium Phosphate Coatings for Medical Implants, Springer Science + Business Media, LLC, 26, 2009.

${ }^{116}$ H. Aoki, Science and medical applications of hydroxyapatite, Tokyo, Japan: Takayama Press, 1991.
} 
El fosfato cálcico amorfo (ACP) es un precipitado de composición variable que se forma en las reacciones de doble descomposición que implican un hidrogeno fosfato soluble $\left(\mathrm{NH}_{4}\right)_{2} \mathrm{HPO}_{4}$, y nitrato de calcio $\mathrm{Ca}\left(\mathrm{NO}_{3}\right)_{2}{ }^{117}$. Los precipitados que se obtienen, en base a las condiciones de temperatura y de $\mathrm{pH}$, pueden ser compuestos de muy variada estequiometría ${ }^{118}$. La composición del fosfato de calcio amorfo es $\mathrm{Ca}_{\mathrm{x}} \mathrm{H}_{\mathrm{y}}\left(\mathrm{PO}_{4}\right)_{\mathrm{z}}$. $\mathrm{nH}_{2} \mathrm{O}$, con $n$ entre 3,0 y 4,5. Los estudios consultados muestran que el fosfato de calcio amorfo carece, a largo alcance, de orden periódico respecto a los fosfatos de calcio cristalinos. El patrón de difracción de rayos $\mathrm{X}$ se muestra generalmente amplio y difuso con un máximo a $25^{\circ}$ a $2 \theta$, y no hay otras características que los diferencian comparándolo con la hidroxiapatita cristalina. Con las observaciones por microscopia electrónica, el fosfato amorfo se muestra como pequeñas partículas esferoidales con un tamaño de décimas de nm.

La hidroxiapatita (HA) está formada por fosfato de calcio cristalino que puede describirse con la formula química $\mathrm{Ca}_{10}\left(\mathrm{PO}_{4}\right)_{6}(\mathrm{OH})_{2}$. Se caracteriza por una relación $\mathrm{Ca} / \mathrm{P}$ de 1,67 y presenta una disposición hexagonal de los iones calcio $\mathrm{Ca}^{2+}$ y fosfato $\mathrm{PO}_{4}{ }^{3-}$ alrededor de las columnas constituidas por los iones hidroxilo $\mathrm{OH}^{-}$. Como ya se ha descrito anteriormente, este fosfato cristaliza en el sistema hexagonal, con grupo espacial $\mathrm{PO}_{3} / m$. La celda unitaria contiene una representación completa del cristal de apatita con grupos $\mathrm{Ca}^{2+}, \mathrm{PO}_{4}{ }^{3-}$ y $\mathrm{OH}^{-}$estrechamente empaquetados ${ }^{119}$.

La representación estructural de la hidroxiapatita se muestra en la Figura $4.1^{120}$, donde los parámetros de la celda unitaria son $\mathrm{a}=\mathrm{b}=9,418 \AA \mathrm{A} \mathrm{c}=6,884 \AA^{121}$. La red cristalina de la hidroxiapatita viene definida por los grupos fosfatos $\mathrm{PO}_{4}{ }^{3-}$. Los tetraedros de fosfato están dispuestos en forma de empaquetamiento compacto hexagonal ( $\mathrm{ABABA}$ ), siendo los iones $\mathrm{Ca}^{2+}$ los modificadores de la red cristalina, ocupando las vacantes generadas dentro de la celda unitaria ${ }^{122}$.

\footnotetext{
${ }^{117}$ A. Destainville, E. Champion, D. Bernache Assollant, E. Laborde, Synthesis, characterization and thermal behavior of apatitic tricalcium phosphate, Materials Chemistry and Physics. 80 (1), 269-277, 2003.

${ }^{118}$ V. Dorozhkin, Amorphous calcium (ortho)phosphates, Acta Biomaterialia. 6 (12): 4457-4475, 2012.

${ }^{119}$ J.F. Kay, Calcium phosphate coatings for dental implants, Dental Clinics of North America, 36, 1-18, 1992.

${ }^{120}$ I. Motoji, New applications of electron spin resonance: ESR dating, dosimetry \& microscopy, World Scientific Publishing, 1993.

${ }^{121}$ T.S.B. Narasaraju, D.E. Phebe, Some physico-chemical aspects of hydroxylapatite, J. Mater. Sci. 31, 1-21, 1996.

${ }^{122} \mathrm{~V}$. Uskokovic, The role of hydroxyl channel in defining selected physicochemical peculiarities exhibited by hydroxyapatite, RSC Adv. 5, 36614-36633, 2015.
} 


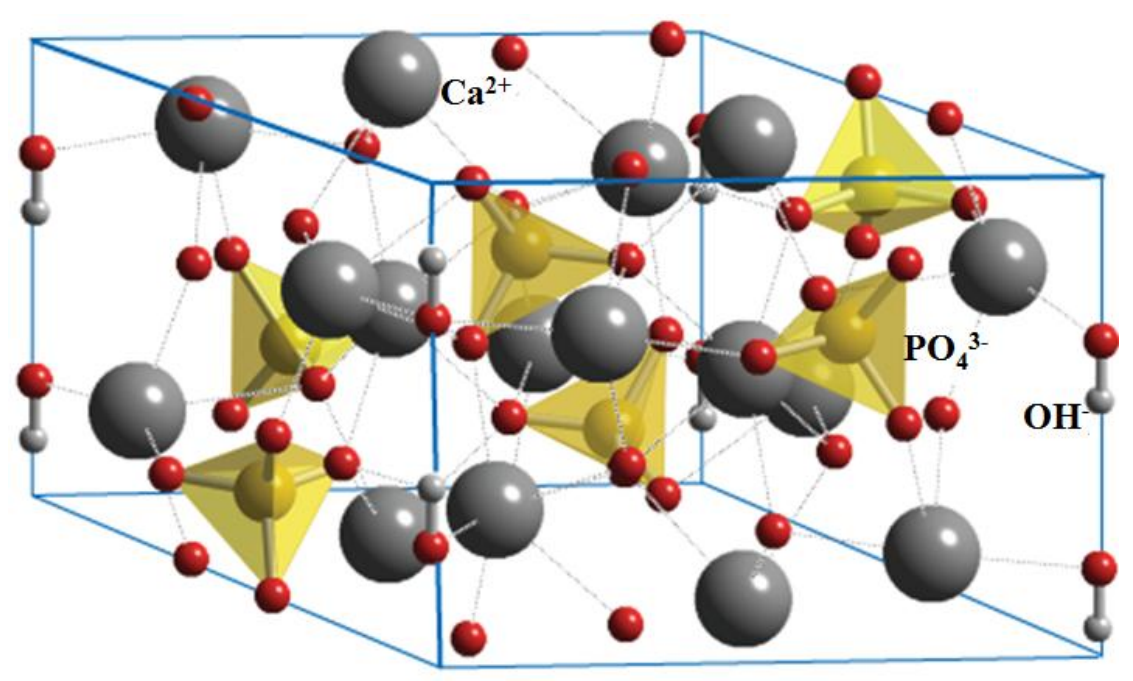

Figura 4.1. Estructura cristalina de la hidroxiapatita en el sistema hexagonal, con grupo espacial $P 6_{3} / m$.

La hidroxiapatita presenta un carácter iónico que le confiere las características de ser un material cerámico duro, refractario y con punto de fusión mayor de $1500{ }^{\circ} \mathrm{C}$. También este carácter iónico proporciona a la hidroxiapatita la capacidad de la sustitución parcial o completa de iones $\mathrm{PO}_{4}{ }^{3-}, \mathrm{HPO}_{4}{ }^{2-}$ y $\mathrm{Ca}^{2+}$ de la red por otros de tamaño similar tales como $\mathrm{K}^{+}, \mathrm{Mg}^{2+}, \mathrm{OH}^{-}, \mathrm{F}^{-}, \mathrm{Br}^{-}$en prácticamente todos los sitios disponibles de la red unitaria ${ }^{123,124}$. Esta flexibilidad estructural de la hidroxiapatita, que se debe a la presencia de defectos estructurales como vacantes, permite crear distorsiones en la celda unitaria, variando las longitudes o los ángulos entre los enlaces Ca-O y $\mathrm{P}-\mathrm{O}$, sin que haya una ruptura de la estructura hexagonal de la red cristalina $^{125}$. De esta manera, la red cristalina de la hidroxiapatita hexagonal puede expandirse o contraerse considerablemente en presencia de sustituciones iónicas y/o vacantes, teniendo un intervalo considerable en los parámetro de red que van desde 9,41 y $9,44 \AA$ A para el parámetro $a$, y de 6,84 a $6,94 \AA$ en parámetro $c^{126}$, 127

\footnotetext{
${ }^{123}$ R.A.D. Williams, J.C. Elliot, Bioquímica dental básica y aplicada, El Manual Moderno. México, 316.

${ }^{124}$ E. Boanini, M. Gazzano, A. Bigi, Ionic substitutions in calcium phosphates synthesized at low temperature, Acta Biomater. 6, 1882-1894, 2010.

${ }^{125}$ F. Ren, R. Xin, X. Ge, Y. Leng, Characterization and structural analysis of zinc-substituted hydroxyapatites, Acta Biomater. 5, 3141-3149, 2009.

${ }^{126}$ J.C. Elliot, Structure and Chemistry of the Apatites and Other Calcium Orthophosphates, Studies in Inorganic Chemistry, Elsevier Publisher, Vol. 18, 1994.

${ }^{127} \mathrm{~V}$. Uskokovic, The role of hydroxyl channel in defining selected physicochemical peculiarities exhibited by hydroxyapatite, RSC Adv. 5, 36614-36633, 2015.
} 


\subsection{Síntesis de la hidroxiapatita}

La literatura muestra que se han llevado a cabo en los últimos años han sido estudiados distintos métodos de síntesis para obtener los fosfatos de calcio en forma de nanopartículas en sus distintas fases para aplicaciones biomédicas, tales como la fase hidroxiapatita y los fosfatos de calcio di y trifásico ${ }^{128,129}$.

Entre las rutas de síntesis para la obtención de compuestos a base de fosfatos de calcio, se encuentran los métodos por vía seca, donde se incluyen las reacciones en estado sólido a bajas o altas temperaturas y los mecanismos por molienda mecánica ${ }^{130,}{ }^{131}$. En cuanto a los métodos vía húmeda, se encuentran el procedimiento de precipitación química ${ }^{132,133,134}$, los métodos hidrotermales ${ }^{135}$ y el método sol-gel ${ }^{136}$. Es posible precipitar varias fases de los fosfatos de calcio, dependiendo de las condiciones experimentales en que tiene lugar la reacción. Parámetros como el pH y la temperatura son determinantes en la obtención de las fases de fosfato de calcio ácidas, básicas o hidratadas.

\footnotetext{
${ }^{128}$ M. Sadat Shojai, M.T. Khorasani, E. Dinpanah Khoshdargi, A. Jamshidi, Synthesis methods for nanosized hydroxyapatite with diverse structures, Acta Biomater. 9, 7591-7621, 2013.

${ }^{129}$ K. Lin, C. Wu, J. Chang, Advances in synthesis of calcium phosphate crystals with controlled size and shape, Acta Biomater. 10, 4071-4102, 2014.

${ }^{130}$ A.S. Karpov, J. Nuss, M. Jamsen, P.E. Kazin, Y.D. Tretyakov, Synthesis, crystal structure and properties of calcium and barium hydroxyapatites containing copper ions in hexagonal channels, Solid State Sci. 5, 1277-1283, 2003.

${ }^{131}$ X. Guo, H. Yan, S. Zhao, Z. Li, Y. Li, X. Liang, Effect of calcining temperature on particle size of hydroxyapatite synthesized by solid-state reaction at room temperature, Adv. Powder Technol. 24, 1034-1038, 2013.

${ }^{132}$ L.M. Rodríguez Lorenzo, M. Vallet Regí, Controlled crystallization of calcium phosphate apatites, Chem. Mater. 12, 2460-2465, 2000.

${ }^{133}$ T.T.T. Pham, T.P. Nguyen, T.N. Pham, T.P. Vu, D.L. Tran, H. Thai, T.M.T. Dinh, Impact of physical and chemical parameters on the hydroxyapatite nanopowder synthesized by chemical precipitation method, Adv. Nat. Sci. Nanosci. Nanotechnol. 4, 035014, 2013.

${ }^{134} \mathrm{Y}$. Pang, X. Bao, Influence of temperature, ripening time and calcination on the morphology and crystallinity of hydroxyapatite nanoparticles, J. Eur. Ceram. Soc. 23, 1697-1704, 2003.

${ }^{135}$ A. Lak, M. Mazloumi, M. Mohajerani, A. Kajbafvala, S. Zanganeh, H. Arami, S.K. Sadrnezhaad, Self-assembly of dandelion-like hydroxyapatite nanostructures via hydrothermal method, J. Am. Ceram. Soc. 91, 3292-3297, 2008.

136 U.V. Natarajan, S. Rajeswari, Influence of calcium precursors on the morphology and crystallinity of sol-gel-derived hydroxyapatite nanoparticles, J. Cryst. Growth. 310, 4601-4611, 2008.
} 
En la Figura 4.2, se observan las posibles fases precipitadas en las que varían algunos parámetros de la reacción $(\mathrm{pH} \text {, relación } \mathrm{Ca} / \mathrm{P})^{137}$. La solubilidad del fosfato de calcio disminuye drásticamente de izquierda a derecha, siendo la hidroxiapatita la fase más estable e insoluble.

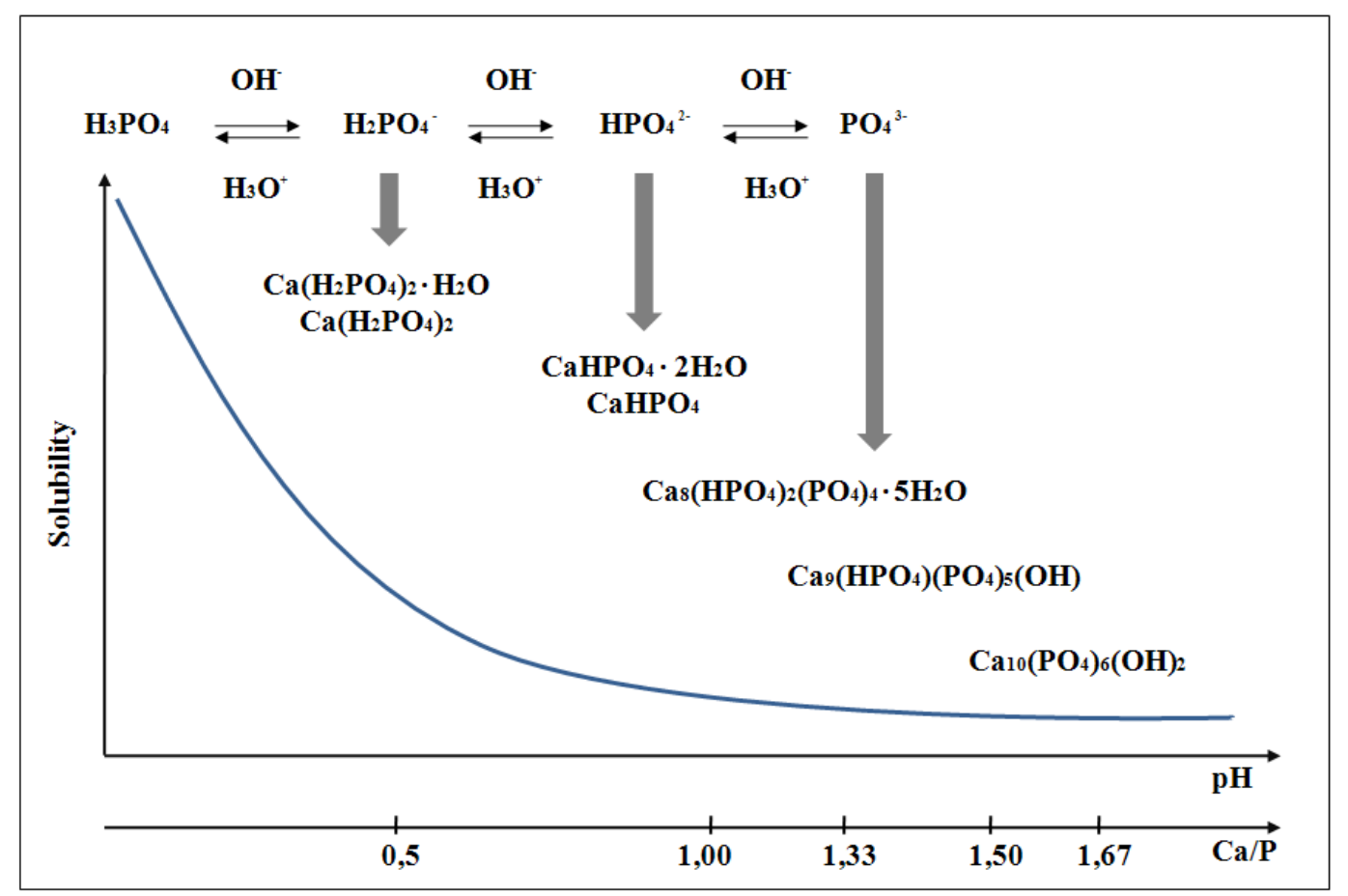

Figura 4.2. Compuestos a base de fosfato de calcio obtenidos por neutralización del ácido fosfórico.

${ }^{137}$ B. León, J.A. Jansen, Thin Calcium Phosphate Coatings for Medical Implants, Springer Science + Business Media, LLC, 26, 2009. 


\subsubsection{Rutas de síntesis por métodos vía seca}

Las rutas de síntesis de los fosfatos de calcio por métodos de vía seca utilizan reacciones en estado sólido a partir de óxidos con la posterior sinterización de los mismos ${ }^{138}$. Mediante este tratamiento térmico se implica la transición de un polvo muy fino con un tamaño de partícula inferior igual a $1 \mu \mathrm{m}$, a un sólido denso o poroso. Es el resultado del movimiento atómico estimulado por temperaturas muy altas en el que los procesos de difusión suelen ser dominantes ${ }^{139}$. A través de esta técnica, por reacciones en estado sólido, solo se pueden obtener determinados compuestos de los fosfato de calcio como se describe en la Tabla $4.2^{140}$. Mediante sinterización es posible preparar hidroxiapatita de calcio a una temperatura entre $1000-1300{ }^{\circ} \mathrm{C}$, con la siguiente reacción:

$\mathrm{CaHPO}_{4} \cdot 2 \mathrm{H}_{2} \mathrm{O}+4 \mathrm{CaCO}_{3} \rightarrow \mathrm{Ca}_{10}\left(\mathrm{PO}_{4}\right)_{6}(\mathrm{OH})_{2}+4 \mathrm{CO}_{2}+14 \mathrm{H}_{2} \mathrm{O}$

Tabla 4.2. Compuestos a base de fosfato de calcio que se pueden obtener por las rutas de síntesis vía seca.

\begin{tabular}{|c|c|c|}
\hline Compuesto & Relación Ca/P & Formula química \\
\hline$\alpha$-Fosfato tricálcico & 1,5 & $\alpha-\mathrm{Ca}_{3}\left(\mathrm{PO}_{4}\right)$ \\
\hline$\beta$-Fosfato tricálcico & 1,5 & $\beta-\mathrm{Ca}_{3}\left(\mathrm{PO}_{4}\right)$ \\
\hline Hidroxiapatita sinterizada & 1,67 & $\mathrm{Ca}_{10}\left(\mathrm{PO}_{4}\right)_{6}(\mathrm{OH})_{2}$ \\
\hline Fosfato tetracálcico & 2,0 & $\mathrm{Ca}_{4}\left(\mathrm{PO}_{4}\right)_{2} \mathrm{O}$ \\
\hline
\end{tabular}

\footnotetext{
${ }^{138}$ H. Aoki, Medical Applications of Hydroxyapatite, Takayama Press System Center Co., Inc. 94-75937, 1994.

${ }^{139}$ M.G. Randall, Engineered Materials Handbook. Fundamentals of Sintering: Ceramics and Glasses, v. 4. ASM International, 260, 1991.

${ }^{140}$ K. De Groot, Bioceramics of calcium phosphate, Boca Raton, Florida: CRC Press Inc., 1983.
} 


\subsubsection{Rutas de síntesis por métodos vía húmeda}

Los polvos cristalinos o las nanopartículas de fosfatos de calcio puros o dopados pueden ser obtenidos mediante rutas de síntesis que empleen métodos por vía húmeda. Entre los métodos vía húmeda destacan la neutralización de soluciones ácidas y alcalinas, y las reacciones entre disoluciones que contienen sales de fosfato y sales de calcio. Las reacciones se pueden realizar en disolventes orgánicos o acuosos, a bajas o altas temperaturas. Estos métodos de síntesis permiten la obtención de partículas de forma, tamaño y composición diversa, a través de la variación de los parámetros de síntesis como temperatura, tiempos de reacción, disolventes o concentraciones de los precursores.

A continuación se detalla el método de síntesis por vía húmeda utilizado para la preparación de nanopartículas de hidroxiapatita de calcio: método por precipitación.

\subsubsection{Método por precipitación}

La ruta de síntesis por precipitación implica reacciones vía húmeda utilizando disoluciones acuosas de los precursores de $\mathrm{Ca}^{2+} \mathrm{y} \mathrm{PO}_{4}{ }^{3-}$ controlando parámetros de reacción como el tiempo, temperatura y $\mathrm{pH}^{141,142}$. En la metodología de síntesis por precipitación, la formación del sólido amorfo o cristalino se produce por una reacción química en disolución en la cual la concentración de un compuesto es mayor que su valor de solubilidad. En este sentido, se alcanza el valor de supersaturación en la disolución, permitiendo la precipitación del producto $^{143}$. Las características del producto resultante son esencialmente dependientes de la forma en que se mezclan los precursores. Con la optimización de los parámetros de síntesis tal como temperatura, tiempo de reacción, tiempo de curado o $\mathrm{pH}$, es posible obtener materiales de distintas características, como morfología, cristalinidad y tamaño de partículas.

\footnotetext{
${ }^{141}$ G. Bezzi, G. Celotti, E. Landi, T.M.G. La Torretta, I. Sopyan, A. Tampieri, Mat Chem Phys 78, 816-824, 2003.

${ }^{142}$ M.L. Santos, A.O. Florentino, M.J. Saeki, A.H. Aparecida, M.V. Lia Fook, A.C. Guastaldi, Ecl Quim 30, (3), 29-35, 2005.

${ }^{143}$ B. Wopenka, J.D. Pasteris, A mineralogical perspective on the apatite in bone, Mater. Sci. Eng. C. 25, 131-143, 2005.
} 
En la Tabla 4.3 se muestran los sólidos cristalinos a base de fosfato de calcio que se pueden obtener por precipitación a temperatura ambiente ${ }^{144}$.

Tabla 4.3. Sistema $\mathrm{Ca}(\mathrm{OH})_{2}-\mathrm{H}_{3} \mathrm{PO}_{4}-\mathrm{H}_{2} \mathrm{O}$ obtenidas por precipitación a temperatura ambiente.

\begin{tabular}{|c|c|}
\hline Formula química & Relación Ca/P \\
\hline $\mathrm{Ca}\left(\mathrm{H}_{2} \mathrm{PO}_{4}\right)_{2} \cdot \mathrm{H}_{2} \mathrm{O}$ & 0,5 \\
\hline $\mathrm{CaHPO} \cdot 2 \mathrm{H}_{2} \mathrm{O}$ & 1,0 \\
\hline $\mathrm{Ca}_{8}\left(\mathrm{HPO}_{4}\right)_{2}\left(\mathrm{PO}_{4}\right)_{4} \cdot 5 \mathrm{H}_{2} \mathrm{O}$ & 1,33 \\
\hline $\mathrm{Ca}_{9}\left(\mathrm{HPO}_{4}\right)\left(\mathrm{PO}_{4}\right)_{5}(\mathrm{OH})$ & 1,5 \\
\hline $\mathrm{Ca}_{10}\left(\mathrm{PO}_{4}\right)_{6}(\mathrm{OH})_{2}$ & 1,67 \\
\hline
\end{tabular}

La reacción de precipitación para obtener cristales de tamaño nanométricos de HA sigue la siguiente ecuación ${ }^{145}$ :

$10 \mathrm{Ca}(\mathrm{OH})_{2}+6 \mathrm{H}_{3} \mathrm{PO}_{4} \rightarrow \mathrm{Ca}_{10}\left(\mathrm{PO}_{4}\right)_{6}(\mathrm{OH})_{2}+18 \mathrm{H}_{2} \mathrm{O}$

La ruta de precipitación descrita permite obtener polvos de hidroxiapatita estequiométrica con las mejores propiedades fisicoquímicas en cuanto a composición, estructura y textura para su óptimo desempeño como material de implante óseo. Como se ha descrito anteriormente, solo introduciendo pequeñas modificaciones en la ruta de síntesis, mecanismos y velocidad de adicción de las disoluciones de los precursores, concentraciones de los precursores, temperatura de la reacción, pH, atmósfera de reacción etc., se pueden introducir diferentes cambios en el material sintetizado como composición, tamaño de partícula, cristalinidad y morfología ${ }^{146}$. Además, es posible obtener muestras de hidroxiapatita de calcio con diferente relación molar $\mathrm{Ca} / \mathrm{P} \mathrm{y}$, en consecuencia, muestras con diferentes propiedades estructurales y de reactividad.

144 K. De Groot, Tissue Eng 4, 337, 1998; F.C.M. Driessens, J.A. Planell, F.J. Gil, Calcium phosphate bone cements, In: Encyclopedic Handbook of Biomaterials and Bioengeneering, Part B. Applications, DL Wise, D.J. Trantolo, D.E. Altobelli, M.J. Yaszemski, J.D. Gresser, E.R. Schwarz, New York, USA, Eds.: Marcel Dekker Inc., 1995.

${ }^{145}$ E. Bouyer, F. Gitzhofer, M.I. Boulos, Morphological study of hydroxyapatite nanocrystal suspension, Journal of Materials Science: Materials in Medicine. 11 (8), 523-31, 2000.

${ }^{146}$ J. Perks, R. Lakes, Biomaterials: an introduction, New York, Plenum PRESS, 1992; J. Liu, X. Ye, H. Wang, M. Zhu, B. Wang, $\mathrm{H}$. Yan, The influence of $\mathrm{pH}$ and temperature on the morphology of hydroxyapatite synthesized by hydrothermal method, Ceramics International. 29, 629-633, 2003. 
Técnicas instrumentales de caracterización de materiales y de evaluación de los tratamientos de consolidación y protección 


\section{Capítulo 5. Técnicas instrumentales de caracterización de materiales y de evaluación de los tratamientos de consolidación y protección}

5.1. Caracterización de los materiales constituyentes los bienes culturales en soporte pétreo y pintura mural

5.2. Caracterización de las muestras sintetizadas con estequiometría de hidroxiapatita

5.3. Caracterización de probetas y evaluación de los tratamientos de consolidación y protección

5.3.1. Colorimetría

5.3.2. Perfilometría

5.3.2.1. Parámetros de rugosidad

5.3.3. Absorción de agua por capilaridad

5.3.4. Determinación de la permeabilidad al vapor de agua 


\section{Capítulo 5. Técnicas instrumentales de caracterización de materiales y de evaluación de los tratamientos de consolidación y protección}

En este capítulo se indican aquellos aspectos relacionados con los procedimientos de caracterización de los materiales que constituyen los bienes culturales en soporte pétreo y pintura mural, así como de las técnicas analíticas para el estudio de caracterización química y estructural de las muestras sintetizadas con estequiometría de hidroxiapatita. Para finalizar, se presentan los aspectos relativos a la preparación tanto de las probetas de soporte pétreo y de pintura mural así como las condiciones experimentales con las que se han aplicado las diferentes técnicas utilizadas para la evaluación de la acción consolidante y protectora de los compuestos preparados. 


\subsection{Caracterización de los materiales constituyentes los bienes culturales en soporte pétreo y pintura mural}

Los estudios petrográficos y petrofísicos del soporte pétreo y de los fragmentos de la pintura mural, así como la caracterización de los materiales y el diagnóstico del estado de conservación, se realizaron mediante un trabajo normalizado ${ }^{147,148}$, con extracción de fragmentos y análisis de laboratorio.

En una primera fase se utilizó el microscopio estereoscópico para el estudio preliminar de los fragmentos y su preparación para los análisis sucesivos. Las observaciones se llevaron a cabo con el microscopio estereoscópico NIKON SMZ1000 con cámara NIKON DS-2Mv. Se capturaron imágenes de los fragmentos a distintos aumentos, desde $1 \mathrm{x}$ hasta $8 \mathrm{x}$.

Una parte importante del estudio se realizó mediante la preparación de los fragmentos pétreos y de pintura mural en corte transversal y en láminas delgadas con un espesor de $20 \mu \mathrm{m}$ aproximadamente. Los fragmentos de piedra seleccionados para la preparación de las láminas delgadas, han sido embutidos en frío mediante una resina epóxica; seguidamente, una de las caras de la muestra ha sido desbastada a mano mediante el empleo de papeles abrasivos con tamaño de grano fino. Se efectúo el pegado de la cara pulida a un porta objetos de vidrio tamaño geológico estándar mediante una resina de cianoacrilato de índice de refracción similar al bálsamo del Canadá $(\mathrm{n}=1,55)$. El acabado de la muestra se realizó a mano utilizando papeles abrasivos hasta obtener una lámina de aproximadamente $20 \mu \mathrm{m}$ de grosor. Las láminas han sido pulidas a calidad espejo para no necesitar cubre-objetos y para poder ser analizadas por SEM-EDX y MO con luz transmitida.

Las muestras se observaron con el microscopio óptico ECLIPSE 80i de Nikon Corporation que lleva acoplada una cámara DS-Fi1 con aumentos de 5 x a 100 x. En el examen de una lámina delgada se opera combinando la observación mediante luz normal y luz polarizada, al tiempo que se rota la muestra para observar la interacción de la luz en diferentes direcciones de la muestra. De esta manera es posible determinar:

- Propiedades ópticas: color, relieve, índice de refracción, pleocroísmo, birrefringencia, etc.

- Texturas: formas y hábitos cristalinos, dimensiones, distribución de cemento y matriz, etc.

- Determinaciones mineralógicas, a partir del estudio de las propiedades ópticas.

\footnotetext{
${ }^{147}$ M. Montoto, Aplicación de diferentes técnicas microscópicas sobre la misma muestra de roca: multimágenes, XVII Reunión Bienal, Sociedad Española de Microscopia Electrónica. Oviedo, 30-31. 1995.

${ }^{148}$ M. Montoto, Petrophysics: The petrographic interpretation of the physical properties of rocks, 5 Int. Cong. of the Int. Soc. for Rock Mechanics, Melbourne, 93-98. 1983.
} 
- Caracterización de la piedra a partir de la mineralogía y del examen de textura y morfología.

- Caracterización de los morteros mediante el examen mineralógico de los constituyentes (aglomerante y árido).

- Caracterización de pigmentos minerales y estudio de la técnica pictórica.

- Microfisuración y alteraciones y estudio del sistema poroso (macroporoso).

Las micrografías obtenidas por SEM y los microanálisis EDX se obtuvieron empleando el microscopio Hitachi Ltd. (VP-SEM), modelo S-3400N equipado con un espectrómetro de rayos X de energía dispersiva (EDX) de Bruker Corporation XFlash ${ }^{\circledR}$ con un voltaje de aceleración $20 \mathrm{kV}$. Los fragmentos pétreos y morteros a examinar eran muestras rugosas sobre las que se estudiaron superficies de corte fresco (superficies de fractura), superficies alteradas y productos de alteración; y muestras con superficies pulidas como en el caso de los cortes transversales o de las láminas delgadas. Los fragmentos han sido observados en modalidad electrones retrodispersados (BSE), lo que nos permite obtener imágenes con distintos tonos de grises (contraste composicional) en función de las fases presentes con elementos pesados o ligeros.

Los espectros IR por transformada de Fourier (FTIR) ${ }^{149}$, necesarios para la identificación de las fases mineralógicas de los soportes y de los productos de alteración, se obtuvieron en modo trasmisión con un espectrómetro Bruker-Tensor 27, utilizando un dispositivo de ATR de cristal de diamante acoplado a la bancada del espectrómetro, en el intervalo $4000-400 \mathrm{~cm}^{-1}$ con una resolución de $4 \mathrm{~cm}^{-1}$. Para garantizar la homogeneidad de la muestra analizada, se realizó la recogida de las muestras y su molturación en mortero de ágata.

En cuanto a los difractogramas de rayos $\mathrm{X}$ en polvo de muestras de los soportes y productos de alteración, se registraron con un difractómetro de Bruker Corporación D4 Endeavor AXS, con radiación $\mathrm{Cu} \mathrm{K} \alpha 1$ con una longitud de onda $\lambda=0,154 \mathrm{~nm}$. Las medidas se tomaron con $40 \mathrm{kV}$ y $20 \mathrm{~mA}$, en un intervalo de $2 \theta$ de $15-70$, un paso de $0,05^{\circ}$ y un tiempo de $1,5 \mathrm{~s}$. Mediante el programa Crystallographica Search-Match se realizó la selección de los picos de difracción y una búsqueda de fases, posteriormente completada con la consulta de los patrones de difracción JCPDS-ICDD.

\footnotetext{
${ }^{149}$ I. Adrover Garcia, Appliccazioni della spettrofotometria IR allo studio dei beni culturali, Collana i Talenti, Il Prato, 2001.
} 


\subsection{Caracterización de las muestras sintetizadas con estequiometría de hidroxiapatita}

La caracterización de las muestras preparadas se realizó inicialmente con medidas de difracción de rayos X. Los análisis se hicieron sobre las muestras en forma de polvo compactado con las condiciones descritas anteriormente.

Las medidas para obtener los espectros IR por transformada de Fourier (FTIR) se llevaron a cabo usando un espectrofotómetro Jasco, modelo FT/IR-6200. Las muestras fueron preparadas mezclando un 3\% en peso de los compuestos con $\mathrm{KBr}$ y se conformaron como pastillas. Los espectros se recogieron en el intervalo de 4000 a $400 \mathrm{~cm}^{-1}$ con una media de 36 scans.

Las micrografías obtenidas por SEM de los polvos sintetizados se obtuvieron empleando el microscopio JEOL modelo 7001F con un voltaje de aceleración de $20 \mathrm{kV}$. Para la preparación de las muestras, éstas se adhirieron sobre un soporte portamuestras que se recubre con una cinta adhesiva conductora de doble cara y se metalizaron con una fina capa de platino mediante pulverización catódica con el objeto de hacer la superficie conductora.

Finalmente, se realizaron observaciones por TEM con el equipo JEOL 2100 equipado con un espectrómetro EDX de INCA Energy TEM (Oxford). Para la preparación de las muestras se depositó una gota de la suspensión del material sobre una rejilla de cobre (300 mesh) recubierta con una película de grafito. La valoración de las distribuciones de tamaño de partícula de las muestras de hidroxiapatita se realizó mediante tratamiento estadístico con el programa ImajeJ. Las dimensiones de las partículas se estimaron utilizando distintas imágenes TEM de las tres muestras sintetizadas. El número de recuento requerido para los análisis estadísticos ha sido de 100 partículas. 


\subsection{Caracterización de probetas y evaluación de los tratamientos de consolidación y protección}

La evaluación de las muestras preparadas se realizó mediante la selección y adecuación de probetas de soporte pétreo y de fragmentos de pintura mural que han sido caracterizadas previamente a la realización de los tratamientos. El estudio se realizó a través de la valoración de los cambios producidos en las propiedades de los sustratos antes y después de la aplicación de los producos. Se han evaluado variables como penetrabilidad, modificación de la porosidad, así como la cuantificación de las capacidades de adsorber agua y las variaciones de adhesión-coeshion entre los constituyentes o el cambio de la rugosidad superficial, etc. Asimismo, se han estudiado las variaciones de las propiedades estéticas superficiales como el cambio de las coordenadas colorimetricas y morfología. Para este estudio se ha desarrollado una metodología de trabajo normalizado tal y como se muestra con el diagrama de la Figura 5.1.

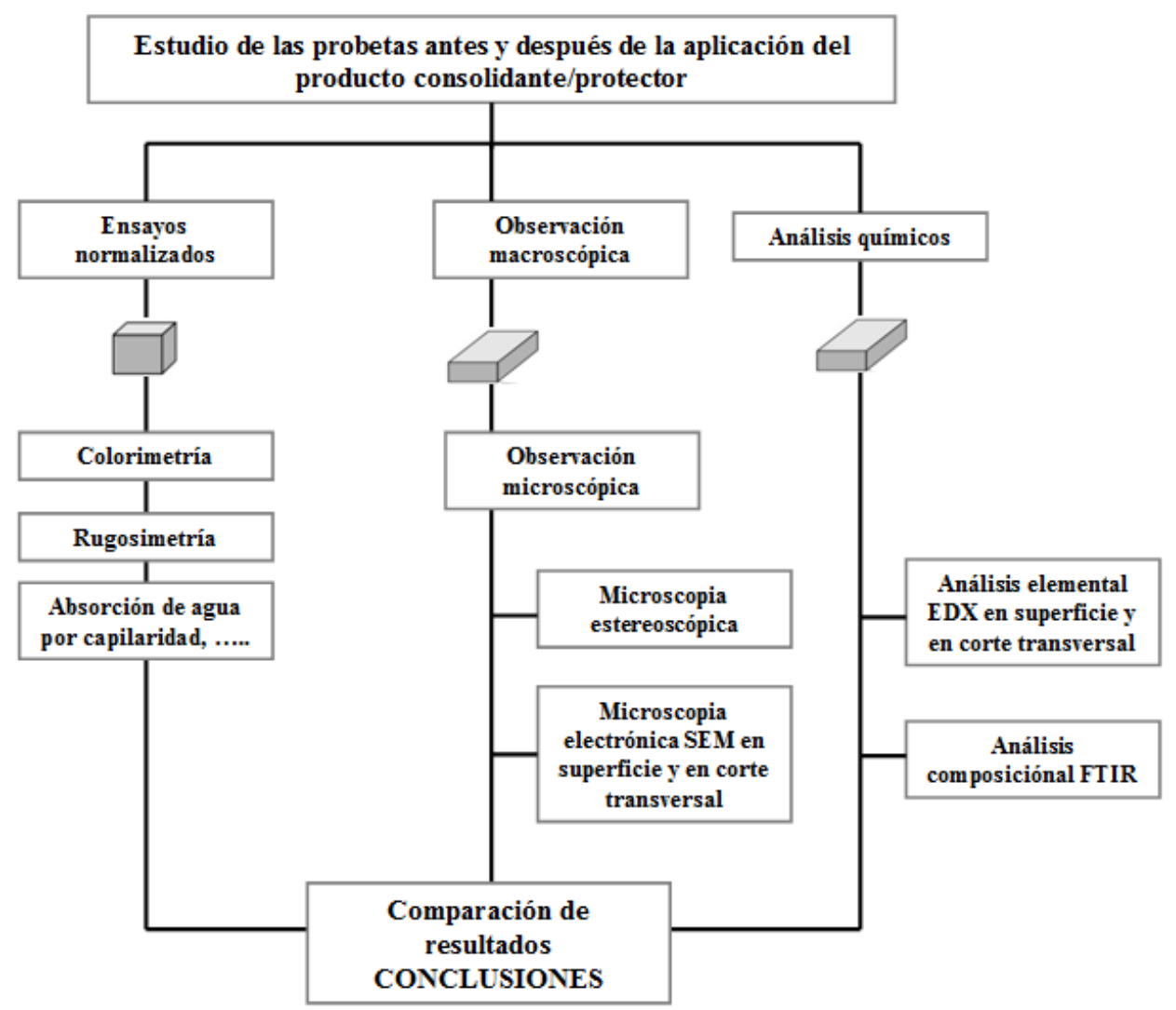

Figura 5.1. Esquema de la metodología de trabajo desarrollada para la evaluación del tratamiento de consolidación y protección sobre probetas. 
La primera observación de las probetas y fragmentos antes y después de la aplicación de los productos a evaluar, se realizó con el microscopio estereoscópico. Se capturaron imágenes de todas las probetas a distintos aumentos, desde $1 \mathrm{x}$ hasta $8 \mathrm{x}$. Se han observado los posibles cambios de la morfología y del color producidos con la aplicación de los productos.

Gran parte del estudio de evaluación de la acción consolidante y protectora por parte de los productos aplicados se realizó mediante observaciones SEM y microanálisis EDX de superficie y en corte transversal de las probetas y fragmentos. Las micrografías de SEM se obtuvieron trabajando en modalidad presión variable (VP-SEM). Aunque implica una pérdida en la resolución, el hecho de trabajar con un microscopio de presión variable permite introducir las probetas y los fragmentos que se quieren investigar sin someterlas al proceso de metalizado para hacerlas conductoras. Para cada probeta o fragmento se capturaron imágenes en modalidad electrones retrodispersados (BSE) a distintos aumentos, desde $50 \mathrm{x}$ hasta $800 \mathrm{x}$ tanto antes como después del tratamiento.

El estudio realizado con el VP-SEM ha permitido valorar la acción consolidante y protectora de los materiales aplicados, su distribución, la afinidad y capacidad de adhesión y cohesión con los constituyentes de las probetas y fragmentos, capacidad de penetración en los poros de los sustratos y proporcionar informaciones sobre cambios de la morfología superficial, apreciando posibles acumulaciones de los productos aplicados.

Con la finalidad de controlar la presencia de los productos aplicados en las probetas y fragmentos, se recogieron muestras para ser analizadas mediante espectroscopia de infrarrojo por transformada de Fourier (FTIR). También en este estudio, para garantizar la homogeneidad de la muestra analizada, se realizó la recogida de las muestras y su molturación.

La eficacia de una correcta acción consolidante o de protección por parte de un producto incluye una serie de medidas de las propiedades superficiales tales como el color y rugosidad, así como ensayos para valorar los posibles cambios producidos después del tratamiento en la porosidad del material. En este último caso, un ensayo a realizar es la medida de absorción de agua por capilaridad. A continuación se describen con más detalle las condiciones experimentales para la medida de color, rugosidad y de absorción de agua por capilaridad que han sido realizados. 


\subsubsection{Colorimetría}

Las mediciones se llevaron a cabo con un espectrofotómetro Konica Minolta CM-700d acoplado a un software (Color Data Software CM-S100w). El procedimiento consistió en realizar tres mediciones, tanto antes como después de la aplicación de las muestras sintetizadas, a partir de las cuales el programa obtuvo una media y calculó los parámetros. El procedimiento siguió las directrices de la norma UNE EN 15886:2011 ${ }^{150}$ referida a los métodos de ensayo para la medición del color de superficies porosas de materiales inorgánicos. El espectrofotómetro se sometió al procedimiento de calibrado previo al inicio de la toma de medidas. Se trabajó con el iluminante estándar de referencia D65, que se identifica aproximadamente con la misma distribución relativa de poder espectral que la luz diurna, con una temperatura de color aproximada de $6500 \mathrm{~K}$. La medición colorimétrica se realizó con el espectrofotómetro en los mismos puntos en los que se había realizado previamente a los tratamientos. El procedimiento fue idéntico al llevado a cabo anteriormente. Una vez obtenidos estos nuevos valores, el programa calcula la diferencia y proporciona un factor denominado $\Delta \mathrm{E}^{*}$, según la siguiente ecuación:

$\Delta \mathrm{E} *=\sqrt{ }(\Delta \mathrm{L} *)+(\Delta \mathrm{a} *)+(\Delta \mathrm{b} *)$

Dónde: $\Delta \mathrm{L}^{*}=\mathrm{L} * \mathrm{f}-\mathrm{L} * \mathrm{i}$; corresponde a la diferencia de los valores de luminosidad. $\Delta \mathrm{a} *=\mathrm{a} * \mathrm{f}-\mathrm{a} * \mathrm{i}$; corresponde a la diferencia de los valores de rojo/verde. $\Delta \mathrm{b}^{*}=\mathrm{b} * \mathrm{f}-\mathrm{b} * \mathrm{i}$; corresponde a la diferencia de los valores de amarillo/azul. No obstante, existen algunos parámetros de ajuste que el programa aplica para corregir la inexactitud del espacio de color $\mathrm{L}^{*} \mathrm{a} \mathrm{b}^{*}$ en la equidistancia de la percepción cromática (las diferencias colorimétricas entre colores saturados son más difíciles de percibir). Por eso, los valores obtenidos no son exactamente los que resultarían de aplicar la ecuación de forma directa.

Resulta difícil establecer un valor límite de $\Delta \mathrm{E}^{*}$ a partir del cual considerar un consolidante o un protector como apto o no apto para su aplicación en restauración. Por lo general, se toma como referencia el valor a partir del cual se considera que los cambios son apreciables a simple vista por el ojo humano, pero existen pocas referencias estandarizadas a este respecto y prácticamente ninguna del ámbito del Patrimonio Cultural $^{151,152}$. Aun así, si bien hay un cierto consenso en contemplar valores por debajo de 10, la principal

\footnotetext{
${ }^{150}$ A. E. de N. y Certificación, Conservación del patrimonio cultural. Métodos de ensayo. Medición del color de superficies. UNEEN 15886:2011. AENOR, Madrid, 2011.

${ }^{151}$ P. Ortiz, V. Antúnez, R. Ortiz, J. M. Martín, M. A. Gómez, A. R. Hortal, B. Martínez Haya, Comparative study of pulsed laser cleaning applied to weathered marble surfaces, Appl. Surf. Sci., Vol. 283, 193-201, 2013.
} 
conclusión a la que se puede llegar tras realizar una búsqueda entre las publicaciones que documentan el uso de la técnica colorimétrica es que el valor, en concreto, depende en gran medida de las condiciones y particularidades del material que es objeto de la investigación. Por norma general, para soportes de piedra, la mayoría de artículos y publicaciones toman un valor entre 5 y $6^{153,154,155}$. En este caso, por similitud textural de los materiales en los que se centra este estudio con los materiales pétreos porosos se tomará un valor de $\Delta \mathrm{E}^{*}<6$ como umbral de cambio de color superficial demasiado apreciable para las diferentes aplicaciones establecidas en el procedimiento.

\subsubsection{Perfilometría}

La perfilometría es una técnica que permite la caracterización topográfica de superficies realizando perfiles o reconstrucciones tridimensionales además de análisis de rugosidad y ondulación. Por este motivo es una herramienta útil para el análisis de microlentes, elementos difractivos, membranas, capas de polímeros, materiales cerámicos u otros. En nuestro caso, la técnica ha sido empleada para determinar las modificaciones superficiales que se producen en las probetas de soporte pétreo con la aplicación de las muestras de hidroxiapatita preparadas con el relleno parcial de los poros presentes en la superficie de las probetas de piedra. Exactamente ha sido evaluada la correlación entre los parámetros Ra (valor promedio de rugosidad) y Rz (distancia entre el punto más alto y el más bajo del registro perfilométrico), ambos usados en la valoración de la lisura de las superficies.

Las mediadas han sido realizadas mediante el perfilómetro mecánico Dektak 6M Veeco del Servicio Central de Instrumentación Científica de la Universitat Jaume I. El Dektak 6M es un perfilómetro de contacto capaz de medir escalones por debajo de $100 \AA$ y hacer análisis de rugosidad y ondulación en el rango del subnanómetro. El dispositivo toma medidas electromecánicas moviendo la muestra debajo un lápiz con

\footnotetext{
${ }^{152}$ V. Antúnez, P. Ortiz, J. M. Martín, A. Gómez Morón, R. Ortiz, Evaluación de Métodos de Limpieza de Graffiti en Mármol, Macla. Rev. la Soc. Española Mineral., Vol. 16, no. 4, 68-69, 2012.

${ }^{153}$ A. Macchia, O. Bettucci, E. Gravagna, D. Ferro, R. Albini, B. Mazzei, L. Campanella, Calcium hydroxide nanoparticles and hypogeum environment: Test to understand the best way of application, J. Nanomater., Vol. 2014, 2014.

${ }^{154}$ S.A. Ruffolo, M.F. La Russa, P. Aloise, C.M. Belfiore, A. Macchia, A. Pezzino, G.M. Crisci, Efficacy of nanolime in restoration procedures of salt weathered limestone rock, Appl. Phys. A Mater. Sci. Process., Vol. 114, no. 3, 753-758, 2014.

${ }^{155}$ M. Licchelli, M. Malagodi, M. Weththimuni, C. Zanchi, Anti-graffiti nanocomposite materials for surface protection of a very porous stone, Appl. Phys. A Mater. Sci. Process., Vol. 116, no. 4, 1525-1539, 2014.
} 
punta de diamante mediante una etapa de alta precisión. La muestra se mueve de acuerdo a parámetros definidos por el usuario como longitud y velocidad del barrido, y fuerza de la punta. Mientras se mueve la etapa, las variaciones en la superficie de la muestra producen translaciones verticales del lápiz, que está dentro de un bobinado, generándose variaciones de voltaje que son proporcionales les variaciones de altura. A partir de la digitalización de estos voltajes se representa el perfil.

Para la medida de perfilometría se prepararon probetas de soporte pétreo de 10 x $10 \mathrm{~mm}$ específicas para el estudio. La superficie de la probeta sometida a medición se dividió en dos zonas (zona A y zona B): la zona A representa la superficie del soporte pétreo sin tratamiento, mientras que la zona B representa la superficie del soporte con tratamiento donde se aplicaron las dispersiones acuosas de las muestras preparadas. Sobre cada probeta se realizaron tres mediciones, con el desplazamiento del lápiz de $8000 \mu \mathrm{m}$ y ejerciendo una fuerza de $1 \mathrm{mg}$, desde la zona A hasta la zona B, a partir de las cuales se calcularon los siguientes parámetros respecto a la línea media (M). La línea media se define como la línea localizada en la parte media del perfil de rugosidad, con la misma forma que el perfil geométrico, dispuesta paralela a la dirección general del perfil, dentro de los límites comprendidos como base de medición, de modo que la suma de las áreas por encima de ella sean exactamente iguales a la suma de las áreas que están por debajo.

\subsubsection{Parámetros de rugosidad ${ }^{156}$}

Se pueden distinguir los siguientes parámetros:

\section{- $\quad$ Rugosidad media aritmética (Ra)}

Se define como la media aritmética de los valores absolutos de las coordenadas de los puntos del perfil de rugosidad en relación a la línea media dentro de la longitud de medición $l$.

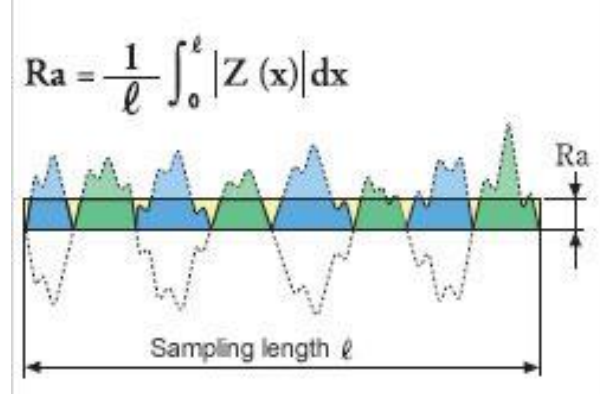

${ }^{156}$ Adaptado de: https://www.olympus-ims.com/es/knowledge/metrology/roughness/2d_parameter. 
- $\quad$ Altura máxima del perfil de rugosidad (Rz)

Es la distancia vertical entre el pico más alto y el valle más profundo dentro de la longitud de medición.

Esto expresa la suma del valor máximo de la altura del pico Rp en la curva del perfil de rugosidad y el valor máximo de la profundidad del valle $\mathrm{Rv}$ del perfil de rugosidad en una longitud de medida $l$.

\section{- $\quad$ Pico máximo del perfil de rugosidad (Rp)}

Es la distancia entre el punto más alto del perfil y la línea media. Esto expresa el valor máximo de la altura de pico $\mathrm{Zp}$ en la curva del perfil de rugosidad, dentro de la longitud de medida $l$.

\section{- Pico máximo más profundo del perfil de rugosidad}

(Rv)

Es la distancia entre el punto más bajo del perfil y la línea media.

Esto expresa el valor máximo de la profundidad de pico $\mathrm{Zv}$ en la curva de perfil de rugosidad, dentro de la longitud de medida $l$.
$\mathrm{Rz}=\mathrm{Rp}_{\mathrm{p}}+\mathrm{R}_{\mathrm{v}}$

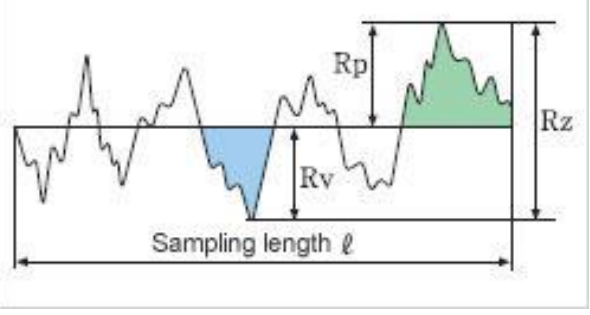

$\mathrm{R} \mathbf{p}=\max (\mathrm{Z}(\mathbf{x}))$

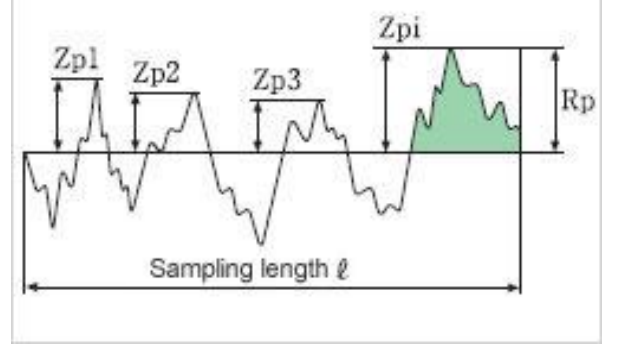

$\mathrm{Rv}=\min (\mathrm{Z}(\mathbf{x}))$

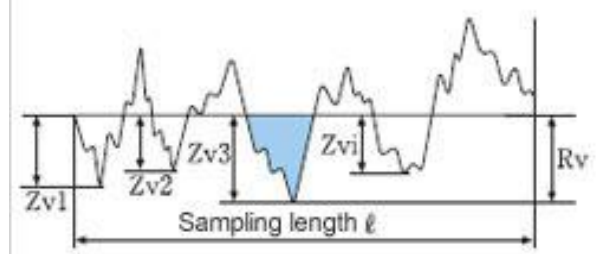




\subsubsection{Absorción de agua por capilaridad}

Las medidas de absorción de agua por capilaridad se realizaron con el protocolo de trabajo de la norma UNI EN 15801:2010 157 . La norma específica un método para determinar la absorción de agua por capilaridad de materiales inorgánicos porosos utilizados en bienes culturales. El método puede ser aplicado tanto a materiales inorgánicos porosos no tratados como a materiales inorgánicos sometidos a tratamiento o envejecidos. Según la norma, vienen calculados y determinados los siguientes parámetros:

- Cálculo de absorción de agua por capilaridad $\mathbf{Q}_{\mathbf{i}}$, que corresponde a la cantidad de agua absorbida por parte de la probeta por unidad de superficie por tiempo, calculado con la siguiente ecuación:

$$
Q_{i}=\frac{\left(m_{i}-m_{0}\right)}{A}
$$

Se expresa en $\mathrm{mg} / \mathrm{cm}^{2}$, donde $\mathrm{m}_{\mathrm{i}}$ es la masa de la probeta mojada en el tiempo $\mathrm{t}_{\mathrm{i}} \mathrm{s}^{1 / 2}$, expresada en gramos $\mathrm{y}$ $\mathrm{m}_{0}$ es la masa de la misma probeta seca, también expresada en gramos.

- Cálculo del coeficiente de absorción capilar que corresponde al coeficiente angular de la curva de absorción capilar en el primer tramo linear hasta los treinta minutos:

$$
C A=\frac{\underline{Q}_{30}-Q_{0}}{\sqrt{t_{30}}}
$$

Se expresa en $\mathrm{mg} / \mathrm{cm}^{2} \mathrm{~s}^{-1 / 2}, \mathrm{Q}_{30}$ representa la cantidad de agua absorbida por parte de la probeta de piedra por unidad de superficie a los treinta minutos, $\mathrm{Q}_{0}$ es el punto de intersección obtenido en la ordenada de la recta trazada en la parte linear del grafico, $\mathrm{y} \mathrm{t}_{30}{ }^{1 / 2}$ la raíz cuadrada del tiempo a 30 minutos.

\footnotetext{
${ }^{157}$ Conservazione dei beni culturali - Metodi di prova - Determinazione dell'assorbimento dell'acqua per capillarità. Norma UNI EN 15801:2010.
} 


\subsubsection{Determinación de la permeabilidad al vapor de agua}

La permeabilidad al vapor de agua es un parámetro característico de cada material. Su medida ha permitido verificar si los tratamientos con las diferentes dispersiones acuosas de las muestras sintetizadas presentan compatibilidad con el material pétreo, sin causar una disminución significativa de este valor en el material tratado. Es importante determinar este parámetro en cuanto la natural transpirabilidad de un soporte puede verse afectada con la aplicación de consolidantes o protectores. La fuerte disminución de este parámetro después de un tratamiento, puede causar la retención de agua liquida en los porosos del sustrato, favoreciendo de esta manera a fenómenos de degradación vinculados a la presencia de agua, tales como disoluciones, migraciones y cristalizaciones de sales, desintegración o formación de un entorno favorable para el ataque biológico. Además, cualquier falta de homogeneidad del tratamiento, puede provocar una disminución de la transpiración del sustrato en áreas localizadas, causando en este caso la formación de manchas de humedad antiestéticas.

La determinación de la permeabilidad al vapor de agua se realizó con el protocolo de trabajo adaptado a la norma UNI EN 1015-19:2008 ${ }^{158}$. Algunos parámetros tal como el coeficiente de permeabilidad se calcularon en base a las normas DIN 52615 ${ }^{159}$ y UNI EN ISO 7783-2:2011 ${ }^{160}$. Las medidas se realizaron preparando contenedores de ensayo de base cuadrada como esquematizado en la Figura 5.2, con un espesor de $5 \mathrm{~mm}$ de la solución saturada de nitrato de potasio $\mathrm{KNO}_{3}$, y un espacio de aire entre probeta y solución salina de 10 mm. Las probetas de piedra (3 para cada producto ensayado), han sido adaptadas en forma de paralelepípedos de 20x20x5 mm.

\footnotetext{
${ }^{158}$ Metodi di prova per malte per opere murarie - Parte 19: Determinazione della permeabilità al vapore d'acqua delle malte da intonaco indurite. Norma UNI EN 1015-19:2008.

${ }^{159}$ Testing of thermal insulating materials; determination of water vapour (moisture) permeability of construction and insulating materials. Norma DIN 52615.

${ }^{160}$ Paints and varnishes - Determination of water-vapour transmission properties - Cup method. Norma UNI EN ISO 7783-2:2011.
} 


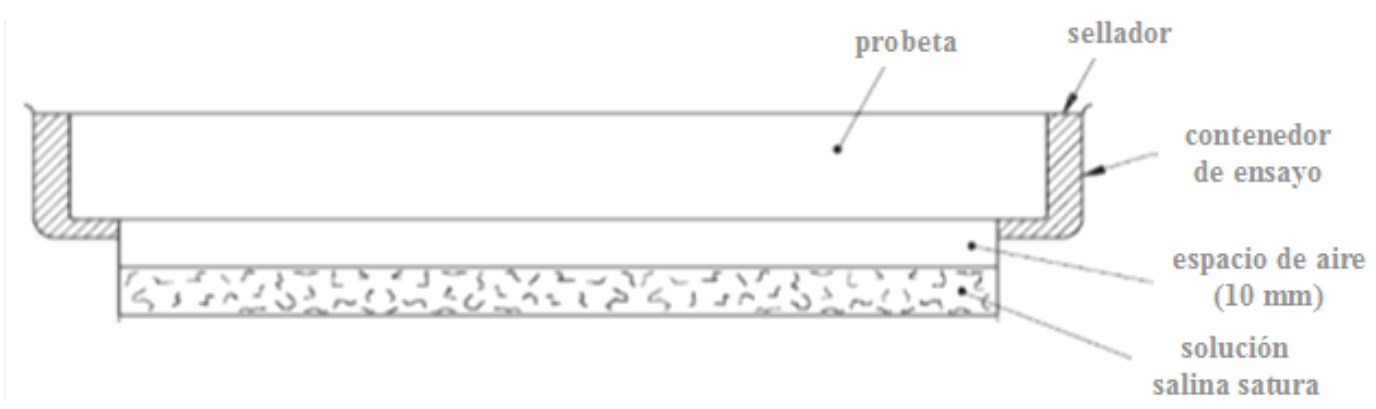

Figura 5.2. Esquema de los contenedores de ensayo para la determinación de la permeabilidad al vapor de agua.

Los contenedores se colocaron en una camera climática a $20 \pm 2{ }^{\circ} \mathrm{C}$ y con humedad relativa de $50 \pm 5 \%$ y a intervalos de 24 horas se midió el peso. Los valores de la masa se relacionan en un diagrama en función del tiempo. Cuando tres puntos se disponen en una línea recta, se considera que hay una condición de estacionariedad, donde la cantidad de vapor de agua que pasa a través de la probeta por unidad de tiempo es constante. Según las normas vienen calculados y determinados los siguientes parámetros:

- Grado de transmisión del vapor de agua WDD, que corresponde a la masa de vapor de agua transmitida en un periodo de tiempo establecido a través de una probeta con área específica, en las condiciones detalladas en la norma y con un valor constante de humedad relativa en las dos caras de la probeta. El WDD se calcula en base a la siguiente ecuación:

$$
W D D=\frac{\Delta M}{A}
$$

Se expresa en $\mathrm{g} /\left(\mathrm{m}^{2} \cdot 24 \mathrm{~h}\right)$ a $20^{\circ} \mathrm{C}$, donde $\Delta M$ es el valor promedio de la variación de peso en el intervalo de tiempo de 24 horas y $A$ es el área superficial de la probeta expresada en $\mathrm{m}^{2}$.

- Permanecia al vapor de agua, que corresponde al flujo de vapor de agua en condiciones estacionarias a través de la probeta en referencia a una superficie unitaria y por una diferencia unitaria de la tensión del vapor del agua. Se calcula en pase a la ecuación:

$$
\Lambda=\frac{1}{A \cdot \Delta_{p} /\left(\Delta G / \Delta t-R_{A}\right)}
$$


Se expresa en $\mathrm{Kg} / \mathrm{m}^{2} \mathrm{~s} \cdot \mathrm{Pa}$ donde $A$ es el área de la probeta en $\mathrm{m}^{2}, \Delta_{p}$ es la diferencia de la tensión de vapor del agua entre el aire del ambiente y la solución salina. $\Delta G / \Delta t$ es el flujo del vapor de agua expresado en $\mathrm{Kg} / \mathrm{s}$ y $R_{A}$ representa la resistencia a la difusión del vapor de agua en el espacio entre probeta y solución salina expresada en $\mathrm{Pa} \cdot \mathrm{m}^{2} \cdot \mathrm{s} / \mathrm{Kg}$.

- Coeficiente de permeabilidad, calculado de la permanencia al vapor de agua multiplicado por el espesor de la probeta, viene expresado en metros:

permeabilidad $=\Lambda \times$ espesor probeta $(\mathrm{m})$

- Factor de resistencia al vapor de agua $\boldsymbol{\mu}$, indica cuánto mayor es la resistencia al vapor de agua proporcionada por el material en comparación con la resistencia al vapor de un estrato de aire libre del mismo espesor y a la misma temperatura. Es un factor adimensional y se determina mediante las siguientes fórmulas:

$$
\mu=\frac{\delta_{L} \cdot 2400 \cdot\left(p_{1}-p_{2}\right)}{W D D \cdot s} \quad \delta_{L}=\frac{D}{R_{D} \cdot T}
$$

Donde $s$ es el espesor de la probeta expresada en metros, $p_{1}$ y $p_{2}$ representan las presiones parciales del vapor en las dos caras de la probeta expresadas en $\mathrm{Pa}, \delta_{L}$ es el coeficiente de difusión del vapor de agua en el aire, $D$ es el coeficiente de difusión del vapor del agua en $\mathrm{m}^{2} / \mathrm{h}, R_{D}$ es la constante de gas del vapor de agua (462 $\mathrm{Nm} /(\mathrm{Kg} \cdot \mathrm{K})$ y $T$ es la temperatura de la medida expresada en grados Kelvin. 
Caracterización del soporte pétreo de la portada de la Iglesia de Nuestra Señora de la Asunción de Corral de Almaguer y de los fragmentos de pintura mural de la Casa de Ariadna en Pompeya 
Capítulo 6. Caracterización del soporte pétreo de la portada de la Iglesia de Nuestra Señora de la Asunción de Corral de Almaguer y de fragmentos de pintura mural de la Casa de Ariadna en Pompeya

6.1. Introducción

6.2. Portada de la Iglesia de Nuestra Señora de la Asunción de Corral de Almaguer (Toledo)

5.2.1. Caracterización del soporte pétreo sin alteración: muestra EP19.2P

5.2.2. Caracterización del soporte pétreo alterado: muestras EP19.4P - EP19.5P

6.3. Las pinturas murales de la Casa de Ariadna en Pompeya (Italia)

6.3.1. Caracterización de los materiales constituyentes

6.3.2. Evaluación del estado de conservación

6.4. Conclusiones 


\section{Capítulo 6. Caracterización del soporte pétreo de la portada de la Iglesia de Nuestra Señora de la Asunción de Corral de Almaguer y de fragmentos de pintura mural de la Casa de Ariadna en Pompeya}

En este capítulo se exponen los resultados de la caracterización de los materiales constituyentes de los bienes culturales seleccionados para el desarrollo de la investigación de la presente tesis doctoral. Se describe, en primer lugar, el estudio de los fragmentos pétreos extraídos de la portada principal de la Iglesia de Nuestra Señora de la Asunción de Corral de Almaguer (Toledo) del siglo XV.

En segundo lugar se presenta el resultado de la identificación de los materiales constituyentes de diferentes fragmentos de pintura mural sobre mortero del siglo I d.C., procedentes del yacimiento arqueológico de la Casa de Ariadna en Pompeya (Italia). El objetivo de este estudio va encaminado a la caracterización de la naturaleza de los distintos materiales presentes en los fragmentos, así como el estudio de los mecanismos de alteración, antes de la incorporación del tratamiento con las muestras con estequiometría de hidroxiapatita sintetizadas. 


\subsection{Introducción}

La evaluación de la aplicabilidad y de la acción consolidante y protectora de las muestras preparadas en esta tesis se ha realizado sobre dos tipologías diferentes de soportes. Exactamente, sobre probetas de soporte pétreo con diferente estado de conservación, procedentes de la portada principal de la Iglesia de Nuestra Señora de la Asunción de Corral de Almaguer (Toledo) del siglo XV (Figura 6.1), y sobre fragmentos de morteros con pintura mural procedentes de las excavaciones arqueológicas realizadas en la Casa de Ariadna en Pompeya (Italia) del siglo I d.C. (Figura 6.2). Los fragmentos de soporte pétreo de la portada y de pintura mural han sido seleccionados por su representatividad en materiales constitutivos, así como en los mecanismos de alteración de numerosas obras de Interés Cultural (monumentos, portadas, decoraciones parietales, etc.).

Como fase preliminar, antes de realizar la aplicación de las muestras con estequiometría de hidroxiapatita sintetizadas para su estudio de viabilidad y eficacia como productos consolidantes y protectores para soporte pétreo y decoraciones parietales, se ha procedido en la caracterización químico física de los materiales constituyentes en los fragmentos del soporte pétreo y de pintura mural. Esta primera fase de investigación es necesaria para la caracterización de materiales y diagnosis del estado de conservación, con el fin de proceder a una correcta conservación científica del bien cultural ${ }^{161}$.

\footnotetext{
${ }^{161}$ AA.VV., Proyecto Coremans: Criterios de Intervención en materiales pétreos. Ministerio de Educación, cultura y Deporte. 2013.
} 


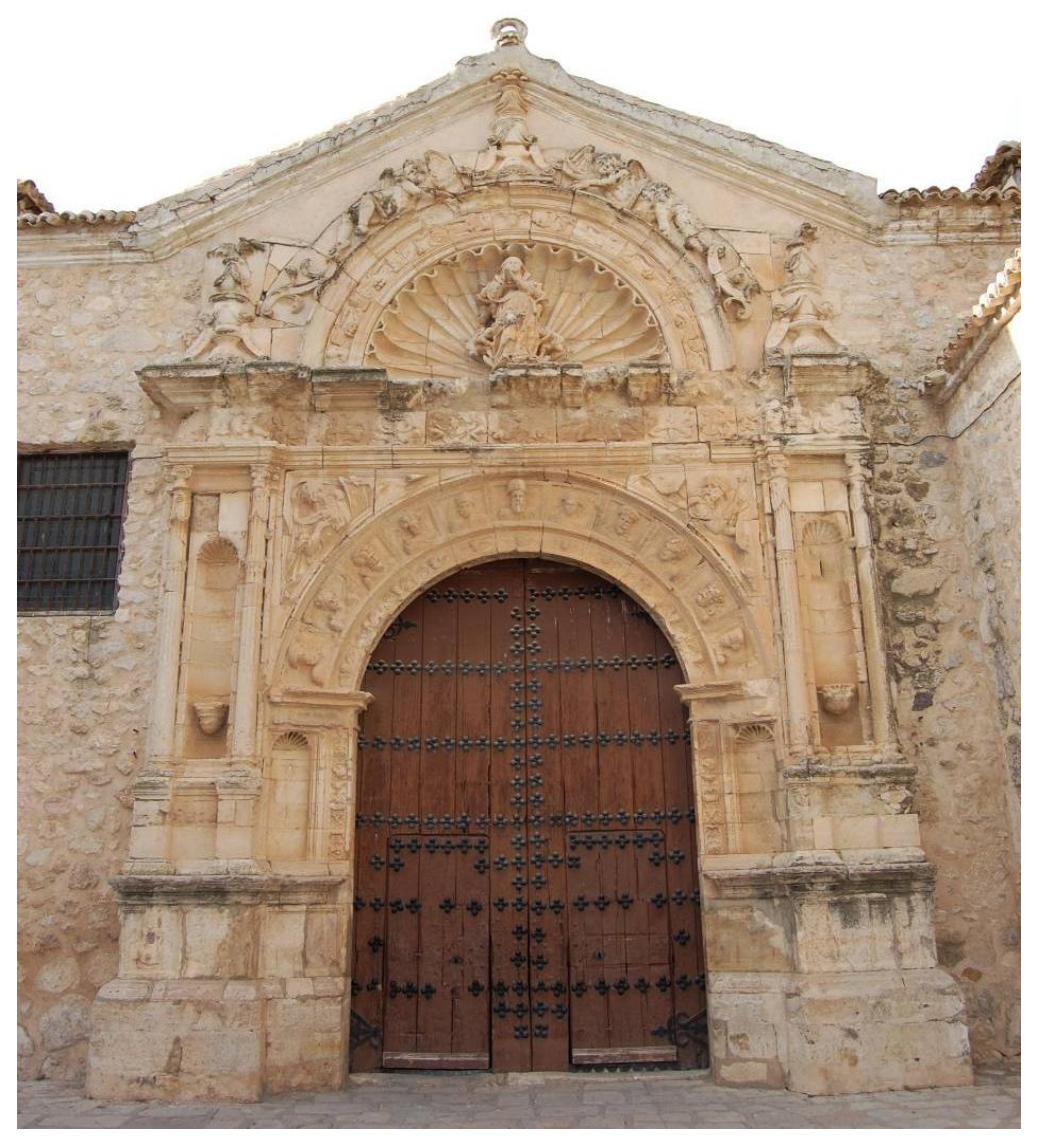

Figura 6.1. Portada principal del siglo XV de la Iglesia de Nuestra Señora de la Asunción de Corral de Almaguer (Toledo) antes de las intervenciones de restauración.
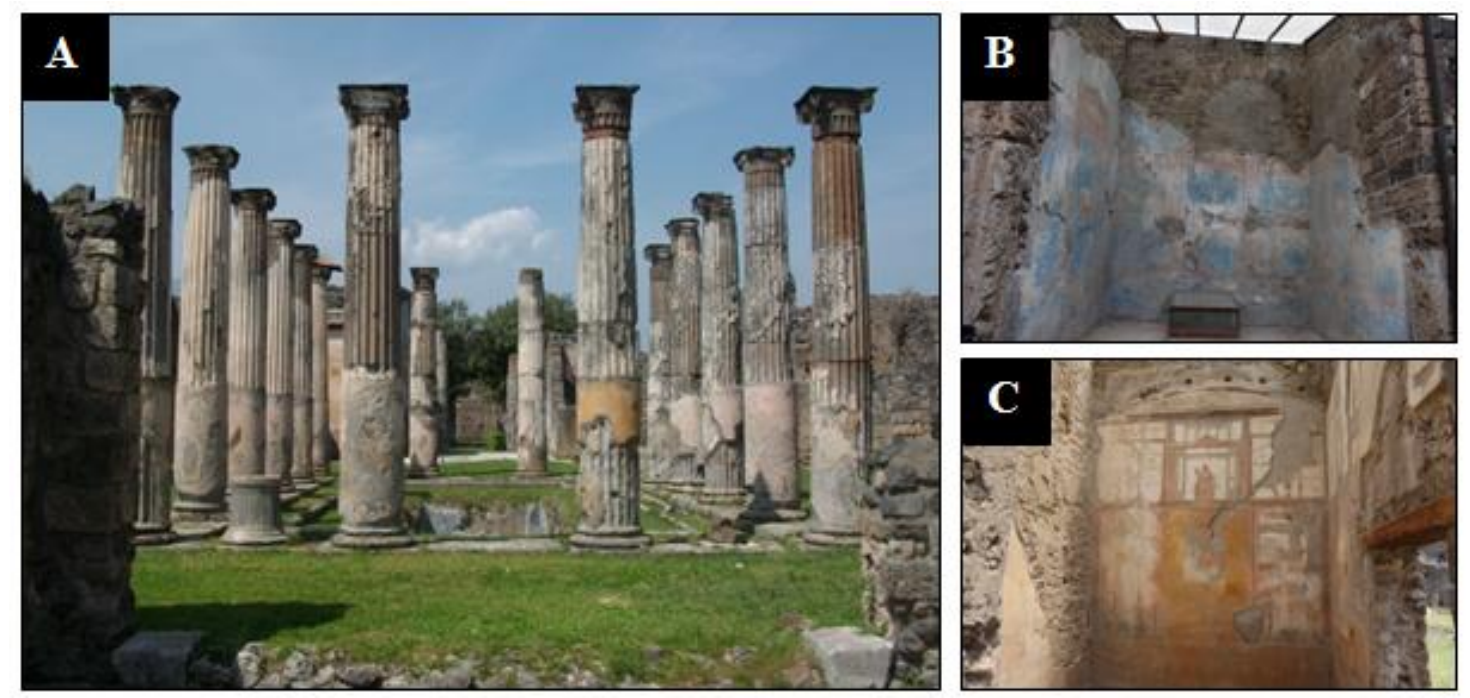

Figura 6.2. Casa de Ariadna, Pompeya (Italia). A) Vista del peristilo.

B y C) Vista de las salas que presentan decoraciones parietales del siglo I d.C. 


\subsection{Portada de la Iglesia de Nuestra Señora de la Asunción de Corral de Almaguer (Toledo)}

Con el fin de proceder a la restauración de la portada principal de la Iglesia Parroquial de Corral de Almaguer (Toledo), se realizaron los estudio de caracterización de materiales y diagnosis del estado de conservación, así como la evaluación de los tratamientos de restauración, limpieza, consolidación y protección de la superficie pétrea, incluyendo la evaluación de las muestras sintetizadas en la presente tesis doctoral.

Dada la situación en la que se encontraban gran parte de los elementos que componen la portada, y que bien podía calificarse de deterioro severo, tendente al estado de ruina, se decidió poner en marcha un proyecto de restauración que implicara un estudio exhaustivo del soporte pétreo mediante la caracterización mineralógica y de las propiedades físicas de la obra. El objetivo principal de este trabajo fue documentar, además, las condiciones de conservación y las causas de deterioro de los materiales constituyentes la portada, determinando las diferentes patologías de alteración y degradación de la piedra, formación de sales, alteraciones cromáticas y patinas biológicas, centrando la atención sobre los mecanismos de la degradación química por sulfatación de la piedra. Los resultados han permitido definir las metodologías más adecuadas para realizar las intervenciones directas e indirectas sobre la portada, necesarias para eliminar o limitar la influencia de los factores ambientales en los procesos de degradación, incluyendo las intervenciones de conservación y protección de las estructuras arquitectónicas y de las decoraciones.

En este capítulo se detallan los resultados obtenidos del estudio del soporte pétreo realizado sobre un fragmento extraído de un sillar de la portada (del presente sillar se obtuvieron las distintas probetas de soporte pétreo necesarias para la posterior aplicación de las muestras con estequiometría de hidroxiapatita preparadas). Igualmente se describen los resultados del estudio de unos fragmentos de soporte pétreo extraídos del friso y cornisa que, mediante un primer examen visual, resultó ser un área de la portada afectada por mecanismos de alteración química, con disgregación y pulverización del sustrato pétreo.

En la Figura 6.3 se señalan los puntos de extracción de los fragmentos de soporte pétreo (EP19.2P, EP19.4P y EP19.5P), necesarios para proceder en los estudios de caracterización y del deterioro. La extracción de los fragmentos se ha realizado a través de un primer examen visual, necesario para definir las áreas de la portada donde el sustrato pétreo resulta aparentemente sano, respecto a otras áreas que presentan manifestaciones de alteración de la piedra, con presencia de descamación y pulverización del sustrato, así como la presencia de un estrato superficial de tonalidad ocre que se puede relacionar con cristalizaciones de sales solubles. 


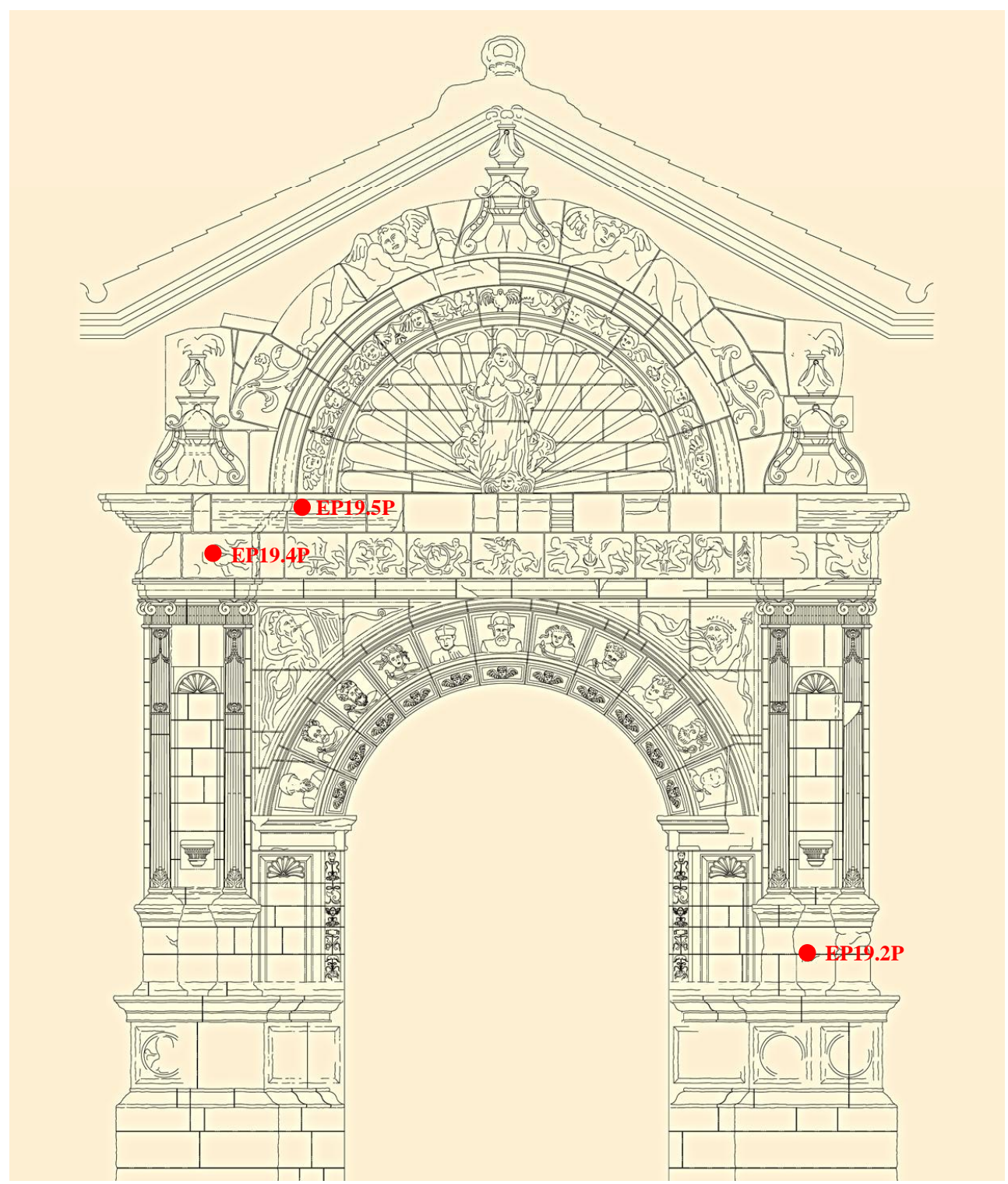

Figura 6.3. Áreas de extracción de las muestras estudiadas en la portada de la Iglesia de Nuestra Señora de la Asunción de Corral de Almaguer (Toledo). Imagen de SFC Arquitectura. 
En las imágenes de las Figuras 6.4 - 6.6 se muestran los fragmentos estudiados: soporte pétreo aparentemente poco alterado, sin manifestaciones evidentes de mecanismos de alteración, extraído de un sillar del cuerpo central de la portada (fragmento EP19.2P) ${ }^{162}$, soporte pétreo que presentan manifestaciones de alteración, fragmento extraído del friso (EP19.4P) y fragmento del soporte pétreo extraído de la cornisa (EP19.5P).
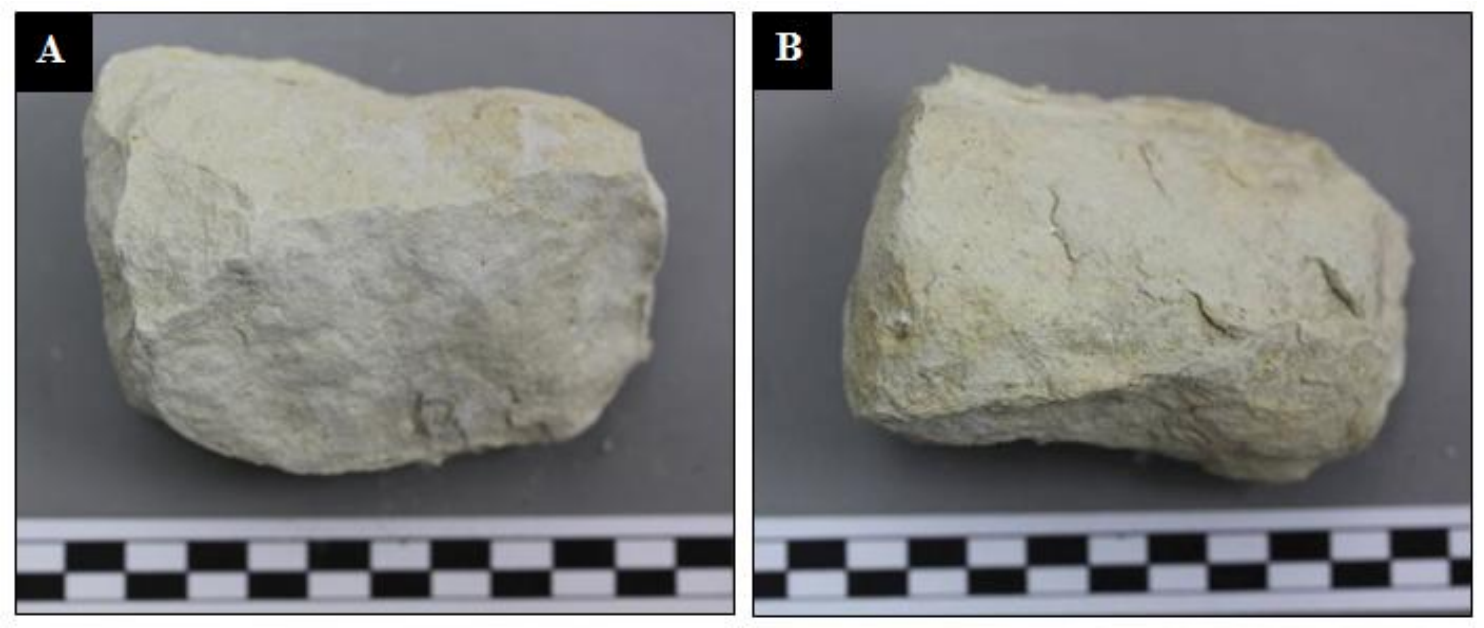

Figura 6.4. Imágenes del fragmento del soporte pétreo. Muestra EP19.2P. Imágenes del reverso (A) y del anverso (B).
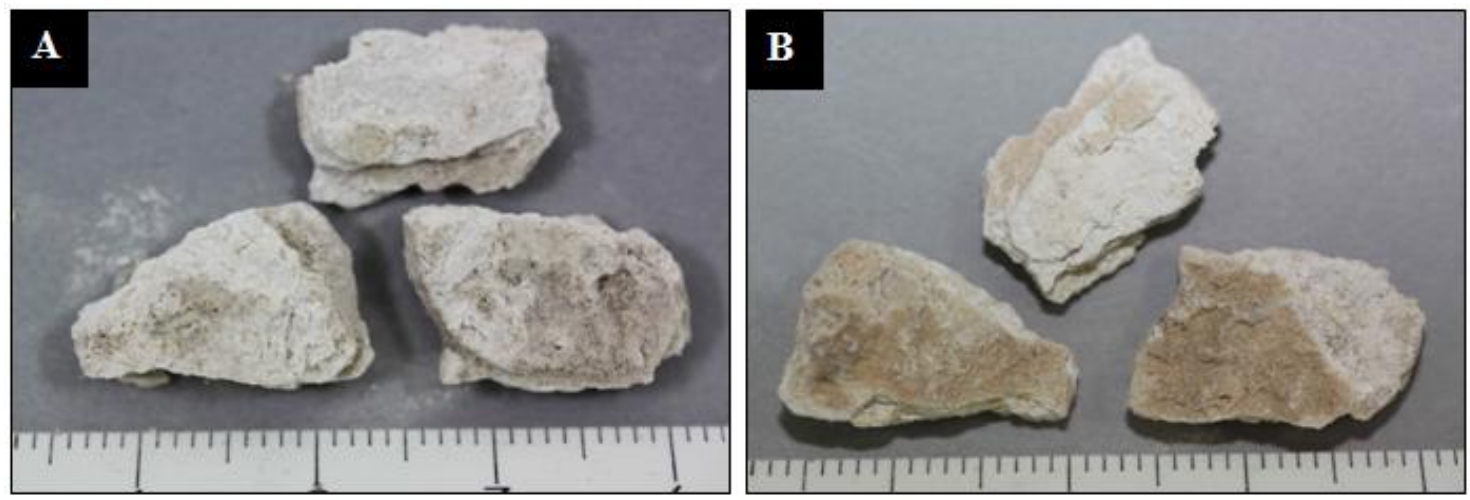

Figura 6.5. Imágenes del reverso (A) y del anverso (B) de los fragmentos del soporte pétreo correspondientes a la muestra EP19.4P.

\footnotetext{
${ }^{162} \mathrm{La}$ enumeración de las muestras sigue el código utilizado por el Departamento Científico del Instituto Valenciano de Conservación, Restauración e Investigación (IVCR+i).
} 

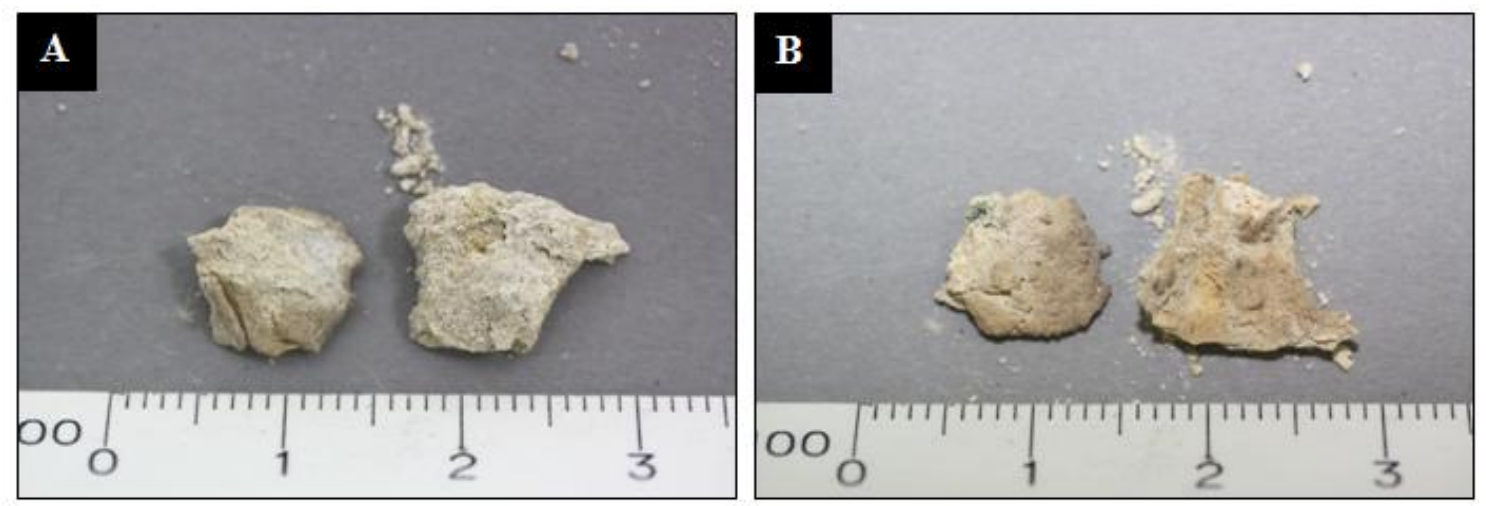

Figura 6.6. Imágenes del reverso (A) y del anverso (B) de los fragmentos del soporte pétreo correspondientes a la muestra EP19.5P. 


\subsubsection{Caracterización del soporte pétreo sin alteración: muestra EP19.2P}

El estudio del fragmento de soporte pétreo realizado mediante DRX y FTIR, completado con observaciones y microanálisis superficiales y sobre secciones estratigráficas con microscopia óptica y SEM-EDX, ha permitido adquirir la información necesaria para caracterizar la naturaleza de la piedra.

Como tipología de soporte pétreo se ha identificado la dolomía, una roca sedimentaria de origen químico compuesta básicamente de dolomita, cuya composición química es el carbonato de calcio y magnesio $\mathrm{CaCO}_{3}$ - $\mathrm{MaCO}_{3}$. Como se muestra en el difractograma de la Figura 6.7, se identifica únicamente la fase mineralógica de la dolomita. En la figura se incluye, como comparación, la ficha de difracción JCPDS-ICDD No. 031209 (PDF Nº. 75-1655).

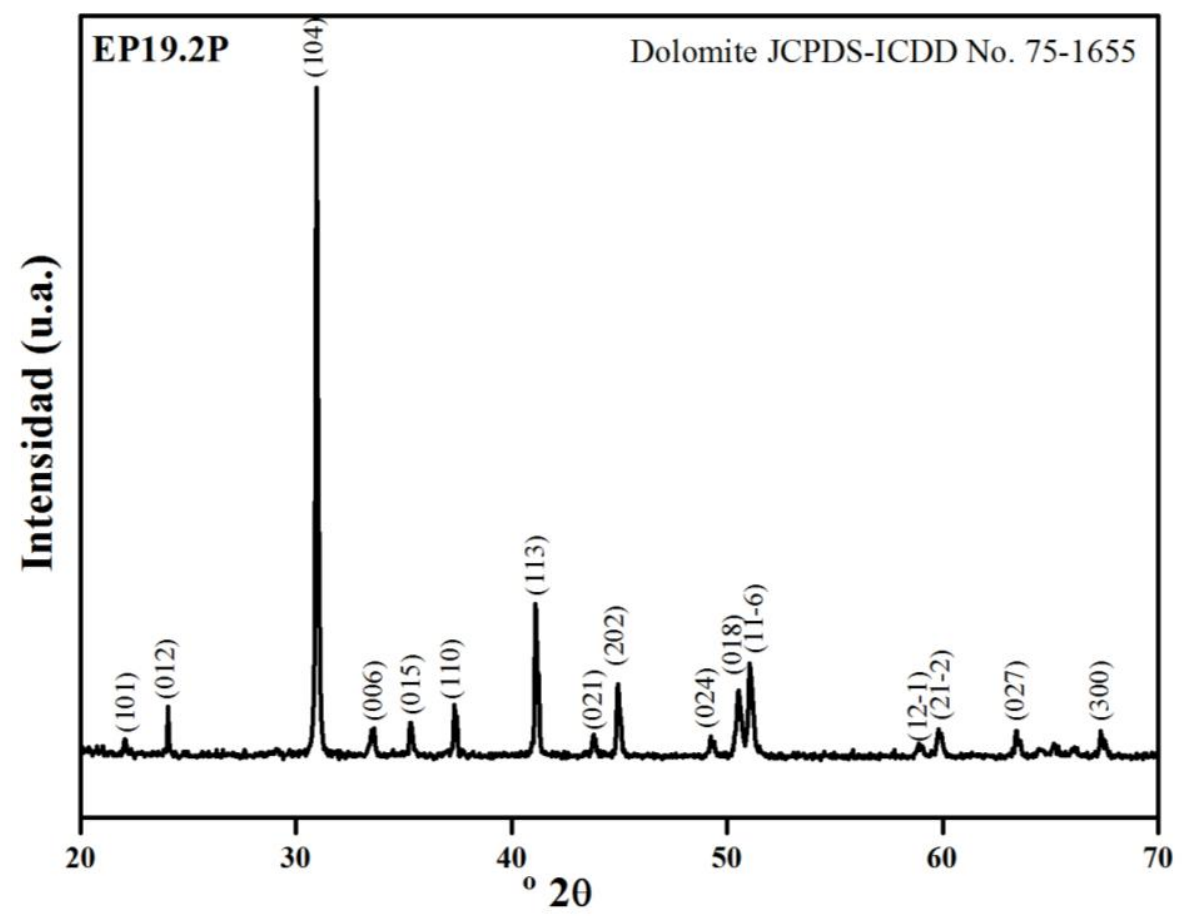

Figura 6.7. Difractograma de la muestra EP19.2P. 
La caracterización de la fase mineralógica del soporte pétreo se completó con los análisis FTIR. En la Figura 6.8 se muestra el espectro FTIR con la tabla en la que se especifican las frecuencias características de los grupos inorgánicos poliatómicos de nuestro interés ${ }^{163}$.

Se detecta la presencia de carbonato con la banda característica del $\mathrm{CO}_{3}{ }^{2-}$ a $1440 \mathrm{~cm}^{-1}$. Las bandas a 874 y $725 \mathrm{~cm}^{-1}$ son también asignadas al grupo del $\mathrm{CO}_{3}{ }^{2-}$ de la estructura de la dolomita ${ }^{164,}{ }^{165}$. La banda de vibración que se observa a $1030 \mathrm{~cm}^{-1}$ señala la presencia de silicatos, mientras que las bandas que se observan en la región de $3500-3400 \mathrm{~cm}^{-1}$ son asignadas a presencia de agua.

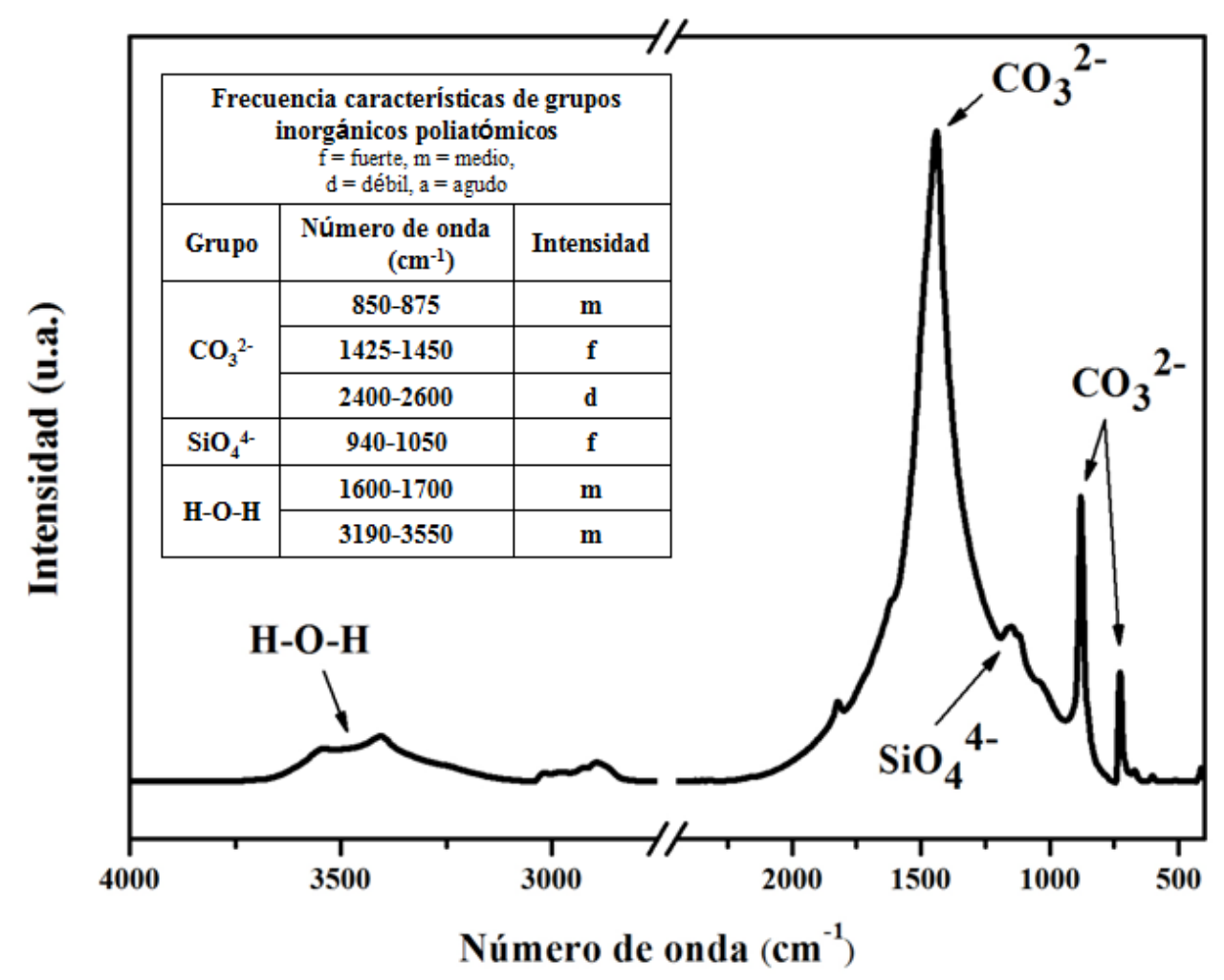

Figura 6.8. Espectro FTIR del soporte pétreo correspondiente a la muestra EP19.2P.

\footnotetext{
${ }^{163}$ K.A. Rubinson, J.F. Rubinson, Análisis Instrumental, Ed. Pearson Educación, 2000.

${ }^{164}$ J. Junfeng, G. Yun, B. William, J.E. Damuth, J. Chen, Rapid identification of dolomite using a Fourier Transform Infrared Spectrophotometer (FTIR): A fast method for identifying, Heinrich events in IODP Site U1308, Marine Geology, Vol. 258, Issues 14, 15. 60-68, 2009.

${ }^{165}$ T.T. Nguyen, L.J. Janik, M. Raupach, Diffuse Reflectance Infrared Fourier-Transform (DRIFT) spectroscopy in soil studies, in Australian Journal of Soil Research 29(1): 49-67, 1991.
} 
Tras la identificación de las fases mineralógicas del soporte pétreo mediante los análisis DRX y FTIR, se ha procedido al estudio petrográfico a través de la preparación en lámina delgada de una parte del fragmento pétreo. Este estudio ha sido necesario para realizar un examen óptico de la piedra, lo que ha proporcionado informaciones sobre el aspecto, textura, color, tamaño de grano y porosidad.

En las Figuras 6.9 y 6.10 se muestran imágenes correspondientes a diferentes áreas del soporte pétreo observadas y fotografiadas a partir de la misma lámina delgada. Este estudio indica que se trata de un material microcristalino homogéneo fosilífero por la presencia de hormas de bioclastos mineralizados. Con la observación microscópica de la roca, se determina un tamaño de cristal que oscila entre un mínimo de 2 $\mu \mathrm{m}$ a un máximo de $40 \mu \mathrm{m}$, con un valor medio entre los 20-40 $\mu \mathrm{m}$, roca que se clasifica como microesparita y esparita (área señalada en A en la Figura 6.9). La esparita consiste en granos de calcita de tamaño de grano superior a las $5 \mu \mathrm{m}$. Normalmente, cuando el tamaño de grano está entre 5 y $10-15 \mu \mathrm{m}$ se denomina microesparita, reservándose el término de esparita para los granos de tamaño superior.

Dentro de este mosaico se observan nubes de agregados de dolomita micrítica (áreas señaladas en B en la Figura 6.9) ${ }^{166,167,168}$. La micrita es el sedimento carbonatado de tamaño de grano inferior a $5 \mu \mathrm{m}$, por lo que no pueden observarse granos discretos al microscopio, sino una masa informe de tonos más o menos oscuros. Con la Figura 6.10 se muestra en detalle los agregados de cristales de dolomita, las partículas de cuarzo con un tamaño medio de $70 \mu \mathrm{m}$, y hormas de restos fósiles mineralizados por el proceso de dolomitización (respectivamente área $\mathrm{A}, \mathrm{B}$ y $\mathrm{C}$ ). Mediante estudio petrográfico el cuarzo se identifica por algunas características en lámina delgada. Se observa como incoloro, transparente o translúcido. Con determinados filtros de polarización del microscopio, el cuarzo se ve de color gris claro a gris oscuro o negro.

Los microanálisis EDX han detectado dentro de la matriz del soporte pétreo, algunos minerales en traza e impurezas a base titanio (Ti) y hierro (Fe). Las Figuras 6.11 - 6.14 muestran los espectros EDX del soporte así como de los elementos trazas e impurezas detectadas y las respetivas imágenes SEM donde se evidencian las zonas de los microanálisis EDX realizados.

\footnotetext{
${ }^{166}$ W.S. Mackenzie, A.E. Adams, Atlas en color de Rocas y Minerales en Lámina Delgada, Masson, S.A. 215, 1997.

167 P.A. Schölle, D. Ülmer Schölle, A color guide to de petrography of carbonate rocks: grains, textures, porosity, diagenesis. A.A.P.G., Memoir 77, 474, 2003.

168 A.E. Adams, W.S. Mackenzie, A colour Atlas of Carbonate Sediments and Rocks under the microscope. Mason Publishing, 180, 2001.
} 


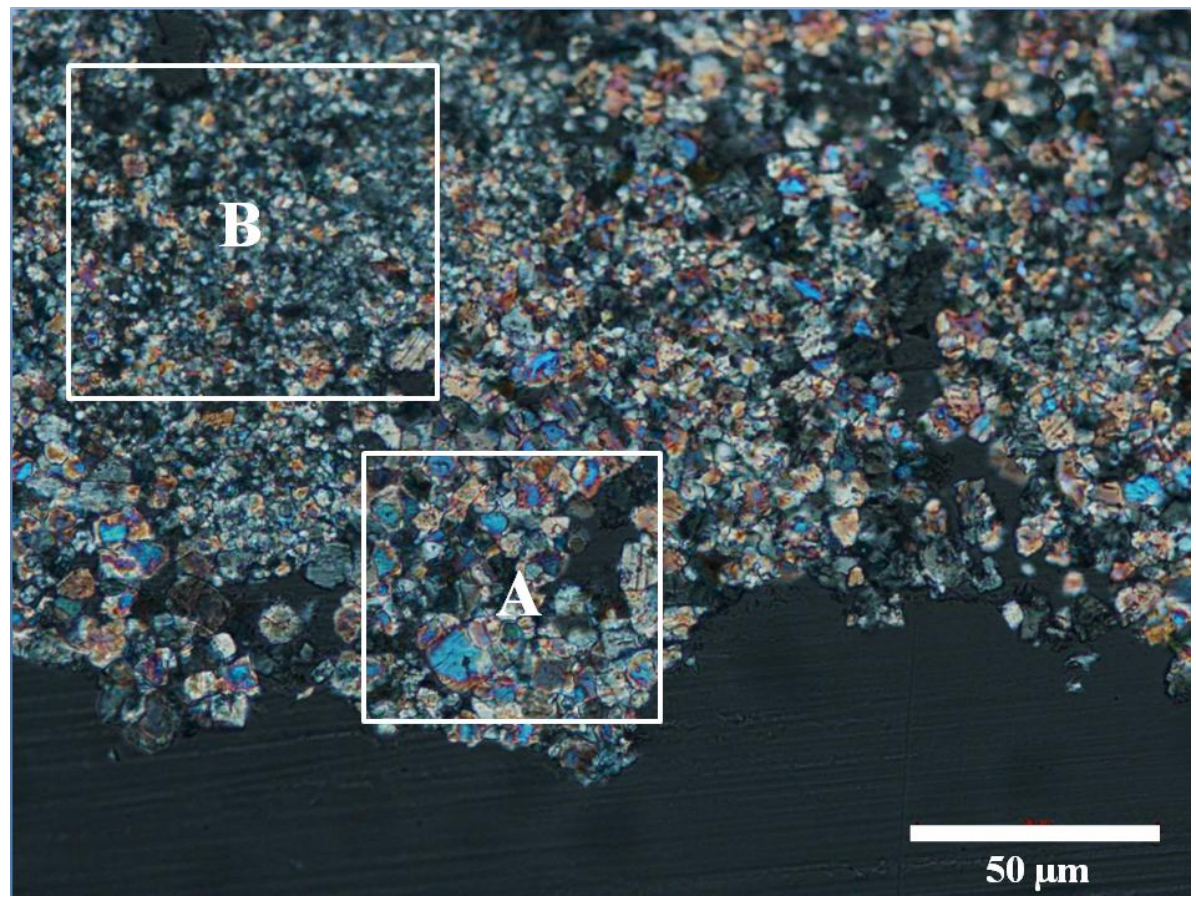

Figura 6.9. Detalle de la muestra del soporte pétreo en lámina delgada. Microscopia óptica con fuente de luz visible, 50 $\mathrm{x}-\mathrm{XN}$. Cristales de dolomita microesparítica (A), nubes de micrita (B).

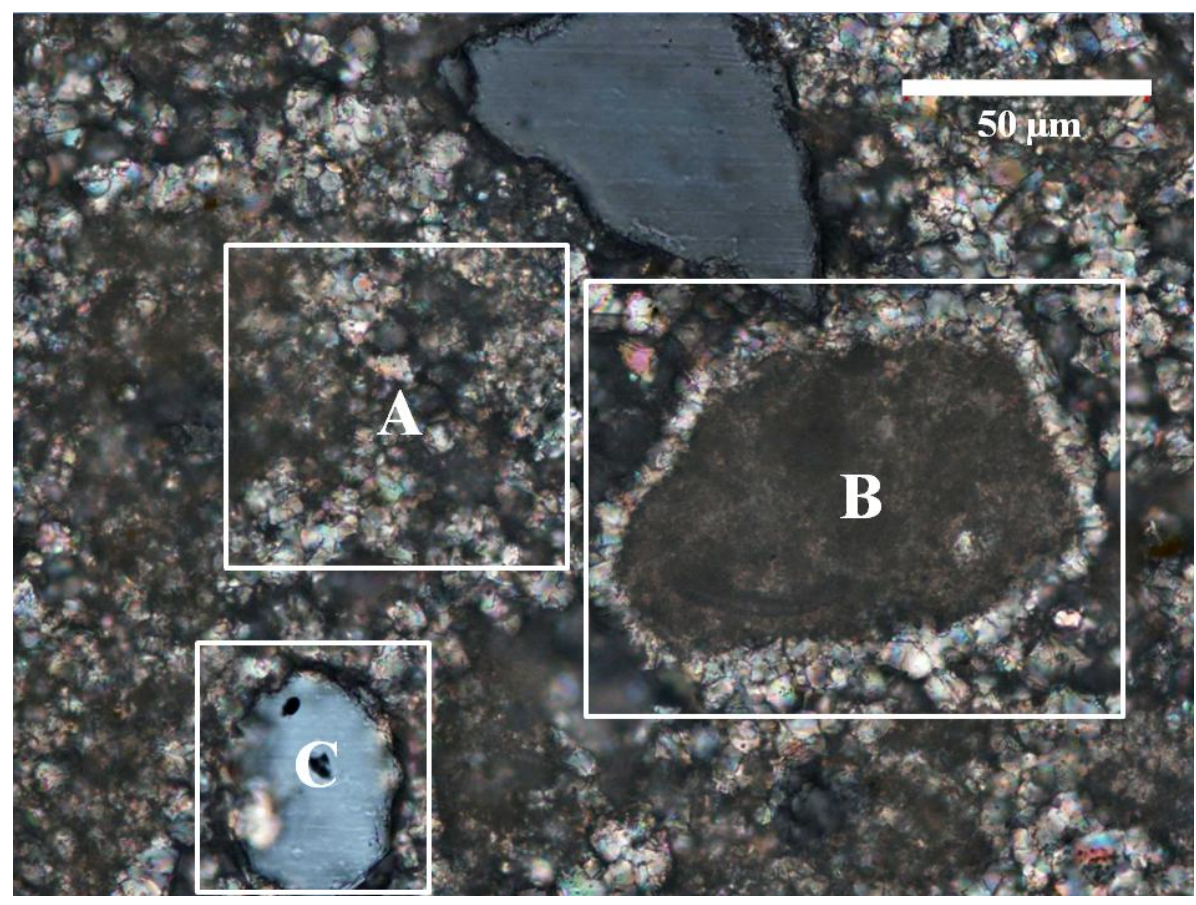

Figura 6.10. Detalle de la muestra del soporte pétreo en lámina delgada. Microscopía óptica con fuente de luz visible, $50 \mathrm{x}$-XN. Se observan las hormas de los bioclastos mineralizados. Se mercan los agregados de cristales de dolomita (A), las hormas de restos fósiles mineralizados (B) y las partículas de cuarzo (C). 


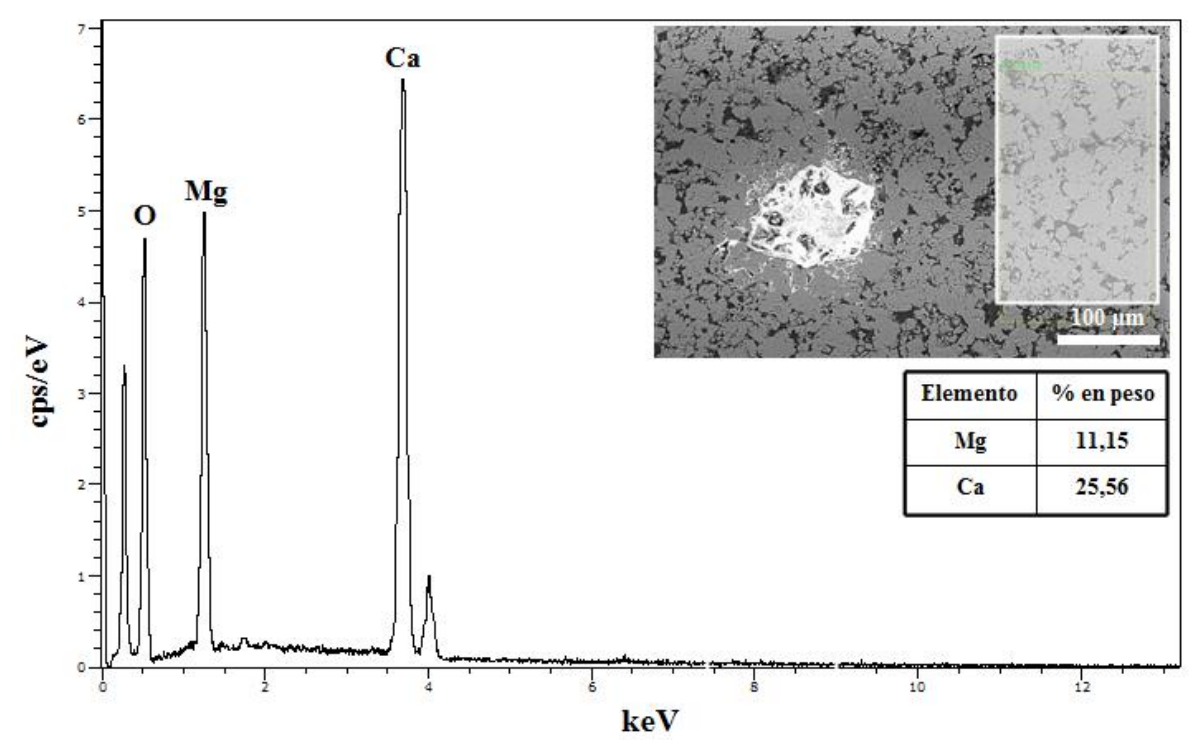

Figura 6.11. Micrografía obtenida por SEM (inset) de un área del soporte pétreo observado en corte transversal, y espectro EDX de la región marcada en la imagen. En forma de tabla se expresa el \% en peso de los diferentes elementos detectados.

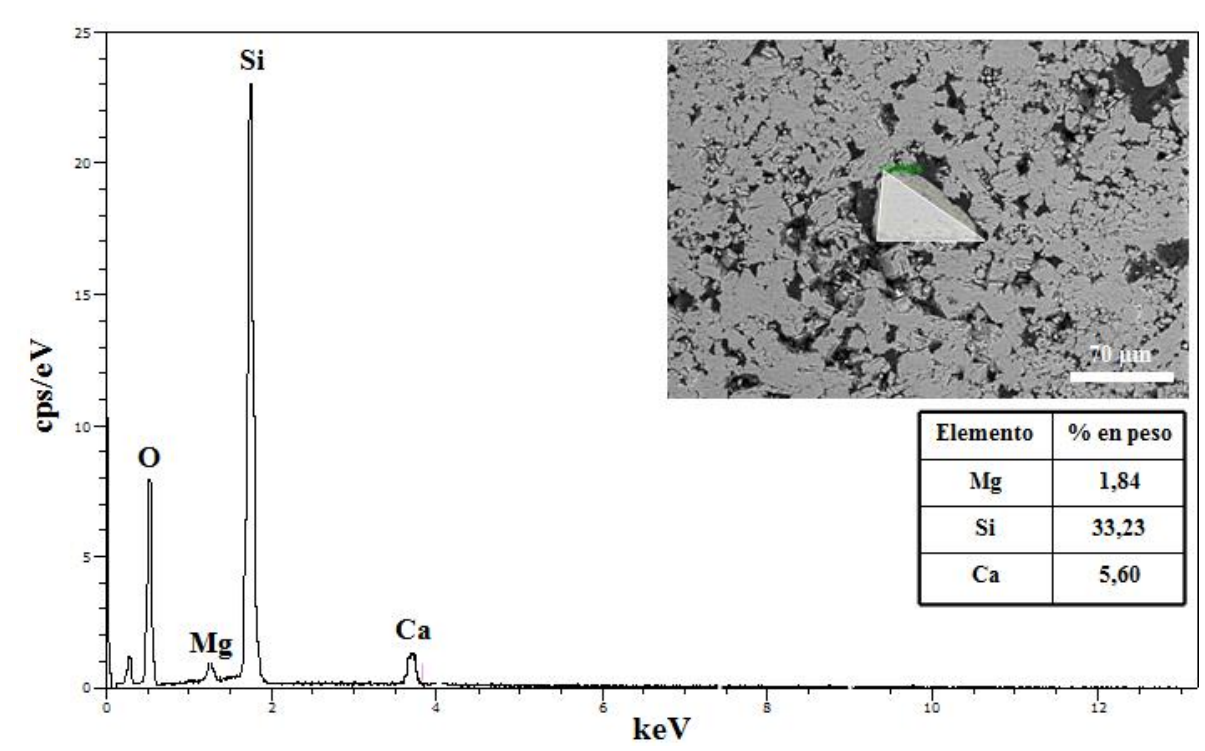

Figura 6.12. Micrografía obtenida por SEM (inset) de un área del soporte pétreo observado en corte transversal, y espectro EDX de la región marcada en la imagen. En forma de tabla se expresa el \% en peso de los diferentes elementos detectados. 


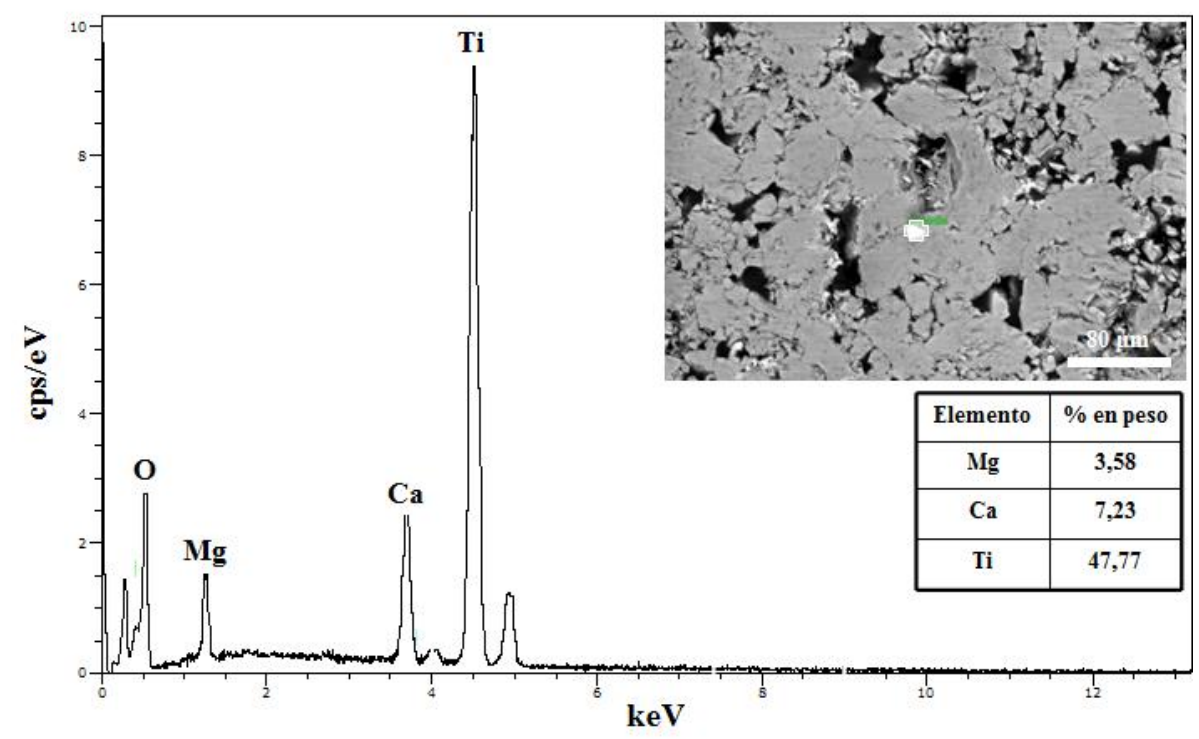

Figura 6.13. Micrografía obtenida por SEM (inset) de un área del soporte pétreo observado en corte transversal, y espectro EDX de la región marcada en la imagen. En forma de tabla se expresa el \% en peso de los diferentes elementos detectados.

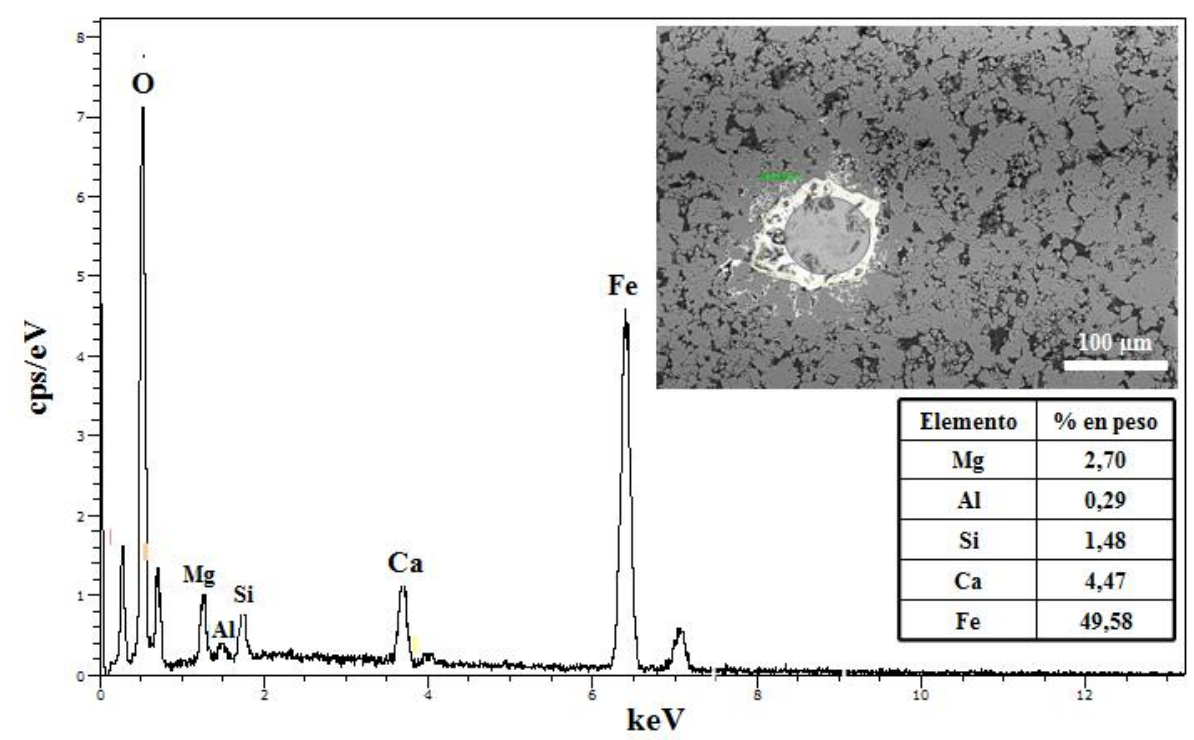

Figura 6. 14. Micrografía obtenida por SEM (inset) de un área del soporte pétreo observado en corte transversal, y espectro EDX de la región marcada en la imagen. En forma de tabla se expresa el \% en peso de los diferentes elementos detectados. 
El mapping de distribución de elementos (Figura 6.15) nos permite ver la distribución del calcio (Ca) y magnesio $(\mathrm{Mg})$ en un corte transversal del fragmento pétreo, así como la distribución del silicio ( $\mathrm{Si}$ ) correspondiente, como se ha comentado con anterioridad, a inclusiones de cuarzo.
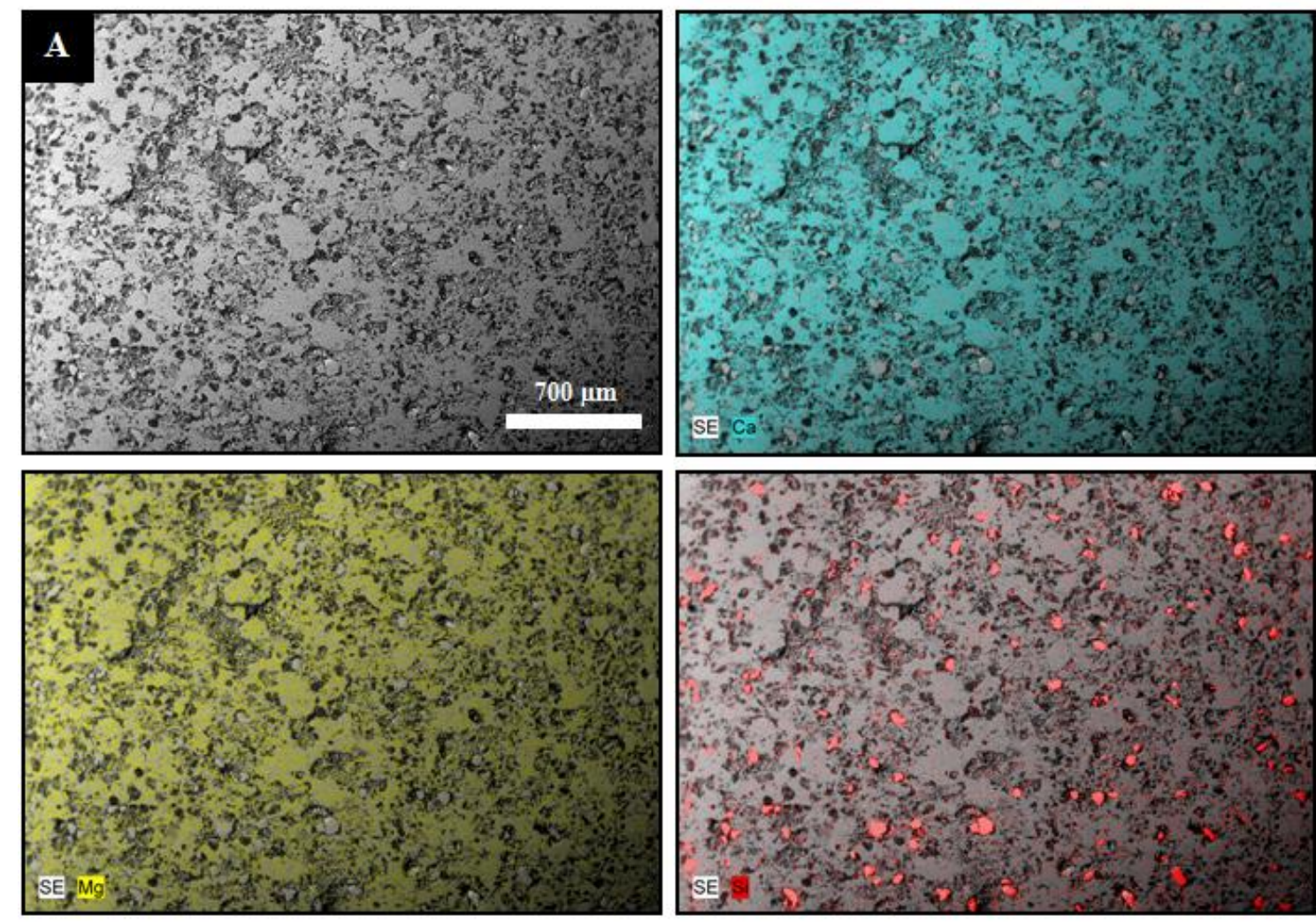

Figura 6.15. Imagen por SEM del soporte pétreo en sección transversal y distribución de los elementos químicos del calcio $(\mathrm{Ca})$, magnesio $(\mathrm{Mg})$ y silicio $(\mathrm{Si})$.

Las observaciones al SEM de la lámina delgada muestran como el soporte pétreo se caracteriza por una alta porosidad intercristalina. Como se aprecia en las imágenes por SEM de la Figura 6.16 correspondientes a diferentes áreas de la misma lámina delgada, la piedra se caracteriza por la presencia de poros de tamaño medio entre los 50-70 $\mu \mathrm{m}$, de tipo móldica (producto de disolución de los bioclastos), vacuolar (en espacios discretos más o menos esféricos) e intergranular (localizada dentro de granos particulares, como bioclastos $)^{169}$. Como se puede observar en la Figura 6.16 B, los poros presentan una alta interconexión creando canales de longitud hasta $500 \mu \mathrm{m}$ aproximadamente.

\footnotetext{
${ }^{169}$ R. Riding, Microbial carbonates: the geological record of calcified bacterial-algal mats and biofilms, Sedimentology 47(s1), Springer, 179-214, 2000.
} 

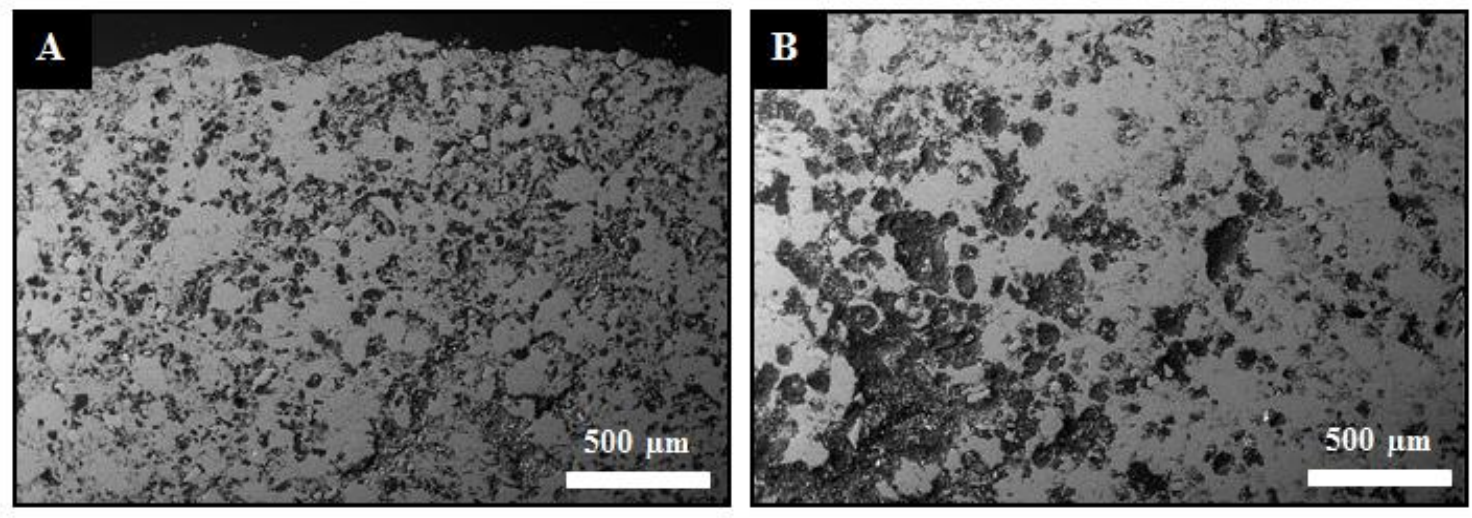

Figura 6.16. A) Detalle de la parte superior de la lámina delgada de la muestra del soporte pétreo EP19.2P observada con microscopía electrónica de barrido en modalidad electrones retrodispersados. B) Detalle de la parte central de la lámina delgada.

La porosidad del soporte pétreo es una característica intrínseca que determina una estructura bastante blanda y fácilmente sujeta a las diferentes dinámicas de alteración y degradación de tipo físico-químico y biológico. Como se puede observar en la imagen SEM de la Figura 6.17, la piedra presenta un alto grado de poros. Estos espacios vacíos determinan el comportamiento de la piedra frente al agua como la absorción y desorción, la succión capilar, la permeabilidad al vapor de agua, etc., propiedades que influyen directamente en los procesos de alteración y degradación.

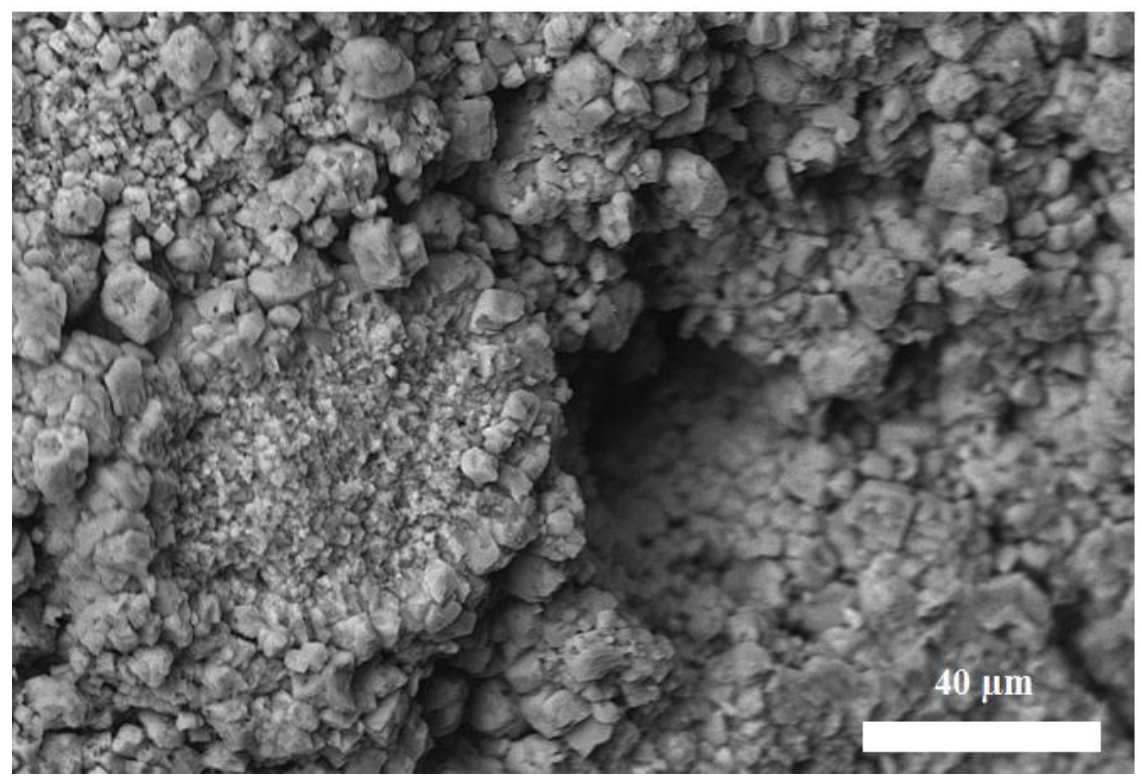

Figura 6.17. Estudio con microscopía electrónica de barrido en modalidad electrones retrodispersados. 


\subsubsection{Caracterización del soporte pétreo alterado: muestras EP19.4P - EP19.5P}

En la primera fase de estudio de los fragmentos de soporte pétreo con manifestaciones de alteración, se ha realizado un estudio morfológico y composicional a nivel superficial con microscopia estereoscópica y SEMEDX. Como se observa en las imágenes de microscopia estereoscópica de la Figura 6.18, los fragmentos presentan una tonalidad ocre con aspecto pulverulento y disgregado.
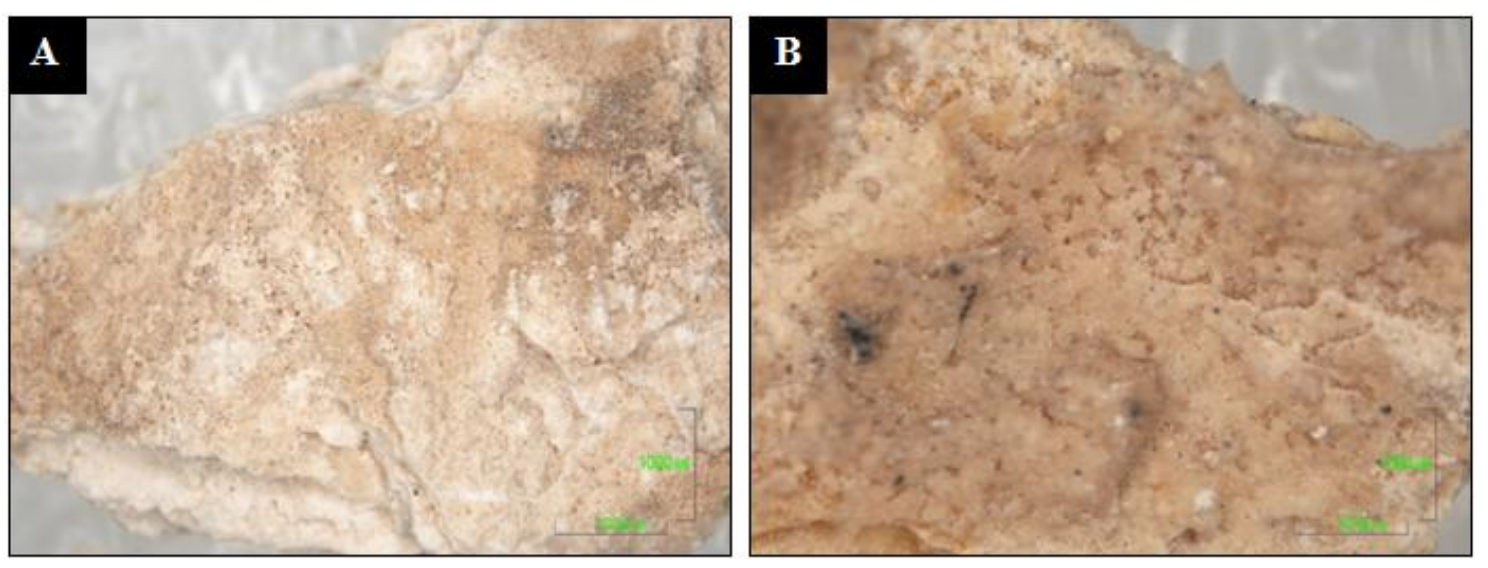

Figura 6.18. A) Fragmento que constituye las muestra del soporte pétreo EP19.4P. B) Fragmento que constituye las muestra del soporte pétreo EP19.5P. Imágenes de microscopía estereoscópica, 0,8 x.

La micrografía obtenidas por SEM de la Figura 6.19 muestra una superficie caracterizada por una extensa cristalización de sales solubles de morfología laminares, que provocan la disgregación de la estructura cristalina de la piedra. Los microanálisis EDX han detectado como elementos químicos mayoritarios, el oxigeno (O), el calcio (Ca) y el azufre (S), lo cual indicaron que las cristalizaciones de las sales corresponderían con la posible presencia de sulfato de calcio (imagen SEM y espectro EDX de la Figura $6.20)$. 


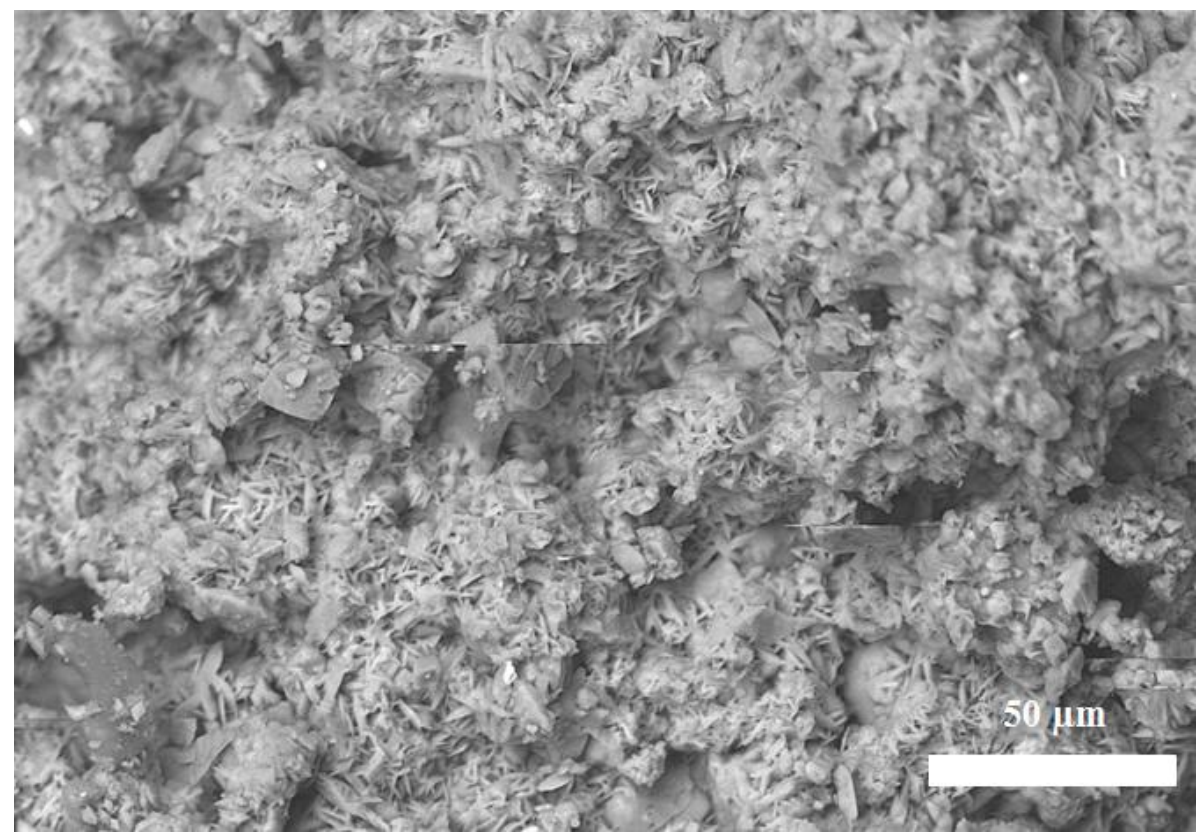

Figura 6.19. Imagen por SEM en modalidad electrones retrodispersados de la superficie del fragmento EP19.4P.

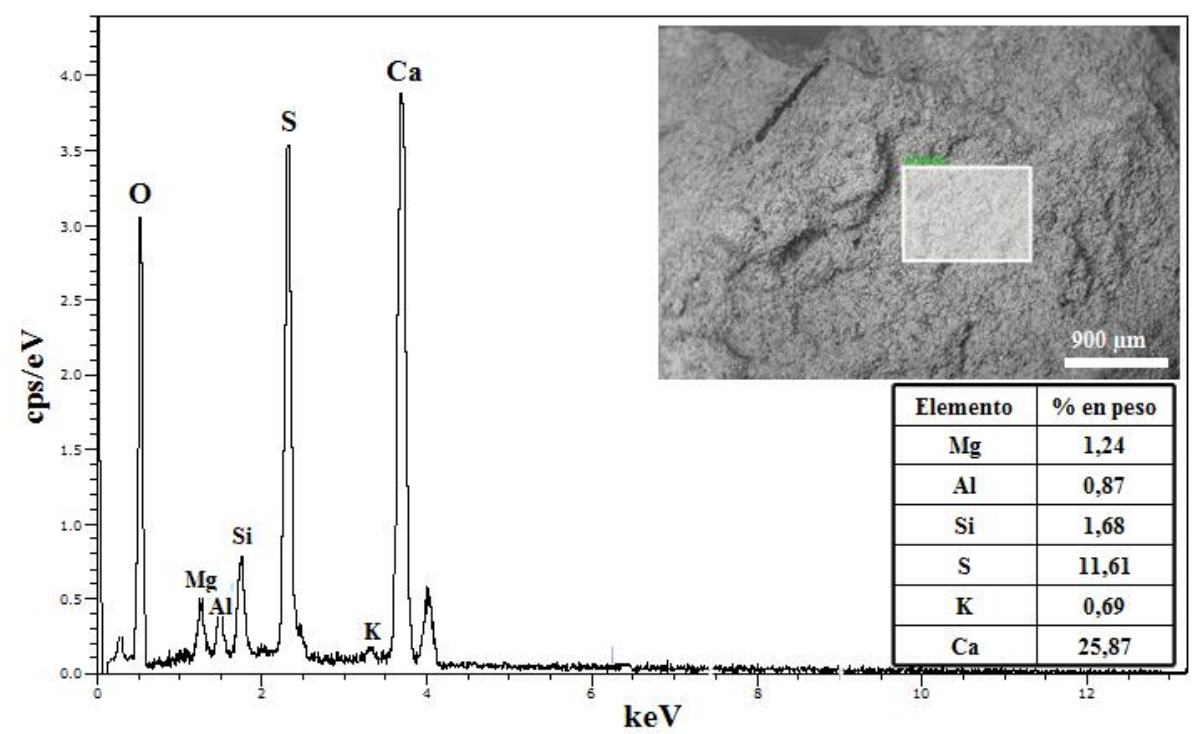

Figura 6.20. Micrografía obtenida por SEM (inset) de un área del soporte pétreo observado en superficie, y espectro EDX de la región marcada en la imagen. En forma de tabla se expresa el \% en peso de los diferentes elementos detectados. 
La caracterización a partir de la espectroscopia IR en los fragmentos de piedra alterada se muestra en la Figura 6.21. Se observan los espectros obtenidos para la muestra EP19.4P -en negro- y de la muestra EP19.5P -en rojo-.

Se han identificado bandas vibracionales correspondientes al grupo sulfato $\mathrm{SO}_{4}{ }^{2-}$ a $1100 \mathrm{~cm}^{-1}$ y en el intervalo $580-660 \mathrm{~cm}^{-1}$, indicando la presencia de sulfato de calcio ${ }^{170}$. Las bandas a $1450 \mathrm{~cm}^{-1}$ y a 1420 $1450 \mathrm{~cm}^{-1}$ resultan ser características del grupo $\mathrm{CO}_{3}{ }^{2-}$ relacionado al soporte pétreo. Las bandas de absorción marcadas con el punto rojo, aproximadamente a 1620 y $1390 \mathrm{~cm}^{-1}$, corresponderían a la presencia de oxalato de calcio $^{171}$, mientras las bandas que se muestran en la región 3540-3400 $\mathrm{cm}^{-1}$ corresponden a la presencia de agua posiblemente a la hidratación del sulfato de calcio identificado.

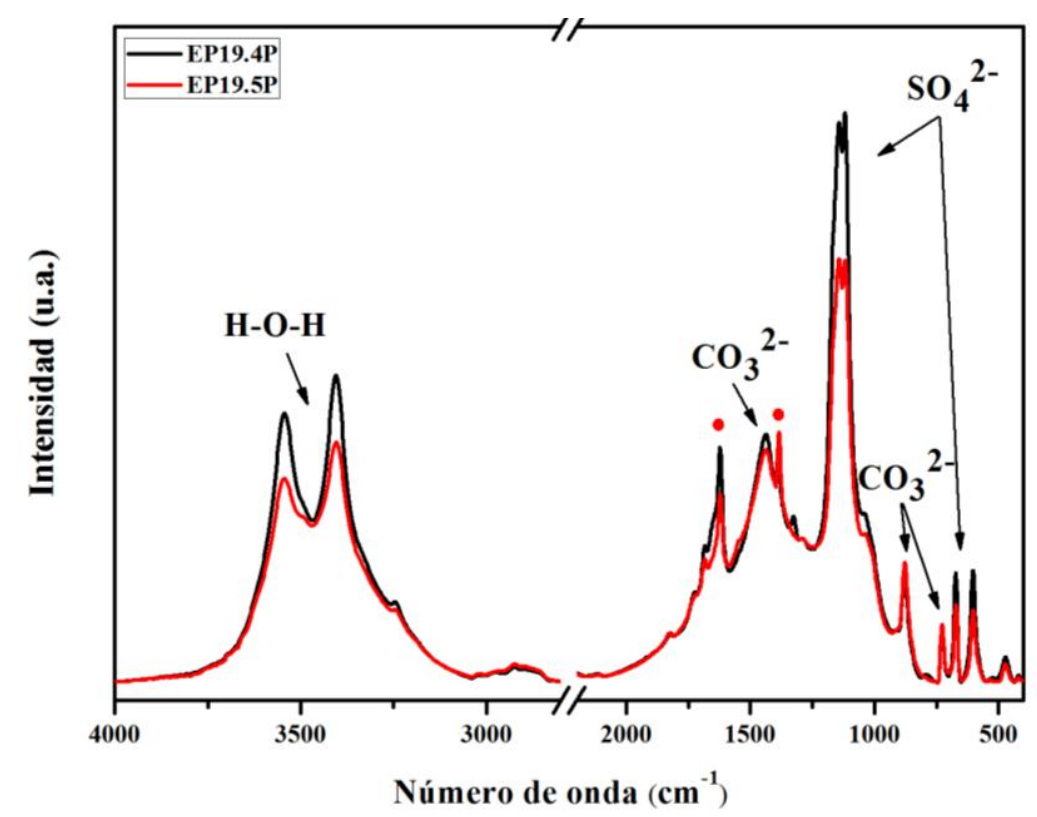

\begin{tabular}{|c|c|c|}
\hline \multicolumn{2}{|c|}{$\begin{array}{r}\text { Frecuencia características de grupos } \\
\text { inorgánicos poliatómicos } \\
\mathrm{f}=\text { fuerte, } \mathrm{m}=\text { medio, } \\
\mathrm{d}=\text { débil, } \mathrm{a}=\text { agudo }\end{array}$} \\
\hline Grupo & $\begin{array}{c}\text { Número de } \\
\text { onda }\left(\mathbf{c m}^{-1}\right)\end{array}$ & Intensidad \\
\hline $\mathrm{CO}_{3}{ }^{2-}$ & $850-875$ & $\mathrm{~m}$ \\
\cline { 2 - 3 } & $1425-1450$ & $\mathrm{f}$ \\
\cline { 2 - 3 } & $2400-2600$ & $\mathrm{~d}$ \\
\hline $\mathrm{SO}_{4}{ }^{2-}$ & $585-660$ & $\mathrm{f}$ \\
\cline { 2 - 3 } & $1080-1130$ & $\mathrm{f}$ \\
\hline $\mathrm{H}_{-} \mathrm{O}-\mathrm{H}$ & $1600-1700$ & $\mathrm{~m}$ \\
\cline { 2 - 3 } & $3190-3550$ & $\mathrm{~m}$ \\
\hline
\end{tabular}

Figura 6.21. Espectros FTIR de la muestra procedente del fragmento EP19.4P (en negro) y EP19.5P (en rojo).

El estudio de los fragmentos se completó con las observaciones al microscopio óptico y al SEM con microanálisis EDX sobre láminas delgadas. En los fragmentos estudiados se evidencian fenómenos de alteración posiblemente causados por acciones fisicoquímicas o mecánicas que han provocado un menoscabo de material, principalmente por pérdida de cohesión entre los constituyentes de la roca o por los procesos de

\footnotetext{
${ }^{170}$ I. Adrover García, Applicazioni della spettrofotometria IR allo studio dei Beni Culturali, Collana i Talenti, 2001.

${ }^{171}$ M. Del Monte, Microbioerosion and biodeposits on stone monuments: pitting and calcium oxalate patinas, Advanced Workshop, Analytical Methodologies for the Investigation of Damaged Stones. 29, 1990.
} 
disolución del material y su posterior precipitación. Como se observa en las microfotografías de la Figura 6.22 A y B (imágenes de diferentes áreas de la lámina delgada de la muestra del soporte pétreo EP19.5P), hay una pérdida de la cohesión entre los componentes mineralógicos causada por la cristalización interna de sales solubles. Estos últimos, posiblemente a base de sulfato de calcio, tal y como se ha analizado con FTIR y con los microanálisis EDX (ver espectro del microanálisis EDX de la Figura 6.23).
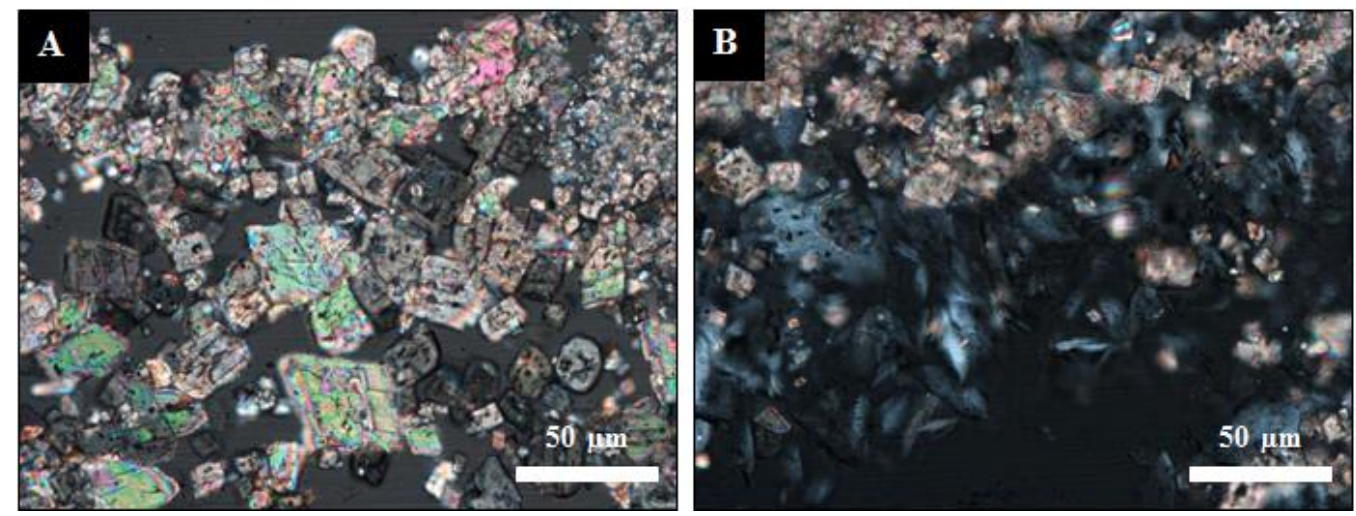

Figura 6.22. Detalles de diferentes áreas de la lámina delgada de la muestra del soporte pétreo EP19.5P. Microscopia óptica con fuente de luz visible, 50 x-XN. A) Se observa la disgregación de la matriz dolomítica. B) Se observan, además, las cristalizaciones blancas de las sales solubles.

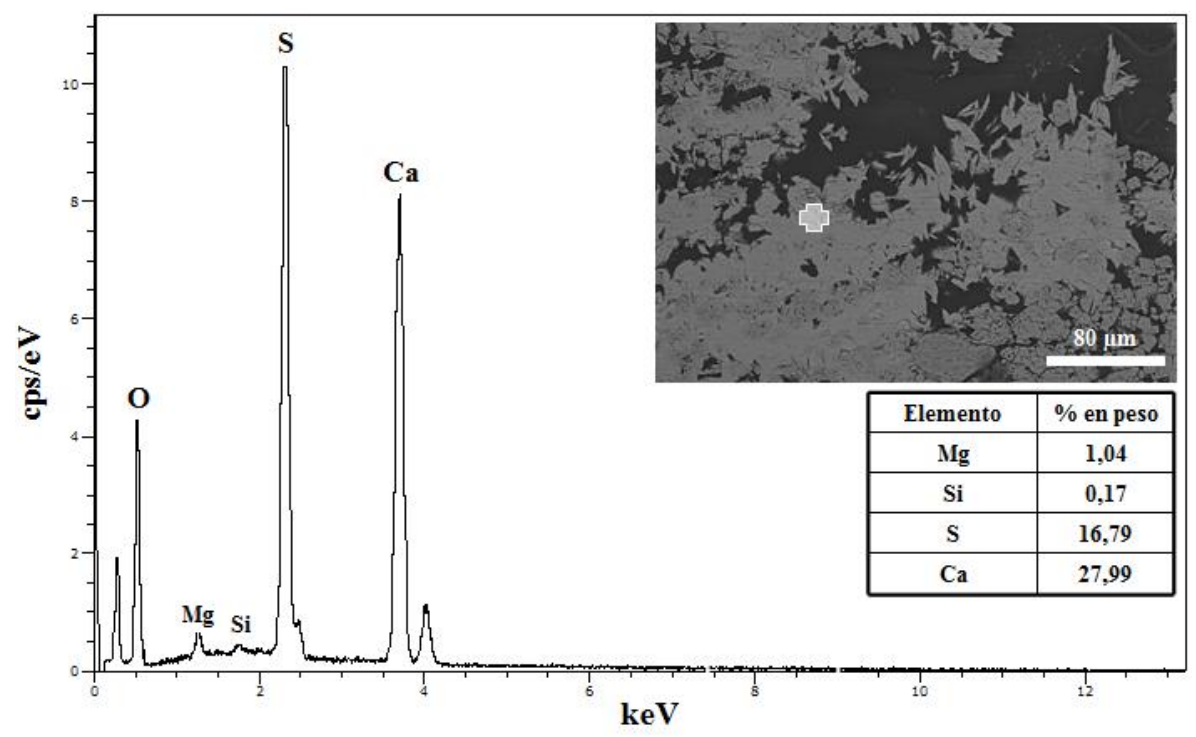

Figura 6.23. Micrografía obtenida por SEM (inset) de un área del soporte pétreo observado en corte transversal, y espectro EDX del punto marcado en la imagen. En forma de tabla se expresa el \% en peso de los diferentes elementos detectados. 
Los resultados evidencian que la causa principal de daño y pérdida de material pétreo en algunas áreas de la portada es sin duda la alteración química de la piedra con formación de sulfato de calcio hidratado. Es un claro proceso de erosión del sustrato pétreo por efecto de los contaminantes atmosféricos donde el sulfato de calcio cristaliza superficialmente formando eflorescencias salinas o costras de sulfatación, o en base a fenómenos de difusión, que pueden cristalizar internamente formando criptoeflorescencias ${ }^{172,}{ }^{173}$. El fragmento estudiado presenta varios estratos con diferentes contenidos en sulfato de calcio y diferentes estados de agregación, conformando una compleja estructura de alteración (las disoluciones acuosas de sulfato de calcio penetran en el interior de la piedra generando un proceso de cementación de la piedra, dando lugar a lo que se denomina incrustaciones). Con los resultados alcanzados en este estudio, se ha determinado como la alteración por formación de sulfato de calcio ha producido una disminución en la cantidad de la dolomita original. Los procesos de cristalización interna de sulfato de calcio resultan ser importantes, porque consigue tapizar la superficie de los huecos y crear espesos estratos amorfos entre la estructura dolomítica con el sulfato de calcio.

En el mapping de la Figura 6.24 se muestra la distribución del calcio (Ca) y del azufre (S) dentro de un corte transversal del fragmento del soporte pétreo. Se aprecia la gravedad del proceso de sulfatación que interesa el soporte pétreo en superficie y en el interior de la estructura causando cristalización de sulfato de calcio en toda la estructura de la piedra y su disgregación.
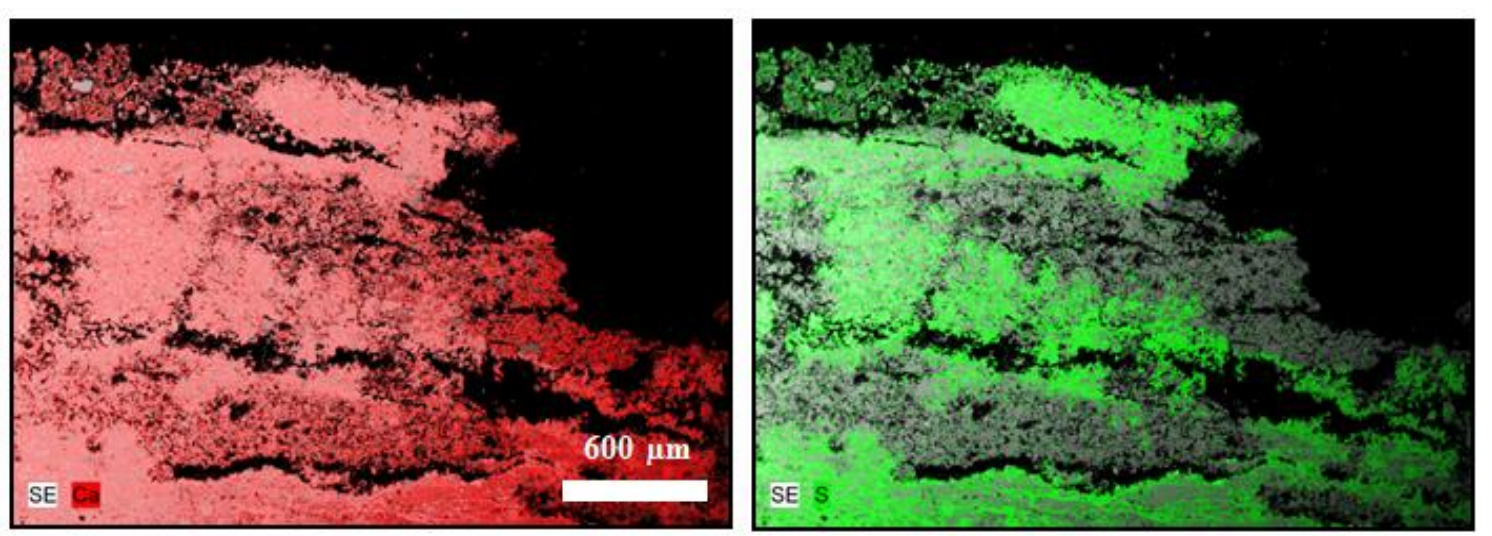

Figura 6.24. Mapping de la distribución del calcio (Ca) y del azufre (S) en la estructura del soporte pétreo alterado visto en corte transversal.

\footnotetext{
${ }^{172}$ R. M. Esbert, F. J. Alonso, J. Ordaz, La petrofísica en la interpretación del deterioro y la conservación de la piedra de edificación, Trabajos de Geologías, Universidad de Oviedo, 28, 87-95, 2008.

${ }^{173}$ C.M. Grossi, R.M. Esbert, Las sales solubles en el deterioro de rocas monumentales. Revisión bibliográfica, Materiales de Construcción, Vo1.44, no 235, 15-29, 1994.
} 


\subsection{Las pinturas murales de la Casa de Ariadna en Pompeya (Italia)}

Se ha realizado el estudio científico de distintos fragmentos de pintura mural procedente de la Casa de Ariadna en Pompeya (Italia) $)^{174,175}$, pintura datada el siglo I d.C. En general, todos los fragmentos estudiados se han realizado con la misma técnica de ejecución y varían únicamente las tonalidades de las policromías. Por esta razón, en el siguiente apartado se detallan los aspectos más significativos del estudio de caracterización de los materiales y de los mecanismos de alteración. Existen numerosos estudios realizados por parte de distintas instituciones internacionales ${ }^{176,177}$ sobre los materiales constitutitos de morteros y policromías de las pinturas murales de época romana, así como de la técnica pictórica.

El estudio ha resultado de gran interés ya que ha estado sustentado por un trabajo de preparación de las muestras en sección transversal, que ha permitido efectuar observaciones y análisis químico elemental de la secuencia estratigráfica, tanto de las capas pictóricas como de los morteros de preparación, así como la observación del aspecto, textura, granulometría, espesor, etc. de cada capa. Estas investigaciones han sido necesarias también para evaluar el estado de conservación de las pinturas a nivel microscópico. El estudio ha permitido, sobre todo, comprobar los factores químico-físicos que han determinado la formación de polvo y el desprendimiento de amplias áreas de policromías, debido al fenómeno de eflorescencias y subeflorescencias salinas y de las alteraciones mecánicas producidas por agentes biológicos.

\footnotetext{
${ }^{174}$ C. Pérez García, F. García Diego, P. Merello, A. Ribera, L. Ferrazza, J. Perez Miralles, Pinturas Murales de la Casa de Ariadna (Pompeya, Italia): Un estudio multidisciplinar de su estado actual enfocado a una futura restauración y conservación preventiva, Revista Materiales de Construcción. 63 - 311, 449 - 467. Instituto de Ciencias de la Construcción Eduardo Torroja (CSIC), 2013.

${ }^{175}$ C. Pérez García, L. Ferrazza, M. Domenech, F. Sarrio Martín, A. Ribera, Las pinturas murales de la Casa de Ariadna en Pompeya: Un ejemplo de estudios e investigaciones científicas aplicados en el proyecto de conservación y restauración, La Ciencia y el Arte II - Ciencias experimentales y Conservación del Patrimonio Histórico. 59 - 70. Ministerio de Cultura, 2010.

${ }^{176}$ D. Miriello, D. Barca, A. Bloise, A. Ciarallo, G.M. Crisci, T. De Rose, C. Gattuso, F. Gazineo, M.F. La Russa, Characterisation of archaeological mortars from Pompeii (Campania, Italy) and identification of construction phases by compositional data analysis, J. Arch. Sci., Vol. 37, 2207-2223, 2010.

${ }^{177}$ M. Maguregui, U. Knuutinen, K. Castro, J.M. Madariaga, Raman spectroscopy as a tool to diagnose the impact and conservation stateof Pompeian second and fourth style wall paintings exposed to diverseenvironments (House of Marcus Lucretius), Journal of Raman Spectroscopy 41 (11), 1400-1409, 2010.
} 


\subsubsection{Caracterización de los materiales constituyentes}

Ha sido seleccionado un fragmento de pintura mural para realizar el estudio de caracterización de materiales. Los estudios muestran que la pintura mural está elaborada con una estratigrafía compuesta por 3 capas de morteros de diferente espesor, sobre las cuales se extienden las capas de policromías. En la Figura 6.25 se observa el corte transversal del fragmento de pintura mural donde se marcan las diferentes capas de morteros ( $\mathrm{I}^{\mathrm{o}}$ mortero grisáceo, $\mathrm{II}^{\mathrm{o}}$ mortero blanco, $\mathrm{III}^{\mathrm{o}}$ mortero blanco).

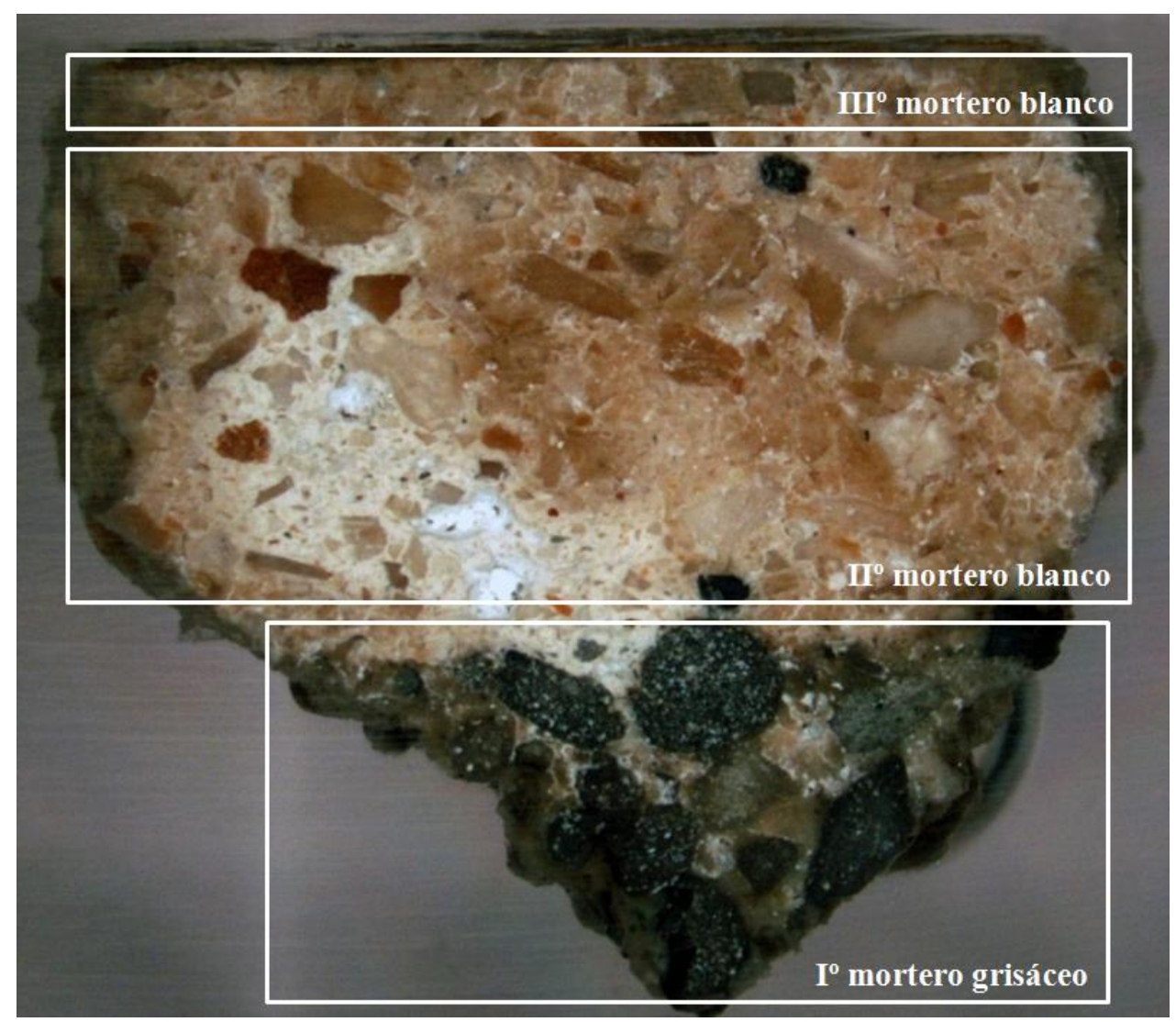

Figura 6.25. Imagen de la sección transversal del fragmento de pintura mural estudiado. Imagen de microscopia estereoscópica, 2x. 
En base a las observaciones petrográficas en sección transversal se han identificado los diferentes compuestos mineralógicos que se detallan a continuación:

$\mathbf{I}^{\mathbf{0}}$ mortero grisáceo: Este primer mortero de tonalidad grisácea presenta un aglomerante blanco constituido fundamentalmente por calcio $(\mathrm{Ca})$, como se muestra con el microanálisis EDX de la Figura 6.26 de una primera región analizada. Este resultado indicaría la presencia de carbonato de calcio, como se confirma con el análisis FTIR. En la Figura 6.27 están presentes las bandas de vibración del grupo $\mathrm{CO}_{3}{ }^{2-}$ a 1440,726 y 710 $\mathrm{cm}^{-1}$. La banda que aparece a $1030 \mathrm{~cm}^{-1}$ se podría asignar a la presencia de silicatos.

Los silicatos detectados corresponderían al árido gris del mortero. Como se observa en las micrografías por SEM de la Figura 6.28, este constituyente presenta una forma generalmente esferoidal o irregular, con bordes redondeados y con un tamaño de partículas que varía de un mínimo de $30 \mu \mathrm{m}$ a un diámetro máximo de 3-4 $\mathrm{mm}$. El árido presenta un alto grado de porosidad, indicando su posible origen volcánico, y como se observa en el análisis EDX de la Figura 6.29, se caracteriza por su naturaleza prevalentemente a base de silicio ${ }^{178}$.

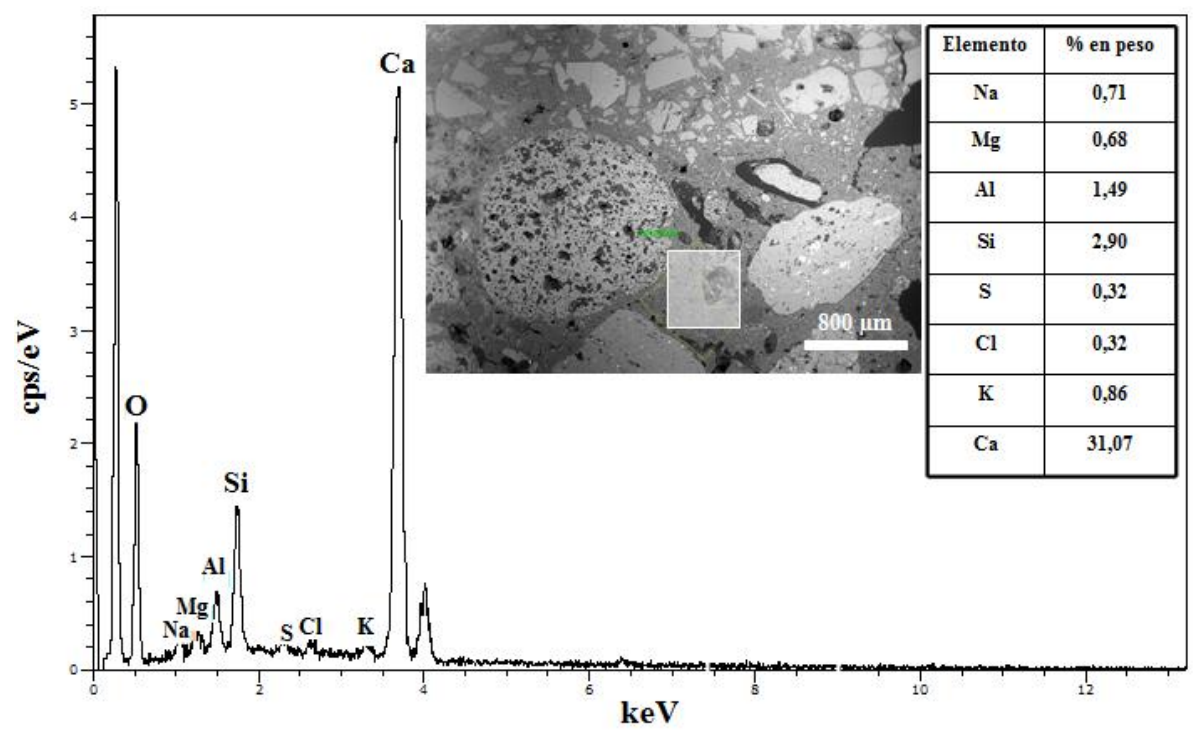

Figura 6.26. Micrografía obtenida por SEM (inset) de un área del primer estrato de mortero observado en corte transversal, y espectro EDX de la región marcada en la imagen. En forma de tabla se expresa el \% en peso de los diferentes elementos detectados.

178 R. Snelling, G. Mertens, J. Elsen, Supplementary cementitious materiales, Reviews in Mineralogy and Geochemistry 74. 211$278,2012$. 


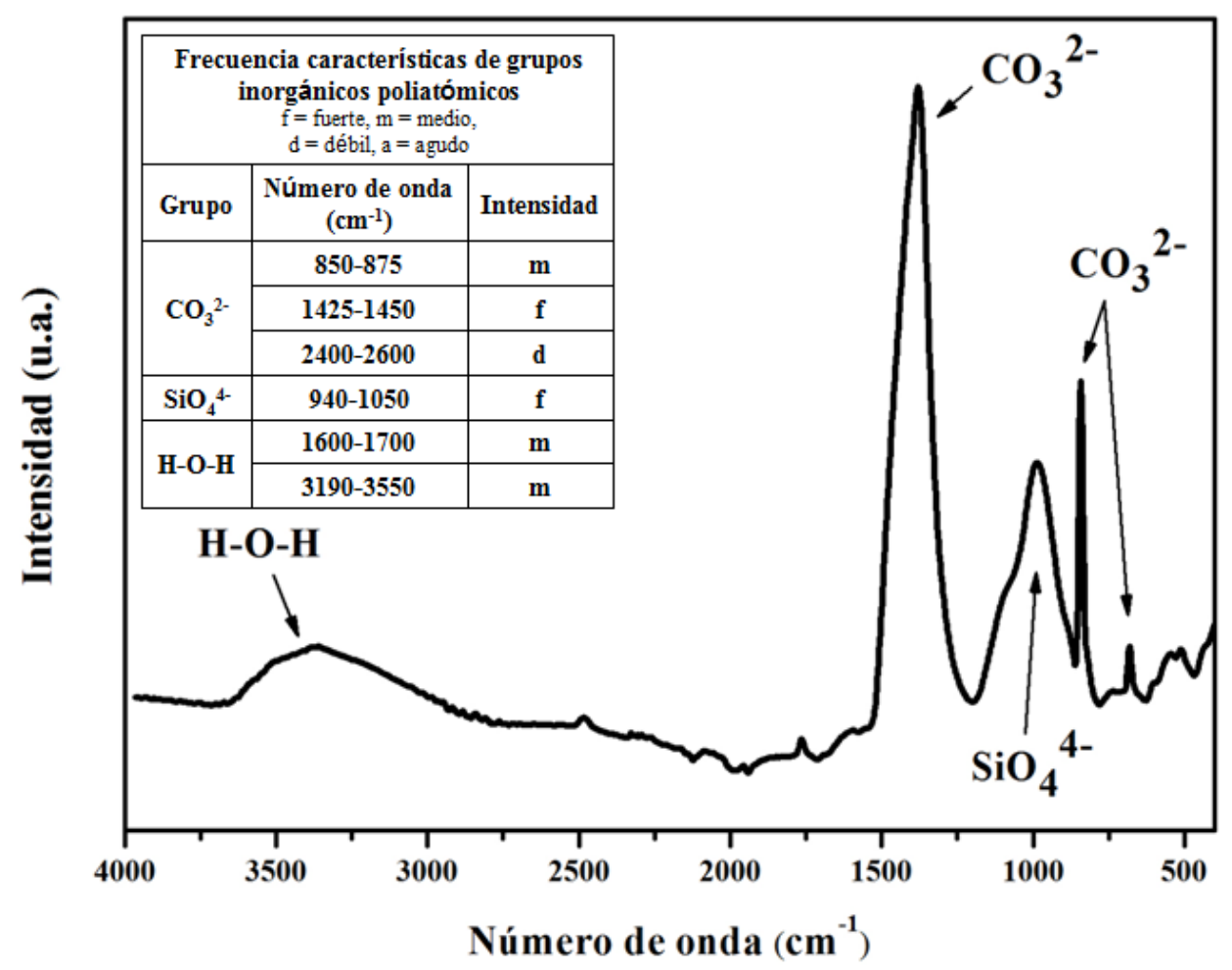

Figura 6.27. Espectro FTIR de la muestra extraída de la capa de mortero grisáceo.
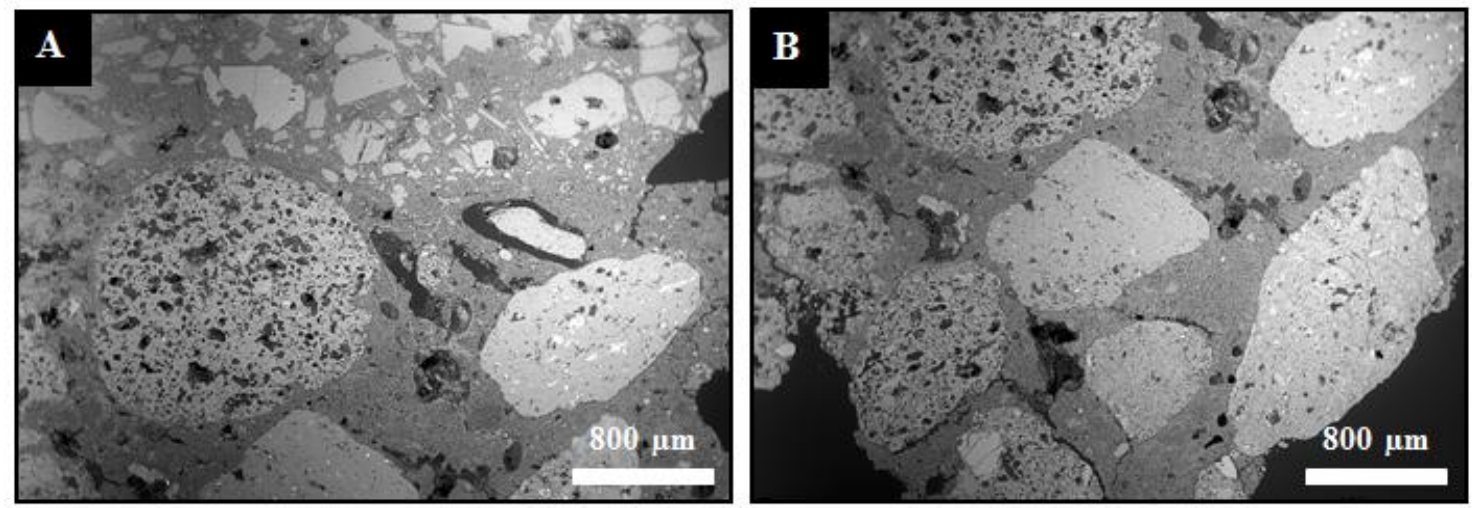

Figura 6.28. A y B) Imágenes por SEM en modalidad electrones retrodispersados de diferentes áreas de la primera capa del mortero grisáceo observado en corte transversal. 


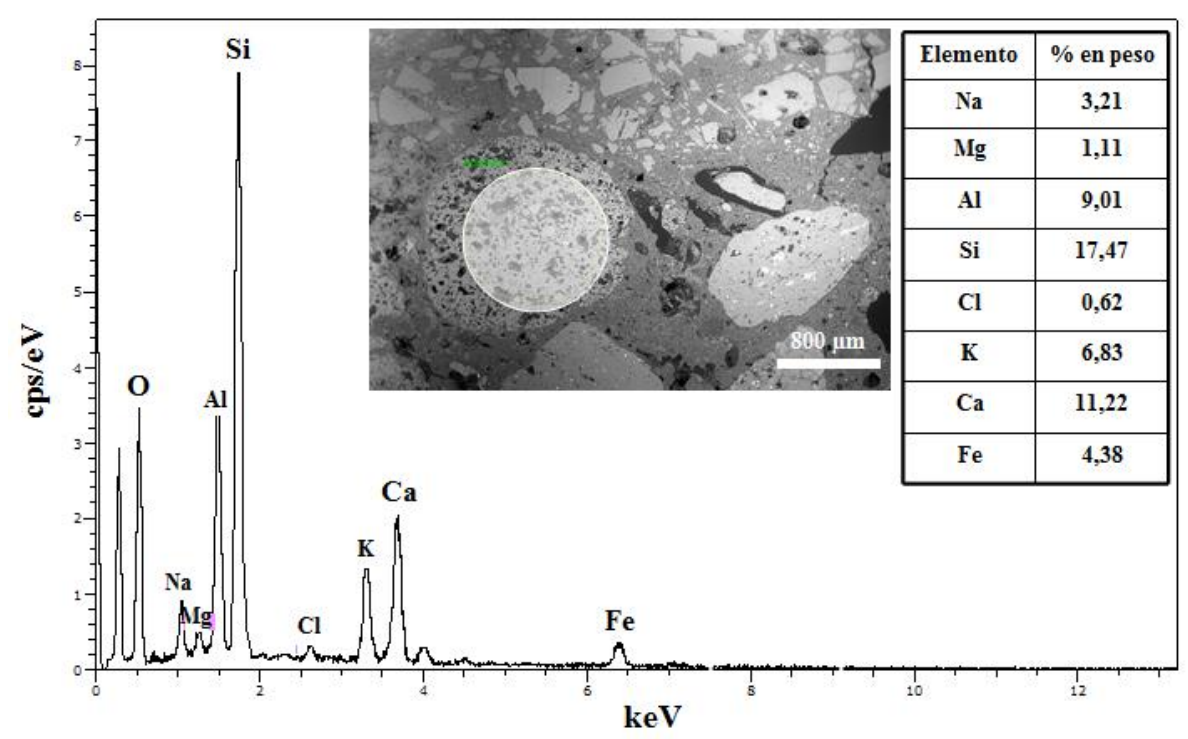

Figura 6.29. Micrografía obtenida por SEM (inset) de un área del primer estrato de mortero observado en corte transversal, y espectro EDX de la región marcada en la imagen. En forma de tabla se expresa el \% en peso de los diferentes elementos detectados.

II $^{\mathbf{0}}$ mortero blanco: Esta capa de mortero blanco, del mismo modo, esta formado por un aglomerante blanco de carbonato cálcico como se confirma con el microanálisis EDX de una región analizada de la zona II, donde se detecta como componente mayoritario el calcio (Figura 6.31). Microanálisis del árido en diferentes regiones detectan como elementos químicos el calcio $(\mathrm{Ca})$ o el silicio ( $\mathrm{Si}$ ) como mayoritarios, y en proporciones inferiores elementos como el hierro $(\mathrm{Fe})$, potasio $(\mathrm{K})$ y aluminio $(\mathrm{Al})$, Figuras 6.32 - 6.33. Este resultado indicaría que las partículas están constituidas posiblemente por calcita con pequeñas cantidades de silicatos. El tamaño de grano es irregular, con granos de árido de unos $\mu \mathrm{m}$ (aunque hay granos menores que se confunden con el aglomerante), a granos con un diámetro máximo de $1 \mathrm{~mm}$ aproximadamente (Figura $6.30)$. 

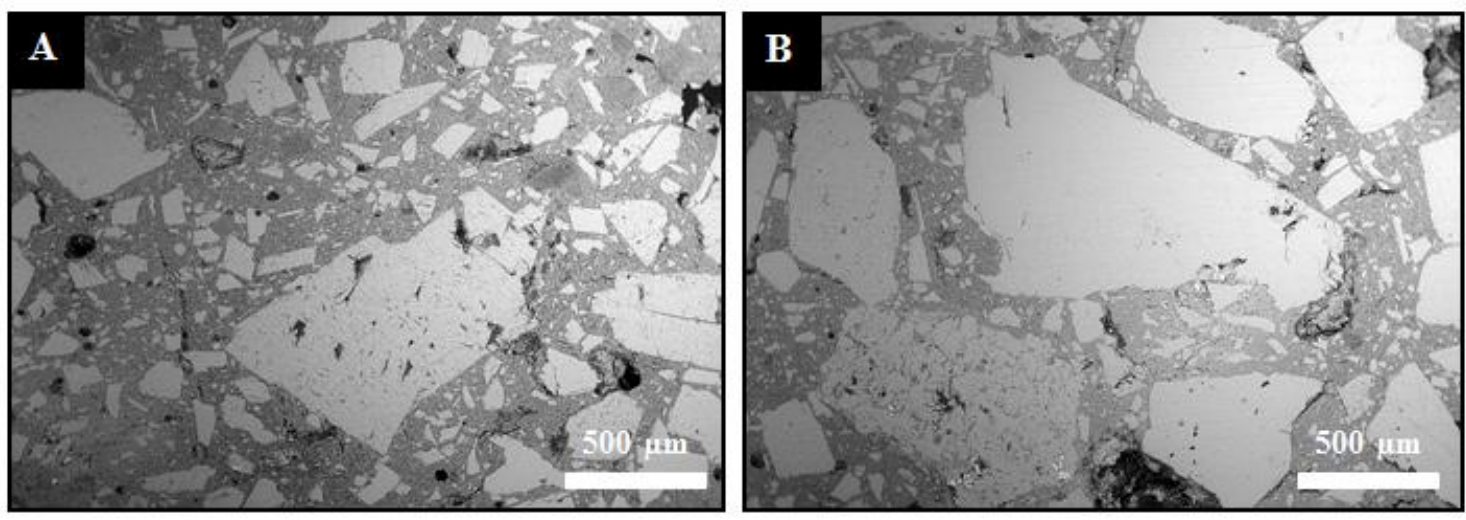

Figura 6.30. A y B) Imágenes por SEM en modalidad electrones retrodispersados de diferentes áreas de la segunda capa del mortero blanco observado en corte transversal.

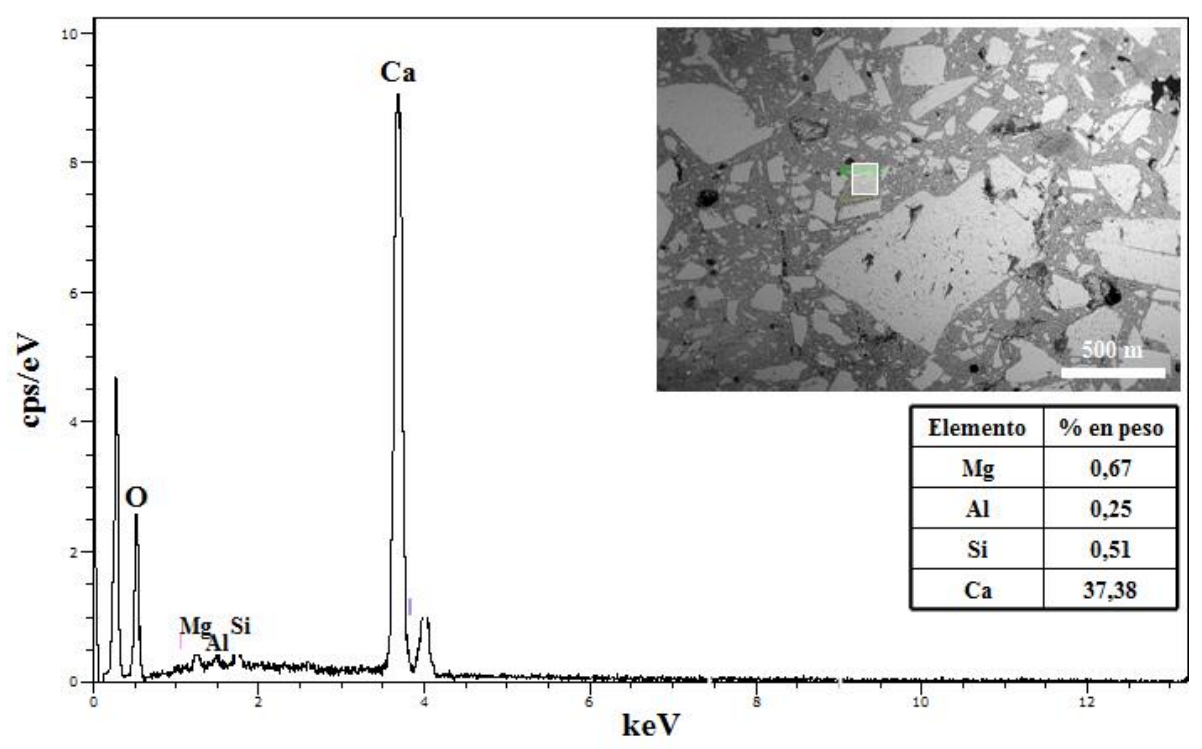

Figura 6.31. Micrografía obtenida por SEM (inset) de un área del segundo estrato de mortero observado en corte transversal, y espectro EDX de la región marcada en la imagen. En forma de tabla se expresa el \% en peso de los diferentes elementos detectados. 


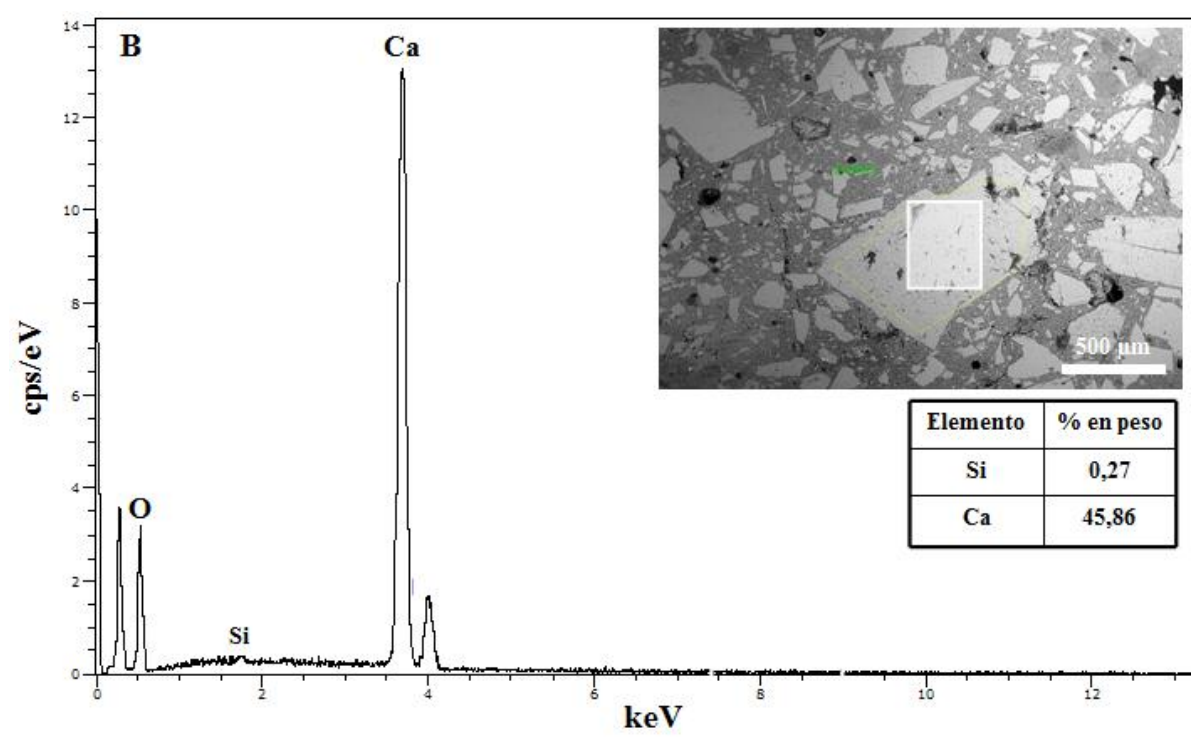

Figura 6.32. Micrografía obtenida por SEM (inset) de un área del segundo estrato de mortero observado en corte transversal, y espectro EDX de la región marcada en la imagen. En forma de tabla se expresa el \% en peso de los diferentes elementos detectados.

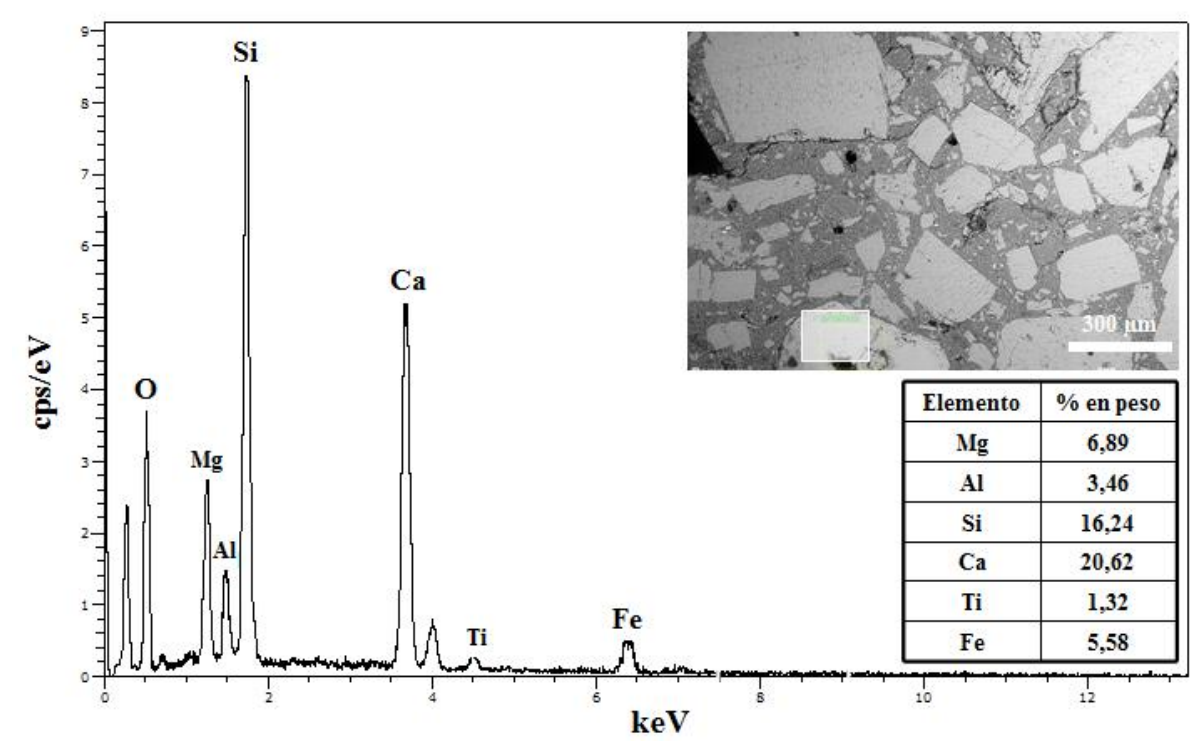

Figura 6.33. Micrografía obtenida por SEM (inset) de un área del segundo estrato de mortero observado en corte transversal, y espectro EDX de la región marcada en la imagen. En forma de tabla se expresa el \% en peso de los diferentes elementos detectados. 
El estudio del mortero, completado con análisis FTIR (Figura 6.34) muestra, efectivamente, la naturaleza prevalentemente a base de carbonato de calcio de los constituyentes -bandas del grupo $\mathrm{CO}_{3}{ }^{2-}$ a 1440,726 y $710 \mathrm{~cm}^{-1}$-, con presencia de silicatos que corresponden a la banda de vibración a $1030 \mathrm{~cm}^{-1}$.

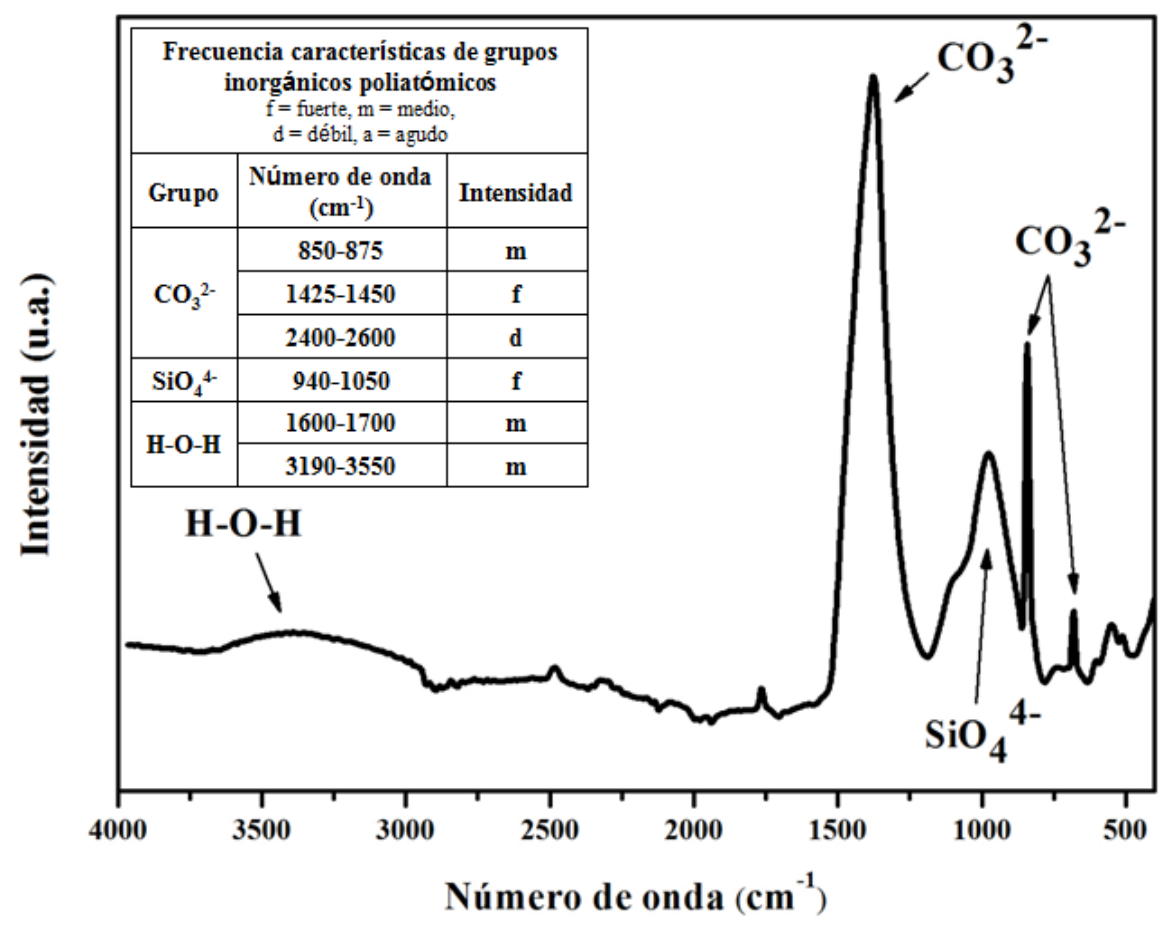

Figura 6.34. Espectro FTIR del aglomerante blanco extraído de la segunda capa de mortero.

III' mortero blanco: En la Figura 6.35 se observa el último estrato de mortero que resulta ser el más superficial. Está en contacto directo con la policromía y está formado, como se observa en los espectros EDX y análisis FTIR, Figuras 6.36 - 6.37, por un aglomerante a base de carbonato de calcio. El espesor que presenta este mortero resulta ser generalmente entre 2-4 $\mathrm{mm}$ aproximadamente. El árido se presenta con un tamaño de granos que oscila entre unos $\mu \mathrm{m}$ a 130-150 $\mu \mathrm{m}$. Los granos de calcita presentan estructura angulosa con baja esfericidad. En superficie, el mortero sostiene las partículas de pigmento. 


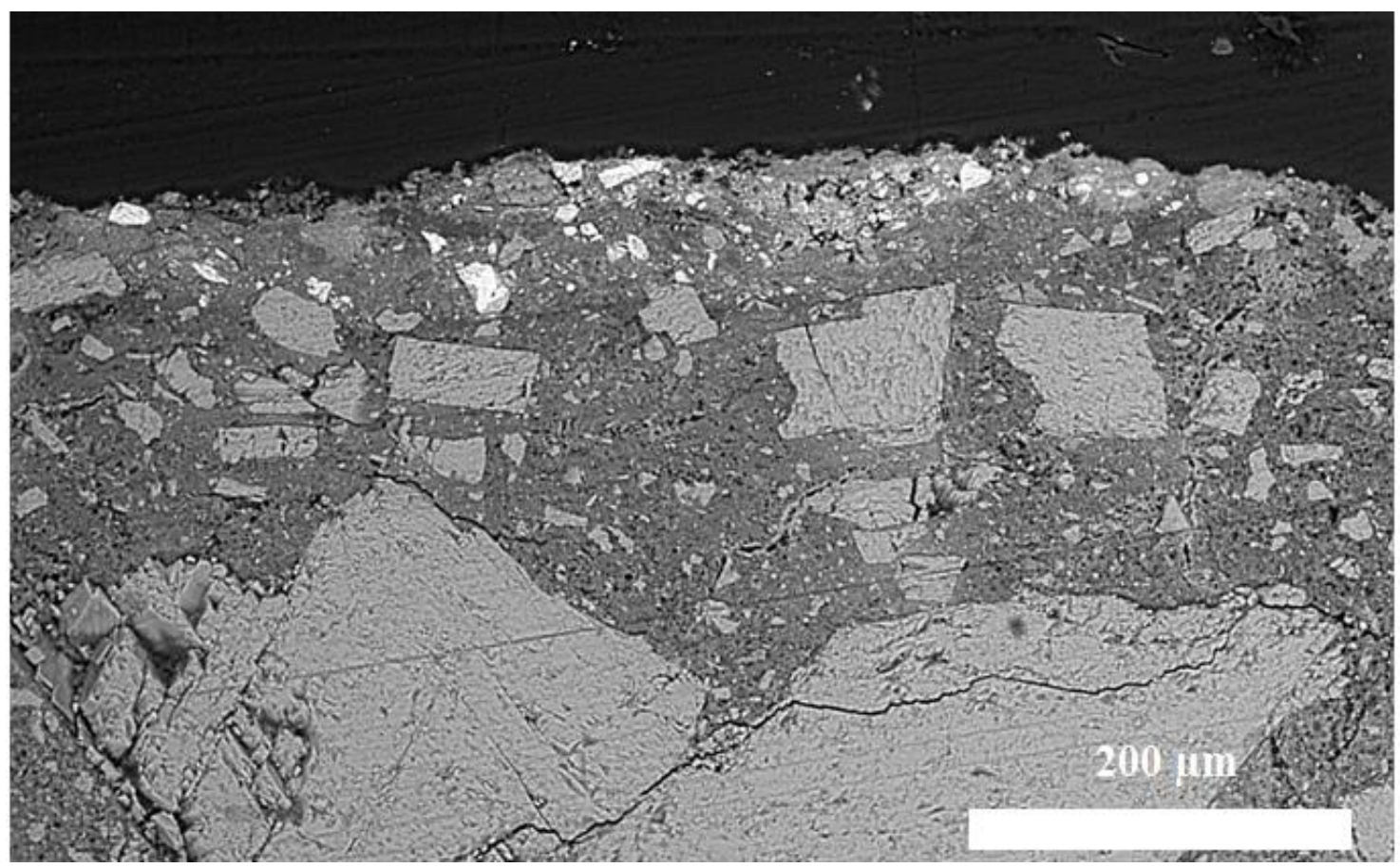

Figura 6.35. Imagen por SEM en modalidad electrones retrodispersados de la tercera capa del mortero blanco observado en corte transversal.

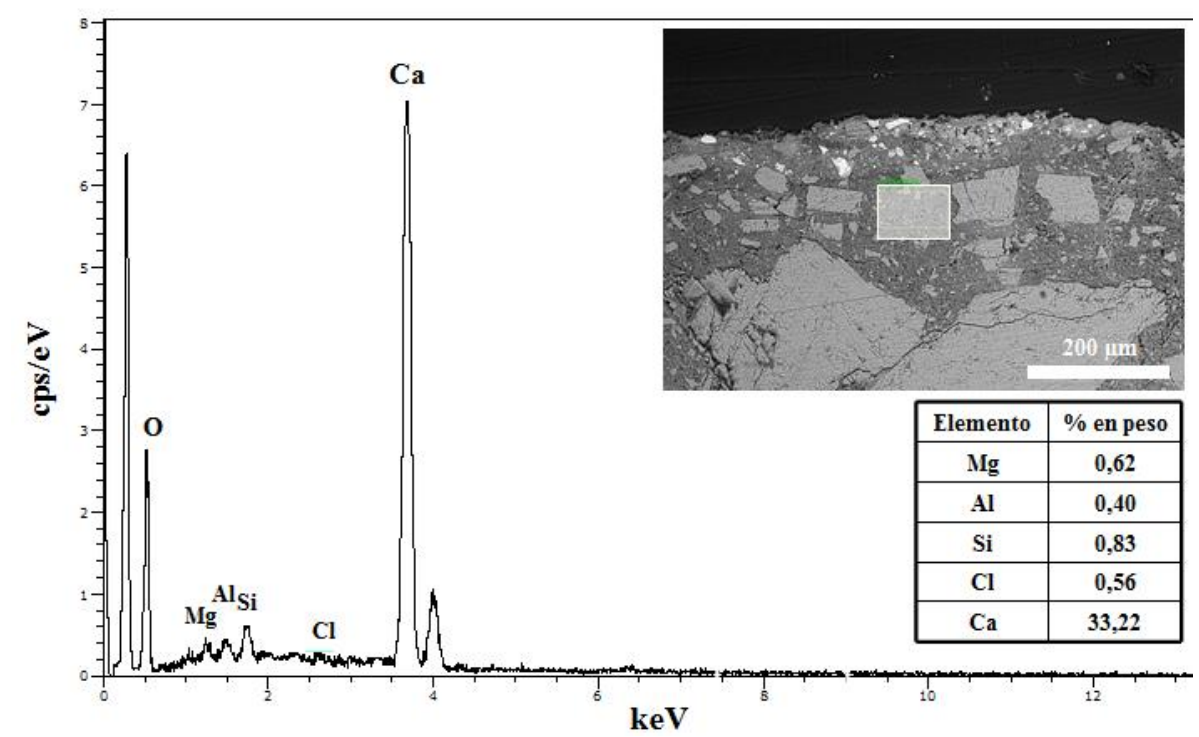

Figura 6.36. Micrografía obtenida por SEM (inset) de un área del tercer estrato de mortero observado en corte transversal, y espectro EDX de la región marcada en la imagen. En forma de tabla se expresa el \% en peso de los diferentes elementos detectados. 


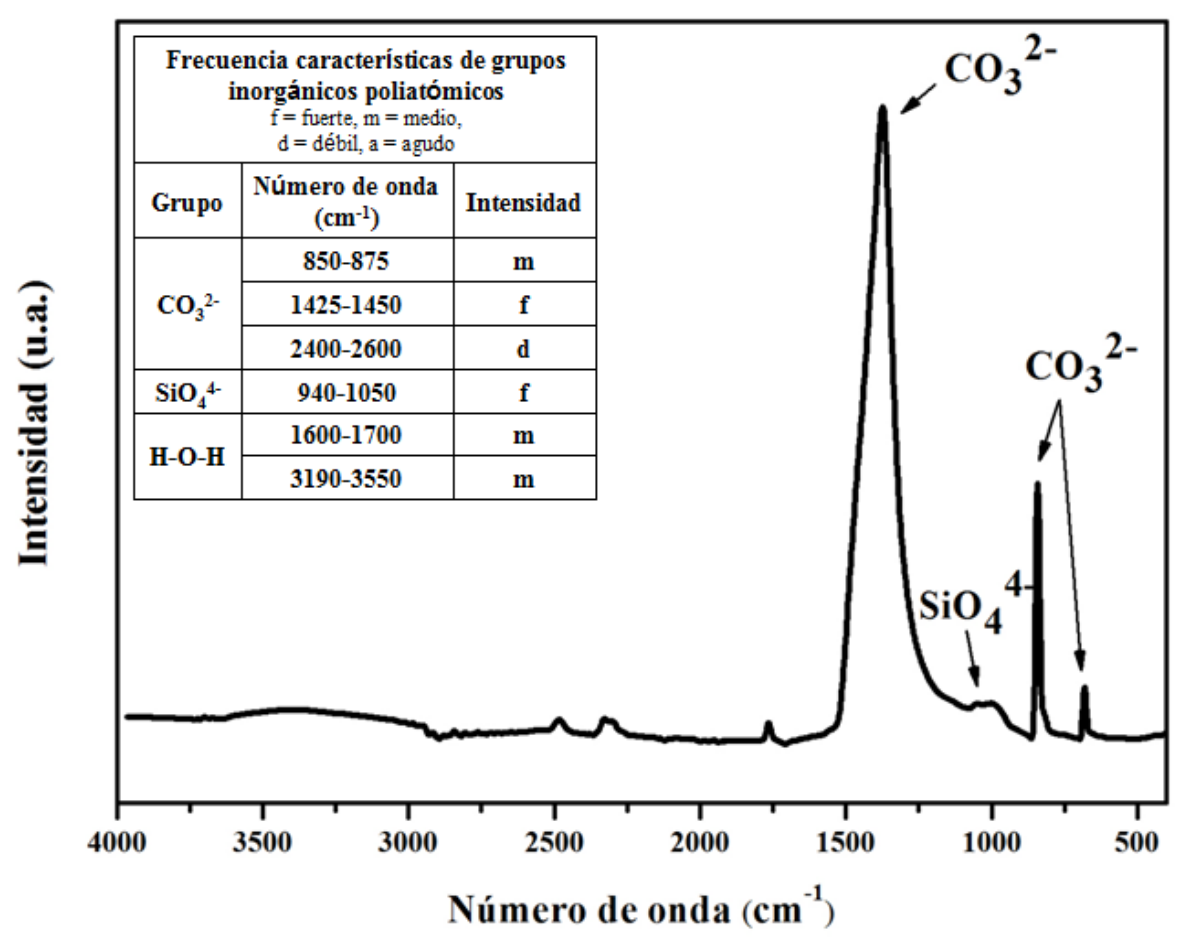

Figura 6.37. Espectro FTIR de la muestra extraída de la capa del mortero más superficial.

El estudio estratigráfico de distintas muestras de policromía ha determinado que la técnica de ejecución de las pinturas murales podría ser al fresco y al secco. En los microanálisis EDX de las capas de pintura se detecta, en concentraciones variables, el calcio que se atribuye a la utilización de cal del mortero sobre el cual se aplica el pigmento disuelto en agua (técnica al fresco), o a la utilización de una mezcla de agua de cal con los pigmentos (técnica al secco).

En la Figura 6.38, se muestra el espectro obtenido del microanálisis EDX de una partícula amarilla de la capa de pintura donde se detecta como elementos químicos mayoritarios el oxigeno $(\mathrm{O})$ y el hierro $(\mathrm{Fe})$, pudiendo corresponder a un pigmento de hierro como el ocre amarillo a base de hidróxido de hierro $\mathrm{Fe}(\mathrm{OH})_{2}$. Este pigmento suele estar asociado a pequeñas concentraciones de elementos arcillosos tales como el silicio ( $\mathrm{Si}$ ) y el aluminio $(\mathrm{Al})^{179}$. Junto a los elementos mencionados, se detecta una concentración de calcio $(\mathrm{Ca})$ alrededor del 6\%, relacionado con la presencia de carbonato de calcio generado a partir del hidróxido de calcio utilizado en el mortero o en mezcla con el pigmento, tal y como descrito con anterioridad.

${ }^{179}$ AA.VV., La fabbrica dei colori, pigmenti e coloranti nella pittura e nella timtoreria, Il Bagatto, Roma, 1986. 


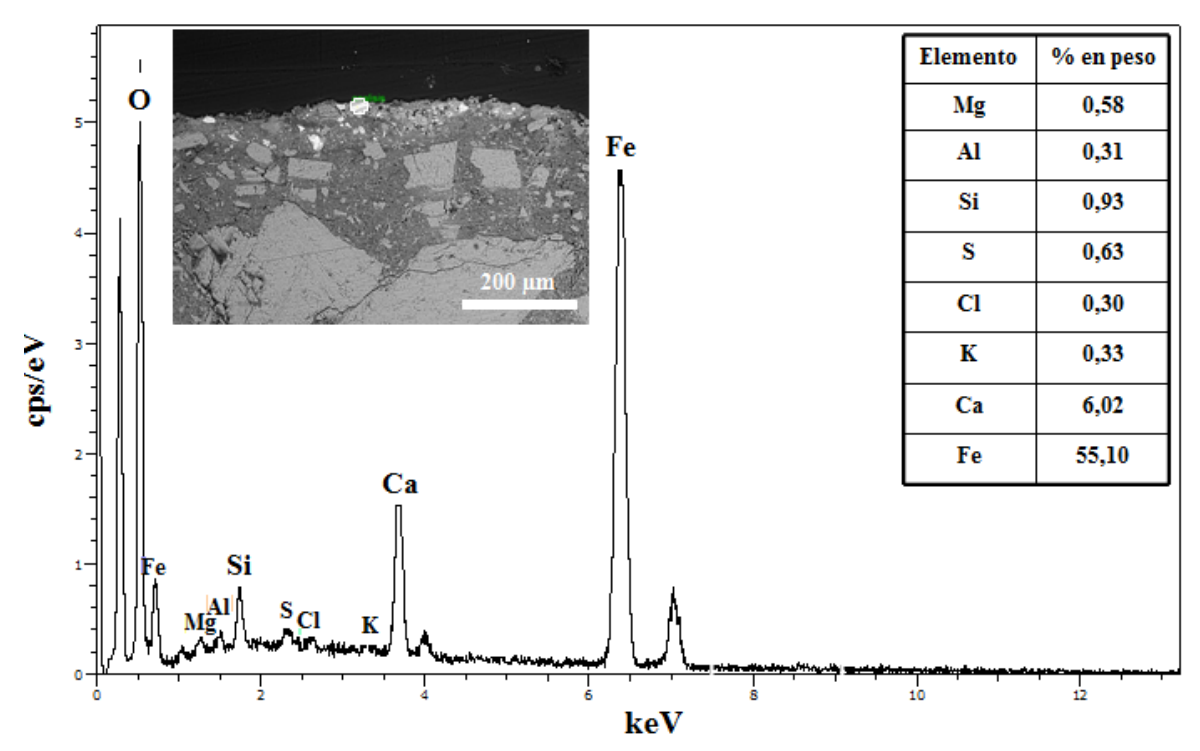

Figura 6.38. Micrografía obtenida por SEM (inset) de un área del tercer estrato de mortero observado en corte transversal, y espectro EDX del punto marcado en la imagen. En forma de tabla se expresa el \% en peso de los diferentes elementos detectados.

Tras el estudio estratigráfico realizados a partir de la microscopia óptica, junto con los microanálisis realizados mediante SEM-EDX, es posible apreciar la superposición de las diferentes capas de policromía, identificar la naturaleza de los pigmentos y de las cargas minerales, además, permite estudiar la técnica pictórica y evaluar el estado de conservación de los materiales.

En la Figura 6.39 se observa un ejemplo del estudio estratigráfico realizado sobre muestras de policromía de la pintura mural de Pompeya. Son imágenes de microscopia óptica de secciones estratigráficas que revelan como la técnica pictórica desarrollada en el antiguo Imperio Romano podía llegar a ser extremamente cuidadosa con la aplicación de varias capas de policromía y con el uso de una gama de pigmentos bastante extensa. Los pigmentos que han sido caracterizados en los distintos fragmentos de pintura mural analizados están referenciados en la Tabla 6.1. 

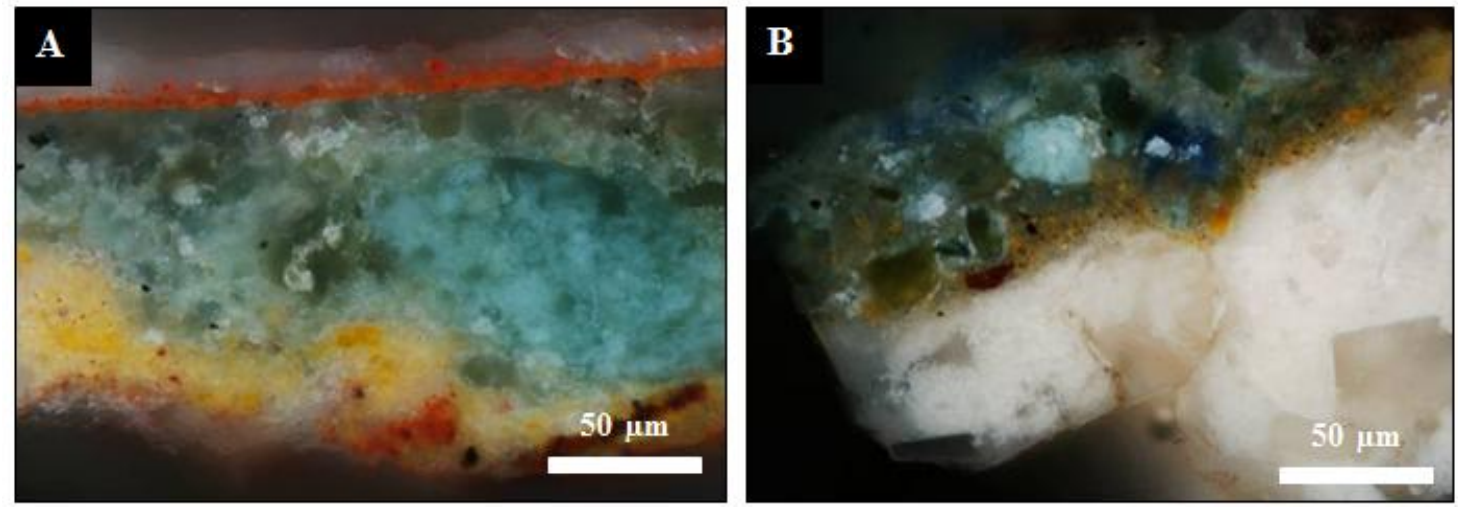

Figura 6.39. Estudio sobre la técnica de ejecución y de los materiales que constituyen las pinturas murales de la Casa de Ariadna en Pompeya. Imágenes de microscopia óptica de las secciones transversales de una muestra de policromía roja (A) y muestra de policromía verde azulado (B).

Tabla 6.1. Pigmentos identificados en las pinturas murales de la Casa de Ariadna en Pompeya.

\begin{tabular}{lll}
\hline Color & Nombre antiguo & Composición \\
\hline Blanco & Creta calcarea & Carbonato de calcio \\
\hline Amarillo & Ochra & Ocre amarilla a base de hidróxido de hierro (II) \\
\hline \multirow{2}{*}{ Rojo } & Rubricae & Ocre roja a base de óxidos de hierro (III) con óxidos de \\
& Minium & $\mathrm{Si}, \mathrm{Al}, \mathrm{Ca}$ y Mg \\
\hline \multirow{2}{*}{ Verde } & Creta viridis & Tierra verde a base de arcilla colorada por silicatos de \\
& & hierro (III) \\
\hline Azul & Cearuleum & Azul pompeyano a base de silicato de cobre (II) y calcio \\
\hline
\end{tabular}

A continuación se muestran los microanálisis EDX realizados mediante SEM en diferentes muestras de policromías observadas y analizadas en sección estratigráfica, en los cuales se han identificado varios de estos pigmentos inorgánicos naturales o artificiales.

En la Figura 6.40 se muestra el estudio de microscopía óptica y SEM-EDX realizado sobre una partícula de pigmento azul. La imagen A corresponde a un área de la sección estratigráfica de la muestra de policromía observada con microscopia óptica, mientras que la imagen B es la micrografía SEM donde se señala el área 
del microanálisis EDX de la partícula de pigmento azul. El microanálisis de esta zona ha detectado como elementos mayoritarios el silicio ( $\mathrm{Si}$ ) con una proporción en peso del 22,13\%, el oxigeno (O) con un 48,35\%, el cobre $(\mathrm{Cu})$ con un $14,42 \%$ y el calcio $(\mathrm{Ca})$ con un $12,68 \%$. En base a los estudios consultados ${ }^{180,181}$, este resultado indicaría que estamos observando el pigmento Azul egipcio o Azul pompeyano (Caeruleum), un mineral artificial constituido por un silicato de cobre (II) y calcio con una formula química propuesta $\mathrm{CaCuSi}_{4} \mathrm{O}_{10}$.

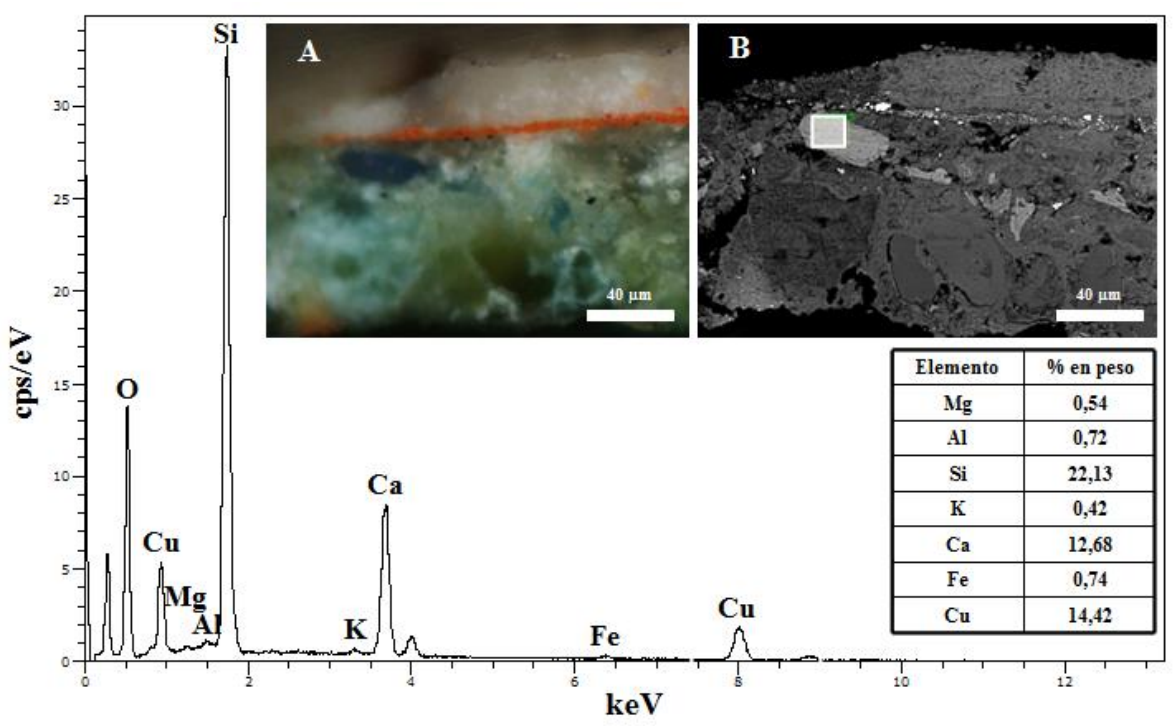

Figura 6.40. A) Imagen de microscopia óptica de un área de la sección estratigráfica de una muestra de policromía donde se observa la presencia de pigmento azul. B) Micrografía por SEM de la misma área de la sección estratigráfica donde se señala el área del microanálisis EDX. En forma de tabla se expresa el \% en peso de los diferentes elementos detectados.

\footnotetext{
${ }^{180}$ K. Wehlte, Werkstoffe und Techniken der Malerei, Ravensburg, Otto Maier, 155, 1967; L. Nicolini, M. Santini, Contributo alla conoscenza del blu egiziano, in Bollettino dell' Istituto Centrale per il Restauro, nn. 34-35, 59-70, 1958.

${ }^{181}$ P. García Fernadez, M. Moreno, J.A. Aramburu, Origin of the Exotic Blue Color of Copper-Containing Historical Pigments, Inorg. Chem., 54 (1), 192-199, 2015.
} 
La caracterización de un pigmento verde se muestra en las imágenes de la Figura 6.41. En el microanálisis EDX (de la región marcada en B) referente a una partícula verde, se detectan los elementos del silicio (Si), oxigeno $(\mathrm{O})$, aluminio $(\mathrm{Al})$, potasio $(\mathrm{K})$, hierro $(\mathrm{Fe})$, magnesio $(\mathrm{Mg})$ y calcio $(\mathrm{Ca})$. Las proporciones de cada elemento se muestran en la tabla. En este caso los resultados indicarían a la presencia del pigmento Tierra verde (Creta viridis), un compuesto mineral constituido principalmente por silicatos de potasio y hierro (III). Varios estudios consultados ${ }^{182,}{ }^{183}$ han detectado, a través de técnicas de análisis tal y como la DRX, la presencia de compuestos minerales de la glauconita y celadonita. La glauconita es un hidroxi-silicato con numerosos iones metálicos, generando muchas variedades y coloraciones verdosas del mineral, en general la formula química del compuesto puede ser escrito como $(\mathrm{K}, \mathrm{Na})\left(\mathrm{Fe}^{3+}, \mathrm{Al}, \mathrm{Mg}\right)_{2}(\mathrm{Si}, \mathrm{Al})_{4} \mathrm{O}_{10}(\mathrm{OH})_{2}$. La celadonita igualmente es un silicatos cuya fórmula química puede ser descrita como $\mathrm{K}\left(\mathrm{Mg}, \mathrm{Fe}^{2+}\right)\left(\mathrm{Fe}^{3+}, \mathrm{Al}\right)\left[(\mathrm{OH})_{2} \cdot \mathrm{Si}_{4} \mathrm{O}_{10}\right]^{184}$.

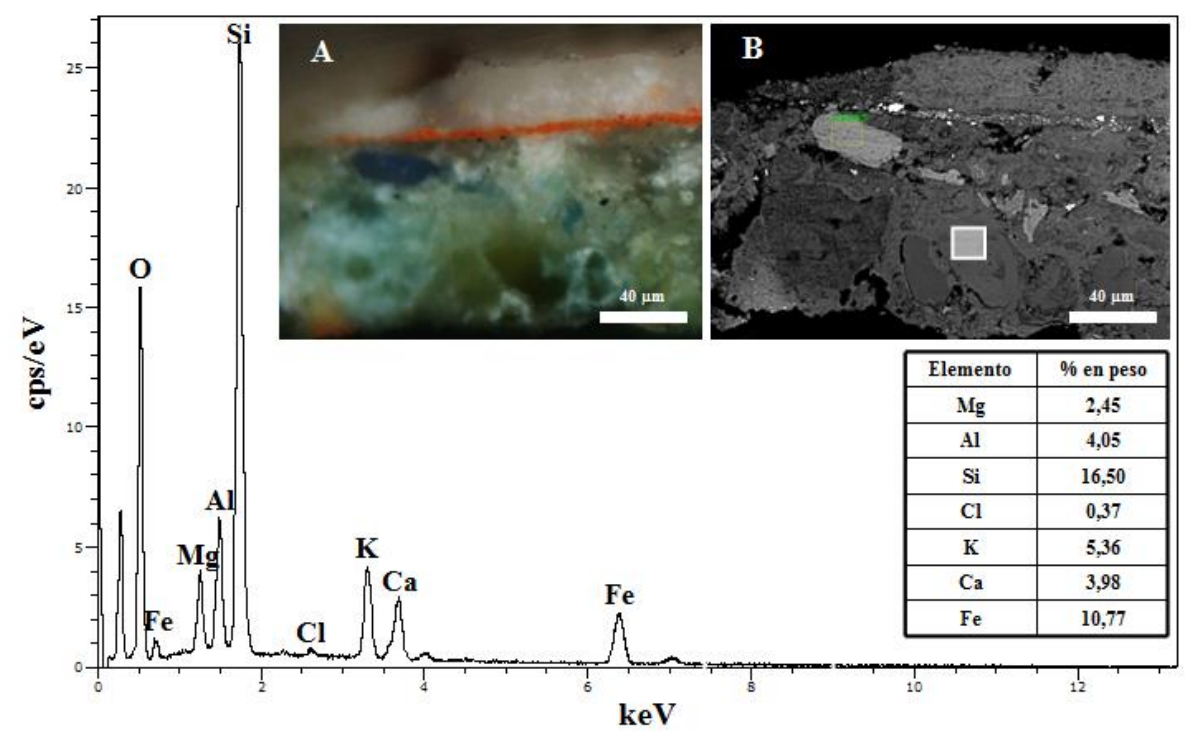

Figura 6.41. A) Imagen de microscopia óptica de un área de la sección estratigráfica de una muestra de policromía donde se observa la presencia de pigmento azul. B) Micrografía por SEM de la misma área de la sección estratigráfica donde se señala el área del microanálisis EDX. En forma de tabla se expresa el \% en peso de los diferentes elementos detectados.

\footnotetext{
182 Rieder et.al. 1998, Nomenclature of the Micas: IMA Mica Subcommittee report, Canadian Mineralogist 36, 905-912, 1998.

${ }^{183}$ V. Walsh, R. Siddal, N. Eastaugh, T. Chaplin, Pigmenti di Pompeii: verso la definizione di uno standart di riferimento per la ricerca su pigmenti romani, in Scienze e arqueologia, 181-196, 2003.

${ }^{184}$ H. Strunz, E.H. Nickel, Strunz Mineralogical Tables. Chemical-structural Mineral Classification System. 9. Auflage. E. Schweizerbart'sche Verlagsbuchhandlung (Nägele u. Obermiller), S. 665, 2001.
} 
En cuanto a los pigmentos de tonalidad rojiza que se utilizaban en Pompeya y que han sido analizados, figuran los pigmentos minerales a base de hierro tales como las tierras rojas (Rubricae, Ochra, Sinopia), o el pigmento nombrado en edad clásica como Minium, a base de sulfuro de mercurio $\mathrm{HgS}$ (II).

Las imágenes de la Figura 6.42 muestran la caracterización del pigmento rojo presente en la capa de policromía tal y como se observa en el microanálisis EDX donde se detecta el hierro (Fe) con un 59,25\% y oxigeno (O) con un 30,56\%, indicando a un pigmento a base de óxido de hierro (III).

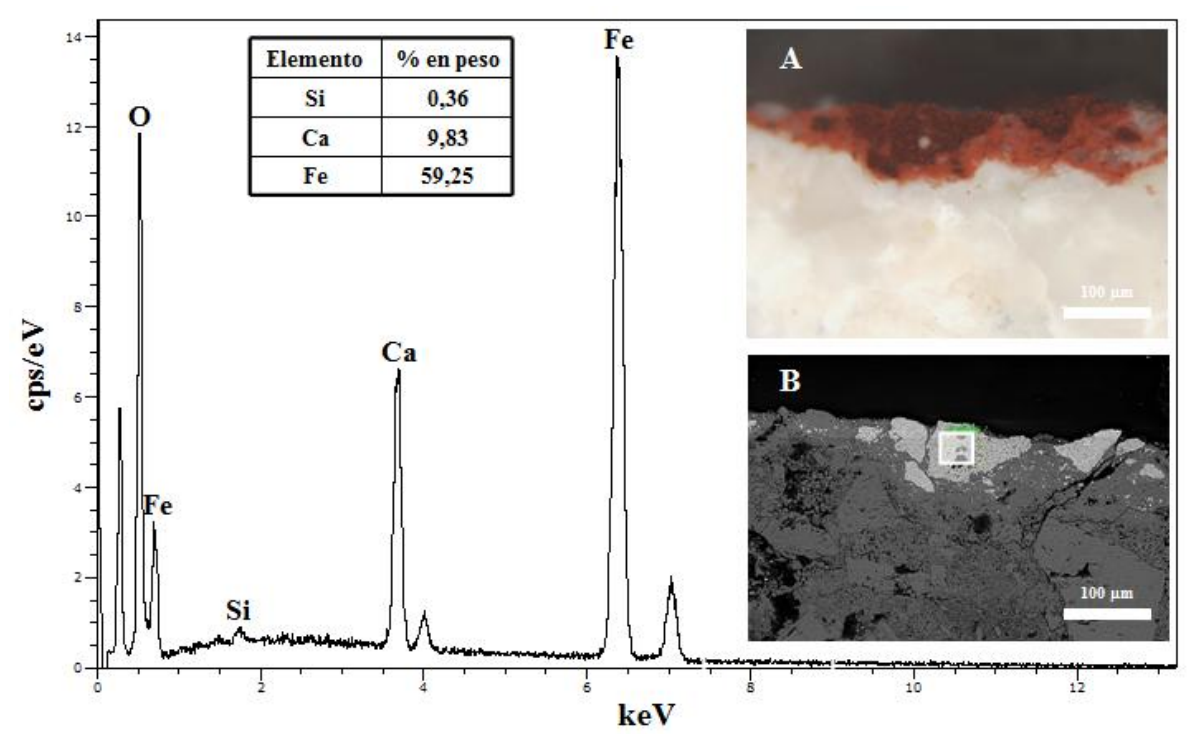

Figura 6.42. A) Imagen de microscopia óptica de un área de la sección estratigráfica de una muestra de policromía donde se observa la presencia de pigmento azul. B) Micrografía por SEM de la misma área de la sección estratigráfica donde se señala el área del microanálisis EDX. En forma de tabla se expresa el \% en peso de los diferentes elementos detectados.

El microanálisis detecta calcio con un contenido del 10\% aproximadamente. Este elemento, tal y como descrito anteriormente, correspondería a la presencia de carbonato de calcio que se forma con la reacción de carbonatación del hidróxido de calcio utilizado en el mortero o como aglutinante del pigmento. En el mapping de la Figura 6.43 se observa la distribución del calcio y del hierro a lo largo de la sección estratigráfica de la muestra. El calcio se presenta como constituyente principal del mortero y de la capa de policromía. En este último caso se observan las partículas de pigmento ricas en hierro. 


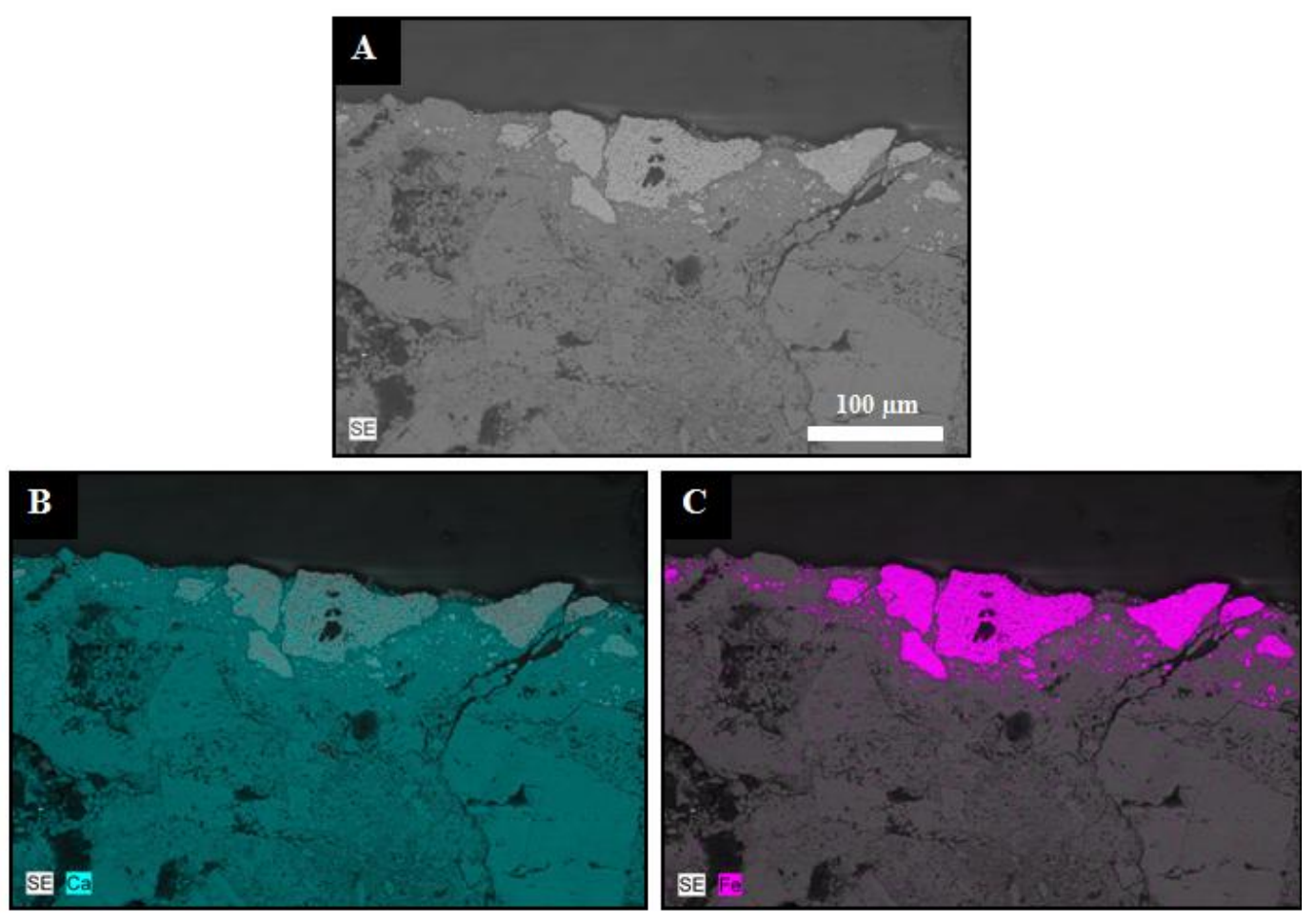

Figura 6.43. A) Imagen por SEM en modalidad electrones retrodispersados de un área de la sección estratigráfica de la muestra de policromía roja. B y C) Se observa la distribución espacial del calcio (Ca) y hierro (Fe).

Para la identificación del pigmento rojo a base de sulfuro de mercurio $\mathrm{HgS}$, el microanálisis EDX detecta en este caso altas concentraciones de los elementos químicos del mercurio ( $\mathrm{Hg}$ ) y azufre (S), tal y como se muestra en la Figura 6.44. El sulfuro de mercurio correspondería al mineral del cinabrio, un sulfuro que en base a la bibliografía consultada, está compuesto por el $85 \%$ de mercurio y un $15 \%$ de azufre ${ }^{185,186}$.

\footnotetext{
185 J. Martín Gil, F.J. Martín Gil, G. Delibes de Castro, P. Zapatero Magdaleno, F.J. Sarabia Herrero, The first known use of vermillion, Cellular and Molecular Life Sciences, 51(8), 759-761, 1995.

${ }^{186}$ G. Barone, M. Di Bella, M.A. Mastelloni, P. Mazzoleni, S. Quartieri, S. Raneri, G. Sabatino, C. Vailati, Pottery production of the pittore di lipari: chemical and mineralogical analysis of the pigments, in 2 end European Mineralogical Conference, emc2016 Minerals, fluids and rocks: alphabet and words of planet earth, 716, 2016.
} 


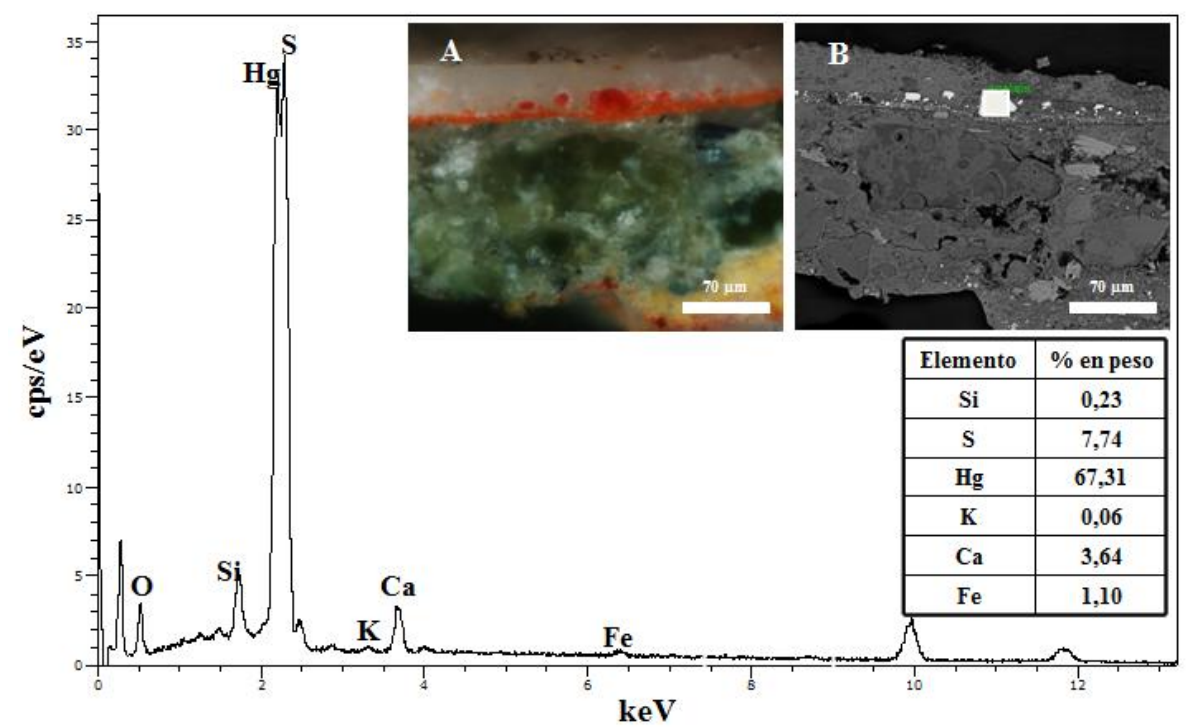

Figura 6.44. A) Imagen de microscopia óptica de un área de la sección estratigráfica de una muestra de policromía donde se observa la presencia de pigmento azul. B) Micrografía por SEM de la misma área de la sección estratigráfica donde se señala el área del microanálisis EDX. En forma de tabla se expresa el \% en peso de los diferentes elementos detectados. 


\subsubsection{Evaluación del estado de conservación}

En los distintos fragmentos de mortero con policromía procedente de Pompeya, los estudios realizados han permitido determinar los mecanismos de alteración que afectan la conservación del estrato de color. Como se observa en la imagen de la Figura 6.45, las pinturas presentan, generalmente, un aspecto pulverulento con desprendimiento de las capas de policromía respecto al mortero. Se observa la descamación de la capa de color por cristalización de sales solubles y la aparición de las eflorescencias salinas blancas. Con los análisis por DRX y EDX de distintas muestras, se ha observado que este mecanismo de alteración es causado, principalmente, por la cristalización de sales solubles entre el soporte y la policromía.

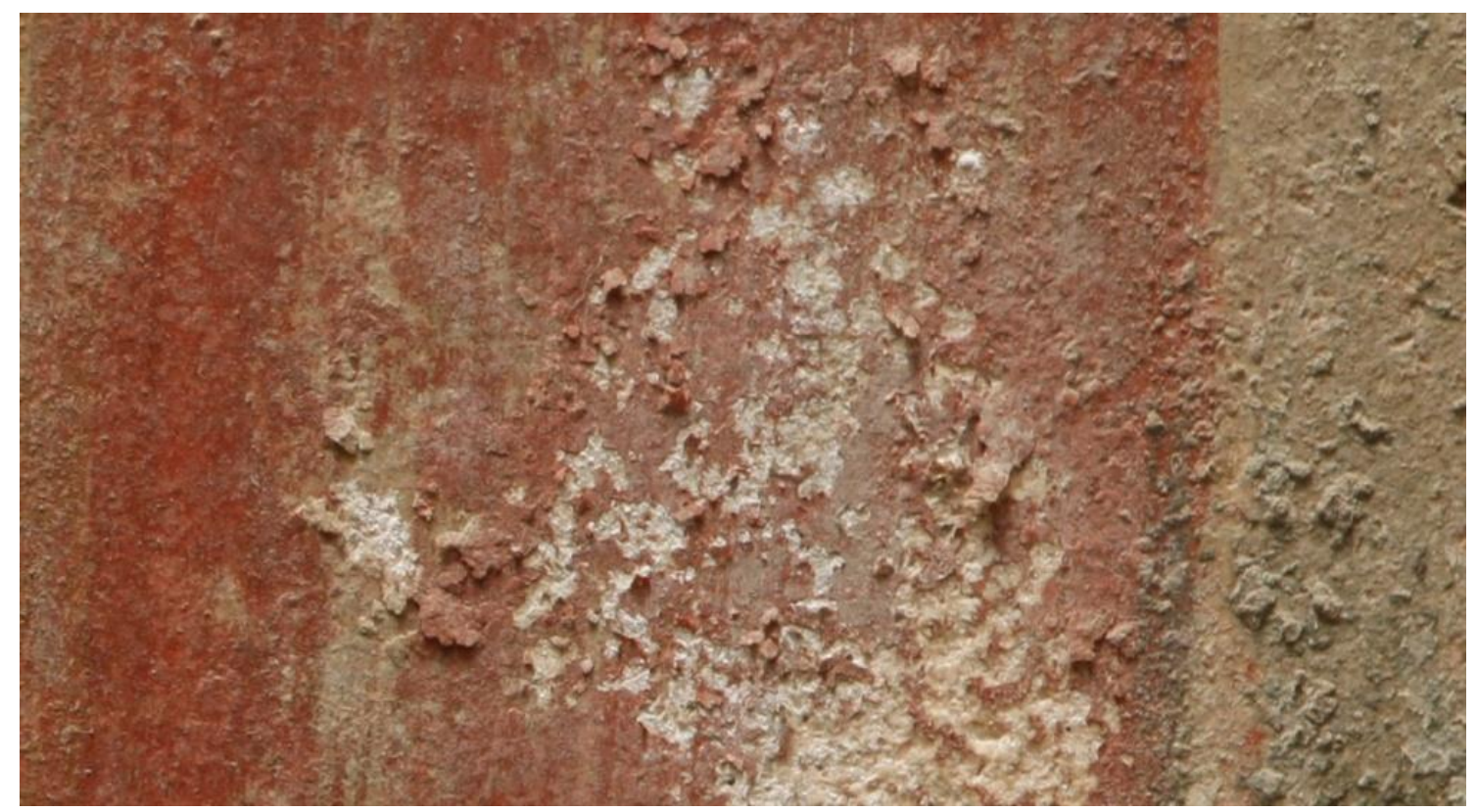

Figura 6.45. Detalle de la superficie policroma de un fragmento de pintura mural procedente de la Casa de Ariadna en Pompeya.

En el difractograma de la Figura 6.46 se identifican las fases cristalinas de distintas sales alcalinas, principalmente el sulfato de sodio $\mathrm{Na}_{2} \mathrm{SO}_{4}$-en forma mineral de la thenardita- (JCPDS-ICDD No. 030260) y el sulfato de sodio y potasio $\mathrm{K}_{2} \mathrm{SO}_{4}-\mathrm{Na}_{2} \mathrm{SO}_{4}$ (JCPDS-ICDD No. 026018). 
Estas sales suelen originarse generalmente por la presencia de sales alcalinas $\mathrm{Na}_{2} \mathrm{O}$ y $\mathrm{K}_{2} \mathrm{O}$ presentes en los materiales de construcción como los cementos utilizados en épocas recientes para las intervenciones de mantenimiento y conservación de las estructuras arqueológicas.

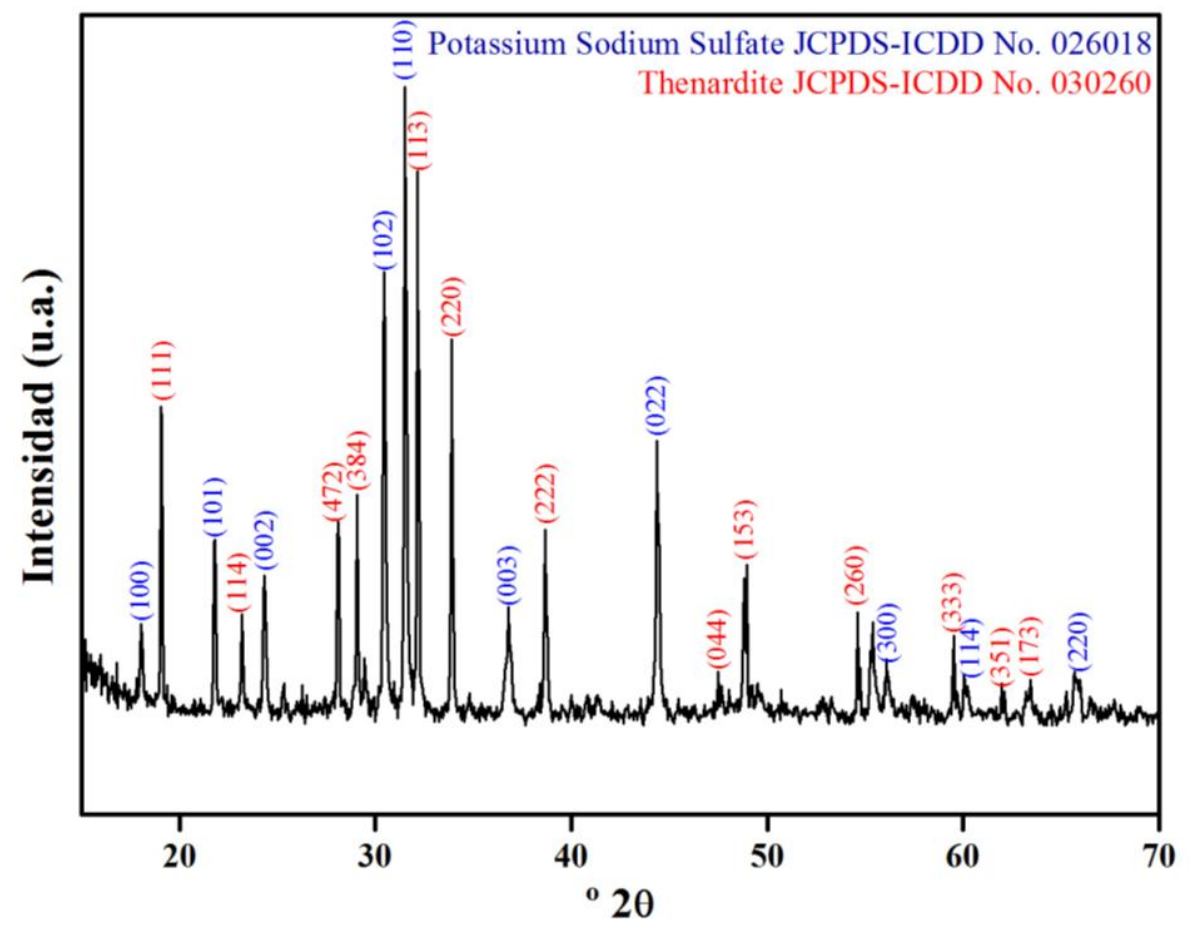

Figura 6.46. Difractograma de la muestra de la eflorescencia salina blanca extraída de la superficie de una pintura mural en la Casa de Ariadna en Pompeya. Se identifican las fases mineralógicas del sulfato de sodio $\mathrm{Na}_{2} \mathrm{SO}_{4}$ y del sulfato de sodio y potasio $\mathrm{K}_{2} \mathrm{SO}_{4}-\mathrm{Na}_{2} \mathrm{SO}_{4}$.

Los sulfatos se presentan a nivel superficial e interno en la estructura muraría, en forma de eflorescencia y sub-eflorescencia salinas blancas. En la muestra de policromía roja estudiada mediante microscopia óptica y SEM-EDX, se puede observar la existencia de un espeso estrato blanco por debajo de la capa de policromía imagen de la sección transversal de la Figura 6.47-. Se observa de como la cristalización de sales induce la separación de la policromía respecto al mortero.

En el análisis EDX, que se muestra en la Figura 6.48, se observan los picos del azufre (S), potasio (K) y sodio $(\mathrm{Na})$ con una proporción determinada según la tabla y que correspondería a sulfato de sodio y potasio $\mathrm{K}_{2} \mathrm{SO}_{4}-\mathrm{Na}_{2} \mathrm{SO}_{4}$. Este estudio indica que el mecanismo de separación entre estratos es provocado por la cristalización interna de sales solubles. 


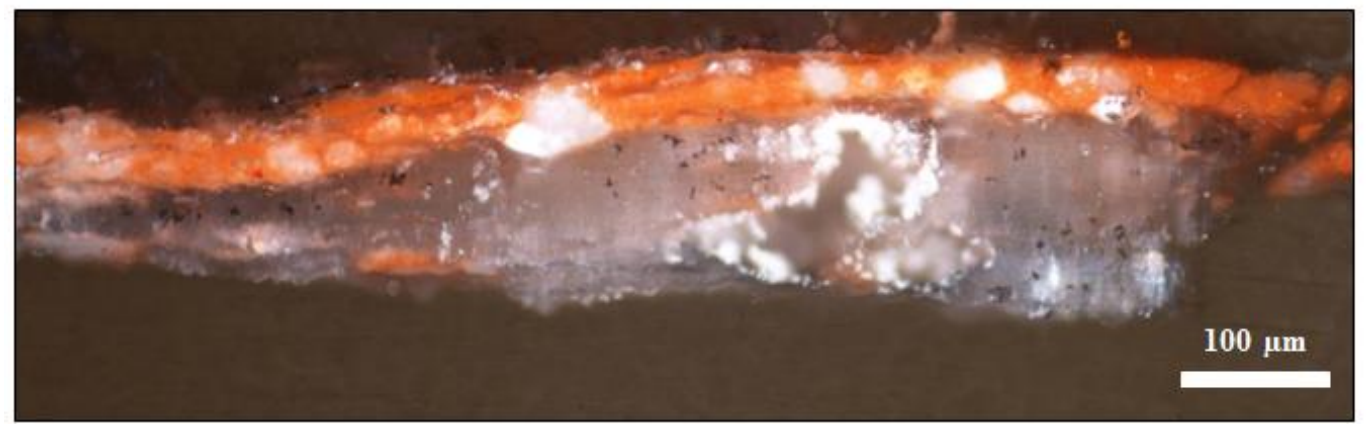

Figura 6.47. Imagen de la sección transversal de una muestra de policromía roja procedente de la pintura mural de la Casa de Ariadna en Pompeya. La imagen se obtiene mediante microscopía óptica con fuente de luz visible.

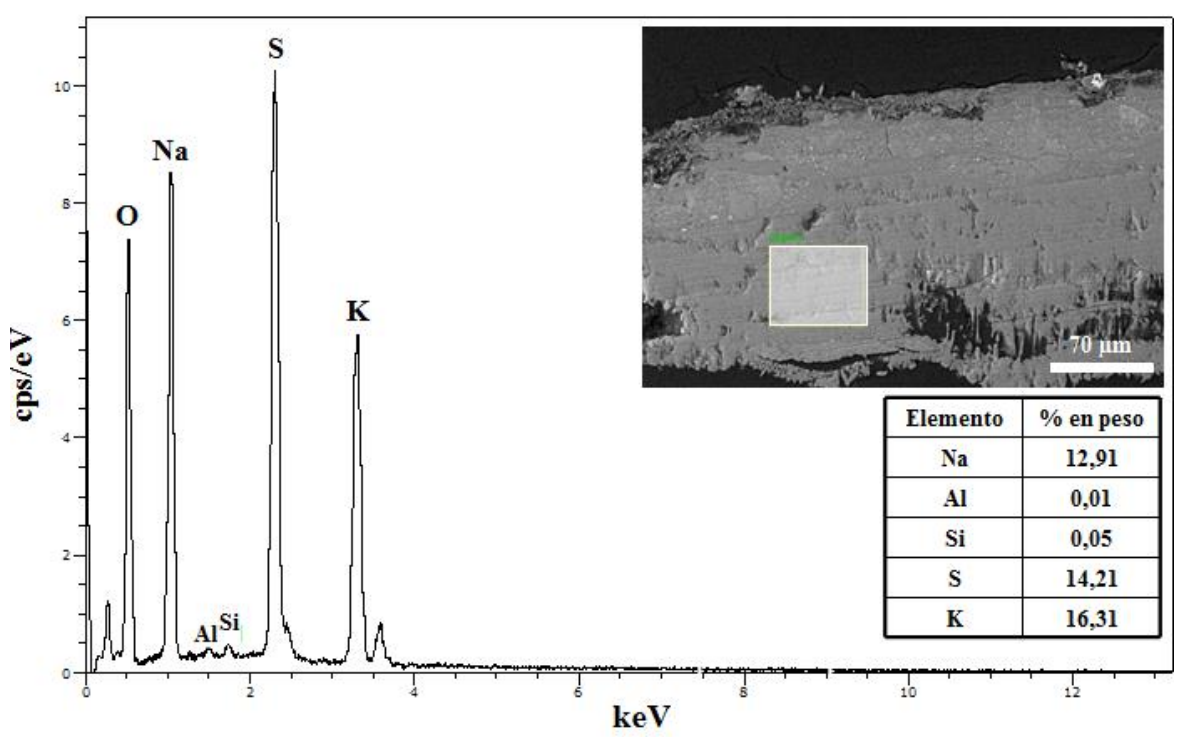

Figura 6.48. Micrografía obtenida por SEM (inset) de un área de la sección estratigráfica de la muestra de policromía roja, y espectro EDX de la región marcada en la imagen. En forma de tabla se expresa el \% en peso de los diferentes elementos detectados.

En las observaciones realizadas al SEM de una muestra de la eflorescencia salina se aprecia la presencia de cristalizaciones laminares o con aspecto de tablillas de diferente tamaño -micrografía por SEM de la Figura 6.49-. En el microanálisis EDX de la Figura 6.49 se detectan los elementos químicos del oxigeno (O), azufre $(\mathrm{S})$, potasio $(\mathrm{K})$ y sodio $(\mathrm{Na})$ relacionados a la presencia de sulfato de sodio y potasio $\mathrm{K}_{2} \mathrm{SO}_{4}-\mathrm{Na}_{2} \mathrm{SO}_{4}$. 


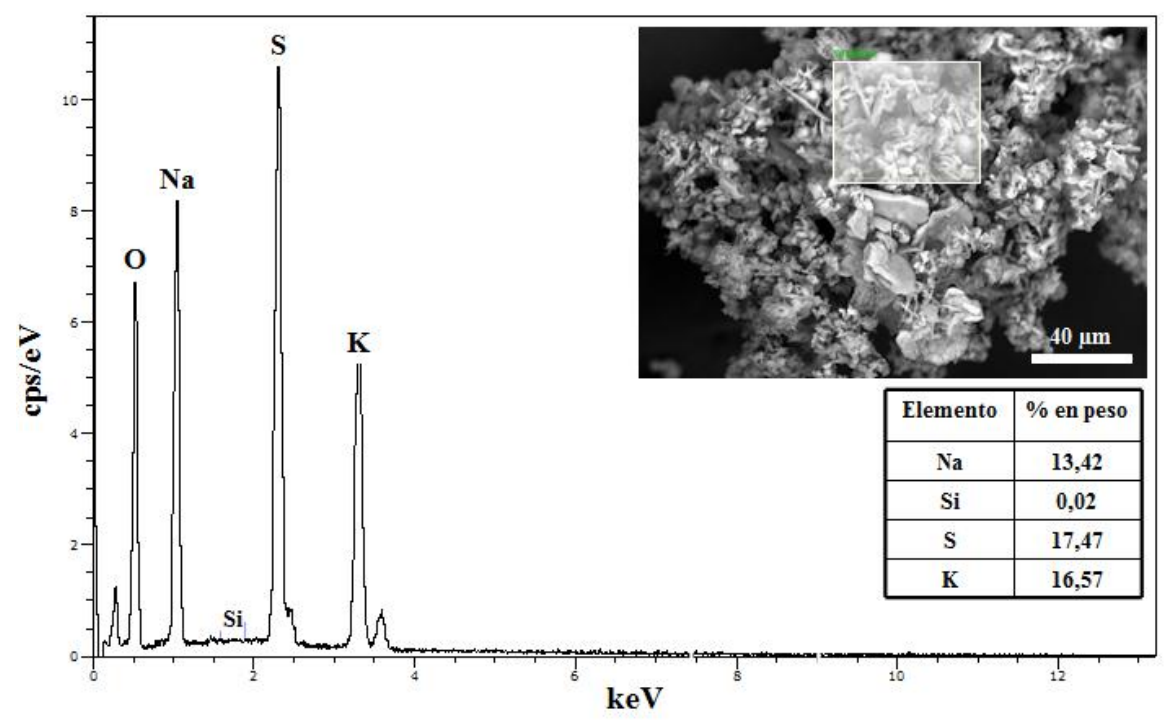

Figura 6.49. Micrografía obtenida por SEM (inset) de un área de las cristalizaciones de sales y espectro EDX de la región marcada en la imagen. En forma de tabla se expresa el \% en peso de los diferentes elementos detectados. 


\subsection{Conclusiones}

Con los estudios realizados sobre los fragmentos pétreos de la portada principal de la Iglesia de Nuestra Señora de la Asunción de Corral de Almaguer (Toledo) y sobre los fragmentos de pintura mural procedente del yacimiento arqueológico de la Casa de Ariadna en Pompeya (Italia), se ha observado que las problemáticas más acentuadas para la conservación futura de los materiales constituyentes de las obras es el fenómeno de la cristalización de sales solubles. Esto provoca la presencia de eflorescencias y subeflorescencias salinas a base de sulfato de calcio, sulfato de sodio y sulfato de sodio y potasio.

En el caso del soporte pétreo, se observa la formación de costras de sulfatación y de depósitos cristalinos de sales que absorben una alta cantidad de sustancias extrañas, que colorean en gris u ocre las costras formadas sobre la piedra. El origen del sulfato de calcio en la piedra de la portada es debido, fundamentalmente, a la acción del ácido sulfúrico sobre el carbonato de calcio y magnesio, con la sucesiva descomposición del carbonato de calcio y la precipitación del sulfato de calcio. Este fenómeno provoca la disgregación y pérdida de sustrato pétreo. La cristalización de las sales solubles en las pinturas pompeyanas, provoca habitualmente la pulverización, descamación y pérdida de la película pictórica.

Estos resultados son necesarios para el desarrollo de un proyecto de conservación que tendrá como eje prioritario la estabilización de los procesos de alteración y la aplicación de una estrategia de conservación preventiva fundamentada en la actuación sobre el origen del deterioro y en los factores externos al propio bien cultural (parámetros del medio ambiente, aportes de sales, etc.). Con la caracterización de los materiales constituyentes y el diagnóstico del estado de conservación, será posible establecer los tratamientos de restauración (limpieza, consolidación, protección, etc.), que se consideren más adecuados para cada caso, tanto en los procesos como en los materiales utilizados. 


\section{Procedimiento experimental}




\section{Capítulo 7. Procedimiento experimental}

7.1. Síntesis de las muestras con estequiometría de hidroxiapatita

7.2. Caracterización estructural y microestructural de las muestras preparadas

7.2.1. Difracción de rayos X (DRX)

7.2.2. Espectroscopia infrarroja por transformada de Fourier (FTIR)

7.2.3. Caracterización microestructural por microscopia electrónica de barrido de alta resolución (HR-SEM)

7.2.4. Caracterización microestructural por microscopia electrónica de transmisión de alta resolución (HR-TEM)

7.3. Caracterización de las probetas de soporte pétreo y pintura mural

7.3.1. Selección de soportes y adecuación

7.3.2. Caracterización de probetas, aplicación de las muestras preparadas y metodología de evaluación de los tratamientos de consolidación y protección

7.3.2.1. Aplicación de las muestras preparadas en probetas

7.3.2.2. Evaluación de la acción consolidante y de protección

7.4. Conclusiones 


\section{Capítulo 7. Procedimiento experimental}

En este capítulo se indican los procedimientos de preparación de las muestras con estequiometría de hidroxiapatita. A partir de los estudios preliminares se han seleccionado tres muestras con diferente grado de cristalinidad y morfología con la finalidad de determinar de como influyen estas características en los tratamientos de protección y consolidación en el soporte pétreo y en la pintura mural.

En segundo lugar se presentan los resultados sobre la caracterización estructural y microestructural de las muestras sintetizadas, así como la adecuación y caracterización de las probetas de soporte pétreo y de los fragmentos de pintura mural. Estos últimos son los necesarios para llevar a cabo la aplicación de las muestras sintetizadas y su evaluación consolidante y protectora. 


\subsection{Síntesis de las muestras con estequiometría de hidroxiapatita}

Las muestras han sido obtenidas por la ruta de precipitación química en disolución acuosa ${ }^{187,}{ }^{188}$. Se han utilizado como precursores el $\mathrm{Ca}\left(\mathrm{NO}_{3}\right)_{2} \cdot 4 \mathrm{H}_{2} \mathrm{O} 99 \%$ (Sigma-Aldrich), $\left(\mathrm{NH}_{4}\right)_{2} \mathrm{HPO}_{4} 98+\%$ (Strem Chemicals), $\mathrm{NH}_{4} \mathrm{OH}$ (ACS, Acros) y agua Mili-Q. El procedimiento experimental se resume en el diagrama de la Figura 7.1. La cantidad de reactivos utilizados se calcularon en base a la siguiente ecuación ${ }^{189}$ :

$10 \mathrm{Ca}\left(\mathrm{NO}_{3}\right)_{2}+6\left(\mathrm{NH}_{4}\right)_{2} \mathrm{HPO}_{4}+8 \mathrm{NH}_{4} \mathrm{OH} \rightarrow \mathrm{Ca}_{10}\left(\mathrm{PO}_{4}\right)_{6}(\mathrm{OH})_{2} \downarrow+20 \mathrm{NH}_{4} \mathrm{NO}_{3}+6 \mathrm{H}_{2} \mathrm{O}$

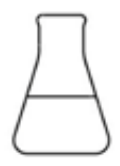

DISOLUCIÓN 1

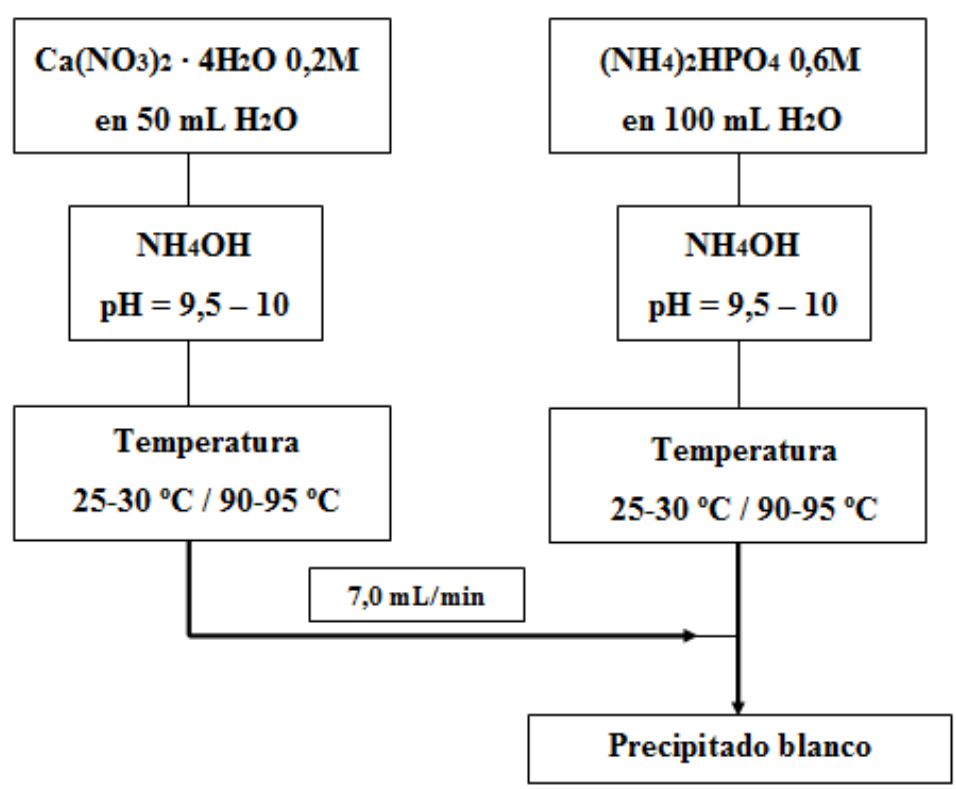

Figura 7.1. Diagrama donde se muestra la ruta de sintesis utilizada para la obtención de hidroxipatita de calcio.

\footnotetext{
${ }^{187}$ N. Kivrak, A.C. Tas, Synthesis of calcium hydroxyapatite-tricalcium phosphate composite bioceramic powders and their sintering behavior, J. Am. Ceram. Soc., 81, 2245, 1998.

${ }^{188}$ R. Rodríguez, J. Gómez, J. Torrent, T. Boix, J. Fraile, Precipitation of stoichiometric hydroxyapatite by a continuous method, Cryst Res Technol. 36(1), 15-26, 2001.

189 T.S.B. Narasaraju, D.E. Phebe, Review: Some physico-chemical aspects of hydroxylapatite, J. Mater. Sci. 31, 1-21, 1996.
} 
Como se observa en el diagrama, para la síntesis de las muestras de hidroxiapatita, se partió de dos disoluciones. La primera disolución contiene una concentración de iones calcio de 0,2M, es decir 10,00 mmol de iones $\mathrm{Ca}^{2+}$ en $50 \mathrm{~mL}$ de agua Mili-Q. El pH se ajustó a un valor de 9,5-10,0 con la adición de $\mathrm{NH}_{4} \mathrm{OH}$. Esta disolución se calentó a dos temperaturas diferentes, a $25-30{ }^{\circ} \mathrm{C}$ y a $90-95{ }^{\circ} \mathrm{C}$. Por otra parte, la segunda disolución se obtuvo a partir de la disolución de $\left(\mathrm{NH}_{4}\right)_{2} \mathrm{HPO}_{4}$ en $100 \mathrm{~mL}$ de agua Mili-Q. La molaridad resultante fue de $0,06 \mathrm{M}$. Al igual que en la disolución anterior, esta se calentó por una parte a 25 $30{ }^{\circ} \mathrm{C}$ y por otra parte a $90-95^{\circ} \mathrm{C}$.

En la Tabla 7.1 se resumen las condiciones seguidas para la preparación de las disoluciones acuosas necesarias en las síntesis de coprecipitación química de las muestras con estequiometría de hidroxiapatita.

Tabla 7.1. Condiciones experimentales seguidas para la preparación de las muestras con estequiometría de hidroxiapatita.

\begin{tabular}{|c|c|c|c|c|c|c|c|}
\hline \multicolumn{3}{|c|}{ Disolución 1 } & \multicolumn{3}{c|}{ Disolución 2 } & \multicolumn{2}{c|}{} \\
\cline { 1 - 5 }$\left[\mathbf{C a}^{2+}\right]$ & $\mathbf{p H}$ & $\mathbf{T}\left({ }^{\mathbf{0}} \mathbf{C}\right)$ & {$\left[\mathrm{HPO}_{4}{ }^{2-}\right]$} & $\mathbf{p H}$ & $\mathbf{T}\left({ }^{\mathbf{0}} \mathbf{C}\right)$ & Envejecimiento & Referencia \\
\hline 0,2 & $9,5-10,0$ & $25-30$ & 0,06 & $9,5-10,0$ & $25-30$ & $60 \mathrm{~s}$ & ACP \\
\hline 0,2 & $9,5-10,0$ & $25-30$ & 0,06 & $9,5-10,0$ & $25-30$ & $24 \mathrm{~h}$ & HA1 \\
\hline 0,2 & $9,5-10,0$ & $90-95$ & 0,06 & $9,5-10,0$ & $90-95$ & $2 \mathrm{~h}$ & HA2 \\
\hline
\end{tabular}

Las condiciones de síntesis tales como la temperatura de las disoluciones y el tiempo de envejecimiento utilizado para la obtención de las tres muestras ACP, HA1 y HA2, se eligieron en base a un estudio preliminar sobre la preparación de nanopartículas con estequiometría de hidroxiapatita por coprecipitación. En esta primera fase de estudio se establecieron las condiciones de síntesis más adecuadas para la síntesis de partículas de diferentes cristalinidad, morfología y tamaño. 
Para las disoluciones a $25-30{ }^{\circ} \mathrm{C}$, se añadió, mediante una bomba peristáltica, la disolución 2 sobre la disolución 1 a una velocidad de 7,0 $\mathrm{mL} / \mathrm{min}$ bajo constante agitación magnética a temperatura ambiente, obteniendo al finalizar la mezcla, un precipitado blanco que se dejó envejecer de dos formas diferentes:

1. En un primer caso, se dejó envejecer durante 60 seg. en agitación magnética. Sucesivamente el sólido fue purificado mediante lavado exhaustivo para eliminar los compuestos del amonio y del nitrato, dos veces con $30 \mathrm{~mL}$ de etanol y una vez con $30 \mathrm{~mL}$ de acetona por centrifugación a 6500 rpm por 5 minutos en cada centrifugado. Por último, el compuesto se secó en estufa a $80{ }^{\circ} \mathrm{C}$ durante 24 h, posteriormente se molturó para la obtención del polvo y almacenado en un vial de vidrio.

2. En el segundo caso, el precipitado se dejó envejecer durante $24 \mathrm{~h}$ en agitación magnética. Sucesivamente el sólido fue purificado mediante lavado exhaustivo para eliminar los compuestos del amonio y del nitrato, ocho veces con $120 \mathrm{~mL}$ de agua y dos veces con $100 \mathrm{~mL}$ de etanol por centrifugación a $6500 \mathrm{rpm}$, por 5 minutos en cada centrifugado. Por último, el compuesto se secó en estufa a $80^{\circ} \mathrm{C}$ por 24 h y se molturó para la obtención del polvo y almacenado en un vial de vidrio.

Para las disoluciones de $90-95^{\circ} \mathrm{C}$, se añadió, mediante una bomba peristáltica, la disolución 2 sobre la disolución 1 a una velocidad de $600 \mathrm{~mL} / \mathrm{min}$, bajo constante agitación magnética a temperatura ambiente, obteniendo un precipitado blanco que se dejó envejecer durante 2 h en agitación magnética. Sucesivamente el sólido fue purificado mediante lavado exhaustivo para eliminar los compuestos del amonio y del nitrato, ocho veces con $120 \mathrm{~mL}$ de agua y dos veces con $100 \mathrm{~mL}$ de etanol por centrifugación a 6500 rpm por 5 minutos en cada centrifugado. Por último, el compuesto se secó en estufa a $80^{\circ} \mathrm{C}$ durante 24 h y se molturó para la obtención del polvo y almacenado en un vial de vidrio. 


\subsection{Caracterización estructural y microestructural de las muestras preparadas}

Los análisis realizados a las muestras ACP, HA1 y HA2 han sido: difracción de rayos X (DRX) y espectroscopia infrarroja por transformada de Fourier (FTIR). La caracterización microestructural de los polvos sintetizados se ha realizado a través de las observaciones al SEM y TEM con microanálisis por dispersión de energía de rayos X (EDX).

\subsubsection{Difracción de rayos $X(D R X)$}

La Figura 7.2 muestra los difratogramas de las muestras sintetizadas ACP, HA1 y HA2. Como se observa en la figura, la muestra ACP presenta un difractograma de RX correspondiente a una material amorfo, mientras que la HA1 y HA2 muestran picos con diferente anchura pero bien definidos, lo que indica que se ha formado un sólido cristalino en ambos casos.

Las muestras HA1 y HA2 se han comparado con el patrón de difracción JCPDS-ICDD No. $26204^{190}$ y se puede afirmar que los picos de difracción de las muestras obtenidas se pueden atribuir a la fase hexagonal de la hidroxiapatita de calcio.

En la muestra HA2 los picos de difracción están bien definidos, lo que indica una mayor cristalinidad. En la muestra HA1, los picos de difracción resultan estar menos definidos con una tendencia a ensancharse, lo que indicaría que nos encontramos ante un material menos cristalino y con menor tamaño de partículas.

Por tanto, la temperatura y el proceso de envejecimiento durante la síntesis de las muestras influyen notablemente en las características del producto final. Una mayor cristalinidad se obtiene cuando la temperatura es de $90-95{ }^{\circ} \mathrm{C}$. Los parámetros de la ruta de síntesis permiten obtener muestras caracterizadas por una única fase cristalina, ya que no se observan otros picos de difracción.

\footnotetext{
${ }^{190}$ K. Sudarsanan, R.A. Young, Significant precision in crystal structural details: Holly springs hydroxyapatite, Acta Crystallogr. B25, 1534-1543, 1969.
} 


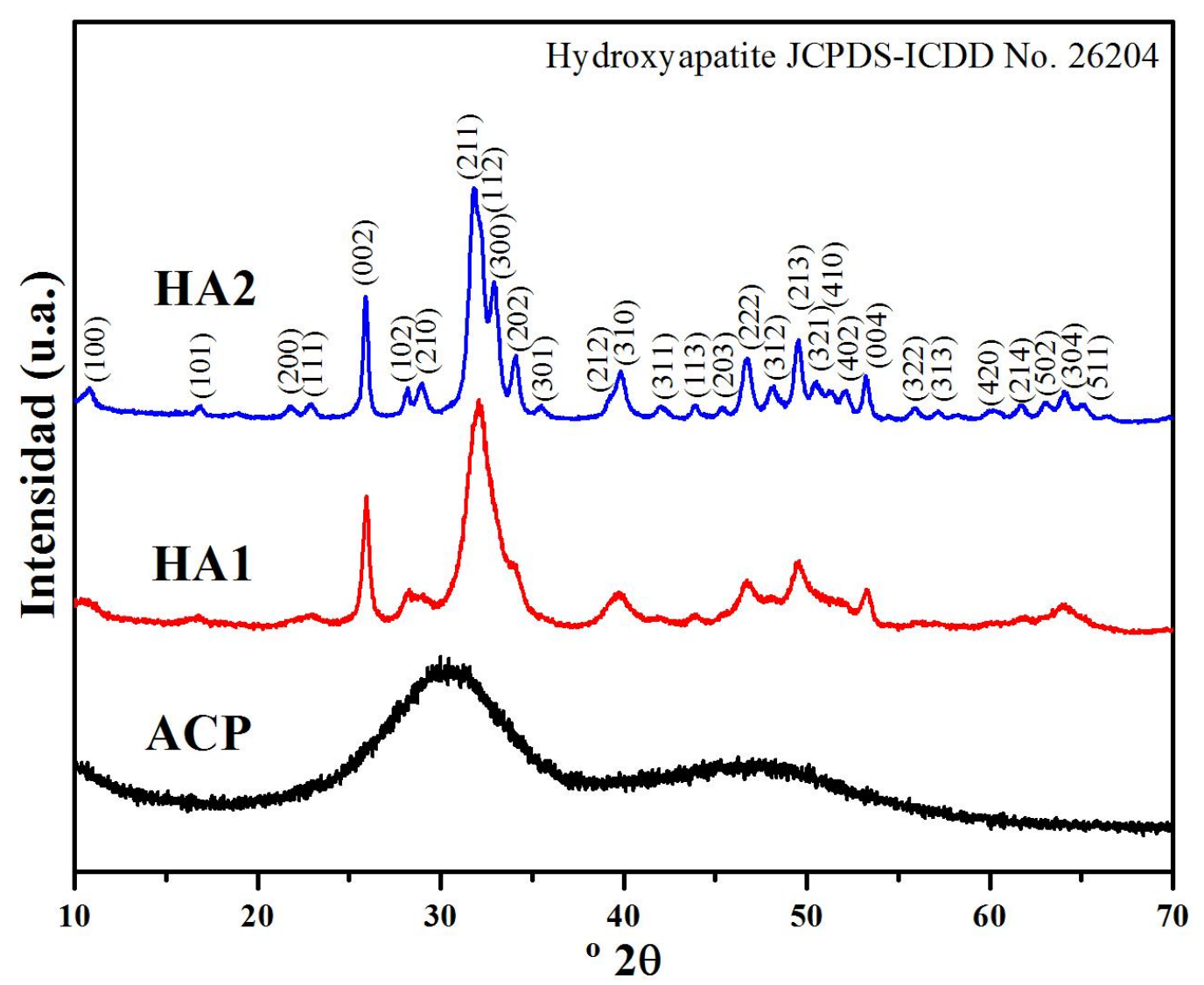

Figura 7.2. Difractogramas de rayos $\mathrm{X}$ de las muestras ACP (preparada con las disoluciones a $25-30{ }^{\circ} \mathrm{C}$ y envejecimeinto de $60 \mathrm{seg}$.), HA1 (preparadas con las disoluciones a $25-30^{\circ} \mathrm{C}$ y envejecimeinto de 24 horas) y HA2 (preparada con las disoluciones a $90-95^{\circ} \mathrm{C}$ y envejecimeinto de 2 horas). 


\subsubsection{Espectroscopia infrarroja por transformada de Fourier (FTIR)}

Los espectros FTIR de las muestras de hidroxiapatita sintetizadas con los códigos ACP, HA1 y HA2 se muestran en la Figura 7.3. En ellos se observan las principales bandas de absorción de IR que pueden ser atribuidos a los grupos funcionales de las muestras de hidroxiapatita ${ }^{191,192}$.

En las muestras preparadas con estructura no amorfa, que corresponden a las muestras preparadas HA1 y HA2 -espectros FTIR en rojo y en azul respectivamente-, se observan todas las bandas de absorción que suelen aparecer en muestras de hidroxiapatita. Se observan las bandas de $\mathrm{PO}_{4}$ a $470 \mathrm{~cm}^{-1}\left(\mathrm{v}_{2}\right)$, a 560 - 605 $\mathrm{cm}^{-1}\left(v_{4}\right)$, a $960 \mathrm{~cm}^{-1}\left(v_{1}\right)$, a $1030 \mathrm{~cm}^{-1}, 1060 \mathrm{~cm}^{-1}$ y a $1095 \mathrm{~cm}^{-1}\left(v_{3}\right)$. También se observan las bandas a $630 \mathrm{y}$ a $3570 \mathrm{~cm}^{-1}$ debidas respectivamente a los modos de vibración por deformación angular $\left(v_{\mathrm{L}}\right)$ y de estiramiento $\left(v_{\mathrm{S}}\right)$ del grupo hidroxilo $\mathrm{OH}^{193,194}$.

En la muestra amorfa ACP (espectro FTIR en negro de la Figura 7.3), las bandas de absorción de radiación infrarroja están en los mismos intervalos de longitud de onda de las muestras cristalinas. En el espectro FTIR de esta ultima muestra, las bandas detectadas en los intervalos a $900-1200 \mathrm{~cm}^{-1}$ y $550-650 \mathrm{~cm}^{-1}$ resultan ser menos definidas; este resultado confirma que el compuesto sintetizado no presenta una estructura cristalina ordenada ${ }^{195,196 .}$

\footnotetext{
${ }^{191}$ R.V. Santos, R.N. Clayton, American Mineralogist 80, 336, 1995; E. Posset, R. Lõcklin, W. Thull, J. Kiefer, Biomed Mater Res 40, 640, 1998.

${ }^{192}$ B. Mayor, J. Arias, S. Chiussi, F. García, J. Pou, B. León, M. Pérez-Amor, Thin Solid Films, 317, 363, 1998.

${ }^{193}$ D. Choi, K. Marra, P.N. Kumta, Materials Research, Bulletin 39, 417-432, 2004; W. Weng, J.L. Baptista, Journal of materials science: materials in medicine 9, 159-163, 1998.

${ }^{194}$ K. Agrawal, G. Singh, D. Puri, S. Prakash, Journal of Minerals \& Materials Characterization \& Engineering 10, (8), 727-734, 2011; S. Koutsopoulos, Biomed Mater Res, 62, 600-12, 2002.

195 N. Pleshko, A. Boskey, R. Mendelsohn, Novel infrared spectroscopic method for the determination of crystallinity of hydroxyapatite minerals, Biophysical Journal, Vol. 60, 786-793, 1991.

${ }^{196}$ E.D. Eanes, I.H. Gillessen, A.S. Posner, Intermediate states in the precipitation of hydroxyapatite, Nature, 208:365-7, 1965.
} 


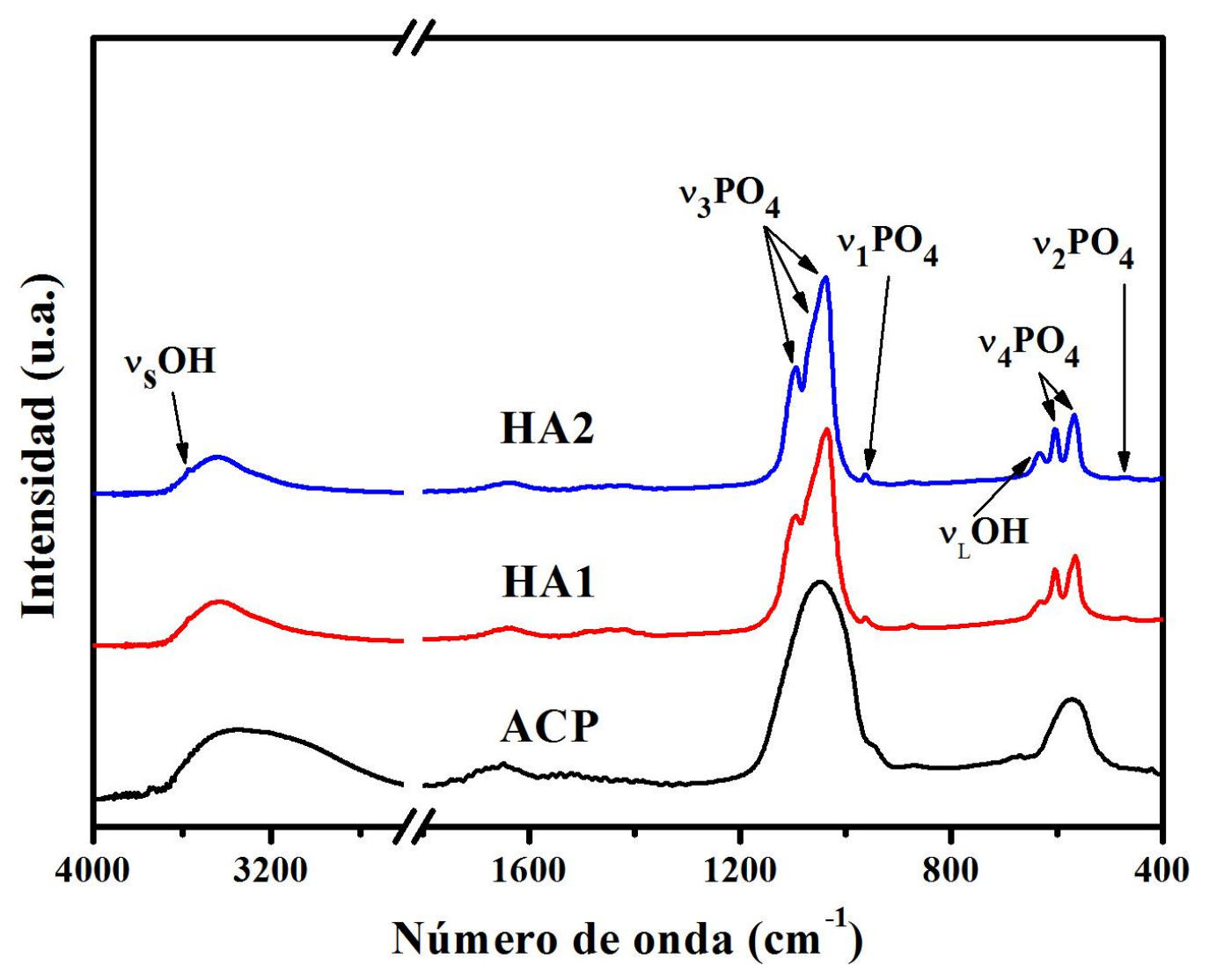

Figura 7.3. Espectros de infrarrojos de las muestras ACP (preparada con las disoluciones a $25-30^{\circ} \mathrm{C}$ y envejecimeinto de 60 seg.), HA1 (preparadas con las disoluciones a $25-30^{\circ} \mathrm{C}$ y envejecimeinto de 24 horas) y HA2 (preparada con las disoluciones a $90-95^{\circ} \mathrm{C}$ y envejecimeinto de 2 horas). 


\subsubsection{Caracterización microestructural por microscopia electrónica de barrido de alta resolución (HR-SEM)}

En la Figura 7.4 se representan las micrografías obtenidas al SEM de las muestras ACP, HA1 y HA2. En ellas se pueden observar pequeños cambios morfológicos de las partículas dependiendo de las condiciones de síntesis utilizada. Para la muestra ACP (Figura 7.4 A), las partículas que forman los agregados no presentan una morfología bien definida. En las micrografías SEM de la Figura 7.4 B y 7.4 C, se muestran la morfología de los polvos de las muestras de hidroxiapatita HA1 y HA2 respectivamente. En ambas síntesis se han obtenido partículas que exhiben morfologías ligeramente distintas. Se aprecia, en general, la aglomeración de las partículas de manera más acentuada en la muestra HA1. En la muestra HA2 se percibe la formación de partículas de forma alargada o acicular, más definidas e igual que en las muestras anteriores, todas de dimensiones nanométricas. Por tanto, podríamos afirmar que un incremento de la temperatura durante la fase de la síntesis permite un crecimiento de las partículas con una morfología más definida en forma acicular, manteniendo el tamaño nanométrico.
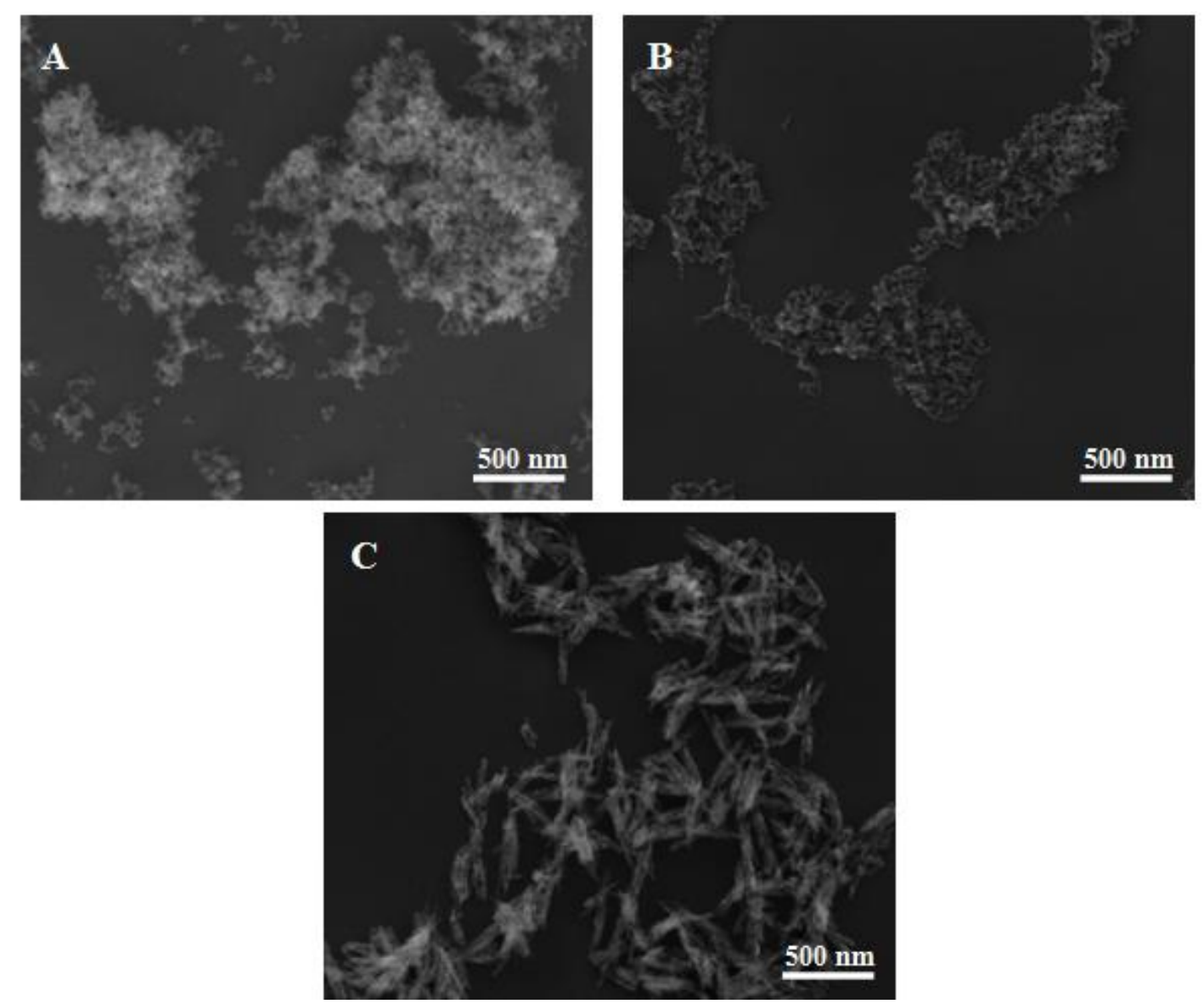

Figura 7.4. Imágenes SEM en modalidad electrones secundarios del polvo sintetizado ACP (A), HA1 (B) y HA2 (C). 


\subsubsection{Caracterización microestructural por microscopia electrónica de transmisión de alta resolución (HR-TEM)}

Las dos muestras que presentan la fase hidroxiapatita por DRX (muestras HA1 y HA2) y la muestra amorfa (ACP) han sido estudiadas mediante microscopia electrónica de transmisión de alta resolución con el fin de poder realizar una descripción exacta de la microestructura.

Para la muestra ACP, los principales resultados del estudio se muestran en la Figura 7.5. A partir de las micrografías TEM se aprecian unas nanopartículas de morfología esferoidal con un tamaño medio de $26 \mathrm{~nm}$, como puede observarse en la imagen situada en el vértice superior derecho de la figura.

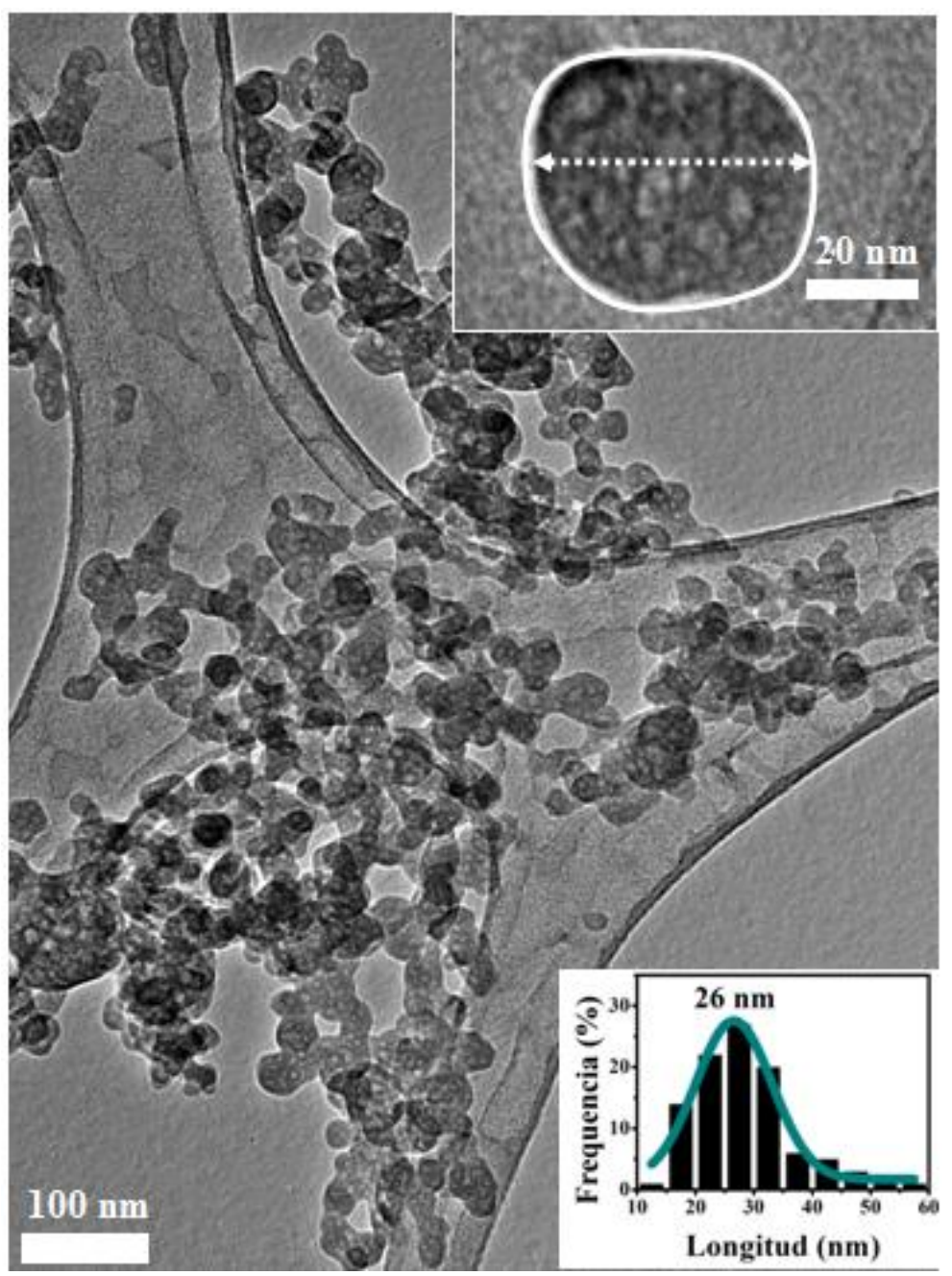

Figura 7.5. Imagen por TEM donde se observan las nanopartículas sintetizadas de la muestra ACP de forma esferoidal. Se observa como la distribución del tamaño de las partículas indica a una valor medio de $26 \mathrm{~nm}$. 
A partir de la difracción de electrones (SAED) se advierte que la muestra ACP carece de planos cristalográficos definidos, obteniendo un patrón de difracción con anillos de reflexión típico de un material amorfo como se muestra en la Figura 7.6 A.

La composición química de las partículas determinada mediante microanálisis EDX se muestra en el espectro de la Figura 7.6 B. A partir de esta técnica no es posible determinar con precisión la relación molar $\mathrm{Ca} / \mathrm{P}$. A pesar de esto, en base a las cantidades de los elementos detectados por EDX la relación molar Ca/P es de 1,27 . Este valor se encuentra dentro del intervalo de valores teóricos de las relaciones $\mathrm{Ca} / \mathrm{P}$ de la hidroxiapatita de calcio con estructura amorfa de 1,2 - 2,2 documentado en la bibliografía consultada ${ }^{197,198}$.

En base a los resultados TEM, junto con el de XRD, se puede confirmar que el material examinado se caracteriza por la ausencia de orden cristalino a largo alcance.
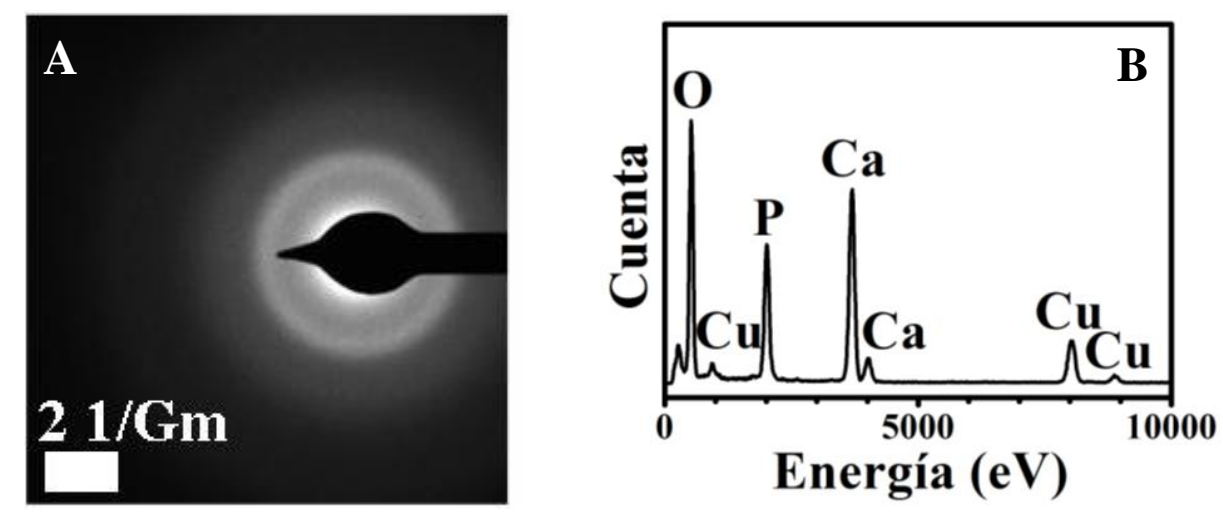

Figura 7.6. A) Patrón de difracción de electrones de la muestra ACP donde se observan anillos de difracción correspondiente a un compuesto amorfo. B) Microanálisis general de la muestra.

Los resultados del estudio TEM de la muestra HA1 se detallan en la Figura 7.7. En estas imágenes se observan nanopartículas con morfología alargadas con extremos redondeados. En la distribución de tamaño de partícula que se ha calculado estadísticamente, se ha obtenido una longitud media de $21 \mathrm{~nm}$ y un diámetro medio de $10 \mathrm{~nm}$. Tanto la morfología como el tamaño de partícula se pueden apreciar en la micrografía del vértice superior derecho de la Figura 7.7.

\footnotetext{
${ }^{197}$ B. León, J.A. Jansen, Thin Calcium Phosphate Coatings for Medical Implants, Springer Science + Business Media, LLC, 26, 2009.

${ }^{198}$ U. Vijayalakshmi Natarajan, S. Rajeswari, Influence of calcium precursors on the morphology and crystallinity of sol-gel derived hydroxyapatite nanoparticles, Journal of Crystal Growth, Vol. 310, 4601-4611, 2008.
} 
Con difracción de electrones sobre el área seleccionada (SAED) se ha obtenido el patrón de difracción como se muestra en Figura 7.8 A. Los anillos corresponden a las reflexiones por parte de los siguientes planos cristalográficos (200) y (002) de la fase hidroxiapatita. Los picos de difracción están relacionados con la fase de la hidroxiapatita hexagonal con grupo espacial $P 6_{3} / m$ : JCPDS-ICDD N ${ }^{\circ} .26204^{199,} 200$.

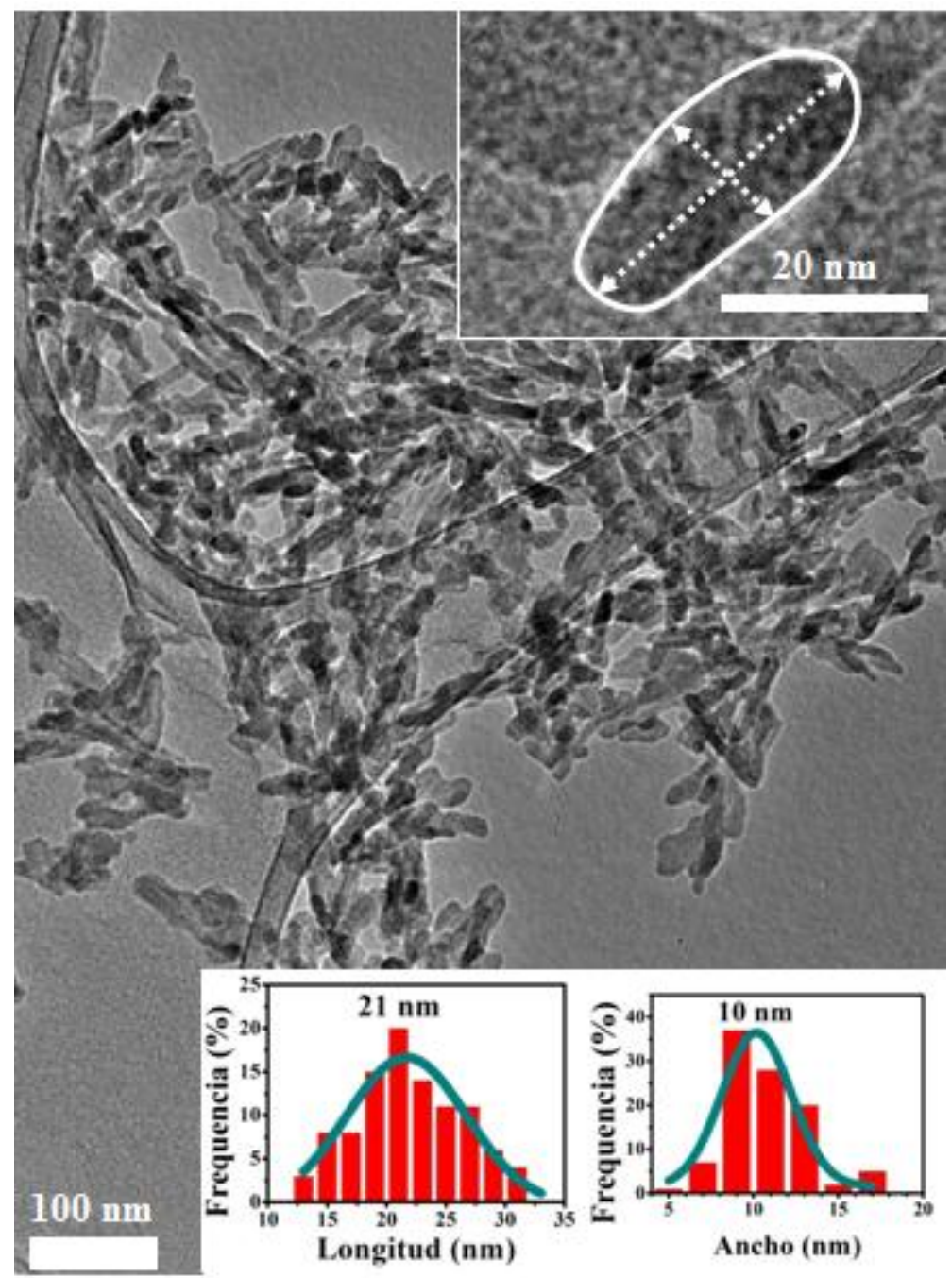

Figura 7.7. Micrografía TEM donde se observan las nanopartículas sintetizadas de la muestra HA1 con la distribución estadística del tamaño de partículas.

\footnotetext{
${ }^{199}$ J. Ryu, S. H. Ku, H. Lee, C. B. Park, Adv. Funct. Mater, 20, 2132-2139, 2010.

${ }^{200}$ K. Sudarsanan, R.A. Young, Significant Precision in Crystal Structural Details: Holly Springs Hydroxyapatite, Acta Cryst., B25, 1534-1543, 1969.
} 
El microanálisis EDX -Figura $7.8 \mathrm{~B}$ - indica una relación molar $\mathrm{Ca} / \mathrm{P}$ de 1,57 . Este valor se acerca a la relación $\mathrm{Ca} / \mathrm{P}$ teórica de 1,67 de la hidroxiapatita estequiométrica.
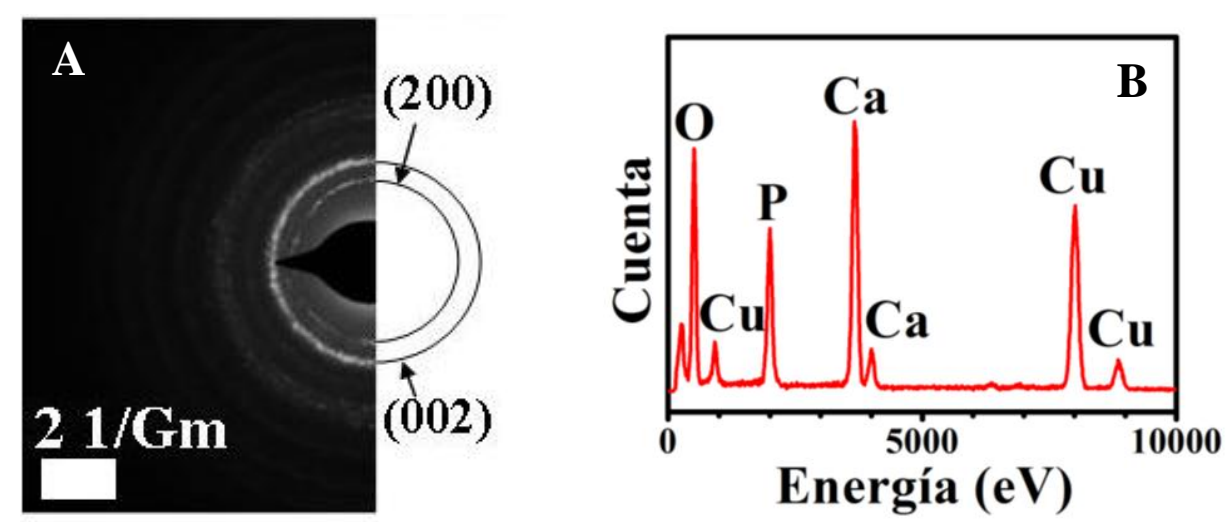

Figura 7.8. A) Patrón de difracción de electrones de la muestra HA1 donde se observan anillos de difracción correspondiente a un compuesto cristalino. B) Microanálisis general de la muestra.

Por último, la observación por TEM para la muestra HA2 se presentan en la Figura 7.9. La morfología de las partículas resulta ser alargada con una longitud media de $28 \mathrm{~nm}$ y un diámetro medio de $15 \mathrm{~nm}$. Se confirma la presencia de hidroxiapatita de calcio a través del patrón de difracción de electrones donde se repite la familia de planos cristalográficos (200) y (002), como se muestra en la Figura 7.10 A.

El microanálisis de la Figura 7.10 B muestra también para este compuesto una relación Ca/P de 1,67. Este resultado indicaría como la síntesis de hidroxiapatita a altas temperaturas $\left(90-95{ }^{\circ} \mathrm{C}\right)$ favorece la formación de un compuesto caracterizado por nanopartículas cristalinas, con un tamaño ligeramente mayor respecto a las partículas sintetizadas a $25-30{ }^{\circ} \mathrm{C}$. 


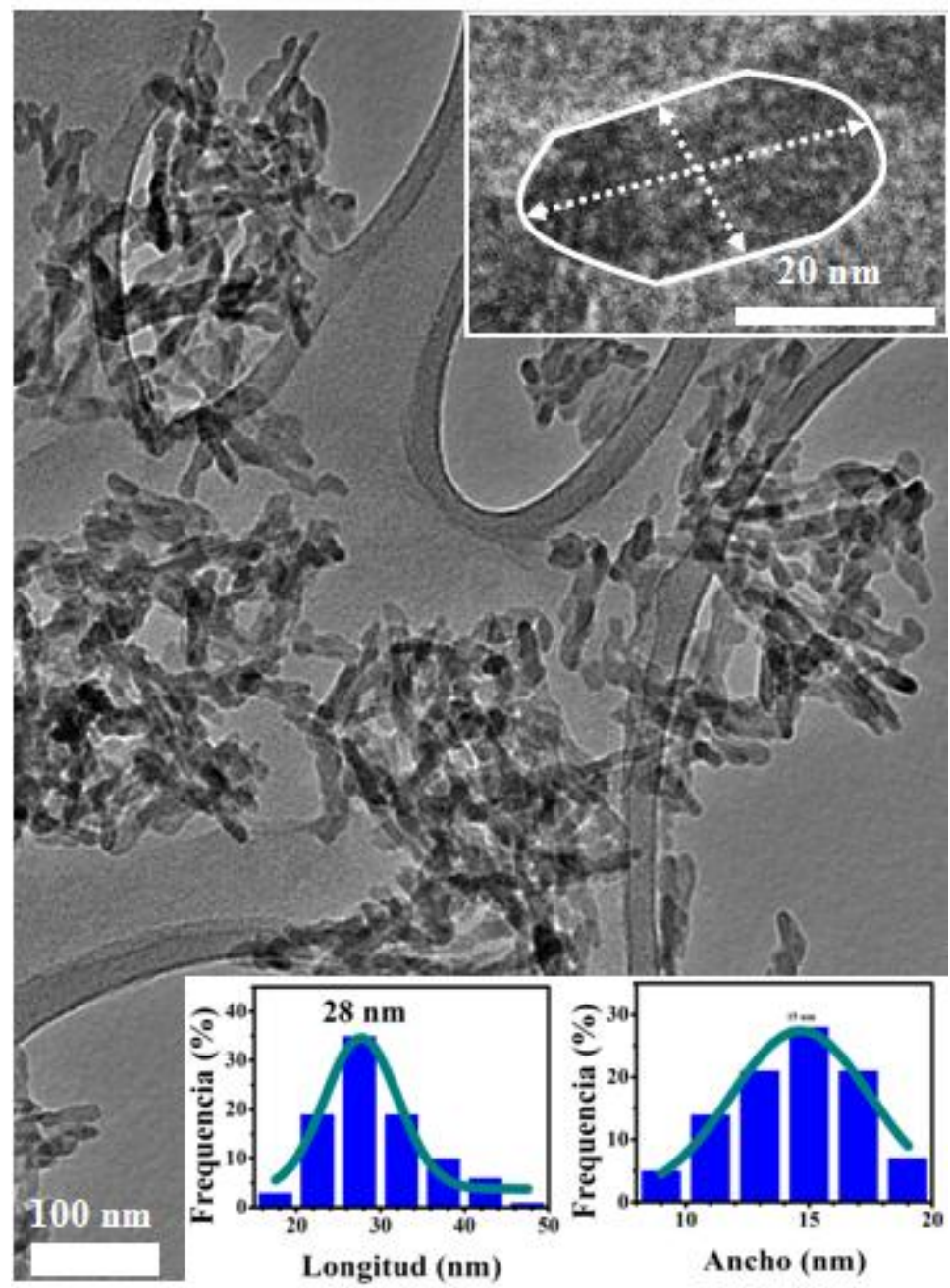

Figura 7.9. Micrografía TEM donde se observan las nanopartículas sintetizadas de la muestra HA2 con la distribución estadística del tamaño de partículas.
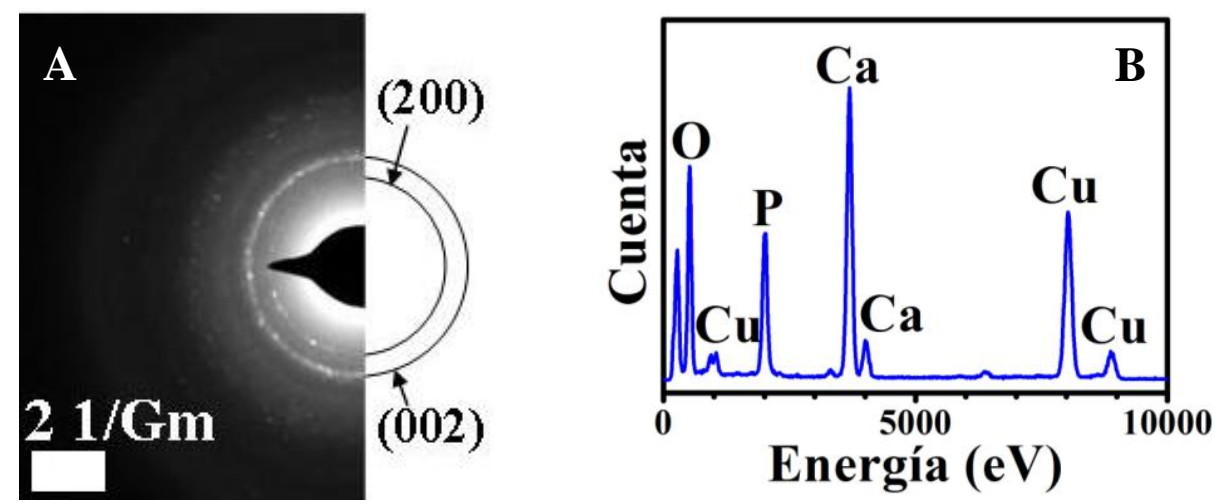

Figura 7.10. A) Patrón de difracción de electrones de la muestra HA2 donde se observan anillos de difracción correspondiente a un compuesto cristalino. B) Microanálisis general de la muestra. 


\subsection{Caracterización de las probetas de soporte pétreo y pintura mural}

La evaluación de las muestras preparadas con diferente grado de cristalinidad y morfología se ha realizado tras la aplicación de dispersiones acuosas de las muestras en polvo en probetas de soporte pétreo y fragmento de pintura mural. Tanto las probetas como el fragmento han sido caracterizados previamente a la aplicación de las dispersiones de las muestras sintetizadas. Esta fase de estudio proporcionará resultados que permitirán valorar la acción y la eficacia de los tratamientos de consolidación y de protección de los nuevos materiales experimentales en comparación con los productos comerciales actualmente en uso o en proceso de investigación.

\subsubsection{Selección de soportes y adecuación}

Dentro de esta tarea se seleccionaron los distintos soportes para el desarrollo del estudio. Estas probetas han sido las suficientes para llevar a cabo todos los ensayos y la evaluación de los productos a ensayar. Se han tenido en cuenta los distintos formatos necesarios para cada una de las técnicas analíticas que se han utilizado en el desarrollo del estudio. La preparación y caracterización de las probetas se ha basado en los protocolos establecidos por las normativas italianas sobre bienes culturales UNI y Raccomandazioni NorMal, las normativas españolas UNE-AENOR y las indicaciones dictadas por publicaciones científicas editadas por instituciones que operan en el sector de la conservación de bienes culturales.

Las probetas de soporte pétreo se han obtenido de fragmentos de un sillar procedente de la portada principal de la Iglesia de Nuestra Asunción de Corral de Almaguer (Toledo). Los fragmentos se cortaron en placas con diferentes espesores (de $5 \mathrm{~mm}$ y $10 \mathrm{~mm}$ ), a partir de las cuales se troquelaron probetas de 10x10x5 mm para los estudios al SEM-EDX, colorimetría y FTIR. Igualmente, a partir de estas mismas placas, se prepararon probetas de 10x10x10 mm para medidas de absorción de agua por capilaridad y para las medidas de perfilometría. En las imágenes de la Figura 7.11 se muestran las probetas preparadas.

En cuanto a las probetas de pintura mural, estas corresponden exactamente a un fragmento que pertenece a las decoraciones parietales de la Casa de Ariadna en Pompeya (Italia). El fragmento se encontró durante las excavaciones arqueológicas y los trabajos de estudio y restauración realizados por parte de la Sección de Arqueología Municipal del Ayuntamiento de Valencia y el Instituto Valenciano de Conservación, Restauración e Investigación (IVCR+i). Para la evaluación de la aplicabilidad y de la acción consolidante y de protección superficial por parte de las muestras de hidroxiapatita, se decidió utilizar directamente este 
fragmento de pintura mural, ya que resulta sumamente provechoso para los estudios de investigación de laboratorio por ser representativo para técnica de realización y procesos de alteración. En la imagen de la Figura 7.12 se muestra el fragmento de pintura mural utilizado para el desarrollo de la investigación.
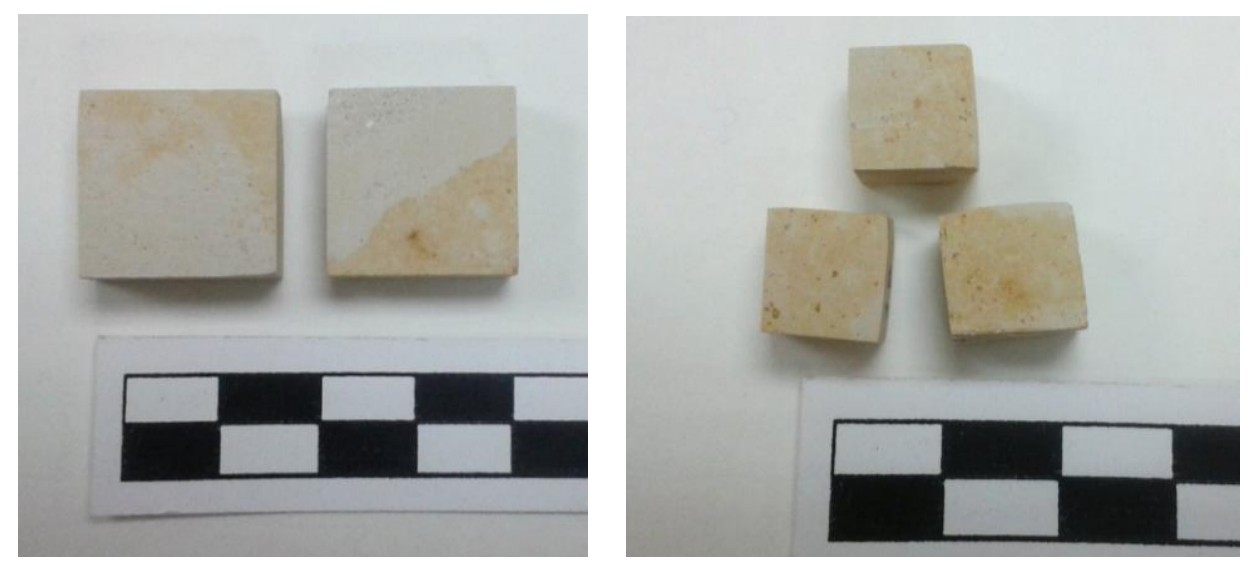

Figura 7.11. Probetas de soporte pétreo de dolomía utilizadas en la evaluación de los tratamientos de consolidación y protección con las tres muestras preparadas.

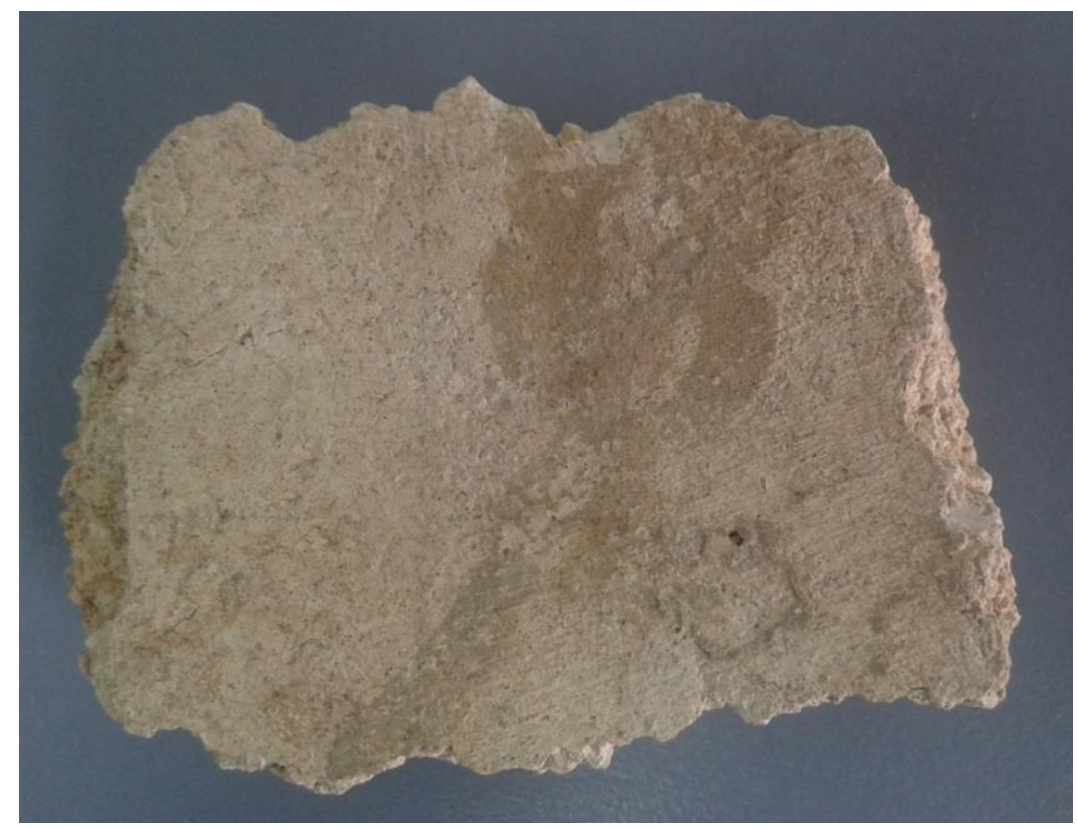

Figura 7.12. Fragmento de pintura mural del siglo I d.C. procedente de la Casa de Ariadna en Pompeya utilizado en la evaluación de la acción consolidante y protectora de las muestras con estequiometría de hidroxipatita. 


\subsubsection{Caracterización de probetas, aplicación de las muestras preparadas y metodología de evaluación de los tratamientos de consolidación y protección}

Antes de la aplicación en las probetas de las diferentes dispersiones acuosas de las muestras preparadas (ACP, HA1 y HA2), se realizó un primer estudio superficial y en corte transversal del sustrato pétreo y del fragmento de pintura mural con las técnicas de microscopia estereoscópica (ME), microscopía óptica (MO) y microscopia electrónica de barrido a presión variable (VP-SEM) donde la modalidad presión variable permite observar la misma superficie en diferentes tiempos, sin la necesidad de prepararla previamente con el sombreado de platino o grafito. El estudio en sección transversal ha necesitado de una preparación previa de las probetas y de los fragmentos que han sido incluidos en resina poliéster, cortados transversalmente y pulidos. Esta preparación permite obtener una superficie perfectamente lisa, para ser observada y estudiada con las técnicas de MO y SEM-EDX.

En esta primera etapa también se realizó microanálisis (EDX), análisis de espectroscopia infrarroja por transformada de Fourier (FTIR) y medidas de las coordenadas colorimétricas de las superficies. En el caso de las probetas de soporte pétreo se ha incluyó la medida de absorción de agua por capilaridad, la determinación de la permeabilidad al vapor de agua y la medida de rugosidad. Esta fase fue necesaria para caracterizar la naturaleza química y mineralógica de los sustratos, observando las características morfológicas de las superficies, así como estudiando el sistema poroso de cada sustrato y determinando sus propiedades físicas y ópticas (absorción de agua, color, etc.).

Los resultados de los estudios de caracterización de las probetas se describen en detalle en el Capítulo 6, en caracterización de los materiales de la portada principal de la Iglesia de Nuestra Señora de la Asunción de Corral de Almaguer y de los fragmentos de pintura mural procedente de la Casa de Ariadna en Pompeya.

\subsubsection{Aplicación de las muestras preparadas en probetas}

Las muestras preparadas se dispersaron con una concentración del $0,5 \%$ en peso en agua mili-Q $(0,03 \mu \mathrm{S}$ a $18,5^{\circ} \mathrm{C}$ ) homogeneizando con ultrasonido durante 30 minutos. La aplicación se realizó con un pincel, aplicando $35 \mu 1 \mathrm{x} \mathrm{cm}^{2}$ de cada dispersión sobre la superficie de la probeta de piedra y del fragmento de pintura mural. 
La aplicación de las dispersiones acuosas se realizó mediante una metodología habitual de intervención para productos consolidantes y protectores sobre soporte pétreo ${ }^{201,202}$. En cuanto a los métodos de aplicación, existen diferentes opciones para proceder a la introducción de los productos consolidantes en el interior de los materiales que se quieren conservar. Para seleccionar la técnica más adecuada es necesario valorar diversos factores como las dimensiones, su estado de conservación, tratamientos de carácter puntual o generalizado. Después del tratamiento, las probetas de piedra y del fragmento de pintura mural se depositaron dentro de una cámara climática Climacell Komfort-line, en condiciones controladas durante 72 horas a $60 \pm 5 \% \mathrm{HR}$ y $23 \pm 2{ }^{\circ} \mathrm{C}$ antes de realizar los estudios de evaluación. Las cámaras Climacell cuentan con un sistema de control de las condiciones termo-higrométricas por microprocesador múltiple y programa Fuzzy-Logic.

Es aconsejable dejar el tiempo suficiente para el secado después de la aplicación de las disoluciones acuosas, con el objeto de que tenga lugar la evaporación del agua. La duración de esta etapa depende, en parte, de la volatilidad del disolvente que se emplee, la cual no debe ser excesiva para que el producto activo tenga tiempo de precipitar y fijarse sobre los granos de la piedra o mortero y no retorne hacia la superficie. El curado puede realizarse en condiciones de temperatura y humedad relativa controladas y constantes, de forma que se pueda reproducir el proceso. Es conveniente que la temperatura no sea muy elevada para que el secado no sea excesivamente rápido.

\subsubsection{Evaluación de la acción consolidante y de protección de las muestras preparadas}

En esta fase se pretende la obtención de resultados para valorar la eficacia de los distintos tratamientos de consolidación de los materiales aplicados, mediante la variación de las diferentes propiedades observadas y caracterizadas antes y después de la aplicación en las probetas.

Se han evaluado variables como penetrabilidad, reactividad, estabilidad y efectividad, con especial hincapié en la determinación de la porosidad de las piezas y la modificación de las mismas con la aplicación de los diferentes productos, así como la cuantificación de la modificación de las capacidades de adsorber agua y las variaciones de adhesión-coeshion entre los constituyentes. Asimismo, se han registrado las variaciones de las

\footnotetext{
201 AA.VV., Técnicas de consolidación en pintura mural, Actas del Seminario I Internacional sobre Consolidación DE Pinturas Murales (19-20 Agosto 1998)”. Aguilar del Campo (Palencia). Fund. Santa María La Real. Centro de Estudios del Románico, 1998.

202 AA.VV., Criterios de Intervención en Materiales Pétreos, Bienes Culturales, Revista del Instituto del Patrimonio Histórico Español. N 2, 2003.
} 
propiedades estéticas superficiales como el cambio de las coordenadas coolorimetricas, morfología y rugosidad.

En lineas generales, el trabajo se ha desarrollado siguiendo los protocolos establecidos por las normativas italianas sobre bienes culturales UNI y Raccomandazioni NorMal, las normativas españolas UNE-AENOR y las indicaciones dictadas por publicaciones científicas editadas por instituciones que operan en el sector de la conservación de bienes culturales, entre los cuales destacan:

- UNI 10921:2001 Beni culturali - Materiali lapidei naturali ed artificiali - Prodotti idrorepellenti Applicazione su provini e determinazione in laboratorio delle loro caratteristiche.

- Evaluación de los cambios de las coordenadas colorimetricas y de brillo de las superficies tratadas. Norma de referencia: UNI EN 15886:2010 Conservazione dei Beni Culturali - Metodi di prova Misura del colore delle superfici.

- Ensayos de determinación de la porosidad y distribución de tamaño de poro. Para ello se ha utilizado la técnica de microscopia electronica de barrido mediante observaciones en superficie y en corte trasnversal, determinando las modificaciones de la porosidad y su distribución. Normas de referencia que ha sido adaptada al presente estudio:

- UNE-EN1936:2007 Métodos de ensayo para piedra natural. Determinación de la densidad real y aparente y de la porosidad abierta y total.

- Ensayos de adsorción/desorción de agua y determinación de la permeabilidad al vapor de agua. Normas de referencia:

- UNI EN 15801:2010 Conservazione dei beni culturali - Metodi di prova - Determinazione dell'assorbimento dell'acqua per capillarità.

- $\quad$ UNI EN 1015-19:2008 Metodi di prova per malte per opere murarie - Parte 19: Determinazione della permeabilità al vapore d'acqua delle malte da intonaco indurite.

- UNI EN ISO 7783-2:2011 Paints and varnishes - Determination of water-vapour transmission properties - Cup method.

- DIN 52615 Testing of thermal insulating materials; determination of water vapour (moisture) permeability of construction and insulating materials.

- Evaluación de los cambios de textura de las superficies tratadas mediante la determinación de la forma de depósito de los productos aplicados, generación de subproductos, etc. El estudio se ha 
realizado mediante diferentes tecnicas instrumentales como la microscopia estereoscopica, SEMEDX, FTIR. Norma de referencia que ha sido adaptada al presente estudio:

- UNE EN16140:2011 Métodos de ensayo para la piedra natural. Determinación de la sensibilidad a los cambios en la apariencia producida por ciclos térmicos.

- Evaluación sobre la penetración de los productos aplicados en las probetas. El estudio se ha realizado mediante la microscopia electronica de barrido con microanalisis SEM-EDX a través de observaciones en modalidad BSE y microanalisis EDX en corte transversal.

- Evaluación sobre la capacidad de protección superficial de los consolidantes aplicados en las probetas. El estudio se ha realizado mediante diferentes tecnicas como la microscopia electronica de barrido con microanalisis SEM-EDX o espectroscopìa FTIR, a través de observaciones y analisis químicos superficiales.

En el desarrollo de este estudio se ha descartado la valoración sobre la variación de las propriedades mecánicas del material pétreo y de la pintura mural antes y después de la aplicación de los tratamientos. En general, los tratamientos de consolidación y protección resultan tener una acción muy superficial, con una penetración en los poroso de algunos centerares de micras. Estos tratamientos no provocarían cambios tan altos como para poder ser registrados y evaluados mediante ensayos de resistencia de los materiales con ensayos mecánicos normalizados.

En líneas generales, el estudio de evaluación ha seguido el protocolo de trabajo tal y como se ha mostrado en el Capítulo 3: La aplicación científica aplicada al estudio de bienes culturales: Caracterización de materiales, diagnosis del estado de conservación y evaluación de los tratamientos de restauración.

Se efectuó un primer estudio sobre la evaluación de la aplicabilidad y de la acción consolidante y protectora por parte de las dispersiones acuosas de las muestras preparadas, comparando la misma superficie pétrea y de pintura mural antes y después de la aplicación de cada producto. Este tipo de estudio ha sido posible mediante la observación por microscopia electrónica de barrido a presión variable VP-SEM, ya que permite observar la misma superficie en diferentes tiempos, sin la necesidad de prepararla previamente con el sombreado de platino o grafito. Se continuó con el estudio de las muestras por SEM-EDX sobre un corte transversal de las probetas necesario para valorar la penetración de los productos aplicados en los poros del sustrato tratado. En la evaluación del tratamiento en corte transversal, se ha necesitado de una preparación previa de las probetas, que han sido incluidas en resina poliéster, cortadas transversalmente y pulidas. Esta preparación nos permite obtener una superficie perfectamente lisa para ser observada y estudiada con 
microanálisis EDX con el fin de detectar la distribución del fósforo $(\mathrm{P})$ desde la superficie hasta el interior de la estructura del soporte pétreo o de la pintura mural. Sucesivamente, el estudio continúa con la valoración del cambio de otras propiedades tal como la absorción de agua por capilaridad, la variación de la rugosidad superficial y la medida de la variación del color de la superficie tratada.

En conjunto, el trabajo descrito tiene la finalidad de corroborar la viabilidad de las muestras de hidroxiapatita en los tratamientos de consolidación y protección de soportes pétreos o en pintura mural. Este resultado se alcanza a través de una serie de objetivos secundarios que se describen a continuación:

- Verificar la distribución del producto objeto de análisis sobre la superficie y en el interior de la estructura del soporte.

- Estudiar la compatibilidad química entre producto aplicado y soporte.

- Estudiar como la morfología y el tamaño de las muestras preparadas influyen en el tratamiento de consolidación y protección del soporte pétreo y pintura mural.

- Verificar los cambios de las propiedades ópticas del material tratado como la variación de las coordenadas colorimétricas y la variación de los parámetros de rugosidad.

- Verificar los cambios de las propiedades físicas del material tratado como la variación de absorción de agua por capilaridad, rugosidad, etc. 


\subsection{Conclusiones}

Las conclusiones procedentes de los estudios realizados en este capítulo se enumeran a continuación:

- La ruta de síntesis de coprecipitación introducida en el Capítulo 4 se ha aplicado para obtener muestras con potencial uso como material consolidante y protector. Aportando pequeñas modificaciones en la metodología de síntesis empleada $-\mathrm{T}^{\mathrm{o}}$ y tiempo de curado- se han obtenido nanopartículas de diferente grado de cristalinidad y morfología, corroborado a partir de DRX, FTIR, HR-SEM y HR-TEM.

- Las muestras sintetizadas con estequiometría de hidroxiapatita se han dispersadas en agua y han sido aplicadas sobre probetas de soporte pétreo y fragmento de pintura mural, previamente caracterizados. Asimismo se ha desarrollado una metodología de estudio para evaluar la aplicabilidad y la eficacia del tratamiento de consolidación y protección por parte de las muestras preparadas mediante técnicas tales como MO, VP-SEM, EDX, FTIR o ensayos necesarios para verificar los cambios de las propiedades físicas del material tratado como la variación de absorción de agua por capilaridad, rugosidad, etc. 
Evaluación de los tratamientos de consolidación y protección en soporte pétreo 


\section{Capítulo 8. Evaluación de los tratamientos de consolidación y protección en soporte pétreo}

\subsection{Introducción}

8.2. Evaluación en probetas de soporte pétreo sin alteración

8.2.1. Evaluación del tratamiento con fosfato de calcio amorfo: muestra ACP

8.2.1.1. Evaluación del tratamiento en superficie

8.2.1.2. Evaluación del tratamiento en corte transversal

8.2.1.3. Estudio de espectroscopia infrarroja por transformada de Fourier (FTIR)

8.2.2. Evaluación del tratamiento con hidroxiapatita cristalina: muestra HA1

8.2.2.1. Evaluación del tratamiento en superficie

8.2.2.2. Evaluación del tratamiento en corte transversal

8.2.2.3. Estudio de espectroscopia infrarroja (FTIR)

8.2.3. Evaluación del tratamiento con hidroxiapatita con alta cristalinidad: muestra HA2

8.2.3.1. Evaluación del tratamiento en superficie

8.2.3.2. Evaluación del tratamiento en corte transversal

8.2.3.3. Estudio de espectroscopia infrarroja por transformada de Fourier (FTIR)

\subsubsection{Colorimetría}

8.2.5. Perfilometría

8.2.6. Estudio de absorción de agua por capilaridad

8.2.7. Estudio de la determinación de la permeabilidad al vapor de agua

8.3. Evaluación de la hidroxiapatita HA2 sobre soporte pétreo con alteración

8.3.1. Estudio de microscopia electrónica de barrido a presion variable (VP-SEM) con microanálisis EDX

8.3.2. Estudio de espectroscopia infrarroja por transformada de Fourier (FTIR)

8.4. Conclusiones 


\section{Capítulo 8. Evaluación de los tratamientos de consolidación y protección en soporte pétreo}

En este capítulo se muestran los resultados referentes a la valoración de la acción de consolidación y protección en soporte pétreo sin alteración con las muestras sintetizadas con diferente grado de cristalinidad y morfología. En primer lugar se presentan los resultados de microscopia electrónica de barrido sobre los cambios en las características superficiales y en la penetración en las probetas de piedra tras el tratamiento. En segundo lugar, se muestran los análisis obtenidos por espectroscopia infrarroja por transformada de Fourier (FTIR). Seguidamente se detallan los resultados de la variación de las propiedades físicas con los ensayos de absorción de agua por capilaridad, el estudio de la rugosidad superficial y las medidas de las coordenadas colorimétricas, calculando la variación de color.

Este capítulo concluye con una segunda fase de estudio, donde se ha incorporado a una probeta de soporte pétreo alterado por sulfatación, la muestra sintetizada que mejor resultado ha proporcionado en la primera fase de evaluación. Se presentan, en este caso, los resultados del estudio de microscopia electrónica de barrido a presión variable (VP-SEM) con microanálisis EDX y de espectroscopia infrarroja por transformada de Fourier (FTIR). 


\subsection{Introducción}

Los compuestos con estequiometría de hidroxiapatita anteriormente caracterizados, corresponden a las muestras sintetizadas con el código:

ACP: fosfato de calcio amorfo

HA1: hidroxiapatita caracterizada por una de baja cristalinidad

HA2: hidroxiapatita caracterizada por una alta cristalinidad

La evaluación se realizó con las probetas de soporte pétreo sin alteración obtenidas de un sillar procedente de la portada de la Iglesia de Nuestra Señora de la Asunción de Corral de Almaguer (Toledo). La caracterización y adecuación de las probetas pétreas se ha descrito en el Capítulo 7. En una segunda fase de estudio, se ha aplicado la muestra de hidroxiapatita que mejor resultado ha proporcionado en un fragmento pétreo alterado por sulfatación. 


\subsection{Evaluación en probetas de soporte pétreo sin alteración}

\subsubsection{Evaluación del tratamiento con la muestra ACP}

En este apartado se muestran los resultados de los estudios sobre la acción consolidante y protectora de la dispersión acuosa de la muestra ACP, correspondiente a la muestra que por DRX presentaba características amorfas.

\subsubsection{Evaluación del tratamiento en superficie}

En las imágenes de la Figura 8.1 hay una primera valoración con las observaciones por microscopia estereoscópica de la superficie del sustrato pétreo antes del tratamiento (imagen A) y después del tratamiento con la muestra ACP (imagen B) aplicada según la modalidad descrita en el Capítulo 7. Se observa un pequeño cambio en las características superficiales del soporte pétreo con la formación de un ligero depósito del producto aplicado formando un velo blanquecino. A nivel microscópico no se detecta algún cambio importante en la textura del soporte pétreo después de la aplicación de la dispersión acuosa de la muestra de fosfato de calcio amorfo.
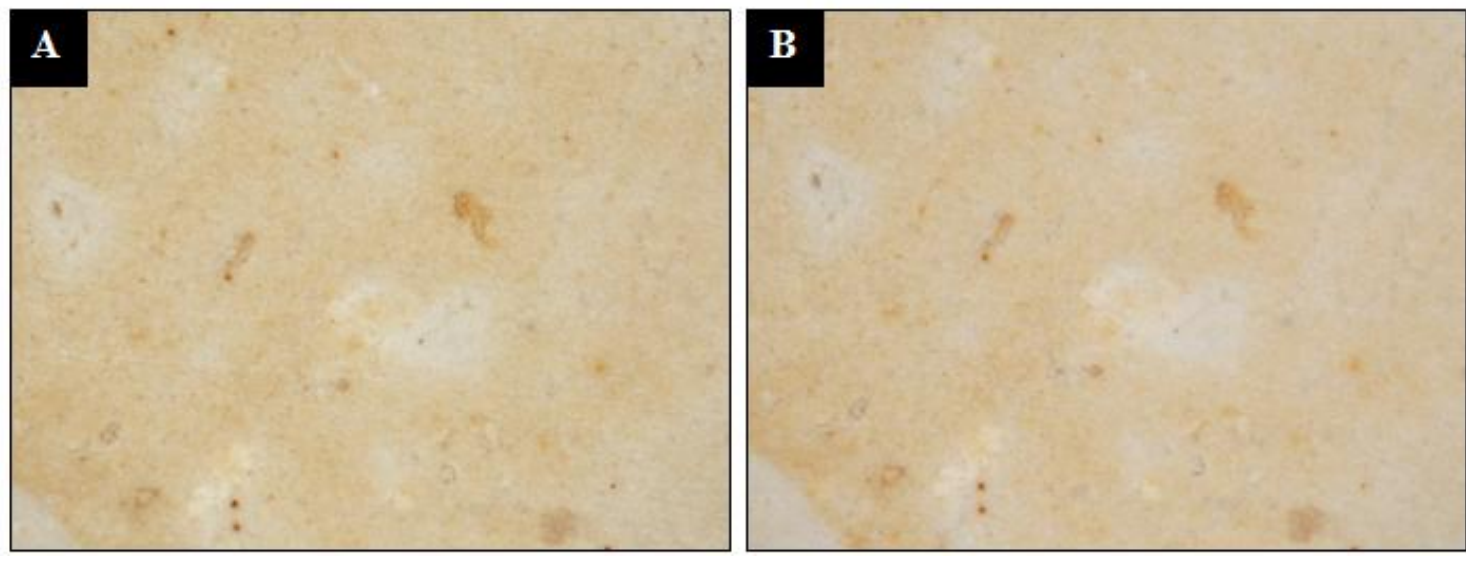

Figura 8.1. Detalles del fragmento pétreo antes de la aplicación (A) y después de la aplicación de la muestra ACP (B). Imágenes de microscopia estereoscópica con aumento de 2 x. 
Diferentes áreas del soporte pétreo sometidas a una observación por SEM a distintos aumentos se muestran en la Figura 8.2. En estas imágenes se compara la misma superficie pétrea antes (figuras A y B), y después del tratamiento (imágenes C y D). Se observa que el soporte pétreo con el producto aplicado presenta una distribución poco uniforme sobre la superficie, con un parcial relleno de las cavidades y porosidades de mayor tamaño. En general se observa que las partículas sólidas adicionadas forman agregados sobre la superficie mostrando una interacción producto-soporte pétreo insuficiente.
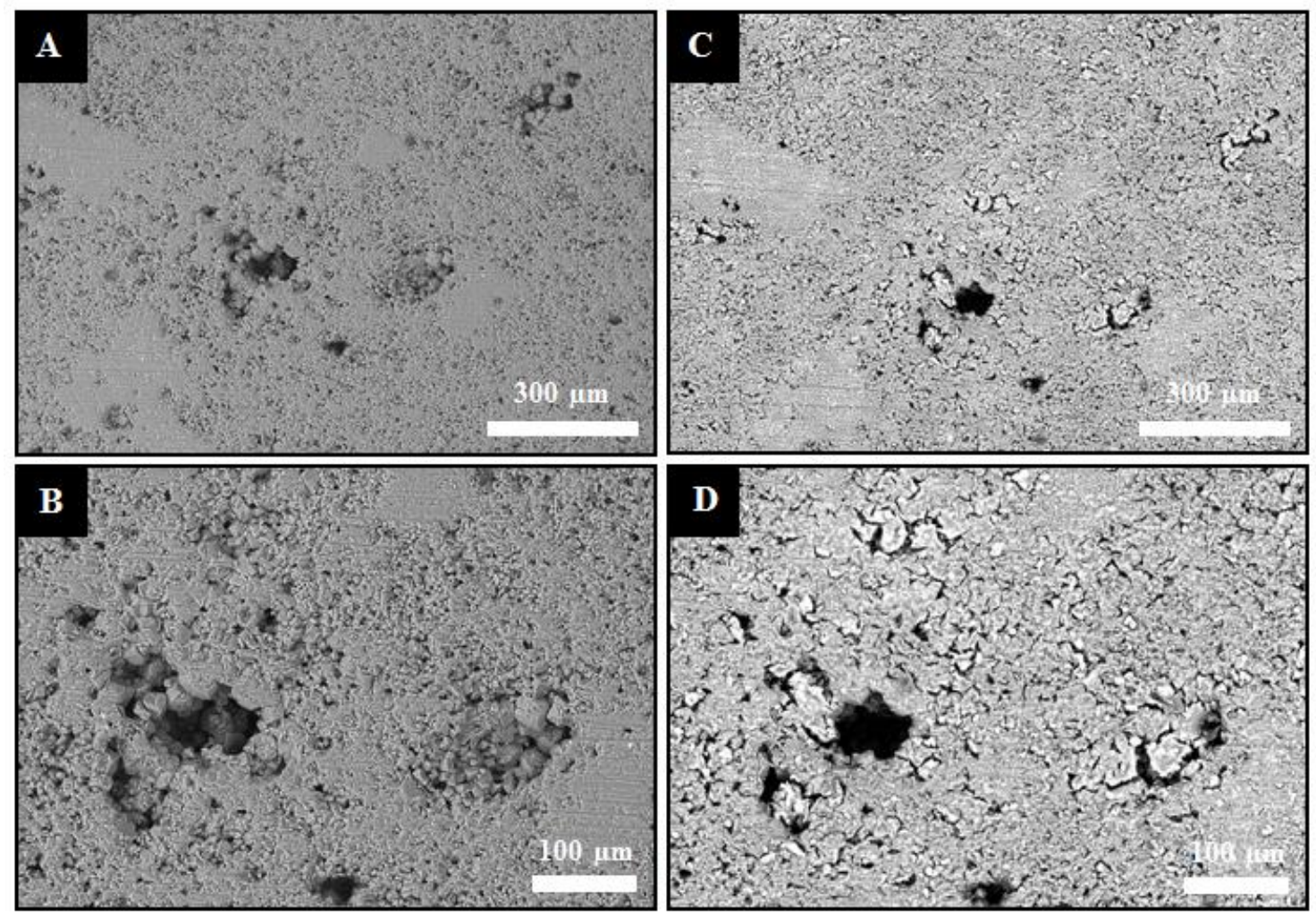

Figura 8.2. Imágenes por SEM en modalidad electrones retrodispersados a distintos aumentos de las superficies del soporte pétreo antes del tratamiento (A y B) y después del tratamiento con la muestra ACP (C y D).

Los agregados anteriormente descritos se muestran con mayor claridad en las imágenes SEM de la Figura 8.3 de otras regiones del soporte pétreo. Además, también aparecen agrietamientos en la superficie con una dudosa adherencia con el soporte pétreo. 

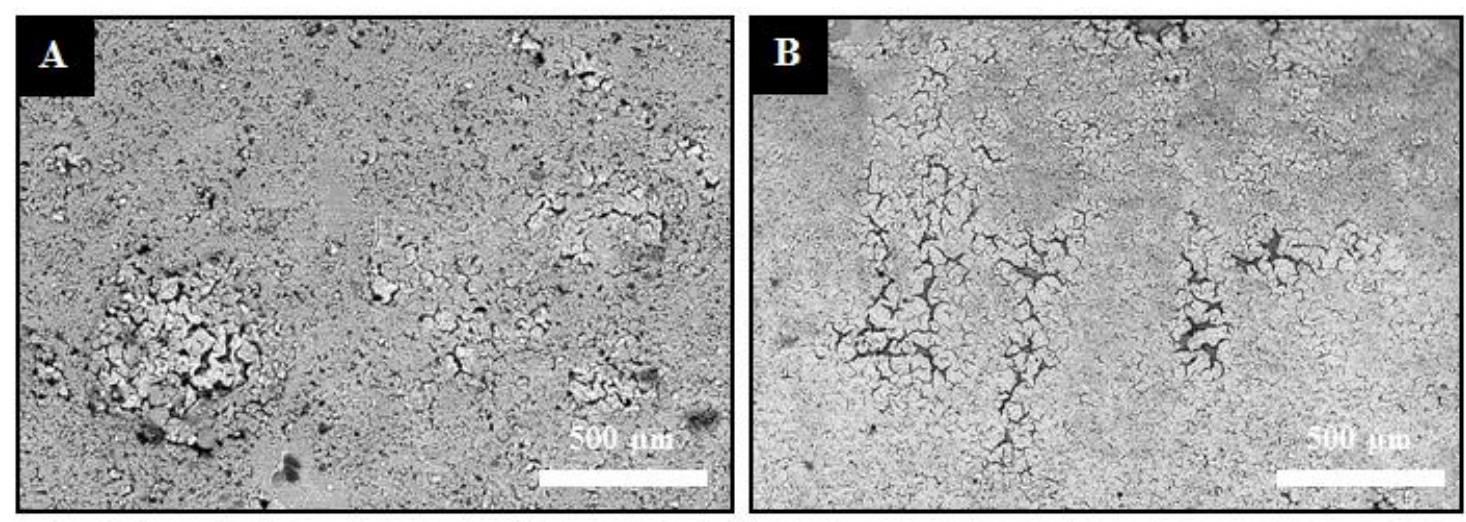

Figura 8.3. Imágenes por SEM en modalidad BSE de la superficie pétrea después del tratamiento con ACP. A) Imagen SEM a 100 x. B) Imagen por SEM a 50 x. Se observa como los agregados del producto aplicado presentan agrietamientos y poca afinidad con los constituyentes mineralógicos del soporte pétreo.

Antes de la aplicación como se muestra en la Figura 8.4, mediante la observación en una región del soporte pétreo y con el análisis EDX se detecta la presencia mayoritaria del calcio $(\mathrm{Ca})$ y magnesio $(\mathrm{Mg})$, con pequeñas cantidades de silicio $(\mathrm{Si})$, aluminio $(\mathrm{Al})$, azufre $(\mathrm{S})$ y hierro $(\mathrm{Fe})$. Todos los elementos detectados se asocian al soporte pétreo.

Sin embargo, después del tratamiento con la aplicación de la dispersión acuosa, aparece además la señal correspondiente al pico del fósforo $(\mathrm{P})$ asociado a la composición de la muestra aplicada, así como un aumento en la concentración del calcio (Figura 8.5). En base a los valores que se muestran en la tabla de la Figura 8.4 y 8.5, la relación molar $\mathrm{Ca} / \mathrm{Mg}$ pasa de un valor de 2,61 para el soporte pétreo sin tratamiento, a un valor de relación molar $\mathrm{Ca} / \mathrm{Mg}$ de 6,5 después del tratamiento, indicando un aumento de la concentración del calcio, como cabría esperar. 


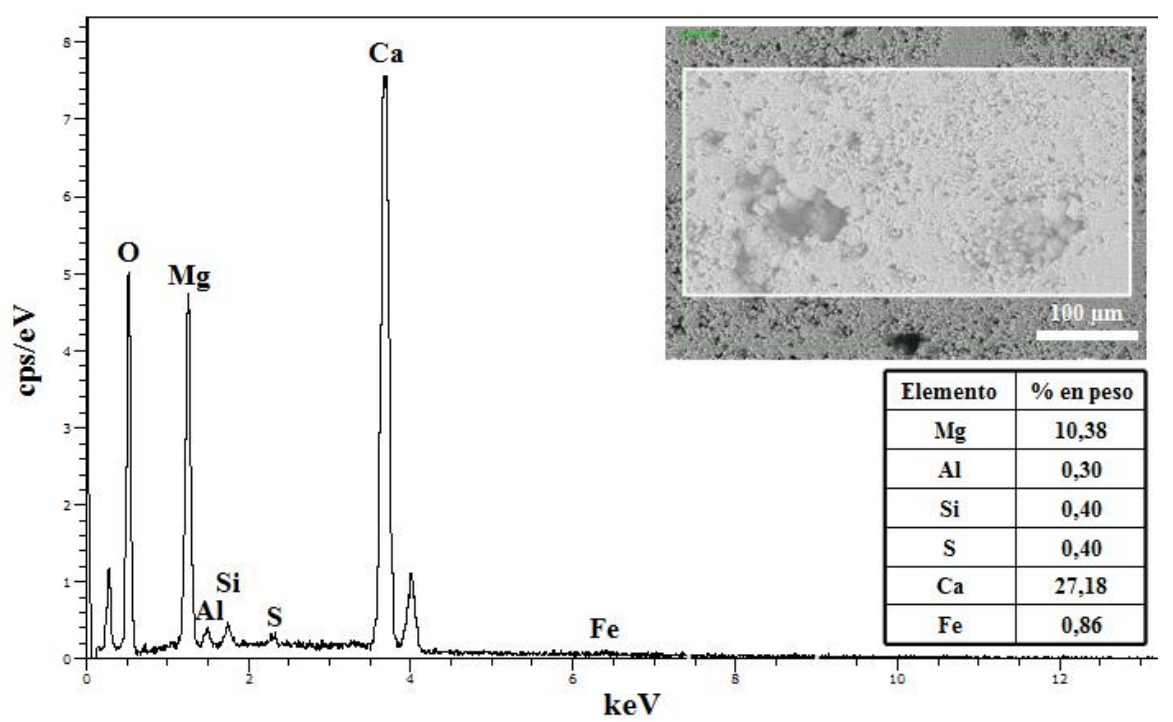

Figura 8.4. Micrografía obtenida por SEM (inset) de un área de la probeta de soporte pétreo sin tratar y espectro EDX de la región marcada en la imagen. En forma de tabla se expresa el \% en peso de los diferentes elementos detectados.

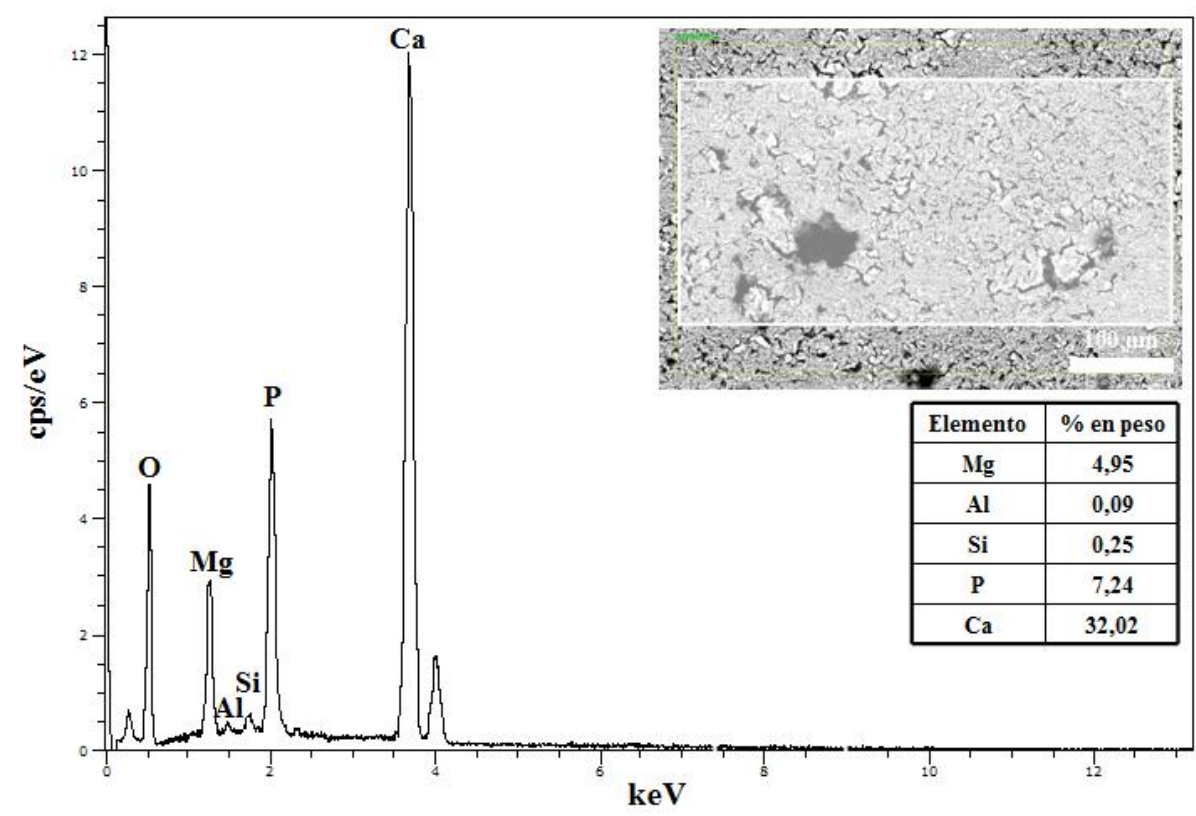

Figura 8.5. Micrografía obtenida por SEM (inset) de un área de la probeta de soporte pétreo tratado con ACP y espectro EDX de la región marcada en la imagen. En forma de tabla se expresa el \% en peso de los diferentes elementos detectados. 
La distribución del fósforo (P) sobre la superficie de la piedra tratada con ACP se muestra en la Figura 8.6 a partir de las imágenes de mapping. La concentración del fósforo aumenta con el tamaño de los poros por el efecto de relleno que se obtiene mediante la aplicación de la muestra ACP.
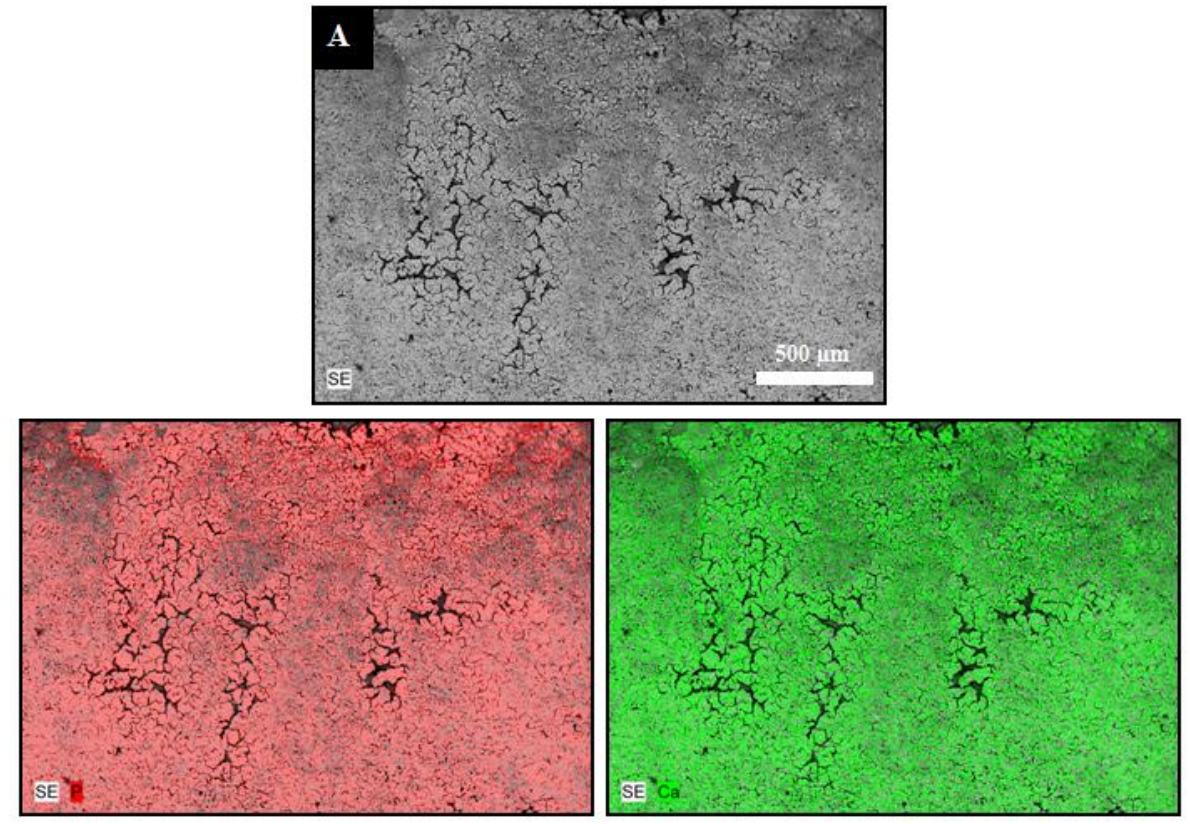

Figura 8.6. A) Imagen por SEM de un área de la superficie pétrea donde se muestra la distribución espacial de los elementos del fósforo (P) y del calcio (Ca). 


\subsubsection{Evaluación del tratamiento en corte transversal}

La valoración de la penetración de la muestra ACP en el soporte pétreo tratado se ha realizado a través de observaciones y análisis SEM-EDX sobre un corte transversal de la probeta. En las imágenes de la Figura 8.7 se observa como la muestra ACP aplicada penetra de manera irregular en la estructura porosa de la piedra. A través de la micrografía SEM de la Figura 8.7 A, se resalta la distribución del fósforo dentro de la estructura del soporte pétreo, mediante la aplicación digital de un filtro azul.

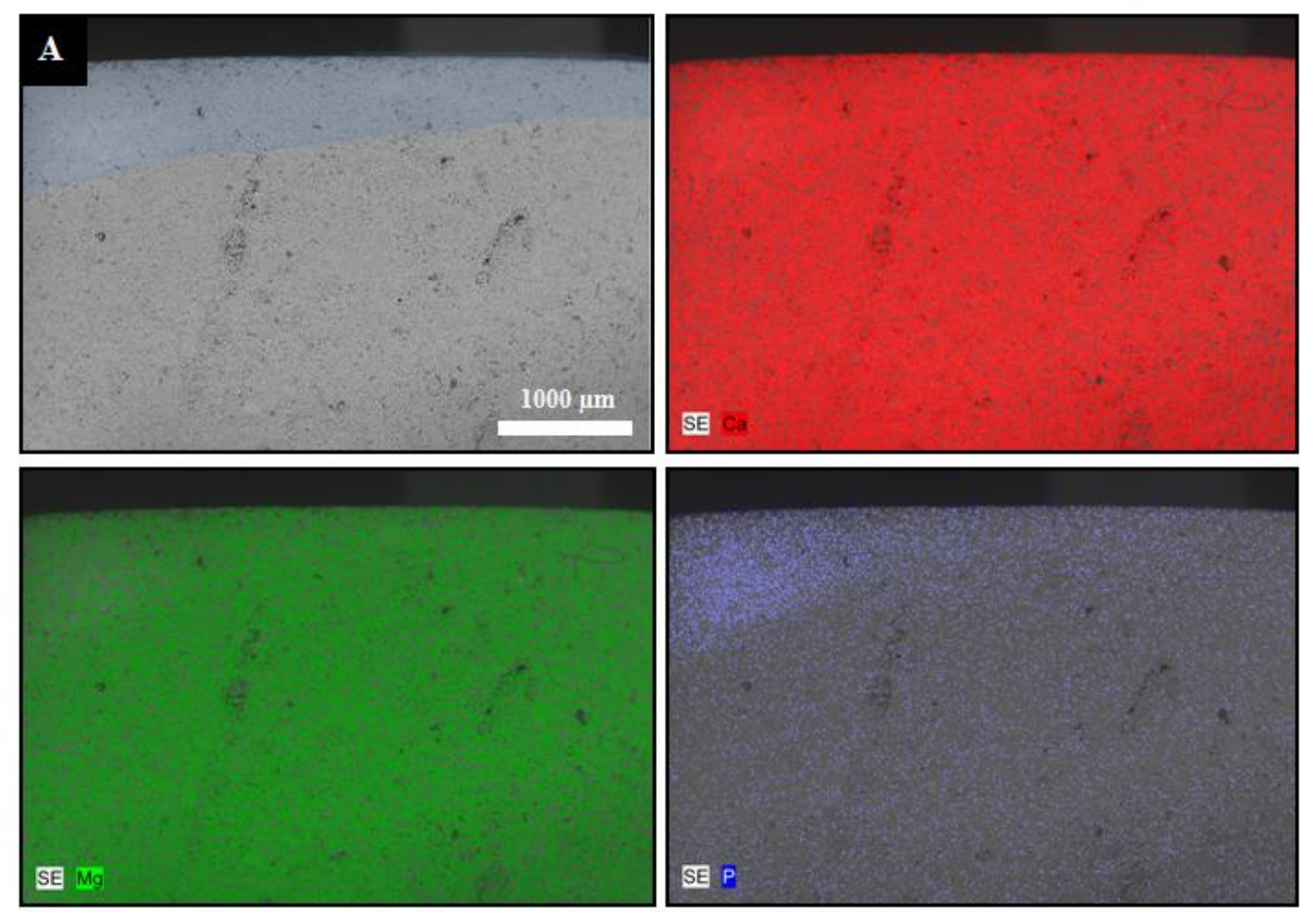

Figura 8.7. A) Imagen por SEM del corte transversal de la probeta pétrea donde se resalta en azul la penetración del fosforo. Distribución espacial de los elementos del calcio $(\mathrm{Ca})$, magnesio $(\mathrm{Mg})$ y fósforo $(\mathrm{P})$. Se observa como este último elemento presenta una distribución irregular dentro de la estructura del soporte pétreo.

Los microanálisis realizados en áreas del corte transversal a diferentes profundidades (Figura 8.8 y 8.9) indican que el fósforo (P) se detecta hasta una profundidad máxima de $1000 \mu \mathrm{m}$ aproximadamente. En estos análisis -necesarios para determinar la penetración de las partículas de la muestra introducida en la estructura de la piedra-, el fósforo, como ya se ha descrito con anterioridad, es el único elemento que proporciona información, por lo que se utiliza como marcador para determinar el grado de penetración dentro de los 
poros de la piedra mediante microanálisis EDX. Con los análisis realizados en las áreas señaladas, se produce una reducción de un $0,89 \%$ de fósforo desde un área cercana a la superficie (Figura 8.8), respecto a otra área a $1000 \mu \mathrm{m}$ de profundidad (Figura 8.9).

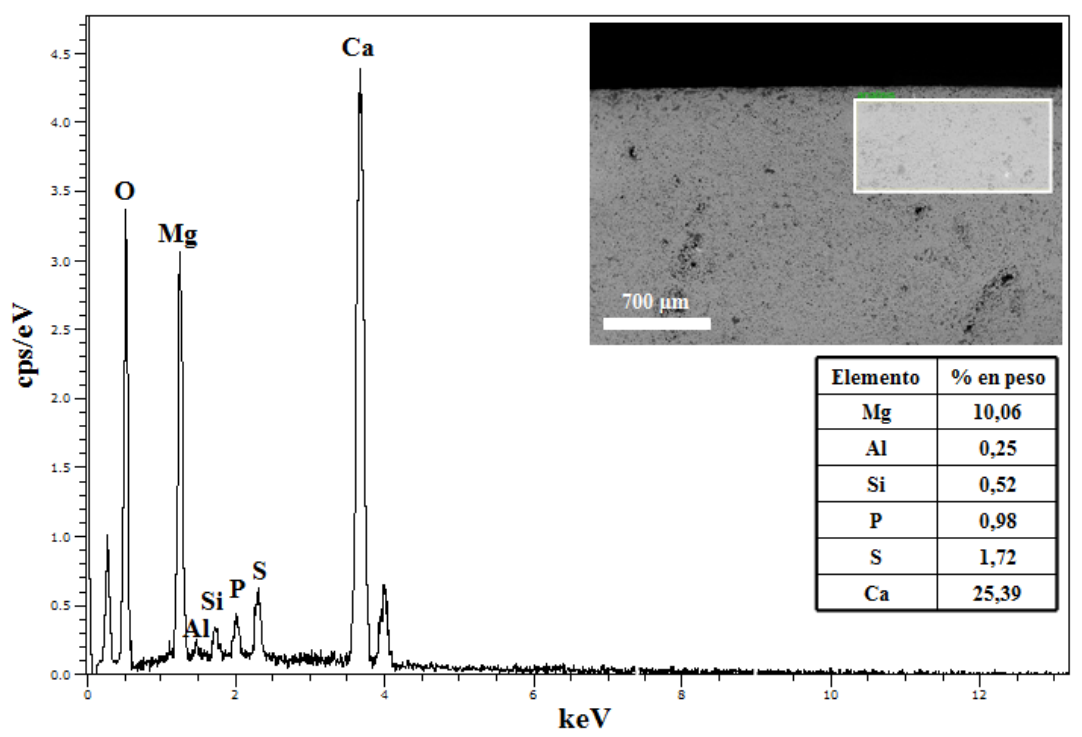

Figura 8.8. Micrografía obtenida por SEM (inset) de un área de la probeta de soporte pétreo tratado con ACP observado en corte transversal, y espectro EDX de la región marcada en la imagen. En forma de tabla se expresa el \% en peso de los diferentes elementos detectados.

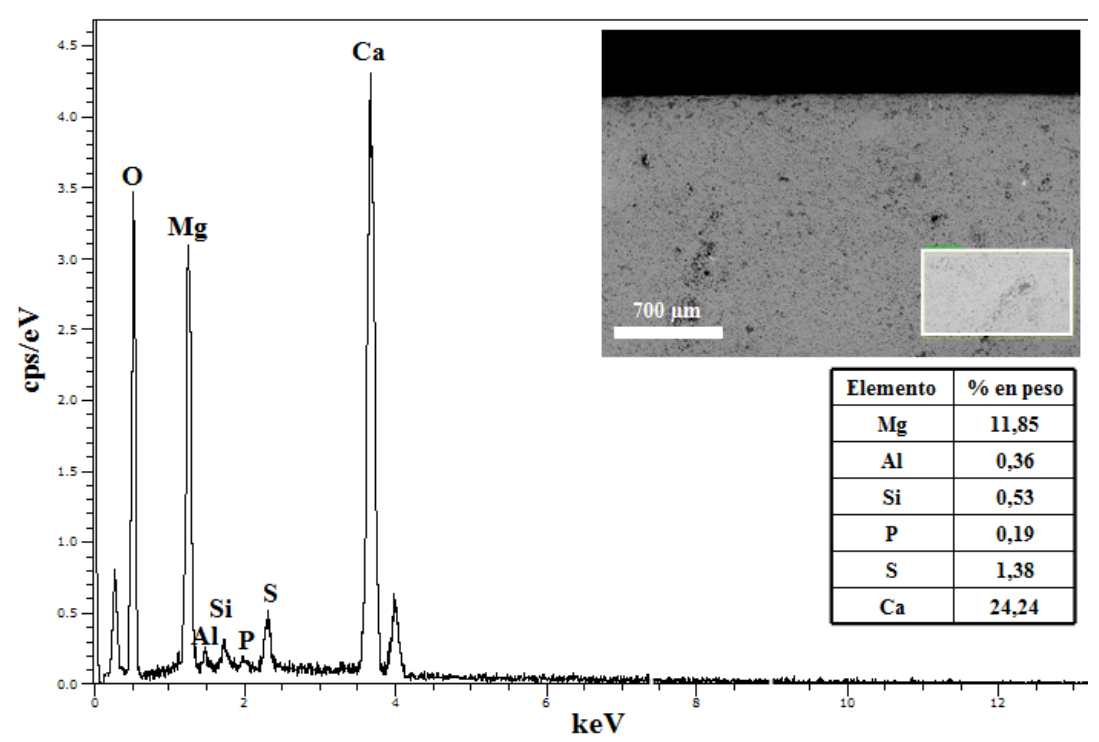

Figura 8.9. Micrografía obtenida por SEM (inset) de un área de la probeta de soporte pétreo tratado con ACP observado en corte transversal, y espectro EDX de la región marcada en la imagen. En forma de tabla se expresa el \% en peso de los diferentes elementos detectados. 


\subsubsection{Estudio de espectroscopia infrarroja por transformada de Fourier (FTIR)}

Con espectroscopia infrarroja por transformada de Fourier (FTIR) se realizaron controles para confirmar la presencia de la muestra introducida en el sustrato pétreo. En la Figura 8.10 se presentan los espectros FTIR del soporte pétreo sin tratar -en gris- respecto al soporte pétreo tratado con la dispersión acuosa de la muestra ACP -en negro-.

En la probeta sin tratar, se identifican las bandas típicas del $\mathrm{CO}_{3}{ }^{2-}$ relacionadas con el soporte pétreo ${ }^{203,204}$. En cuanto al soporte pétreo tratado con la muestra ACP, junto con las bandas del carbonato aparecen las bandas características de los modos vibracionales del grupo fosfato $\mathrm{PO}_{4}{ }^{3-}$ de la muestra introducida. Estas bandas aparecen alrededor de $560-600 \mathrm{~cm}^{-1}$ y una banda más intensa a $1100 \mathrm{~cm}^{-1}$.

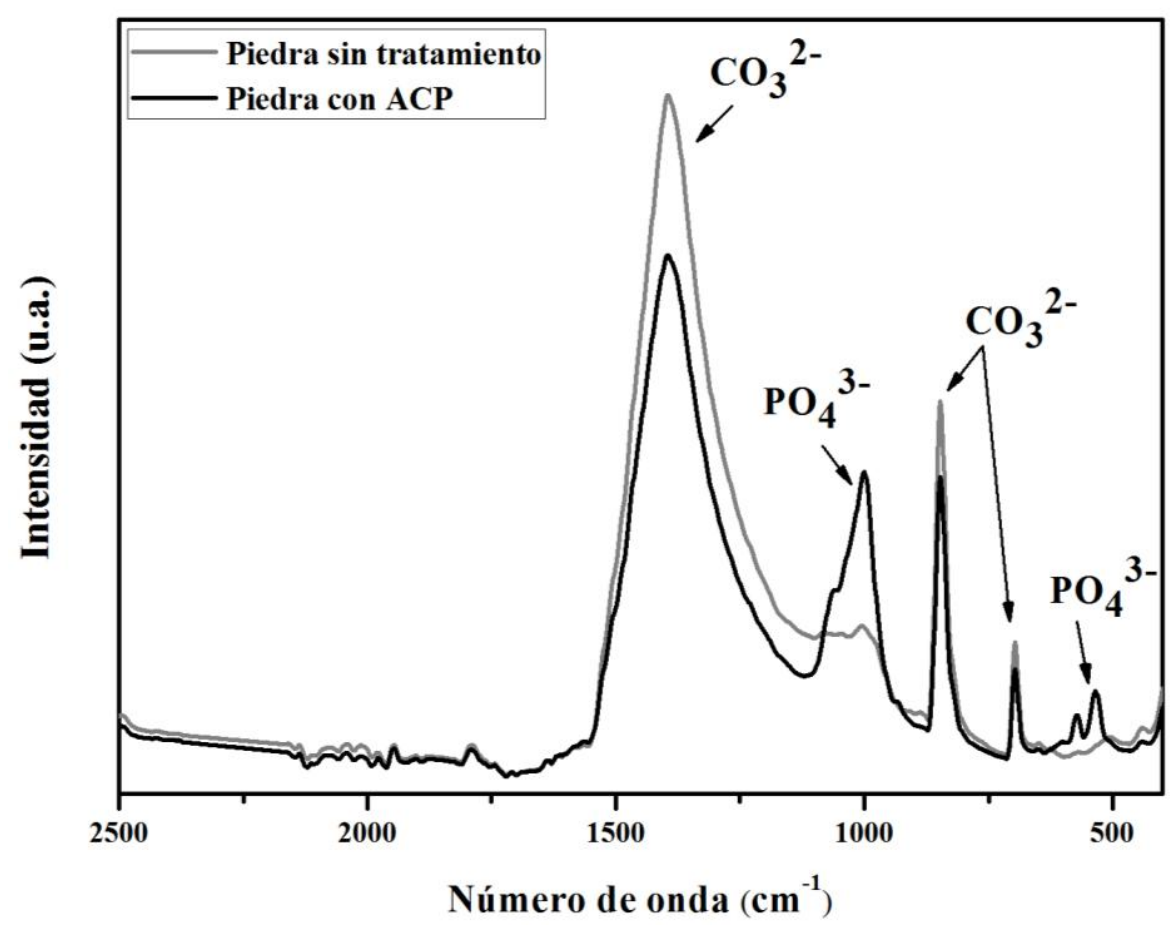

Figura 8.10. Espectro FTIR de la piedra sin tratar (gris) y de la piedra tratada con ACP (negro).

\footnotetext{
${ }^{203}$ J. Junfeng, G. Yun, J.E. William, E. John E, C. Jun, Rapid identification of dolomite using a Fourier Transform Infrared Spectrophotometer (FTIR): A fast method for identifying, Heinrich events in IODP Site U1308, Marine Geology, Vol. 258, Issues 14, 15, 60-68, 2009.

${ }^{204}$ T.T. Nguyen, L.J. Janik, M. Raupach, Diffuse Reflectance Infrared Fourier-Transform (DRIFT) spectroscopy in soil studies, in Australian Journal of Soil Research, 29(1), 49-67, 1991.
} 


\subsubsection{Evaluación del tratamiento con hidroxiapatita cristalina: muestra HA1}

La muestra HA1 corresponde a la hidroxiapatita caracterizada por una cristalinidad intermedia.

\subsubsection{Evaluación del tratamiento en superficie}

Al igual que en el caso anterior, la primera observación se realizó con microscopia estereoscópica -imagen de la Figura 8.11 A, antes de la aplicación de la muestra HA1-, donde tras el tratamiento con la hidroxiapatita HA1 (imagen B), no se aprecia ningún cambio en las características superficiales del soporte pétreo como el color y la textura.
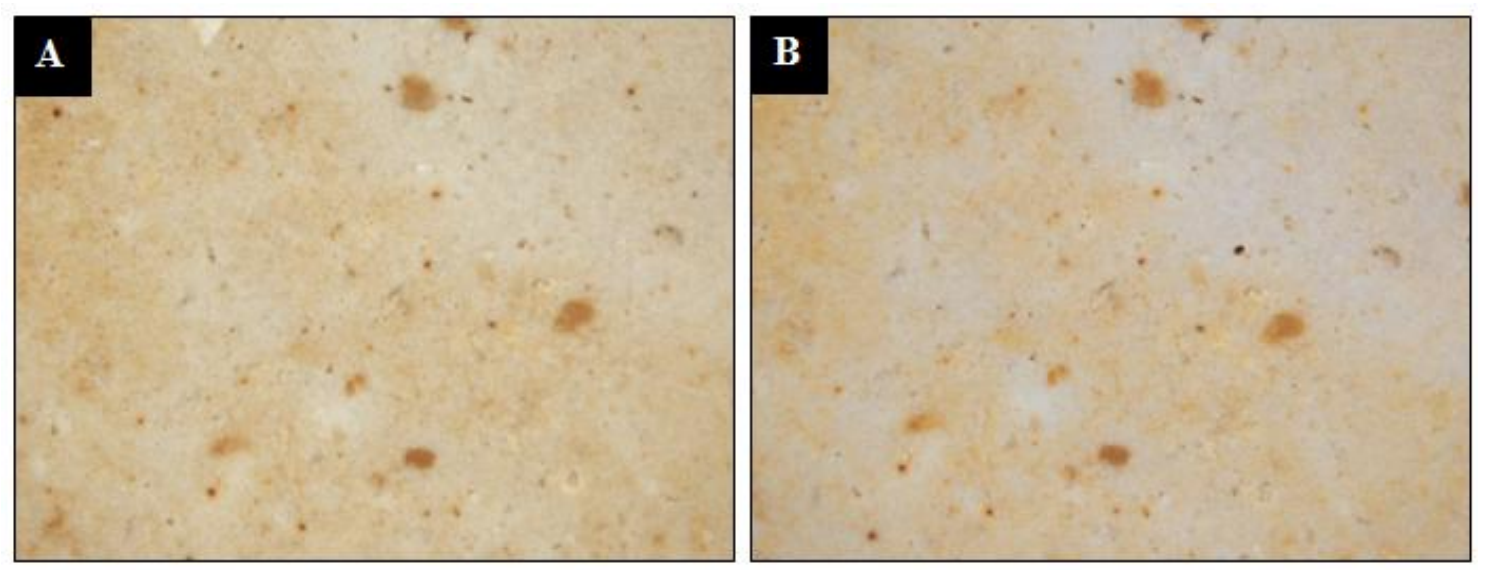

Figura 8.11. Detalles del fragmento pétreo antes de la aplicación de la muestra HA1 (A) y después del tratamiento (B). Imágenes de microscopia estereoscópica con aumento de 2 x.

Las micrografías de la Figura 8.12 obtenidas al SEM a distintos aumentos, muestran la superficie pétrea antes del tratamiento (imágenes A y B) y la misma superficie después de la aplicación de la muestra de hidroxiapatita HA1 (imágenes C y D). En este caso, se observa que las partículas se distribuyen sobre la superficie pétrea de manera poco uniforme. Sin embargo, parece que las partículas aplicadas rellenan mejor los poros que en el caso analizado anteriormente con la muestra ACP.

En general, se distingue como la muestra aplicada va rellenando adecuadamente las micro-cavidades y porosidades de mayor tamaño del soporte pétreo, un aspecto valorado positivamente en cuanto el tratamiento permite incrementar la resistencia mecánica del soporte frente a la acción de pulverización-disgregación. 
Además, la hidroxiapatita introducida parece tener una buena cohesión y adhesión con el soporte, incrementando también, en este caso, la resistencia mecánica del sustrato.
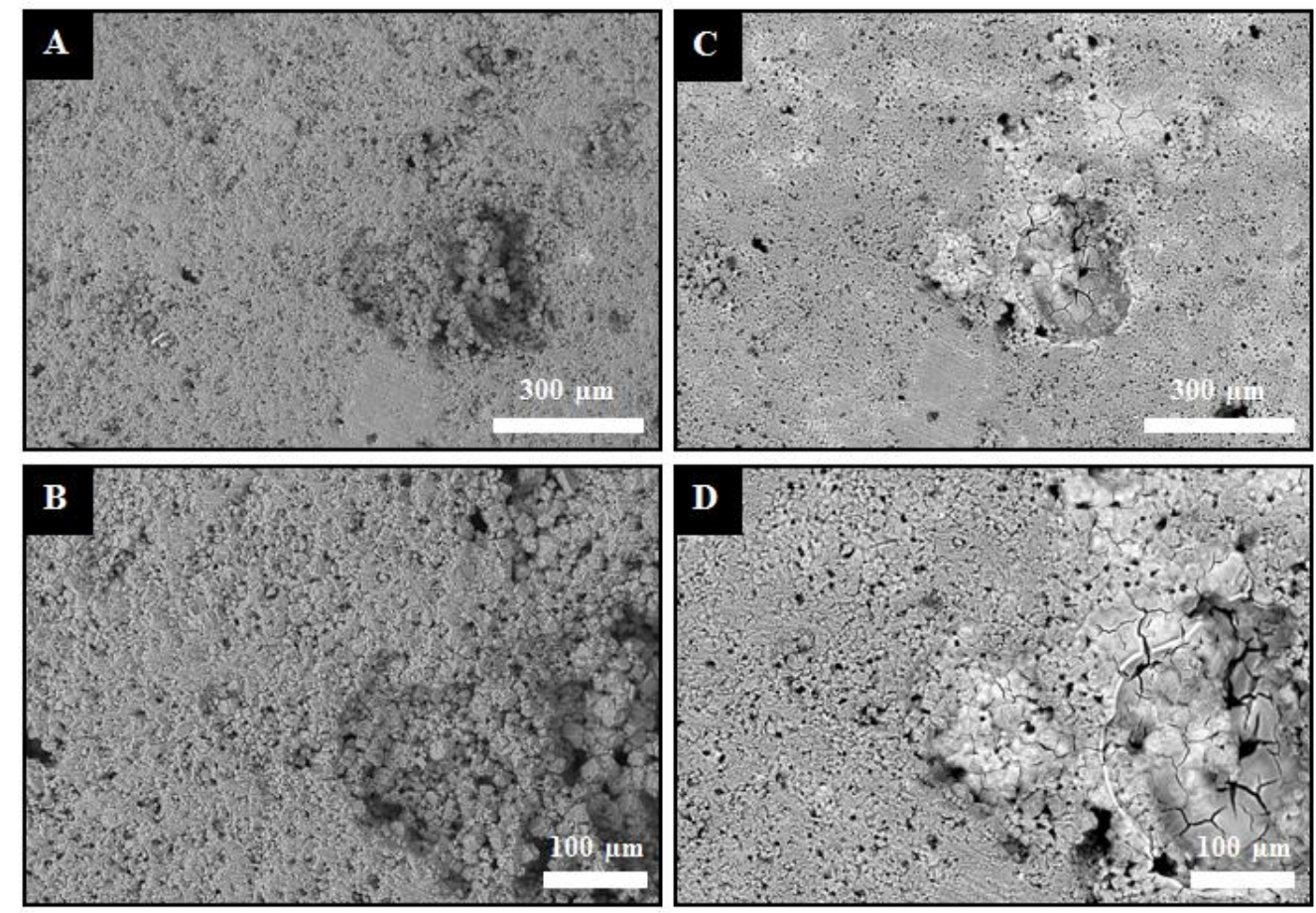

Figura 8.12. Imágenes por SEM en modalidad electrones retrodispersados a distintos aumentos de las superficies del soporte pétreo antes del tratamiento (A y B) y después del tratamiento con la muestra HA1 (C y D).

En otras áreas del mismo soporte, se observa como la hidroxiapatita aplicada crea una capa que conduce a la formación de un microagrietado (imágenes SEM de la Figura 8.13).
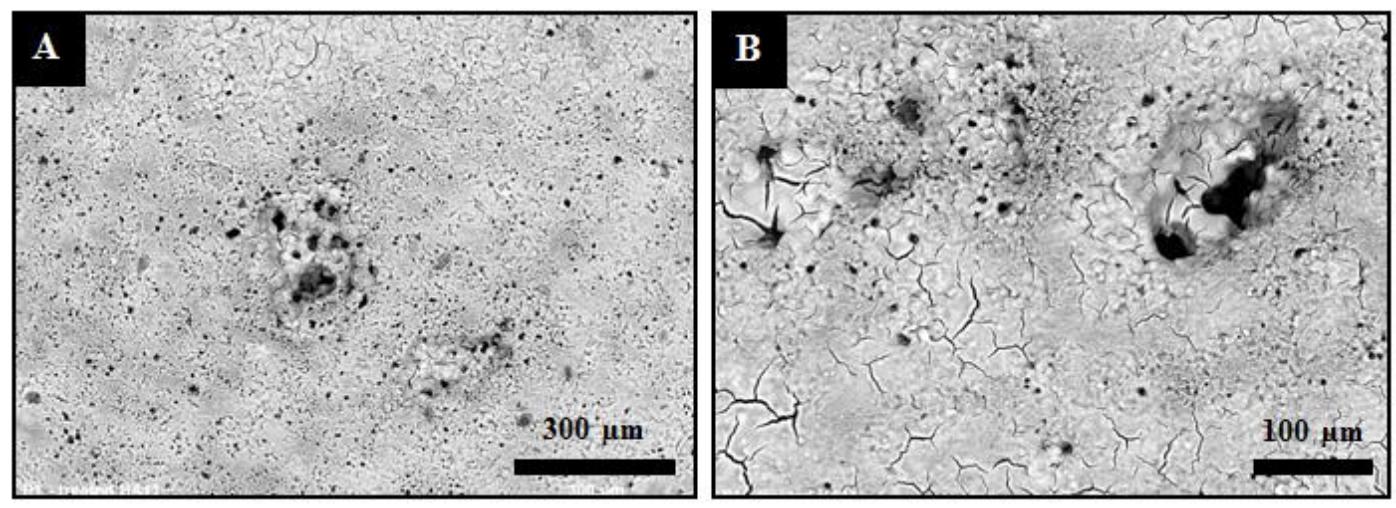

Figura 8.13. Imágenes por SEM en modalidad BSE de la superficie pétrea después del tratamiento con HA1. A) Imagen SEM a 100 x. B) Imagen SEM a 200 x. Se observa como en algunas áreas hay el agrietamiento del estrato de hidroxiapatita depositado en la superficie del sustrato pétreo. 
Después del tratamiento, el microanálisis EDX mostrado en la Figura 8.14 indica una señal correspondiente al pico del fósforo (P) asociada a la hidroxiapatita de la muestra HA1 aplicada. Igual que en el caso anterior, hay un incremento de la concentración del calcio como se muestra en la tabla, con una relación molar Ca/Mg de 6,1 .

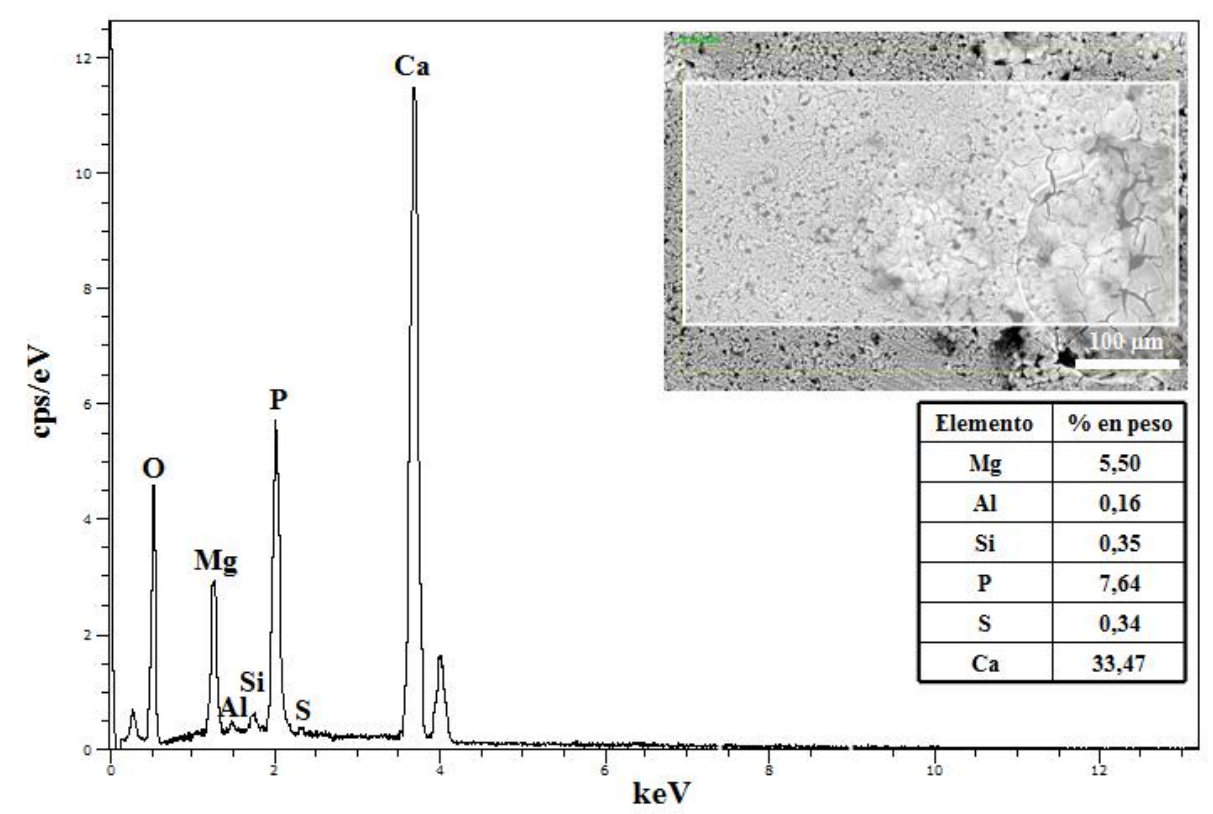

Figura 8.14. Micrografía obtenida por SEM (inset) de un área de la probeta de soporte pétreo tratado con HA1 y espectro EDX de la región marcada en la imagen. En forma de tabla se expresa el \% en peso de los diferentes elementos detectados.

En la Figura 8.15 se indica la distribución espacial de los elementos. Se observa la distribución del fósforo (P) sobre la superficie de la piedra tratada con HA1. La concentración del fósforo aumenta con la presencia de porosidades de mayor tamaño por el efecto de relleno, que se obtiene mediante la aplicación de la dispersión de la muestra HA1. 


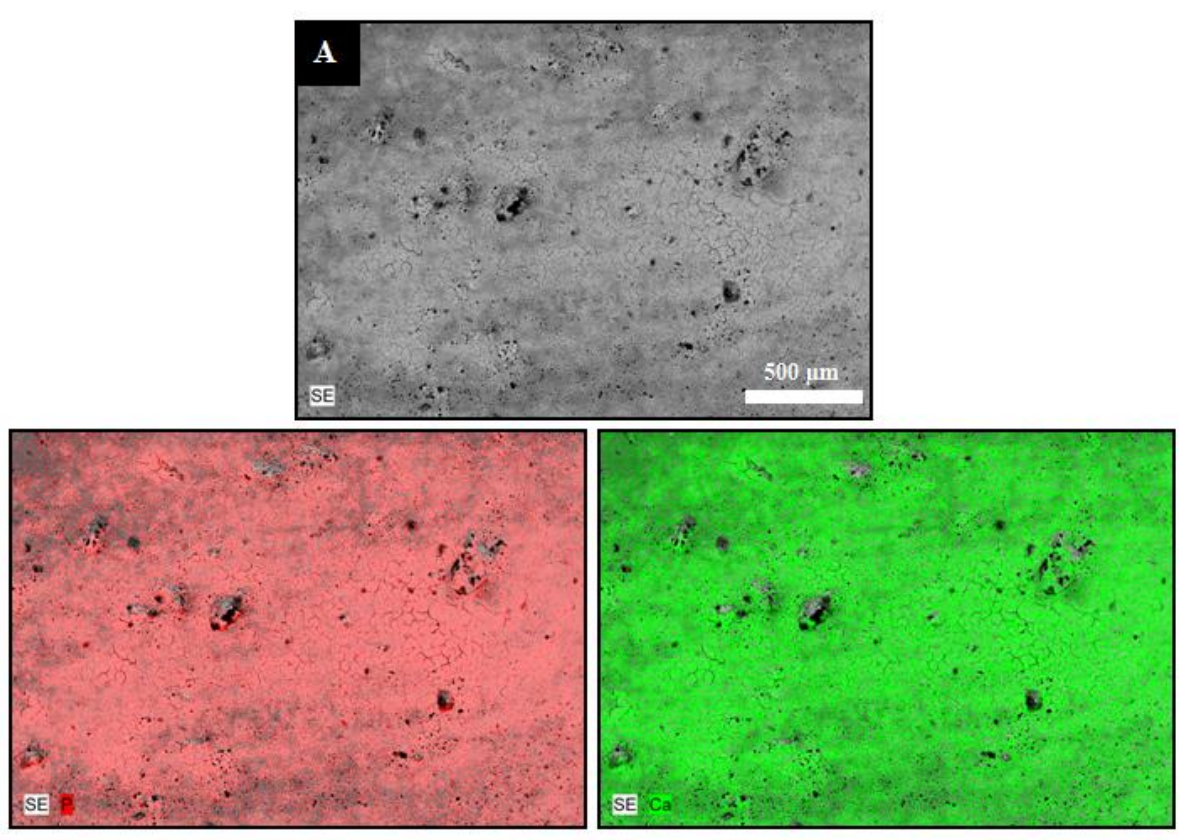

Figura 8.15. A) Imagen por SEM de un área de la superficie pétrea. Se muestra la distribución espacial de los elementos del fósforo (P) y del calcio (Ca). 


\subsubsection{Evaluación del tratamiento en corte transversal}

Tal y como se observa en el mapping de la Figura 8.16 con la distribución del fósforo (P) a lo largo de la sección transversal de la probeta, el elemento penetra de manera homogénea hasta una profundidad de 2000 $\mu \mathrm{m}$ aproximadamente, con lo que el grado de penetración de la hidroxiapatita HA1 en el sistema poroso del soporte rocoso resulta ser mejor que el de la muestra ACP.
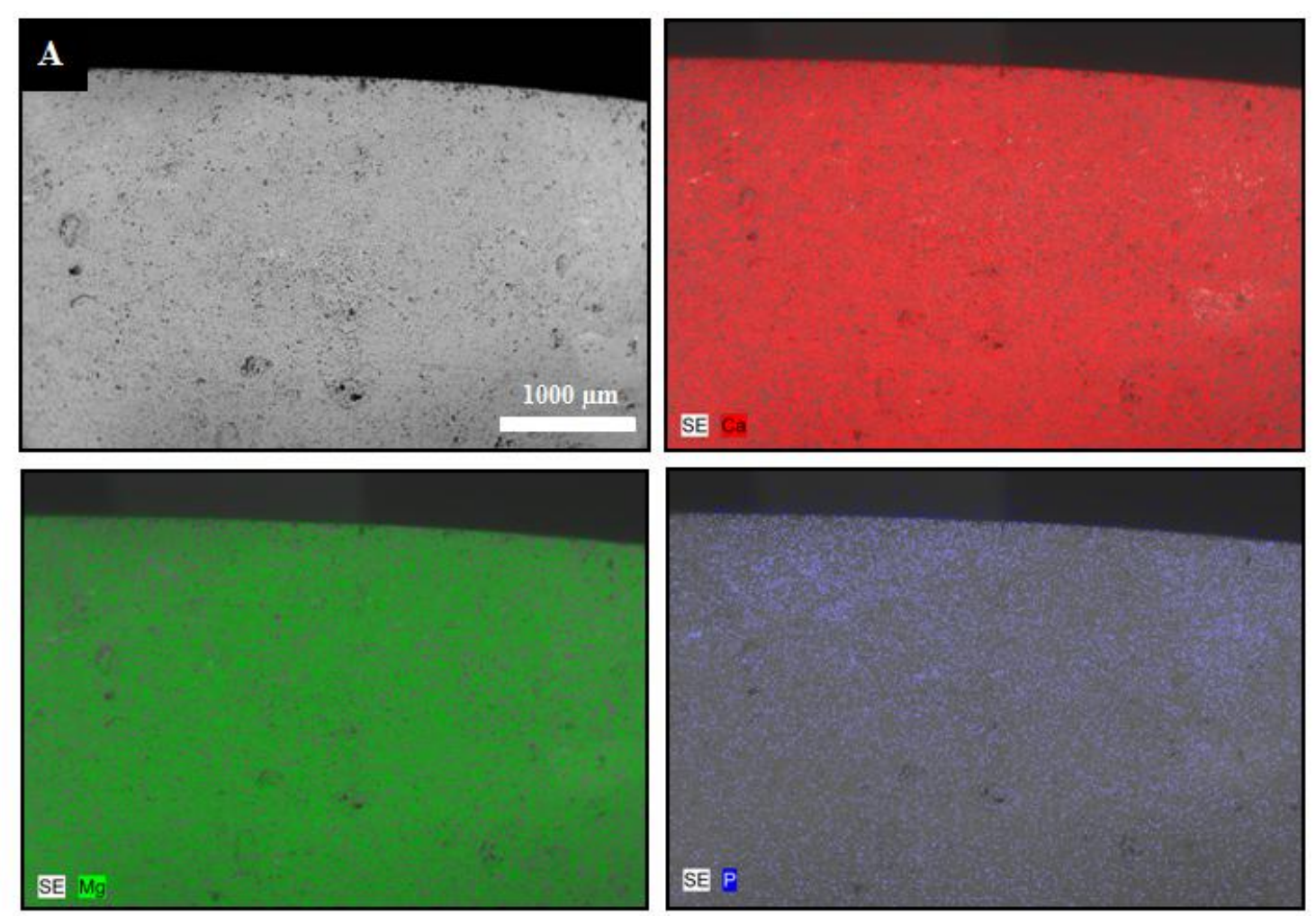

Figura 8.16. A) Imagen por SEM del corte transversal de la probeta pétrea. Distribución espacial de los elementos del calcio $(\mathrm{Ca})$, magnesio $(\mathrm{Mg})$ y fósforo $(\mathrm{P})$. Se observa como el fósforo presenta una distribución más homogénea dentro de la estructura del soporte pétreo.

Este resultado viene confirmado por los microanálisis EDX realizados en distintas áreas en un corte transversal de la probeta después del tratamiento. En el primer microanálisis efectuado en el área señalada cercana a la superficie (Figura 8.17), se detecta una concentración del fósforo (P) del 0,97\%. Este contenido disminuye a $0,21 \%$ en el microanálisis EDX de la Figura 8.18, realizado en el área señalada a una profundidad de $2000 \mu \mathrm{m}$ aproximadamente. 


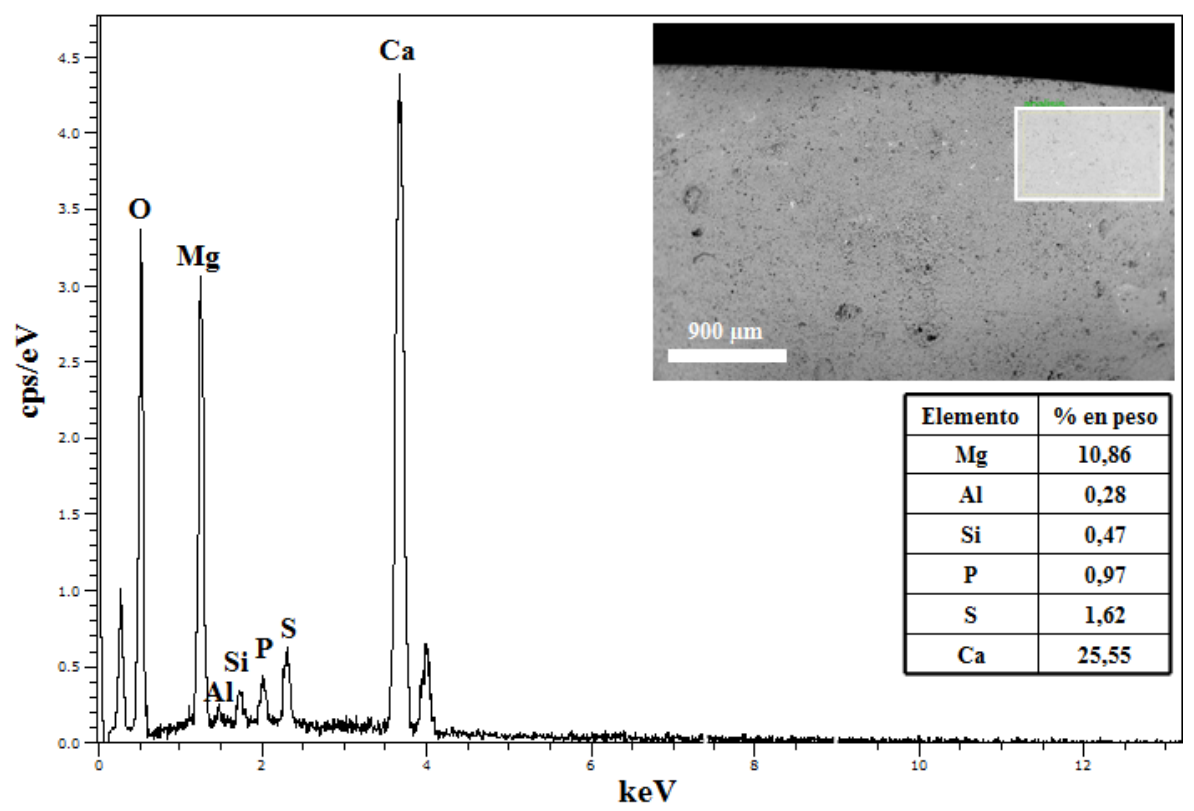

Figura 8.17. Micrografía obtenida por SEM (inset) de un área de la probeta de soporte pétreo tratado con HA1 observado en corte transversal, y espectro EDX de la región marcada en la imagen. En forma de tabla se expresa el \% en peso de los diferentes elementos detectados.

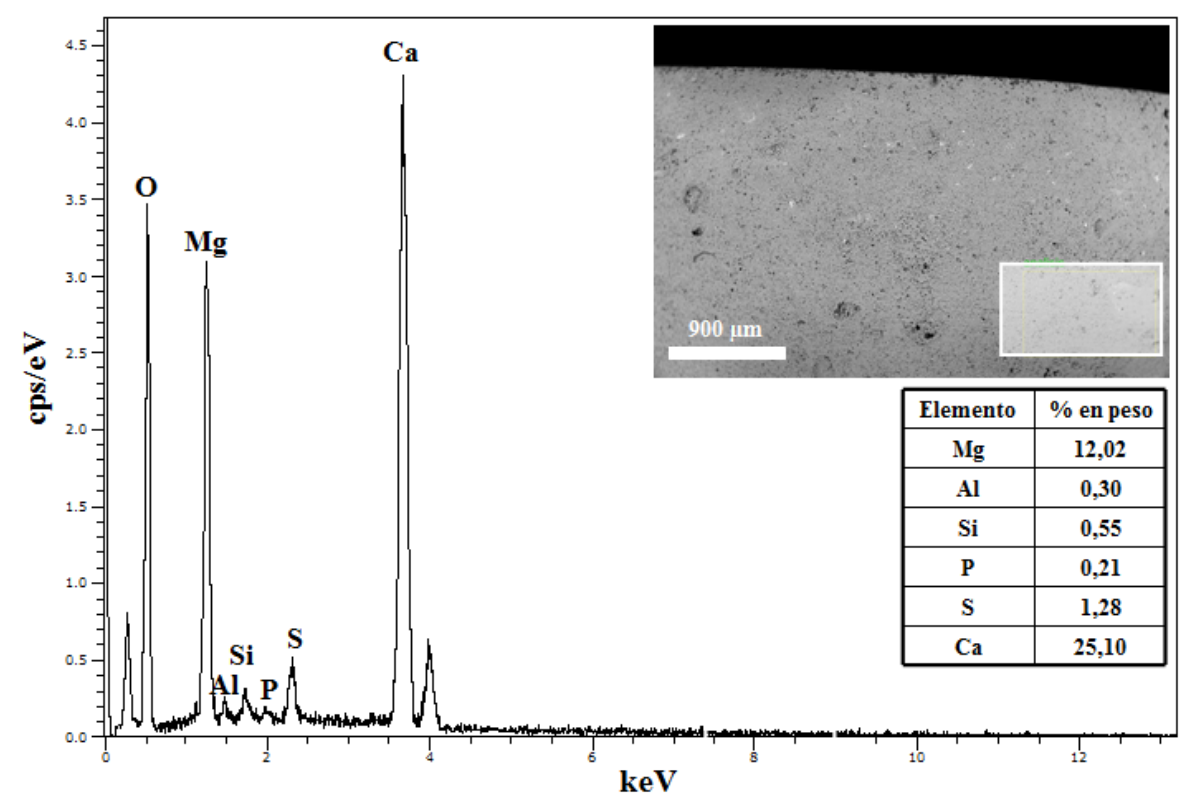

Figura 8.18. Micrografía obtenida por SEM (inset) de un área de la probeta de soporte pétreo tratado con HA1 observado en corte transversal, y espectro EDX de la región marcada en la imagen. En forma de tabla se expresa el \% en peso de los diferentes elementos detectados. 


\subsubsection{Estudio de espectroscopia infrarroja por transformada de Fourier (FTIR)}

Como en el caso anterior, en el espectro FTIR de la Figura 8.19 del soporte pétreo tratado con la muestra HA1 (espectro en rojo), junto con las bandas del carbonato asociadas al soporte pétreo, aparecen las bandas de absorción características de los modos vibracionales del grupo fosfato $\mathrm{PO}_{4}{ }^{3-}$ de la hidroxiapatita a 560$600 \mathrm{~cm}^{-1}$ y $1100 \mathrm{~cm}^{-1}$ aplicada.

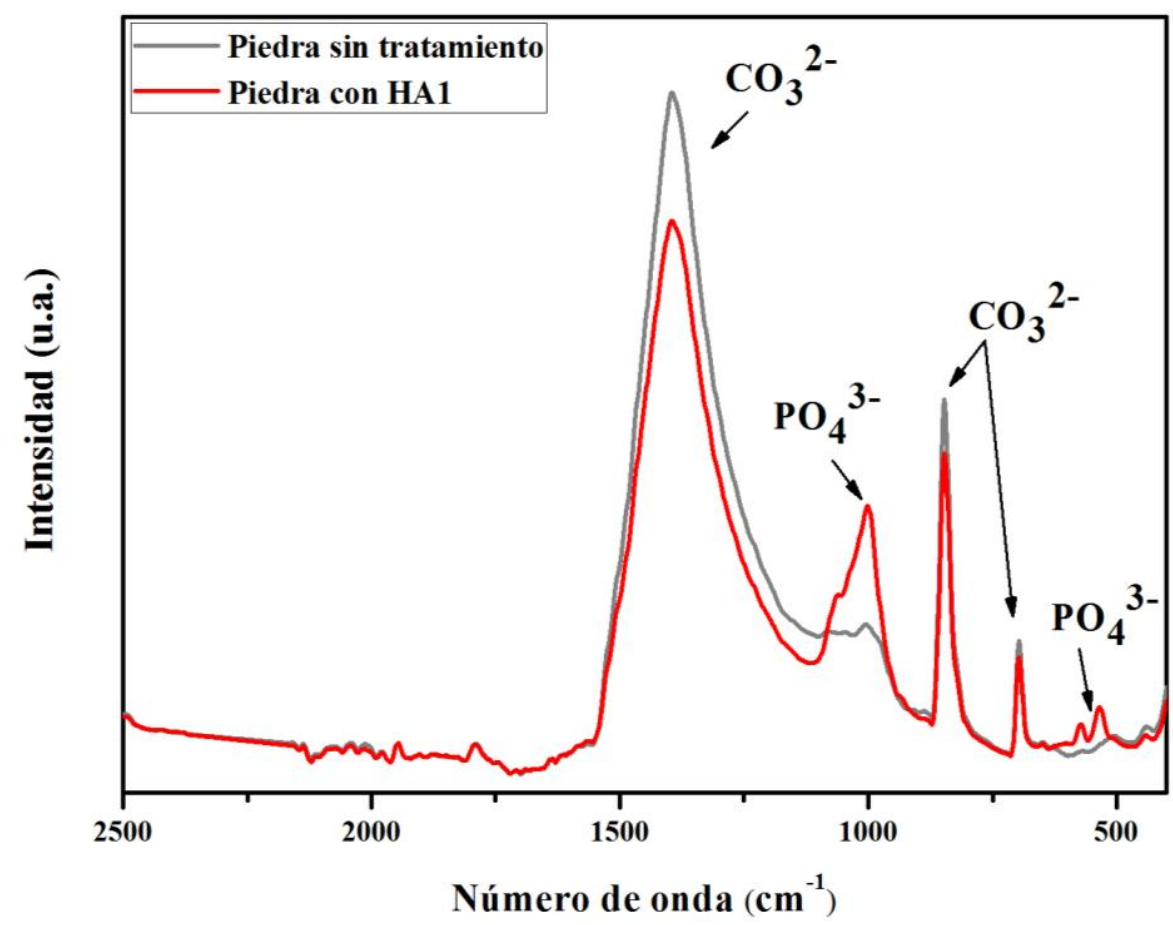

Figura 8.19. Espectro FTIR de la piedra sin tratar (gris) y de la piedra tratada con HA1 (rojo). 


\subsubsection{Evaluación del tratamiento con hidroxiapatita con alta cristalinidad: muestra HA2}

La muestra HA2 corresponde a la hidroxiapatita caracterizada por una alta cristalinidad.

\subsubsection{Evaluación del tratamiento en superficie}

Con microscopia estereoscópica (imágenes de la Figura 8.20), no se aprecia ningún cambio en las características superficiales del soporte pétreo como el color y textura después del tratamiento (imagen B). Del mismo modo que se observó en el tratamiento con la muestra HA1, a nivel macroscópico las dos muestras de hidroxiapatita cristalinas no provocan cambios en el aspecto estético de las superficies del soporte pétreo.
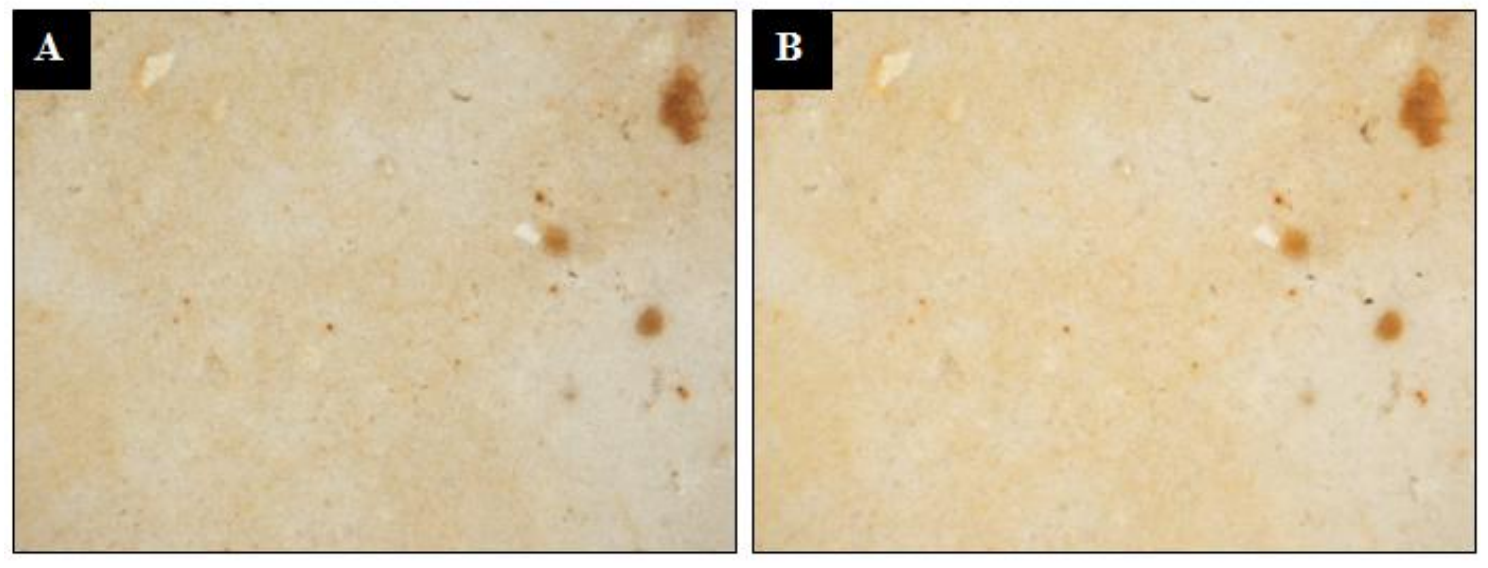

Figura 8.20. Detalles del fragmento pétreo antes del tratamiento (A) y después de la aplicación de la muestra HA2 (B). Imágenes de microscopia estereoscópica con aumento de 2 x.

Con el estudio mediante microscopia electrónica de barrido, se observa una distribución uniforme del producto aplicado sobre la superficie del soporte pétreo. En las imágenes SEM de la superficie pétrea después del tratamiento con HA2 (Figura 8.21, imágenes C y D) se observa como la hidroxiapatita se deposita en superficie formando una capa fina y homogénea. El tratamiento proporciona el relleno de las micro-cavidades y porosidades de mayor tamaño por parte de la hidroxiapatita. Este último aspecto se valora positivamente ya que el tratamiento permite incrementar la resistencia mecánica del soporte pétreo frente a la acción de pulverización-disgregación. 

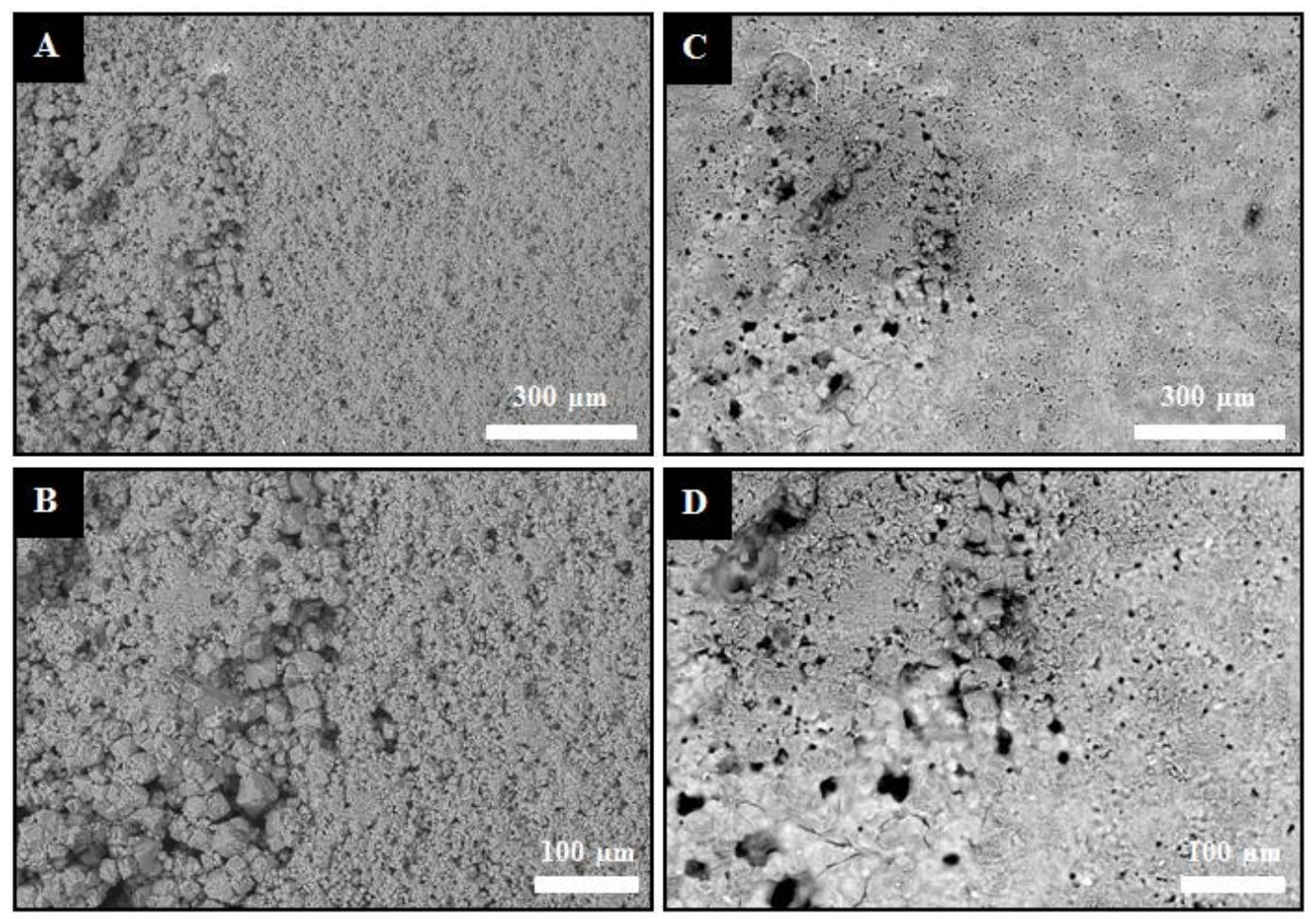

Figura 8.21. Imágenes por SEM en modalidad electrones retrodispersados a distintos aumentos de las superficies del soporte pétreo antes del tratamiento (A y B) y después del tratamiento con la muestra HA2 (C y D).

En las micrografías SEM de la Figura 8.22 se puede ver de como la hidroxiapatita tiene una buena adhesión y cohesión con los constituyentes del soporte pétreo, indicando que esta tipología de muestra presenta un mayor grado de afinidad con la naturaleza del sustrato pétreo, sin presentar agrietamientos.
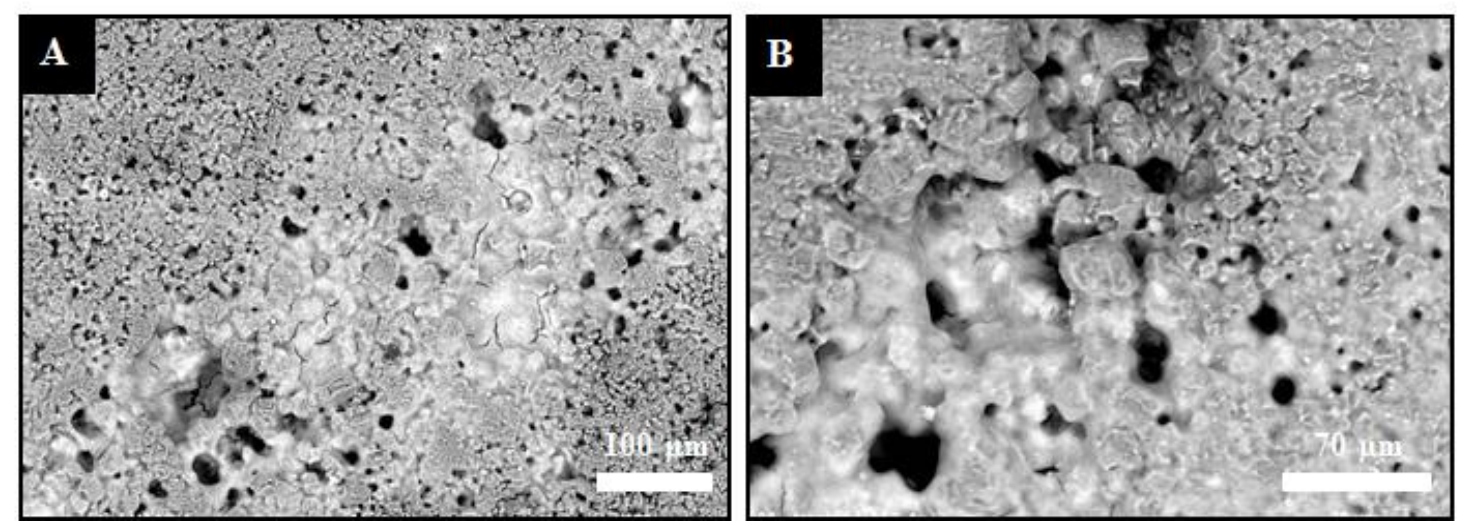

Figura 8.22. Imágenes por SEM en modalidad BSE de la superficie pétrea después del tratamiento con HA2. A) Imagen SEM a 200 x. B) Imagen SEM a 400 x. 
El microanálisis EDX realizado después del tratamiento (Figura 8.23) detecta sobre la superficie pétrea una alta concentración del fósforo $(\mathrm{P})$ asociado a la hidroxiapatita aplicada. Igual que para las muestras ACP y HA1 hay un aumento de la concentración del calcio $(\mathrm{Ca})$. En la tabla se muestran las concentraciones de los elementos detectados. La relación molar $\mathrm{Ca} / \mathrm{Mg}$ en este caso resulta ser de 7,5. Comparando este resultado con los obtenidos con las dos muestras anteriores, se puede ver que la concentración del calcio es superior en este último caso.

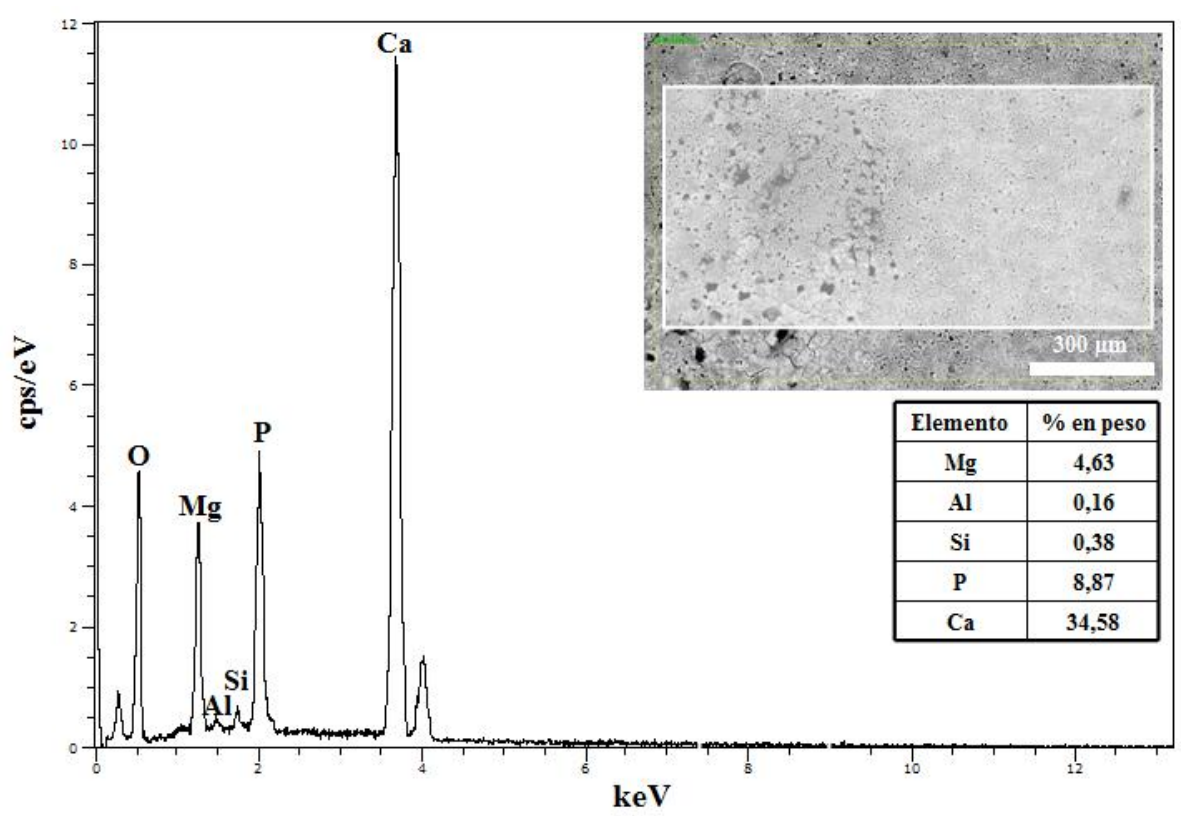

Figura 8.23. Micrografía obtenida por SEM (inset) de un área de la probeta de soporte pétreo tratado con HA2 y espectro EDX de la región marcada en la imagen. En forma de tabla se expresa el \% en peso de los diferentes elementos detectados.

Con la distribución espacial de los elementos a través del mapping de la Figura 8.24 se observa, igual que en el caso anterior, como el fósforo (P) está presente de manera uniforme en la superficie de la piedra. La concentración del elemento aumenta en correspondencia con porosidades de mayor tamaño por el efecto relleno que se obtiene mediante la aplicación de la hidroxiapatita. 

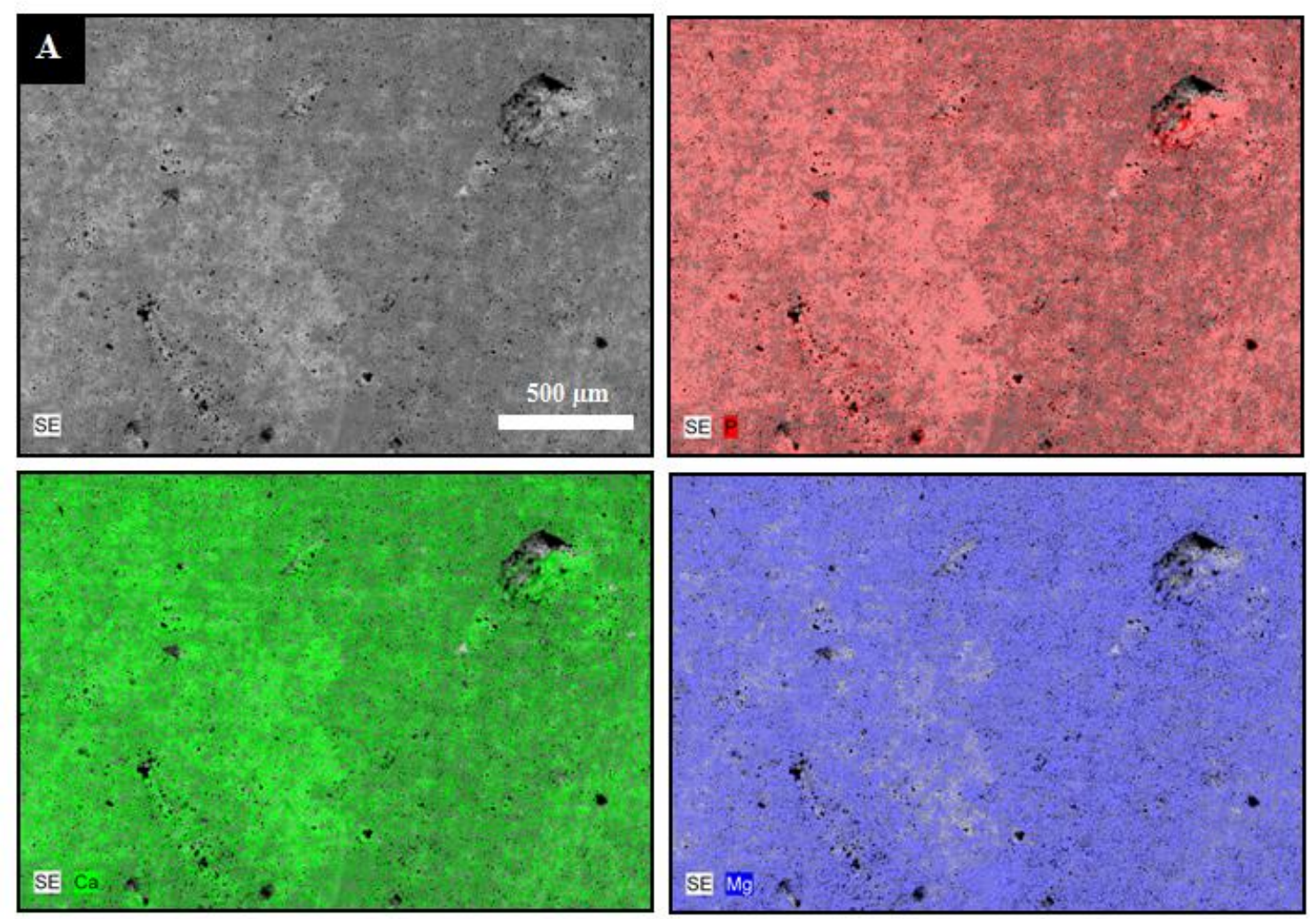

Figura 8.24. A) Imagen por SEM de la superficie de la probeta pétrea. Se muestra la distribución espacial de los elementos del fósforo $(\mathrm{P})$, calcio $(\mathrm{Ca})$ y magnesio $(\mathrm{Mg})$. 


\subsubsection{Evaluación del tratamiento en corte transversal}

Al igual que los resultados obtenidos con la probeta tratada con HA1, en este último caso la hidroxiapatita HA2 penetra también de manera homogénea en la estructura porosa del soporte pétreo. El mapping de la Figura 8.25 y los microanálisis EDX detectan el fósforo (P) en áreas próximas a la superficie de 2,43\% (área señalada de la Figura 8.26), disminuyendo su contenido a un valor de $0,18 \%$ en un área más profunda como se muestra en la Figura 8.27. En este último caso el área señalada se sitúa a una profundidad de $2000 \mu \mathrm{m}$.
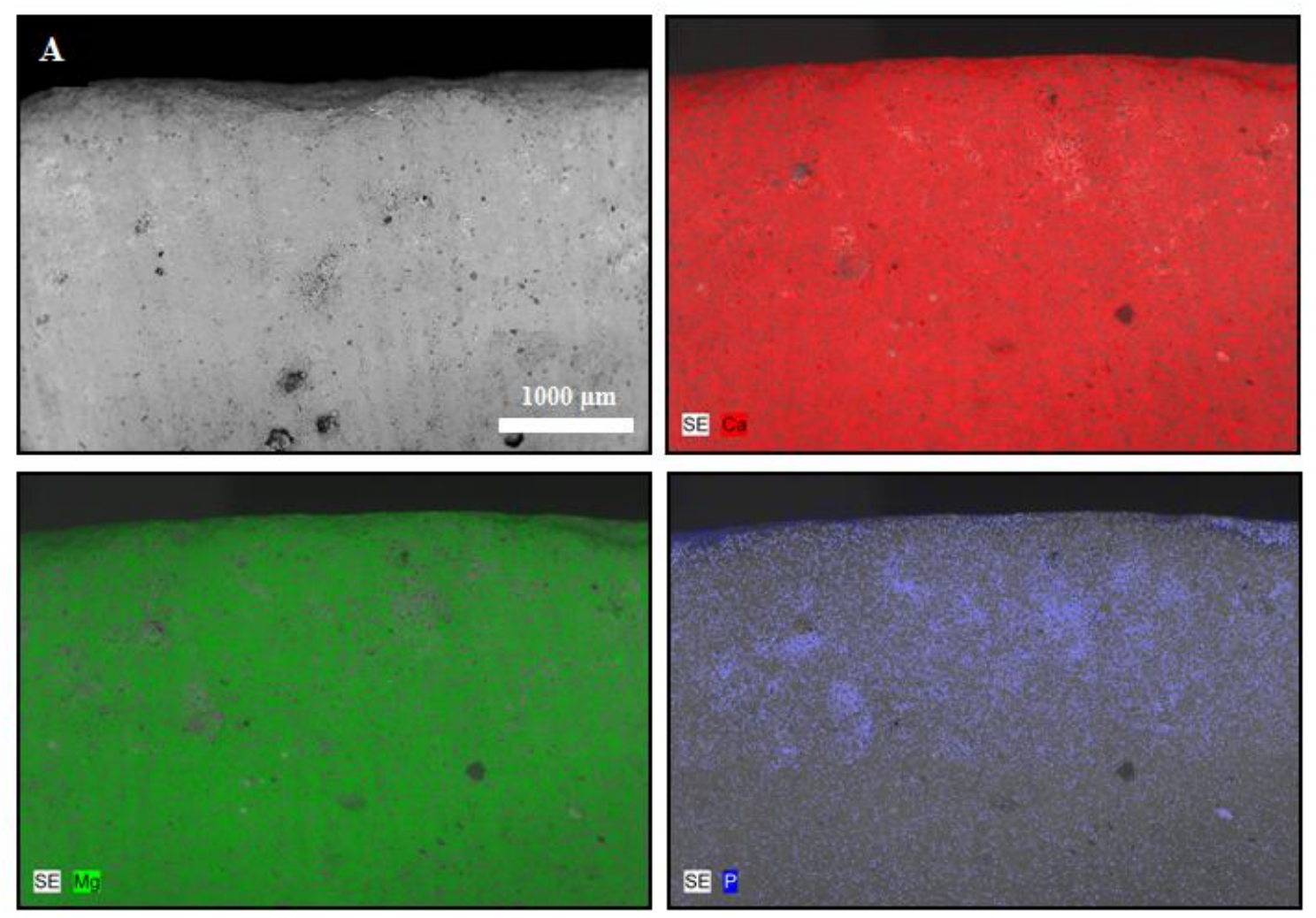

Figura 8.25. A) Imagen por SEM del corte transversal de la probeta pétrea tratada con la muestra HA2. Distribución espacial de los elementos del fósforo $(\mathrm{P})$, calcio $(\mathrm{Ca})$ y magnesio $(\mathrm{Mg})$. 


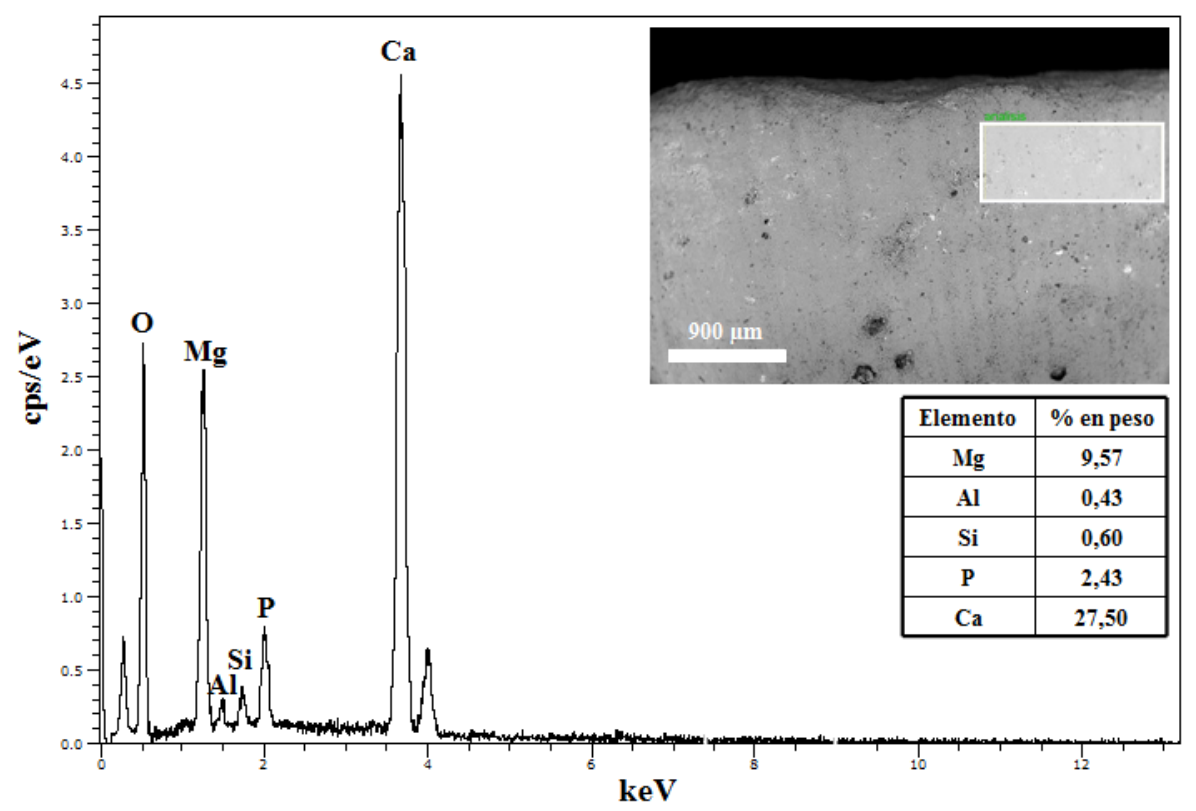

Figura 8.26. Micrografía obtenida por SEM (inset) de un área de la probeta de soporte pétreo tratado con HA2 observado en corte transversal, y espectro EDX de la región marcada en la imagen. En forma de tabla se expresa el \% en peso de los diferentes elementos detectados.

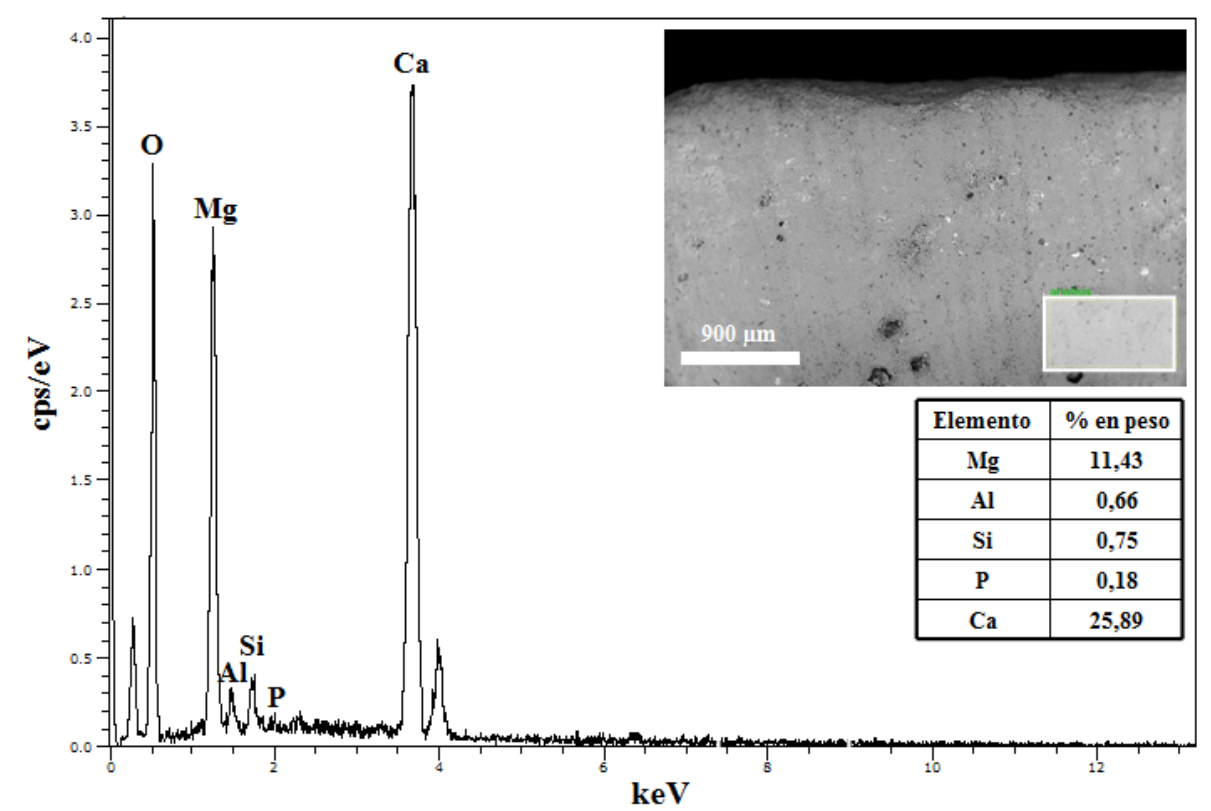

Figura 8.27. Micrografía obtenida por SEM (inset) de un área de la probeta de soporte pétreo tratado con HA2 observado en corte transversal, y espectro EDX de la región marcada en la imagen. En forma de tabla se expresa el \% en peso de los diferentes elementos detectados. 


\subsubsection{Estudio de espectroscopia infrarroja por transformada de Fourier (FTIR)}

También en este caso, en el espectro FTIR (Figura 8.28) correspondiente al soporte pétreo tratado con la muestra de hidroxiapatita cristalina HA2 (en azul), aparecen las bandas del grupo fosfato $\mathrm{PO}_{4}{ }^{3-}$ a $560-600$ $\mathrm{cm}^{-1}$ y $1100 \mathrm{~cm}^{-1}$. La banda intensa a $1400 \mathrm{~cm}^{-1}$ y las bandas de menor intensidad a $650-870 \mathrm{~cm}^{-1}$ corresponden a la presencia de carbonato del soporte pétreo.

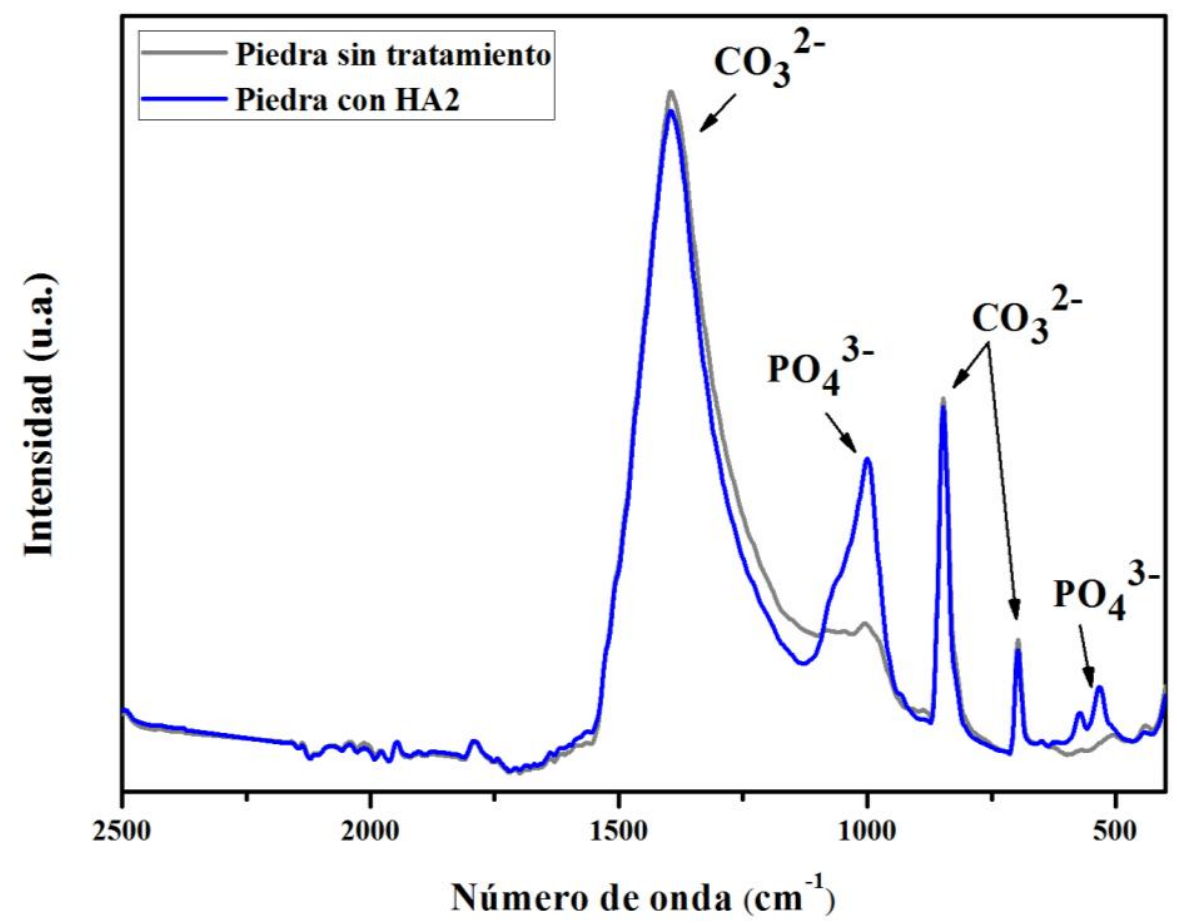

Figura 8.28. Espectro FTIR de la piedra sin tratar (gris) y de la piedra tratada con HA2 (azul). 


\subsubsection{Colorimetría}

La evaluación de una correcta acción consolidante o de protección por parte de un producto, incluye los posibles cambios de las propiedades cromáticas de la superficie pétrea con el tratamiento. La evaluación de este estudio ha continuado con la medida de las coordenadas colorimétricas CIEL*a*b* en las áreas seleccionadas preliminarmente antes y después de la aplicación de los productos.

En la Tabla 8.1 se resumen los resultados de espectrofotometría, donde se indican los parámetros cromáticos de los diferentes colores antes y después de aplicar el tratamiento con las tres dispersiones acuosas de ACP, HA1 y HA2. Con los parámetros cromáticos obtenidos, se calculó la variación total del color $\Delta \mathrm{E}^{*}$.

Tabla 8.1. Valores promedios colorimétricos CIEL*a*b* iniciales y finales, diferenciales de cada parámetro y valor del cambio total del color $\Delta \mathrm{E}^{*}$.

\begin{tabular}{|c|c|c|c|c|c|c|c|c|c|c|}
\hline \multirow[b]{2}{*}{ Muestra } & \multicolumn{3}{|c|}{$\begin{array}{l}\text { Valores } \mathrm{L}^{*} \mathrm{a}^{*} \mathbf{b}^{*} \\
\text { sin tratamiento }\end{array}$} & \multicolumn{3}{|c|}{$\begin{array}{l}\text { Valores } \mathbf{L}^{*} \mathbf{a}^{*} \mathbf{b}^{*} \\
\text { con tratamiento }\end{array}$} & \multicolumn{4}{|c|}{$\begin{array}{l}\text { Variaciones de los valores } \\
\mathbf{L}^{*} \mathbf{a}^{*} \mathbf{b}^{*}\end{array}$} \\
\hline & $\begin{array}{l}\mathbf{L}_{\mathrm{i}} \\
(\mathrm{D} 65)\end{array}$ & $\begin{array}{l}\mathbf{a}^{*} \\
(\mathbf{D 6 5})\end{array}$ & $\begin{array}{l}\mathbf{b}^{*}{ }_{i} \\
(\mathrm{D} 65)\end{array}$ & $\begin{array}{l}\mathbf{L} *_{\mathrm{f}} \\
\text { (D65) }\end{array}$ & $\begin{array}{l}\mathbf{a}_{\mathrm{f}} \\
(\mathrm{D} 65)\end{array}$ & $\begin{array}{l}\mathbf{b}_{\mathrm{f}} \\
(\mathbf{D} 65)\end{array}$ & $\Delta \mathbf{L}^{*}$ & $\Delta \mathbf{a}^{*}$ & $\Delta \mathbf{b}^{*}$ & $\Delta \mathbf{E}^{*}$ \\
\hline $\mathbf{A C P}$ & 77,06 & 5,01 & 24,82 & 79,39 & 2,8 & 17,91 & 2,33 & $-2,21$ & $-6,91$ & 7,62 \\
\hline HA1 & 77,6 & 4,57 & 23,04 & 79,77 & 3,11 & 18,68 & 2,17 & $-1,46$ & $-4,36$ & 5,08 \\
\hline HA2 & 78,85 & 4,26 & 19,55 & 79,24 & 3,38 & 20,64 & 0,39 & $-0,88$ & 1,1 & $\overline{1,46}$ \\
\hline
\end{tabular}

En general, se observa como la cristalinidad de las muestras aplicadas influye en el cambio de los parámetros cromáticos de la superficie pétrea. Hay un ligero incremento del cambio de color $\Delta \mathrm{E}^{*} \mathrm{y}$ tan sólo se producen pequeñas modificaciones en los parámetros $\mathrm{L}^{*}, \mathrm{a}^{*} \mathrm{y} \mathrm{b}^{*}$. Se observa que con la disminución de la cristalinidad de las muestras hay un aumento en la diferencia de color $\Delta \mathrm{E}^{*}$. Para la dispersión de HA2 (mayor cristalinidad) se registra un cambio de color de $\Delta \mathrm{E}^{*}=1,46$, manteniéndose por debajo del valor límite de 6, por lo que el producto ensayado no afecta a los parámetros colorimétricos de la superficie después del tratamiento. Al reducir la cristalinidad de la muestra el cambio de color aumenta. En la dispersión acuosa de HA1 caracterizada por la hidroxiapatita de menor cristalinidad el cambio de color $\Delta \mathrm{E}^{*}$ sube a un valor límite de 5,08. En el caso de la muestra ACP se registra una diferencia de color de 7,62. El tratamiento, en este último caso, provoca una alteración en los parámetros cromáticos, que en base a los principios de intervención en obras de arte, no resulta ser aceptable. 


\subsubsection{Perfilometría}

Los resultados de perfilometría confirman la existencia de una modificación en la porosidad de superficie del material pétreo después del tratamiento. En la Tabla 8.2 y en la gráfica de la Figura 8.29 se indican los valores promedios de rugosidad iniciales y finales. Las probetas de soporte pétreo utilizadas para las medidas de los parámetros de rugosidad tienen una porosidad natural muy variable entre ellas. Esto determina la diferencia de los valores de perfilometría, a veces muy distantes entre ellos, de una muestra a otra.

En base a la bibliografía consultada ${ }^{205,206}$, para simplificar el estudio de perfilometría de las probetas de soporte pétreo antes y después de la aplicación de las muestras de hidroxiapatita, sin detrimento del rigor científico, se pueden considerar únicamente los parámetros $\mathrm{Ra}$ (valor promedio de rugosidad), y $\mathrm{Rz}$ (distancia entre el punto más alto y el más bajo del registro perfilométrico), las cuales presentan una alta correlación entre ellas. En el caso de las probetas tratadas con la muestra ACP se registra una disminución de Ra del $47 \%$ y de Rz del 30\%, mientras para las probetas tratadas con HA1 la disminución de Ra es del $46 \%$ y $\mathrm{Rz}$ del $44 \%$. Finalmente para las probetas tratadas con la muestra de hidroxiapatita HA2 se registra igualmente una disminución significativa de los parámetros Ra y Rz del 37\% y del 56\% respectivamente.

En todos los casos hay una disminución importante de los valores de rugosidad de la superficie, y se aprecia que todas las variables estudiadas (Ra, Rz, Rp y Rv), tienen un alto nivel de correlación.

Tabla 8.2. Valores promedios de rugosidad iniciales y después del tratamiento con las muestras de hidroxiapatita.

\begin{tabular}{|c|c|c|c|c|c|c|c|c|}
\hline & \multicolumn{4}{|c|}{ Valores de rugosidad $(\boldsymbol{\mu m})$ sin tratamiento } & \multicolumn{4}{|c|}{ Valores de rugosidad $(\boldsymbol{\mu m}) \mathbf{c o n}$} \\
tratamiento \\
\hline Muestra & $\mathbf{R a}_{\mathbf{i}}$ & $\mathbf{R z}_{\mathbf{i}}$ & $\mathbf{R} \mathbf{p}_{\mathbf{i}}$ & $\mathbf{R v}_{\mathbf{i}}$ & $\mathbf{R a}_{\mathbf{f}}$ & $\mathbf{R z}_{\mathbf{f}}$ & $\mathbf{R p}_{\mathbf{f}}$ & $\mathbf{R v}_{\mathbf{f}}$ \\
\hline ACP & 4,586 & 17,279 & 11,645 & $-7,227$ & 2,424 & 11,745 & 4,518 & $-5,634$ \\
\hline HA1 & 5,229 & 32,612 & 25,172 & $-27,439$ & 3,579 & 18,230 & 14,758 & $-13,472$ \\
\hline HA2 & 4,203 & 12,958 & 10,517 & $-11,941$ & 2,651 & 5,631 & 2,580 & $-3,051$ \\
\hline
\end{tabular}

\footnotetext{
${ }^{205}$ W.B. Davis, A comparison of dentin abrasion data generated by radiotracer and surface profilometer methods, J Oral Rehabil, 6 , 177-181, 1979.

${ }^{206}$ G.R. Goldstein, B.R. Barnhard, B. Penugonda, Profilometer, SEM, and visual assessment of porcelain polishing methods, J Prosthet Dent, 65, 627-634, 1991.
} 


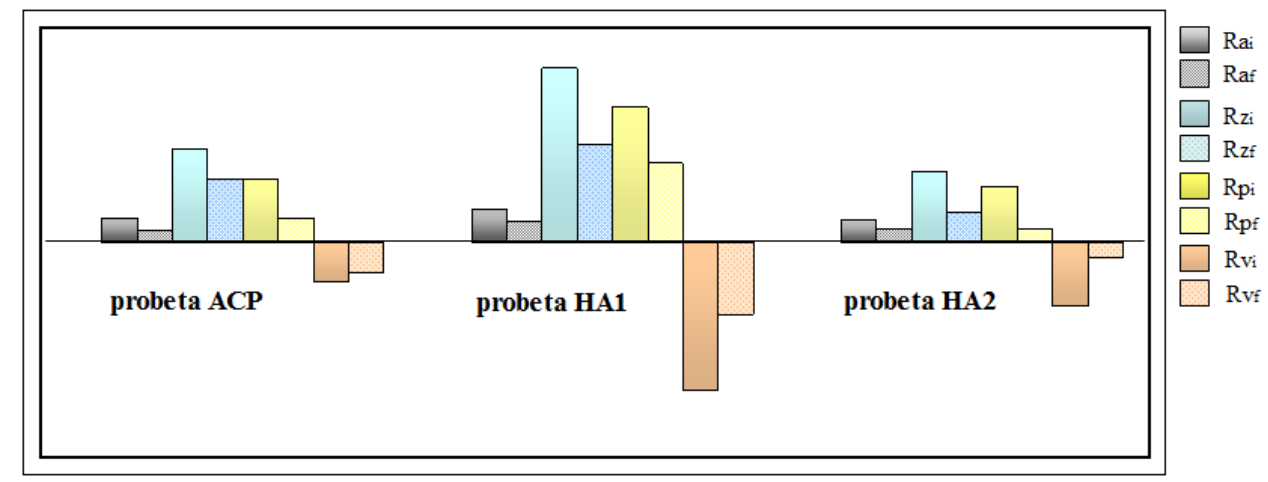

Figura 8.29. Variación de los valores de perfilometría Ra, Rz, Rp y Rv iniciales y finales.

Posteriormente se estudiaron los perfiles de rugosidad de las probetas de soporte pétreo tratadas con las muestras ACP, HA1 y HA2. En la Figura 8.30 se presentan los valores obtenidos desde 0 a $3900 \mu \mathrm{m}$ correspondiente a la zona de la probeta pétrea sin tratamiento (Zona A), y de 4000 a $8000 \mu \mathrm{m}$ de la zona tratada con la muestra ACP (Zona B). Se observa como las profundidades y alturas de los picos negativos y positivos se reducen significativamente formando un perfil de rugosidad más homogéneo pasando de la zona sin tratamiento a la zona tratada con ACP.

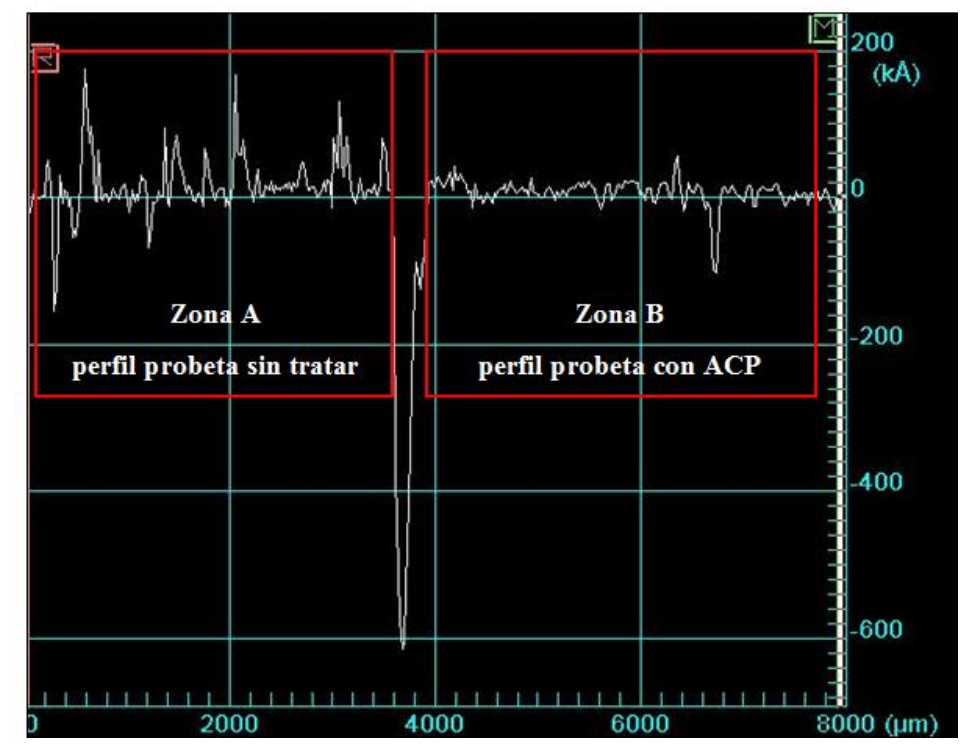

Figura 8.30. Grafico obtenido por perfilometría donde se muestra el perfil de rugosidad de la probeta de soporte pétreo. 
Para las probetas tratadas con las restantes muestras se pueden apreciar resultados similares al caso anterior. En los perfiles de rugosidad de la probeta con HA1 de la Figura 8.31 y de la probeta con HA2 de la Figura 8.32 se evidencia el perfil obtenido en la parte de la probeta sin tratamiento (Zona A, de 0 a $3800 \mu \mathrm{m}$ ) y el perfil de la zona tratada con HA1 (Zona B, de 4100 a $8000 \mu \mathrm{m}$ ). Se observa que la aplicación de las muestras HA1 y HA2 permite pasar a un perfil más uniforme con la reducción de las profundidades y de los picos después del tratamiento.

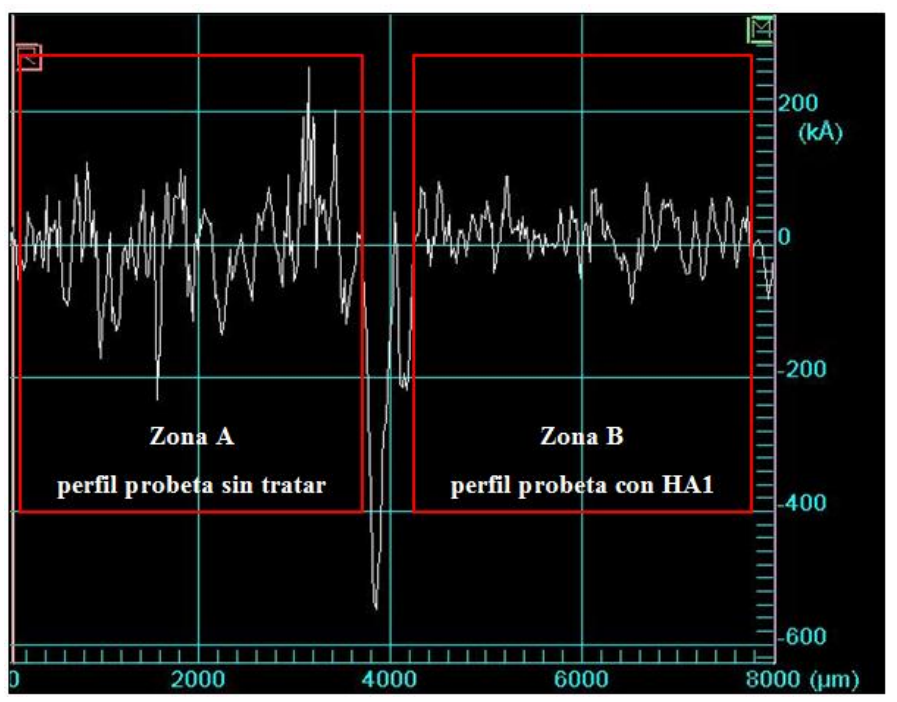

Figura 8.31. Grafico obtenido por perfilometría donde se muestra el perfil de rugosidad de la probeta de soporte pétreo.

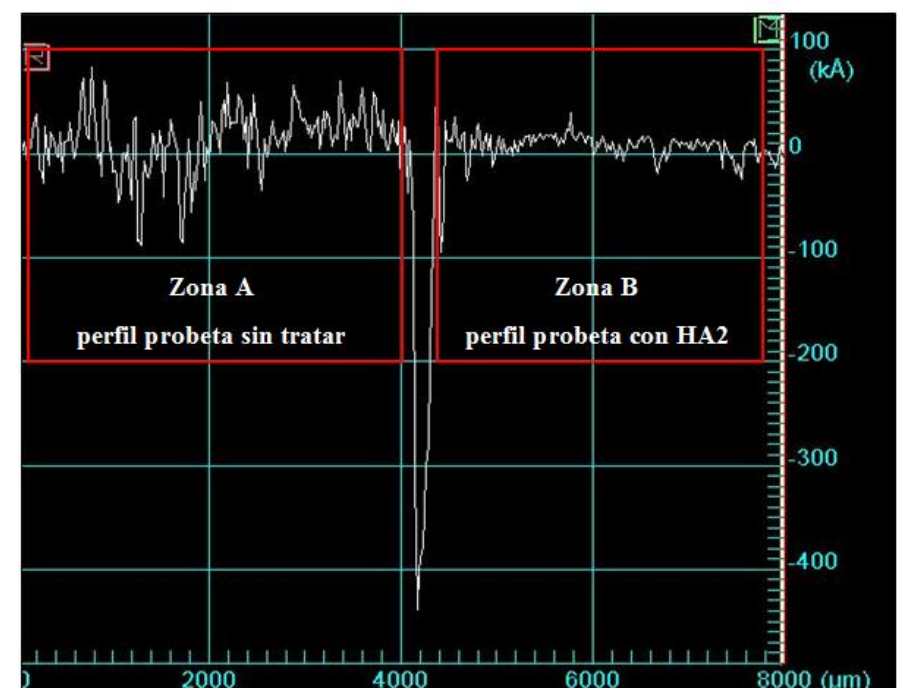

Figura 8.32. Grafico obtenido por perfilometría donde se muestra el perfil de rugosidad de la probeta de soporte pétreo. 


\subsubsection{Estudio de absorción de agua por capilaridad}

El análisis de la absorción de agua por capilaridad nos permitió observar los cambios en el comportamiento de absorción de agua por parte del material pétreo tras el tratamiento con las diferentes muestras ensayadas. El análisis se llevó a cabo antes y después del tratamiento -un mes después de la aplicación de las dispersiones acuosas-. De esta manera ha sido posible diseñar un gráfico con la curva de absorción de las probetas de piedra no tratadas, que se relacionan con las mismas probetas tratadas. Todos los perfiles de absorción obtenidos para cada muestra se presentan en las Figuras 8.33-8.35. Los resultados obtenidos se promedian sobre la base de las mediciones realizadas en tres probetas de piedra diferentes para cada tratamiento según la normativa anteriormente citada.

En general, las probetas de soporte pétreo no tratadas poseen una cinética de absorción de agua por capilaridad extremadamente rápida durante la etapa inicial de las medidas, tal y como se muestra en la alta pendiente del tramo inicial de la curva de absorción. La absorción se ralentiza de manera bastante evidente después de treinta minutos aproximadamente, presentando una cinética de absorción más lenta ya que se va alcanzando la saturación. Con el tiempo el grado de saturación de las probetas se acerca cada vez más a un valor asintótico.

En las probetas tratadas con la muestra ACP (Figura 8.33) hay un aumento inicial de la velocidad de absorción de agua. La cantidad total de agua absorbida por parte de las probetas resulta ser ligeramente inferior a la cantidad de agua absorbida por parte de las mismas probetas sin tratamiento, alcanzando un valor aproximado de $1,3 \mathrm{~g} / \mathrm{cm}^{2}$ de agua absorbida. Para las probetas tratadas con la muestra HA1 (ver grafico de la Figura 8.34) hay una disminución inicial de la velocidad de absorción de agua creando un sistema que parece alcanzar los valores de saturación de manera menos rápida. La cantidad total de agua absorbida por parte de las probetas es similar a la cantidad de agua absorbida por parte de las mismas probetas sin tratamiento, alcanzando un valor aproximado de $1,3 \mathrm{~g} / \mathrm{cm}^{2}$ de agua absorbida.

Finalmente, para las probetas tratadas con la hidroxiapatita HA2, como se muestra en las graficas de la Figura 8.35, hay un pequeño incremento de la velocidad inicial de absorción de agua. La piedra, después del tratamiento, presenta una cinética de absorción de agua con el tiempo prácticamente similar a la piedra no tratada. La cantidad total de agua absorbida por parte de las probetas resulta ser inferior a la cantidad de agua absorbida por parte de las mismas probetas sin tratamiento (diferencia de $0,3 \mathrm{~g} / \mathrm{cm}^{2}$ ), alcanzando un valor aproximado de $1,5 \mathrm{~g} / \mathrm{cm}^{2}$ de agua absorbida.

En el último caso, la disminución del grado de absorción tras la aplicación de los productos, respecto al material pétreo no tratado es, posiblemente, inducida por el efecto de relleno de los poros de la piedra, en 
particular de la porosidad más pequeña y superficial. Para todos los productos ensayados, el sustrato pétreo después del tratamiento con las tres muestras es totalmente humectable.

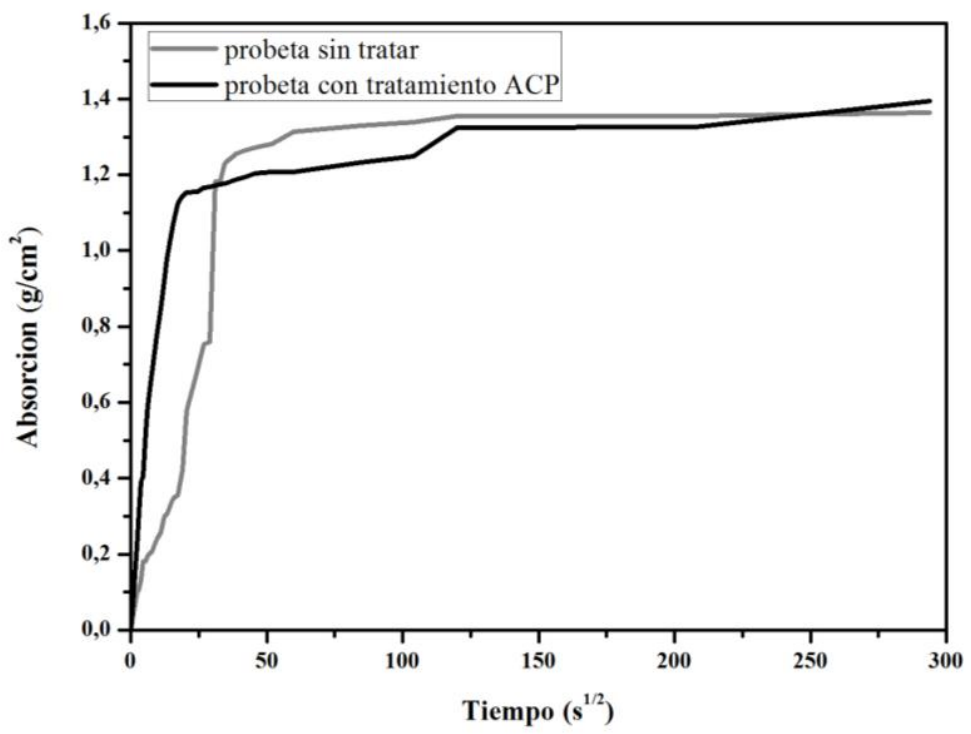

Figura 8.33. Perfil promedio de absorción de agua por capilaridad de las probetas pétreas tratadas con la muestra ACP.

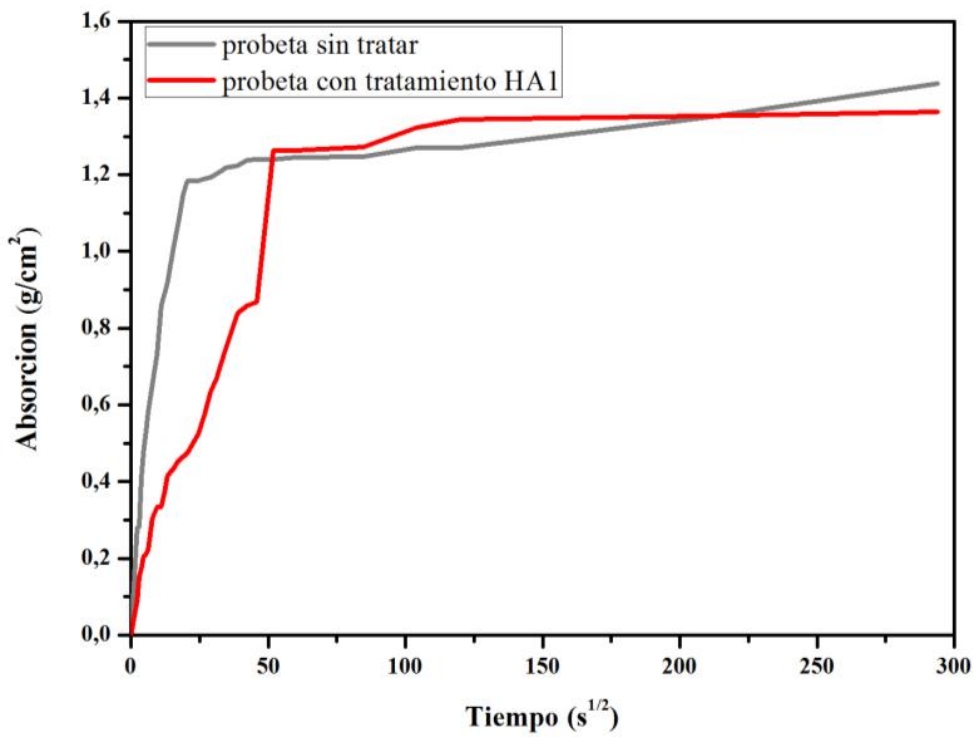

Figura 8.34. Perfil promedio de absorción de agua por capilaridad de las probetas pétreas tratadas con la muestra HA1. 


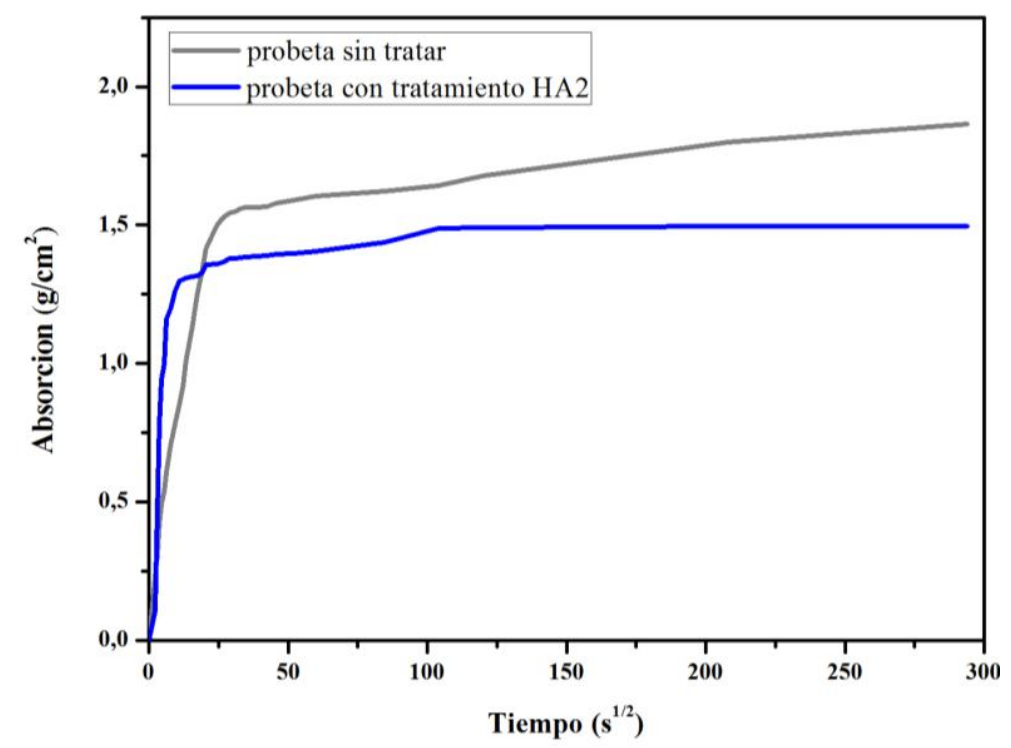

Figura 8.35. Perfil promedio de absorción de agua por capilaridad de las probetas pétreas tratadas con la muestra HA2.

En la tabla 8.3 se muestran los valores medios de absorción de agua de las probetas antes y después de la aplicación de las muestras. Los valores de la absorción de agua por capilaridad $\mathrm{Q}_{\mathrm{i}}$ calculados para cada tratamiento, resultan coherentes con lo expuesto anteriormente. Se advierte como los valores siguen los procesos de absorción de agua con una tendencia a disminuir sensiblemente después del tratamiento. La absorción de agua se reduce más con la aplicación de las muestras de HA1 y HA2 donde se registra una disminución del 4,70\% y 7,25\% respectivamente, respecto a las probetas con ACP donde la reducción es del $2,19 \%$.

Tabla 8.3. Valores medios de absorción de agua por capilaridad $\mathrm{Q}_{\mathrm{i}}$.

\begin{tabular}{|l|c|c|c|}
\hline & \multicolumn{2}{|c|}{ Valores de la absorción de agua por capilaridad $\mathbf{Q}_{\mathbf{i}}$} & Variación (\%) \\
\hline & Sin tratamiento & Con tratamiento & \\
\hline ACP & 1395,041 & 1364,462 & $-2,19$ \\
\hline HA1 & 1438,381 & 1370,707 & $-4,70$ \\
\hline HA2 & 1865,000 & 1729,721 & $-7,25$ \\
\hline
\end{tabular}


En la Tabla 8.4 se muestran los valores del coeficiente de absorción capilar (CA), calculados según lo establecido en la norma de referencia.

Tabla 8.4. Coeficientes de absorción capilar (CA).

\begin{tabular}{|c|c|}
\hline \multicolumn{2}{|c|}{ Coeficientes de absorción capilar $(\mathbf{C A})$} \\
\hline Muestra & $\mathbf{C A}\left(\mathbf{m g} / \mathbf{c m}^{2} \mathbf{~}^{1 / 2}\right)$ \\
\hline Promedio sin tratamiento & 34,65 \\
\hline ACP & 24,91 \\
\hline HA1 & 23,58 \\
\hline HA2 & 22,75 \\
\hline
\end{tabular}

Los valores de los coeficientes de absorción calculados para cada tipo de tratamiento se ajustan plenamente con lo expuesto anteriormente basándonos en la observación de las curvas de absorción de las probetas. El coeficiente más alto se ha obtenido de la curva de las probetas tratadas con la muestra ACP. En general, con la aplicación de las tres muestras en las probetas se produce un comportamiento similar con un disminución progresiva, desde la muestra ACP hasta la HA2, en el proceso de absorción por capilaridad. En ningún caso se observa una reducción drástica de absorción de agua, lo que indica que la hidroxiapatita no cierra totalmente el sistema de poros de la piedra. Tal y como comentado anteriormente, el soporte pétreo después del tratamiento sigue totalmente humectable. 


\subsubsection{Estudio de la determinación de la permeabilidad al vapor de agua}

De igual manera que en las evaluaciones anteriores, la medida de la permeabilidad al vapor de agua se llevó a cabo en las probetas antes y después de la aplicación del tratamiento con el fin de tener una comparación exacta sobre la misma probeta del cambio producido en el parámetro de la permeabilidad al vapor de agua en condiciones de alta humedad y baja humedad.

Para la determinación de la permeabilidad al vapor de agua se consideró inicialmente el grado de transmisión del vapor de agua WDD a partir del cual se obtuvieron los valores promedios de la permeabilidad calculados en base las normas de referencia. Se ha determinado también el factor a la resistencia al vapor de agua $\mu$ que, al ser un parámetro bastante difuso en estudios similares, permitiría realizar fácilmente comparaciones con otras investigaciones y materiales. El cálculo de los distintos parámetros se ha realizado teniendo en cuenta la fase de equilibrio de las probetas de piedra, es decir, cuando la variación del peso se mantuvo constante durante al menos tres pesadas sucesivas realizadas a una veinticuatro horas de diferencia entre ellas. En las Tablas 8.5 y 8.6 se muestran respectivamente los valores promedios calculados antes y después de la aplicación de las muestras con estequiometría de hidroxiapatita y las variaciones de los parámetros considerados.

Tabla 8.5. Valores promedios para la determinación de la permeabilidad al vapor de agua de las probetas de soporte pétreo antes y después del tratamientos con las muestras sintetizadas.

\begin{tabular}{|c|c|c|c|c|c|c|}
\hline & \multicolumn{3}{|c|}{ Antes del tratamiento } & \multicolumn{3}{|c|}{ Después del tratamiento } \\
\hline Muestra & $\begin{array}{c}\text { WDD } \\
\left(\mathrm{g} / \mathrm{m}^{2} 24 \mathrm{~h}\right)\end{array}$ & $\begin{array}{l}\text { Permeabilidad } \\
\text { (g/m² } 24 \text { h Pa) }\end{array}$ & $\boldsymbol{\mu}$ & $\begin{array}{c}\text { WDD } \\
\left(\mathrm{g} / \mathrm{m}^{2} 24 \mathrm{~h}\right)\end{array}$ & $\begin{array}{l}\text { Permeabilidad } \\
\text { (g/m² } 24 \text { h Pa) }\end{array}$ & $\boldsymbol{\mu}$ \\
\hline $\mathrm{ACP}$ & 169,25 & $3,25 \cdot 10^{-3}$ & 5,02 & 105,25 & $2,98 \cdot 10^{-3}$ & 29,79 \\
\hline HA1 & 175,89 & $3,46 \cdot 10^{-3}$ & 4,83 & 126,83 & $3,12 \cdot 10^{-3}$ & 21,83 \\
\hline HA2 & 203,72 & $3,76 \cdot 10^{-3}$ & 4,41 & 158,41 & $3,59 \cdot 10^{-3}$ & 18,37 \\
\hline
\end{tabular}

Tabla 8.6. Valores de las variaciones de los parámetros calculados por efectos de los tratamientos en las probetas de soporte pétreo con las muestras sintetizadas.

\begin{tabular}{|c|c|c|c|c|}
\hline Muestra & $\boldsymbol{\Delta}$ WDD & Variación WDD (\%) & $\Delta$ Permeabilidad & Variación permeabilidad (\%) \\
\hline ACP & $-64,00$ & $-37,81$ & $-2,7 \cdot 10^{-4}$ & $-8,30$ \\
\hline HA1 & $-49,59$ & $-27,89$ & $-3,4 \cdot 10^{-4}$ & $-9,82$ \\
\hline HA2 & $-45,31$ & $-22,24$ & $-1,7 \cdot 10^{-4}$ & $-4,52$ \\
\hline
\end{tabular}


Con los datos obtenidos se aprecia como los tratamientos en las probetas de piedra por parte de los tres tratamientos provocan variaciones estimables de transpirabilidad, con una tenue disminución del grado de transmisión WDD y de los valores de permeabilidad. Se registra en todos los casos un incremento del factor $\mu$ inherente a la resistencia al vapor de agua.

En general, los cambios resultan ser poco significativos con una reducción del valor de la permeabilidad que se encuentra por debajo del 10\% en todos los casos. En base a la disminución de los parámetros calculados, que muestra efectivamente la presencia del producto aplicado en la estructura porosa de la piedra, la transpirabilidad permanece de todos modos a niveles aceptables dentro de un valor límite entre 10-20\% tal y como indicado en la bibliografía consultada ${ }^{207,208,209}$. En definitiva, los tratamientos evaluados en todos los casos permiten conservar una buena transpirabilidad y circulación del vapor de agua en la estructura de la piedra sin modificar excesivamente la natural permeabilidad del material.

\footnotetext{
207 D. Melica, L. Matera, A. Calia, M. Dilillo, S. Luppino, G. Lanza, G. Riccardi, Valutazione dell'efficacia di trattamenti conservativi a base de silicato de etilo su pietra arenaria: il caso della cinta muraria de Castiglione di Paludi (CS), Actas del IX Congresso Nazionale IGIIC, Lo Stato dell'Arte, 2011.

${ }^{208}$ L. Appolonia, V. Fassina, U. Matteoli, A.M. Mecchi, M.P. Nugari, D. Pinna, R. Peruzzi, O. Salvadori, U. Santamaria, A. Scala, P. Tiano, Methodology for the evaluation of protective products for stonematerials. Part II: experimental tests on treated samples, International Colloqium Methods ofevaluating products for the conservation of porous building materials in monuments, 301-316, 1995.

${ }^{209}$ A. Glisenti, B. Biscontin, A. Viscardi, Valutazione di protettivi all'acqua ed in solvente per superfici lapidee, Actas del Convegno Internazionale "Le pietre nell'Architettura: struttura e superfici”, 473-484, 1991.
} 


\subsection{Evaluación de la hidroxiapatita HA2 sobre soporte pétreo con alteración}

Tras los resultados obtenidos con la evaluación de las muestras ACP, HA1 y HA2 sobre probetas de soporte pétreo sin alteración, se ha procedido en ensayar la muestra de hidroxiapatita que mejor resultado ha proporcionado en un fragmento de soporte pétreo con alteración por sulfatación. De esta manera, se pretende profundizar el estudio de la aplicabilidad y efectividad de la muestra HA2.

La finalidad es estudiar como actúa la hidroxiapatita HA2 sobre un sustrato pétreo alterado, con presencia de sulfato de calcio que resulta ser soluble y que proporciona, generalmente, una baja resistencia mecánica del soporte pétreo con tendencia a la disgregación. Es un ejemplo interesante de alteración donde no es posible intervenir a través de tratamientos de eliminación de sales ya que esto provocaría el deterioro de la estructura cristalina del sustrato pétreo y por tanto su pérdida.

La aplicación de la dispersión acuosa de la muestra HA2 se ha realizado sobre un fragmento de soporte pétreo afectado por sulfatación que se muestra en la Figura 8.36 A. Este fragmento, igual que las probetas utilizadas en el estudio anterior, procede de la portada principal de la Iglesia de Nuestra Señora de la Asunción de Corral de Almaguer (Toledo), extraído del friso (ver Figura 8.36 B), una zona gravemente afectada por mecanismos de alteración del soporte pétreo con formación, disolución y cristalización de sulfato de calcio.
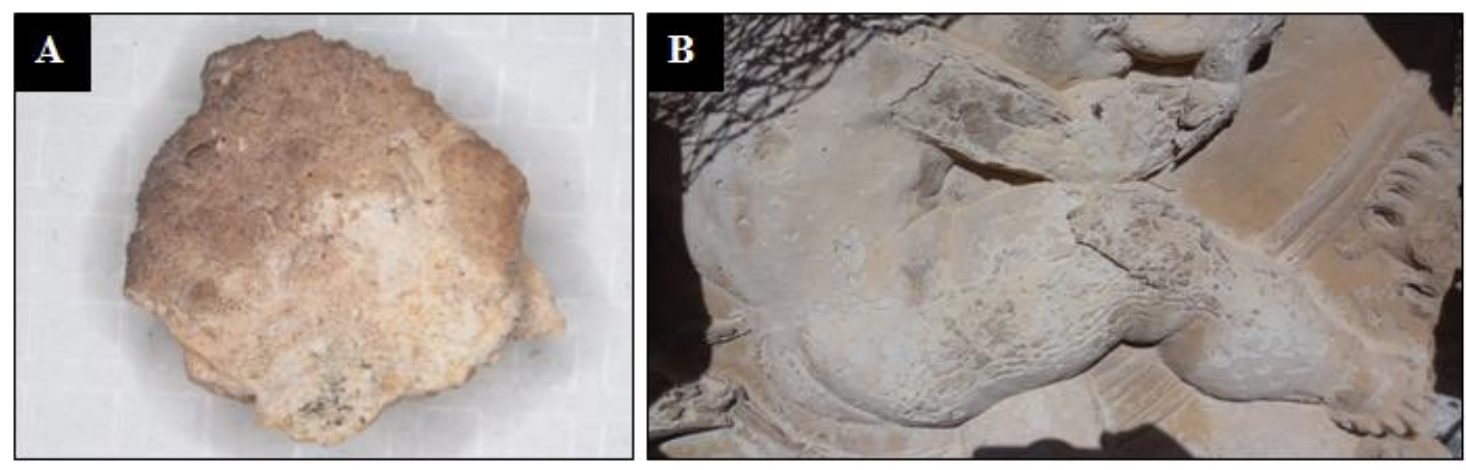

Figura 8.36. A) Fragmento pétreo afectado por mecanismos de alteración. Microscopia estereoscópica, 1,5 x. B) Figura en bajorrelieve del friso de la portada principal de la Iglesia de Nuestra Señora de la Asunción de Corral de Almaguer (Toledo). 
Tal y como se ha descrito con los estudios de evaluación anteriores, el fragmento pétreo ha sido inspeccionado y analizado en superficie y en corte transversal antes y después del tratamiento con HA2 con microscopia estereoscópica, microscopia electrónica de barrido a presión variable VP-SEM con microanálisis EDX y espectroscopia infrarroja FTIR. Las observaciones y los análisis al SEM-EDX se realizaron después de 72 horas tras la aplicación de la muestra HA2, para garantizar la completa evaporación del agua. El fragmento se almacenó en condiciones controladas por 72 horas a $60 \pm 5 \% \mathrm{HR}$ y $23 \pm 2{ }^{\circ} \mathrm{C}$ antes de testarlas.

En este caso hay una reducción de las pruebas de evaluación de la acción consolidante y protectora por parte de la muestra HA2 sobre el fragmento pétreo alterado. Al ser una superficie irregular, rugosa y muy deteriorada, esto imposibilita la realización de pruebas tal como la medida de las coordenadas colorimétricas, de rugosidad o la realización de los ensayos de absorción de agua por capilaridad. 


\subsubsection{Estudio de microscopia electrónica de barrido a presión variable (VP-SEM) con microanálisis EDX}

Las observaciones y los microanálisis EDX realizados antes de la aplicación de la hidroxiapatita HA2 ponen de manifiesto de como extensas áreas superficiales del soporte presentan cristalizaciones laminares que posiblemente sean de sulfato de calcio. Como se muestra en la micrografía de la Figura 8.37, el soporte pétreo presenta una alteración mecánica por disgregación por efecto de la cristalización, provocando una disminución de la resistencia mecánica del soporte y un progresivo aumento de la porosidad.

Los microanálisis EDX de las Figuras 8.38 y 8.39 realizados en diferentes áreas superficiales del fragmento pétreo alterado, confirman la presencia en concentraciones variables desde un mínimo del 3\% hasta un máximo del $9 \%$ en peso de azufre (S), elemento químico relacionado a la cristalización de sulfato de calcio en las zonas que presentan cristalizaciones.

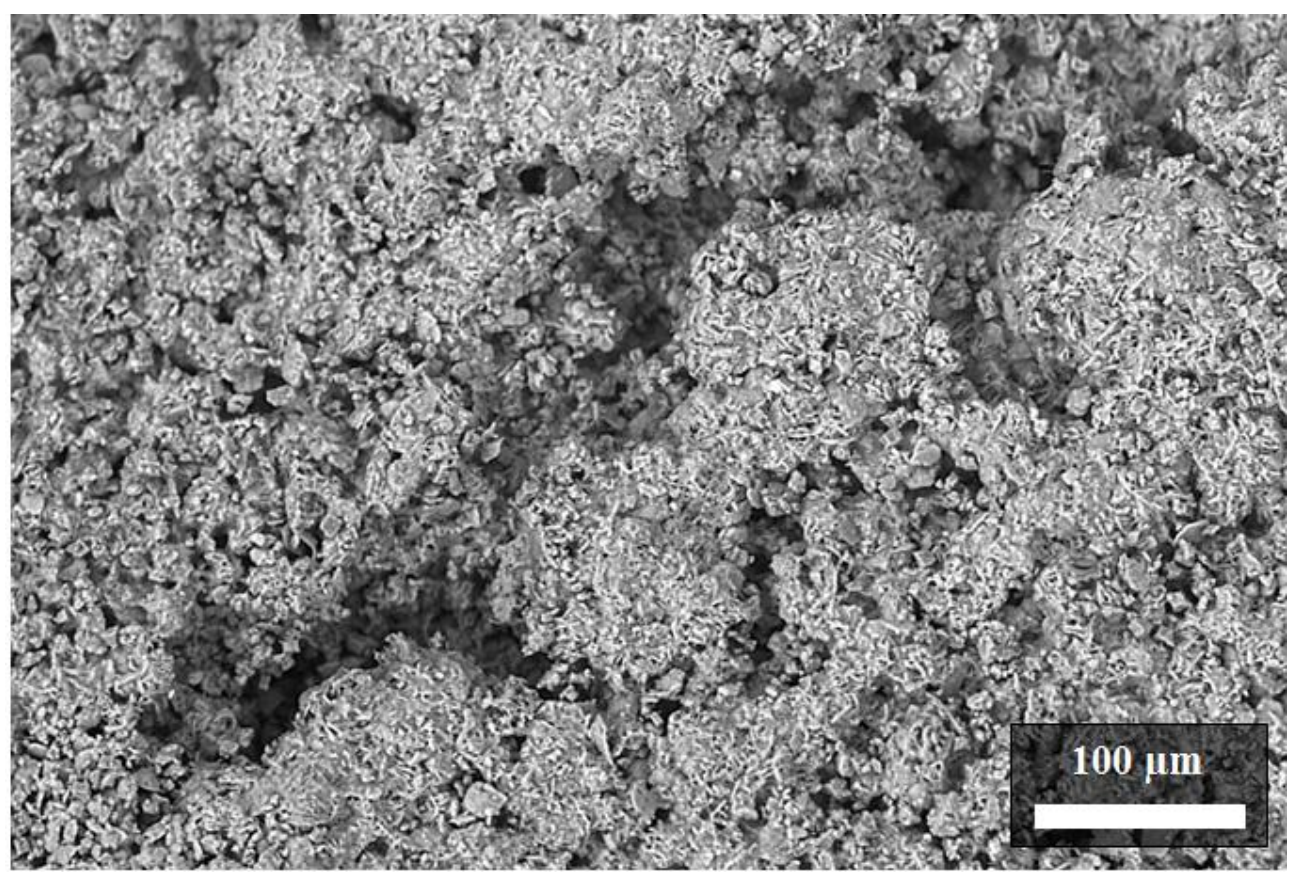

Figura 8.37. Imagen por SEM en modalidad electrones retrodispersados BSE de un área de la superficie del fragmento pétreo alterado por cristalizaciones de sulfato de calcio. El fragmento ha sido seleccionado para la evaluación de la acción consolidante de la hidroxiapatita cristalina HA2. 


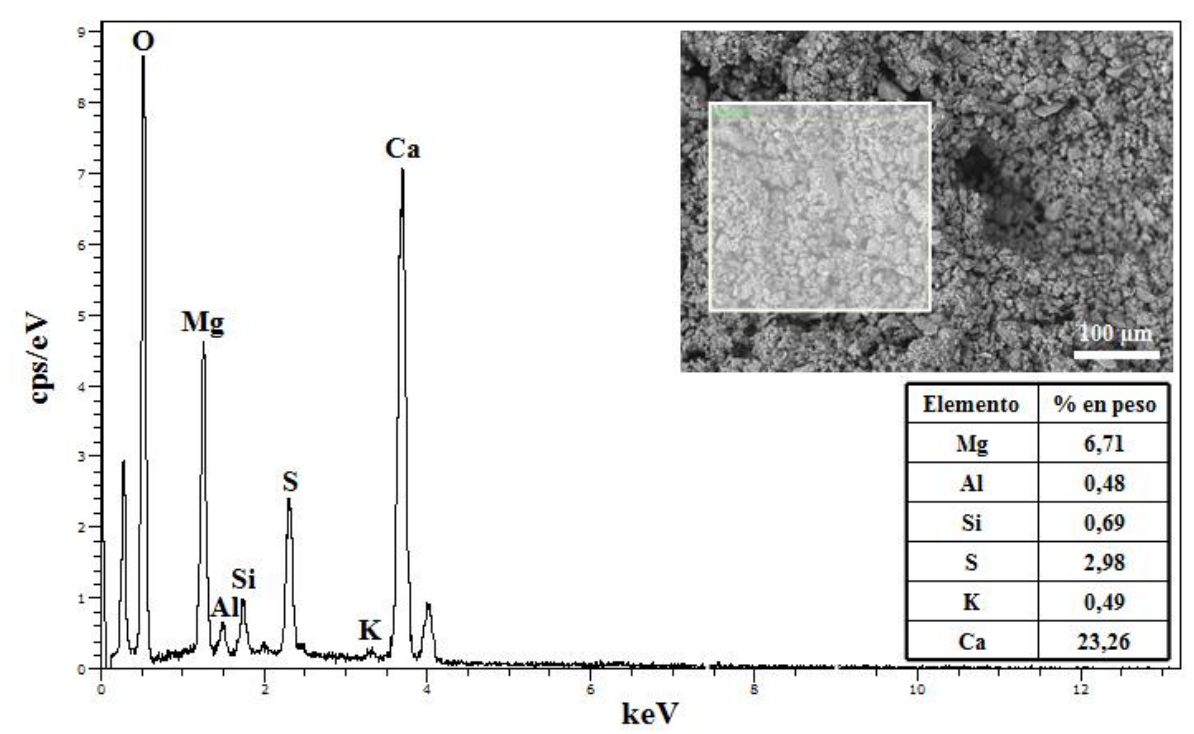

Figura 8.38. Micrografía obtenida por SEM (inset) de un área del fragmento de soporte pétreo alterado observado en superficie, y espectro EDX de la región marcada en la imagen. En forma de tabla se expresa el \% en peso de los diferentes elementos detectados.

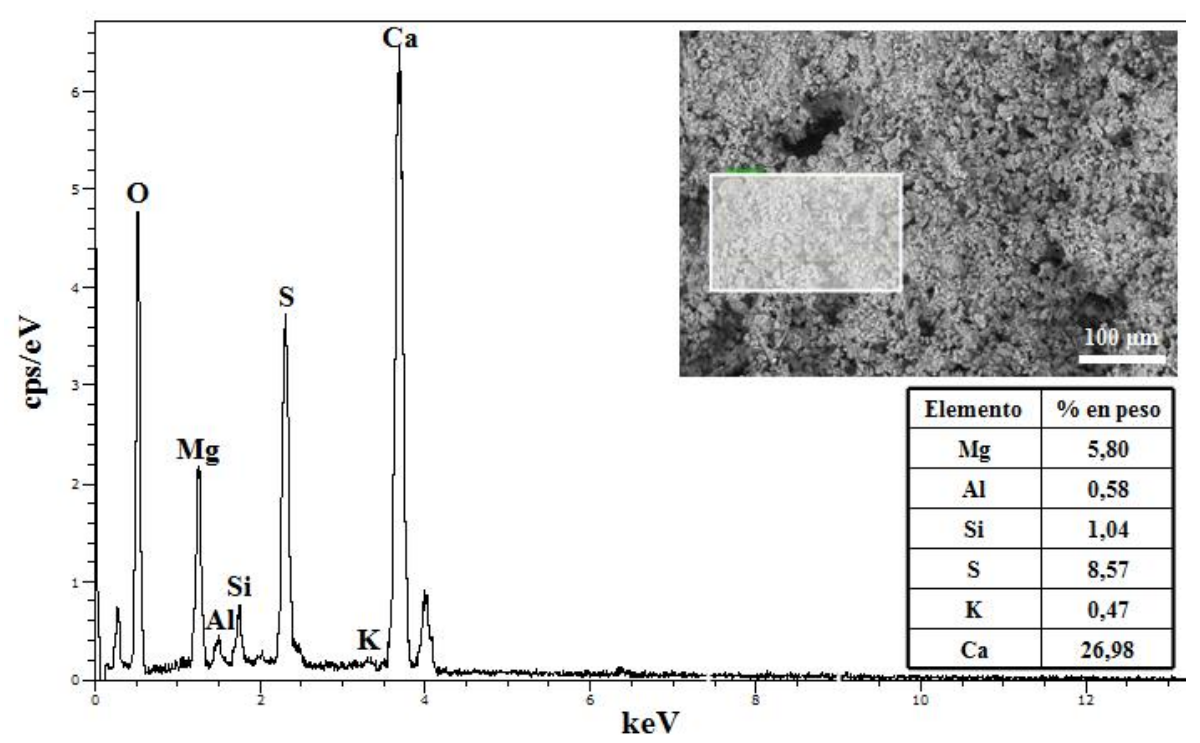

Figura 8.39. Micrografía obtenida por SEM (inset) de un área del fragmento de soporte pétreo alterado observado en superficie, y espectro EDX de la región marcada en la imagen. En forma de tabla se expresa el \% en peso de los diferentes elementos detectados. 
Después del tratamiento con la dispersión acuosa de HA2 se observa una movilización de partículas descohesionadas. En las imágenes de microscopia estereoscópica de la Figura 8.40 se puede apreciar como, tras la aplicación del tratamiento (imágenes $\mathrm{C}$ y D), se produce una ligera variación del tono a nivel macroscópico, con saturación del color de la superficie del sustrato pétreo.
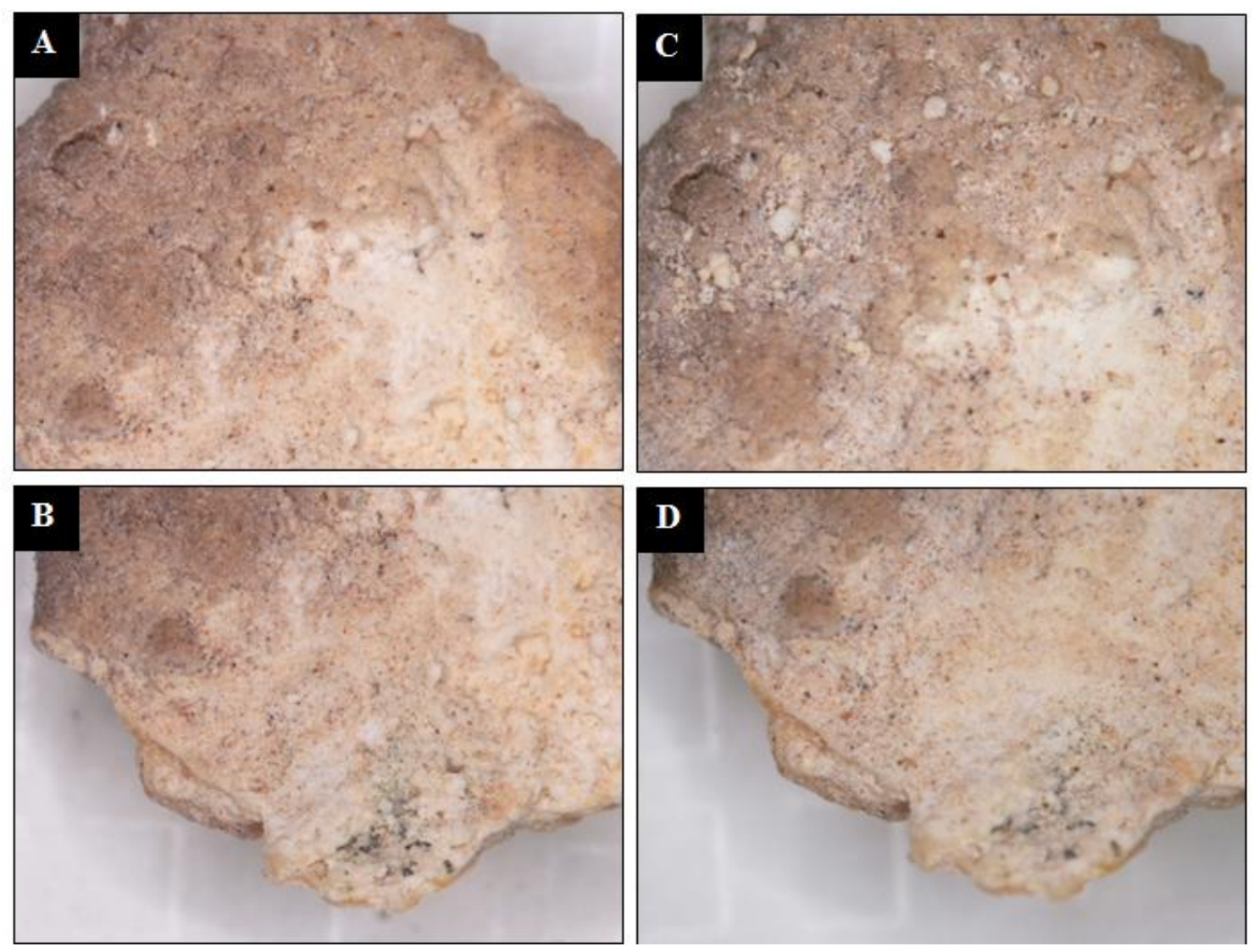

Figura 8.40. Detalles del fragmento pétreo antes de la aplicación de la muestra HA2 (A y B) y después del tratamiento (C y D). Microscopia estereoscópica, 2 x.

Mediante observaciones por SEM se ha realizado un examen de la superficie del fragmento pétreo, operando también en este caso con imágenes composicionales obtenidas a partir de las señales de electrones retrodispersados que ponen de manifiesto la diferente composición de los materiales presentes: soporte, sulfato de calcio e hidroxiapatita. En las imágenes SEM de las Figuras 8.41 se observa el soporte pétreo con su aspecto inicial y como después del tratamiento (imagen SEM de la Figura 8.42) se produce una acción 
cementante con la agregación de los cristales de dolomita y del sulfato de calcio, mostrando así una buena interacción producto-soporte-sistema poroso.

El tratamiento no provoca la formación de películas o costras superficiales continuas e impermeables del producto aplicado conservando, de esta manera, una superficie con porosidad abierta necesaria para que el sustrato tenga transpirabilidad con la humedad del medio ambiente. En las regiones más afectadas por cristalizaciones de sulfato de calcio, se observa un alto contenido en fósforo (P) tal y como se muestra en el análisis EDX de la Figura 8.43, indicando el depósito y la acción cementante de la hidroxiapatita en superficie. En contraposición, en las áreas del sustrato pétreo menos afectadas por cristalización de las sales solubles, la concentración del fósforo (P) disminuye de un 50\% aproximadamente (microanálisis EDX de la Figura 8.44). Esto es posiblemente debido que la hidroxiapatita penetra en los poros menos afectados por la presencia de sales solubles, creando una acción consolidante dentro de la estructura de la piedra.

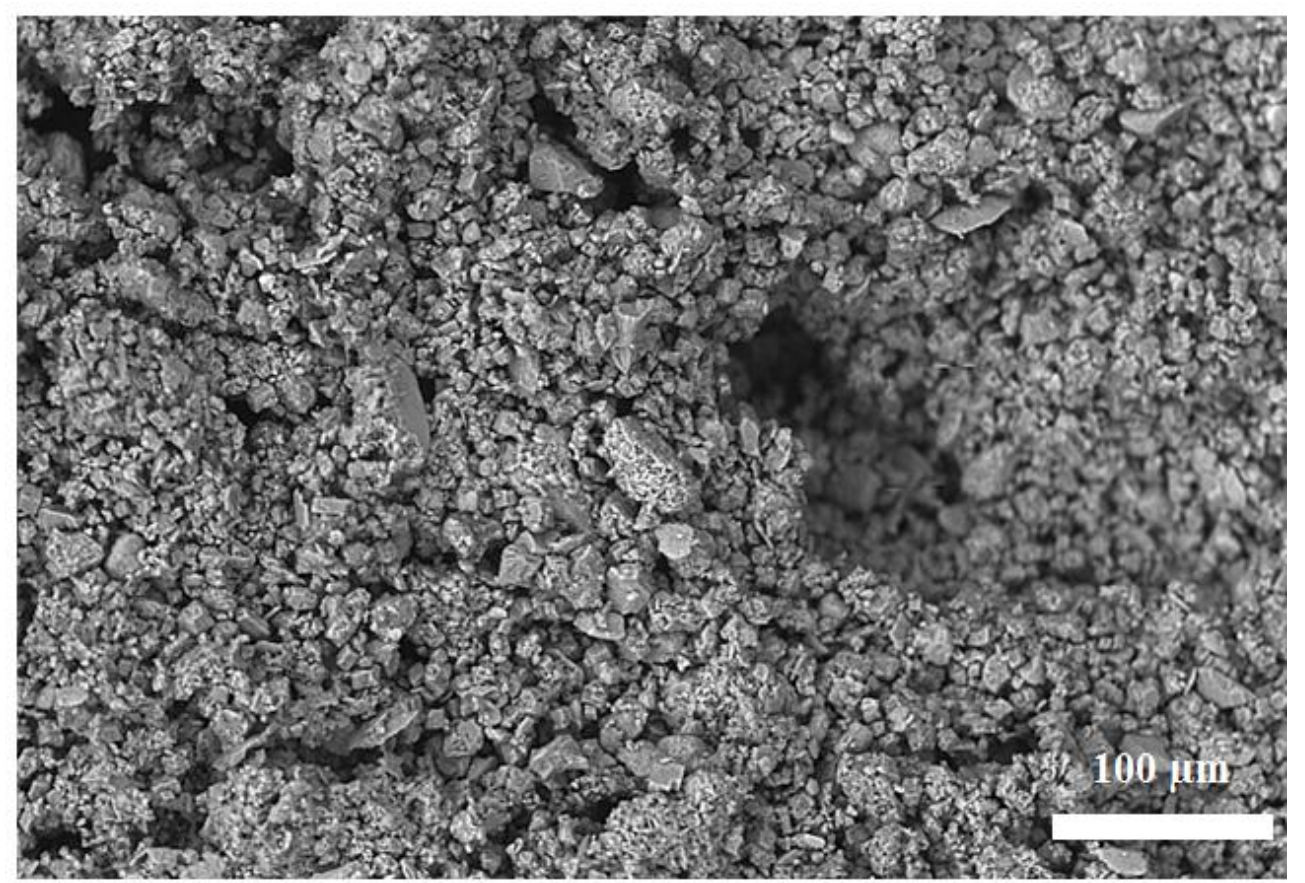

Figura 8.41. Imagen por SEM en modalidad electrones retrodispersados de la superficie del soporte pétreo antes de la aplicación de la muestra de HA2. 


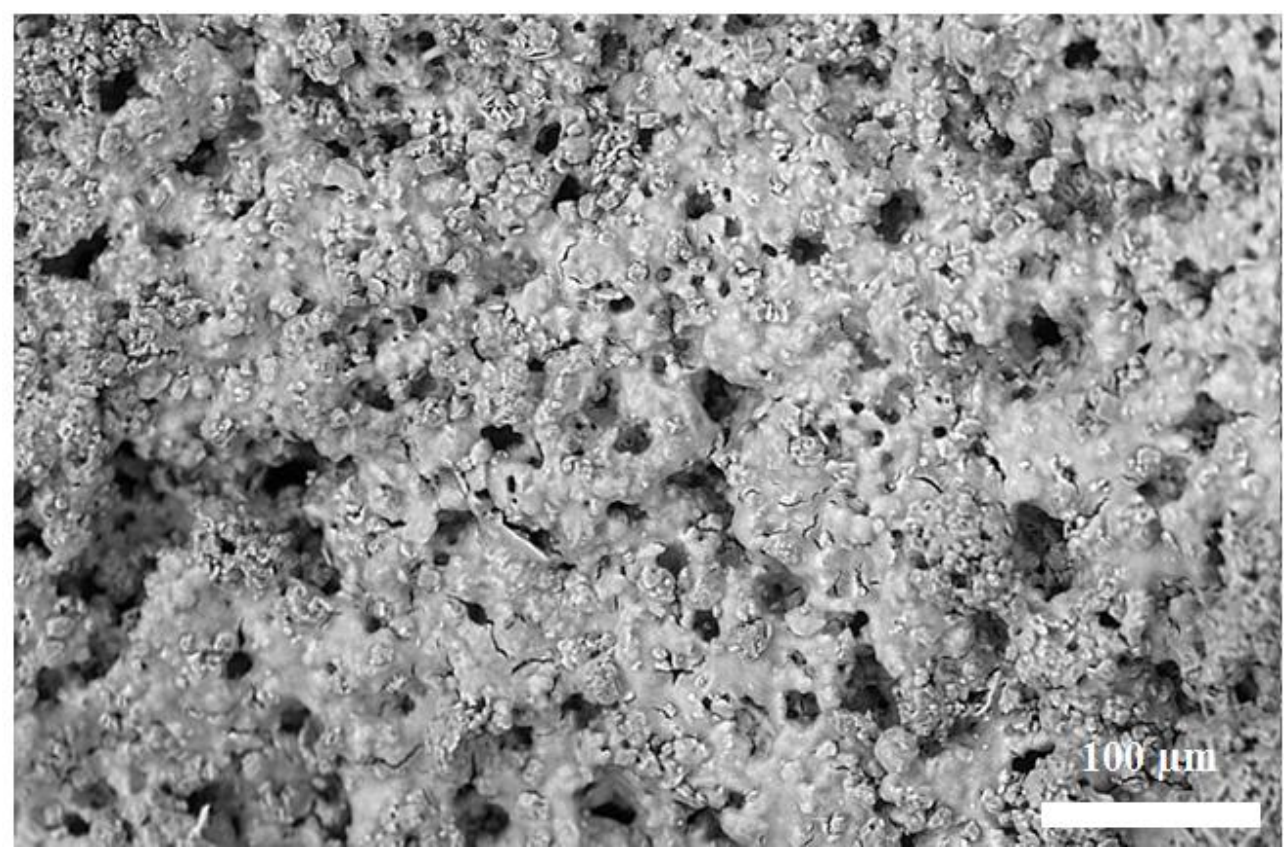

Figura 8.42. Imagen por SEM de la superficie del soporte pétreo después del tratamiento con HA2.

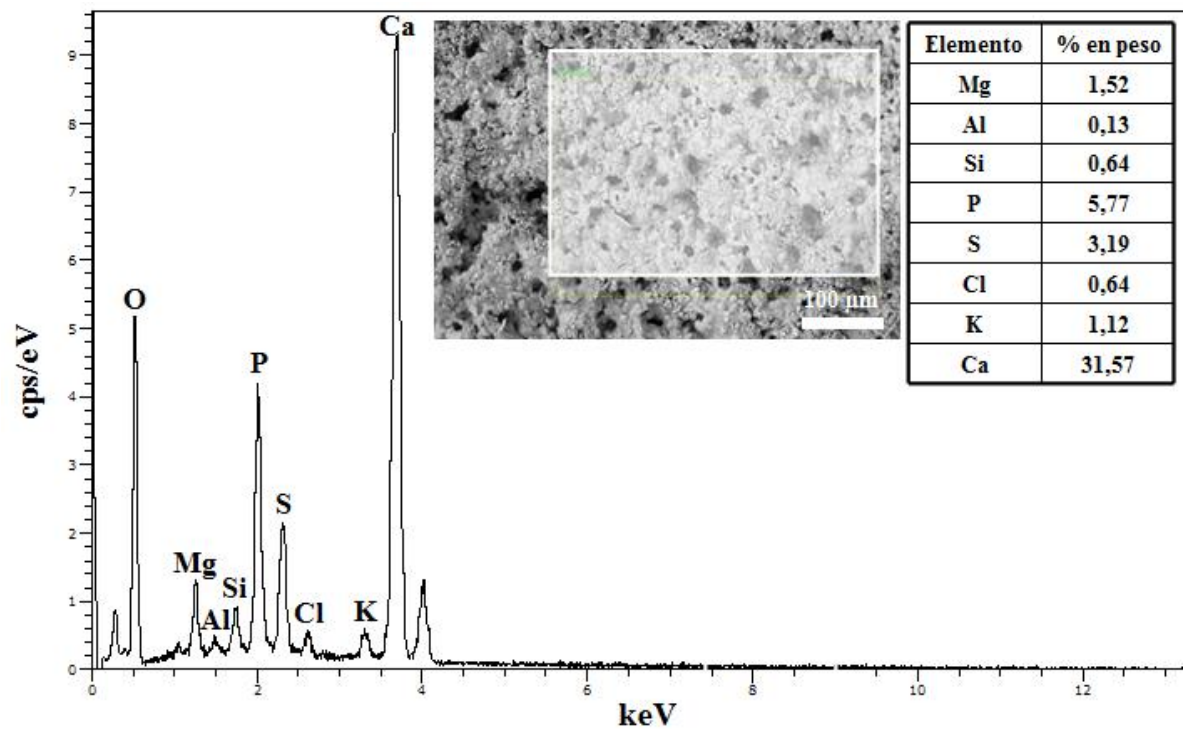

Figura 8.43. Micrografía obtenida por SEM (inset) de un área del fragmento de soporte pétreo tratado con HA2 observado en superficie, y espectro EDX de la región marcada en la imagen. En forma de tabla se expresa el \% en peso de los diferentes elementos detectados. 


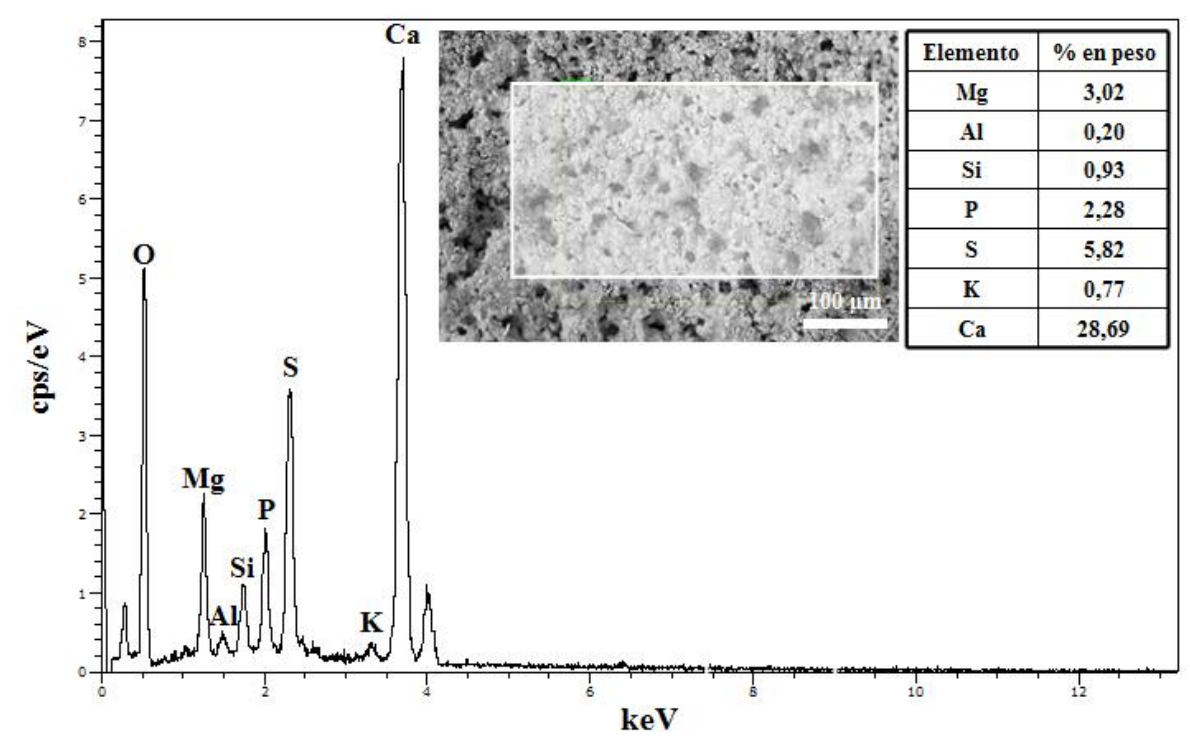

Figura 8.44. Micrografía obtenida por SEM (inset) de un área del fragmento de soporte pétreo tratado con HA2 observado en superficie, y espectro EDX de la región marcada en la imagen. En forma de tabla se expresa el \% en peso de los diferentes elementos detectados.

Se llevaron a cabo una serie de observaciones y microanálisis con SEM-EDX sobre la sección transversal antes y después de la aplicación de la muestra HA2. Se observó que el fragmento, antes de la aplicación del tratamiento, presenta sulfato de calcio en toda su estructura. Los análisis EDX de las Figura 8.45 y 8.46 muestran la presencia de azufre (S) en las áreas más superficiales así como en áreas más profundas del fragmento. Este resultado se demuestra, también, en el mapping de distribución de los elementos químicos de la Figura 8.47. 


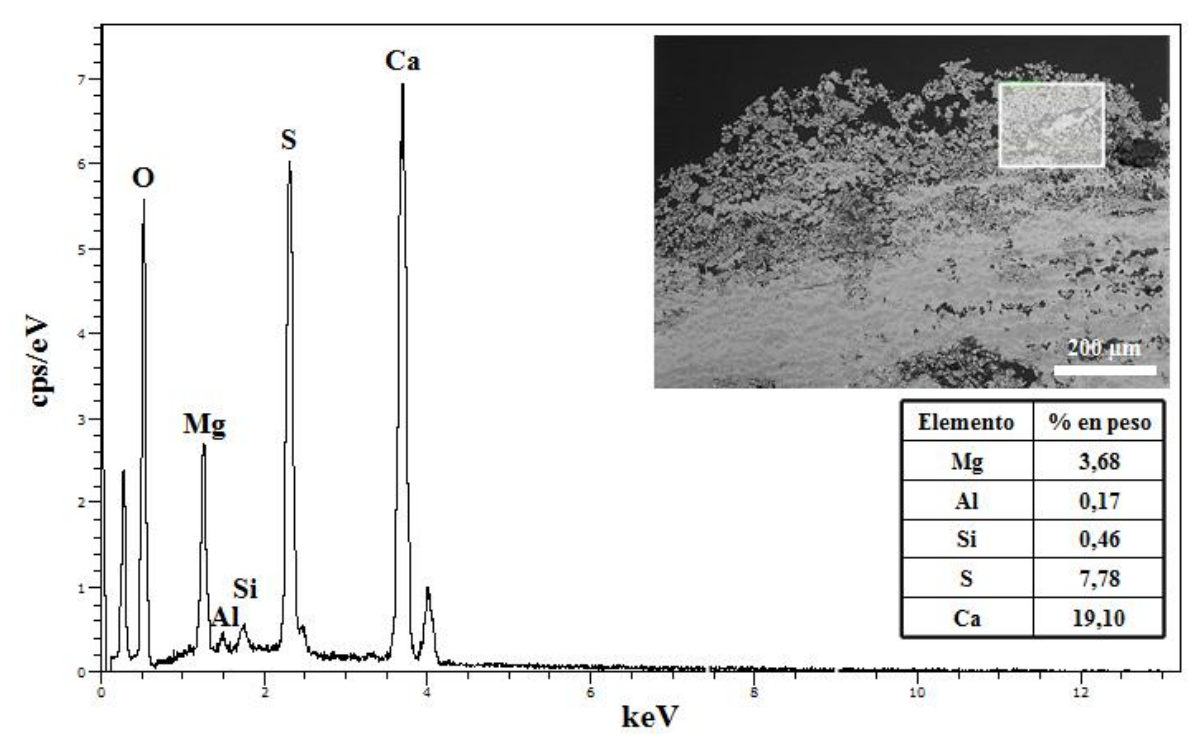

Figura 8.45. Micrografía obtenida por SEM (inset) de un área del fragmento de soporte pétreo sin tratar observado en corte transversal, y espectro EDX de la región marcada en la imagen. En forma de tabla se expresa el \% en peso de los diferentes elementos detectados.

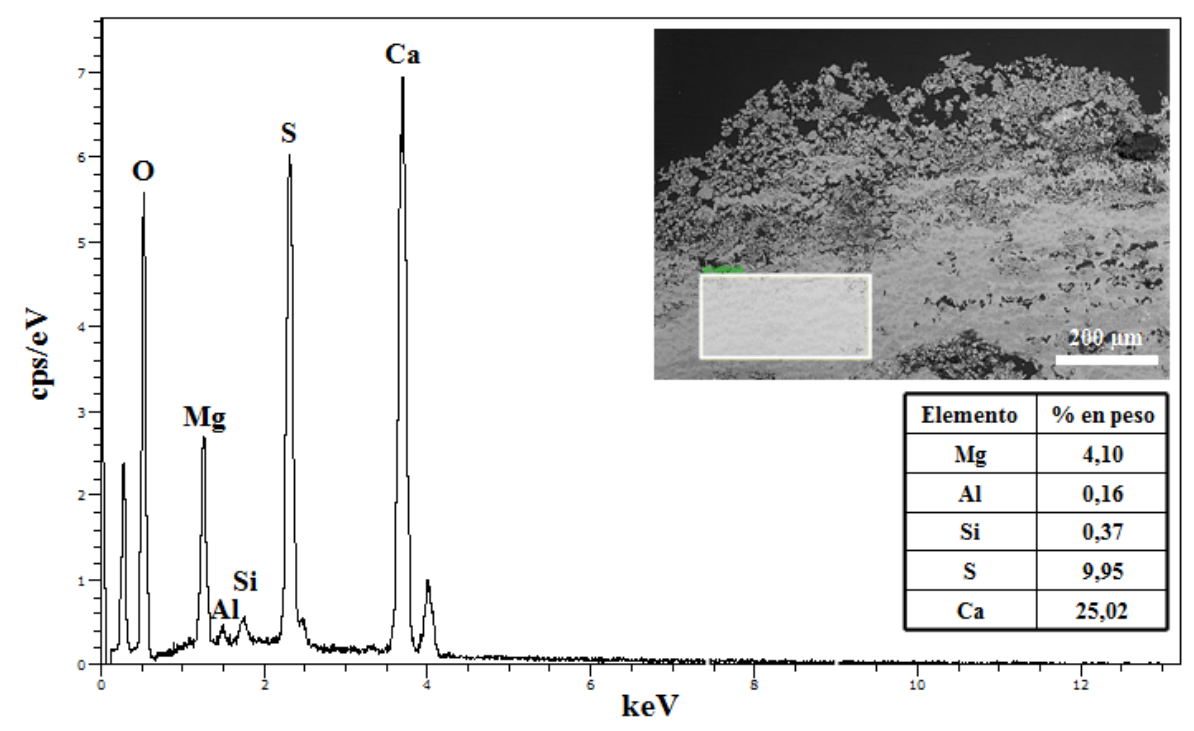

Figura 8.46. Micrografía obtenida por SEM (inset) de un área del fragmento de soporte pétreo sin tratar observado en corte transversal, y espectro EDX de la región marcada en la imagen. En forma de tabla se expresa el \% en peso de los diferentes elementos detectados. 

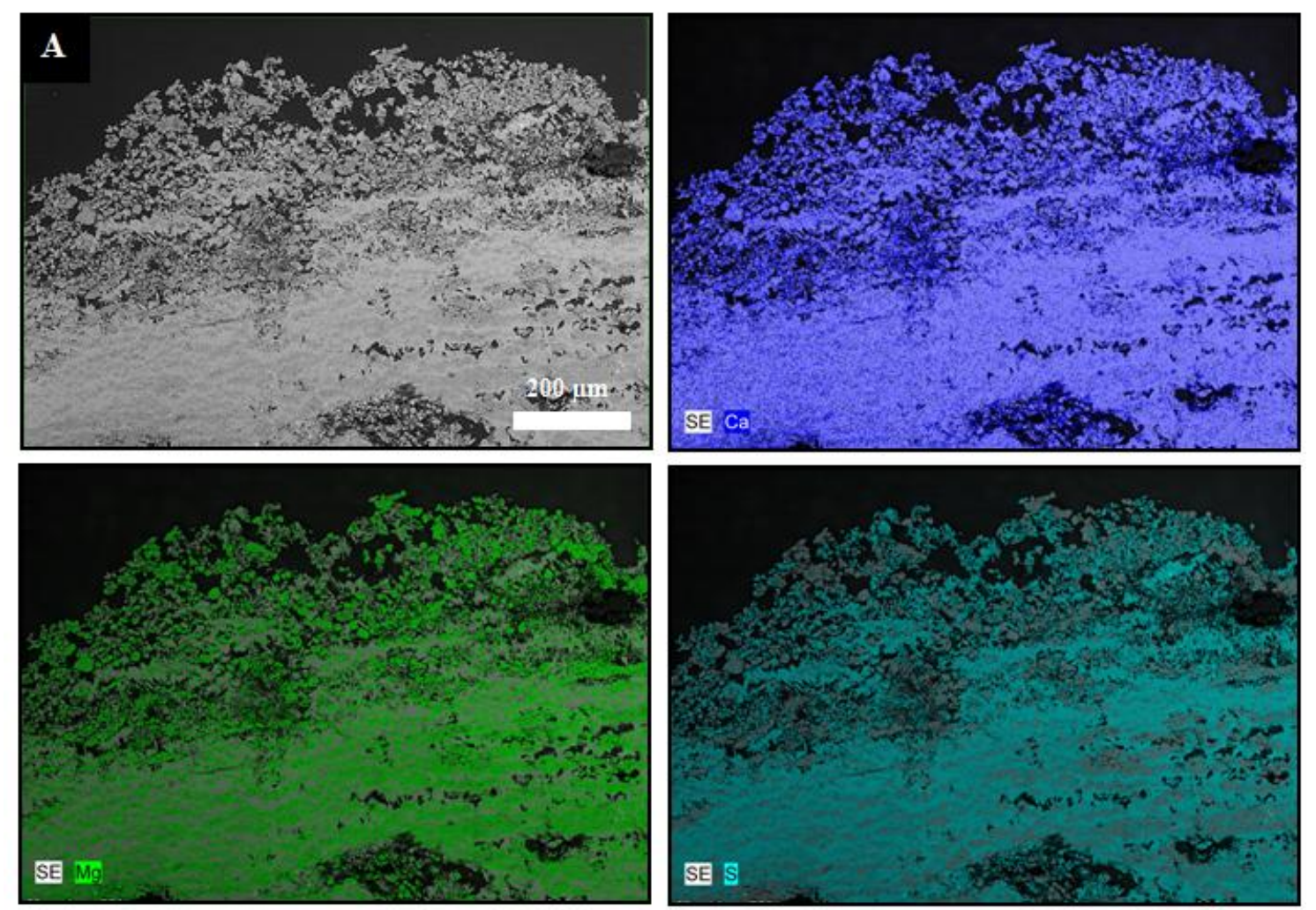

Figura 8.47. A) Imagen por SEM del soporte pétreo en sección transversal antes del tratamiento con HA2 y distribución espacial de los elementos químicos del calcio $(\mathrm{Ca})$, magnesio $(\mathrm{Mg})$ y azufre $(\mathrm{S})$.

Después del tratamiento se detecta el fósforo $(\mathrm{P})$ en toda la estructura del fragmento analizado en corte transversal. En los microanálisis EDX de la Figura 8.48 y de la Figura 8.49 se detectan concentraciones de fósforo relativamente altas tanto en áreas de proximidad a la superficie del corte transversal, así como en áreas más internas del fragmento. 


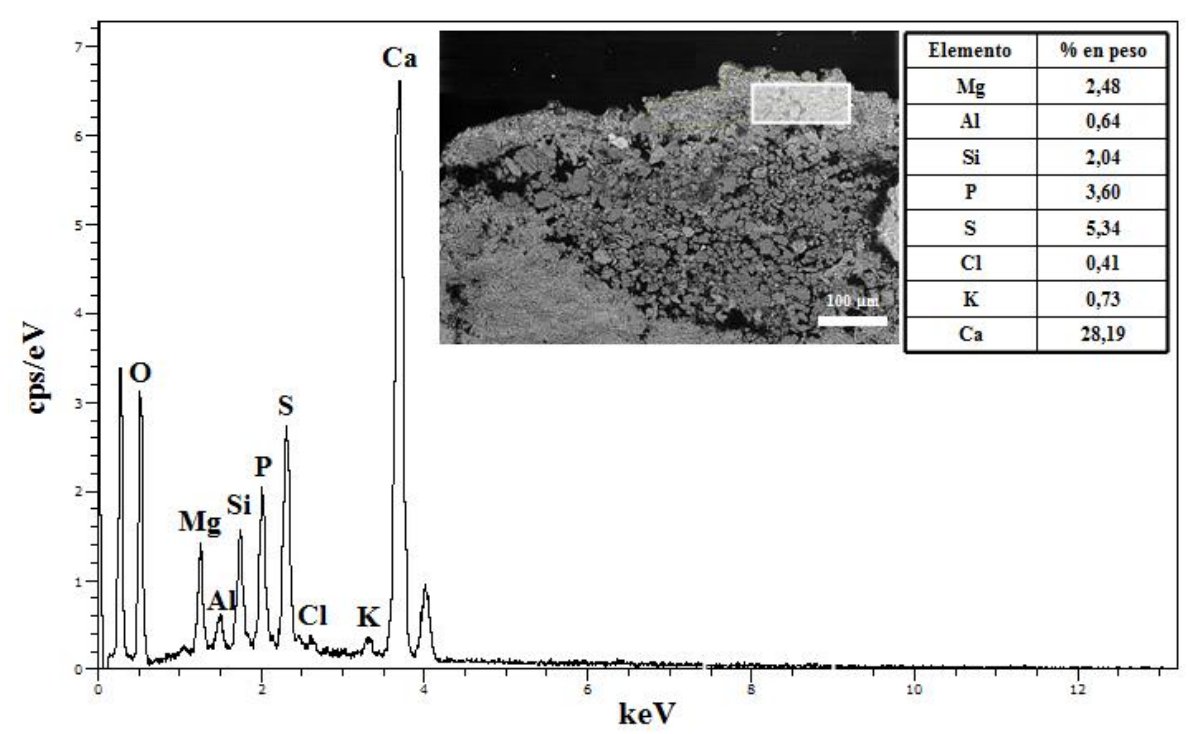

Figura 8.48. Micrografía obtenida por SEM (inset) de un área del fragmento de soporte pétreo tratado con HA2 observado en corte transversal, y espectro EDX de la región marcada en la imagen. En forma de tabla se expresa el \% en peso de los diferentes elementos detectados.

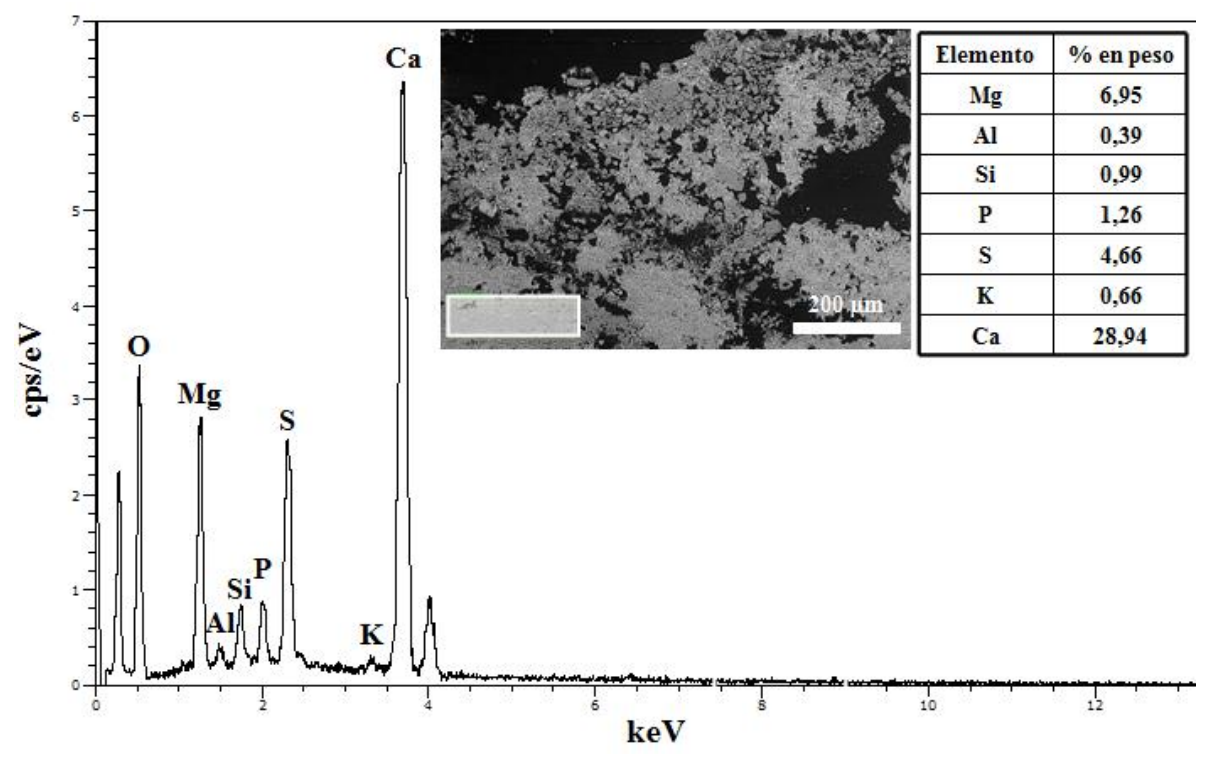

Figura 8.49. Micrografía obtenida por SEM (inset) de un área del fragmento de soporte pétreo tratado con HA2 observado en corte transversal, y espectro EDX de la región marcada en la imagen. En forma de tabla se expresa el \% en peso de los diferentes elementos detectados. 
Como se muestra con el mapping de la Figura 8.50 hay la presencia de fósforo (P) tanto en áreas superficiales como en áreas internas del fragmento pétreo estudiando en corte transversal.
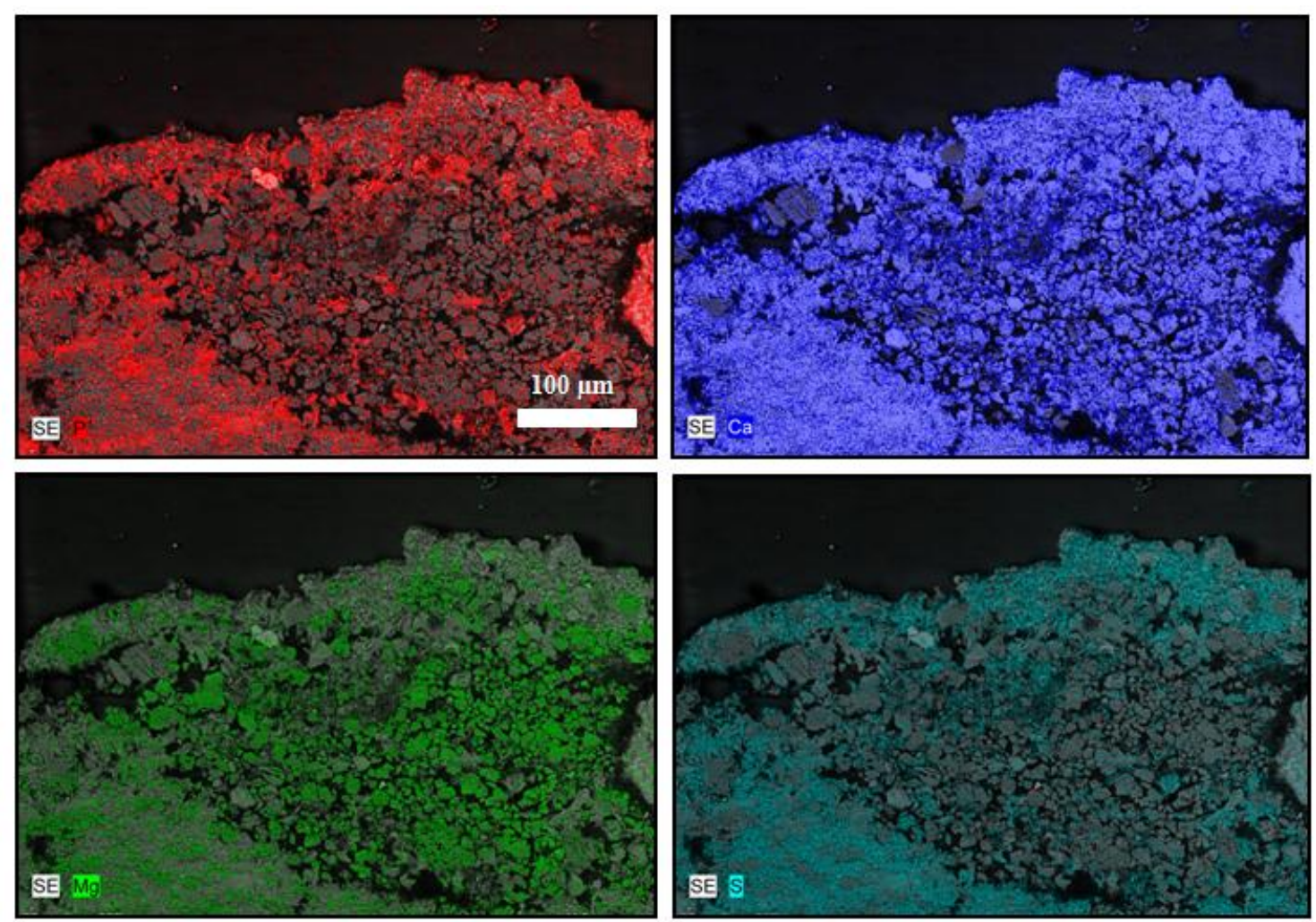

Figura 8.50. Mapping del soporte pétreo en sección transversal después del tratamiento con HA2 donde se muestra la distribución espacial de los elementos químicos del fósforo (P), calcio $(\mathrm{Ca})$, magnesio $(\mathrm{Mg})$ y azufre $(\mathrm{S})$. 


\subsubsection{Estudio con espectroscopia infrarroja por transformada de Fourier (FTIR)}

Con espectroscopia infrarroja por transformada de Fourier (FTIR) se realizaron controles para confirmar la presencia de la hidroxiapatita introducida en el sustrato pétreo sulfatado.

En la Figura 8.51 se presentan los espectros FTIR del soporte rocoso sin tratar (en verde) y tratado con la muestra de hidroxiapatita de calcio HA2. Como elementos más importantes se identifica el carbonato del soporte pétreo con los picos del grupo $\mathrm{CO}_{3}{ }^{2-}$. Se aprecian los picos relacionados con el grupo sulfato $\mathrm{SO}_{4}{ }^{2-} \mathrm{y}$ el grupo H-O-H (agua de hidratación) ${ }^{210}$. Respecto a la piedra sin tratar, las nuevas bandas que aparecen están relacionadas con los modos vibracionales de los grupos fosfato $\mathrm{PO}_{4}{ }^{3-}$ de la hidroxiapatita de calcio introducida a $600 \mathrm{~cm}^{-1}$ y a $1030 \mathrm{~cm}^{-1}$.

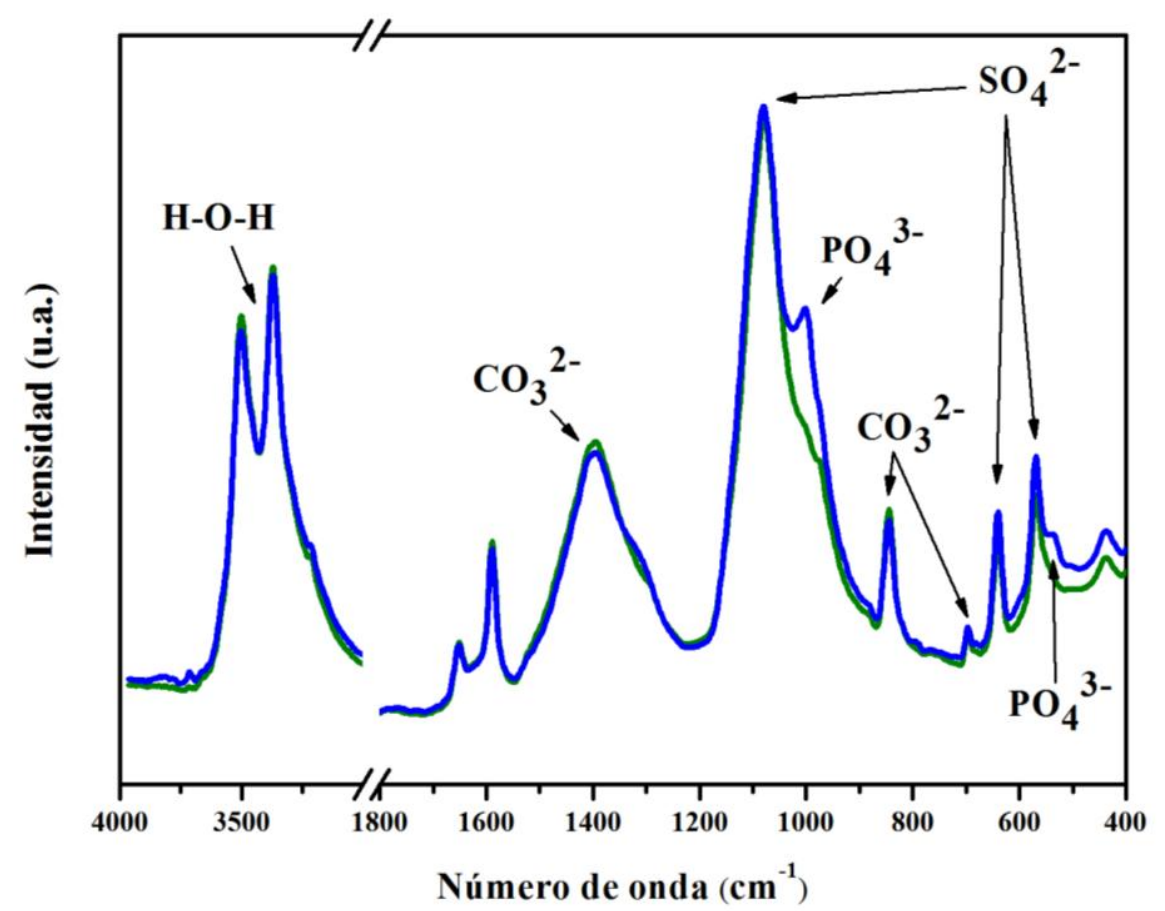

\begin{tabular}{|c|c|c|}
\hline \multicolumn{3}{|c|}{ Frecuencia características de } \\
grupos inorgánicos poliatómicos \\
$\mathrm{f}=$ fuerte, $\mathrm{m}=$ medio, \\
$\mathrm{d}=$ débil, a = agudo
\end{tabular}

Figura 8.51. Espectros FTIR de la piedra sin tratar (verde) y de la piedra tratada con HA2 (azul). Se muestra la tabla con las frecuencias características de los grupos inorgánicos poliatómicos de nuestro interés ${ }^{211}$.

\footnotetext{
${ }^{210}$ I. Adrover Gracia, Aplicazioni della Spettrofotometria IR allo studio dei Beni Cultural, Collana i Talenti, 2001.

${ }^{211}$ K.A. Rubinson, J.F. Rubinson, Análisis Instrumental, Ed. Pearson Educación, 2000.
} 


\subsection{Conclusiones}

El estudio desarrollado en este capítulo ha permitido alcanzar óptimos resultados a través de la comparación de las distintas muestras con estequiometría de hidroxiapatita preparadas. Ha sido posible observar y entender como la morfología y cristalinidad de las muestras sintetizadas influyen en la capacidad de consolidación y protección superficial del sustrato pétreo, a la vez que respetan las propiedades del material tratado. Para los tratamientos de consolidación y protección de soportes pétreos, la aplicación de las dispersiones acuosas de muestras con estequiometría de hidroxiapatita se ha mostrado eficaz dependiendo de la cristalinidad, tamaño y forma de las muestras evaluadas.

Se ha determinado como una mayor cristalinidad de las nanopartículas de hidroxiapatita produce una distribución más uniforme del producto sobre la superficie del soporte pétreo, asimismo se produce un grado de penetración bastante alto en los poros de la piedra. En general, se observa una buena compatibilidad química y física del producto aplicado con el sustrato pétreo al conseguir una buena adhesión y cohesión con el material sin producir importantes cambios morfológicos, texturales y de color importantes. Se han detectado variaciones significativas en la distribución, penetración y en los parámetros colorimétricos con las disoluciones acuosas de hidroxiapatita con menor cristalinidad.

En base a estos resultados se puede concluir que el tratamiento con la hidroxiapatita HA2 puede ser idóneo para la protección superficial y consolidación de soportes pétreos considerando que la aplicación del producto incrementa la adhesión y cohesión entre los constituyentes de la piedra, además de ser un producto compatible con la naturaleza química del soporte. A la vista de los resultados conseguidos, las nanopartículas de la muestra HA2 pueden tener, también, una acción consolidante y de protección en presencia de un sustrato pétreo alterado mecánicamente por cristalizaciones de sales solubles. Se ha observado que el producto introducido en la piedra alterada permite cementar la estructura disgregada de la misma, aumentando de esta manera su resistencia mecánica tanto a nivel superficial como en la estructura interna.

El presente estudio se podría desarrollar y ampliar con otras líneas de investigación centradas en pruebas mecánicas superficiales para valorar el grado de adhesión y cohesión proporcionado por parte de las muestras de hidroxiapatita introducidas en el soporte, y como la acción consolidante y protectora, así como la penetración, pueden verse modificadas cambiando el disolvente o la concentración de dispersión de las partículas. Otro estudio interesante debería enfocarse en como las propiedades del sustrato rocoso tratado pueden modificarse tras ciclos de envejecimiento natural y artificial en condiciones controladas de temperatura y humedad. 
Estudio de la aplicabilidad en pintura mural 


\section{Capítulo 9. Estudio de la aplicabilidad en pintura mural}

9.1. Fragmento de pintura mural

9.2. Metodología

9.3. Resultados

9.3.1. Evaluación en superficie y en corte transversal de la muestra ACP

9.3.2. Evaluación en superficie y en corte transversal de la muestra HA1

9.3.3. Evaluación en superficie y en corte transversal de la muestra HA2

9.3.4. Espectroscopia infrarroja por transformada de Fourier (FTIR)

9.3.5. Colorimetría

9.4. Conclusiones 


\section{Capítulo 9. Estudio de la aplicabilidad en pintura mural}

En este capítulo se muestran los principales resultados derivados de los primeros estudios sobre la valoración de la acción consolidante y protectora de las muestras preparadas sobre un fragmento de pintura mural procedente de la Casa de Ariadna de Pompeya (Italia).

La experimentación se ha basado en la aplicación sobre un fragmento de pintura mural de las dispersiones acuosas de las muestras preparadas. Mediante las técnicas de microscopia electrónica de barrido con microanálisis (SEM-EDX), espectroscopia infrarroja por transformada de Fourier (FTIR) y medida de las coordenadas colorimétricas, se ha realizado un estudio comparativo a nivel superficial y composicional referido principalmente a posibles cambios de color, penetración e interacción con el sustrato por parte de las muestras aplicadas. 


\subsection{Fragmento de pintura mural}

En la Figura 9.1 se muestra el fragmento de pintura mural seleccionado para valorar el resultado de la acción consolidante y protectora por parte de las muestras objeto de estudio. El fragmento procede de las excavaciones arqueológicas realizadas en la Casa de Ariadna en Pompeya (Italia). En el Capítulo 6 se ha descrito tanto la caracterización de los materiales constitutivos así como los mecanismos de alteración que se han detecto en esta tipología de bienes culturales.

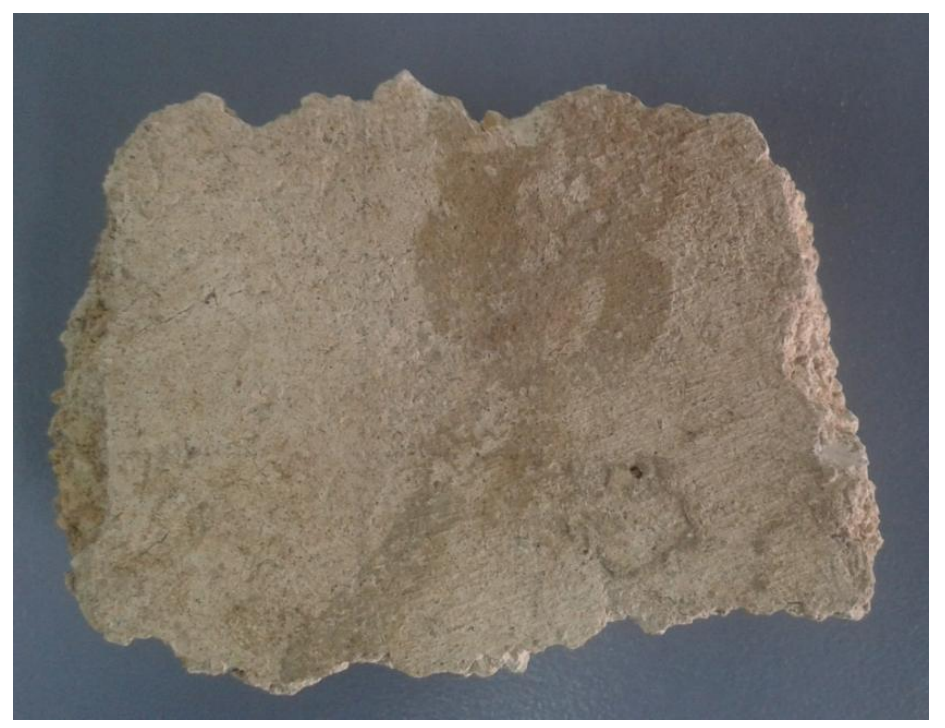

Figura 9.1. Fragmento de pintura mural utilizado en la evaluación de los tratamientos de consolidación y protección con las muestras sintetizadas.

\subsection{Metodología}

Como en los casos anteriores, las muestras utilizadas corresponden a ACP, HA1 y HA2. Para el desarrollo de este trabajo se ha seguido la metodología descrita en el Capítulo 7.

El estudio realizado en este capítulo de la evaluación de la acción consolidante y protectora sobre el fragmento de pintura mural, se basa en observaciones y microanálisis realizados al SEM-EDX, en análisis de espectroscopia infrarroja por transformada de Fourier (FTIR) y medidas de las coordenadas colorimétricas. 


\subsection{Resultados}

\subsubsection{Evaluación en superficie y en corte transversal de la muestra ACP}

Mediante microscopia estereoscópica se observó la parte del fragmento de pintura mural sin tratamiento (imagen de la Figura 9.2 A) y la parte con tratamiento (imagen de la Figura 9.2 B). Comparando las dos áreas, se percibe que el tratamiento provoca la formación superficial de una fina película blanquecina, con un pequeño cambio en el color de la superficie tratada.

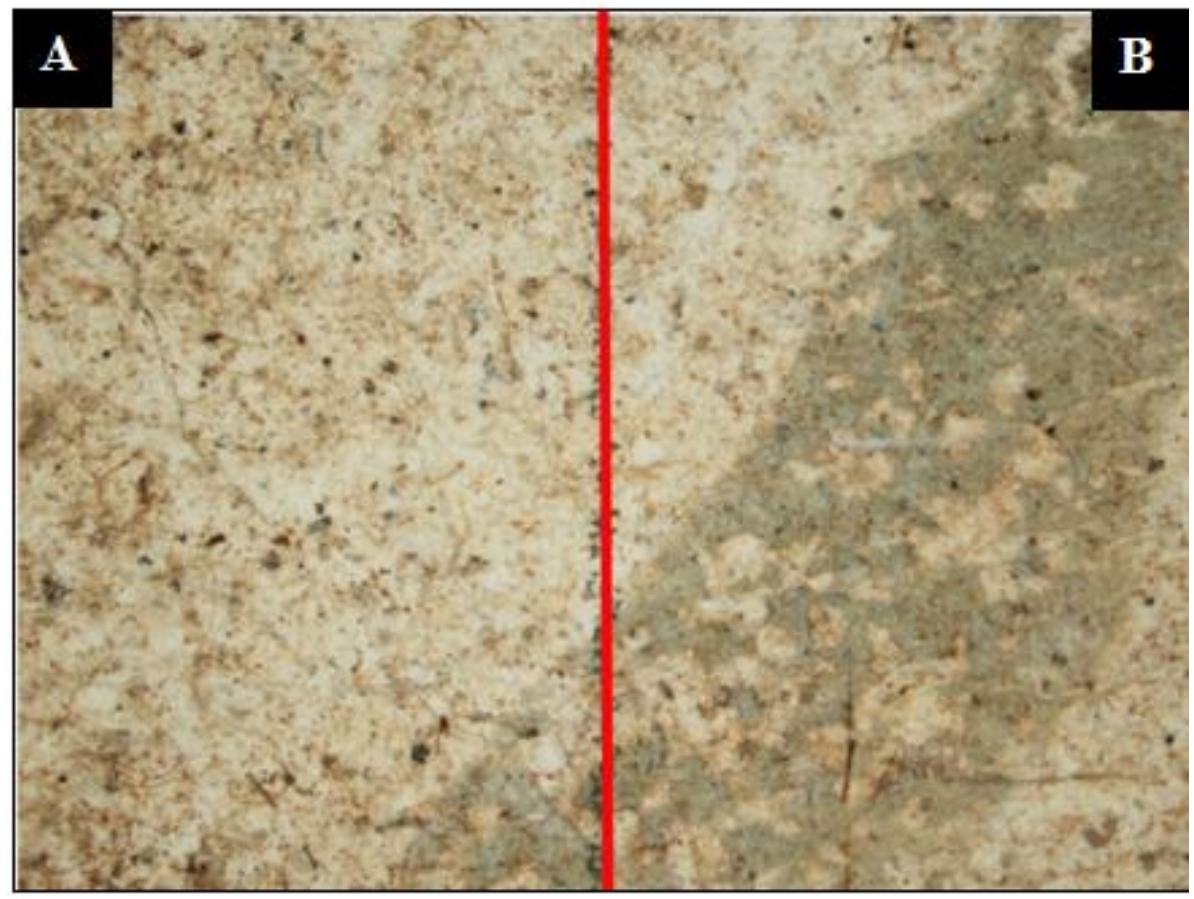

Figura 9.2. Imagen de microscopia estereoscópica $(1 \mathrm{x})$ de la superficie de la pintura mural antes del tratamiento (A) y después del tratamiento con la muestra ACP (B).

Las observaciones realizadas mediante SEM se detecta la formación sobre la superficie de la pintura mural de estratos diferenciados con relleno de las irregularidades de la superficie pictórica por la dispersión acuosa (Figura 9.3). No obstante, su adherencia a la superficie parece escasa, ya que se observa la presencia de agrietado y desprendimiento en varias zonas. 


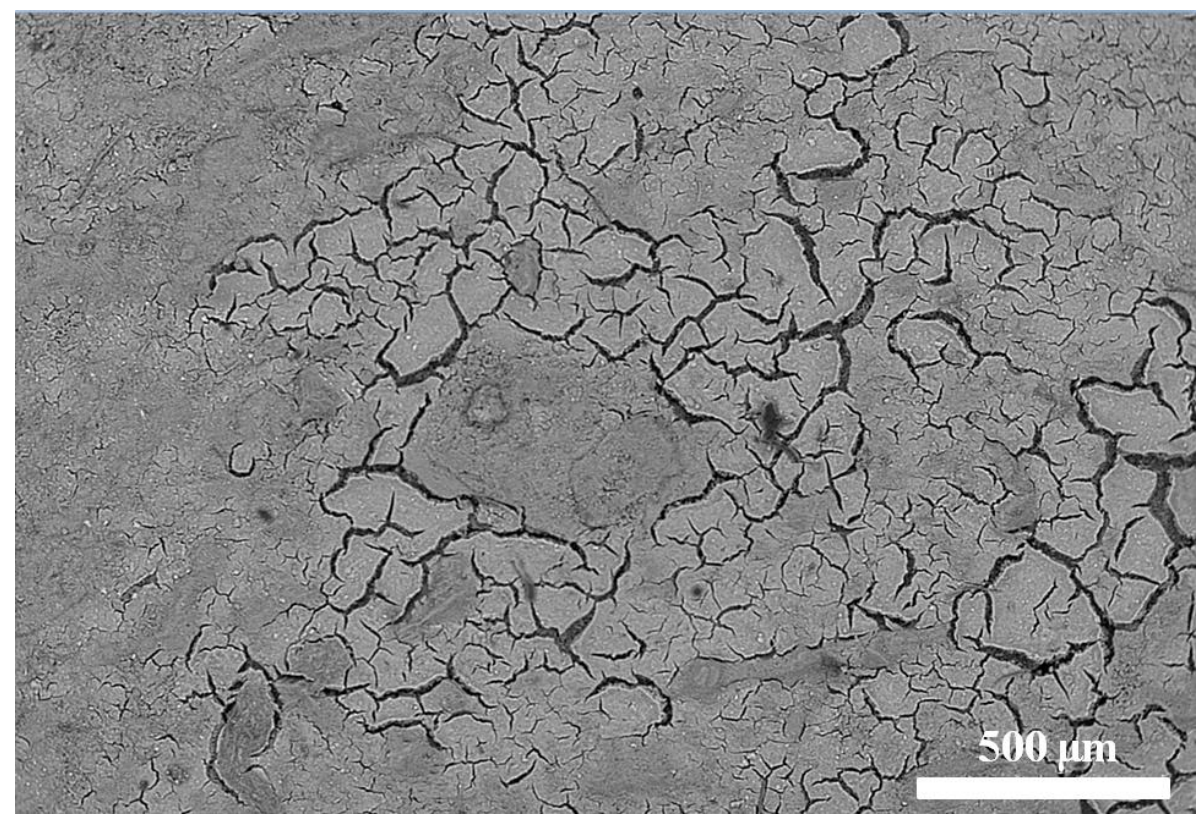

Figura 9.3. Imagen por SEM en modalidad BSE de la superficie del fragmento de pintura mural después del tratamiento con ACP. Se observa que la muestra depositada en la superficie presenta agrietamientos.

El microanálisis EDX (Figura 9.4) muestra una alta concentración de calcio (Ca) y, en menores cantidades, de fósforo $(\mathrm{P})$. Estos elementos se refieren a los constituyentes de la pintura mural a base de carbonato de calcio y de la muestra incorporada con el tratamiento.

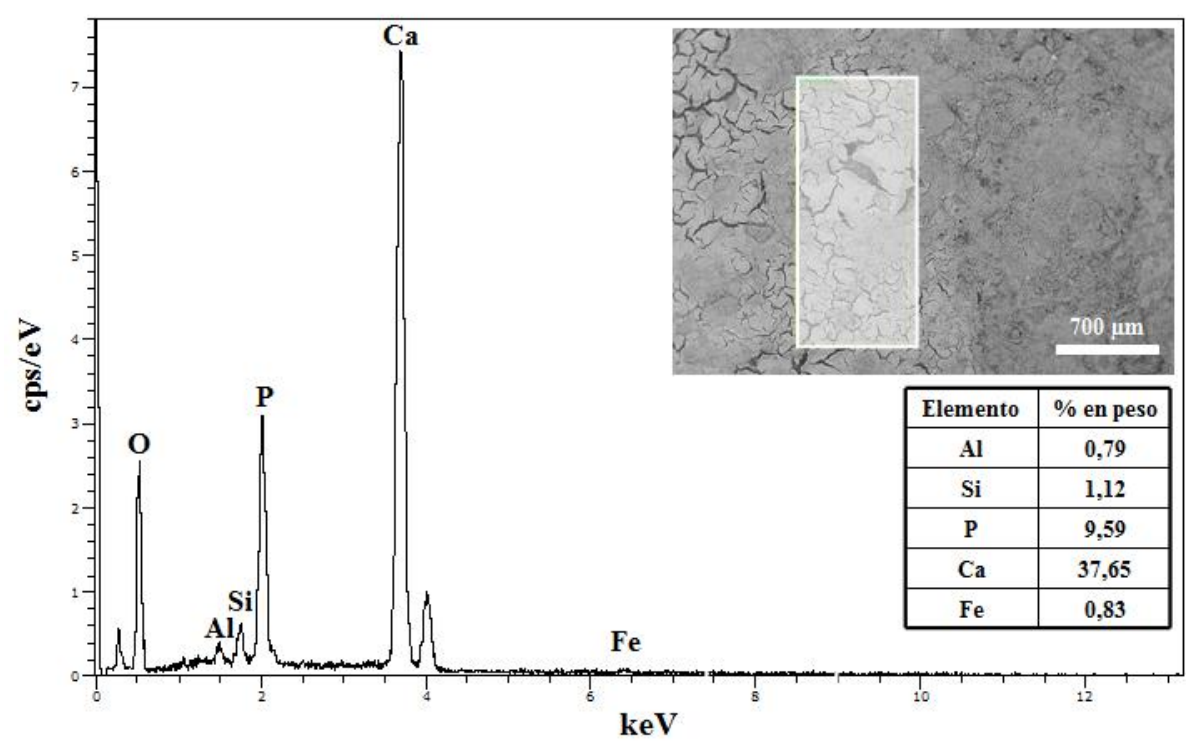

Figura 9.4. Micrografía obtenida por SEM (inset) de un área del fragmento de pintura mural tratado con ACP observado en superficie, y espectro EDX de la región marcada en la imagen. En forma de tabla se expresa el \% en peso de los diferentes elementos detectados. 
Entre los resultados más significativos obtenidos a través del estudio en un corte transversal del fragmento de pintura mural destaca la formación de una capa superficial. Como se observa en la micrografía SEM de la Figura 9.5 aparece la formación de una capa en superficie. Tal y como se puede valorar en el espectro del microanálisis EDX de la Figura 9.6 de esta capa, hay un alto contenido en calcio $(\mathrm{Ca})$ y fósforo $(\mathrm{P})$. Los diferentes elementos que se detectan con el microanálisis son silicio $(\mathrm{Si})$, aluminio $(\mathrm{Al})$, cloro $(\mathrm{Cl})$ azufre $(\mathrm{S})$, etc., relacionados con el fragmentos de pintura mural.

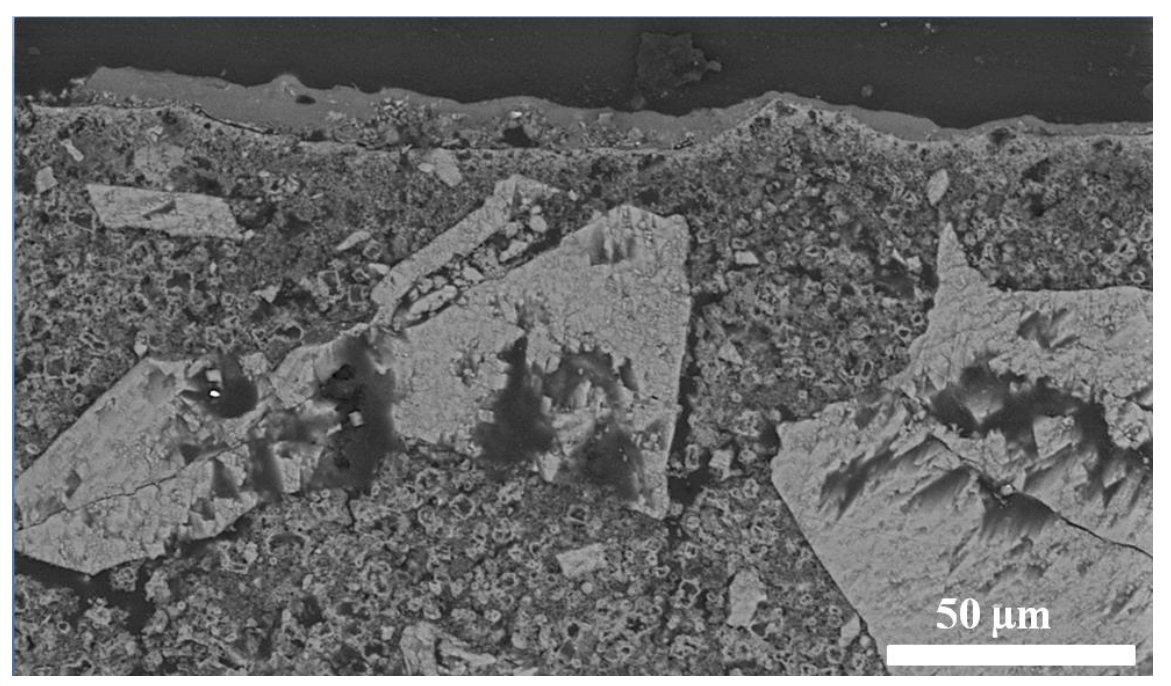

Figura 9.5. Imagen por SEM del corte transversal del fragmento de pintura mural tratado con la muestra ACP donde se observa la formación de la película superficial.

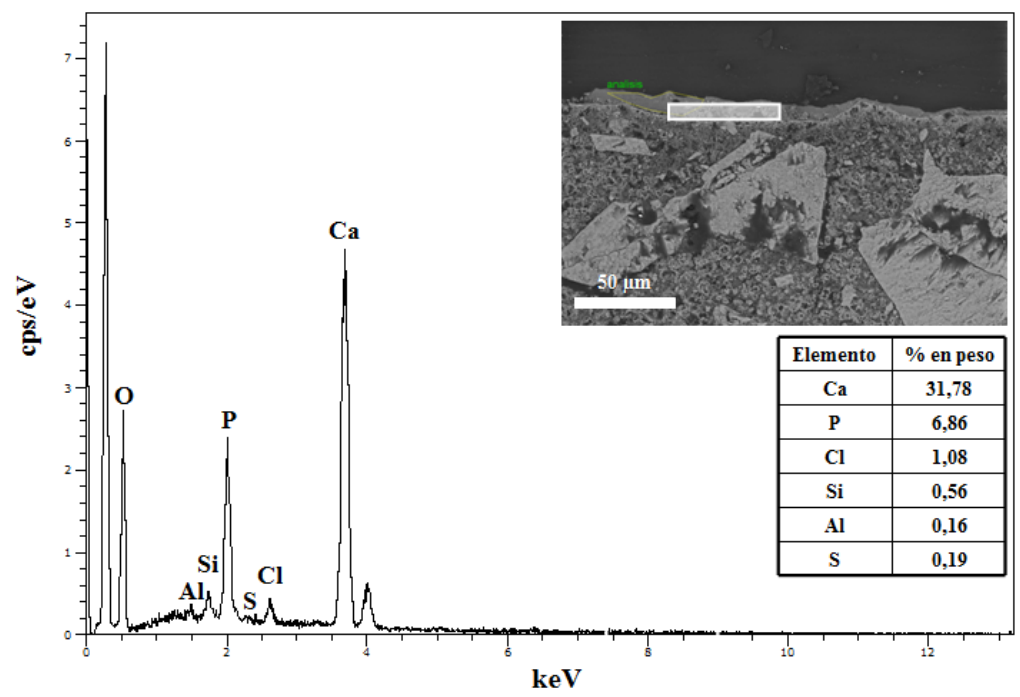

Figura 9.6. Micrografía obtenida por SEM (inset) de un área del fragmento de pintura mural tratado con ACP observado en corte transversal, y espectro EDX de la región marcada en la imagen. En forma de tabla se expresa el \% en peso de los diferentes elementos detectados. 
La película presenta un espesor máximo de $12 \mu \mathrm{m}$ aproximadamente, con distribución homogénea en la superficie de la pintura mural. Se observa una pequeña penetración del producto aplicado en el interior del mortero que constituye la pintura, ya que como se puede observar del microanálisis realizado donde se ha detectado una concentración del fósforo de 0,1\% hasta una profundidad de 120-150 $\mu$ m (espectro EDX de la Figura 9.7).

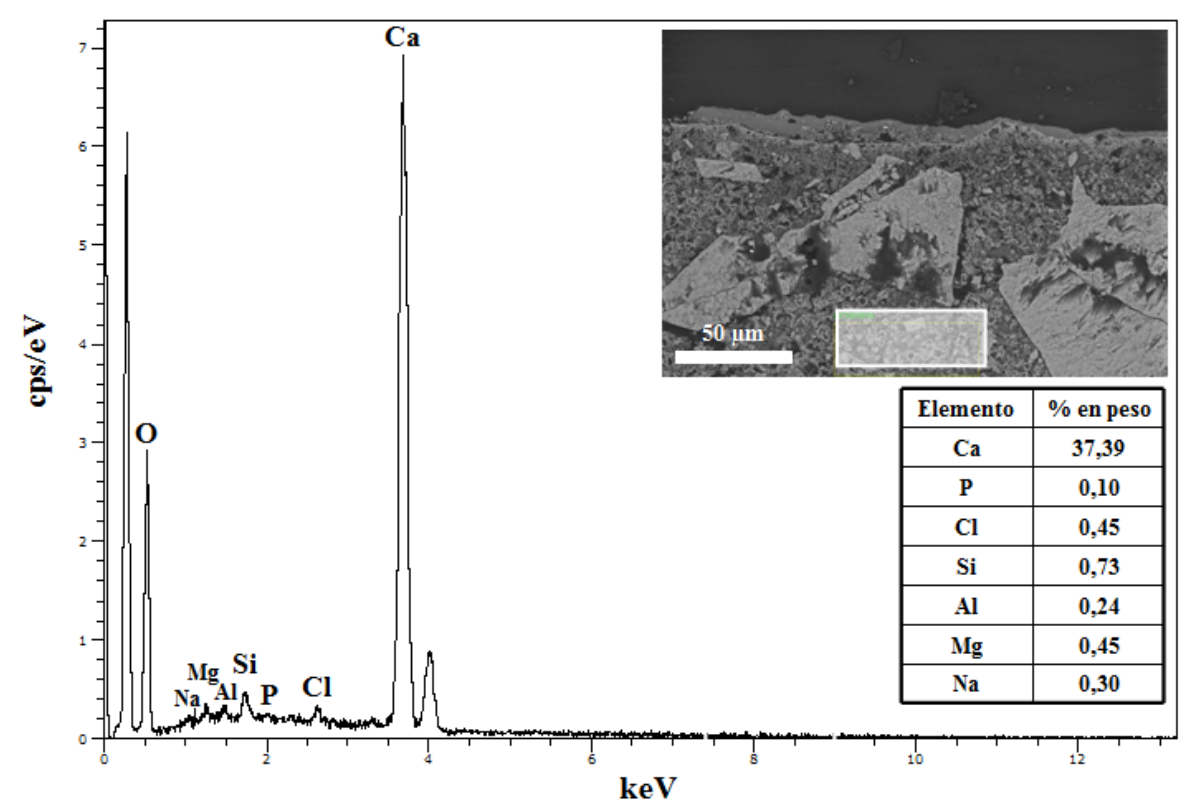

Figura 9.7. Micrografía obtenida por SEM (inset) de un área del fragmento de pintura mural tratado con ACP observado en corte transversal, y espectro EDX de la región marcada en la imagen. En forma de tabla se expresa el \% en peso de los diferentes elementos detectados. 


\subsubsection{Evaluación en superficie y en corte transversal de la muestra HA1}

La imagen de la Figura 9.8 A corresponde a un área del fragmento de pintura mural sin tratamiento y esta se compara con el área tratada con la muestra HA1 (imagen B). En esta imagen de microscopia estereoscópica no se aprecia ningún cambio significativo en las características superficiales de la pintura mural, ni el color y morfología después del tratamiento se ven alterados.

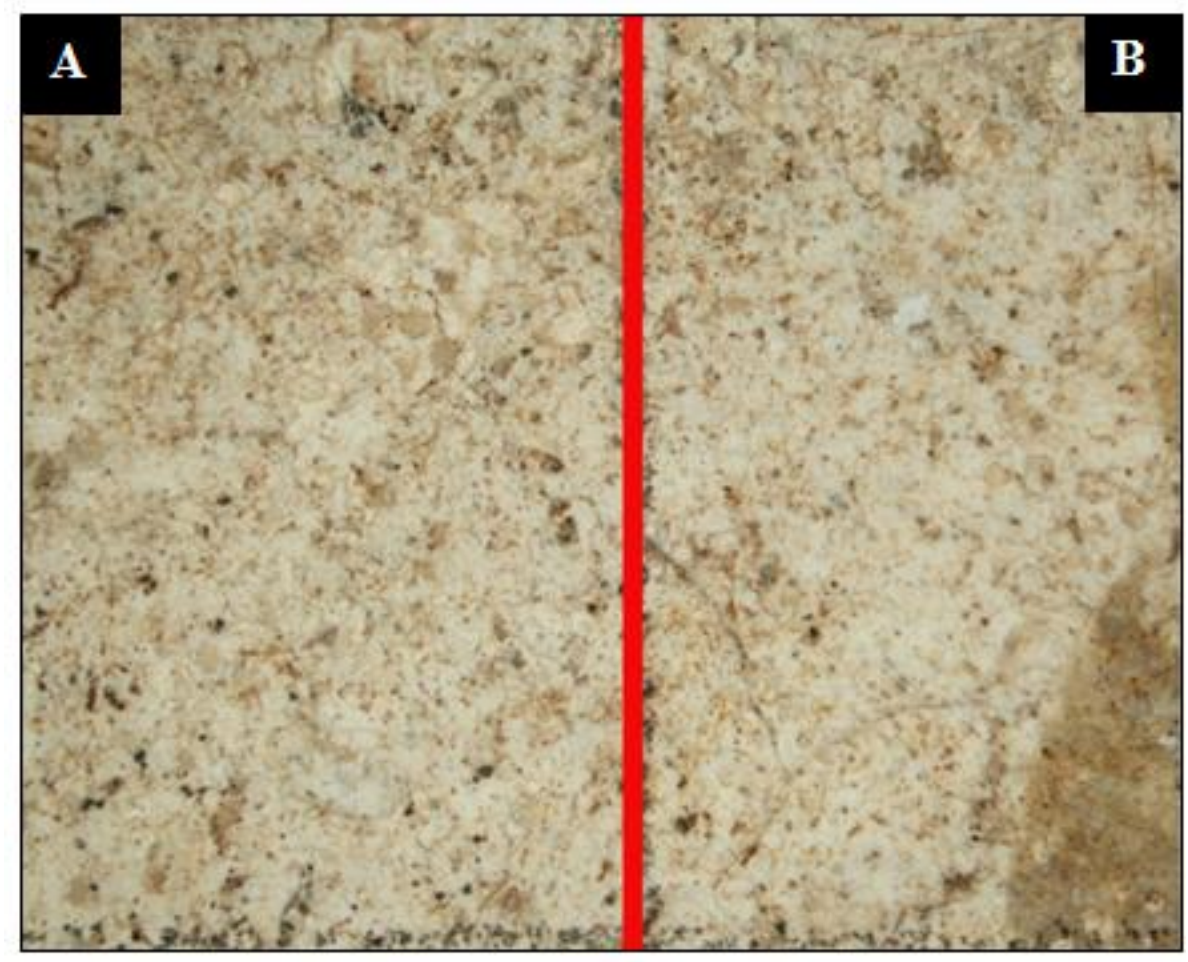

Figura 9.8. Imagen de microscopia estereoscópica $(1 \mathrm{x})$ de la superficie de la pintura mural antes del tratamiento (A) y después del tratamiento con la muestra de hidroxiapatita HA1 (B).

Las observaciones al SEM con distintos aumentos permiten apreciar que después del tratamiento con la muestra HA1, la superficie pictórica presenta estratos diferenciados con un relleno de las irregularidades de la superficie pictórica por parte de la hidroxiapatita (micrografía de la Figura 9.9). No obstante, la adherencia de la suspensión aplicada en la superficie parece escasa ya que se aprecia la presencia de agrietado y desprendimiento en varias zonas. 
El microanálisis EDX de la Figura 9.10 detecta una alta concentración de calcio (Ca) y en menores cantidades el fósforo $(\mathrm{P})$, elementos relacionados con los constituyentes de la pintura mural y con la hidroxiapatita introducida con el tratamiento.

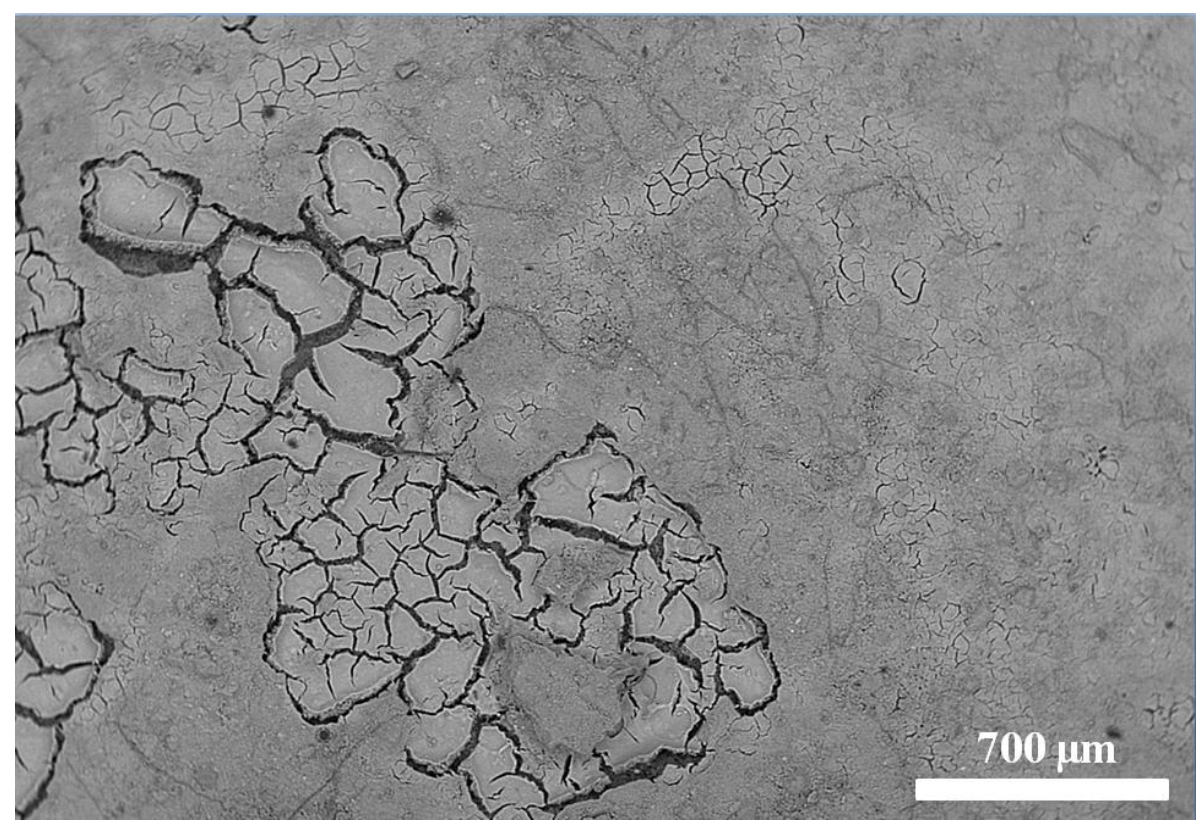

Figura 9.9. Imagen por SEM en modalidad BSE de un área de la superficie del fragmento de pintura mural después del tratamiento con la muestra de hidroxiapatita HA1.

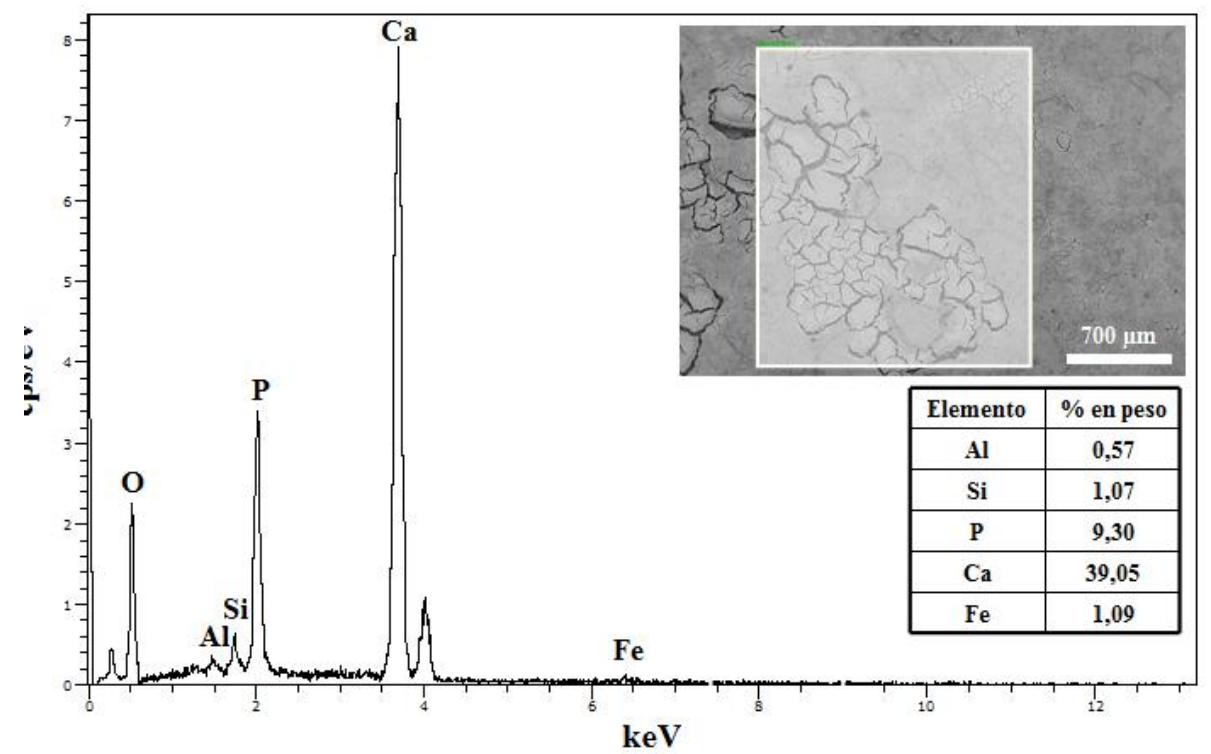

Figura 9.10. Micrografía obtenida por SEM (inset) de un área del fragmento de pintura mural tratado con HA1 observado en superficie, y espectro EDX de la región marcada en la imagen. En forma de tabla se expresa el \% en peso de los diferentes elementos detectados. 
Los resultados proporcionados por el estudio realizado sobre un corte transversal del fragmento de pintura mural tratado con la muestra HA1 resultan ser similares a los resultados obtenidos con la muestra ACP. Como se muestra en la micrografía SEM de la Figura 9.11, también en la muestra HA1 existe una formación de una capa en superficie rica en calcio $(\mathrm{Ca})$ y fósforo $(\mathrm{P})$ tal y como se muestra en el microanálisis EDX de la Figura 9.12. Al contrario que en el caso anterior, el estrato que se forma se presenta más homogéneo y fino con un espesor medio entre los 2-4 $\mu \mathrm{m}$.

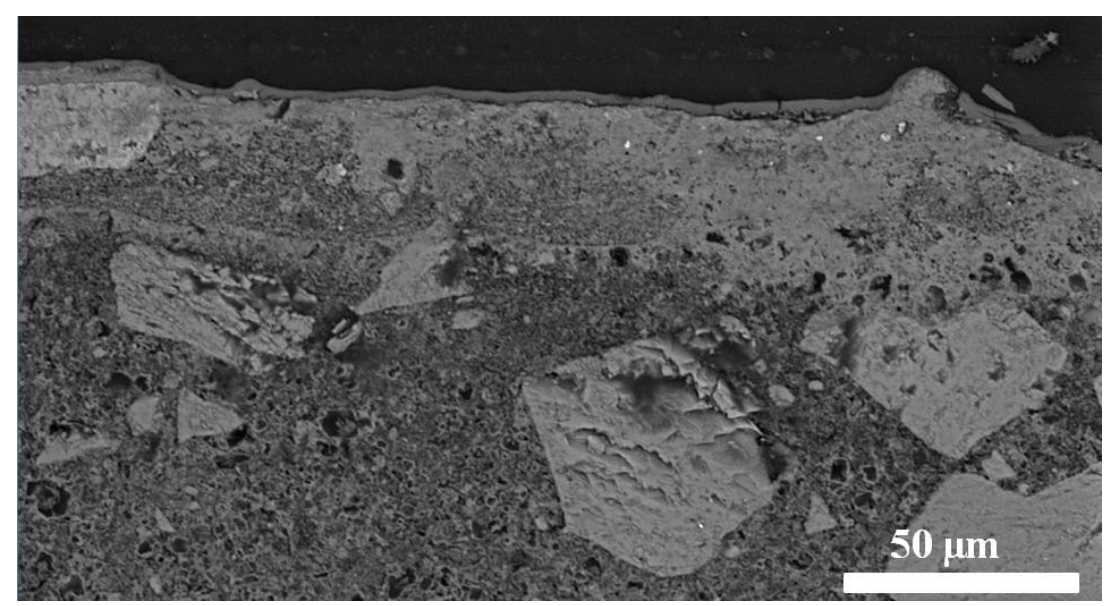

Figura 9.11. Imagen por SEM del corte transversal del fragmento de pintura mural tratado con la muestra de hidroxiapatita HA1 donde se observa la formación de la película superficial.

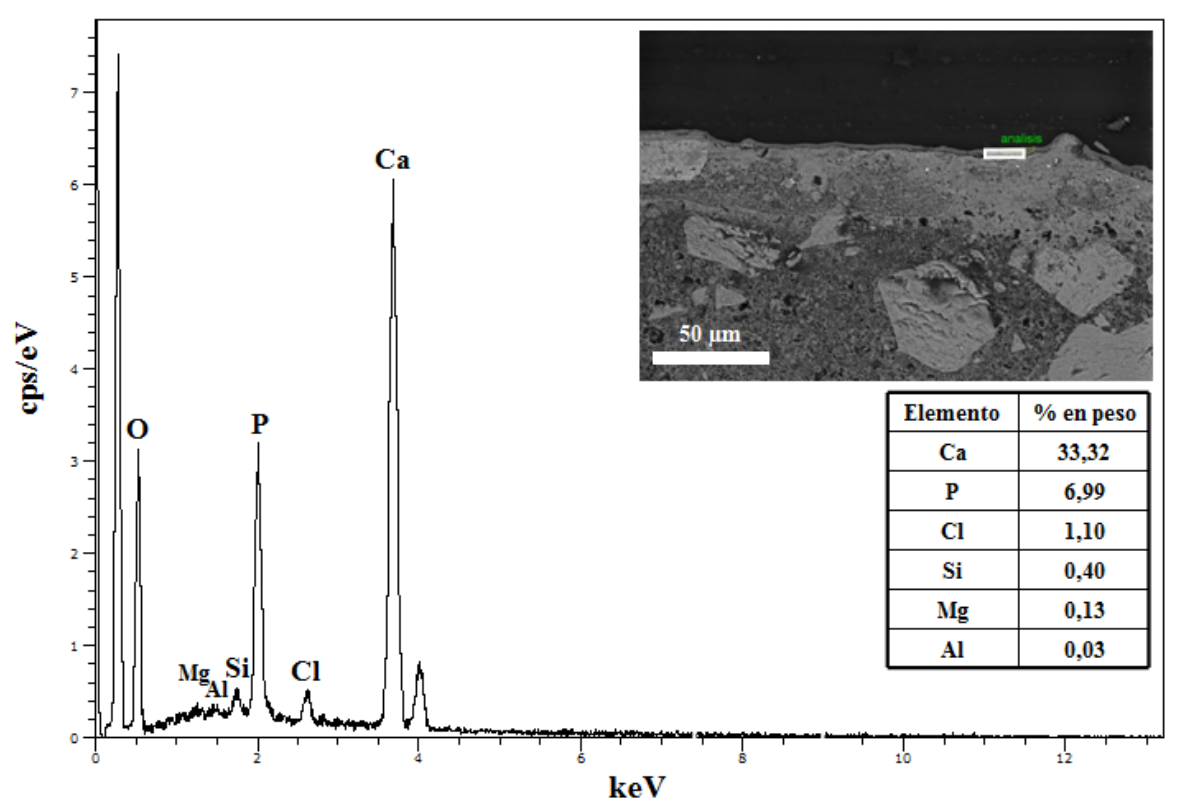

Figura 9.12. Micrografía obtenida por SEM (inset) de un área del fragmento de pintura mural tratado con HA1 observado en corte transversal, y espectro EDX de la región marcada en la imagen. En forma de tabla se expresa el \% en peso de los diferentes elementos detectados. 
Los microanálisis EDX realizados a diferentes niveles de profundidad en un corte transversal han detectado la presencia de fósforo con una concentración inferior a $0,1 \%$ hasta una profundidad máxima de 150-200 $\mu \mathrm{m}$ (espectros de las Figuras 9.13 y 9.14).

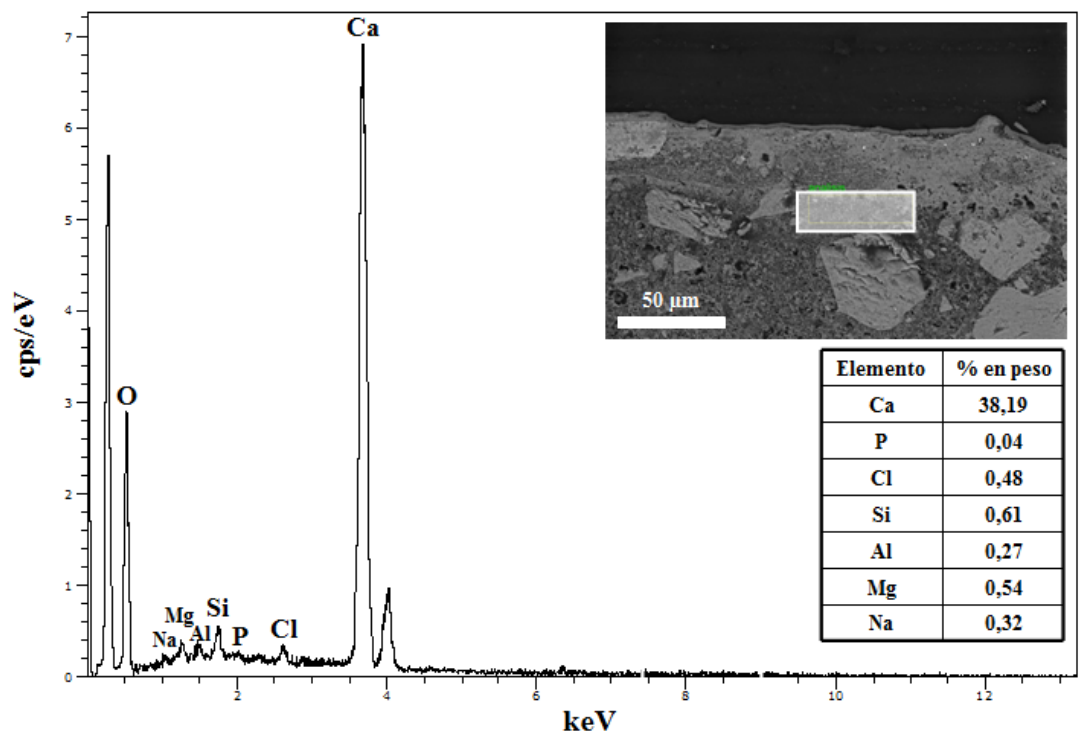

Figura 9.13. Micrografía obtenida por SEM (inset) de un área del fragmento de pintura mural tratado con HA1 observado en corte transversal, y espectro EDX de la región marcada en la imagen (área interna 50 um aprox.). En forma de tabla se expresa el \% en peso de los diferentes elementos detectados.

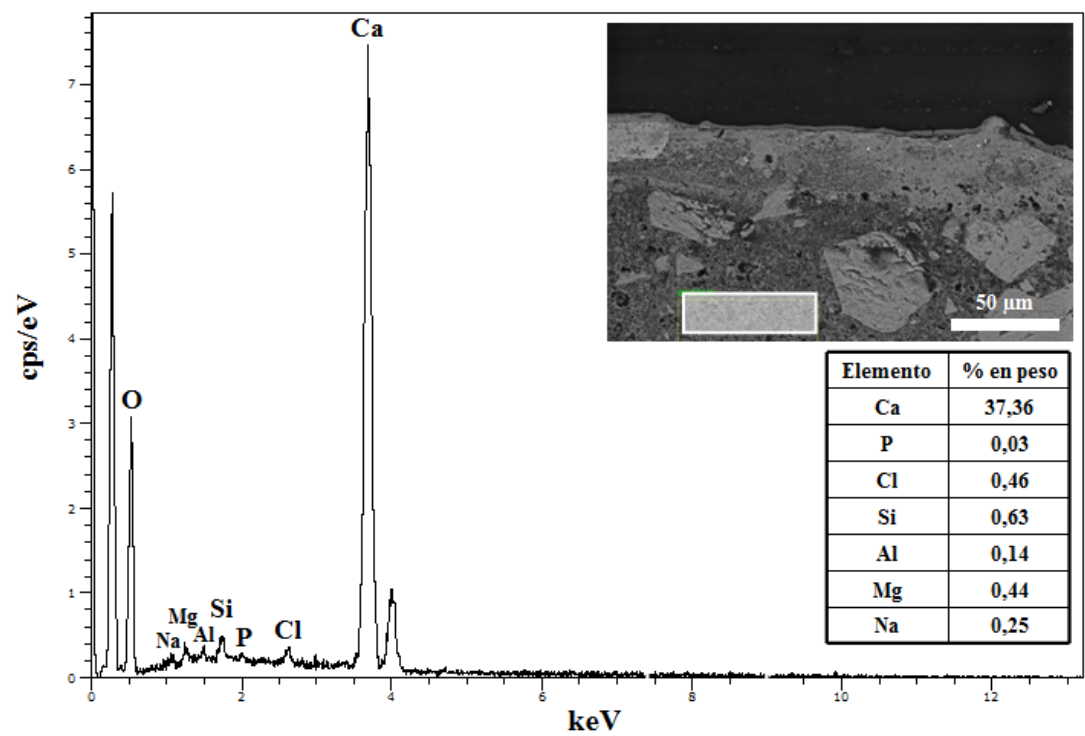

Figura 9.14. Micrografía obtenida por SEM (inset) de un área del fragmento de pintura mural tratado con HA1 observado en corte transversal, y espectro EDX de la región marcada en la imagen (área interna $200 \mu \mathrm{m}$ aprox.). En forma de tabla se expresa el \% en peso de los diferentes elementos detectados. 


\subsubsection{Evaluación en superficie y en corte transversal de la muestra HA2}

En la evaluación del tratamiento de consolidación y protección con las distintas disoluciones acuosas de las muestras preparadas sobre el fragmento de pintura mural, la aplicación de la muestra HA2 es la que mejores resultados ha proporcionado. Tras la aplicación del producto, tal y como se muestra en la imagen B de la Figura 9.15 que corresponde al área de la superficie de pintura mural tratada, no se aprecia a nivel macroscópico la presencia de depósitos superficiales, ni un cambio evidente en el color y morfología.

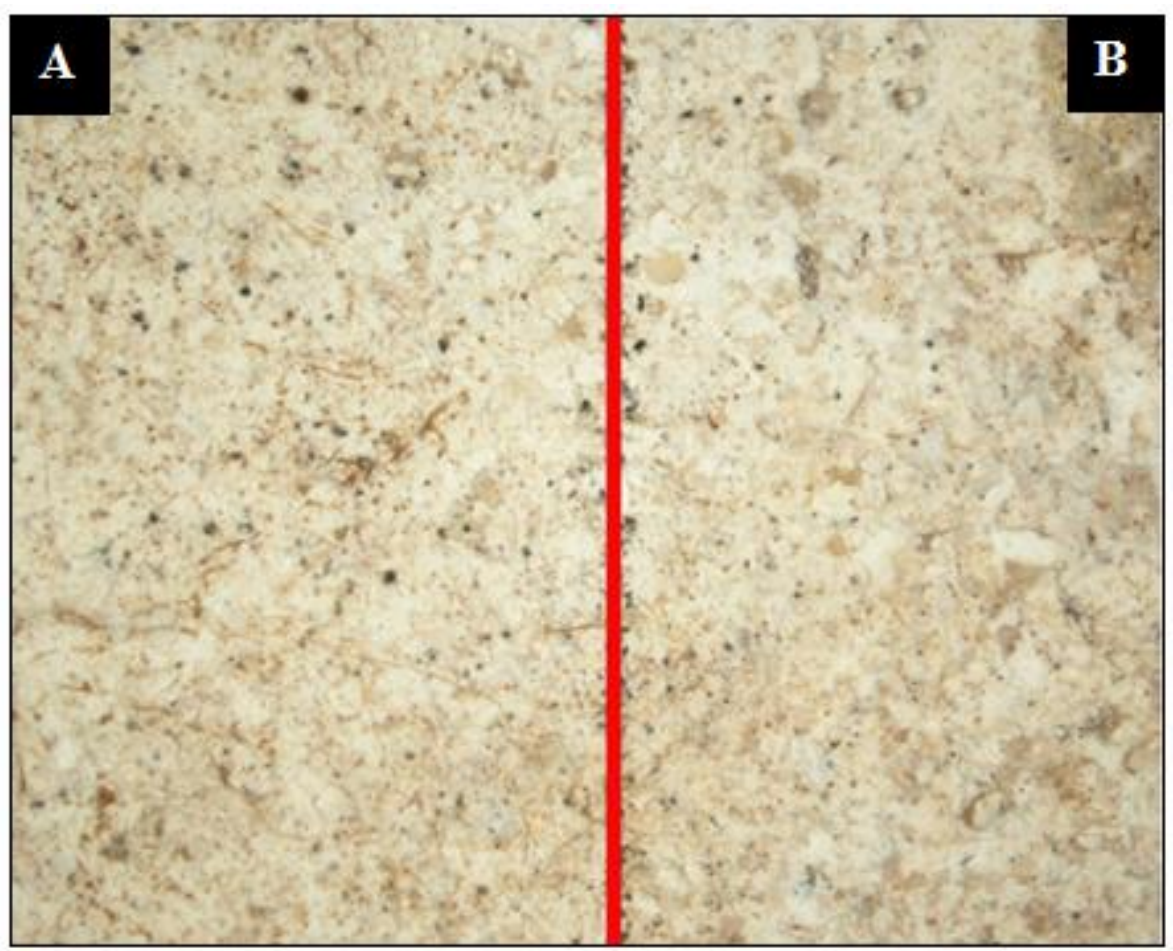

Figura 9.15. Imagen de microscopia estereoscópica $(1 \mathrm{x})$ de la superficie de la pintura mural antes del tratamiento (A) y después del tratamiento con la muestra de hidroxiapatita HA2 (B).

En la micrografía SEM de la Figura 9.16 se observa que el producto aplicado se distribuye de manera uniforme sobre la superficie pictórica, rellenando cavidades y fracturas, incrementando de esta manera la adhesión y cohesión de los constituyentes de la pintura. Por el contrario, y en contraposición a lo observado en los tratamientos con las disoluciones de las muestras ACP y HA1, el grado de agrietamiento y desprendimiento del producto aplicado resulta ser menor, indicando posiblemente una mayor compatibilidad de la hidroxiapatita cristalina con la superficie pictórica. 


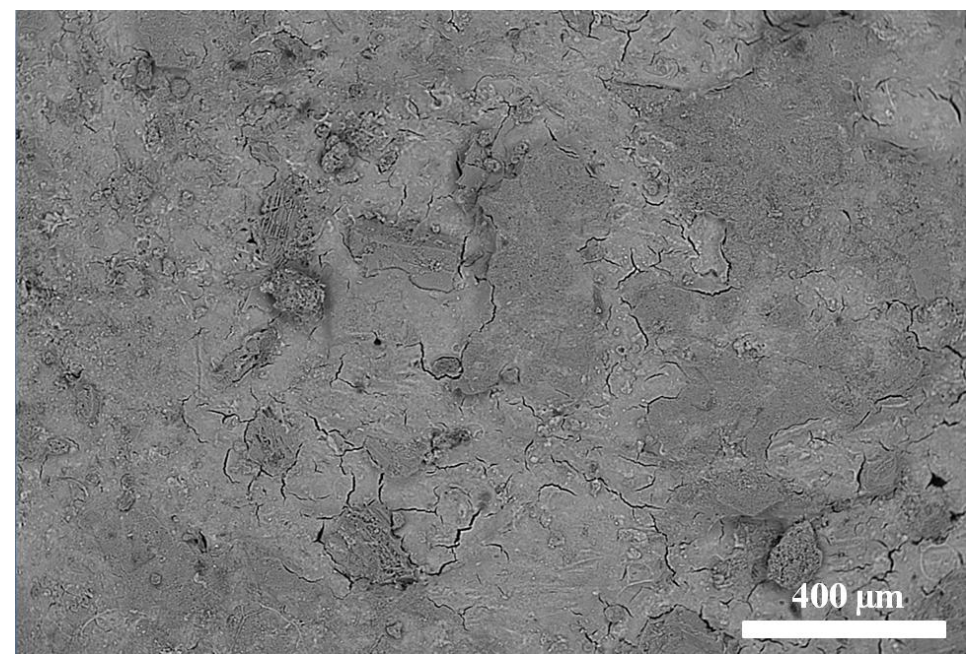

Figura 9.16. Imagen por SEM en modalidad BSE de la superficie del fragmento de pintura mural después del tratamiento con la muestra HA2.

El microanálisis EDX de la superficie de la pintura mural después del tratamiento, detecta una alta concentración de calcio (Ca) y de fósforo (P), que corresponderían a elementos constituyentes mayoritarios de la pintura mural a base de carbonato de calcio y de la hidroxiapatita introducida respectivamente (Figura 9.17). Con el mapping de distribución del fósforo (P) de la Figura 9.18 se observa una distribución prácticamente uniforme sobre la superficie del fragmento de pintura mural, lo que indicaría una aplicación homogénea del producto en toda la superficie.

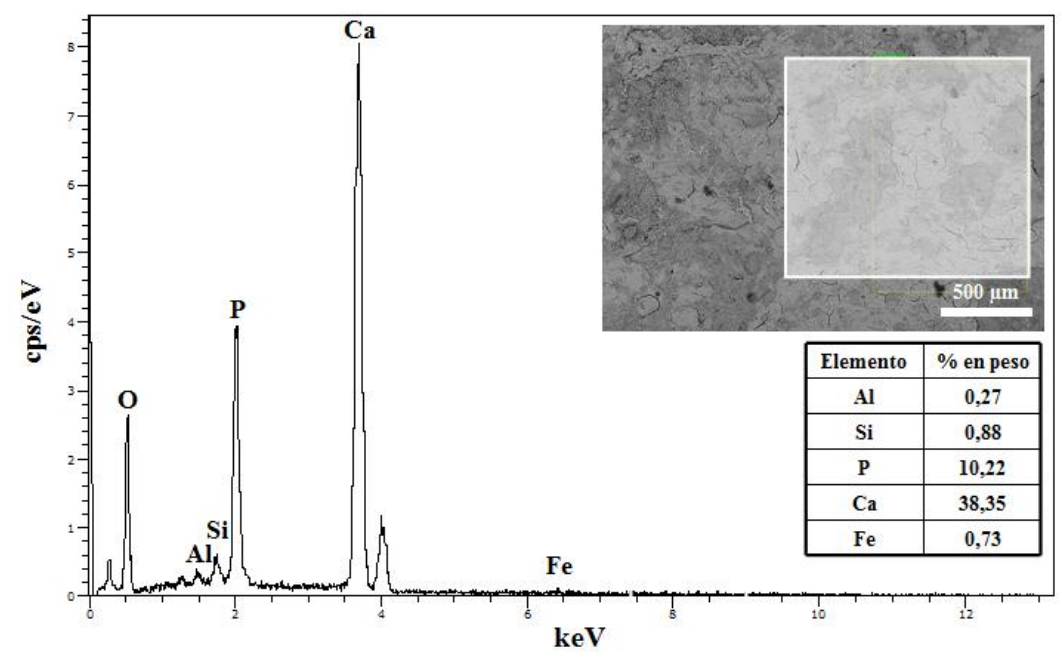

Figura 9.17. Micrografía obtenida por SEM (inset) de un área del fragmento de pintura mural tratado con HA2 observado en superficie, y espectro EDX de la región marcada en la imagen. En forma de tabla se expresa el \% en peso de los diferentes elementos detectados. 

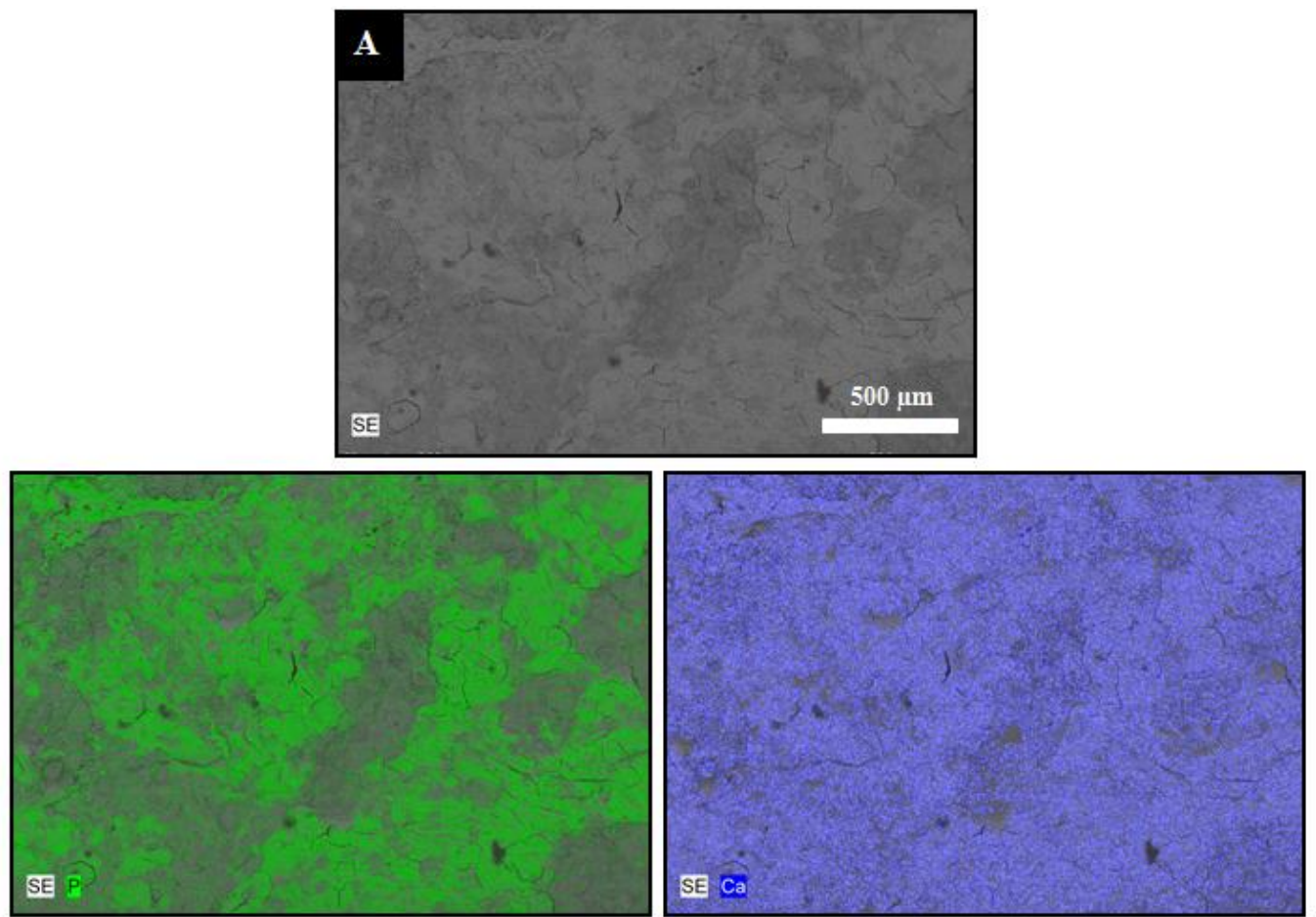

Figura 9.18. A) Imagen por SEM de un área superficial del fragmento de pintura mural tratado con la muestra HA2. Mapping de la distribución de los elementos químicos del fósforo (P) y calcio (Ca).

El tratamiento con la muestra HA2, al igual que en los casos anteriores, crean una película superficial con una distribución y espesores menos uniformes. El espesor máximo medido de $6 \mu \mathrm{m}$ aproximadamente tal como se puede ver en la micrografía SEM de la Figura 9.19.

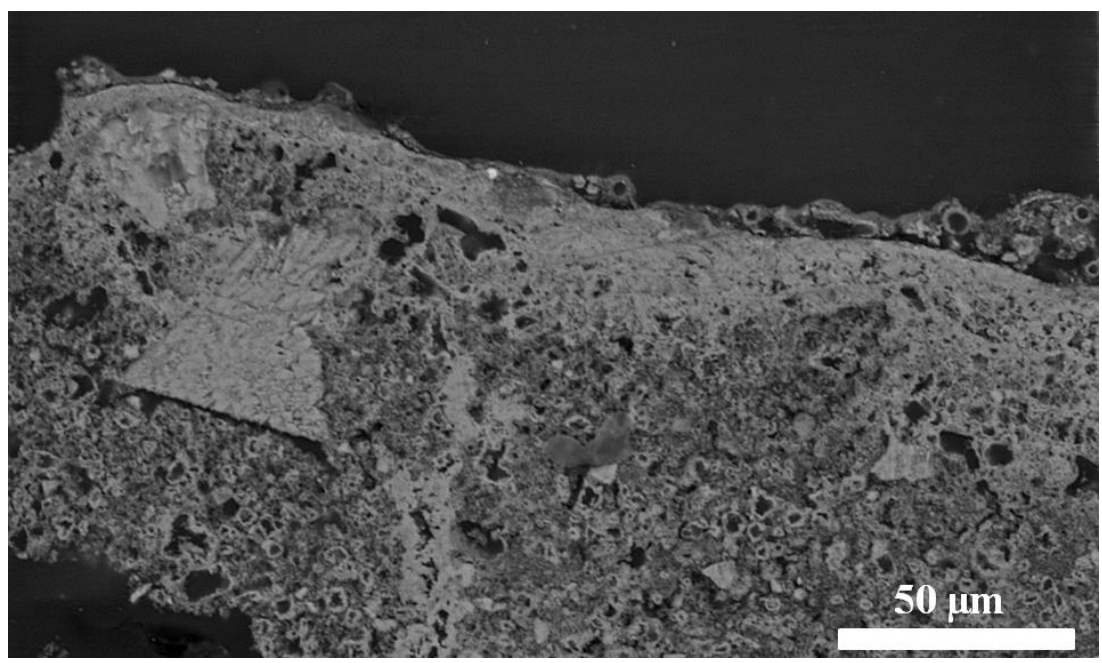

Figura 9.19. Imagen por SEM de un corte transversal del fragmento de pintura mural tratado con la muestra de hidroxiapatita HA2. 
Los microanálisis EDX detectan el calcio (Ca) y fósforo (P) en la película (Figura 9.20) relacionado con la presencia de la hidroxiapatita aplicada. El contenido de este último elemento tiende a disminuir progresivamente hasta una profundidad de $200 \mu \mathrm{m}$ como se señala en los espectros EDX de las Figuras 9.21 y 9.22. En los microanálisis realizados la concentración del fosforo detectado en la zona más interna resulta ser inferior a $0,1 \%$.

Igual que en el caso anterior, hay un grado de penetración inferior a lo que se ha observado en el caso de las probetas de piedra. Esto se debe, posiblemente, a una diferente porosidad del soporte que caracteriza el fragmento de la pintura mural.

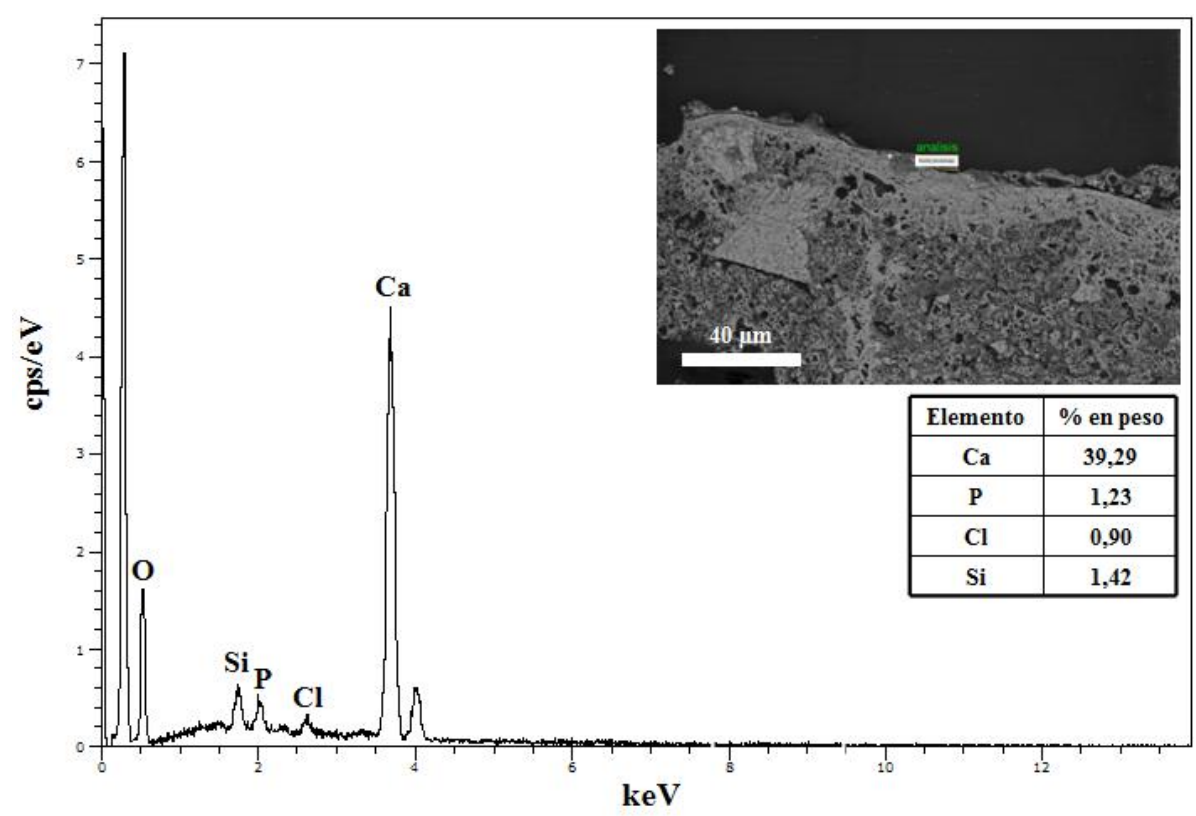

Figura 9.20. Micrografía obtenida por SEM (inset) de un área del fragmento de pintura mural tratado con HA2 observado en corte transversal, y espectro EDX de la región marcada en la imagen. En forma de tabla se expresa el \% en peso de los diferentes elementos detectados. 


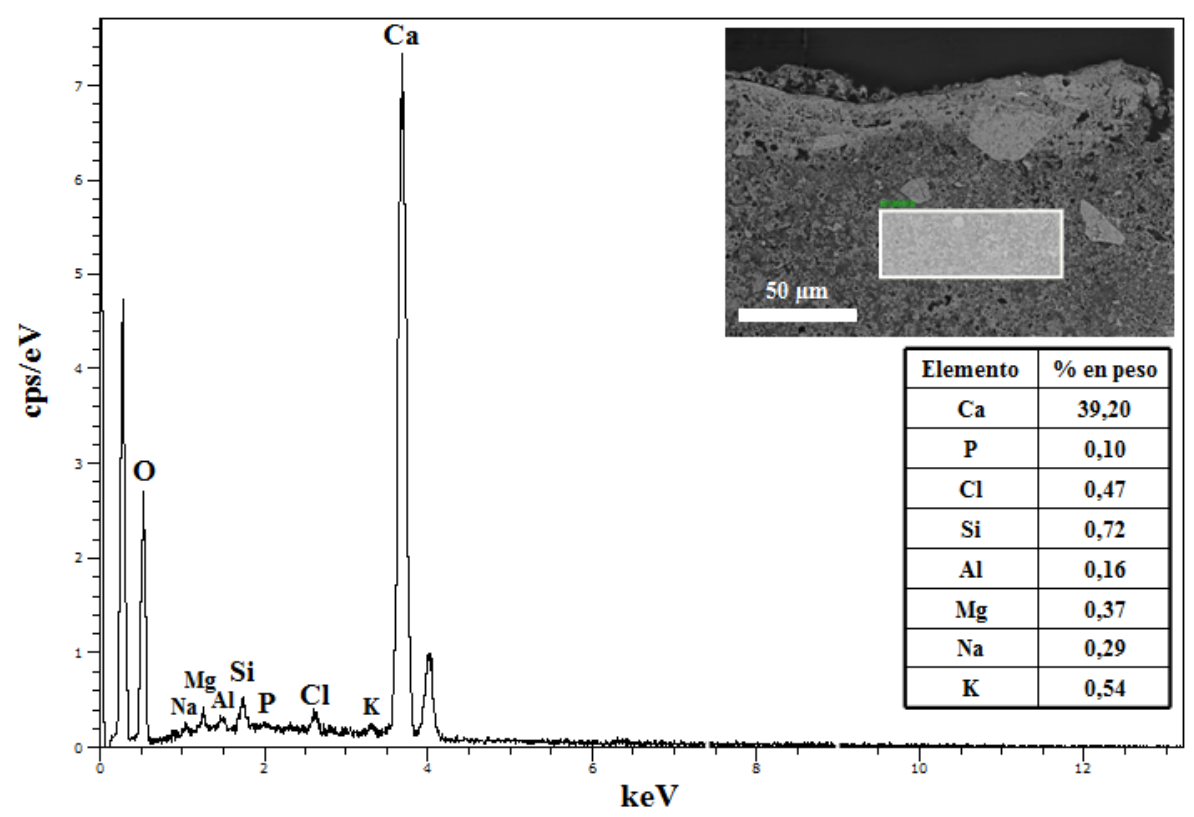

Figura 9.21. Micrografía obtenida por SEM (inset) de un área del fragmento de pintura mural tratado con HA2 observado en corte transversal, y espectro EDX de la región marcada en la imagen (área interna $100 \mu \mathrm{m}$ aprox.). En forma de tabla se expresa el \% en peso de los diferentes elementos detectados.

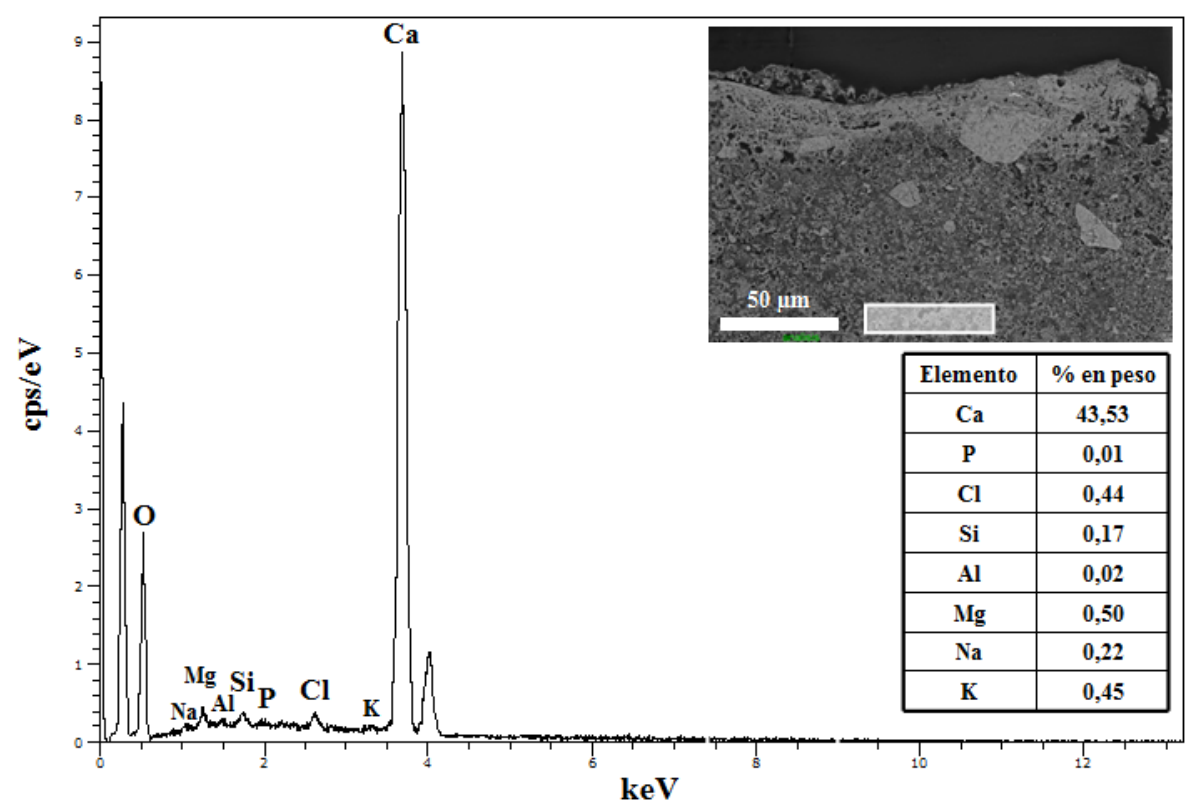

Figura 9.22. Micrografía obtenida por SEM (inset) de un área del fragmento de pintura mural tratado con HA2 observado en corte transversal, y espectro EDX de la región marcada en la imagen (área interna $200 \mu \mathrm{m}$ aprox.). En forma de tabla se expresa el \% en peso de los diferentes elementos detectados. 


\subsubsection{Espectroscopia infrarroja por transformada de Fourier (FTIR)}

El objetivo de los análisis FTIR ha sido el de corroborar, mediante la comparación entre los espectros obtenidos antes y después del tratamiento, la presencia de las muestras aplicadas.

Como se muestra en los espectros FTIR de la Figura 9.23, en la referencia inicial de la muestra superficial de pintura mural sin tratamiento (espectro en gris), se identifican las bandas de vibración típicas del grupo $\mathrm{CO}_{3}{ }^{2-}$ a 690 y $870 \mathrm{~cm}^{-1}$ y en el intervalo de $1380-1500 \mathrm{~cm}^{-1}$. Estas bandas están relacionadas con el carbonato de calcio como constituyente mayoritario en el soporte de mortero y en la capa de pintura. En las muestras extraídas del fragmento de pintura mural tratado con las dispersiones de las muestras preparadas, como se observa en los análisis FTIR, se identificaron las bandas del grupo fosfato $\mathrm{PO}_{4}{ }^{3-}$ a $560-600 \mathrm{~cm}^{-1}$ y $1100 \mathrm{~cm}^{-1}$, confirmando, de esta forma, la introducción y presencia de la muestras preparadas.

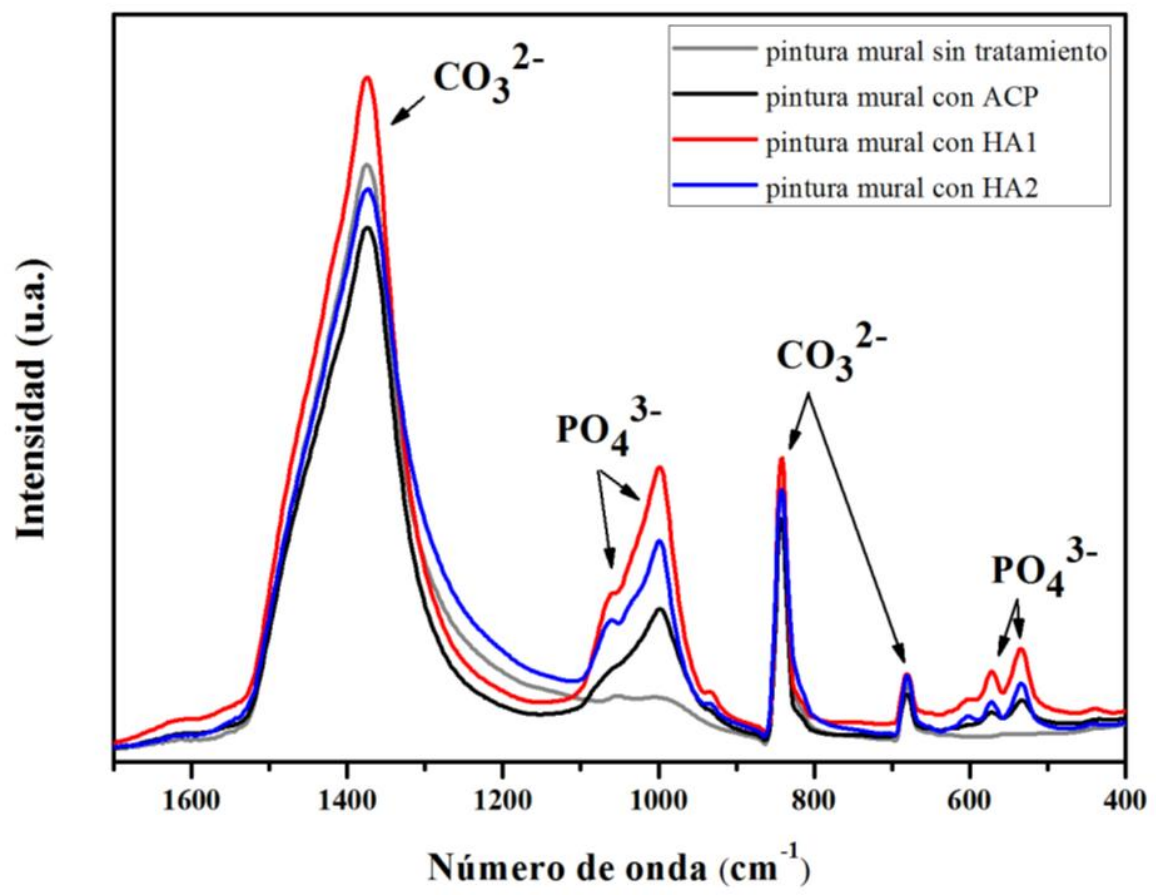

Figura 9.23. Espectros FTIR de las muestras superficiales del fragmento de pintura mural con tratamiento. En gris se muestra la respuesta FTIR de la muestra sin tratamiento. Muestra pintura tratada con ACP (en negro), con HA1 (en rojo) y con HA2 (en azul). 


\subsubsection{Colorimetría}

La medición colorimétrica se realizó con el espectrofotómetro en los mismos puntos en los que se había realizado previamente a los tratamientos con las tres dispersiones acuosas de las muestras ACP, HA1 y HA2. Los valores CIEL*a*b* iniciales y finales medios obtenidos para cada muestra tras las tres mediciones con iluminante de luz diurna (D65), así como los valores diferenciales de cada parámetro y los valores finales de $\Delta \mathrm{E}^{*}$ se recogen en la Tabla 9.1.

Se resaltan los valores de $\Delta \mathrm{E}^{*}>6$ que se corresponden a los resultados obtenidos tras el tratamiento con las muestras ACP y HA1. Se podría concluir, por tanto, que estos productos no serían idóneos para la consolidación de bienes patrimoniales pues generan un cambio de color demasiado significativo.

Sin embargo, el tratamiento con la muestra HA2 más cristalina, da lugar a una variación de color que está dentro de los limites exigidos y que por tanto, nos indicaría que este material podría ser aplicado para los tratamientos de consolidación y protección de pinturas murales como la que va detallando en esta tesis. Del mismo modo tal y como se ha observado en el estudio colorimétrico de las probetas de soporte pétreo tratados con las distintas muestras, la cristalinidad influye en el cambio de las propiedades ópticas de la superficie pictórica.

Tabla 9.1. Valores colorimétricos CIEL*a*b* iniciales y finales, diferenciales de cada parámetro y valor de $\Delta \mathrm{E}^{*}$.

\begin{tabular}{|c|c|c|c|c|c|c|c|c|c|c|}
\hline \multirow[b]{2}{*}{ Muestra } & \multicolumn{3}{|c|}{$\begin{array}{c}\text { Valores } \mathbf{L}^{*} \mathbf{a}^{*} \mathbf{b}^{*} \\
\text { sin tratamiento }\end{array}$} & \multicolumn{3}{|c|}{$\begin{array}{l}\text { Valores } L^{*} \mathbf{a}^{*} \mathbf{b}^{*} \\
\text { con tratamiento }\end{array}$} & \multicolumn{4}{|c|}{$\begin{array}{l}\text { Variaciones de los valores } \\
\qquad \mathbf{L}^{*} \mathbf{a}^{*} \mathbf{b}^{*}\end{array}$} \\
\hline & $\begin{array}{l}\mathbf{L}^{*} \\
(\mathbf{D} 65)\end{array}$ & $\begin{array}{l}\mathbf{a}_{\mathrm{i}}^{*_{\mathrm{i}}} \\
(\mathrm{D} 65)\end{array}$ & $\begin{array}{l}\mathbf{b}_{\mathrm{i}} \\
(\mathbf{D 6 5})\end{array}$ & $\begin{array}{l}\mathbf{L}^{*} \\
(\mathbf{D} 65)\end{array}$ & $\begin{array}{l}\mathbf{a}_{\mathrm{f}} \\
(\mathrm{D} 65)\end{array}$ & $\begin{array}{l}\mathbf{b}_{\mathrm{f}} \\
(\mathbf{D 6 5})\end{array}$ & $\Delta \mathbf{L}^{*}$ & $\Delta \mathbf{a}^{*}$ & $\Delta \mathbf{b}^{*}$ & $\Delta \mathbf{E}^{*}$ \\
\hline ACP & 82,44 & 3,35 & 15,34 & 72,52 & 4,53 & 16,06 & $-9,92$ & 1,17 & 0,73 & 10,02 \\
\hline HA1 & 82,16 & 3,38 & 15,42 & 72,38 & 5,2 & 13,96 & $-9,78$ & 1,82 & $-1,45$ & 10,05 \\
\hline HA2 & 82,16 & 3,38 & 15,42 & 77,3 & 3,68 & 16,12 & $-4,85$ & 0,3 & 0,7 & 4,91 \\
\hline
\end{tabular}




\subsection{Conclusiones}

Los análisis llevados a cabo a lo largo de este estudio sobre la acción consolidante y de protección de las muestras preparadas en un fragmento de pintura mural, han permitido alcanzar las siguientes conclusiones.

En primer lugar se ha observado, igual que en las probetas de soporte pétreo, que las muestras de hidroxiapatita de mayor cristalinidad permiten alcanzar resultados óptimos en cuanto a protección de la superficie y consolidación de la estructura. En cuanto a la penetración de las partículas en los poros del mortero, se consigue una menor penetración respecto a lo observado en las probetas de soporte pétreo, posiblemente debido a la diferente porosidad del mortero, aunque sigue siendo bastante elevada. La capa pictórica, una estructura bastante compacta, igualmente podría limitar la difusión de las dispersiones acuosas de las nanopartículas, limitando su penetración. Asimismo con la colorimetría se ha constatado que para la muestra ensayada de mayor cristalinidad, no se produce un cambio significativo de coloración de la capa pictórica.

A la vista de estas consideraciones, y como resultado final de esta investigación sobre pintura mural, podríamos afirmar que, efectivamente, las nanopartículas cristalinas de hidroxiapatita pueden tener aplicabilidad en los tratamientos de consolidación y protección. 


\section{Estudio de la aplicabilidad en material}

paleontológico 


\title{
Capítulo 10. Estudio de la aplicabilidad en material paleontológico
}

\author{
10.1. Material paleontológico
}

10.1.1. Fragmento de marfil

10.1.2. Fragmento de hueso del Pleistoceno Medio

10.2. Metodología

10.3. Resultados

10.3.1. Evaluación de la muestra ACP sobre fragmentos de marfil y hueso

10.3.2. Evaluación de la muestra HA1 sobre fragmentos de marfil y hueso

10.3.3. Evaluación de la muestra HA2 sobre fragmentos de marfil y hueso

10.3.4. Espectroscopia infrarroja por transformada de Fourier (FTIR)

10.3.5. Colorimetría

10.4. Comparación del producto consolidante en uso a base de hidróxido de calcio respecto a las muestras ACP, HA1 y HA2 en fragmentos de marfil y hueso

10.4.1. Evaluación del producto consolidante de hidróxido de calcio en marfil

10.4.2. Evaluación del producto consolidante de hidróxido de calcio en hueso

10.5. Conclusiones 


\section{Capítulo 10. Estudio de la aplicabilidad en material paleontológico}

En este capítulo se muestran los principales resultados derivados de los primeros estudios sobre la valoración de la acción consolidante y protectora de las muestras preparadas en fragmentos de origen paleontológicos tales como marfil y hueso. El estudio se ha centrado en la valoración de aplicabilidad de varios productos inorgánicos en su uso como consolidantes en material óseo fósil y subfósil (marfil, hueso), que han sido comparados con la aplicabilidad y acción consolidante y protectora por parte de las muestras con estequiometría de hidroxiapatita.

La experimentación se ha basado en la aplicación sobre los fragmentos de las mismas técnicas analíticas antes y después de la aplicación de los consolidantes para poder realizar estudios comparativos a nivel superficial y composicional referidos, principalmente, a posibles cambios de color, penetración e interacción con el sustrato. 


\subsection{Material paleontológico}

De igual manera que los tratamientos de consolidación y protección en material pétreo y pintura mural, los productos a base de hidroxiapatita pueden tener aplicaciones en otros soportes que presentan problemáticas de conservación, como en el caso de restos paleontológicos. Son numerosas las sustancias que han sido utilizadas como consolidantes desde los inicios de las técnicas de conservación paleontológica. Anteriormente a la década de los años 40 del siglo XX se ha documentado el uso de sustancias tan diversas e inadecuadas como colas animales, gelatinas, engrudos de almidón, ceras, nitratos y acetatos de celulosa ${ }^{212}$. Sin embargo, a partir de finales del siglo pasado, los criterios de la conservación moderna se han decantado por otras sustancias, en su mayor parte polímeros sintéticos de fabricación industrial disueltos en disolventes o en emulsión acuosa. En las últimas décadas se ha aplicado y evaluado el uso de productos de formulación diversa como acetato de polivinilo, polivinilbutiral, polibutilmetacrilato, polimetilmetacrilato, alcohol polivinílico, nylon soluble, polietilenglicol, resinas epoxídicas, cianoacrilatos, silicato de etilo y otros productos comerciales de composición menos conocida ${ }^{213}$, 214. En algunos laboratorios también se han utilizado productos como el silicato de etilo, aunque siempre en combinación con las resinas anteriormente $\operatorname{citadas}^{215}$.

Todavía resulta complicado localizar publicaciones referentes al uso de consolidantes inorgánicos en material fósil y por eso, es interesante desarrollar trabajos para comprobar la viabilidad de la aplicación de nuevos productos como en el caso de los productos sintetizados con formulación de hidroxiapatita. Recientemente, las pruebas llevadas a cabo por Natali y col. ${ }^{216}$ abren la posibilidad de que el material óseo sea también un campo viable para la utilización de estos compuestos en tratamientos con fines de consolidación.

\footnotetext{
212 S.Y. Shelton, D. S. Chaney, An evaluation of adhesives ans consolidants recommended for fossil vertebrates, in Vertebrate Paleontological Techniques. Vol. 1, P. Leiggi and P. May, Eds. Cambridge: Cambridge University Press, 35-45, 1994.

${ }^{213}$ A. E. Rixon, Fossil Animal Remains: Their Preparation and Conservation, London: Athlone Press, 1976.

${ }^{214}$ E. Carretti, D. Chelazzi, G. Rocchigiani, P. Baglioni, G. Poggi, L. Dei, Interactions between Nanostructured Calcium Hydroxide and Acrylate Copolymers: Implications in Cultural Heritage Conservation, Langmuir, Vol. 29, no. 31, 9881-9890, 2013.

${ }^{215}$ A. Aberasturi, R. Ferrer, H. Cuenca, J. Escudé, G. Gil, B. Giménez, C. Izquierdo, M. J. Jareño, E. Moreno, La intervención de fósiles de dinosaurio en la Escuela Taller de Restauración Paleontológica (Teruel), Unicum, Vol. 9, 103-111, 2010.

${ }^{216}$ I. Natali, P. Tempesti, E. Carretti, M. Potenza, S. Sansoni, P. Baglioni, L. Dei, Aragonite Crystals Grown on Bones by Reaction of $\mathrm{CO}_{2}$ with Nanostructured $\mathrm{Ca}(\mathrm{OH})_{2}$ in the Presence of Collagen. Implications in Archaeology and Paleontology, Langmuir, Vol. 30, no. 2, 660-668, 2014.
} 


\subsubsection{Fragmento de marfil}

Las aplicaciones de las muestras sintetizadas se realizó sobre un fragmento de marfil procedente de una defensa de mamut subadulto encontrada en el yacimiento de Can Guardiola en Viladecans (Barcelona) durante las obras de ejecución de una balsa de laminación en el año 2008. La cronología del yacimiento se sitúa en el Pleistoceno superior, es decir, en unos 70.000 a 60.000 años antes del presente ${ }^{217}$. Se denomina defensa a los incisivos superiores que diversas especies de proboscídeos desarrollaron como colmillos con fines defensivos. La pieza en cuestión (Figura 10.1) fue encontrada completa en un estrato correspondiente a un paleocanal y fue llevada al Centro de Conservación de Bienes Muebles de Cataluña para su almacenaje y posterior intervención en el año 2014. En la Figura 10.1 A se muestra el aspecto inicial de la defensa, mientras que en la imagen de la Figura $10.1 \mathrm{~B}$ se observan los fragmentos del interior de la defensa desprendidos y desubicados uno de los cuales sirvió como fragmento de este estudio.
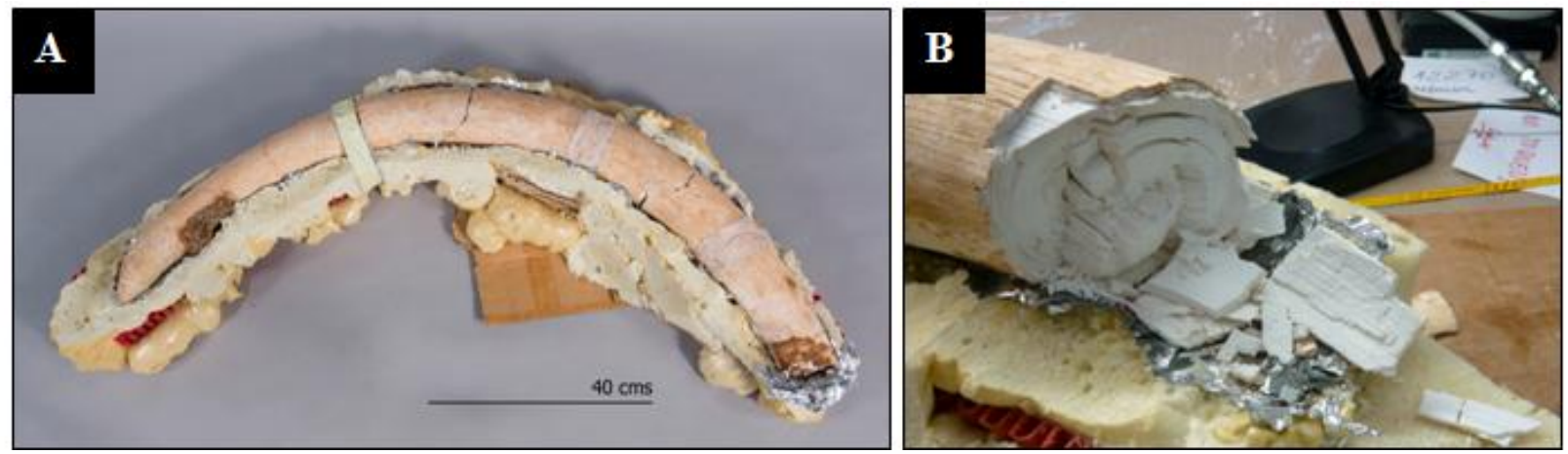

Figura 10.1. A) Aspecto inicial de la defensa (Fuente: R. Maroto). B) Fragmentos del interior de la defensa desprendidos y desubicados (Fuente: J. Escudé).

En cuanto al material, el marfil tiene una composición similar al hueso pero con ciertas variaciones. Está compuesto principalmente de dentina, que tiene una proporción de 3 partes de hidroxiapatita por cada parte de colágeno, además de un contenido del $10 \%$ en peso de agua. Estructuralmente también difiere del hueso en su marcada estructura laminar, causada por los anillos de crecimiento y en la ausencia de un sistema de canales para los vasos sanguíneos. Presenta, en su lugar, una densa red microtubular que tiene una

\footnotetext{
${ }^{217}$ J. Escudé, Defensa de proboscidi de Viladecans, RESCAT. Butlletí del Cent. Restauració Béns Mobles Catalunya, 26, 20-21, 2015.
} 
disposición circular similar a la de los troncos de los árboles ${ }^{218}$. A nivel de conservación, un marfil en buen estado es uno de los materiales más elásticos y resistentes de la naturaleza, sin embargo, los procesos de fosilización favorecen la pérdida del contenido de agua y de su fracción de carácter orgánico, lo que genera un ligero encogimiento y una deformación anisotrópica debido a la disposición radial de la estructura tubular. La capa más externa, compuesta de esmalte, no fractura del mismo modo pero, debido al encogimiento, a menudo se agrieta longitudinalmente creando profundas fisuras ${ }^{219}$. Se trata, por tanto, de un material extremadamente frágil que ha perdido casi todo su contenido en humedad y de carácter muy poroso.

\subsubsection{Fragmento de hueso del Pleistoceno Medio}

Como se observa en la Figura 10.2 se trata de un fragmento de costillas procedente de mamíferos herbívoros de especie indeterminada y encontrados en el yacimiento de la Cova del Llentiscle en Vilamarxant (Valencia). La cronología del yacimiento se sitúa en torno al paso del Pleistoceno Inferior al Medio, es decir, en unos 0,8 a 0,7 millones de años antes del presente ${ }^{220}$. Las costillas son un tipo de huesos curvos y planos, ligeros y resistentes, formados por tejido esponjoso en su interior y recubiertos de una capa fina de tejido compacto.

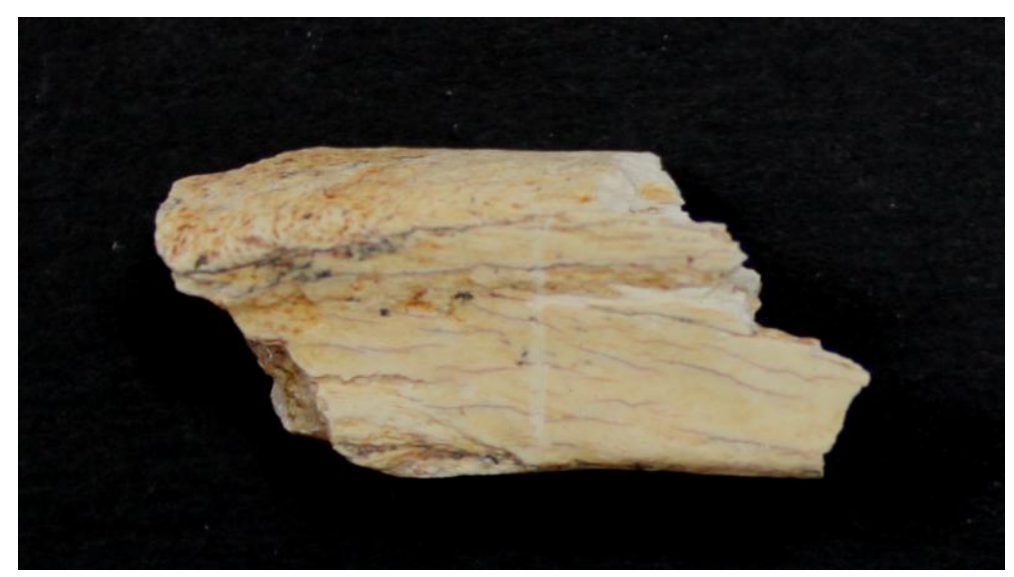

Figura 10.2. Fragmento de costilla de mamíferos herbíveros del Pleistoceno Medio procedente de la Cova del Llentiscle utilizado en el estudio.

\footnotetext{
218 J. M. Cronyn, The Elements of Archaeological Conservation, London: Routledge, 1990.

219 A. E. Rixon, Fossil Animal Remains: Their Preparation and Conservation, London: Athlone Press, 1976.

${ }^{220}$ I. Sarrión Montaña, Puntualizaciones sobre la fauna del Pleistoceno inferior/medio de la Cova del Llentiscle (Vilamarxant, Valencia), Arch. Prehist. levantina, Vol. 28, 11-45, 2010.
} 
El yacimiento de la Cova del Llentiscle se encuentra en un área kárstica, es decir, originada por la meteorización química de los componentes minerales de las rocas solubles en agua y se formó debido a una fractura de las rocas calizas. Los restos fósiles encontrados en el interior de la cueva estaban englobados en una matriz arcillosa muy compactada y cementada. Por su cronología, se trata de materiales óseos con un grado de fosilización bajo, por tanto, de un material que consideraríamos subfósil, con poca resistencia, que aún conserva parte de su componente orgánico y de carácter poroso. Por el carácter kárstico de la cueva en la que fueron encontrados, los materiales presentan algunos restos de matriz arcillosa carbonatada de gran dureza.

\subsection{Metodología}

Las muestras utilizadas corresponden a los polvos preparados en esta tesis doctoral y evaluadas anteriormente sobre piedra y pintura mural. Corresponden a las muestras con código ACP, HA1 y HA2. Para el desarrollo de este trabajo se ha seguido la metodología descrita en el Capítulo 7.

Lo expuesto en este capítulo sobre la estimación de la acción consolidante y protectora de las muestras sintetizadas en los fragmentos de marfil y hueso, se basa principalmente en observaciones al VP-SEM y microanálisis EDX, en análisis de espectroscopia infrarroja por transformada de Fourier (FTIR) y medidas de las coordenadas colorimétricas. 


\subsection{Resultados}

\subsubsection{Evaluación de la muestra ACP sobre fragmentos de marfil y hueso}

Después de la aplicación de la dispersión acuosa de la muestra amorfa ACP, se realizaron las observaciones con microscopía estereoscópica y microscopía electrónica de barrido para aportar imágenes en las que se pudiera apreciar la acción de consolidación y protección en la superficie del fragmento de marfil y de hueso. De igual modo al desarrollado anteriormente en las probetas de soporte pétreo y en el fragmento de pintura mural, para cada fragmento se capturaron imágenes a distintos aumentos de las zonas documentadas en el proceso de caracterización inicial así como otras imágenes y microanálisis EDX de zonas que podían resultar interesantes para el estudio. Como se muestra en las imágenes SEM de la Figura 10.3, en las áreas de la superficie del fragmento de marfil observadas antes del tratamiento (imágenes A y B) se puede apreciar una textura superficial de alta porosidad, con una gran abundancia de espacios intersticiales aunque de pequeño tamaño. Tras el tratamiento con la muestra ACP (imágenes C y D), se puede ver un estrato diferenciado formado sobre la superficie del marfil de espesor grueso. No obstante, su adherencia a la superficie de la muestra resulta insuficiente, ya que se observan agrietamientos y desprendimientos en muchas zonas.
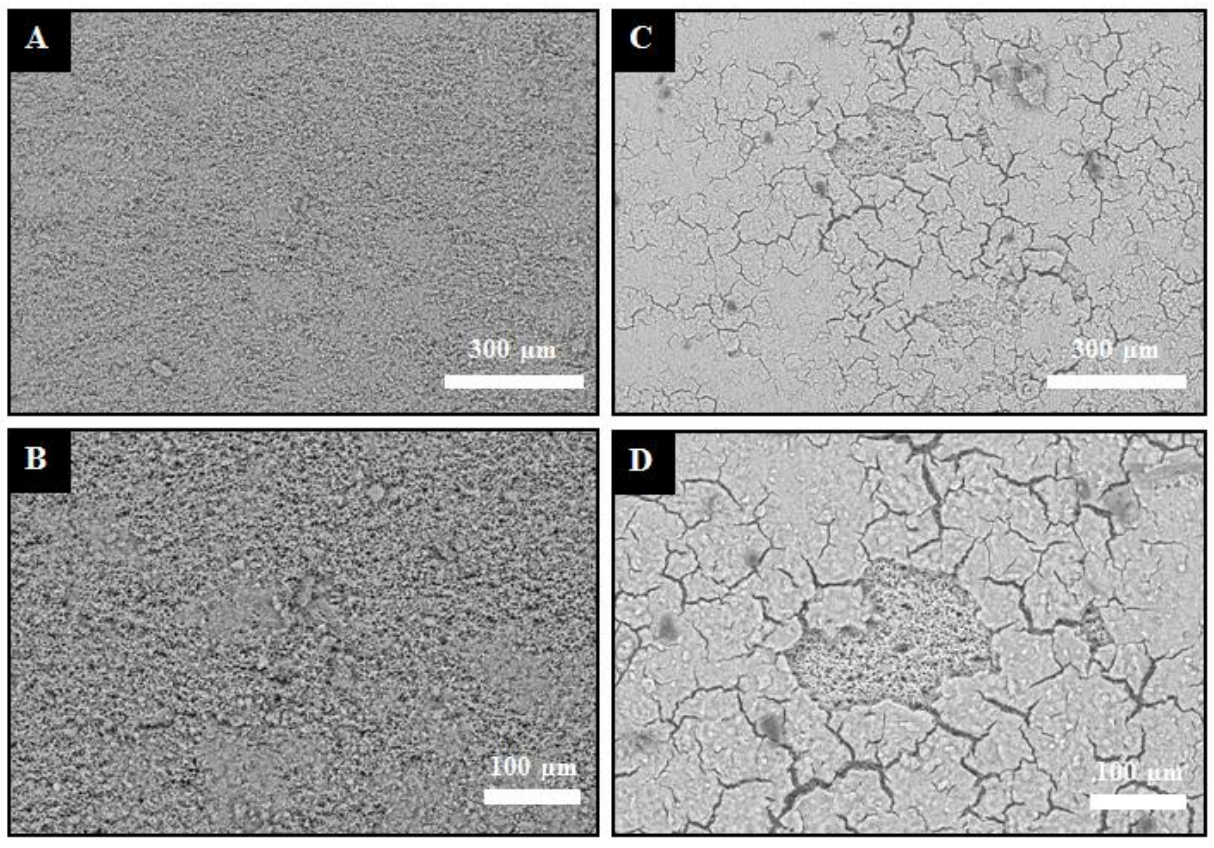

Figura 10.3. Imágenes por SEM en modalidad electrones retrodispersados a diferentes aumentos de un área de la superficie del fragmento de marfil antes del tratamiento (A y B) y después del tratamiento con la muestra ACP (C y D). 
El microanálisis EDX realizado sobre un área de la superficie sin tratamiento (espectro de la Figura 10.4), detecta la presencia de flúor $(\mathrm{F})$, calcio $(\mathrm{Ca})$ y fósforo $(\mathrm{P})$, estos elementos químicos están relacionados con una pequeña concentración de fluorapatita $\mathrm{Ca}_{5}\left(\mathrm{PO}_{4}\right)_{3} \mathrm{~F}$ y con hidroxiapatita $\mathrm{Ca}_{5}\left(\mathrm{PO}_{4}\right)_{3} \mathrm{OH}$ en mayores proporciones. La fluorapatita es un constituyente importante del esmalte de los dientes y, en matrices de origen biológico, que está combinada con la hidroxiapatita de calcio ${ }^{221}$.

En cuanto al microanálisis realizado sobre la superficie del marfil con la película superficial del tratamiento, como se muestra en la Figura 10.5, se detectan el calcio (Ca) y fósforo $(\mathrm{P})$ mientras que la señal del flúor $(\mathrm{F})$ no viene detectado. Este resultado indicaría que la película superficial que se genera después del tratamiento, está constituida únicamente por fosfato de calcio, compuesto relacionado con el producto aplicado.

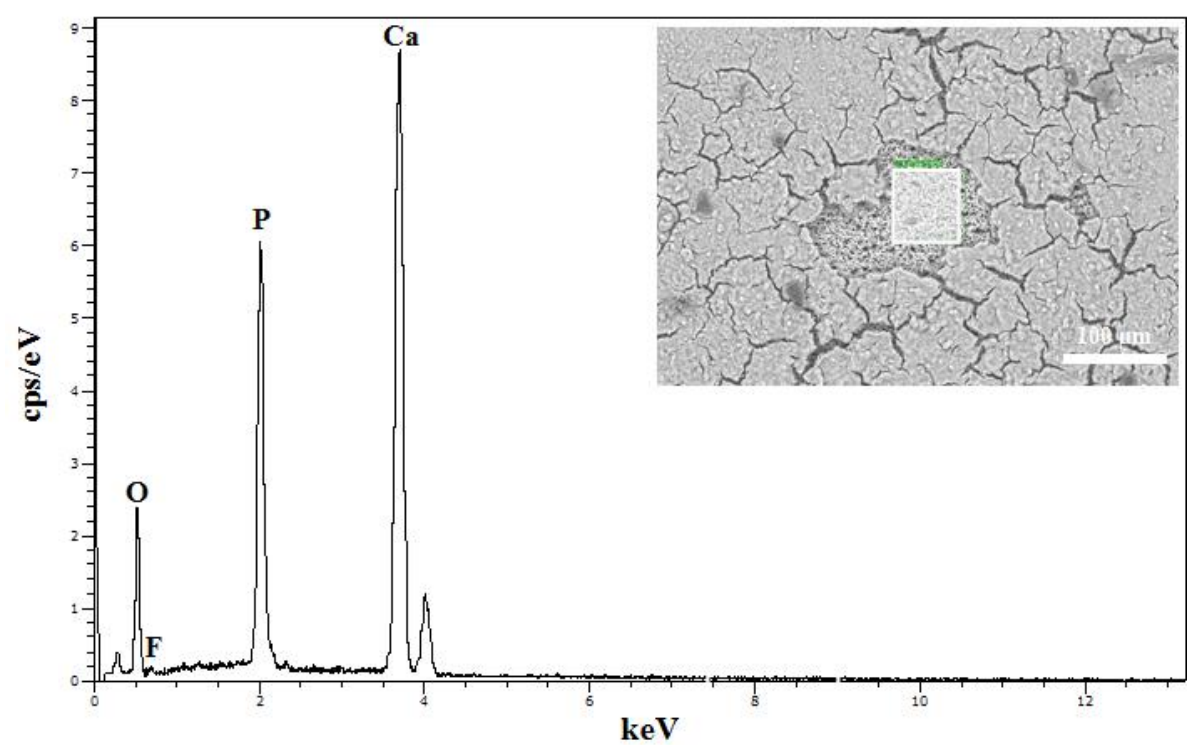

Figura 10.4. Micrografía obtenida por SEM (inset) de un área del fragmento de marfil observado en superficie, y espectro EDX de la región marcada en la imagen.

${ }^{221}$ K. Cornelis, H. Cornelius, J. Dwight, Manual of Mineralogy, Wiley, 1999. 


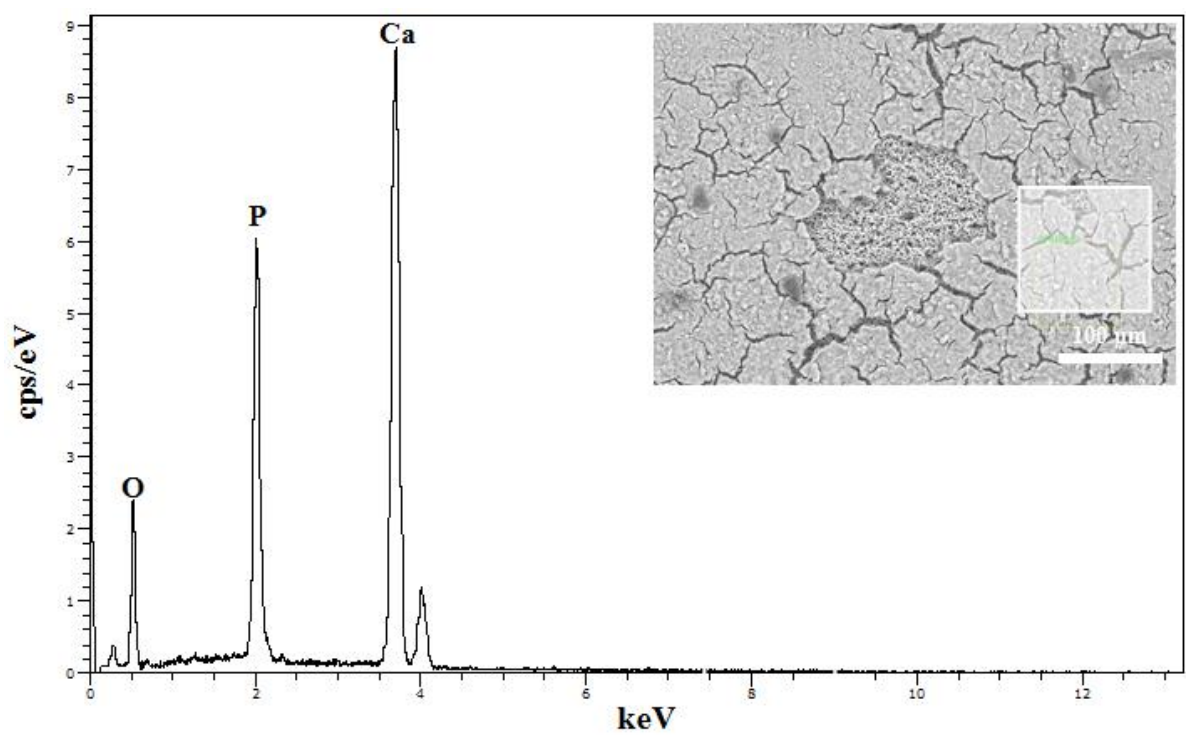

Figura 10.5. Micrografía obtenida por SEM (inset) de un área del fragmento de marfil tratado con ACP observado en superficie, y espectro EDX de la región marcada en la imagen.

Las observaciones de un corte transversal se utilizaron para detectar el nivel de penetración de la muestra ACP en el fragmento de marfil. Como se observa en la micrografía SEM de la Figura 10.6, hay la formación de un estrato uniforme del producto de unas $40 \mu \mathrm{m}$ de grosor sobre la superficie del marfil.

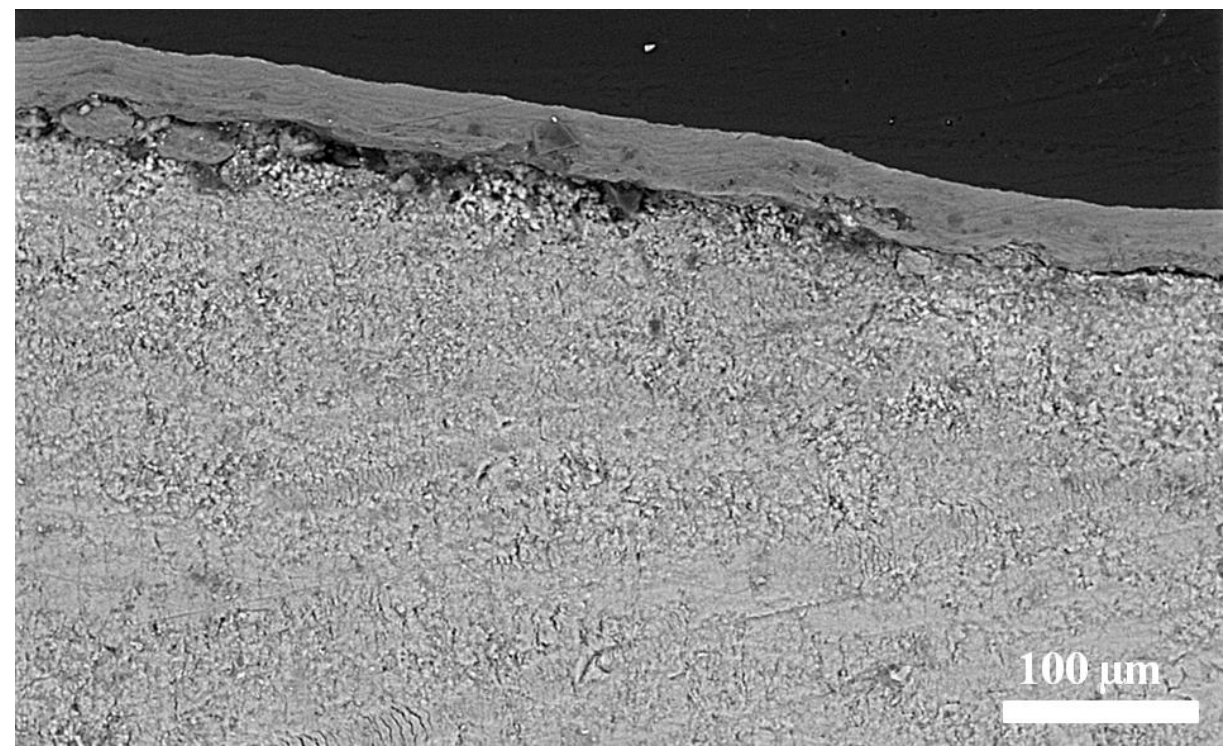

Figura 10.6. Imagen por SEM en modalidad electrones retrodispersados de un corte transversal del fragmento de marfil tratado con la muestra ACP. Se observa la formación de la capa superficial. 
El microanálisis de la Figura 10.7 confirma la naturaleza del estrato superficial a base de calcio (Ca) y fósforo (P). Este resultado indicaría que el grado de penetración de la disolución aplicada resulta ser mínimo, depositándose en la superficie del marfil con la formación del estrato.

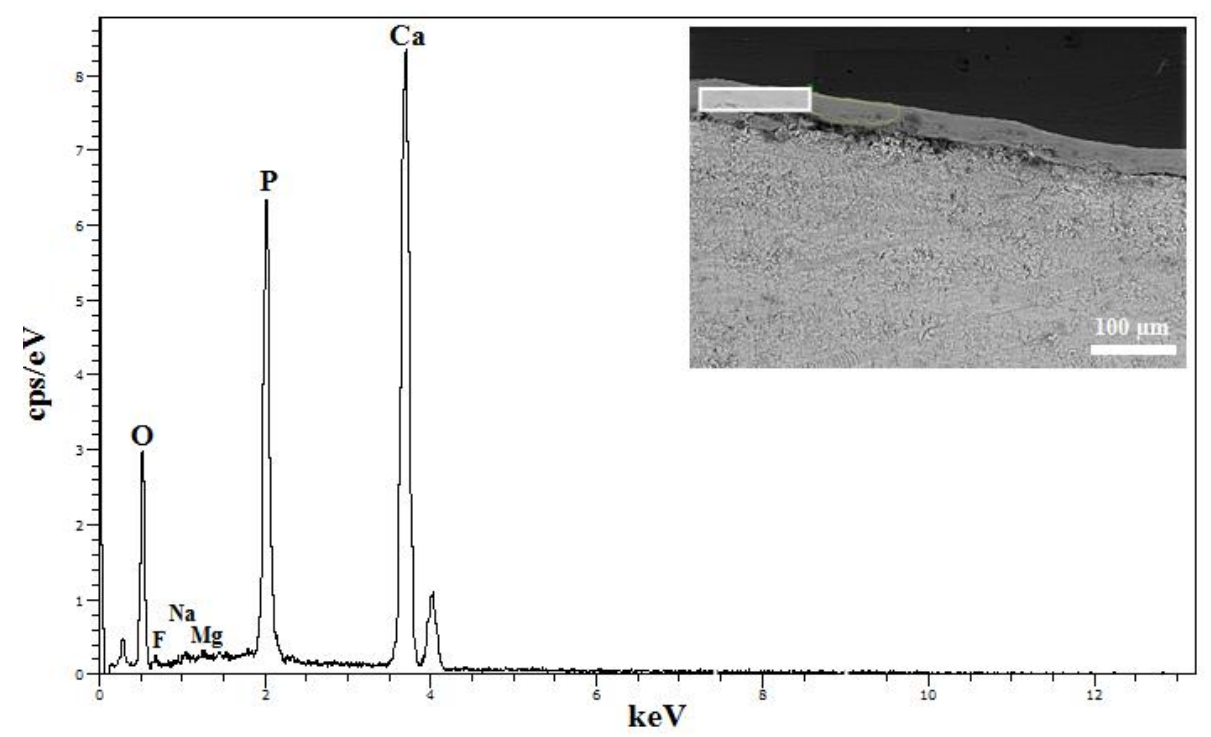

Figura 10.7. Micrografía obtenida por SEM (inset) de un área del fragmento de marfil tratado con ACP observado en corte transversal, y espectro EDX de la región marcada en la imagen.

Con las observaciones con microscopia electrónica del fragmento de hueso se pudo observar cómo tras el tratamiento con la muestra ACP no se detectó ningún cambio superficial apreciable más allá de la acumulación del producto aplicado como depósitos superficiales. En las micrografías SEM de la Figura 10.8 se muestra la misma área del fragmento de hueso (A) antes del tratamiento y después del tratamiento con ACP (imagen B). Se observa que en algunas áreas las grietas se rellenan de la muestra aplicada. Los microanálisis EDX de los agregados observados en superficie confirman la presencia de altas concentraciones de los elementos del fósforo $(\mathrm{P})$ y calcio $(\mathrm{Ca})$, tal y como se muestra en el espectro de la Figura 10.9. 

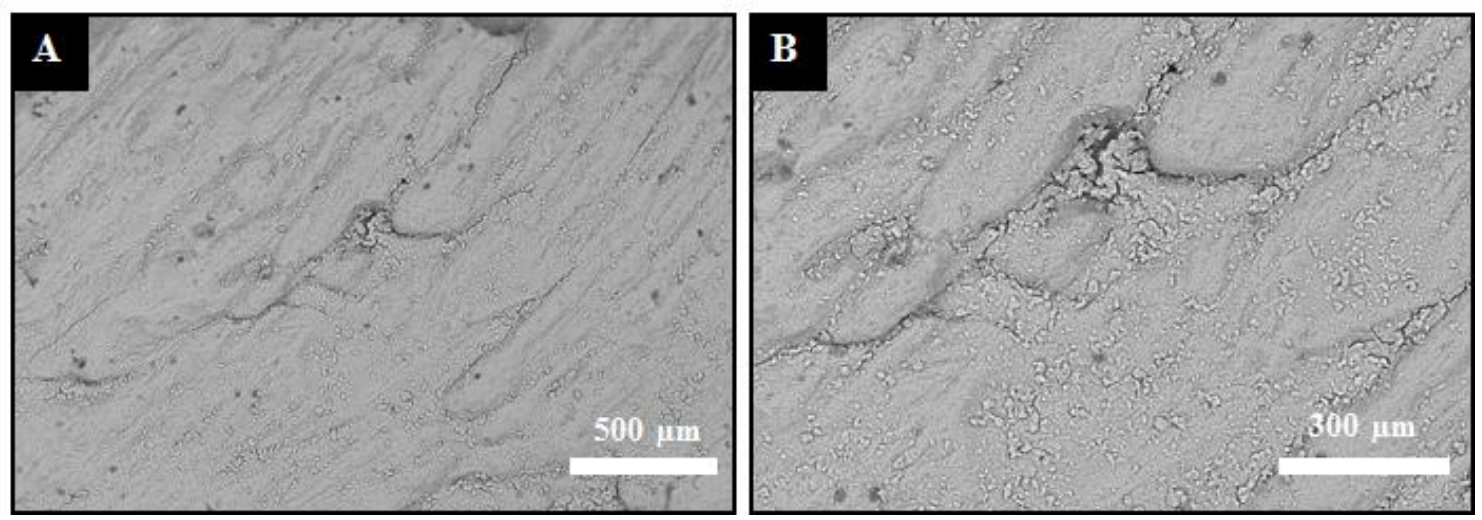

Figura 10.8. Imágenes por SEM en modalidad electrones retrodispersados de un área de la superficie del fragmento de hueso antes del tratamiento con la muestra ACP (A) y después del tratamiento (B).

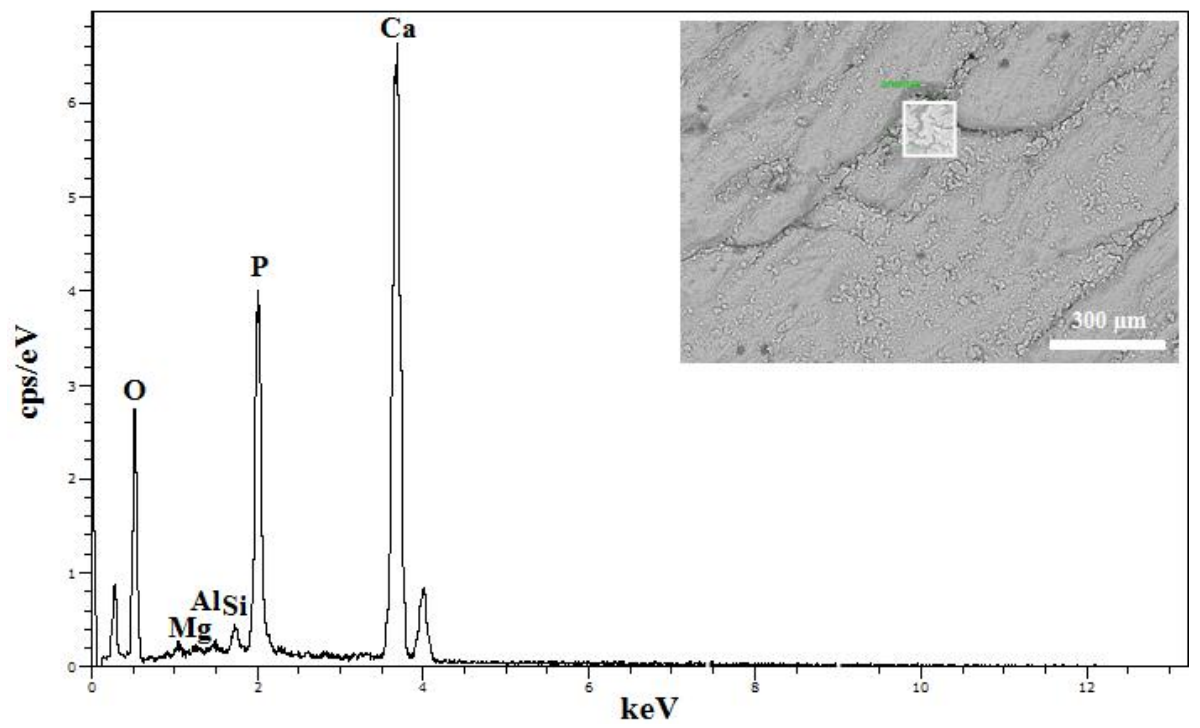

Figura 10.9. Micrografía obtenida por SEM (inset) de un área del fragmento de hueso tratado con ACP observado en superficie, y espectro EDX de la región marcada en la imagen. 


\subsubsection{Evaluación de la muestra HA1 sobre fragmentos de marfil y hueso}

Después del tratamiento con la muestra HA1 aplicada sobre la superficie del fragmento de marfil, a nivel macroscópico no se aprecia ningún cambio en las características superficiales como color y morfología. Esta muestra actuó de manera similar a lo observado en el fragmento de marfil anterior tratado con la muestra ACP.

En la imagen SEM, después del tratamiento -micrografía de la Figura 10.10 B-, se observa la formación de un estrato superficial diferenciado por encima del marfil de espesor más fino y que confiere un aspecto más uniforme y sin porosidad a la superficie del material, actuando como un recubrimiento. Este último aspecto puede ser valorado positivamente en cuanto el tratamiento permite incrementar la resistencia del soporte frente a la acción de disgregación.

El microanálisis EDX de la Figura 10.11 confirma la presencia de calcio $(\mathrm{Ca})$ y el fósforo $(\mathrm{P})$ en la superficie del fragmento de marfil.
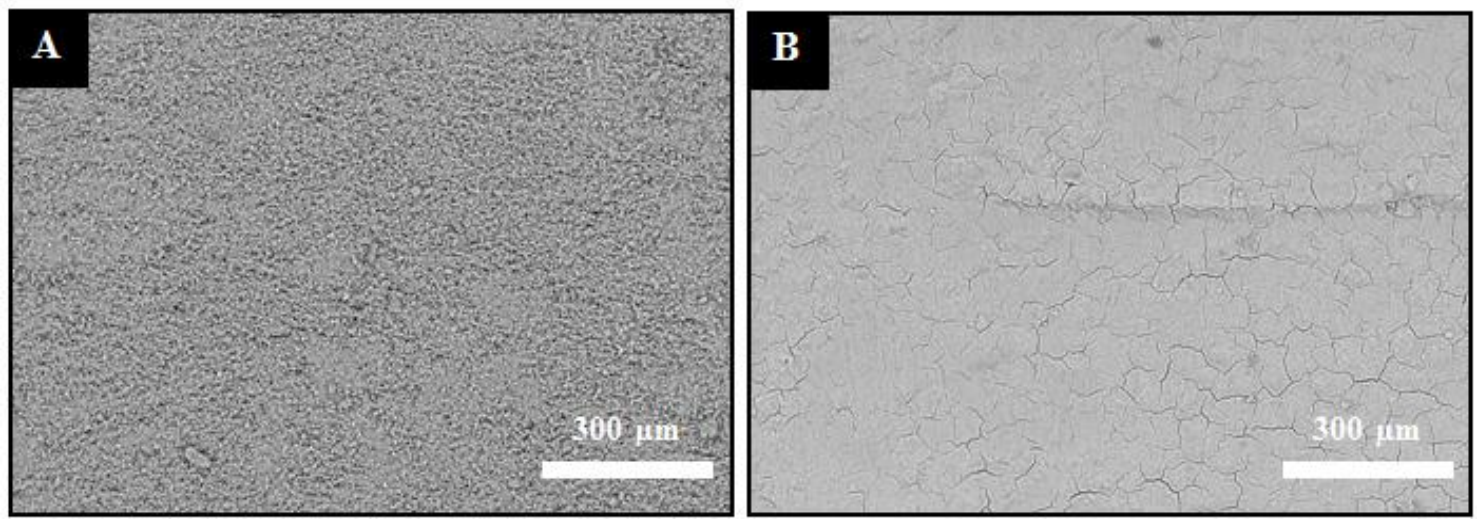

Figura 10.10. Imágenes por SEM en modalidad electrones retrodispersados de la misma área del fragmento de marfil antes del tratamiento con la muestra de hidroxiapatita HA1 (A) y después del tratamiento (B). 


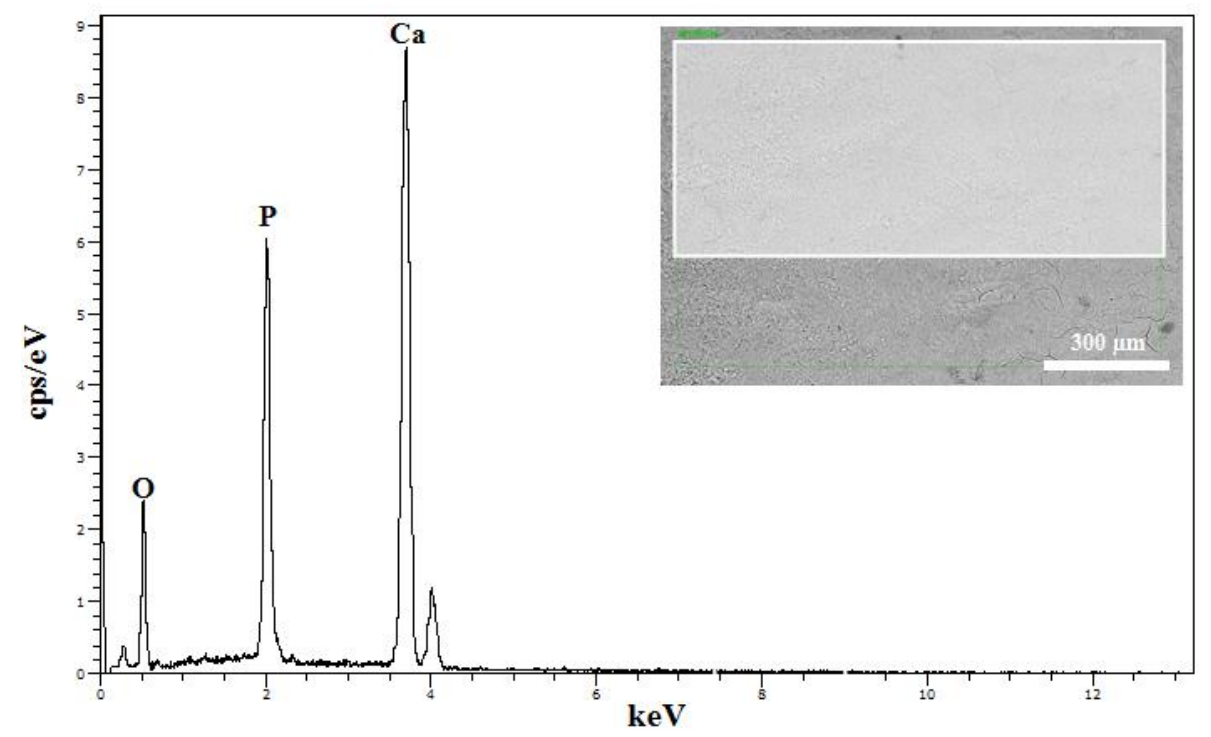

Figura 10.11. Micrografía obtenida por SEM (inset) de un área del fragmento de marfil tratado con HA1 observado en superficie, y espectro EDX de la región marcada en la imagen.

La imagen SEM de un corte transversal del fragmento de marfil es mostrada en la Figura 10.12. La presencia de calcio y fósforo se detecta en la capa superficial que se forma después del tratamiento. El estrato superficial, de distribución uniforme, presenta un espesor homogéneo de unas $40 \mu \mathrm{m}$.

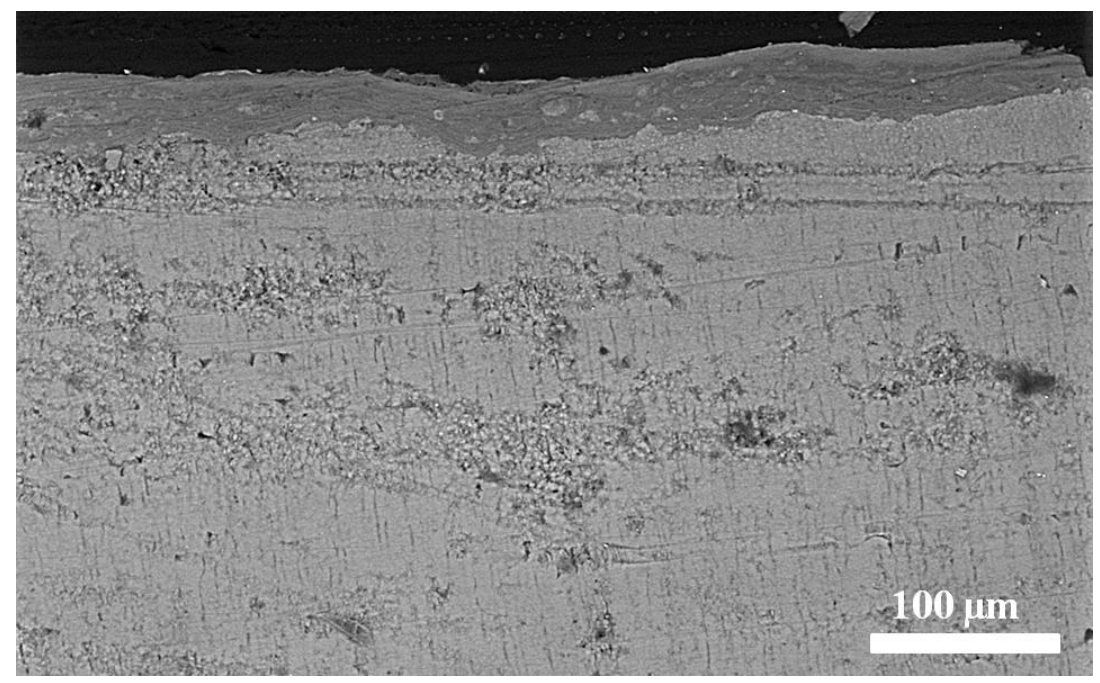

Figura 10.12. Imagen por SEM en modalidad electrones retrodispersados del corte transversal del fragmento de marfil tratado con la muestra HA1. 
Las observaciones y los microanálisis realizados al SEM-EDX sobre la superficie del fragmento de hueso tratado con la muestra HA1 -imagen SEM de la Figura 10.13 y microanálisis EDX de la Figura 10.14-, muestran que el producto aplicado se acumula en correspondencia con las discontinuidades de la superficie del soporte, con tendencia a craquearse.

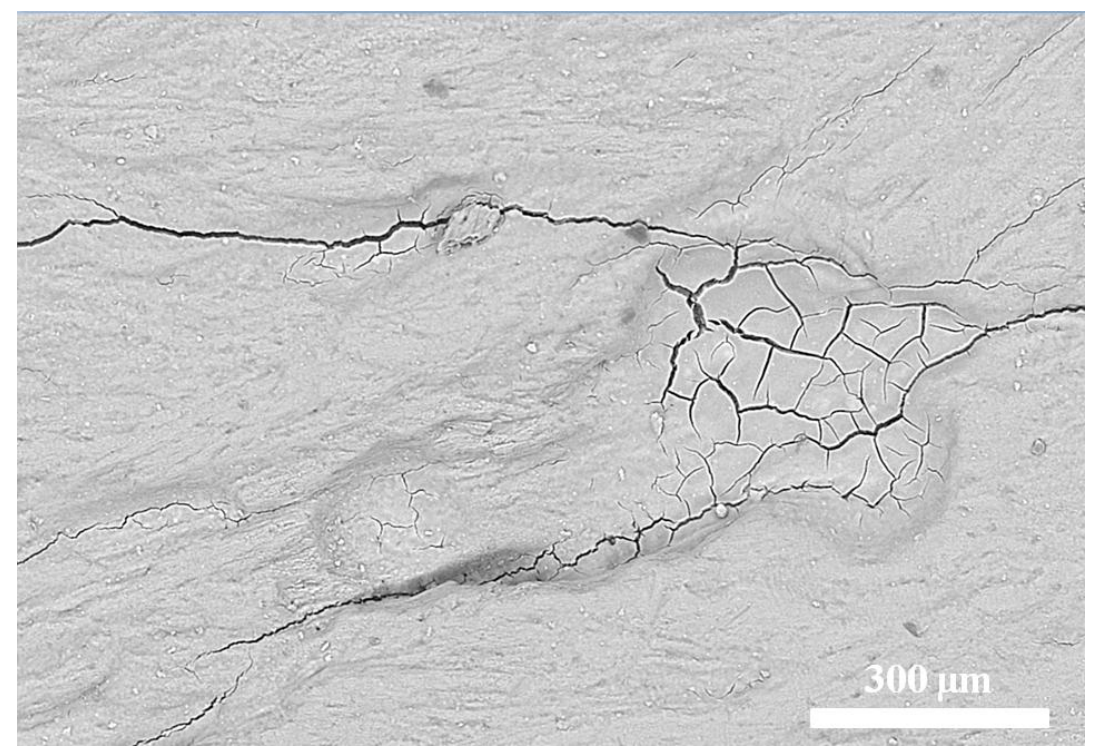

Figura 10.13. Imagen por SEM en modalidad electrones retrodispersados de la superficie del fragmento de hueso después del tratamiento con la muestra de hidroxiapatita HA1.

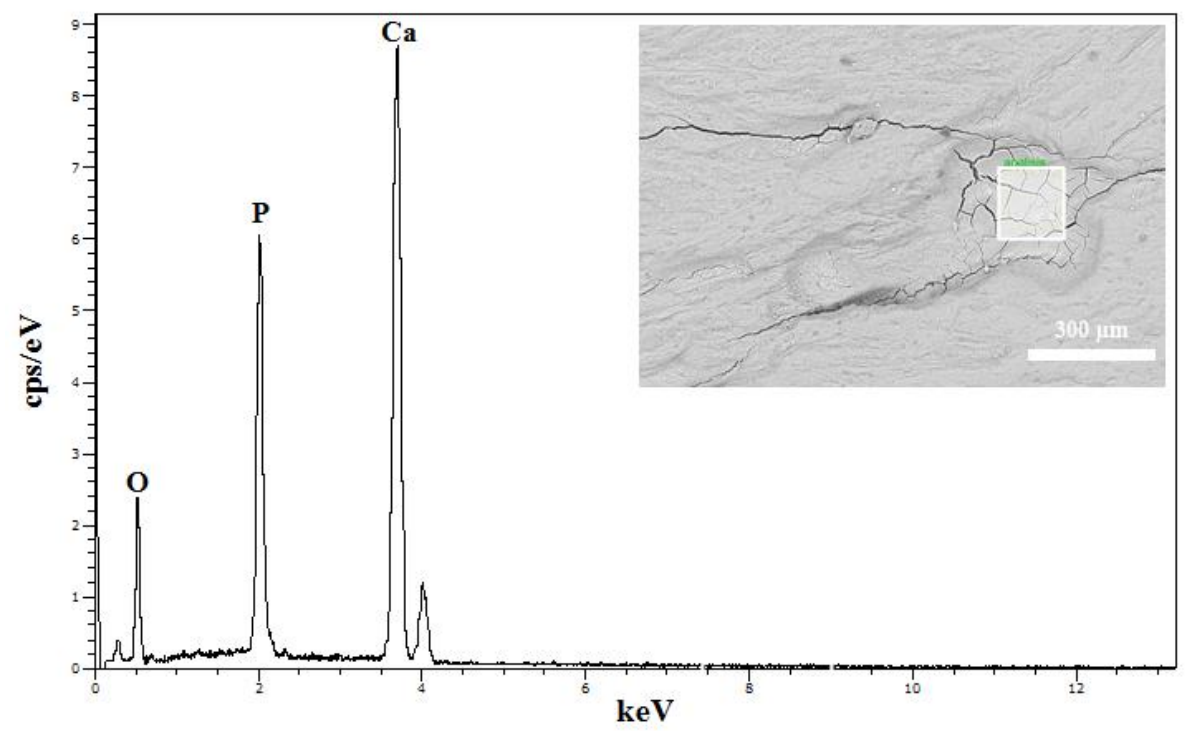

Figura 10.14. Micrografía obtenida por SEM (inset) de un área del fragmento de hueso tratado con HA1 observado en superficie, y espectro EDX de la región marcada en la imagen. 


\subsubsection{Evaluación de la muestra HA2 sobre fragmentos de marfil y hueso}

Con la aplicación de la muestra HA2 también se observa la formación, por encima de la superficie del marfil, de un estrato superficial aunque de espesor más fino. Se puede comprobar en las imágenes SEM de la Figura 10.15 del antes (imagen A) y del después del tratamiento (imagen B), que el tratamiento confiere un aspecto mucho más uniforme y sin porosidad a la superficie del material, actuando como un recubrimiento.
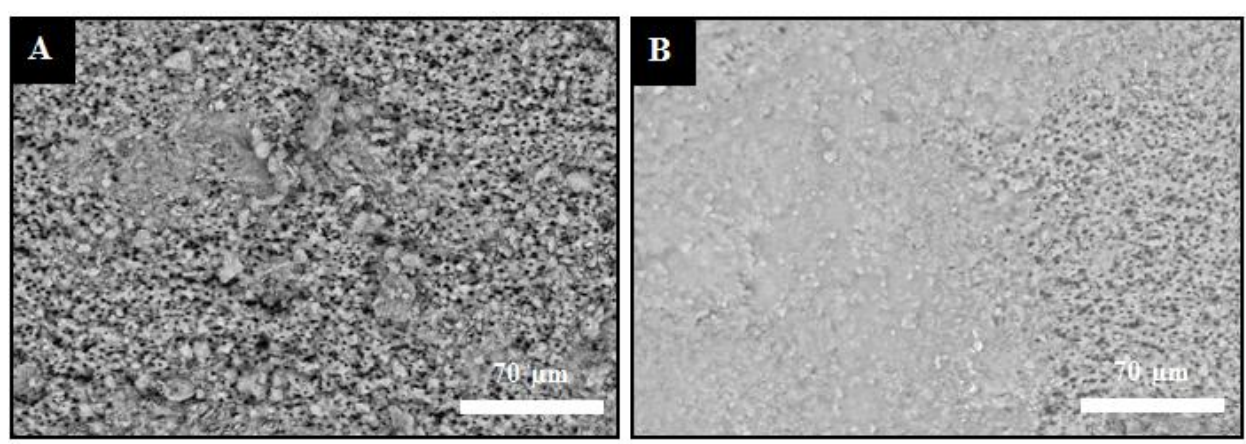

Figura 10.15. Imágenes por SEM en modalidad electrones retrodispersados de un área de la superficie del fragmento de marfil antes del tratamiento con la muestra de hidroxiapatita HA2 (A) y después del tratamiento (B).

El análisis EDX del estrato diferenciado (Figura 10.16), detecta la presencia mayoritaria de los elementos del calcio $(\mathrm{Ca})$ y fósforo $(\mathrm{P})$, indicando a la posible presencia de hidroxiapatita introducida en la superficie con el tratamiento.

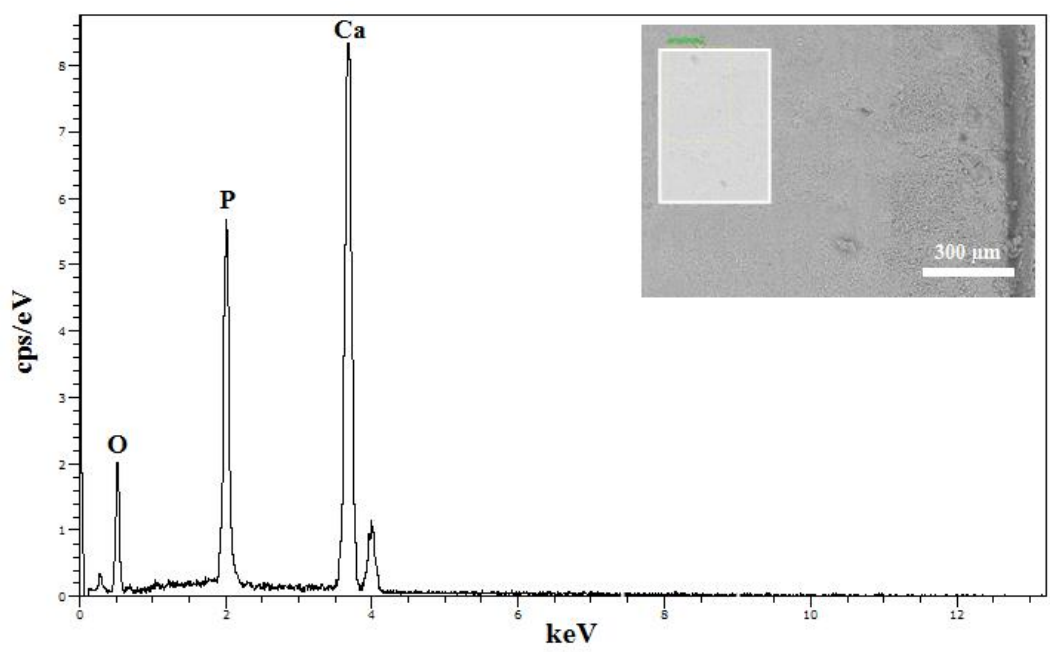

Figura 10.16. Micrografía obtenida por SEM (inset) de un área del fragmento de marfil tratado con HA2 observado en superficie, y espectro EDX de la región marcada en la imagen. 
La observación de un corte transversal del fragmento de marfil tratado con la muestra HA2 por SEM (Figura 10.17) muestra, igualmente, la formación de una película superficial a base de hidroxiapatita (ver espectro EDX de la Figura 10.18). En contraposición a los resultados observados con los tratamientos con las muestras ACP y HA2, la película que se forma resulta ser más fina, con un espesor medio de $20 \mu \mathrm{m}$. Este resultado indicaría que el tratamiento podría alterar menos las características superficiales del fragmento tales como color y morfología, ejerciendo en este caso una función protectora.

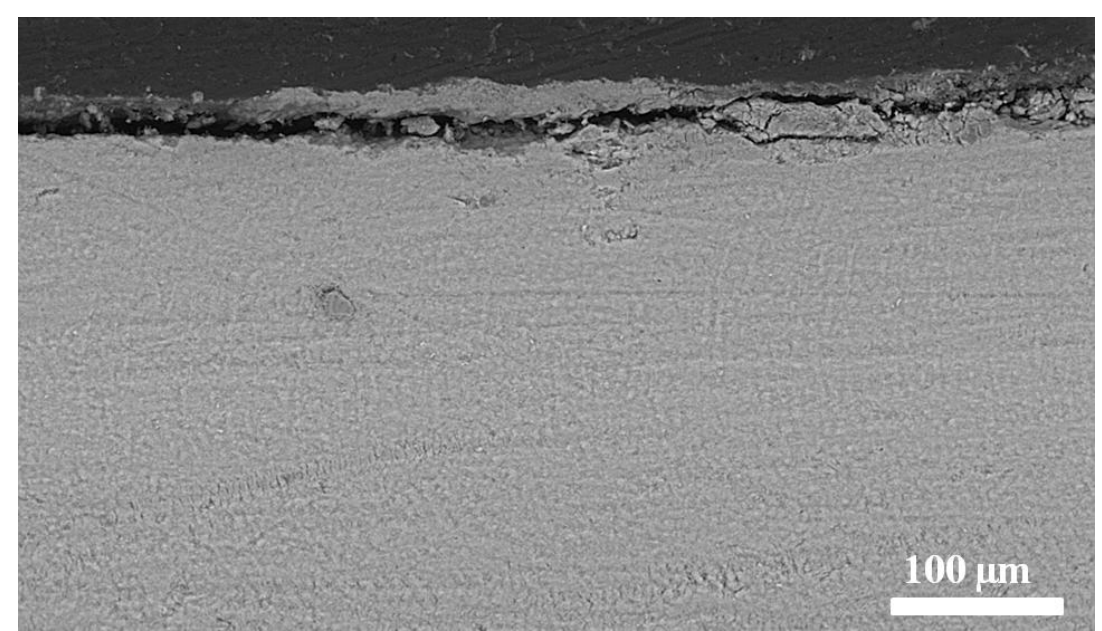

Figura 10.17. Imagen por SEM en modalidad electrones retrodispersados del corte transversal del fragmento de marfil tratado con la muestra HA2.

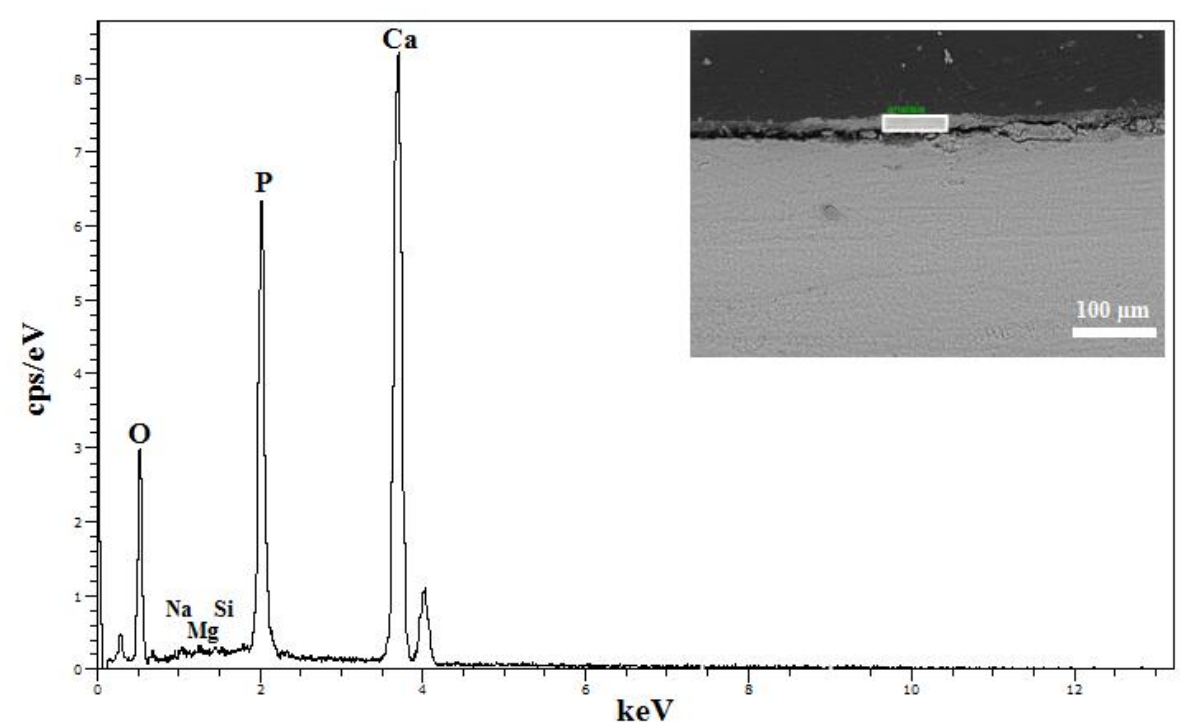

Figura 10.18. Micrografía obtenida por SEM (inset) de un área del fragmento de marfil tratado con HA2 observado en corte transversal, y espectro EDX de la región marcada en la imagen. 
En el fragmento de hueso se pudo observar que después del tratamiento con la muestra HA2, se ha producido el relleno de las grietas que se podían apreciar en las imágenes tomadas antes de la aplicación de las nanopartículas. Se puede comprobar en la imagen SEM de la Figura 10.19 como la fisura aparece más cerrada en casi toda su longitud y como las nanopartículas se han introducido en la separación realizando la función consolidante que se esperaba de ellas. También, en este caso, el microanálisis EDX confirma la presencia de hidroxiapatita en los depósitos que se han formado tras la aplicación del producto (Figura 10.20).

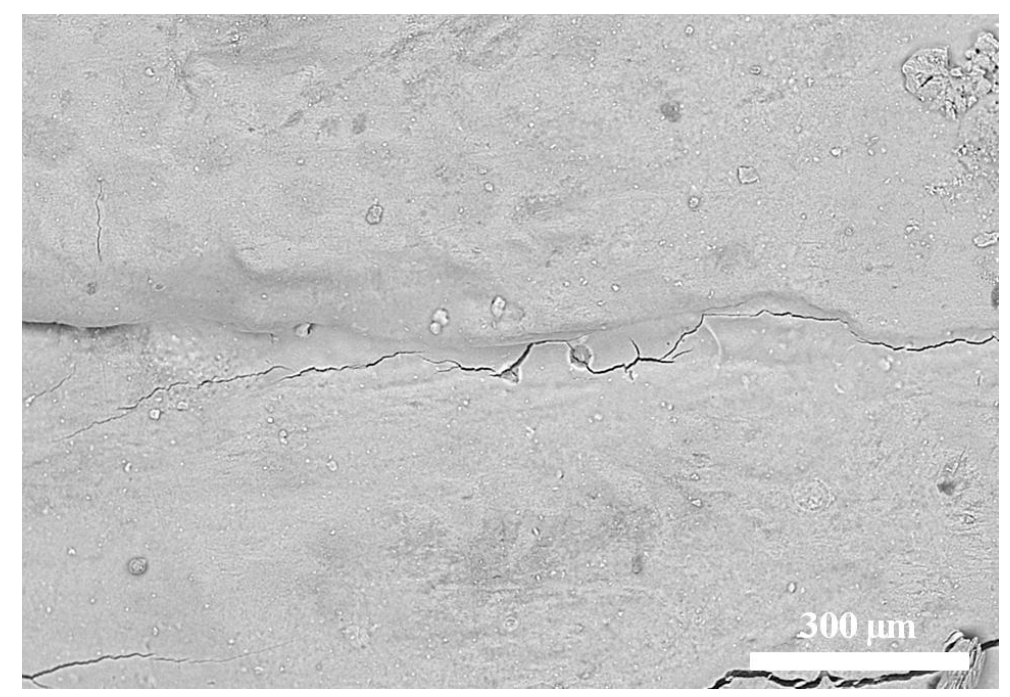

Figura 10.19. Imagen por SEM en modalidad electrones retrodispersados de un área de la superficie del fragmento de hueso después del tratamiento con la muestra HA2.

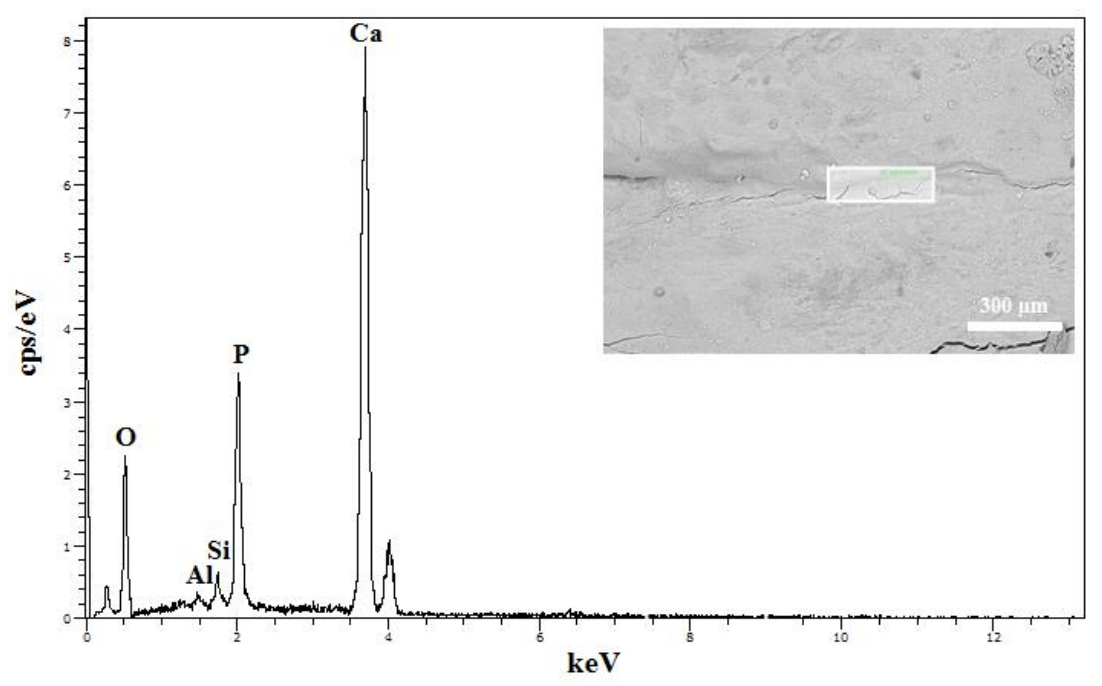

Figura 10.20. Micrografía obtenida por SEM (inset) de un área del fragmento de hueso tratado con HA2 observado en superficie, y espectro EDX de la región marcada en la imagen. 


\subsubsection{Espectroscopia infrarroja por transformada de Fourier (FTIR)}

Para las muestras de marfil se obtuvo un solo espectro común para su análisis antes de la aplicación de las muestras ACP, HA1 y HA2 (espectro FTIR en verde de la Figura 10.21). Se identifican las bandas características de los modos vibracionales de los grupos $\mathrm{PO}_{4}{ }^{3-}$ de la hidroxiapatita con las bandas en el intervalo $470-600 \mathrm{~cm}^{-1}$, y en la región entre $960-1100 \mathrm{~cm}^{-1}$.

El único aspecto a destacar con el estudio FTIR, tras la aplicación de las muestras ACP, HA1 y HA2, es un aumento en casi todos las bandas relativos a los grupos fosfato de la hidroxiapatita, debido a un aporte externo de fosfato que pueda generar este aumento en la señal de detección.

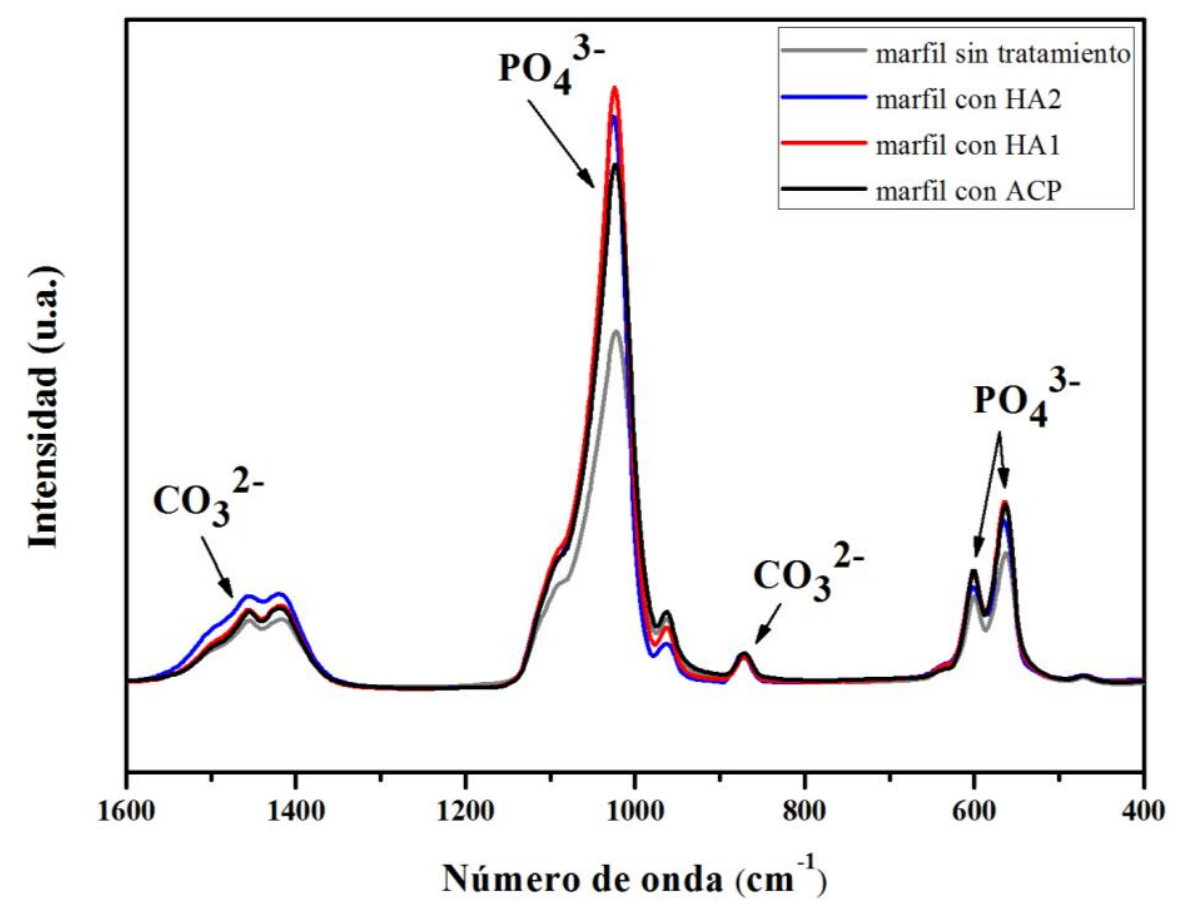

Figura 10.21. Espectros FTIR de las muestras del fragmento de marfil. En gris se muestra la respuesta FTIR de la muestra sin tratamiento. Muestra marfil tratado con ACP (en negro), con HA1 (en rojo) y con HA2 (en azul). 
Del mismo modo, para la muestra de hueso sin tratar (espectro FTIR verde de la Figura 10.22), se identifican las mismas bandas características que en el caso anterior. Tras la aplicación de las muestras, se puede observar únicamente un aumento en todos los picos relativos a los grupos fosfato de la hidroxiapatita.

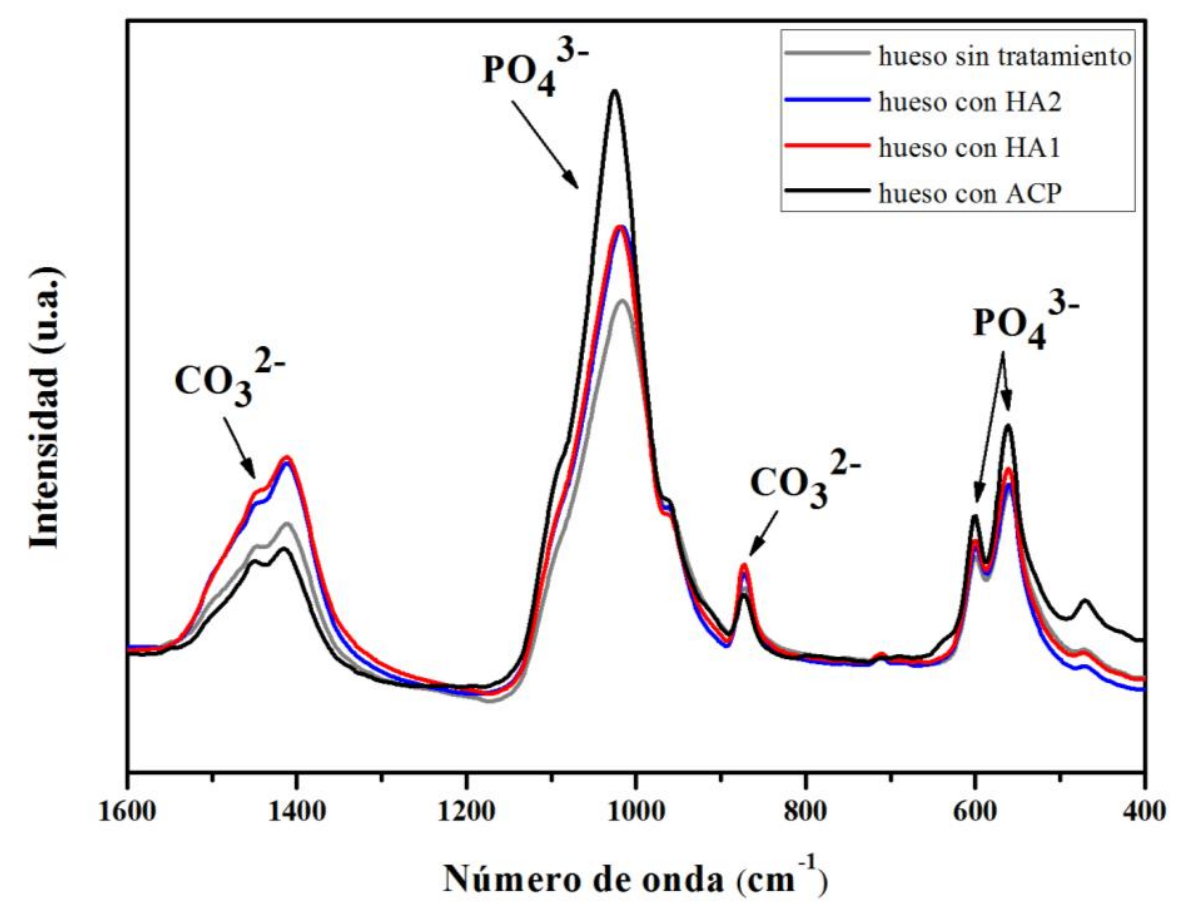

Figura 10.22. Espectros FTIR de las muestras del fragmento de hueso. En gris se muestra la respuesta FTIR de la muestra sin tratamiento. Muestra hueso tratado con ACP (en negro), con HA1 (en rojo) y con HA2 (en azul). 


\subsubsection{Colorimetría}

La medición colorimétrica se realizó con el espectrofotómetro en los mismos puntos en los que se había realizado previamente a los tratamientos. Los valores CIEL*a*b* iniciales y finales medios obtenidos para cada espécimen tras las tres mediciones con iluminante de luz diurna (D65), los valores diferenciales de cada parámetro y los valores finales de $\Delta \mathrm{E}^{*}$ se recogen en la Tabla 10.1 .

Tabla 10.1. Valores colorimétricos CIEL*a*b* iniciales y finales, diferenciales de cada parámetro y valor de $\Delta \mathrm{E}^{*}$.

\begin{tabular}{|c|c|c|c|c|c|c|c|c|c|c|}
\hline & \multicolumn{3}{|c|}{$\begin{array}{l}\text { Valores } \mathbf{L}^{*} \mathbf{a}^{*} \mathbf{b}^{*} \\
\text { sin tratamiento }\end{array}$} & \multicolumn{3}{|c|}{$\begin{array}{l}\text { Valores } \mathbf{L}^{*} \mathbf{a}^{*} \mathbf{b}^{*} \\
\text { con tratamiento }\end{array}$} & \multicolumn{4}{|c|}{$\begin{array}{l}\text { Variaciones de los valores } \\
\qquad \mathbf{L}^{*} \mathbf{a}^{*} \mathbf{b}^{*}\end{array}$} \\
\hline Muestra & $\begin{array}{l}\mathbf{L} *_{i} \\
(\mathrm{D} 65)\end{array}$ & $\begin{array}{l}\mathbf{a}_{\mathrm{i}} \\
(\mathrm{D} 65)\end{array}$ & $\begin{array}{l}\mathbf{b}_{\mathrm{i}}^{*} \\
(\mathrm{D} 65)\end{array}$ & $\begin{array}{l}L_{f}^{*} \\
(D 65)\end{array}$ & $\begin{array}{l}*_{f} \\
(D 65)\end{array}$ & $\begin{array}{l}\mathbf{b}_{\mathrm{f}} \\
(\mathrm{D} 65)\end{array}$ & $\Delta \mathbf{L}^{*}$ & $\Delta \mathbf{a}^{*}$ & $\Delta \mathbf{b}^{*}$ & $\Delta \mathbf{E}^{*}$ \\
\hline $\begin{array}{l}\mathrm{ACP} \\
\text { marfil }\end{array}$ & 97,33 & 0,32 & 2,37 & 96,75 & 0,35 & 2,77 & $-0,58$ & 0,03 & 0,39 & 0,71 \\
\hline $\begin{array}{l}\text { ACP } \\
\text { hueso }\end{array}$ & 82,91 & 4,71 & 18,1 & 79,85 & 5,8 & 21,2 & $-3,06$ & 1,09 & 3,1 & 4,49 \\
\hline $\begin{array}{l}\text { HA1 } \\
\text { marfil }\end{array}$ & 97,6 & 0,27 & 2,11 & 96,2 & 0,31 & 2,63 & $-1,4$ & 0,04 & 0,52 & 1,49 \\
\hline $\begin{array}{l}\text { HA1 } \\
\text { hueso }\end{array}$ & 82,92 & 6,79 & 18,12 & 81,13 & 7,39 & 18,06 & $-1,79$ & 0,6 & $-0,06$ & $\mathbf{1 , 8 9}$ \\
\hline $\begin{array}{l}\mathrm{HA} 2 \\
\text { marfil }\end{array}$ & 97,45 & 0,31 & 2,02 & 97,48 & 0,29 & 2,06 & 0,03 & $-0,03$ & 0,04 & 0,06 \\
\hline $\begin{array}{l}\text { HA2 } \\
\text { hueso }\end{array}$ & 82,64 & 7,38 & 19,76 & 82,63 & 7,25 & 20,0 & 0,0 & $-0,13$ & 0,25 & 0,28 \\
\hline
\end{tabular}

Por similitud textural de los materiales en los que se centra este estudio con los materiales pétreos porosos se tomará un valor de $\Delta \mathrm{E}^{*}<6$ como umbral de cambio de color superficial demasiado apreciable para las diferentes aplicaciones establecidas en el procedimiento.

Se observa que en ningún caso, tras el tratamiento, se produce un cambio de color con un $\Delta \mathrm{E}^{*}>6$. Se consideraría, por tanto, que estos productos serían aptos para la consolidación de esta tipología de bienes ya que no generan un cambio de color demasiado significativo. El valor más alto registrado corresponde a la muestra ACP sobre hueso con un $\Delta \mathrm{E}^{*}=4,49$, posiblemente los agregados que se forman en superficie tras el tratamiento modifican el color sin superar el limite establecido. Las menores variaciones se producen en las muestras de marfil, sea cual sea el producto ensayado, esto se debe a su naturaleza ya son de un color blanco intenso, igual que las muestras preparadas y por eso no se produce un cambio de coloración visible. 


\subsection{Comparación del producto consolidante en uso a base de hidróxido de calcio respecto a las muestras ACP, HA1 y HA2 en fragmentos de marfil y hueso}

A continuación se describen brevemente aquellos resultados más significativos alcanzados con los estudios de comparación entre un producto consolidante en uso a base de hidróxido de calcio ${ }^{222}$ respecto a los resultados obtenidos con la evaluación del tratamiento de consolidación y protección sobre marfil y hueso con las muestras ACP, HA1 y HA2 preparadas en esta tesis. Como se comentó en el Capítulo 1: Fundamentos, en las limitaciones detectadas en los tratamientos en piedra de los consolidantes y protectores en uso, también para fragmentos de marfil y huesos se realizó un estudio similar de valoración. Se detectó básicamente una insuficiente penetración y formación de películas superficiales.

La base de las investigaciones de este trabajo ha consistido en comparar las micrografías SEM y los microanálisis EDX obtenidos previamente a la aplicación del producto comercial con los resultados obtenidos con esa misma técnica con posterioridad a la aplicación y a un tiempo establecido de carbonatación de las partículas de hidróxido de calcio. Se optó por una aplicación del producto preparado comercialmente en forma pura, sin ningún tipo de dilución, además, se adicionaron partículas de dióxido de titanio $\mathrm{TiO}_{2}$ de $21 \mathrm{~nm}$ de tamaño de partícula y un $99,5 \%$ de pureza comercializadas por Aldrich® que, al tener un tamaño análogos a las nanopartículas de $\mathrm{Ca}(\mathrm{OH})_{2}$, tienen la función de marcador. Este marcador es necesario para poder detectar mediante observaciones al SEM el nivel de penetración de las nanopartículas de hidróxido de calcio en el interior del soporte tratado, tal y como se indica en la bibliografía consultada ${ }^{223}$. Una vez finalizada la aplicación de la dispersión de las nanopartículas de hidróxido de calcio, se programó un tiempo de carbonatación al aire de 26 días. La bibliografía varía en cuanto a los tiempos de carbonatación, Natali y col. ${ }^{224}$ lo alargan hasta tres meses, mientras que Giorgi y col. ${ }^{225}$ documentan un periodo de 30 días;

\footnotetext{
${ }^{222}$ Para la experimentación se seleccionó una dispersión consolidantes a base de nanopartículas: Nanorestore®, dispersión de 5g/l de nanocal en alcohol isopropílico desnaturalizado. Patente Italiana Consorcio CSGI-Universidad de los Estudios de Florencia. Comercializado por la empresa CTS.

${ }^{223}$ A. Macchia, O. Bettucci, E. Gravagna, D. Ferro, R. Albini, B. Mazzei, L. Campanella, Calcium hydroxide nanoparticles and hypogeum environment: Test to understand the best way of application, J. Nanomater, Vol. 2014, 2014.

${ }^{224}$ I. Natali, P. Tempesti, E. Carretti, M. Potenza, S. Sansoni, P. Baglioni, L. Dei, Aragonite Crystals Grown on Bones by Reaction of $\mathrm{CO}_{2}$ with Nanostructured $\mathrm{Ca}(\mathrm{OH})_{2}$ in the Presence of Collagen. Implications in Archaeology and Paleontology, Langmuir, Vol. 30 , no. 2, 660-668, 2014.

${ }^{225}$ R. Giorgi, L. Dei, P. Baglioni, A New Method for Consolidating Wall Paintings Based on Dispersions of Lime in Alcohol, Stud. Conserv., Vol. 45, no. 3, 154-161, 2000.
} 
en otro estudio sobre pintura mural, Natali y col. ${ }^{226}$ lo limitan a dos semanas e incluso El-Turki y col. ${ }^{227}$ consiguen la carbonatación en 6 días con la ayuda de una corriente forzada de $\mathrm{CO}_{2}$ sobre las probetas y unas condiciones de humedad relativa alta. En este caso se ha optado por una solución intermedia de 14 días, donde los fragmentos fueron introducidos en una cámara acondicionada Climacell Komfort-line, con unas condiciones ambientales controladas de $25{ }^{\circ} \mathrm{C}$ y un $80 \%$ de humedad relativa ya que una alta humedad favorece los procesos de carbonatación de las nanopartículas de hidróxido de calcio ${ }^{228}$.

\subsubsection{Evaluación del producto consolidante de hidróxido de calcio en marfil}

En el fragmento de marfil antes del tratamiento, tal y como se muestra en la imagen SEM de la Figura 10.23 A, se puede apreciar una textura superficial de alta porosidad con una gran abundancia de espacios intersticiales aunque de pequeño tamaño. Con el microanálisis EDX superficial se detectaron, tal y como se observa en el espectro de la Figura 10.24, los elementos del oxigeno (O), flúor (F), fósforo (P) y calcio (Ca). Estos elementos están relacionados a la fluorapatita e hidroxiapatita, constituyentes del marfil. La relación molar $\mathrm{Ca} / \mathrm{P}$ resulta ser de 2,97.

Con la aplicación de las nanopartículas de hidróxido de calcio se puede observar la formación de un estrato diferenciado en la superficie de marfil (imagen SEM de la Figura 10.23 B). Todo el sistema poroso del sustrato ha sido cubierto y solo se observa una abundante dispersión de partículas de hidróxido cálcico y óxido de titanio. Como se muestra en el espectro del microanálisis EDX de la Figura 10.25 aumenta la concentración del calcio (Ca), teniendo en este caso una relación de Ca/P de 10,55.

\footnotetext{
${ }^{226}$ I. Natali, M. L. Saladino, F. Andriulo, D. Chillura Martino, E. Caponetti, E. Carretti, L. Dei, Consolidation and protection by nanolime: Recent advances for the conservation of the graffiti, Carceri dello Steri Palermo and of the 18th century lunettes, SS. Giuda e Simone Cloister, Corniola (Empoli), J. Cult. Herit., Vol. 15, no. 2, 151-158, 2014.

227 A. El-Turki, R. J. Ball, and G. C. Allen, "The influence of relative humidity on structural and chemical changes during carbonation of hydraulic lime," Cem. Concr. Res., vol. 37, no. 8, 1233-1240, 2007.

${ }^{228}$ V. Daniele, G. Taglieri, R. Quaresima, The nanolimes in Cultural Heritage conservation: Characterisation and analysis of the carbonatation process, J. Cult. Herit., Vol. 9, no. 3, 294-301, 2008.
} 

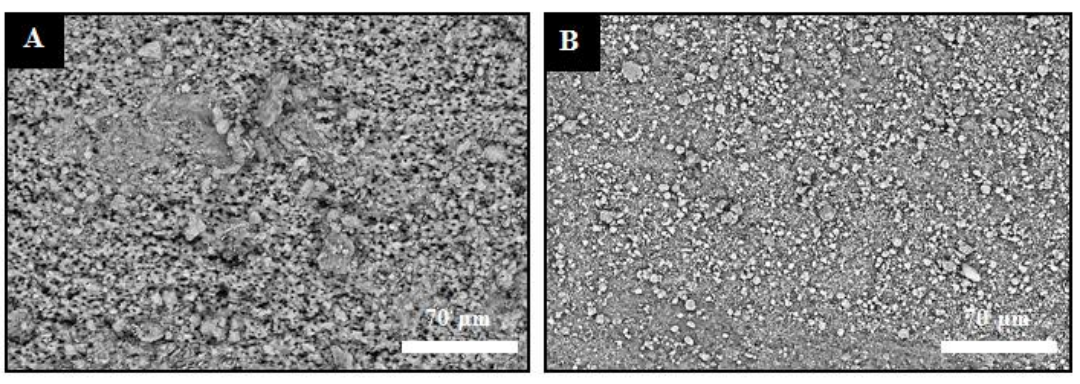

Figura 10.23. Imágenes por SEM en modalidad BSE de la misma área de la superficie del fragmento de marfil antes del tratamiento (A) y después del tratamiento (B) con hidróxido de calcio y titanio.

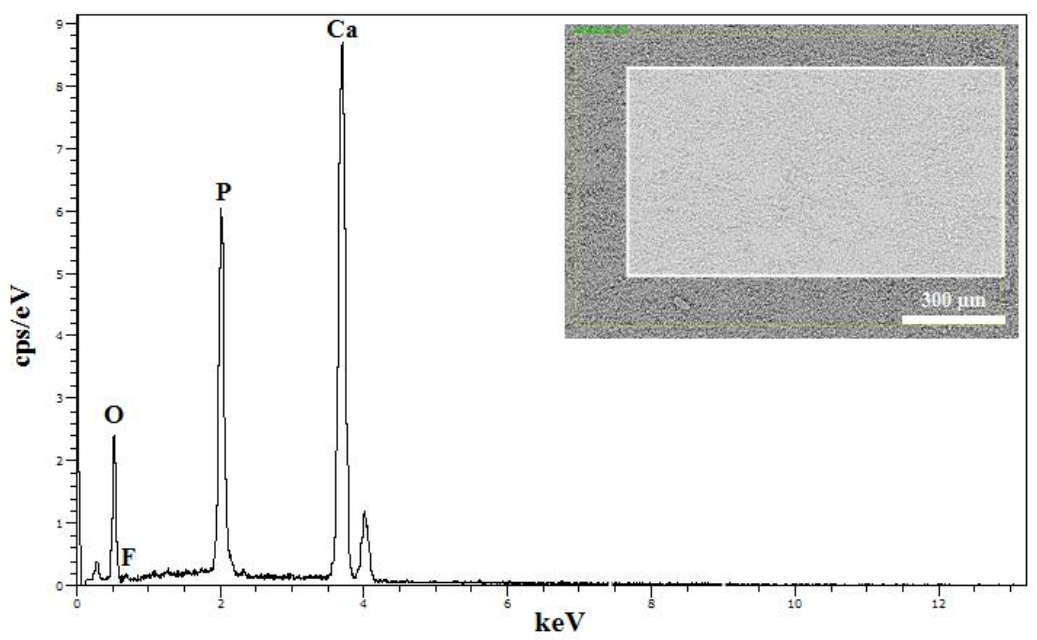

Figura 10.24. Micrografía obtenida por SEM (inset) de un área del fragmento de marfil sin tratar observado en superficie, y espectro EDX de la región marcada en la imagen.

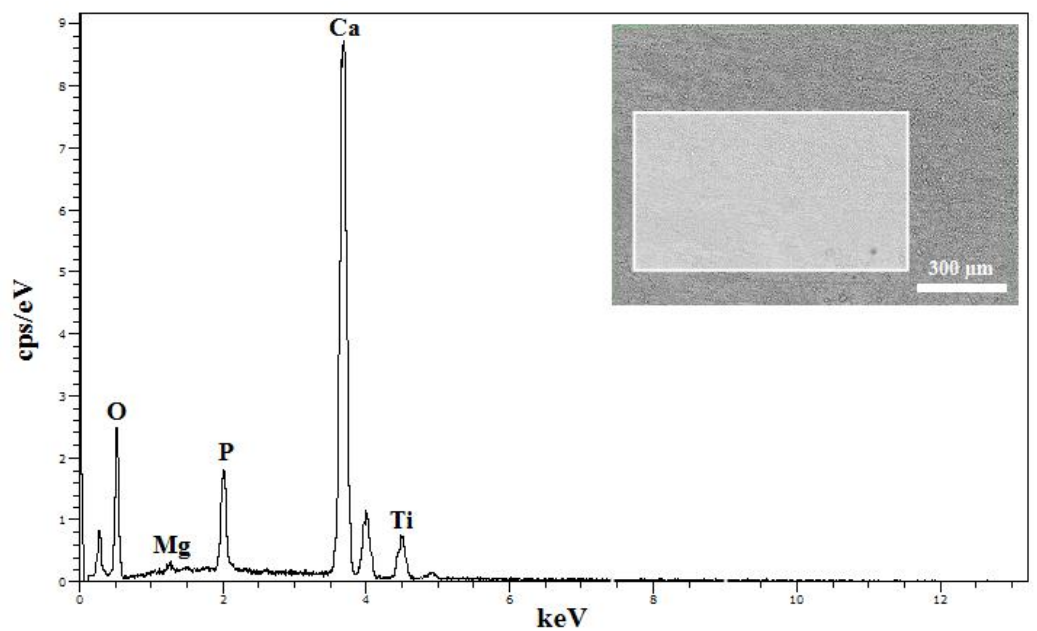

Figura 10.25. Micrografía obtenida por SEM (inset) de un área del fragmento de marfil tratado observado en superficie, y espectro EDX de la región marcada en la imagen. 
En las vistas de un corte transversal del fragmento de marfil tratado se observa, efectivamente, la película superficial. En la micrografía SEM de la Figura 10.26 se muestra que en este estrato se acumulan abundantes agregados de nanopartículas de unas medidas entre 2 y $7 \mu \mathrm{m}$. También, en este caso, el microanálisis EDX de la capa superficial (Figura 10.27) detecta una alta concentración de calcio relacionado al producto a base de hidróxido de calcio introducido con el tratamiento. En lo referente a la penetración, mediante la detección del marcador de titanio en los fragmentos en sección transversal, se pudo comprobar que es prácticamente nula más allá de la capa formada en superficie.

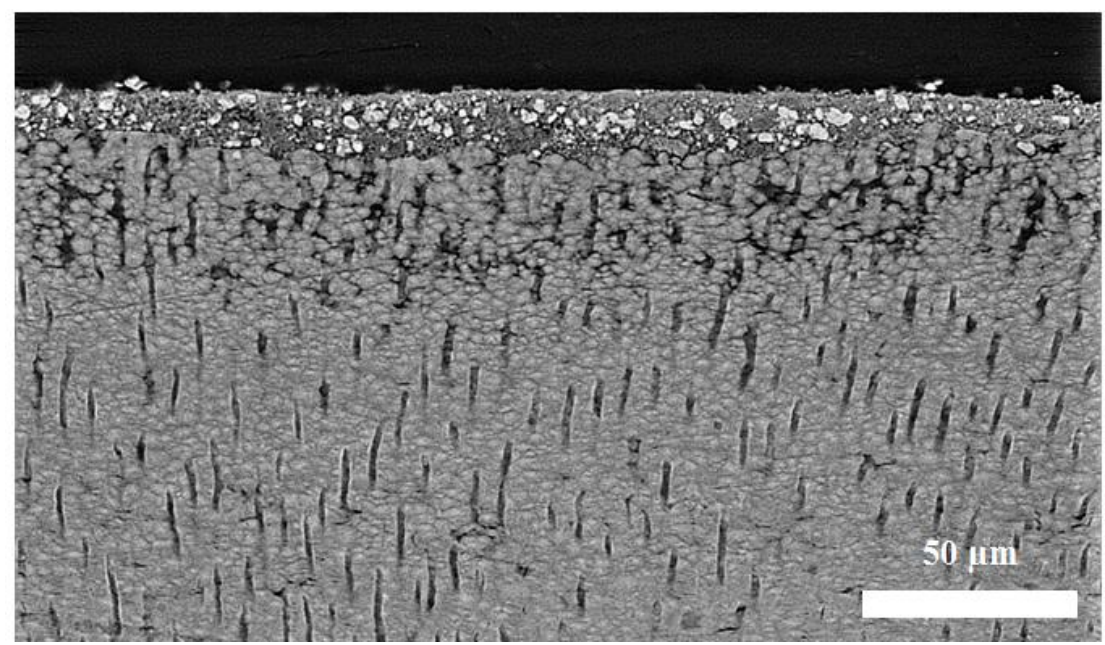

Figura 10.26. Imagen por SEM en modalidad electrones retrodispersados de un corte transversal del fragmento de marfil después del tratamiento con el producto consolidante a base de hidróxido de calcio con titanio.

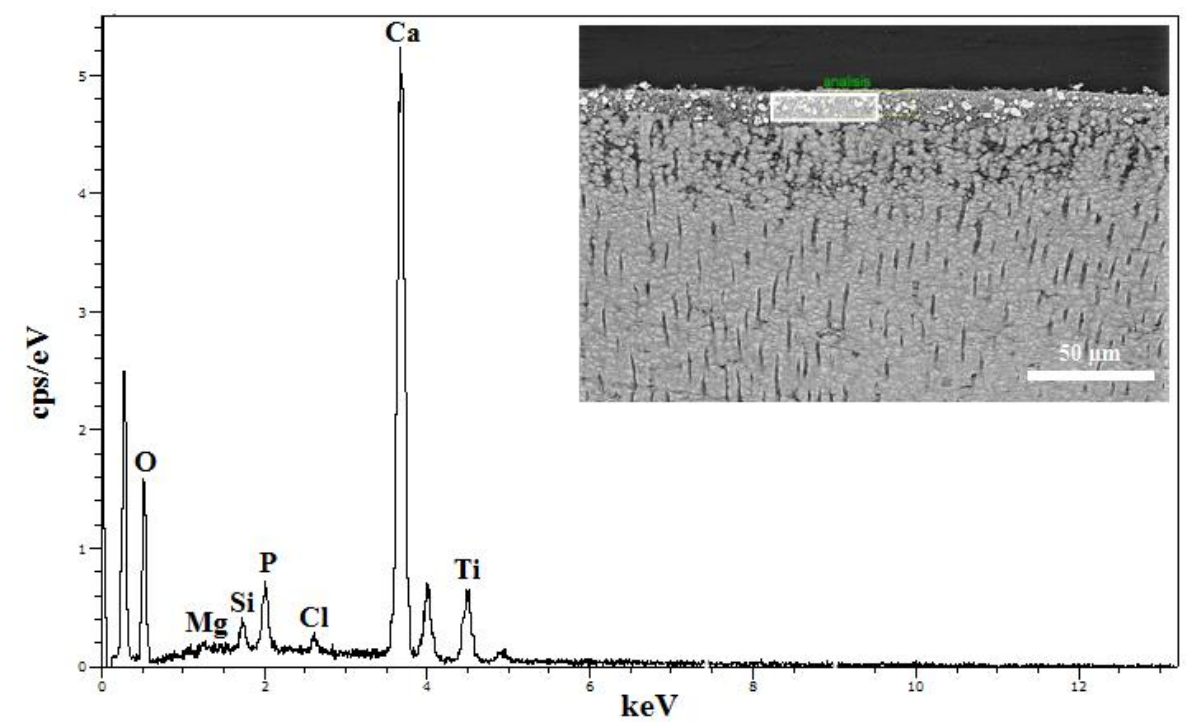

Figura 10.27. Micrografía obtenida por SEM (inset) de un área del fragmento de marfil tratado observado en corte transversal, y espectro EDX de la región marcada en la imagen. 


\subsubsection{Evaluación del producto consolidante de hidróxido de calcio en hueso}

En el fragmento de hueso, después de la aplicación del producto consolidante, se observa un ligero relleno de las grietas y fisuras que se aprecian algo más cerradas -micrografías SEM A y B de la Figura 10.28-. En general, los estudios realizados han puesto en evidencia que la penetración de la solución consolidante y del marcador ha sido nula. Realizando observaciones SEM en detalle, tal y como se puede observar en la imagen de la Figura 10.29, se podría explicar la falta de penetración generalizada que se aprecia durante toda la experimentación. La micrografía muestra la superficie del hueso con depósitos que se identificaron como agregados de las nanopartículas aplicadas. Como se observa en el espectro EDX de la Figura 10.30, estos agregados están constituidos únicamente por calcio. Así, la falta de penetración se explica por el gran tamaño de los agregados de partículas, incapaces de penetrar en los poros del hueso.
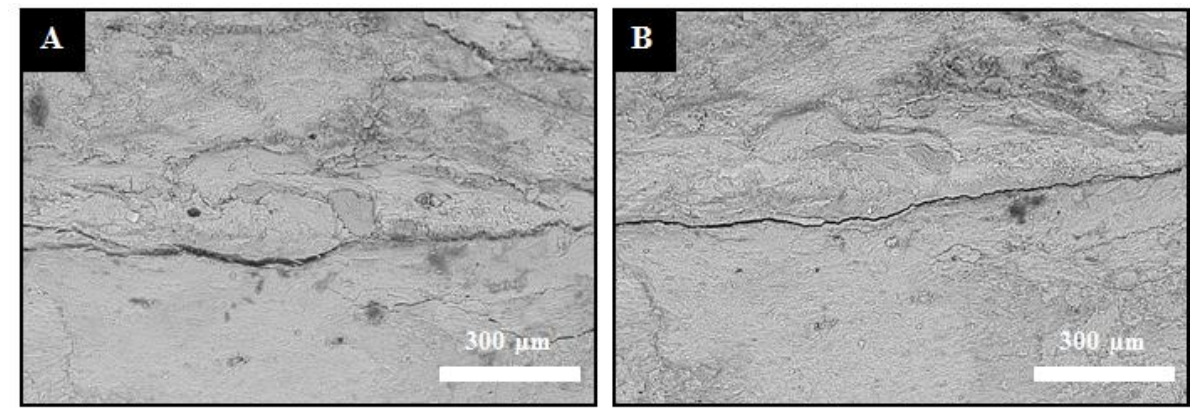

Figura 10.28. Imágenes por SEM en modalidad BSE de la misma área de la superficie del fragmento de hueso antes del tratamiento (A) y después del tratamiento (B) con el producto consolidante a base de hidróxido de calcio.

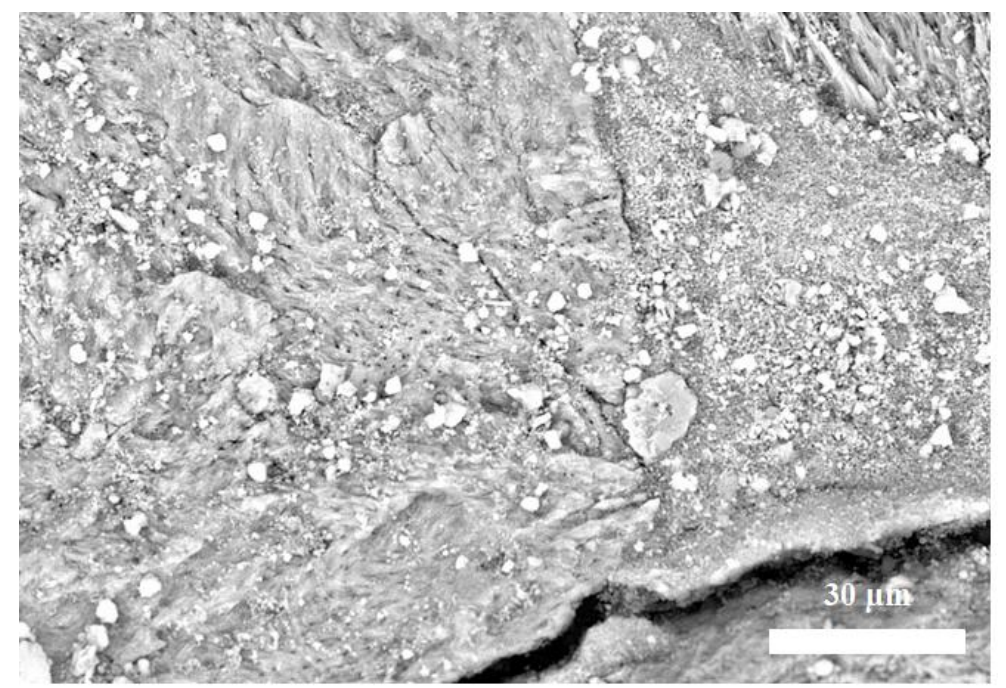

Figura 10.29. Imagen por SEM en modalidad BSE de un área de la superficie del fragmento de hueso después del tratamiento con hidróxido de calcio. Se observa el depósito de las partículas del producto aplicado. 


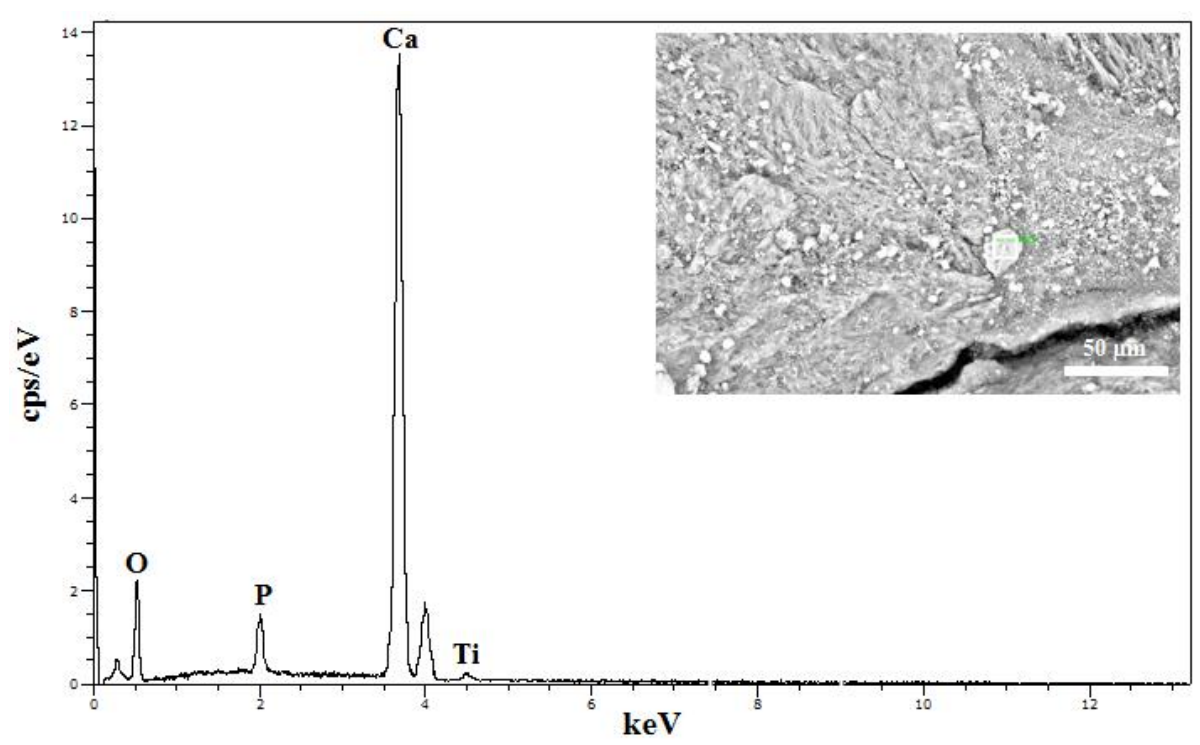

Figura 10.30. Micrografía obtenida por SEM (inset) de un área del fragmento de hueso tratado observado en superficie, y espectro EDX del punto marcado en la imagen.

\subsection{Conclusiones}

Se ha demostrado, con el estudio realizado en los fragmentos de marfil y en el material óseo, que la penetración de las partículas con estequiometría de hidroxiapatita sintetizadas ha sido muy limitada. Sería necesario establecer si este resultado depende de la porosidad del material, ya que se ha podido ver que en los fragmentos de hueso, los menos porosos, la penetración ha sido nula, mientras que en los fragmentos de marfil, de mayor porosidad, se ha detectado un cierto grado de introducción de las partículas en el material. No obstante, las observaciones realizadas al SEM de los fragmentos en sección transversal corroboraron que solo se detecta el producto aplicado en las zonas más superficiales y que en los casos en que ésta se había producido, la penetración no iba más allá de unas decenas de micras. En este caso se ha observado como las muestras preparadas y especialmente la muestra de hidroxiapatita HA2, pueden ser buenos protectores de estos materiales a través de la formación de películas superficiales, totalmente compatibles con la naturaleza del sustrato tratado. Estas modificaciones superficiales se manifiestan con la formación de capas de recubrimiento y el suavizado de grietas y zonas de fractura. 
En cuanto a la comparación de la acción consolidante y de protección entre las nanopartícluas de hidróxido de calcio con las muestras sintetizadas con estequiometría de hidroxiapatita, en los ejemplos mostrados, se reflejan los inconvenientes del producto en uso con la formación de una película superficial con un grado de penetración insuficiente en la estructura del sustrato.

Los resultados de este último estudio de comparación indicarían que las nanopartículas de hidroxiapatita ensayadas pueden presentarse como un producto alternativo y eficaz en los tratamientos de protección de materiales de origen paleontológico. 
Conclusiones 



\section{Capítulo 11. Conclusiones}

A la vista de los resultados obtenidos en cada uno de los capítulos de la presente tesis doctoral, se pueden extraer las siguientes consideraciones:

1. La ruta de síntesis por precipitación química y los parámetros seleccionados permiten la obtención de fases puras de hidroxiapatita con estructura hexagonal. Las propiedades morfológicas y estructurales de las partículas de hidroxiapatita obtenidas varían de manera significativa de acuerdo con el valor de temperatura de síntesis y el tiempo de curado del precipitado. Se ha comprobado que la síntesis de hidroxiapatita a altas temperaturas $\left(90-95{ }^{\circ} \mathrm{C}\right)$ favorece la formación de un compuesto caracterizado por nanopartículas altamente cristalinas, con unos valores de la relación molar del calcio y del fósforo que se aproximan al valor teórico $\mathrm{Ca} / \mathrm{P}$ de 1,67.

2. Se ha observado que las muestras con estequiometría de hidroxiapatita preparadas actúan como consolidantes y protectores en los tratamientos de restauración de soporte pétreo y soportes de pintura mural. Las partículas de hidroxiapatita pueden considerarse como un nuevo material inorgánico óptimo para los tratamientos de restauración, ya que efectúa una acción cementante a nivel superficial como en áreas más internas del sustrato. Esta acción permite incrementar la resistencia mecánica del material a la acción de disgregación, pulverización y pérdida, causada por distintos agentes de alteración de tipo químicos, físicos o biológicos.

3. La hidroxiapatita, constituida por nanopartículas de alta cristalinidad (muestra HA2), es el material más idóneo de todos los descritos y evaluados en la presente tesis para los tratamientos de consolidación y protección en piedra y pintura mural. Se ha demostrado que esta tipología de partículas, con $\mathrm{Ca} / \mathrm{P}$ de 1,67, caracterizadas por una morfología alargada con una longitud media de $28 \mathrm{~nm}$ y un diámetro medio de $15 \mathrm{~nm}$, tienen una buena acción de adhesión y cohesión entre los constituyentes de la piedra o pintura mural con un alto grado de penetración en los poros de los diferentes sustratos. Estas características se han comprobado también en presencia de un sustrato alterado química y mecánicamente por cristalizaciones de sales solubles. Se ha observado que el producto introducido permite cementar la estructura disgregada aumentando, de esta manera, su resistencia mecánica tanto a nivel superficial como interna. 
4. Las nanopartículas de hidroxiapatita son compatibles con la naturaleza química de los soportes utilizados en este estudio -piedra y pintura mural- sin afectar significativamente al aspecto superficial del sustrato, con limitadas variaciones en la morfología y color. Asimismo, las partículas ensayadas no originan cambios en las propiedades químicas o físicas del material tales como disoluciones o cambios en la humectabilidad.

5. Por otro lado, las muestras de hidroxiapatita preparadas no parecen ejercer la misma acción de consolidación en fragmentos de marfil o de hueso. En este caso, la acción consolidante y protectora se limita únicamente a la superficie donde influyen las características de porosidad de estas tipologías de sustratos de origen biológico respecto a la morfología, al tamaño y a la concentración de las disoluciones acuosas de las partículas de hidroxiapatita ensayadas.

En síntesis, los resultados alcanzados ilustran las oportunidades que, desde el punto de vista de la ciencia de los materiales se abren en el sector de la conservación y restauración de bienes culturales en soporte pétreo, pintura mural y material paleontológico. Mediante el desarrollo de nuevos materiales de naturaleza inorgánica, en este caso hidroxiapatita, existe la posibilidad de introducir nuevos compuestos con aplicaciones viables en los tratamientos de restauración en bienes de interés cultural. Compuestos que resultan ser totalmente compatibles con la naturaleza química de los sustratos y en medios acuosos, además, son más respetuosos con la salud humana así como con el medio ambiente. 
Perspectivas de nuevas líneas de investigación 



\section{Capítulo 12. Perspectivas de nuevas líneas de investigación}

Entre otra posible línea de investigación pertinente a los resultados obtenidos con el estudio desarrollado con la presente tesis doctoral destaca:

Desarrollar nuevos nanomateriales con acción consolidante y con efecto bactericida-fungicida basados en las muestras de hidroxiapatita dopadas con nanopartículas de plata y especies basadas en compuestos de cinc o titanio. Con esta línea de investigación sería posible desarrollar una clase de materiales que presentan la ventaja de ejercer, mediante la combinación de nanopartículas de características consolidante y protectora, tal como la hidroxiapatita, con nanopartículas de plata o especie de cinc o titanio, una acción consolidante, de protección y biocida sobre el sustrato tratado de piedra o pintura mural.

De esta manera es posible disponer de nuevos productos más respetuosos con la salud humana y el medioambiente, sustituyendo los actuales productos biocidas orgánicos. Además estos nuevos productos tendrían un poder bactericida y antifúngico más extendido en el tiempo, realizando una acción preventiva contra los mecanismos de degradación y alteración producidos por agentes biológicos. 

Difusión de los resultados 



\section{Capítulo 13. Difusión de los resultados}

El trabajo de investigación que se recopila en la presente tesis doctoral, así como los diversos trabajos de investigación que se encuentran directamente relacionados con el tema de la tesis, han dato lugar a varias publicaciones de carácter nacional e internacional que se enumeran a continuación:

1) L. Ferrazza, D. Juanes Barber, E. Cordoncillo, H. Beltrán Mir, La investigación científica aplicada en el proyecto de conservación de la portada renacentista de la Iglesia de Nuestra Señora de la Asunción de Corral de Almaguer (Toledo), Actas de EMERGE 2014 - Jornadas de Investigación Emergente en Conservación y Restauración de Patrimonio. 773 - 781. Editorial Universitat Politècnica de València, 2015.

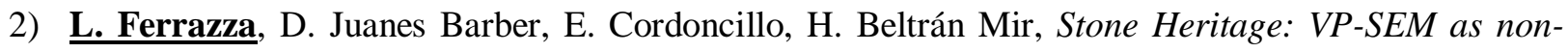
destructive technical in the evaluation of the influence of the petrophysical characteristics in the consolidation treatments, Actas del art'14, 11th international conference on non-destructive investigations and microanalysis for the diagnostics and conservation of cultural environmental heritage. $773-781.2014$.

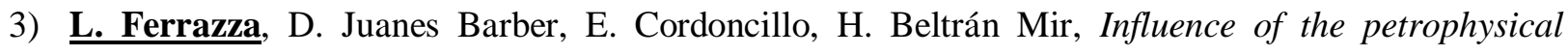
characteristics and state of conservation of stone supports in the penetration and efficiency of consolidation treatments in historic monuments, Actas del 6th International Congress on "Science and Technology for the safeguard of Cultural Heritage in the Mediterranean basin”. 2013.

4) C. Pérez García, F. García Diego, P. Merello, A. Ribera, L. Ferrazza, J. Pérez Miralles, Pinturas Murales de la Casa de Ariadna (Pompeya, Italia): Un estudio multidisciplinar de su estado actual enfocado a una futura restauración y conservación preventiva, Revista Materiales de Construcción. 63 - 311, 449 - 467. Instituto de Ciencias de la Construcción Eduardo Torroja (CSIC), 2013.

5) E. Cordoncillo, L. Ferrazza, T. Machado, D. Juanes Barber, Synthesis and characterization of nanostructured $\mathrm{BaO}$ solution: Aplication in conservation of wall paintings, Actas del 4th International Conference on Cultural Heritage, EUROMED 2012. 801 - 808. Springer, 2012. 
En fase de publicación:

L. Ferrazza, E. Cordoncillo, H. Beltran Mir, T. Macado, Use of hydroxyapatite nanoparticles as a new consolidant and protector for stone support in Cultural Heritage, en Journal of Cultural Heritage, Elsevier.

En el transcurso de la tesis doctoral, los resultados también han sido presentados en forma de comunicaciones orales o presentaciones póster en congresos nacionales e internacionales relacionadas en conservación, quimica y ciencia de materiales para bienes culturales como: II Seminario de Conservación y Restauración de Bienes Culturales Muebles celebrado en Cuzco (Perú), el LIV Congreso de la Sociedad Española de Cerámica y Vidrio (SECV), art'14, 11th International Conference on non-desctructive investigations and microanalysis for the diagnostic and conservation of cultural environmetal heritage, VIII Encuentro Franco-Español de física y química del estado sólido, 6th International Congress on "Science and Technology for the safeguard of Cultural Heritage in the mediterranean basin”, por citar algunos ejemplos. 


\section{Publicaciones}





\title{
LA INVESTIGACIÓN CIENTÍFICA APLICADA EN EL PROYECTO DE CONSERVACIÓN DE LA PORTADA RENACENTISTA DE LA IGLESIA DE NUESTRA SEÑORA DE LA ASUNCIÓN DE CORRAL DE ALMAGUER (TOLEDO)
}

\author{
Livio Ferrazza ${ }^{1,2}$, David Juanes Barber ${ }^{1}$, Eloísa Cordoncillo Cordoncillo ${ }^{2}$, Héctor Beltrán Mir $^{2}$ \\ ${ }^{I}$ Laboratorio de Materiales, Subdirección de Conservación, Restauración e Investigación IVC $+R$ de CulturArts \\ Generalitat, Castellón de la Plana, España \\ ${ }^{2}$ Departamento de Química Inorgánica y Orgánica, Universitat Jaume I de Castellón, Campus del Riu Sec, \\ Castellón de la Plana, España
}

Autor de contacto: Livio Ferrazza, lferrazza@ivcr.es

\begin{abstract}
RESUMEN
En este trabajo se exponen los resultados de los estudios cientificos realizados durante la restauración de la portada principal de la Iglesia de Nuestra Señora de la Asunción de Corral de Almaguer (Toledo). La construcción data de la primera mitad del siglo XVI, de estilo renacentista y perteneciente a la tipología denominada retablo, por sus semejanzas estilísticas con las construcciones en madera dorada y policromada. La portada, que desde su construcción no ha sufrido ninguna modificación arquitectónica importante, ha llegado hasta nuestros días tal y como se configuró en su creación, sumándole las huellas del paso del tiempo correspondientes a tantos años de existencia. Por la situación en que se encontraba gran parte de los elementos que componen la portada, y que podia calificarse de gran deterioro, se decidió realizar un proyecto interdisciplinar para el estudio exhaustivo sobre los materiales lapídeos naturales y artificiales de la portada, el estado de conservación, y desarrollar un programa para la futura restauración, protección y mantenimiento.
\end{abstract}

El estudio de los materiales incluyó la identificación de los soportes pétreos mediante su caracterización petrográfica y petrofisica (sistema poroso, adsorción-desorción, etc.), la identificación de los materiales que constituyen los morteros (aglomerantes y áridos), sus características petrográficas y definición de la técnica de elaboración, la caracterización de los restos de policromía y de las patinas superficiales. Además, el estudio ha permitido determinar las diferentes patologías de alteración y degradación del sustrato pétreo, formaciones de sales, alteraciones cromáticas, patinas biológicas, etc., centrando la atención sobre los mecanismos de degradación química por sulfatación de la roca. Las técnicas petrográficas y petrofisicas empleadas fueron la microscopía óptica de luz polarizada (MO-LP), la difracción de rayos $X(D R X)$, la microscopía electrónica de barrido con microanálisis (SEM-EDX) y la espectroscopia infrarroja por transformada de Fourier (FTIR).

El diagnostico evidenció que el estado de conservación era preocupante debido a la suma de los factores de alteración que alteraban la naturaleza física y química de los materiales. Los estudios petrográficos has identificado dos tipos de piedras relativamente blandas e idóneas para su talla (dolomita y caliza microcristalinas), con un alto valor de microporosidad. La suma de ambas características físicas ha favorecido la degradación de la piedra frente a unas condiciones climatológicas adversas; los cambios drásticos de temperatura entre el día y la noche, la lluvia y las heladas producidas en invierno, que han dañado la portada durante siglos, provocando la aparición de fisuras, grietas, erosión y pérdidas muy importantes de material original. Sin duda la problemática más evidente es el degradación de tipo químico por acción de soluciones acuosas acidas con la formación de costras cristalinas de sales solubles.

PALABRAS CLAVE: Soporte pétreo, Dolomita, Morteros, Patinas, Eflorescencias, SEM-EDX

\section{INTRODUCCIÓN}

Hacia la mitad del s. XV se inició la construcción de la actual Iglesia Parroquial de Corral de Almaguer (Toledo, España), bajo la nombre de Nuestra Señora de la Asunción. La nueva iglesia, se levantó como resultado del enriquecimiento que se estaba produciendo en la comarca a consecuencia de la expansión de la Orden de Santiago, que comenzó un proceso de construcción de iglesias en sus territorios. Entre 1528 y 1534, comienza la construcción de las dos portadas de la iglesia, destacando la principal (Figura 1) por su riqueza 


\section{Emerge}

artística y por pertenecer al estilo híbrido del gótico y del incipiente renacimiento, conocido como Estilo Plateresco.

Este estilo llega de Italia a través de sus maestros o de los propios artistas españoles formados en aquel país. Dicha corriente artística, se caracterizó por una fusión de elementos ornamentales dando lugar a una decoración prolífica en los edificios.
La fachada en general, y la portada en particular se convierte así en el elemento más importante de la arquitectura plateresca.

En este caso, la portada de la iglesia se concibe como una estructura propia cuya principal misión es desarrollar el programa iconográfico que en ella se representa, creando una especie de cuadro o tapiz de piedra que recuerda a un monumental retablo.

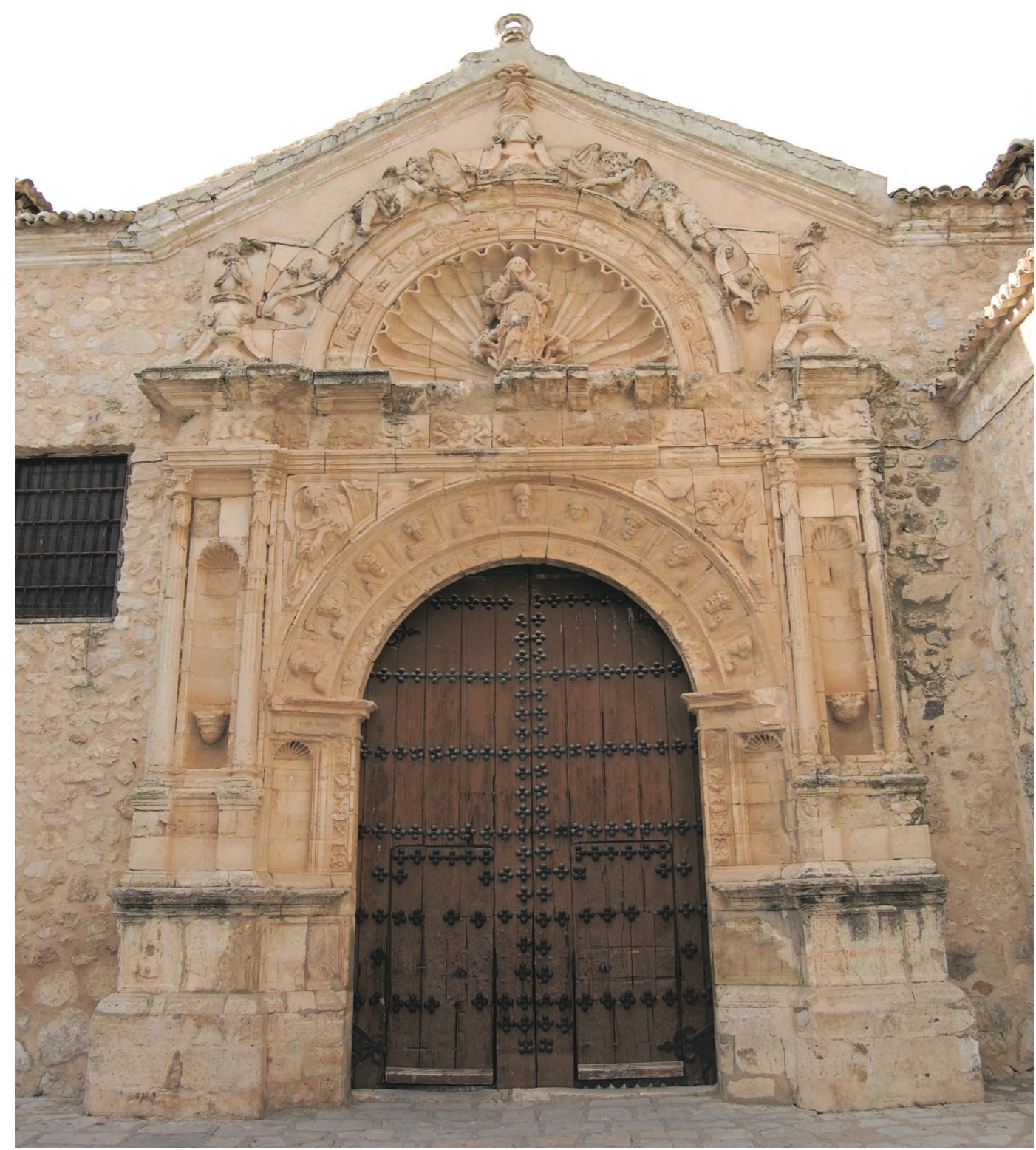

Figura 1. Portada Principal de la Iglesia Ntra. Sra. de la Asunción de Corral de Almaguer (Toledo). 


\section{Emerge}

\section{ESTADO DE CONSERVACIÓN}

La observación inicial mostró que los procesos patológicos, más o menos importantes dependiendo de la zona estudiada, estaban relacionados con la degradación del material pétreo al verse expuesto a la intemperie y a los contaminantes del medioambiente, y al resultado de la acción humana a lo largo de su existencia, sin ningún tipo de control ni mantenimiento (Figuras 2-5).

Dichos procesos, sumados a la composición escultórica del conjunto con numerosos elementos exentos y en

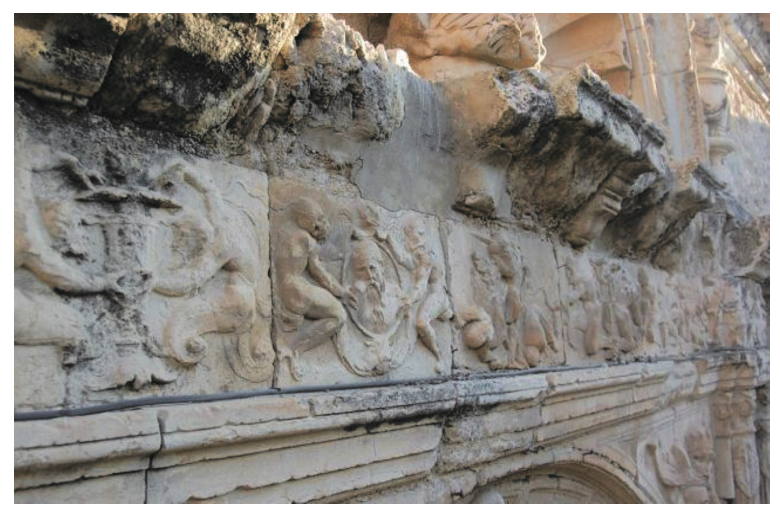

Figura 2. Detalle del friso y cornisa en el que podemos observar la presencia de pátinas de diferente origen y depósitos superficiales. Se observan los sillares que sufren descamaciones superficiales o desplacaciones de diferente entidad con una importante pérdida de volumen.

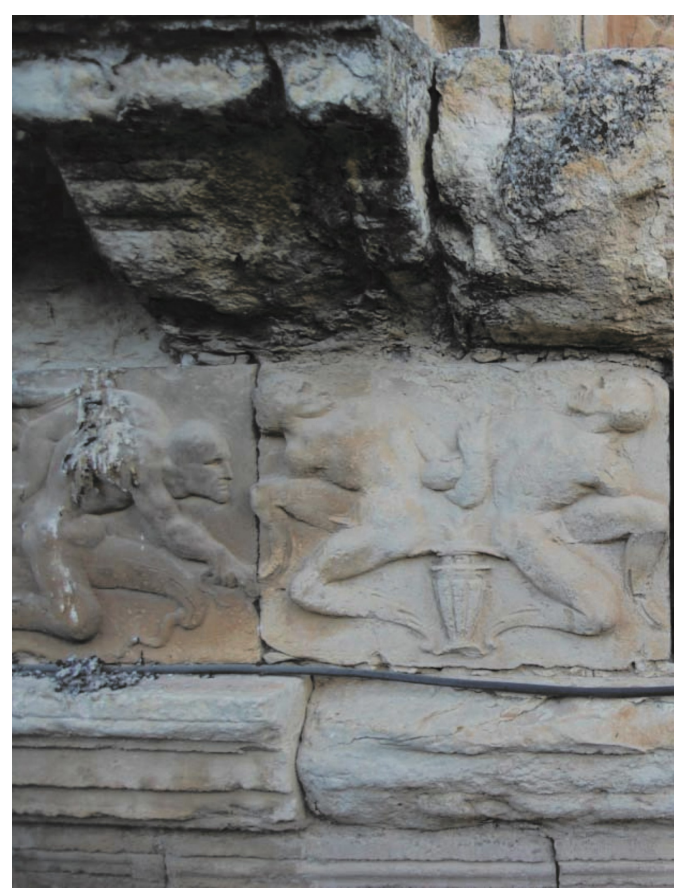

Figura 4. Detalle del estado de conservación de los sillares que componen el entablamento. voladizo, hacían necesaria una rápida intervención a fin de evitar el progreso de las alteraciones existentes que llevarían al estado de ruina, iniciado ya en gran parte de los elementos, y que se evidenciaba en el desprendimiento periódico de parte de los volúmenes.

Las alteraciones que presenta la portada son variadas y han introducido cambios en la piedra a nivel superficial e interno, manifestándose en tonalidad cromática diferencial, cambios en la textura superficial, variación de la composición química y de las propiedades físicas del soporte pétreo.

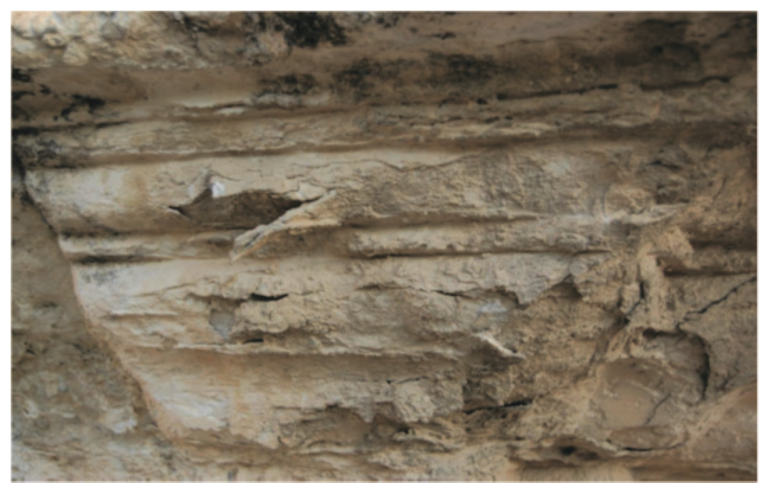

Figura 3. Detalle de la cornisa de arranque del tercer cuerpo. Su exposición al agua de lluvia favorece la migración de las sales que se encuentran en el interior del material pétreo hacia el exterior, en el proceso de secado. Este fenómeno ha provocado la aparición de ampollas y picaduras desvirtuando las molduras originales.

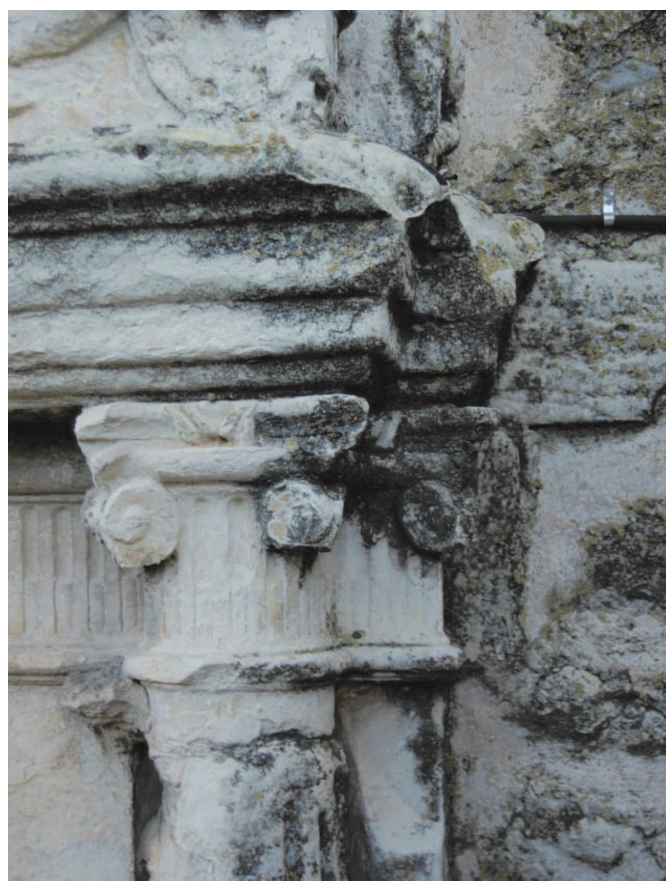

Figura 5. Detalle del estado de conservación de diferentes elementos que componen la portada. 


\section{METODOLOGÍA}

Por la situación que se encontraba gran parte de los elementos que componen la portada, y que podía calificarse de gran deterioro, tendente al estado de ruina, se decidió diseñar un proyecto de restauración que implicaría un estudio exhaustivo del soporte pétreo mediante su caracterización petrográfica y petrofísica, la caracterización de los morteros y de las patinas superficiales.

El objetivo global de este trabajo era documentar también las condiciones de la conservación y las causas de deterioro de los materiales constituyentes la portada, determinando las diferentes patologías de alteración y degradación del sustrato pétreo, formaciones de sales, alteraciones cromáticas, patinas biológicas, etc., centrando la atención sobre los mecanismos del degradación químico por sulfatación de la roca.

Los resultados de la caracterización de materiales y el diagnóstico del estado de conservación, permitieron definir las metodologías más adecuadas para realizar las intervenciones directas e indirectas sobre la portada. Esta fase era necesaria para eliminar o limitar la influencia de los factores ambientales en los procesos de degradación, incluyendo las intervenciones de conservación y protección de las estructuras arquitectónicas y de las decoraciones. Por tanto, no era aconsejable una intervención directa de las estructuras arquitectónica, si no se tomaban las medidas preventivas en el entorno, a fin de eliminar o reducir los efectos de los distintos problemas observados.

Los estudios petrográficos y petrofísicos de los fragmentos del soporte pétreo, de los morteros y de las patinas extraídos de la portada se realizaron mediante las siguientes técnicas instrumentales:

- Microscopia óptica de luz polarizada (MO-LP) mediante el uso del microscopio ECLIPSE 80i de Nikon Corporation que lleva acoplada una cámara DS-Fi1. Las muestras preparadas en láminas delgadas con un espesor de $20 \mu \mathrm{m}$ se observaron en luz trasmitida con aumentos de 50x a 1000x.

- Microscopía electrónica de barrido mediante el uso del microscopio electrónico de barrido de presión variable modelo S-3400N de Hitachi Ltd. (VP$\mathrm{SEM}$ ), equipado con un espectrómetro de rayos $\mathrm{X}$ de energía dispersiva (EDX) de Bruker Corporation XFlash ${ }^{\circledR}$. Las condiciones de trabajo fueron: tensión de aceleración $20 \mathrm{kV}$, tiempo de medición comprendido entre 30 y $100 \mathrm{~s}$, distancia de trabajo de $10 \mathrm{~mm}$.

- La identificación de las diferentes fases cristalinas se realizó mediante difracción de rayos-X utilizando el método de polvo y la espectroscopia infrarroja por transformada de Fourier (FTIR). Los datos XRD se obtuvieron con un difractómetro de
Bruker Corporación D4 Endeavor AXS, con radiación $\mathrm{Cu} \mathrm{K} \alpha 1$. Las medidas se tomaron con 40 $\mathrm{kV}$ y $20 \mathrm{~mA}$, en un rango de 15-70 a (20), un paso de $0,05^{\circ}$ y un tiempo de $1,5 \mathrm{~s}$.

Los análisis IR se realizaron mediante espectrómetro de infrarrojos con transformada de Fourier (FTIR) de Bruker Corporación Vertex 70, con un intervalo 4000-400 $\mathrm{cm}^{-1}$ con resolución de $4 \mathrm{~cm}^{-1}$.

\section{RESULTADOS}

\subsection{Soporte pétreo}

La portada presenta como variedad pétrea una dolomía microcristalina fosilífera homogénea, con presencia de cuarzo y hormas de bioclastos mineralizados. Como elementos accesorios e impurezas se han detectado cristales de feldespatos, compuestos minerales del titanio y una alta concentración de sales ferrosas.

En la figura 6 se observa un sustrato dolomítico constituido por un mosaico hipidiotópico (cristales subhedrales con contactos rectos y curvos) e idiotópico (cristales euhedrales con contactos rectos) de cristales con un tamaño que generalmente oscila entre un mínimo de $2 \mu \mathrm{m}$ a un máximo de $40 \mu \mathrm{m}$ (microesparita y esparita).

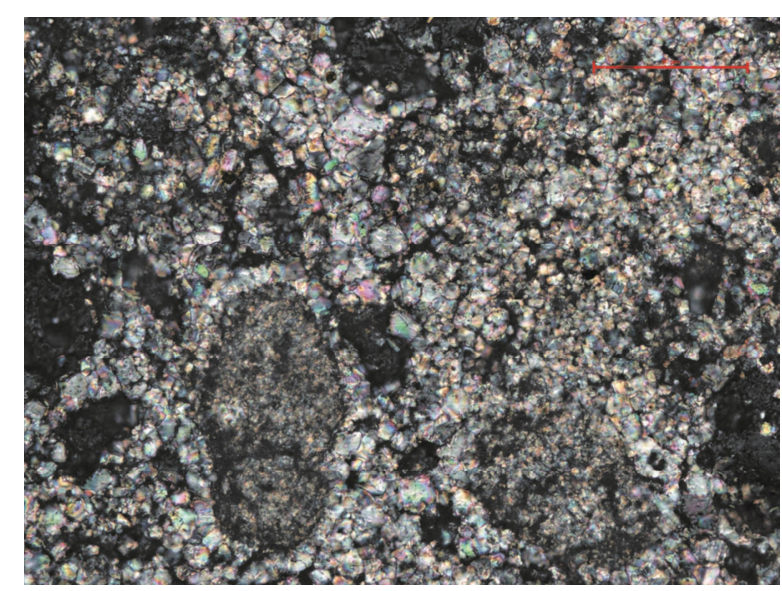

Figura 6. Imagen MO-LP de los componentes de la muestra de dolomita, 500x-XN. Se observan las hormas de los bioclastos mineralizados por el proceso de dolomitización.

Dentro de este mosaico se observan nubes de agregados de dolomita micrítica e inclusiones de diatomeas ricas en sales ferrosas de tonalidad rojiza (Figura 7).

Estas sales, en base a fenómenos de disoluciones forman un cemento ferruginoso que se difunde entre los bordes intercristalinos.

La matriz está caracterizada por la presencia de poros de tamaño medio entre los 50-70 $\mu \mathrm{m}$, de tipo móldica (producto de disolución de los bioclastos), vacuolar e intergranular. 


\section{Emerge}

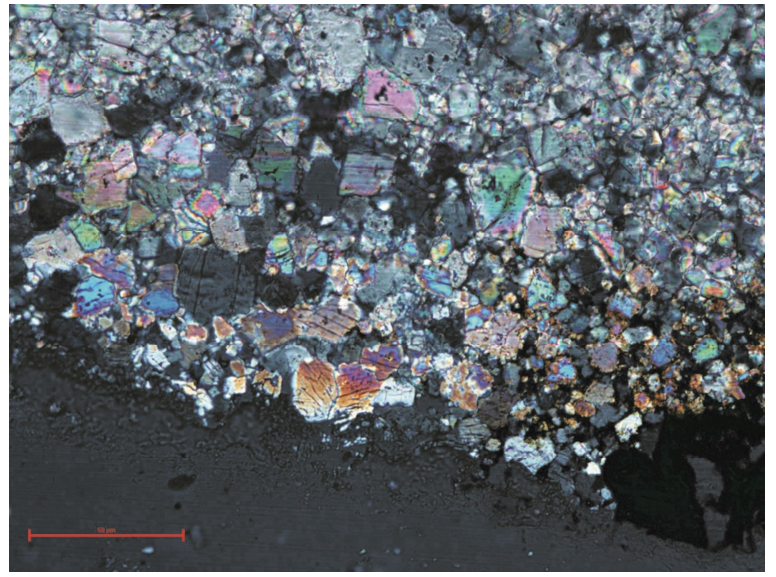

Figura 7. Imagen MO-LP de los componentes de la muestra de dolomita, $500 x-X N$.

La variedad pétrea presente en los sillares del primer cuerpo de la portada es una caliza microcristalina fosilífera homogénea con presencia de hormas de bioclastos mineralizados (Figura 8).

Consiste en un mosaico hipidiotópico e idiotópico de cristales con un tamaño medio entre los 10-50 $\mu \mathrm{m}$ (esparita). Dentro de este mosaico se observan nubes de agregados cristalinos de calcita con un tamaño medio entre los 1-5 $\mu \mathrm{m}$ (micrita). La roca presenta una alta porosidad debida a poros intragranulares y de tipo vacuolar.

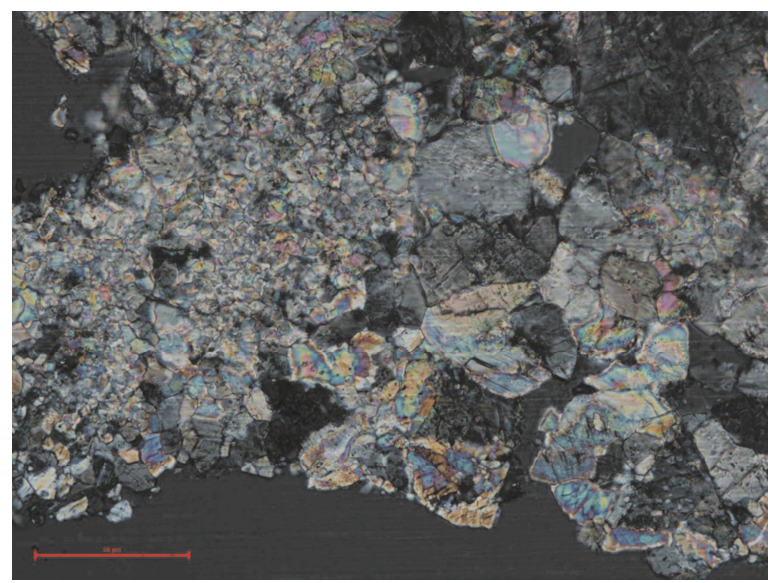

Figura 8. Imagen MO-LP de los componentes de la muestra de caliza, $500 x-X N$.

En el material pétreo de la portada, las características petrológicas de la piedra utilizada inciden directamente en su capacidad de resistencia al deterioro. También las propiedades petrofísicas, principalmente la porosidad y la distribución de tamaños de los poros, influyen claramente en la degradación física, química y biológica. Los estudios muestran generalmente una dolomía caracterizada por una alta porosidad microcristalina, con un alto porcentaje de pequeños poros matriciales e intragranulares (imagen SEM de la Figura 9). Una roca con tal sistema poroso, resulta ser más sensibles a los efectos de alteración por acción del agua y también a los procesos de cristalización de agua $\mathrm{y}$ de sales en el sistema poroso.

La problemática más acentuada en los elementos de la portada es la degradación del material pétreo por el fenómeno de la sulfatación. La disolución que se forma en este proceso, cristaliza superficialmente formando eflorescencias salinas o costras de sulfatación, o en base a fenómenos de difusión, también pueden cristalizar internamente formando criptoeflorescencias (Figura 11). Los depósitos cristalinos de sales que se generan en la superficie de la piedra, se presentan como películas delgadas de aspecto polvoriento. Estos agregados absorben una alta cantidad de sustancias extrañas, las cuales colorean de gris u ocre las costras formadas sobre la piedra.

En los espectros de la Figura 10, se observa la presencia de la fase cristalina del soporte dolomítico no alterado (en rojo) y la presencia de la fase hidratada de sulfato de calcio - $\mathrm{CaSO}_{4} \cdot 2 \mathrm{H}_{2} \mathrm{O}$ de la costra de yesificación (en azul) con los picos de absorción a 3542, 3404 y 1120 $\mathrm{cm}^{-1}$ y los dos picos a 673 y $602 \mathrm{~cm}^{-1}$.

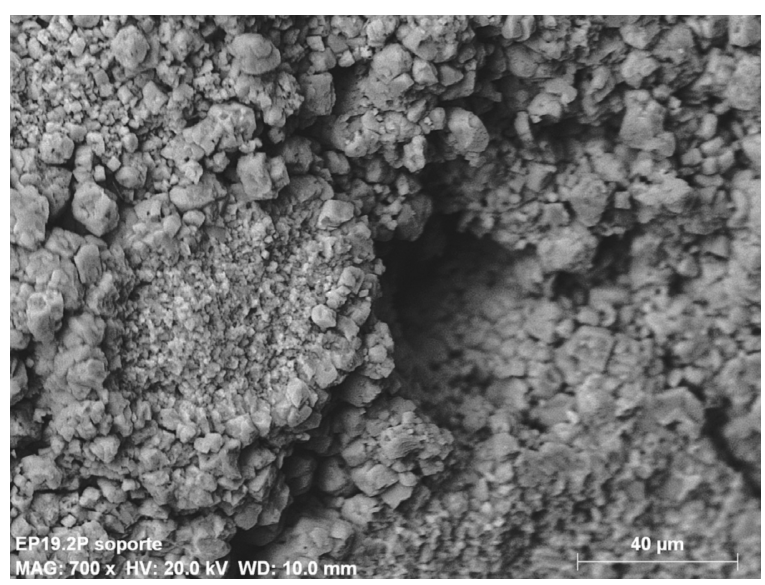

Figura 9. Estudio con microscopía electrónica de barrido en modalidad electrones retrodispersados. La dolomía presenta un alto grado de poros matriciales.

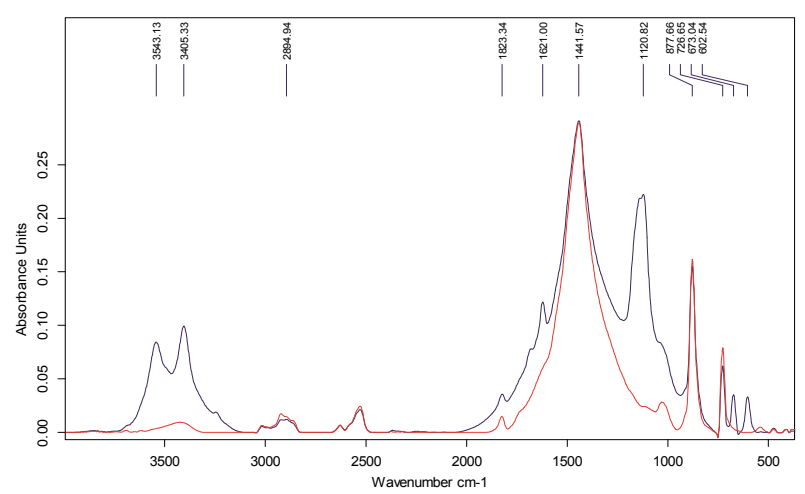

Figura 10. Espectros FTIR de la dolomía no alterada (en rojo) y de la costra de yesificación (en azul). 


\section{Emerge}
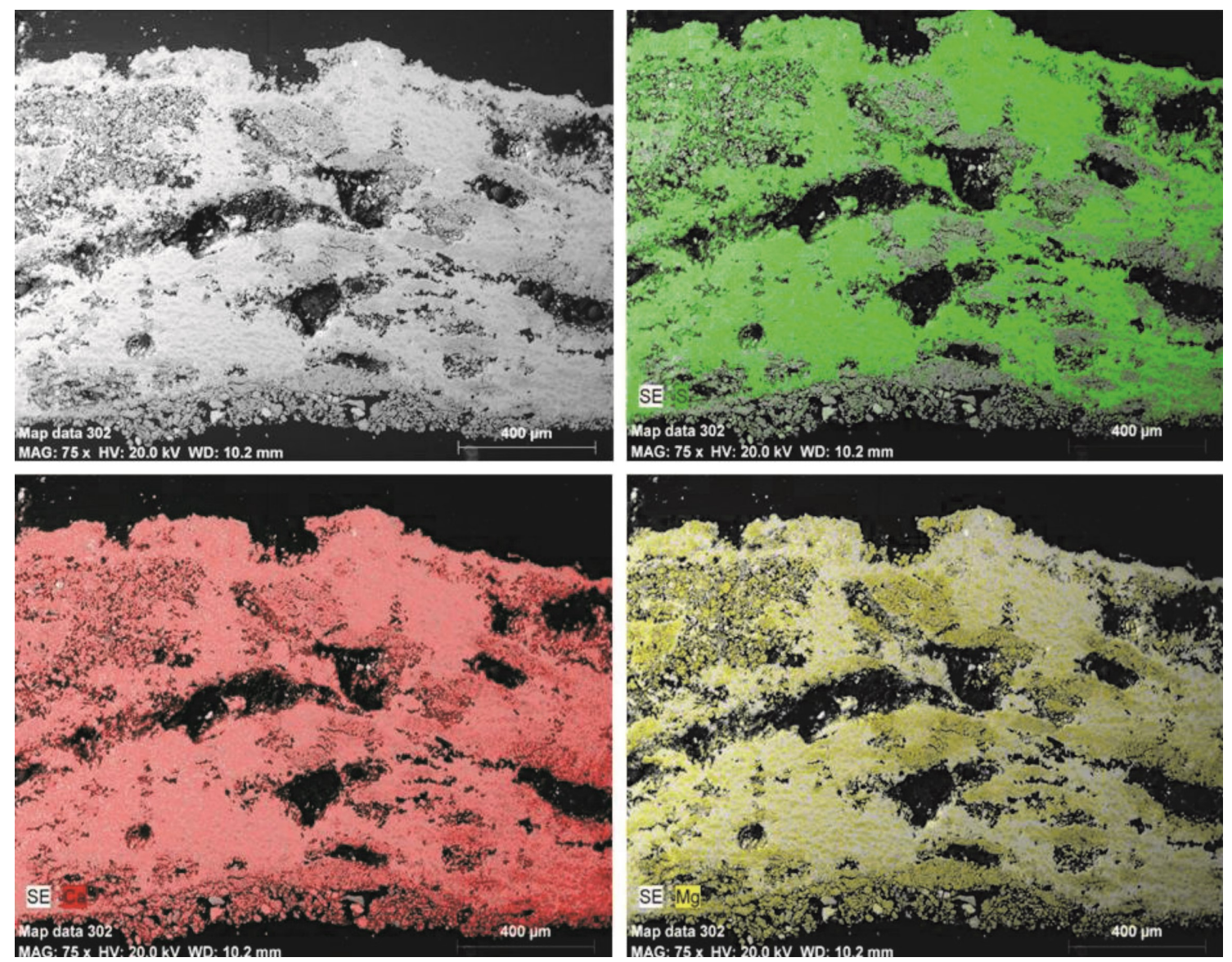

Figura 11. Estudio con microscopía electrónica de barrido en modalidad electrones retrodispersados de una muestra del soporte pétreo en sección transversal. Mapa de distribución del azufre, calcio y magnesio (sulfato de calcio y dolomita).

\subsection{Morteros}

La variedad más abundante son los morteros de cal. Los análisis han evidenciado un mortero antiguo obtenido mediante la mezcla de carbonato de calcio con árido calcáreo fino, arena silícea, tierra rica en oxido/hidróxido de hierro y un pequeño porcentaje de dolomita y feldespatos.

El agregado de coloración generalmente clara y de forma irregular con baja esfericidad, se presenta en una concentración inferior al $40 \%$ y muestra un tamaño pequeño pero variable, desde algunas décimas de micras hasta un máximo de $60 \mu \mathrm{m}$.

Se han identificado diferentes morteros que se relacionan con intervenciones de las últimas décadas (morteros de reparación-revestimiento-decoración). Los análisis han evidenciado una composición similar entre ellos, siendo constituidos por un conglomerante a base de carbonato de calcio y con grandes cuantitativos de árido calcáreo, arena silícea y feldespatos.
Los morteros de yeso están formados por un conglomerante a base de sulfato de calcio con impurezas de cal carbonatada y con pequeños cuantitativos de árido calcáreo fino, arena silícea, feldespatos y negro vegetal. Presentan grandes agregados blancos de forma esferoidal de sulfato de calcio, de tamaño variable desde sub-milimétrico a milimétrico.

El agregado tiene una concentración inferior al 20\% y muestra un tamaño pequeño pero variable, desde algunas décimas de micras hasta un máximo de $800 \mu \mathrm{m}$ aprox. También se observan partículas aisladas de coloración ocre, de forma irregular y de gran tamaño, formadas por una fina masa a base de cal carbonatada que engloba partículas de cuarzo, feldespatos y fragmentos de conchas fosilizadas. Es posible que se trate de grumos de cal ricos en impurezas terrosas presentes en las materias primas utilizadas para la elaboración de los morteros. 


\section{Emerrg Cold}

\subsection{Patinas}

Las patinas que cubren la superficie de la portada constituyen la alteración más visible dada su manifestación como cambios de coloración. Son películas o capas delgadas que no implican necesariamente la existencia de un proceso de deterioro, llegando en algunos casos, a actuar como protección de la superficie pétrea.

Las patinas se presentan generalmente como estratos mineralizados por oxalatos de calcio, en contacto directo con el soporte pétreo, que se pueden deber a algún tratamiento protector o decorativo (policromía a base de yeso y tierras), aplicado en el pasado sobre la superficie de la fachada (Figuras 12 y 13).

Los análisis FTIR de las patinas superficiales (espectro de la Figura 14), han detectado en general la presencia de diferentes componentes mineralógicos: sulfato de calcio (picos de absorción característicos a 1143, 1118, 671 y $602 \mathrm{~cm}^{-1}$ ), silicatos (picos de absorción característicos a $1036 \mathrm{~cm}^{-1}$ ) y oxalatos de calcio Whewellita - con los picos de absorción característicos a $1622,13831324 \mathrm{~cm}^{-1}$.

En este caso el ácido oxálico pudo ser originado por la descomposición de materia orgánica utilizada como tratamiento superficial. Estas patinas con un espesor entre 50-180 $\mu \mathrm{m}$, son ricas en sulfato de calcio, con oxalatos y silicatos. Se observan partículas amarillas y rojas de óxidos-hidróxido de hierro y negro vegetal.

El aspecto, la tonalidad, el espesor y la adhesión al sustrato de estas patinas suele ser variable en base al estado de conservación y su exposición a las intemperies.

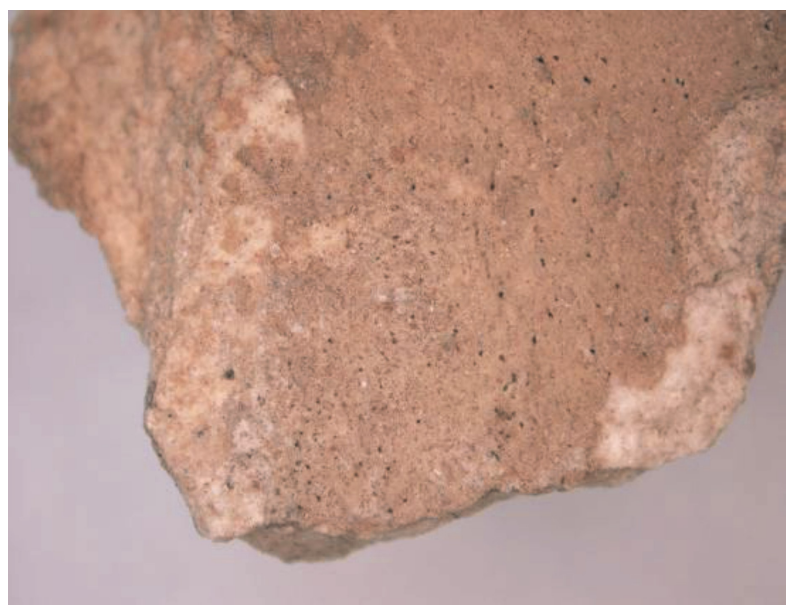

Figura 12. Imagen en microscopía estereoscópica, 0,8x. Pátina de tonalidad ocre presente en la dovela del arco. El estrato es el resultado de mineralización y alteración de la antigua policromía a base de yeso y tierras.

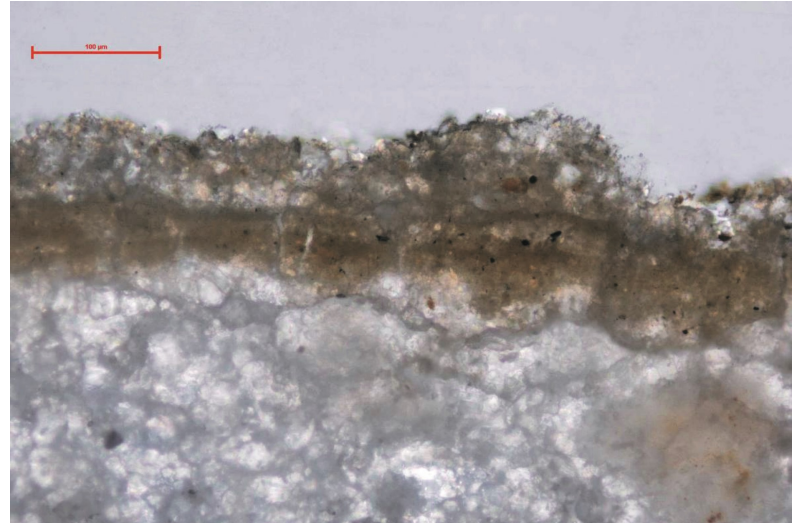

Figura 13. Sección transversal de la muestra de la pátina ocre. Imagen obtenida con microscopía óptica con fuente de luz visible, 200x-XN. Entre el soporte pétreo y el estrato superficial de suciedad, se observa la pátina relativa a la intervención de policromía de la superficie.

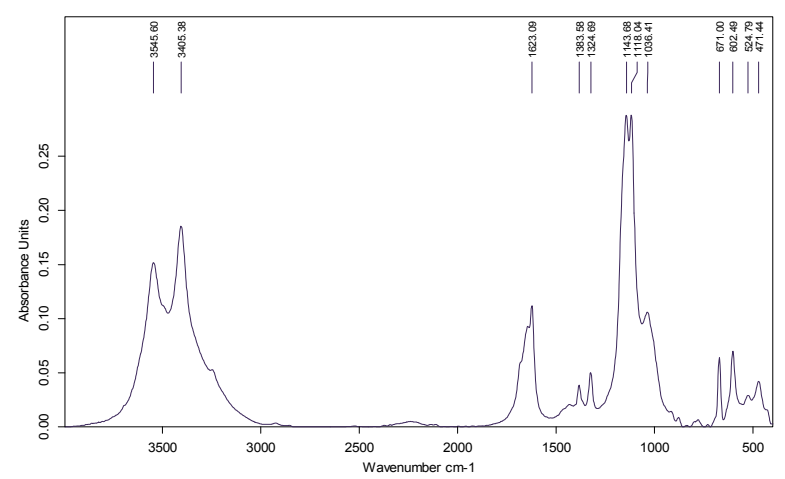

Figura 14. Estudio FTIR de la pátina superficial. Sulfato de calcio (picos de absorción característicos a 1143, 1118, 671 y $602 \mathrm{~cm}^{-1}$ ), silicatos (picos de absorción característicos a $1036 \mathrm{~cm}^{-1}$ ) y oxalatos de calcio - Whewellita (picos de absorción característicos a 1622, $\left.13831324 \mathrm{~cm}^{-1}\right)$.

En diferentes áreas de la portada existe un fino estrato semitransparente, de tonalidad ocre, a base de oxalato de calcio con silicatos únicamente (Figura 15). Como se observa en el estudio en sección transversal de la Figura 16, la pátina se asienta directamente sobre el soporte pétreo, presenta un espesor de 5-20 $\mu \mathrm{m}$, resultando ser muy compacta y formando un estrato completamente impermeable respecto al soporte pétreo. Los diferentes estudios sugieren la hipótesis de que la precipitación del oxalato cálcico se debe a la acción del ácido oxálico secretado por microorganismos tales como líquenes que colonizan los monumentos.

El ácido oxálico por ataque al carbonato, precipita como oxalato de calcio. Estos estratos tienen hoy en día una función importante de protección del sustrato pétreo frente al ataque ácido o a la presencia de sales. En las observaciones con técnicas de microscopía, se observa cómo los componentes del oxalato cementan la estructura dolomítica hasta una profundidad de $100 \mu \mathrm{m}$ aprox., evitando una acción de disgregación y pulverización del material. 


\section{Emerge}

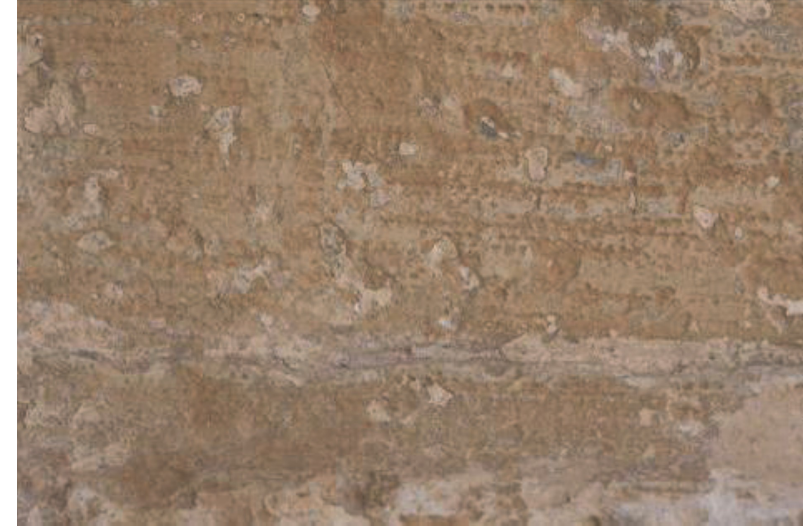

Figura 15. Superficie del zócalo derecho interesada por la formación de una pátina natural de oxalato de calcio. Imagen de microscopía estereoscópica, $0,8 x$.
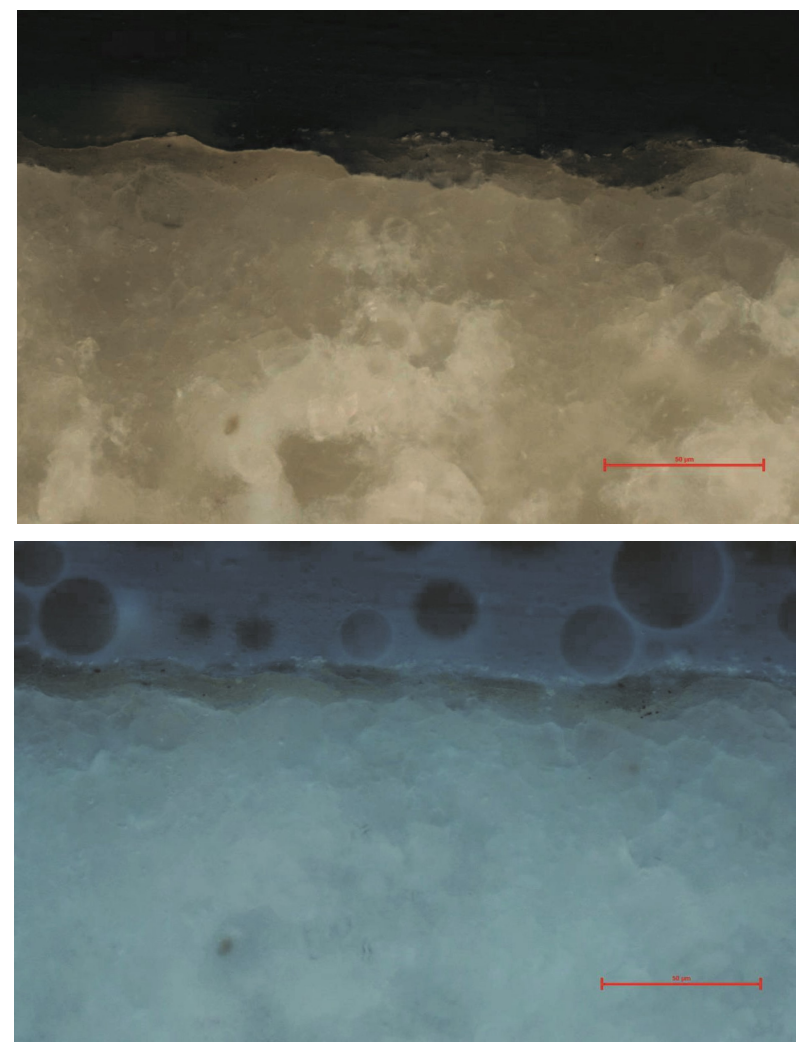

Figura 16. Sección transversal de la muestra de la pátina ocre. Imágenes obtenidas con microscopía óptica con fuente de luz visible y ultravioleta, 500x. Se observa el fino estrato superficial a base de oxalato de calcio.

La colonización de microorganismos (bacterias, algas, hongos, líquenes) desarrollan las denominadas patinas biológicas. La alteración por agentes biológicos se presenta como un fenómeno bastante difuso y generalizado en toda la portada, con la presencia de líquenes crustosos de tipo calcífilo. Los líquenes se encuentran entre los principales agentes de alteración bioquímica implicados en la transformación de la roca por la facilidad de producir $\mathrm{CO}_{2}$ y ácido oxálico, con la sucesiva formación de las patinas de oxalatos.
Otro aspecto critico por la presencia de los agentes biológicos, son los efectos de alteración mecánica producidas por el crecimiento de los rizomas de los líquenes en el sustrato pétreo. Este crecimiento provoca tensiones mecánicas con sucesiva formación de microrupturas y disgregación del material como es visible en la imagen SEM de la Figura 17.

Por último, la presencia de las patinas biológicas es causa de una importante alteración cromática de la superficie (Figura 18).

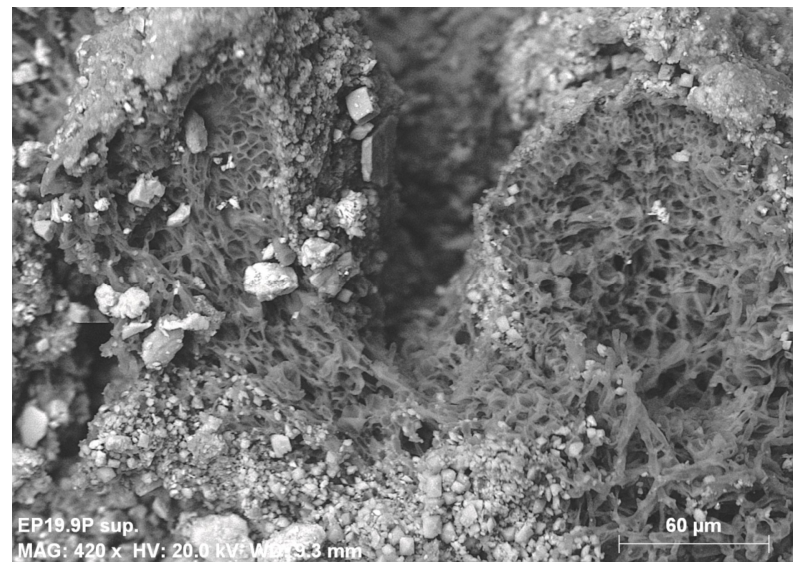

Figura 17. Microscopía electrónica de barrido en modalidad electrones retrodispersados. Se observa la disgregación del material pétreo por acción del crecimiento de la estructura del liquen.

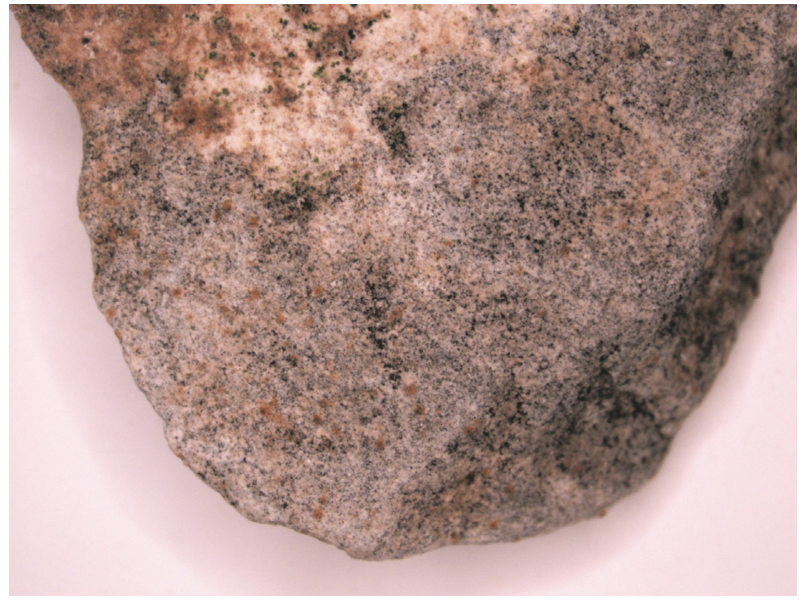

Figura 18. Imágen de una muestra del sustrato petreo con pátina biologica desarrollada por la presencia de líquenes crustosos.

\section{CONCLUSIONES}

El estudio desarrollado en este trabajo permitió documentar el estado de conservación de la portada principal de la Iglesia de Nuestra Señora de la Asunción de Corral de Almaguer (Toledo), así como incrementar el conocimiento de los materiales utilizados en su construcción y su proceso de deterioro. 
Las rocas carbonáticas utilizadas en la construcción de la portada, consisten en dolomía y caliza microcristalinas fosilíferas homogéneas, con presencia de hormas de bioclastos mineralizados.

El grado de alterabilidad de los soportes pétreos guarda una relación directa con la porosidad y la acesibilidad del agua en el sistema poroso de las piedras. Las caracteristicas petrofísicas de la dolomita ha favorecido la degradación de la piedra frente a unas condiciones climatológicas adversas; los cambios drásticos de temperatura entre el día y la noche, la lluvia y las heladas producidas en invierno, han dañado la portada durante siglos, provocando la aparición de fisuras, grietas, erosión y pérdidas.

El principal factor de alteración y degradación de los materiales constituyentes de la portada y que determina el preocupante estado de conservación, es de naturaleza química a través del mecanismo de sulfatación del soporte carbonático. Las formas de alteración más característicos de la portada son las costras debidas a la cristalizaciones de soluciones acuosas salinas y los depósitos superficiales.

Las valoraciones y el diagnóstico del estado de conservación del soporte pétreo, obtenidos a partir de estudios de laboratorios, son completamente contrastables con las observaciones del estado de alteración y degradación de estos materiales carbonáticos en la portada de la iglesia.

\section{AGRADECIMIENTOS}

Los autores agradecen a Carmen Pérez García, Subdirectora de la Subdirección de Conservación, Restauración e Investigación IVC $+\mathrm{R}$ de CulturArts Generalitat, Luis Solano Fernández-Clemente, coordinador del proyecto de conservación y restauración de la portada principal de la Iglesia de Nuestra Señora de la Asunción de Corral de Almaguer (Toledo) y a Fidel Arias García.

\section{REFERENCIAS BIBLIOGRÁFICAS}

Piacenti F., (1994) "Chemistry for the conservation of the cultural heritage", en Science of the Total Environment, Vol. 143, 1994, número 1.

Lazzarini L., Pieper R., (1992) "The Deterioration and Conservation of Stone", en Studies and Documents on the Cultural Heritage, UNESCO, número 16, 1992, pp. 243-270.

Ordaz L., Esbert R.M., (1988) "Glosario de términos relacionados con el deterioro de las piedras de construcción" en Materiales de Construcción, número 38, 1988, pp. 39-44.

Bello M.A., Martin A., (1990) "Estudio sobre los procesos de corrosión (alteración química) de los materiales pétreos de la Catedral de Sevilla (España)" en Materiales de Construcción, número 217, 1990, pp. 17-37.

Alonso F.J., Díaz-Pache F., Esbert R.M., (1994) "Interacción piedra-ambiente, 1. ${ }^{\mathrm{a}}$ parte: Formas de alteración desarrolladas sobre la piedra de la Catedral de Burgos" en Informes de la Construcción, número 433, 1994, pp. 5-18.

Villegas- Sánchez R., Arroyo F., (2013) “The cathedral of Jerez de la Frontera (Cádiz, Spain): Stone degradation and conservation" en Science and Technology for the Safeguard of Cultural Heritage in the Mediterranean Basin, Vol. 14, 2013, pp. 113-116. 



\title{
STONE HERITAGE: VP-SEM AS NON-DESTRUCTIVE TECHNICAL IN THE EVALUATION OF THE INFLUENCE OF THE PETROPHYSICAL CHARACTERISTICS IN THE CONSOLIDATION TREATMENTS
}

\author{
Livio Ferrazza ${ }^{1,2}$, David Juanes Barber ${ }^{1}$, Eloísa Cordoncillo Cordoncillo ${ }^{2}$, Héctor Beltrán Mir ${ }^{2}$ \\ ${ }^{1}$ Laboratorio de Materiales, Instituto Valenciano de Conservación y Restauración de Bienes \\ Culturales - Culturarts Generalitat, Valencia, Spain \\ ${ }^{2}$ Departamento de Química Inorgánica y Orgánica, Universitat Jaume I de Castellón, Spain
}

lferrazza@ivcr.es

\begin{abstract}
Variable pressure scanning electron microscopy (VP-SEM), coupled to a microanalysis system (EDS) represents a useful instrumental technique for the evaluation of different restoration treatments (cleaning, consolidation) in historic stone building or monument. Variable pressure make possible to work with pieces or relatively large fragments of stone materials, and to observe and analyze the same area at different stages of evaluation study (before and after treatment), without the need to coat the surface and recovering integrally the study objects. These advantages allow to develop a nondestructive type research, where the VP-SEM/EDS may be included among the nondestructive testing laboratory, in a microscopic scale study. This paper presents the usefulness of this technique for the study of materials, alterations and the problems of dolomite conservation, focusing attention on consolidation methodologies tests of support, before the restoration of the main portal of the Church of Nuestra Señora de la Asunción of Corral de Almaguer (Toledo, Spain) dated mid-16 ${ }^{\text {th }}$ century. Through VPSEM/EDS we have evaluated different methodologies for consolidation with products based on nanoparticles of $\mathrm{SiO}_{2}, \mathrm{Ca}(\mathrm{OH})_{2}$ and $\mathrm{Ba}(\mathrm{OH})_{2}$, through the changes induced in porosity, the depth of penetration and the possible color changes of surface treated.
\end{abstract}

\section{Introduction}

This work grows out from the need to develop a study metodology of consolidating treatments for a specific historical stone support like dolomite. Generically, in a preventive conservation project, treatments and materials are always more frequently evaluated in order to provide main requisites, such as minimal impact on the original structures, respecting the antique execution techniques, the traditional materials and the history of the cultural heritage $(1,2)$.

In the last years, different products for consolidating materials of architectural and stone surfaces have been developed, focussing on the capability to solve several problems attached with conventional treatments, such as limited depth penetration, and the formation of thin superficial layers. In these last years the consolidation materials has been applied widely, but now, it is necessary to set up more technical and practical studies focalized on real specific cases. 
There are different kind of stone material with its specific intrinsic characteristics (mineralogical composition, pore system). These properties are often modified by different chemical, physical and biological alteration factors. The combination of water, air pollutants, and light interaction with the artefacts structures activates several degradation processes and degradation phenomena: cohesion, crumbling, pulverization, concretion and/or biological patina growth. The properties of each material determine that how it reacts to the consolidation treatment. It is important to have a broader range of published case studies that describe the different consolidation treatments to different environmental situation or on different materials. Consequently, it is necessary to analyze the different consolidation materials in function of its specific application in order to carry out the best applying conditions (3).

The present work tries to get more information about the application of the different consolidation products to a stone support with high sulphatacion process and the presence of natural/artificial patina, and how these factors could affect the result of the treatment. It is highlight important to make test of consolidation treatments directly on original pieces taken from work of art, using non-destructive instrumental techniques such as the variable pressure scanning electron microscopy attached to energy dispersive spectroscopy VP-SEM/EDS. The characterization of chemical microstructure is one of the most important applications of the conventional scanning electron microscope equipped with an energy dispersive x-ray spectrometer $(4,5)$. However, the VP-SEM/EDS gives the possibility to study original fragments that represents a unique and real chance to understand exactly the behavior of the material to be treated with different consolidation products.

\section{Experimental part}

\section{Materials and Methods}

The stone samples examined in the present research were taken from the main portal of the Church of Nuestra Señora de la Asunción of Corral de Almaguer (Toledo, Spain) dated in the first half of the sixteenth century observable in Figure 1.

Different samples of stone support were petrographic and petrophysical characterized. The first phase of this study, the different conditions of alteration and degradation of the stone substrate and the identification of mortar (the binder/aggregate ratio), their petrographic characteristics, the granulometry of the binders and the aggregates and technical elaboration were studied.

Successively, the laboratory evaluation of the different treatments consolidation of stone support was made (Figure 2). With this study we wanted to have a precise knowledge of the relationships among the mode of application of the product, the depth of penetration, the porosity induced, the pore system configuration changes, and possible changes in colour treated surface. The aim was to evaluate the methodology of application of these products and its behaviour, efficiency, compatibility with the original materials, with especial attention in the new formation of secondary products or alteration of the characteristics of the original material. Were used an alcoholic suspension of hydroxide 
nanolime, aqueous suspension of barium hydroxide and aqueous suspension of silicon dioxide with different dilution ratios. The final objective was to choose the optimal suspension for consolidating treatments of the stone portal.

The test treatments were analysed from different points of view. To verify the penetration of the consolidating product, the samples were analysed by SEM-EDS. The analyses were carried out in a HITACHI S-3400 N variable pressure scanning electron microscopy coupled with a BRUKER X Flash X-ray energy dispersive spectrometer. Acceleration voltage of $20.0 \mathrm{kV}$ and a pressure of $60 \mathrm{~Pa}$ in the chamber were used for chemical analyses. Backscattered imaging mode was used for the analyses.

We prepared several cross-sections obtained from fragments of the specimens using an epoxy resin. SEM-EDS was necessary in order to evaluate morphological, structural, and compositional modifications occurred to the material after the consolidation and after the treatment.

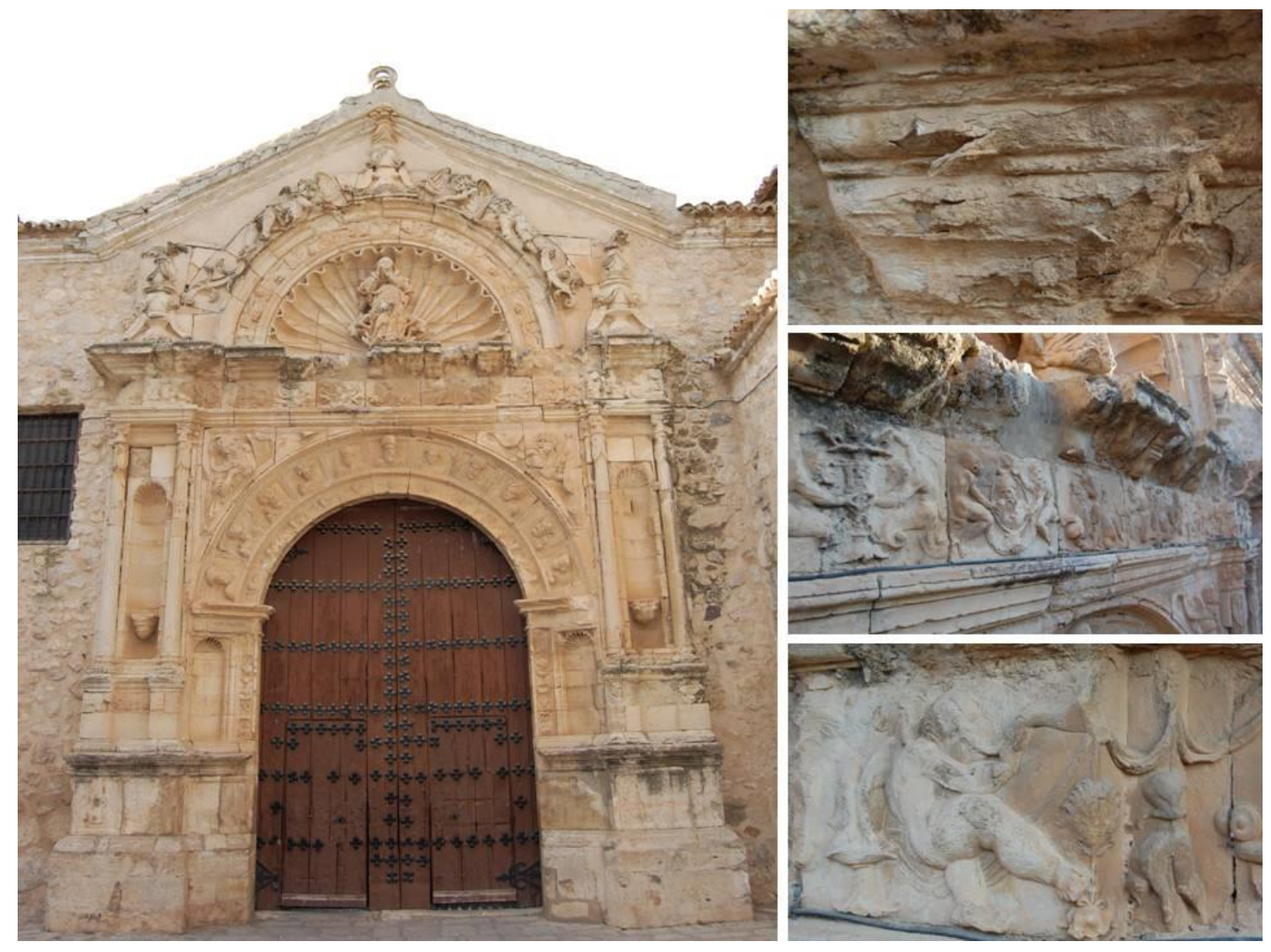

Figure 1. Main portal of the Church of Nuestra Señora de la Asunción (Corral de Almaguer - Toledo) dated mid-16 ${ }^{\text {th }}$ century. The pictures show the conservation state of the stone. Material lost, crystallization of salts, physico-chemical alterations by biological agents. 

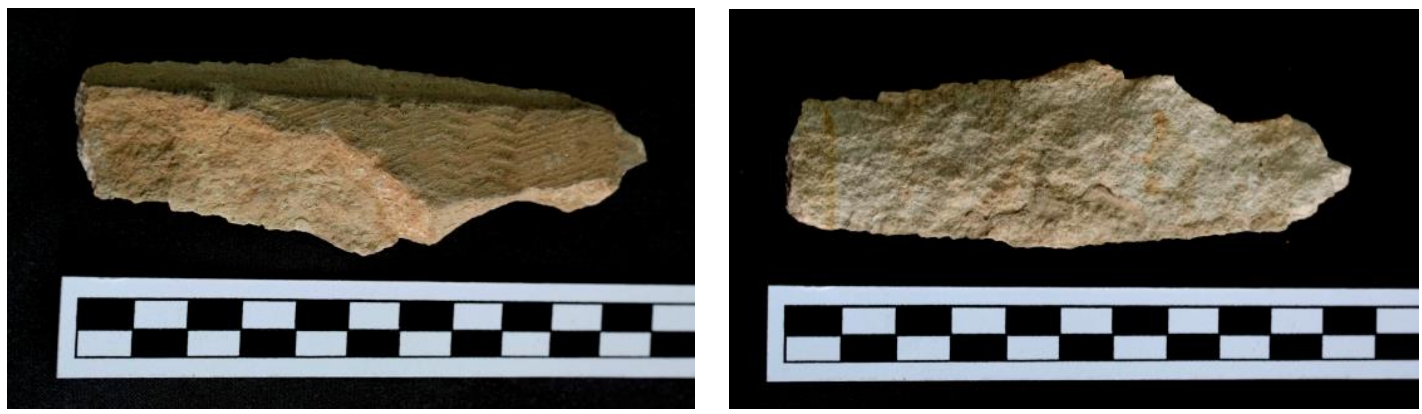

Figure 2. Example of an original stone fragment used in the evaluation of treatments consolidation. The treatments were applied on the obverse surface (with artificial patina) and the reverse surface (natural stone).

\section{Result and Discussion}

\section{Petrographic and petrophysical studies}

The study demonstrated how the state of conservation of the portal was getting worse due to the factors of alteration and degrade, that had altered the physical and chemical nature of the materials. Petrographic studies showed the presence of two types of relatively soft stones: microcrystalline dolomite and limestone, with a high value of micro-porosity (Figure 3). The addition of their physical characteristics, the adverse weather conditions; drastic temperature changes between day and night and rain and frost produced in winter during long time, produced as to result the degradation of the stone, causing the appearance of cracks, erosion and loss of important original material.

The more significant deterioration is the chemical degradation of the stone due to environmenntal pollution. The SEM-EDS study of different fragments of the substrate stone showed crusts, mainly formed by calcium sulphate which frequently possess great thickness, as result of chemical attack by $\mathrm{SO}_{2}$. Some samples had a gypsum layer not only on the surface but even at depths of a few centimeters, so the gypsum crystals occuped the place of primitive microcrystalline matrix (see Figure 4). The variation in the macrochemical composition in the portal is due to a notable increase in the concentration of sulphates, which can range from a value of around $0.5 \%$ of $\mathrm{CaSO}_{4}$ (internal area of material unaltered) to $60 \%$ approximately of $\mathrm{CaSO}_{4}$ in the most deteriorated stones. 

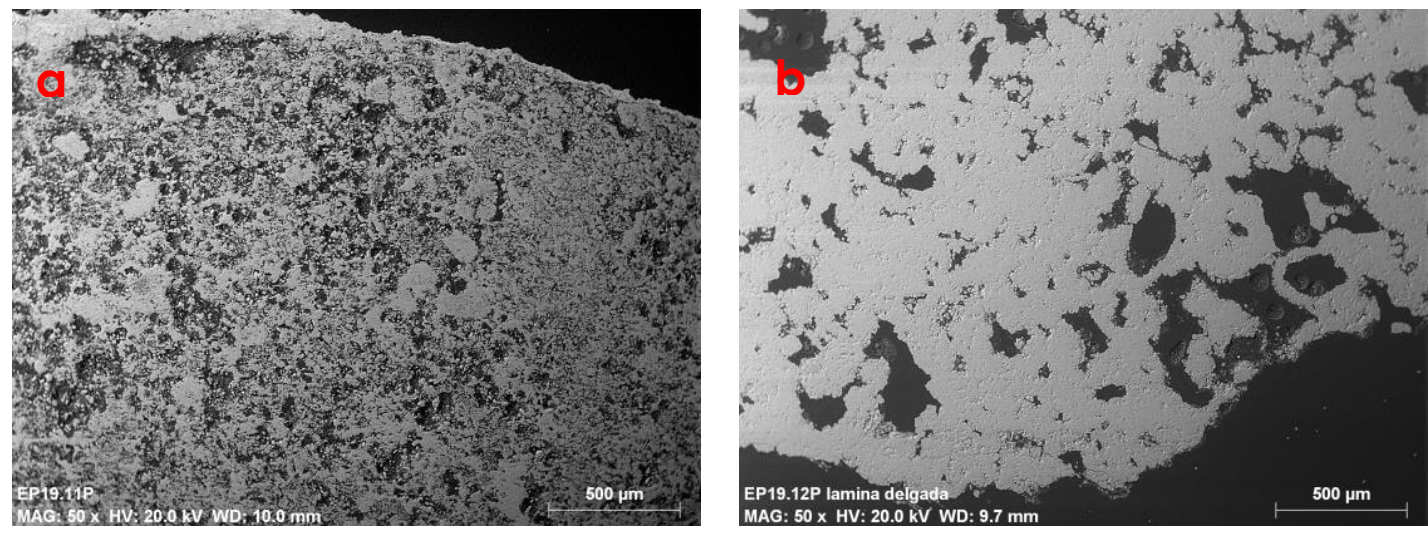

Figure 3. SEM image of the cross-section of stone sample in back scattered electrons. a) Dolomite. b) Limestone.
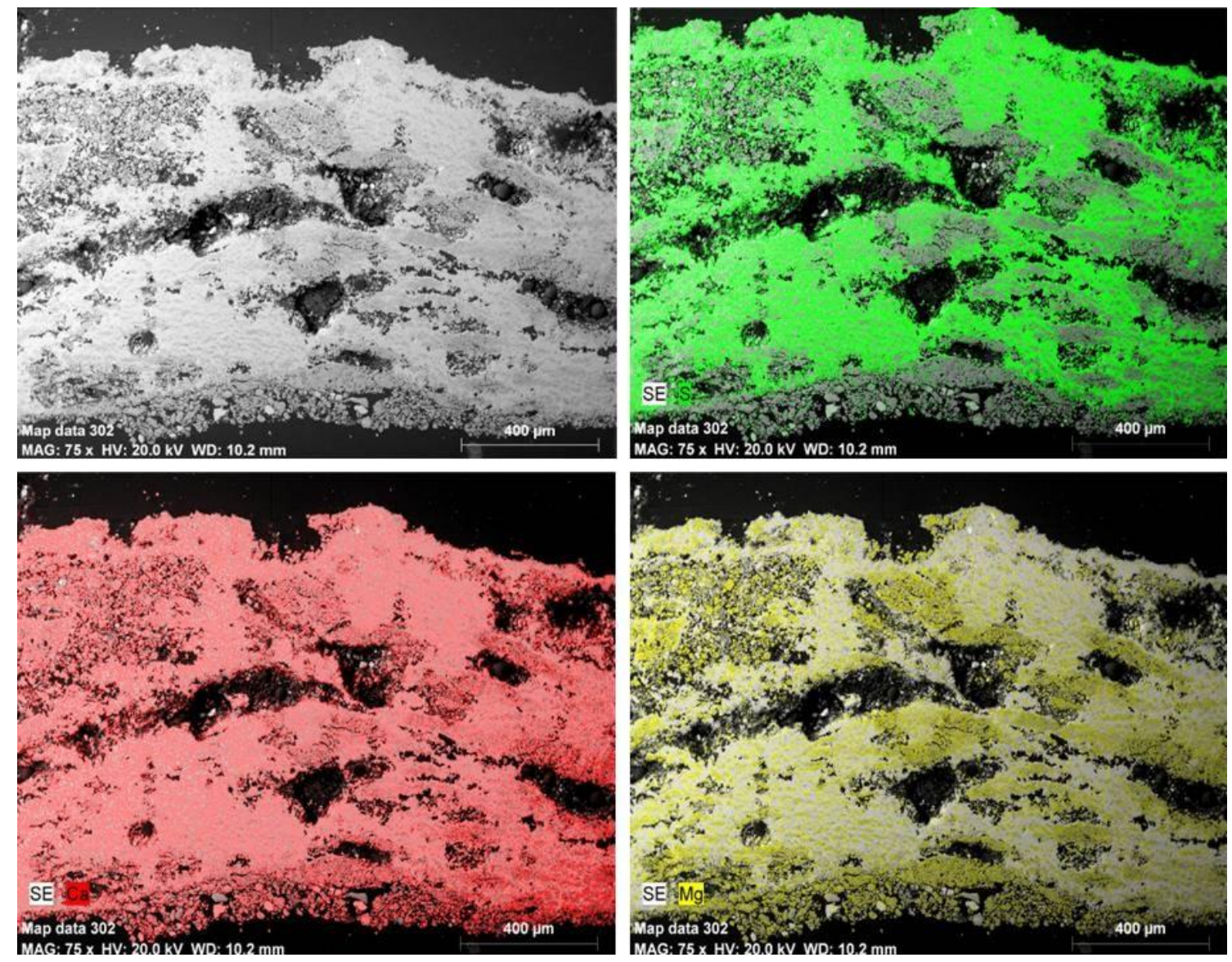

Figure 4. SEM image of the cross-section of stone sample in back scattered electrons and element mapping distribution of Sulphur, Calcium and Magnesium. 


\section{Treatments consolidation evaluation}

The results showed that the alcoholic suspensions of hydroxide nanolime and the aqueous suspension of barium hydroxide, had a surface effect only, creating a limited consolidation treatment "see Figure 5".

Calcium hydroxide preserved the open porosity of the surface. Usually, the product make a white surface patina as shown in Figure 6-A. The solution of barium hydroxide caused a small thickening of the superficial consolidation layer as observable in Figure 6-B.
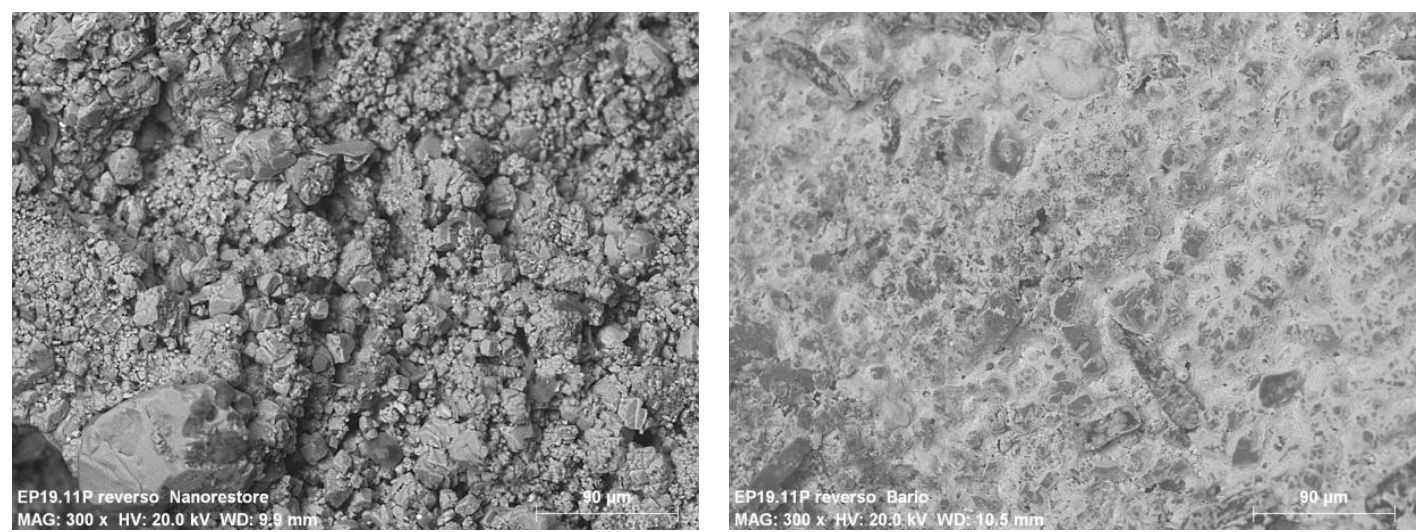

Figure 5. SEM image in back scattered electrons of the reverse surface treated with alcoholic suspension of hydroxide nanolime (A), and the reverse surface treated with aqueous suspension of barium hydroxide (B).
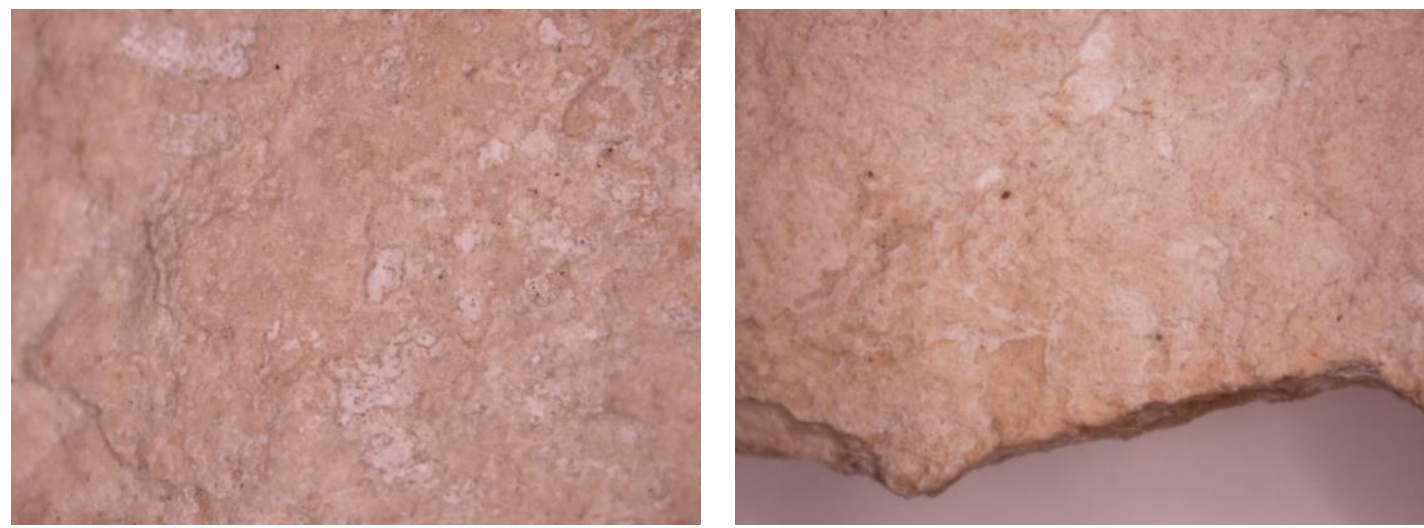

Figure 6. Stereomicroscopy image of the reverse surface treated with alcoholic suspension of hydroxide nanolime (A), and the reverse surface treated with aqueous suspension of barium hydroxide (B).

The aqueous suspension of silicon dioxide with different dilution ratios were tested. The experimental results showed that after the first treatment, the porosity system of the stone was consistently reduced. From the third application of the consolidant product, a thin surface layer of glass aspect was created, that produced a change in the surface appearance. The formation of this layer could be reduced by increasing the dilution. 
We observed in the cross-section SEM images, how increasing the solution concentration caused a small thickening of the superficial consolidation layer with a thickness of $15 \mu \mathrm{m}$ approximate, as we can observe in Figure 9. The images represent the SEM image in back scattered electrons and element mapping of Silicon and Calcium distribution.

Treatments with the different dilutions generally produced less penetration into the stone support, approximately $200 \mu \mathrm{m}$. The consolidant was concentrated in of fracture or large pores. The depth of penetration could be increased to $1000 \mu \mathrm{m}$, increasing dilution.
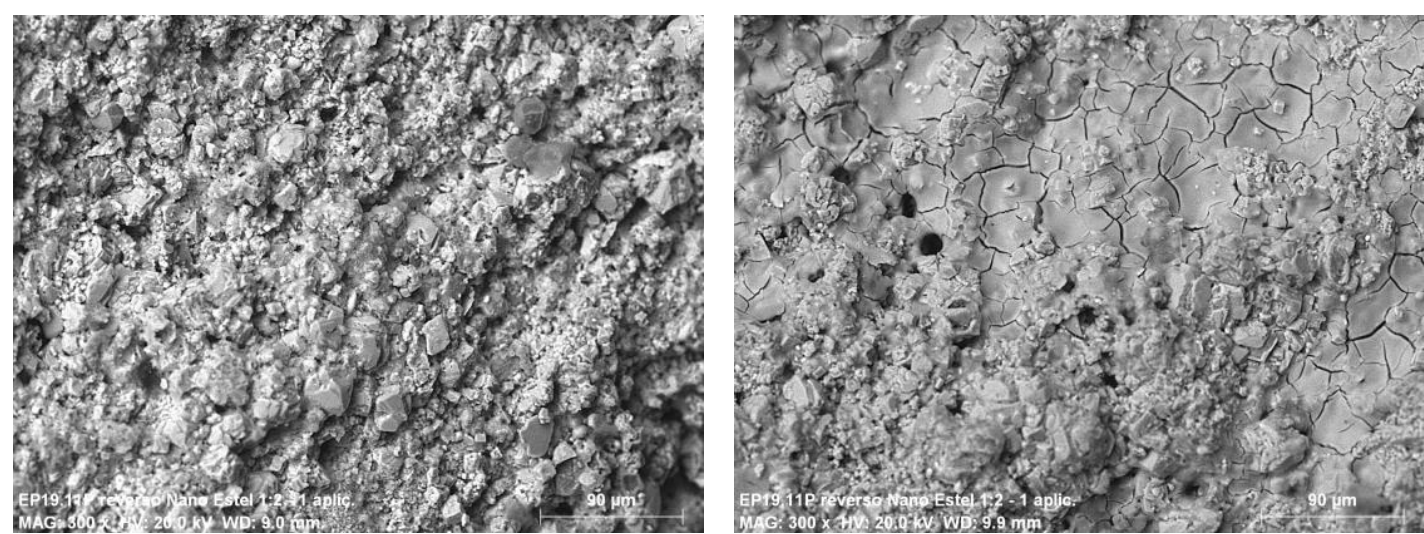

Figure 7. SEM image in back scattered electrons of the reverse surface treated with aqueous suspension of silicon dioxide.
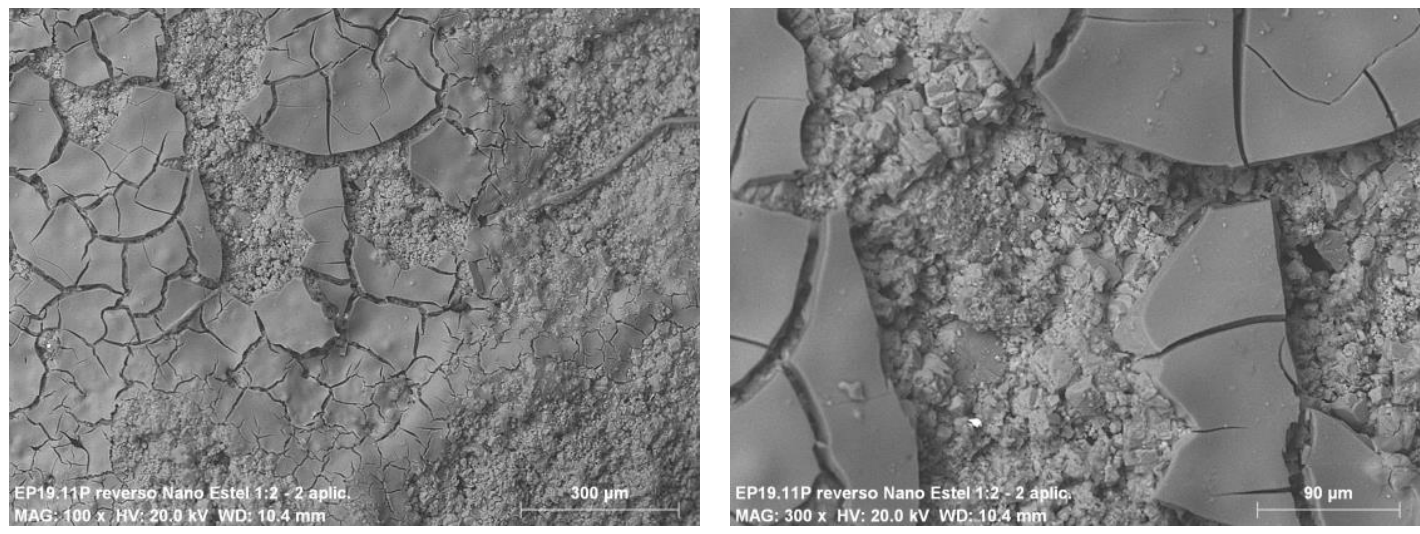

Figure 8. SEM image in back scattered electrons of the obverse surface treated with aqueous suspension of silicon dioxide. 

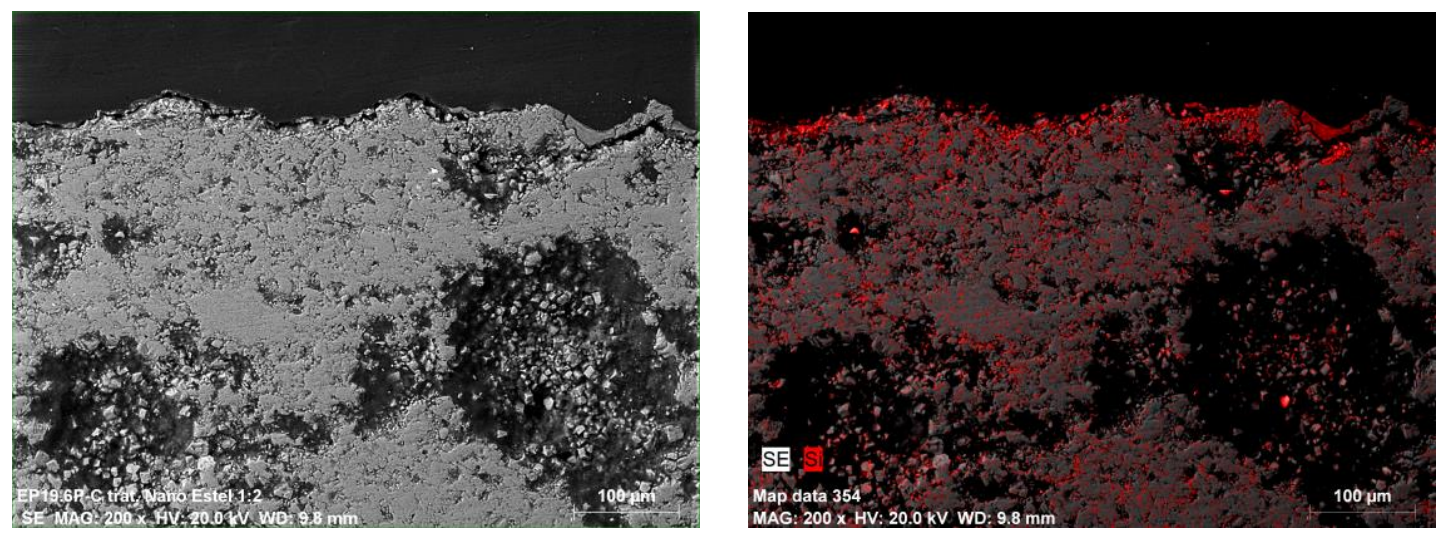

Figure 9. SEM image in back scattered electrons and element mapping of Silicon. The high concentration of silicon at surface level and distribution in the dolomitic support is observed.

\section{Conclusions}

This study shows how the stone samples treated with a consolidating treatment, reflects different reactions depending on its formulation, on the chemical alterations and on the natural or artificial patina of the surfaces. The experimental results achieved helped designing the specific action plan to restore the façade, establishing the correct treatments in regard to the different characteristics of the stone and to its state of conservation.

In relation to the investigation methods on lithic products consolidation, the variable pressure SEM-EDS can constitute a remarkable step forward in different areas: analysis of constituent elements, the observation of porous surfaces, the study of different types of alterations, and the data collection about surfaces morphology and about the application procedures of different consolidating treatments. A single diagnostic study is able to provide answers on most materials in a short lapse of time through nondestructive method.

The results obtained yield an important consideration for the future, the necessity of the use of diagnostic procedure designed for any monument that could be realized with no sophisticated technologies.

\section{ACKNOWLEDGMENTS}

The authors thanks to Carmen Pérez García of the Instituto Valenciano de Conservación y Restauración de Bienes Culturales - Culturarts Generalitat (Valencia, Spain) and Luis Solano Fernández-Clemente, architect of the restoration project of the main portal of the Church of Nuestra Señora de la Asunción of Corral de Almaguer (Toledo, Spain).

\section{References}


(1) F. Piacenti, "Chemistry for the conservation of the cultural heritage", Science of the Total Environment, Vol.143, No.1, 1994, pp.113-120.[journal]

(2) P. D'Armada and E. Hirst, "Nano-lime for the consolidation of plaster and stone", Journal of Architectural Conservation, Vol.18, No.1, 2012, pp.63-80.[journal]

(3) P. López-Arcea, L. S. Gomez-Villabaa, L. Pinhob, M. E. Fernández-Vallec, M. Álvarez de Buergoa and R. Forta, "Influence of porosity and relative humidity on consolidation of dolostone with calcium hydroxide nanoparticles: effectiveness assessment with non-destructive techniques", Materials Characterization, Vol.61, No.2, 2010, pp.168-184.[journal]

(4) J. I. Goldstein, D. E. Newbury, P. Echlin, D. C. Joy, A. D. Romig, Jr., C. E. Lyman, C. Fiori and E. Lifshin, "Scanning Electron Microscopy and X-ray Microanalysis", 2nd Ed., Plenum Press, New York, 1992. [book]

(5) D.E. Newbury, "X-Ray Microanalysis in the Variable Pressure (Environmental) Scanning Electron Microscope", Journal of Research of the National Institute of Standards and Technology, Vol. 107, No.6, 2002, pp.567-603.[journal] 



\title{
Pinturas murales de la casa de Ariadna (Pompeya, Italia): un estudio multidisciplinar de su estado actual enfocado a una futura restauración y conservación preventiva
}

\section{Ariadne 's house (Pompeii, Italy) wall paintings: A multidisciplinary study of its present state focused on a future restoration and preventive conservation}

\author{
M. C. Pérez $(*)$, F. J. García-Diego ${ }^{(* *, * * *)}$, P. Merello(*,**), P. D’Antoni(*), A. Fernández-Navajas(**), \\ A. Ribera i Lacomba $(* * * *)$, L. Ferrazza $(*)$, J. Pérez-Miralles $(*, * * * * *)$, J. L. Baró(**), P. Merce ${ }^{(*)}$, \\ H. D'Antoni(******), J. Curiel-Esparza $(* *, * * *)$
}

Recepción / Received: 22-III-12

Aceptación / Accepted: 28-IX-12

Publicado online / Online publishing: 26-X-12

\section{RESUMEN}

Este trabajo desarrolla un estudio multidisciplinar sobre el actual estado de conservación de la casa de Ariadna (Pompeya, Italia), domus de gran valor arqueológico. El objetivo es aumentar el conocimiento del estado actual de conservación de la casa para la discusión de una futura restauración. Para ello se realizaron estudios ambientales, mediciones de radiación electromagnética, estudio de materiales y un estudio fotográfico. Los estudios revelaron que los tejados que cubrían las salas analizadas estaban originando unas condiciones climatológicas adversas que se traducían en un grave daño para la conservación de las pinturas murales. Entre 2009-2010 se cambiaron las cubiertas y los estudios ambientales fueron repetidos. Los estudios de materiales demostraron que las pinturas coinciden en ejecución y composición con las señaladas por

\section{ABSTRACT}

This paper deals with the development of a multidisciplinary study on the current state of conservation of Ariadne's house (Pompeii, Italy), a domus of great archaeological value. The aim of this study is to undertake the preventive conservation actions required and increase the knowledge about its conservation and to generate discussions and points of view for a future restoration. Environmental studies, electromagnetic radiation measurements, study of materials and a photographical study were carried out. Those studies revealed that the rooftops covering the analyzed rooms resulting in adverse weather conditions causing grave damage to the conservation of the wall paintings. Thus, between 2009-2010 the rooftops were changed and new environmental studies were conducted. Studies of materials showed that the paintings match in execution

\footnotetext{
(*) Instituto Valenciano de Conservación y Restauración de Bienes Culturales (IVC+R) (Castellón, España).

(**) Universidad Politécnica de Valencia (Valencia, España).

(***) Unidad Asociada ICMM- CSIC/UPV.Universidad Politécnica de Valencia (Valencia, España).

(****) Ayuntamiento de Valencia (Valencia, España).

$(* * * * *)$ Exma. Diputación de Castellón (SCRC) (Castellón, España).

$(* * * * * *)$ NASA Ames Research Center, Moffett Field (California, USA).
} 
otros autores. Las sales procedentes de morteros modernos de anteriores restauraciones afectaban a las pinturas, también se describe una fina capa superficial de tonalidad grisácea procedente de contaminantes ambientales.

Palabras clave: Pompeya; conservación preventiva; materiales; monitorización ambiental; fotografía.

\section{INTRODUCCIÓN}

La casa de Ariadna o "dei Capitelli colorati", se encuentra en el "Regio" VII, ínsula 4 (Pompeya, Italia), en una ubicación privilegiada en el centro de la ciudad, a menos de 100 metros del foro. Con $1.700 \mathrm{~m}^{2}$, es una de las domus señoriales más grandes de la arquitectura pompeyana (1).

La casa de Ariadna fue excavada entre 1832 y 1835 y durante el siglo XIX fue una de las casas pompeyanas más famosas y visitadas, cayendo posteriormente en el olvido (2).

En este trabajo vamos a estudiar las pinturas murales de las habitaciones 1, 2, 3 y 4 (Figura 1). Estas cuatro salas se encuentran decoradas con pinturas murales desde el primer al cuarto estilo pompeyano (1). and composition with those reported by other authors. The salts from modern mortars from previous restorations were affecting frescoes, also it is described a thin grayish surface layer from environmental contaminants.

Keywords: Pompeii; preventive conservation; materials; environmental monitoring; photography.

\section{INTRODUCTION}

Ariadne's House or "dei Capitelli Colorati", is located in the "Regio" VII, insula 4 (Pompeii, Italy), in a privileged location at the center of the city, less than 100 meters from the forum. With $1700 \mathrm{~m} 2$ it is one of the biggest stately domus of the private Pompeian architecture (1).

Ariadne's House was excavated between 1832 and 1835 and during the 19th century it was one of the most famous and visited Pompeian houses, later to sink into oblivion afterwards (2).

The rooms considered in this work are: numbers 1, 2, 3 and 4 (Figure 1). These four rooms are decorated with murals from the first to the fourth Pompeian style (1).

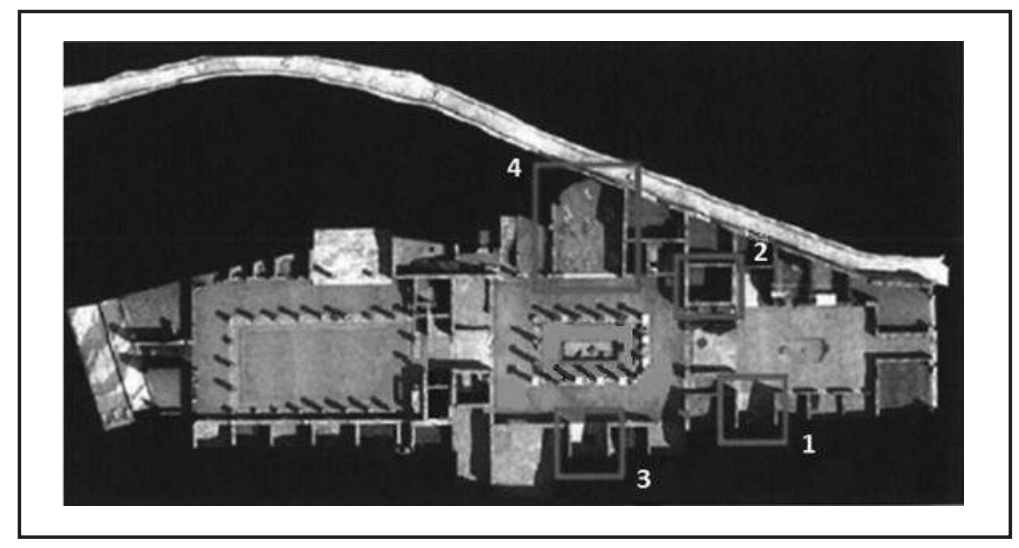

Figura 1. Planta de la casa de Ariadna. Este plano fue realizado por el Ayuntamiento de Valencia. Figure 1. Floor of Ariadne's house. This map was made by the City Council of Valencia.

Durante los años 70 se instalaron unas cubiertas consistentes en una estructura metálica sosteniendo láminas de policarbonato transparente, estos tejados fueron instalados en tres habitaciones de la casa (salas 1,2 y 3 de la Figura 1). En 2010, estas cubiertas transparentes fueron cambiadas por un techo aislado no transparente. La sala 4 (Figura 1) se encuentra parcialmente cubierta de teja.

En la sala 3, se encuentra un mosaico emplazado como emblema central de la planta. El mosaico, de tradición helenística con unas dimensiones de $84 \mathrm{~cm}$ x $77 \mathrm{~cm}$. Se
During the 70 's a rooftop consisting of a metallic structure holding transparent polycarbonate sheets was installed on three rooms of the house (rooms 1, 2 and 3 of Figure 1). In 2010 the transparent polycarbonate sheets were changed for an isolated non transparent roof. Room 4 (Figure 1) is partially covered with a tile rooftop.

In room 3, there is a mosaic as a central emblem of the plant. The Hellenistic tradition mosaic measures $84 x 77 \mathrm{~cm}$ squared. It is thought to have been made within the late 
cree que fue realizado entre el siglo II a.C. y el comienzo del siglo primero antes de Cristo. El suelo del resto de la habitación está pavimentado con teselas diferentes, más modernas, que se remontan al siglo primero. El mosaico está cubierto por una caja compuesta por cinco hojas de vidrio de tres milímetros.

Entre 2004 y 2008, un equipo multidisciplinar dirigido por la Sección de Investigación Arqueológica de la ciudad de Valencia, en colaboración con un número de investigadores vinculados a diferentes instituciones científicas, llevaron a cabo 18 sondeos de un extremo a otro de la Casa de Ariadna encontrando restos arqueológicos de todos los períodos de la casa (1).

Los principales problemas que afectan a la casa de Ariadna son la colonización biológica (plantas superiores y animales) y los problemas de lixiviado causados por las lluvias debido a la prolongada ausencia de tejado.

Durante las últimas décadas, se ha desarrollado un creciente interés en todas las áreas de conservación con un enfoque multidisciplinar. La conservación preventiva, como un método de trabajo, tiene como objetivo controlar el estado de conservación de la obra de arte antes de que el deterioro se produzca. En la actualidad, las medidas de conservación preventiva son reconocidas como importantes para salvaguardar el patrimonio cultural (PC, de aquí en adelante), tanto en términos de preservación del PC, como de reducción de costes de las futuras medidas de conservación (3).

En el caso de pinturas murales, el proceso de deterioro se determina por factores tales como las características petrográficas y químicas de los materiales, la presencia de sales minerales y sustancias orgánicas en las superficies, la contaminación del aire, luz solar, temperatura, contenido de agua de la superficie, etc. (4). Por lo tanto, la conservación preventiva requiere el conocimiento de una serie de parámetros relacionados con un sitio específico del PC, incluyendo las condiciones microclimáticas (5), los estudios mineralógicos, la caracterización de la textura, petrofísica y la durabilidad de los morteros. En nuestro caso, al igual que lo documentado en la bibliografía sobre piedra al aire libre ya que resulta difícil encontrar frescos en estas condiciones (6), otros factores biológicos tales como cianobacterias, líquenes, etc. resultaron insignificantes frente a los factores anteriormente mencionados.

El estudio de las técnicas pictóricas utilizadas en el pasado es esencial para la restauración y la conservación preventiva de la obra. Estos estudios son necesarios para comprender los materiales originales y añadidos, presentes tanto en la superficie como dentro de la estratigrafía de la pintura (7-10). Además, los resultados analíticos pueden mejorar el conocimiento general del conservador sobre los 2nd century BC or at the beginning of 1 st BC. The floor of the rest of the room is formed by a different, more modern, paving from the 1st century $A D$. The mosaic is covered with a box composed by five glass sheets of three millimeter.

Between 2004 and 2008, a multidisciplinary team led by the Archaeological Research Section of the City of Valencia, in collaboration with a number of researchers linked to different scientific institutions, carried out 18 surveys from one extreme to another of Ariadne's House finding archeological remains from all of the periods of the house (1).

The main problems affecting Ariadne's house are biological colonization (superior plants and animals) and water problems caused by rains due to the long absence of a roof.

During the last decades, an increasing interest in all areas of conservation with an multidisciplinary approach has been developed. Preventive conservation, as a method of work, aims to control the state of conservation of the artwork before the deterioration occurs. Currently, preventive conservation measures are acknowledged as important for safeguarding cultural heritage ( $\mathrm{CH}$, from here on), both in terms of preserving $\mathrm{CH}$ and also reducing the cost of future conservation measures (3).

In the case of wall paintings, the deterioration process is determined by factors such as petrographical and chemical characteristics of the materials, presence of mineral salts and organic substances on the surfaces, air pollution, sunlight, temperature, water content of the surface, etc. (4). Hence, preventive conservation requires knowledge of a set of parameters connected to a specific $\mathrm{CH}$ site, including microclimatic conditions (5), mineralogical, textural, petrophysical, and durability characterization studies of mortars. In our case, as documented in the literature on outdoor stone because it is difficult to find frescoes in these conditions (6), other biological factors such as cyanobacteria, lichen, etc., are negligible in front of the above mentioned factors.

The study of the techniques originally used is essential for conservation and restoration, is required in order to understand the original and added materials present both on the surface and within the painting's stratigraphy (7-10). In addition, analytical results can improve a conservator's overall awareness of deterioration processes and mechanisms that influence the condition of wall paintings in 
procesos de deterioro y los mecanismos que influyen en el estado de conservación de las pinturas murales $(11,12)$, datos necesarios para una futura restauración $(13,14)$.

Se sabe que las pinturas murales exteriores se ven especialmente afectadas por los cambios de temperatura y humedad, fenómenos asociados con el deterioro causado por las sales solubles, por la actividad microbiológica, o por daños debidos a actos de vandalismo, iconoclasia, así como el turismo (11). En muchos casos, los nuevos morteros, bien debido a su contenido en sales solubles, su mayor resistencia mecánica o sus diferentes propiedades físicas, han tenido un efecto negativo en la conservación del PC (15). Por lo tanto, son necesarios diferentes estudios antes de comenzar una restauración con el fin de conocer qué tipo de fenómenos están afectando a la obra de arte.

El objetivo global de este trabajo es documentar las condiciones de la conservación y las causas de deterioro de las pinturas murales de la casa de Ariadna para ejecutar una futura restauración intentando prolongar su conservación lo máximo posible. Para ello, se desarrollan estudios multidisciplinares previos a la intervención, incluyendo estudios ambientales, mediciones de radiación electromagnética, estudio de materiales empleados en la ejecución de las pinturas y en restauraciones recientes que podrían generar la aparición de sales, así como un estudio fotográfico.

Específicamente, el objetivo de las técnicas de análisis de materiales será doble, por un lado la caracterización de las pinturas murales para poder proceder a la comparación con la extensa bibliografía ya existente sobre el tema (7, 16-23) y por otro la diferenciación entre los materiales originales de la obra y los añadidos en sucesivas intervenciones de conservación, pudiendo estudiar los fenómenos de degradación de los materiales originales de las pinturas murales, y las interacciones con los modernos, como en el caso de las problemáticas causadas por las cristalizaciones de sales $(24,25)$.

\section{MATERIALES Y MÉTODOS}

\subsection{Estudio microclimático}

La instalación de sensores de temperatura y humedad relativa permite un seguimiento completo, preciso y fiable de las condiciones ambientales, así como la predicción de los mecanismos físico-químicos de degradación, y el estudio de los procedimientos más adecuados para el control de estos (26). general $(11,12)$, providing necessary data for a future restoration $(13,14)$.

It is known that external wall paintings are especially affected by changes in temperature and humidity, deteriorating phenomena associated with soluble salts, microbiological activity, or damage due to vandalism, iconoclasm and tourism (11). In many cases new mortars, whether due to their soluble salt content, their greater mechanical resistance or their different physical properties, had a negative effect on the conservation of $\mathrm{CH}$ (15). Therefore, different studies are needed before a restoration begins in order to know which kinds of phenomena are affecting the artwork.

The objective of this paper is to document the conservation conditions and the causes of deterioration of the wall paintings of Ariadne's house to develop a future restoration trying to prolong its conservation as much as possible. Multidisciplinary studies were developed prior to intervention, including environmental studies, measurements of electromagnetic radiation, study of materials used in the execution of the paintings and in recent restorations that could generate the appearance of salts, as well as a photographic study.

Specifically, the goal of materials analysis techniques will be twofold, on one hand the characterization of the wall paintings in order to proceed to the comparison with the extensive existing literature on the subject (7, 16-23), on the other hand the differentiation between the original materials of the work and added ones in successive conservation interventions, studying the phenomena of degradation of the original materials of the wall paintings, and interactions with the new ones, as in the case of the problems caused by the crystallization of salts $(24,25)$.

\section{MATERIALS AND METHODS}

\subsection{Environmental study}

The application of temperature and $\mathrm{RH}$ sensors permits for a full, accurate and secure monitoring of the environmental conditions and allows for the prediction of physicalchemical mechanisms of degradation, as well as of the most suitable procedures for controlling them (26). 
Con el fin de realizar un estudio ambiental, fueron colocadas 26 sondas, conteniendo, cada una de ellas, un sensor de temperatura y uno de humedad relativa (HR). Una de estas sondas fue colocada en una de las paredes exteriores de la casa para servir como parámetro de control.

Los sensores fueron desarrollados por Maxim Integrated Products, Inc. (Sunnyvale, CA, EE.UU.). Los datos de HR fueron registrados por un DS1923 con una exactitud de $\pm 5 \%$ de humedad relativa y los de temperatura por un DS1922L con una precisión de $\pm 0,5^{\circ} \mathrm{C}$. Los sensores de HR fueron calibrados antes de su instalación como se describe en (27).

Se llevaron a cabo dos estudios ambientales. El primero se elaboró entre 2008 y 2009 (de 23/07/2008 a 30/07/2009) $\mathrm{y}$, dado que el periodo más conflictivo resultó ser el verano, el segundo estudio se realizó únicamente para el verano de 2010 (de 15/7/2010 al 16/10/2010), permitiendo evaluar las consecuencias del cambio realizado en las cubiertas. Los datos fueron tomados cada media hora.

Por otro lado, los estudios microclimáticos fueron combinados con la termografía infrarroja con el fin de completar los resultados obtenidos. La termografía infrarroja es una técnica que nos permite, a cierta distancia y sin contacto directo, medir y mostrar con un sensor infrarrojo la radiación infrarroja emitida por un objeto (28). La cámara utilizada fue una NEC Corporation (Tokio, Japón) TH9260 con una matriz de $640 \times 480$ pixels infrarrojos, una resolución de $0,06{ }^{\circ} \mathrm{C}$ y una gama espectral de 8 a $14 \mu \mathrm{m}$.

\subsection{Mediciones de radiación electromagnética}

Las mediciones de radiación electromagnética son particularmente útiles para el control de monumentos arqueológicos (29). Los espectrómetros CCD permiten la investigación in situ sobre las obras y la medición de los agentes nocivos relacionados con longitudes de onda de radiación electromagnética $(29,30)$.

En este trabajo, las mediciones se llevaron a cabo por un espectrofotómetro portátil. La reflectividad relativa fue calibrada para Blanco Munsell 9. Una fuente de luz de xenón computerizado que emite en el rango de 200 a 1.100 nm (atribuible al Instituto Nacional de EE.UU. de Estándares y Tecnología, NIST) fue utilizada para iluminar los puntos objetivo. Se empleó un espectrómetro avanzado con CCD de rejilla que consiste en un detector SONY ILX511 con 2048 píxeles, empleado para medir reflectividad normal $\left(90^{\circ}\right)$ en el intervalo desde 220 hasta $850 \mathrm{~nm}$. Las señales fueron recogidas por 1.860 píxeles de los 2.040 puntos de la matriz lineal, con $0,37 \mathrm{~nm}$ de resolución media y corrección de la luz difusa. Todos los componentes del equipo de trabajo se encontraban de acuerdo a las especificaciones cuando fueron analizados en el Laboratorio de Ciencia
In order to perform an environmental study, 26 probes were placed, each one containing a temperature and a relative humidity $(\mathrm{RH})$ sensor. One of these probes was placed outside of the house serving as a control.

Each sensor was developed by Maxim Integrated Products, Inc. (Sunnyvale, CA, USA). RH were recorded by a $D S 1923$ with an accuracy of $\pm 5 \% R H$, and temperature by a DS1922L with an accuracy of $\pm 0.5^{\circ} \mathrm{C}$. $\mathrm{RH}$ sensors were calibrated prior to their installation as described in (27).

Two environmental studies were performed. The first one was performed between 2008 and 2009 (from 7/23/2008 to $7 / 30 / 2009$ ) and since the most conflicting data appeared in summer, the second study was conducted within the summer of 2010 (from 7/15/2010 to 10/16/2010), to evaluate the consequences of the rooftop change performed. The data are taken every half an hour.

On the other hand, microclimatic studies have been combined with infrared thermography in order to complete the results obtained. Infrared thermography is a technique that allows us, at certain distance and without direct contact, to measure and display with an infrared sensor the infrared radiation emitted by an object (28). The camera used is a NEC Corporation (Tokyo, Japan) TH9260 with an infrared matrix of $640 \times 480$ pixels, a resolution of $0.06{ }^{\circ} \mathrm{C}$ and a spectral range from 8 to $14 \mu \mathrm{m}$.

\subsection{Electromagnetic radiation measurements}

Electromagnetic radiation measurements are particularly useful for the control of archeological monuments (29). CCD spectrometers allow in situ investigation on artworks and the measurement of harmful agents related to electromagnetic radiation wavelengths $(29,30)$.

In this work, the measurements were carried out by a portable spectrophotometer. Relative reflectivity calibrated to Munsell's White 9. A computerized xenon light source that emits in the 200 to $1100 \mathrm{~nm}$ range (traceable to the U.S. National Institute of Standards and Technology, NIST) was used to illuminate the target points. An advanced CCD grating spectrometer consisting of a SONY ILX511 detector with 2048 pixels was used to measure normal $\left(90^{\circ}\right)$ reflectivity in the 220 to $850 \mathrm{~nm}$ range. The signals were collected by 1860 pixels of the 2040 linear array, with $0.37 \mathrm{~nm}$ mean resolution and stray light correction. All the components of the equipment worked according to specifications when tested in the Plant Science Laboratory of NASA Ames Research Center in California, using a calibrating light source "seasoned" at the NIST. Throughout 
de Plantas del Centro de Investigación Ames de la NASA en California, utilizando una fuente de luz calibrada en el NIST. Durante toda la investigación se utilizó un dispositivo portátil de calibración para verificar la calibración de longitud de onda. No fueron necesarios nuevos ajustes.

\subsection{Estudio de materiales}

Las observaciones y el análisis estratigráfico de muestras de pinturas murales de Pompeya se realizaron mediante microscopía óptica y microscopía electrónica de barrido. El microscopio óptico utilizado es el modelo ECLIPSE 80i de Nikon Corporation que lleva acoplada una cámara DSFi1. Las muestras se observaron en modo de luz reflejada con aumentos desde 5x a 50x. La microscopía electrónica de barrido con microanálisis (SEM-EDX) se realizó con un microscopio electrónico de barrido de presión variable modelo S-3400N de Hitachi Ltd. (VP-SEM), equipado con un espectrómetro de rayos $X$ de energía dispersiva (EDX) de Bruker Corporation XFlash $®$ con detector de Silicon drift droplet (SD3), con una ventana de Dura-Berilio ultrafina $(8 \mu \mathrm{m})$ para elementos ligeros, y una resolución energética de 125 eV. Las condiciones de trabajo han sido: tensión de aceleración $20 \mathrm{kV}$, tiempo de medición comprendido entre 30 y $100 \mathrm{~s}$, distancia de trabajo de $10 \mathrm{~mm}$. Se tomaron 50 pequeñas muestras de diferentes materiales de los morteros y de las capas pictóricas de las pinturas, que fueron incluidos en resina de poliéster de dos componentes (Presi, MECAPREX SS) y preparadas en sección transversal. Esta preparación permite la observación y el análisis químico elemental de la secuencia estratigráfica de cada muestra y la observación de la apariencia, textura, tamaño de grano, grosor y color de cada capa $(31,32)$.

La identificación de diferentes fases cristalinas se realizó mediante difracción de rayos- $X$ utilizando el método de polvo. Los datos XRD se obtuvieron con un difractómetro de Bruker Corporación D4 Endeavor AXS, con radiación $\mathrm{Cu} \mathrm{Ka} 1$. Las medidas se tomaron con $40 \mathrm{kV}$ y $20 \mathrm{~mA}$, en un rango de $15-70$ a $(2 \theta)$, un paso de $0,05^{\circ}$ y un tiempo de $1,5 \mathrm{~s}$.

Para la analítica de morteros se empleó un espectrómetro de infrarrojos con transformada de Fourier (FTIR) de Bruker Corporación Vertex 70, con un intervalo $4.000-400 \mathrm{~cm}^{-1}$ y una resolución de $4 \mathrm{~cm}^{-1}$. Las muestras se prepararon en pastillas (diámetro $13 \mathrm{~mm}$ ), por presión al vacío con bromuro de potasio seco $(1 \mathrm{mg} / 100 \mathrm{mg}$ de $\mathrm{KBr}$ ) a una presión de 10 toneladas durante 4 minutos.

\subsection{Fotografía}

El tratamiento digital de imágenes ha sido ampliamente utilizado en muchos campos diferentes, como por ejemplo, astrofísica, investigación médica, geográfica y militar. En los últimos años, el tratamiento digital de imágenes se the investigation a portable calibrating device was used to verify the wavelength calibration. No new adjustments were needed.

\subsection{Study of materials}

The observations and stratigraphic analysis of samples of wall paintings from Pompeii have been performed with optical microscopy and scanning electron microscopy. The optical microscope is from NIKON Corporation (Tokyo, Japan) ECLIPSE 80i with a DS-Fi1 camera. Samples have been observed in reflected light at magnifications ranging from $5 x$ to 50x. The scanning electron microscopy with microanalysis (SEM-EDX) was performed with a scanning electron microscope of variable pressure from Hitachi LTD (VP-SEM) S-3400N, equipped with energy dispersive X-ray

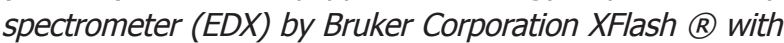
Silicon Drift Droplet detector (SD3), supra light element window/8 $\mu \mathrm{m}$ Dura-Beryllium window, and an energetic resolution of $125 \mathrm{eV}$. With working conditions: accelerating voltage $20 \mathrm{kV}$, measuring time between 30 and $100 \mathrm{~s}$, working distance $10 \mathrm{~mm}$. This research has been performed taking small samples of different materials from the mortars and pictorial layers of frescoes, which have been included in a bi-component polyester resin of self-curing (Presi, MECAPREX SS) and prepared in cross section. This preparation allows for observations and elemental chemi$\mathrm{cal}$ analysis of the stratigraphic sequence of each sample and the observations of appearance, texture, grain size, thickness and color observations of each layer $(31,32)$.

The identification of different crystalline phases has been performed by X-ray diffraction by the method of crystalline powder method. XRD data were obtained with a Bruker Corporation (MA, USA) D4 Endeavor AXS diffractometer, with $\mathrm{Cu}$ Ka1 radiation. The measures were taken with 40 $\mathrm{kV}$ and $20 \mathrm{~mA}$, in a range of 15-70th (20), a step of $0.05^{\circ}$ and a collection time of $1.5 \mathrm{~s}$.

For the analytical of mortars a Fourier transform infrared spectrometer (FTIR) from Bruker Corporation Vertex 70, in the range $4000-400 \mathrm{~cm}-1$ with a resolution of $4 \mathrm{~cm}-1$ was used. Sample tablets were prepared (diameter $13 \mathrm{~mm}$ ), pressed by dry potassium bromide $(1 \mathrm{mg} / 100 \mathrm{mg} \mathrm{KBr}$ ) at a pressure of 10 tons for 4 minutes in vacuum.

\subsection{Photography}

The digital treatment of images has been widely used in many different fields, as for instance, astrophysical, medical, geographical and military research. In the last years, digital elaboration of the images has also been used in the 
ha utilizado también en el campo de la conservación del PC (33). De hecho, la fotografía profesional, especializada en arte y restauración, ofrece una nueva visión para la documentación fotográfica científica (34).

Se utilizó una cámara digital Hasselblad EE.UU. Inc. con un CCD de 55 x $41 \mathrm{~cm}$ y 6.496 x 4.872 píxeles. Las fotos fueron tomadas con una velocidad de obturación de 1/125 y diafragmas $\mathrm{f} 16$ o f11. El número de imágenes tomadas fue superior a 700 .

Como la luz solar que ilumina las pinturas es insuficiente y ofrece resultados de muy baja calidad, en este estudio se utilizó un flash Bron Elektronik AG Verso Broncolor de tamaño A4 con una pantalla difusora y totalmente protegidos de la radiación UV.

El flash se colocó aproximadamente a dos metros de distancia del objeto y a un ángulo de incidencia de 45 grados.

Se tomaron fotografías de falso color IR con una cámara de Sony Corporation, modelo DSC-F828 que cuenta con un CCD Super HAD. Esta cámara es capaz de eliminar el filtro visible (filtro de corte IR).

Para obtener una fotografía infrarroja de falso color se empleó la técnica descrita por Moon et al (35) con una modificación. El canal azul fue sustituido por el nuevo canal de la fotografía de infrarrojos. Esta técnica es ampliamente utilizada (36).

\section{RESULTADOS Y DISCUSIÓN}

Mediante la combinación de diferentes enfoques metodológicos (estudios de las condiciones ambientales, estudio de los materiales, fotografía, etc.), fue posible determinar los principales problemas de conservación que afectan a la casa de Ariadna para una futura decisión de las técnicas más convenientes a emplear en su restauración (37).

\subsection{Estudio ambiental}

La ciudad romana de Pompeya presenta un clima extremo (Figura 2), con grandes fluctuaciones entre la noche y el día, estas fueron, en verano de 2008 en promedio de un $15 \%$ para HR y de $6,5^{\circ} \mathrm{C}$ para la temperatura.

Las fluctuaciones bruscas resultan perjudiciales para la conservación de los frescos, ya que estos cambios producen su deterioro (38). Al tratarse de un lugar arqueológico al aire libre, el clima exterior condiciona el clima de las salas, por ello las actuaciones técnicas deben tratar de amortiguar estas variaciones, suavizar los máximos y los mínimos, creando un ambiente lo más uniforme posible. field of $\mathrm{CH}$ conservation (33). In fact, professional photography, specialized in art and restoration, gives a new vision for scientific photographical documentation (34).

A digital camera Hasselblad USA Inc. (WA, USA) whith a $55 \times 41 \mathrm{~cm} C C D$ of $6496 \times 4872$ pixels was used. The shots were taken with a shutter speed of $1 / 125$ and f16 or f11 aperture. The number of taken images taken exceeds 700.

As the solar light falling on the paintings is inadequate and provides very low quality results, in this study we used a Bron Elektronik AG (Allschwil, Switzerland) Broncolor Verso $A 4$ with a diffusing screen and fully protected from UV radiation.

The flashes were placed approximately two meters away from the object at an incident angle of 45 degrees.

False-color IR photographs were taken by a SONY Corporation (Tokyo, Japan) camera, model DSC-F828 equipped with a Super HAD CCD. This camera is capable of removing the visible filter (IR-cut filter).

To obtain a false-color infrared photography a modified (35) technique has been used. The blue channel was substituted by a new channel from IR photography. This technique is widely used (36).

\section{RESULTS AND DISCUSSION}

By combining different methodological approaches (studies of environmental conditions, study of materials, photography, etc.) it was possible to determine the main problems affecting Ariadne's house for preventive conservation and for a future decision of the most convenient techniques of restoration to be used (37).

\subsection{Environmental study}

The roman city of Pompeii presents an extreme weather (Figure 2), with big fluctuations between night and day, in summer 2008 an average of for $\mathrm{RH}$ and $6.5^{\circ} \mathrm{C}$ for temperature.

Abrupt weather fluctuations are detrimental to conservation since extreme changes produce deterioration (38). As an open-air archaeological site, the outdoor climate determines the climate of the rooms, thus, the technical actions should aim to cushion these jumps, smoothing the maximums and minimums for a uniform environment whenever possible. 


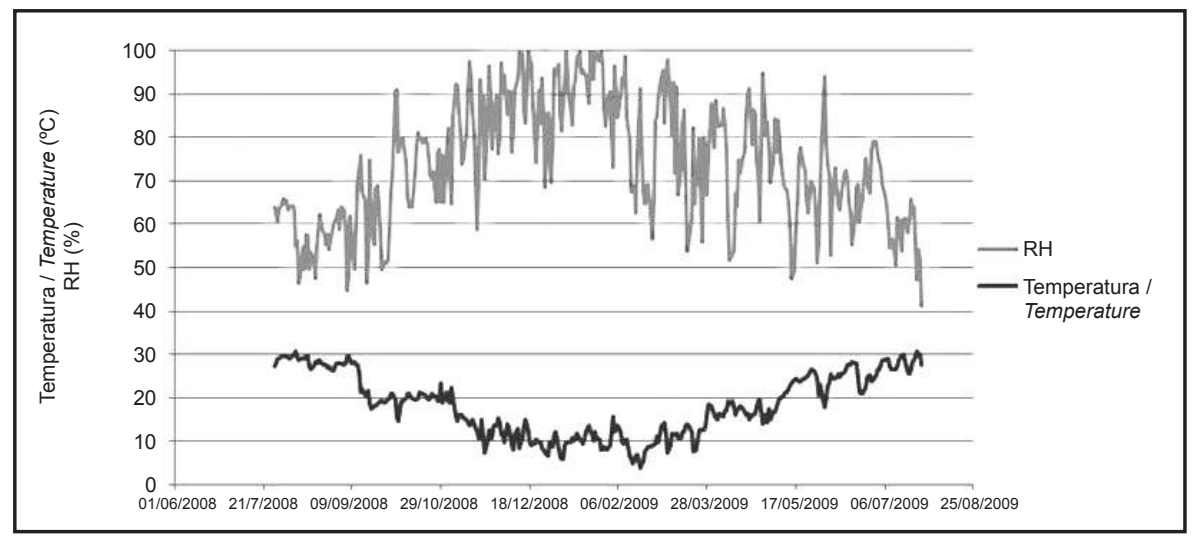

Figura 2. Valores medios diarios de temperatura y humedad relativa exterior de la casa de Ariadna del 23/07/2008 al 30/07/2009. Figure 2. Ariadne's house daily values of outdoor temperature and RH from 07/23/2008 to 07/30/2009.

El análisis exploratorio realizado en el período 2008-2009 detectó diferentes microclimas en las salas, en función de las cubiertas y techos utilizados. A saber (Figura 3-a) un microclima para el techo de teja (sala 4, Figura 1), otro para las cubiertas de policarbonato (salas 1, 2 y 3, Figura 1) y otro para la cubierta de cristal (mosaico). La cubierta opaca (teja, sala 4) configuraba un microclima más adecuado en verano, con mayor atenuación de los cambios climáticos exteriores, tanto en temperatura como en HR. Efecto similar durante el invierno pero de menor intensidad.
Exploratory analysis performed in 2008-2009 showed that different microclimates occurred in the rooms depending on the covers and roofs used. A microclimate for the tile roof (room 4, Figure 1), another for the polycarbonate covers (rooms 1, 2 and 3, Figure 1) and yet another for the glass cover (mosaic) were detected (Figure 3-a). The opaque cover (room 4) configured a suitable microclimate in summer, dimming the exterior climate changes, both in temperature as in $\mathrm{RH}$. During winter it had a similar effect, but of less intensity.

A)

- - Exterior / Outdoor —Habitación / Room 4 …... Mosaico/Mosaic —Habitación / Room 1, 2, 3
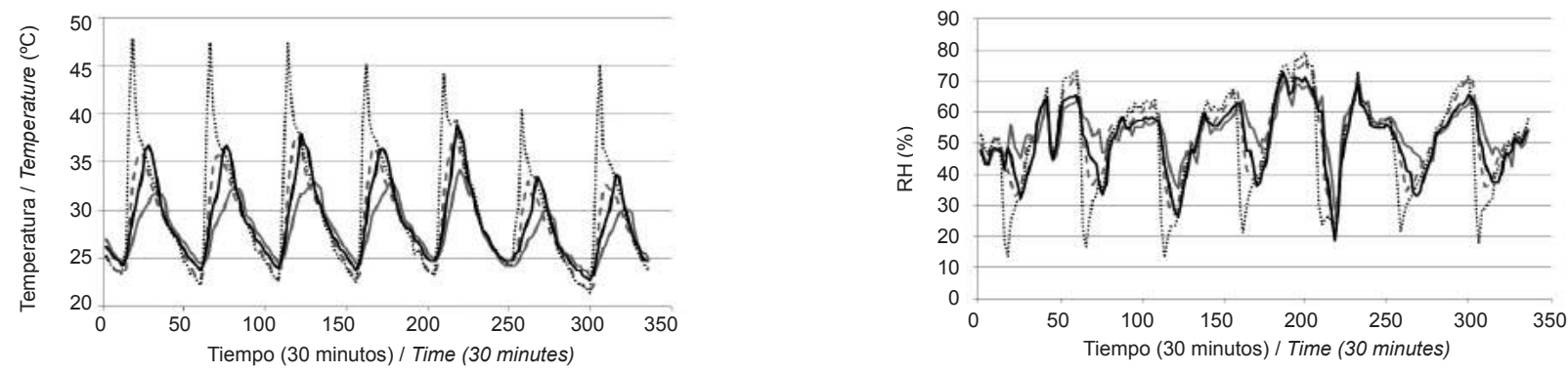

B)
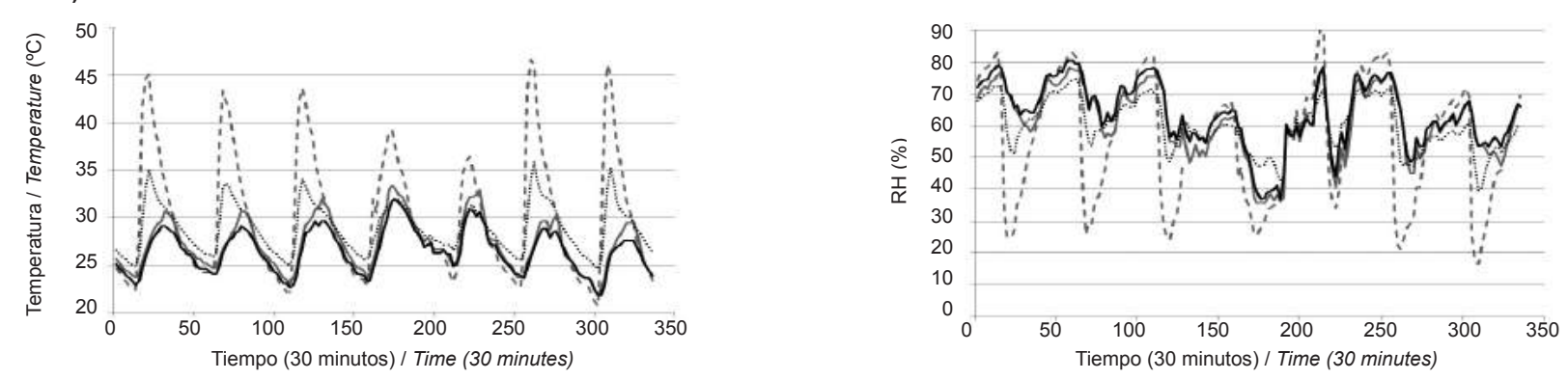

Figura 3. Comparación de los valores de temperatura $\left({ }^{\circ} \mathrm{C}\right)$ y humedad relativa (\%) de una semana de verano en a) 2008 y b) 2010 para los distintos microclimas de la casa de Ariadna. El tiempo 0 corresponde al 11 de agosto de 2008, 00:00 horas. Datos cada media hora.

Figure 3. Comparison of values of temperature $\left({ }^{\circ} \mathrm{C}\right)$ and $\mathrm{RH}(\%)$ of a summer week in a) 2008 and b) 2010, for the different microclimates of Ariadne's house. Time 0 corresponds to August 11th 2008, 00:00 hours. Data every half hour. 
Sin embargo, las cubiertas transparentes de policarbonato (salas 1, 2 y 3, Figura 1) ocasionaban un efecto invernadero en verano, con valores similares para los parámetros meteorológicos a los del microclima exterior (Figura 3-a).

Finalmente, la cubierta de cristal del mosaico de los peces proporcionaba el microclima más perjudicial de todos debido a las grandes variaciones de temperatura y HR (Figura 3). Se aconseja no poner esta cubierta al mosaico, puesto que ya está protegido de la lluvia por el techo de la habitación.

A partir de los resultados anteriormente descritos, se tomaron decisiones con el fin de paliar los efectos de este tipo de cubiertas. Así, se cambiaron los tejados en las salas 1,2 y 3 donde existían cubiertas transparentes.

Las condiciones ambientales que más se alejan de las recomendadas en la norma UNI 10829 (39) para la conservación de los frescos tienen lugar durante el verano, con cambios más bruscos día/noche tanto en temperatura como en HR. Con el fin de evaluar los efectos del cambio de cubierta, se realizó un segundo estudio microclimático únicamente para los meses de verano del 2010. Los resultados obtenidos en el análisis exploratorio muestran cómo la temperatura y HR han sufrido una variación positiva del verano de 2008 al verano de 2010 como consecuencia del cambio de tejados. En 2010 el promedio de la temperatura en las salas disminuyó con respecto a la exterior, debido a la disminución de los máximos (Figura 3-a). Además en 2010, la HR aumentó en promedio con respecto a la exterior, debido al aumento de los mínimos. La temperatura y la HR redujeron su variabilidad y se suavizaron los cambios diarios extremos. Asimismo, en 2010 las principales diferencias entre los microclimas obtenidos en 2008 para HR y temperatura desaparecieron (Figura 3).

De otro lado, el uso de una técnica complementaria, la termografía, permitió evaluar el cambio de microclima producido por los nuevos tejados. Los resultados han demostrado que el cambio de los tejados ha generado una modificación sustancial en el gradiente y los valores de temperatura en las habitaciones (Figura 4), al igual que se ha mostrado en el estudio microclimático. La termografía posee una ventaja sobre los data-loggers ya que permite evaluar zonas de menor temperatura debido a que se produce evaporación de agua o la existencia de cavidades o levantamientos.

Resumiendo, el estudio ambiental ha permitido reconocer las perjudiciales condiciones climáticas en las salas de la casa de Ariadna y proporcionar la solución más adecuada (cambio de tejados). Asimismo, la termografía (Figura 4), ha cuantificado la diferencia en el gradiente de temperatura en el verano de 2008 es de 22 grados centígrados, mientras que en 2010 este se reduce hasta aproximadamente solo
However, the transparent polycarbonate cover (rooms 1, 2 and 3, Figure 1) produced a greenhouse effect, with similar weather parameter values to the outdoor microclimate (Figure 3-a).

Finally, the glass coverage of the fish mosaic provides the most damaging conditions of all micro-climates due to large variations in temperature and $\mathrm{RH}$ (Figure 3). It is advised not to put this covering on the mosaic since it is protected from rain by the roof of the room.

After having these results, decisions for solutions were taken in order to palliate the effects of this kind of covers. Thus, a rooftop change was performed in rooms 1, 2 and 3 where transparent covers were installed.

Environmental conditions further away from those recommended in the standard UNI 10829 (39) for the conservation of frescoes appeared in summer, when abrupt day/night temperature shifts as well as in $\mathrm{RH}$ appeared. Thus, in order to evaluate the effects of the roof change, a second microclimate study was performed only for the summer months in 2010. The obtained results from exploratory analysis show how temperatures and $\mathrm{RH}$ have suffered a positive variation from summer 2008 to summer 2010 as a consequence of the rooftop change performed. In 2010 the average temperature in the room decreased with respect to the outside, due to the decrease of the maximum temperature (Figure 3-a). Also in 2010, the $\mathrm{RH}$ increased on average with respect to the exterior, due to the increase of the minimum. Temperature and $\mathrm{RH}$ have stabilized, reducing its variability and smoothing those extreme daily changes. On the other hand, in 2010 the main differences between microclimates obtained in 2008 for RH and temperature have disappeared (Figure 3).

On the other hand, the use of a complementary technique, thermography, allowed us to assess the changes obtained with the new roofs. The results have shown that changing the rooftops has generated a substantial modification in the temperature gradient and values of the rooms (Figure 4), as well as the microclimatic study showed. Thermography has an advantage over the data-loggers since it allowed evaluating areas with lower temperature due to evaporation of water or problems such as cavities or uprisings.

Summarizing, the environmental study has allowed us to acknowledge the detrimental microclimatic conditions in Ariadne's house rooms, providing an adequate solution (change of roofs). Also it has been possible to evaluate the positive consequences of changing the rooftops (Figure 4). We can see that the difference in temperature gradient in summer 2008 is 22 degrees Celsius, while 


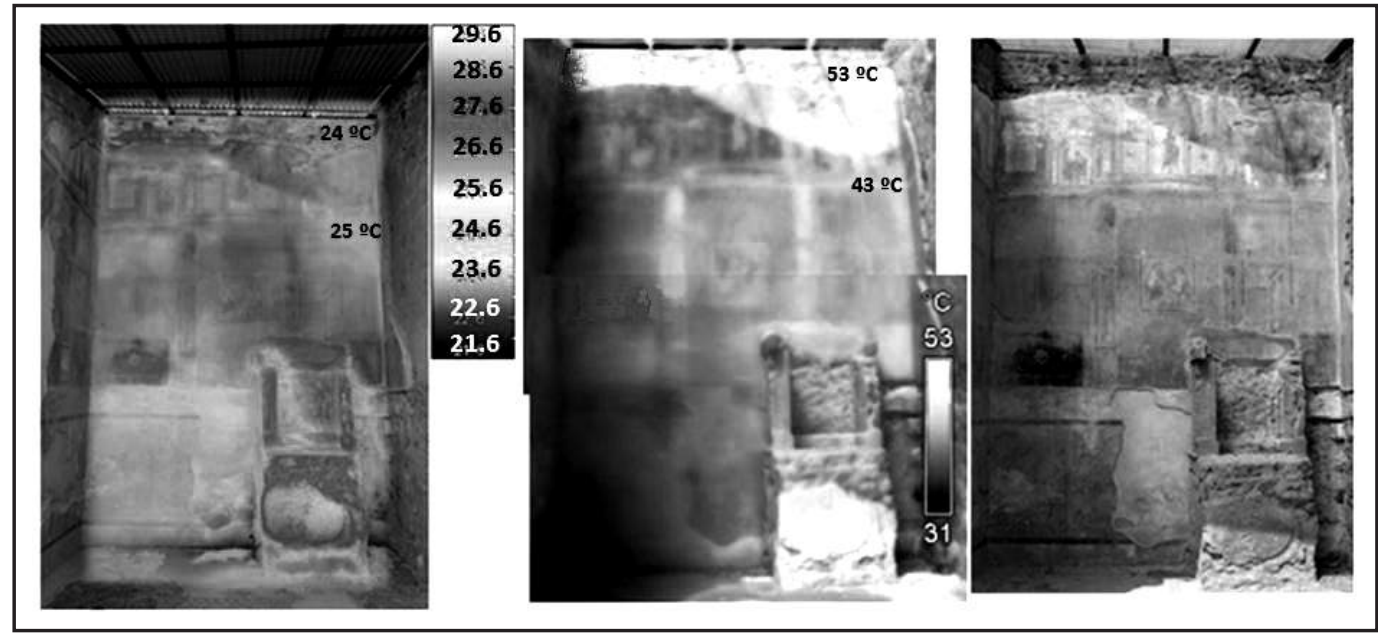

Figura 4. Sala 1, de izquierda a derecha: en 2010 termografía, en 2008 termografía, imagen real de 2008. Estas figuras muestran el cambio de tejado realizado y el consecuente beneficio.

Figure 4. Room 1, from left to right: 2010 thermography, 2008 thermography, 2008 real image (room 1). These Figs. show the roof change performed and its subsequent benefits on temperature.

7 grados centígrados en un día a la misma hora con temperaturas e insolación similares.

Téngase en cuenta, que si no se hubiese realizado este cambio de cubierta, una futura restauración habría sido inútil y fugaz.

\subsection{Mediciones de radiación electromagnética}

Los murales en la casa de Ariadna en Pompeya están expuestos diariamente a la luz del sol. Teniendo en cuenta los posibles daños de esta radiación electromagnética sobre las pinturas, sobre todo ultravioletas, se han realizado mediciones de la radiación solar y de los filtros en las diferentes habitaciones de la casa.

Como se ha mencionado, los techos de policarbonato fueron instalados en las habitaciones 1-3 (Figura 1) de la casa donde los frescos cubren las paredes de arriba a abajo. Las propiedades de filtrado del policarbonato cambian con los años, perdiendo la capacidad de absorber parte de la radiación dañina y la transparencia a la luz visible (40).

Así pues se midió la eficacia de los filtros instalados y se comparó con otros que fueron considerados como posibles opciones para proteger las pinturas, como diferentes tipos de filtros de acrílico.

Se consideraron los filtros como Reflectiv (Bonneuil-surMarne, Francia) SOL 259 interior, que es una película de poliéster de 36 micras que tiene color humo, que bloquea el $95 \%$ de la radiación ultravioleta sin cancelar la luz visible con una transmisión del $11 \%$, lo que permite la in 2010 this gradient is reduced to about only 7 degrees Celsius.

Note that if a roof change had not been performed a future restoration would have been useless.

\subsection{Electromagnetic radiation measurements}

The murals in Ariadne's house in Pompeii are exposed daily to the sunlight. Considering the possible damages of this electromagnetic radiation to the paintings, particularly ultraviolet, measurements of solar radiation and of filters have been taken in the different rooms of the house.

As mentioned, polycarbonate rooftops were installed on rooms 1-3 (Figure 1) of the house where frescoes cover the walls from top to bottom. Some areas of the frescoes are exposed to direct sunlight, because the rooftops not cover completely the artworks. Furthermore, the filtering properties of the polycarbonate change over the years loosing the capacity to absorb some of the harmful radiation and transparency to the visible light (40).

The effectiveness of the installed filters was measured and they were compared with others that were considered as possible options to protect the paintings, such as different types of acrylic filters.

We considered filters such as Reflectiv (Bonneuil sur Marne, France) SOL 259 interior, which is a 36 microns polyester film that has smoke color. It blocks $95 \%$ of the Ultraviolet radiation without canceling the visible light with an $11 \%$ transmission, which allows for daylight viewing 
visualización de la luz del día con una reducción del efecto invernadero y un bloqueo de la radiación UV. Otro filtro considerado fue el UVA 109, filtro que tiene características similares y es también una película de poliéster de 36 micras, pero tiene la ventaja de que bloquea la radiación UV hasta el $99 \%$ y también es más transparente a la luz visible, permitiendo un $73 \%$ de transmisión. with a reduction of the greenhouse effect and a blockage of the UV radiation. Another filter considered was the UVA 109 filter that has similar characteristics and is also a 36 micron polyester film, but it has the advantage that it blocks UV radiation up to $99 \%$ and is also more transparent to visible light, allowing $73 \%$ transmission.

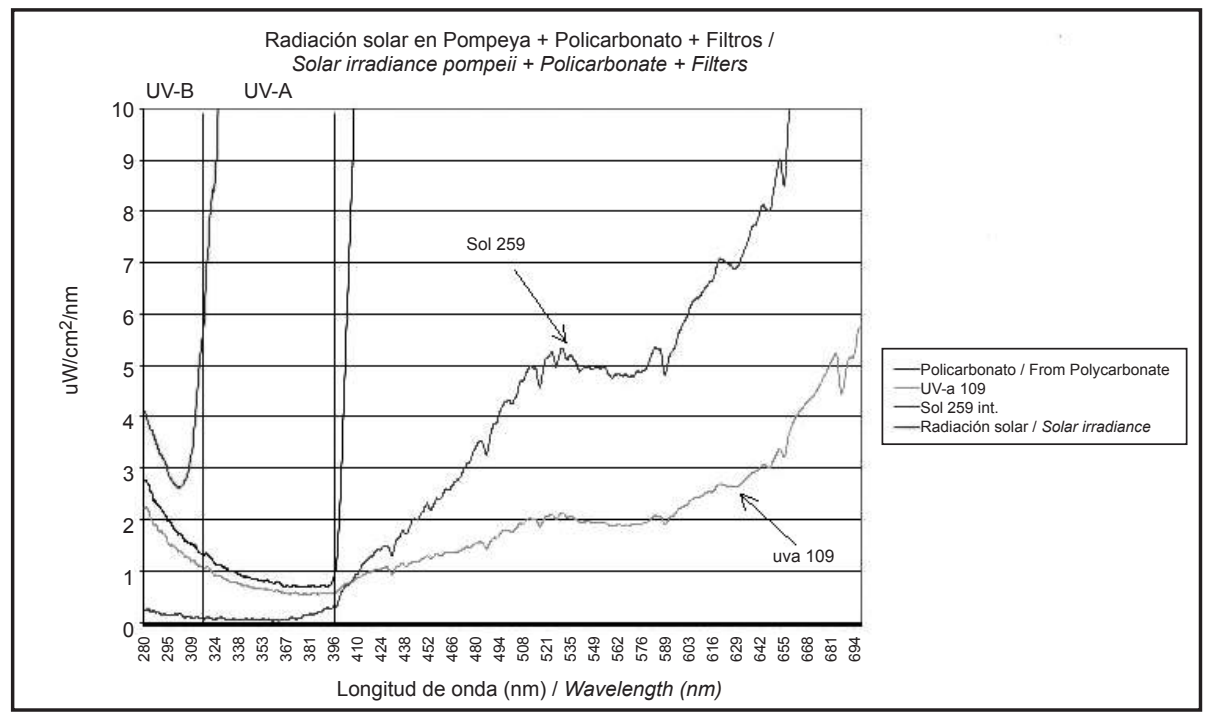

Figura 5. Comparación de la eficacia de filtros de policarbonato y poliéster (Sol 259, UVA 109) bajo la influencia de la radiación solar. Todos estos filtros son eficientes, pero Sol 259 tiene las mejores propiedades de filtrado en la banda ultravioleta $(280-400 \mathrm{~nm})$, además es el más transparente a la luz visible.

Figure 5. Comparison of the effectiveness of polycarbonate and polyester filters (Sol 259, UVA 109) under the influence of solar radiation. All these filters are efficient, but Sol 259 has the best filtering properties in the Ultraviolet band $(280-400 \mathrm{~nm})$ while it is the most transparent to the visible light.

El análisis (Figura 5) muestra que el policarbonato absorbe/refleja una gran proporción de los rayos ultravioleta, pero esto se mejora cuando se añade otro filtro. Los filtros de poliéster no bloquean suficientemente la radiación ultravioleta dañina. Si estos filtros fuesen reemplazados por un techo no transparente, como la madera o tejas, la radiación dañina que llega a las pinturas desde el techo sería cercana a cero.

A su vez, algunas áreas de los frescos están expuestas a la luz solar directa, porque las salas tienen amplias aberturas verticales al exterior. Los resultados sin filtros a las 12:30 PM en verano fueron los siguientes: $6 \mu \mathrm{W} / \mathrm{cm}^{2} / \mathrm{nm}$ de B ultravioleta a $280 \mathrm{~nm}$ y $9 \mu \mathrm{W} / \mathrm{cm}^{2} / \mathrm{nm}$ de $319 \mathrm{~nm}$. En la banda UV-A $10 \mu \mathrm{W} / \mathrm{cm}^{2} / \mathrm{nm}$ a $322 \mathrm{~nm}$ y $48 \mu \mathrm{W} / \mathrm{cm}^{2} / \mathrm{nm}$ a $390 \mathrm{~nm}$. Teniendo en cuenta que la UV debe estar lo más cercana a cero posible, estos datos muestran la necesidad de utilizar un filtro solar para preservar las pinturas.

Los datos obtenidos en este trabajo muestran una gran cantidad de radiación solar que baña los frescos de la casa de Ariadna. Por lo tanto, como conclusión de este
The analysis (Figure 5) shows that the polycarbonate absorbs/reflects a great portion of Ultraviolet, but this is further enhanced when another filter is added. Polyester filters do not block enough the harmful solar ultraviolet radiation. If these filters were replaced by a non-transparent roof, such as wood or tiles, the harmful radiation reaching the paintings from the roof would be close to zero.

In turn, some areas of the frescoes are exposed to direct sunlight, because the rooms have large outdoor vertical openings. Results without filters at 12:30 PM in summer were: $6 \mu W / \mathrm{cm}^{2} / \mathrm{nm}$ of Ultraviolet $B$ at $280 \mathrm{~nm}$ and $9 \mu W / \mathrm{cm}^{2} / \mathrm{nm}$ at $319 \mathrm{~nm}$. In the $U V-A$ band $10 \mu W / \mathrm{cm}^{2} / \mathrm{nm}$ at $322 \mathrm{~nm}$ and $48 \mu W / \mathrm{cm}^{2} / \mathrm{nm}$ at $390 \mathrm{~nm}$. Considering that the UV must be as close to cero as possible, these data showed the necessity of using a solar filter to preserve the paintings.

The data obtained in this work shows a considerable amount of solar radiation that bathes the frescoes in Ariadne's house. Therefore, as a conclusion of this 
estudio de radiación electromagnética, coincidiendo con otras técnicas aplicadas en el presente trabajo, los techos de policarbonato están afectando a la preservación de las pinturas murales.

\subsection{Estudio de materiales}

A continuación se presentan los resultados desde la capa estratigráfica más externa a la más interna.

En primer lugar, se ha encontrado una fina capa de tonalidad grisácea que recubre uniformemente casi todas las superficies policromadas. El análisis por SEM-EDX ha identificado la presencia de compuestos a base de sulfato de calcio y compuestos de silicio, aluminio y potasio, elementos generalmente presentes en el suelo de la sedimentación volcánica y en los contaminantes del medio ambiente que caracterizan la zona arqueológica de Pompeya (41).

En segundo lugar, mediante microscopía óptica, se realizó un estudio de las capas de pintura. Se determinó que el espesor de esta capa no es regular y varía de un mínimo de 10-20 micras a un máximo de 110 micras aproximadamente. En el estudio SEM-EDX de las capas de pintura (Figura 6) se detectó la presencia de calcio. Este elemento, que aparece constantemente en las muestras, está atribuido al uso de cal (carbonatación del mortero fresco o mezcla de cal con pigmentos y agua). electromagnetic radiation study in coincidence with other techniques applied in the present work, the polycarbonate roofs are affecting the wall paintings preservation.

\subsection{Study of materials}

Below the results from the stratigraphic layer outermost to the innermost are showed.

First, note that the polychrome surface is affected by the presence of a thin layer of diffuse grayish hue. The SEMEDX analysis has identified compounds based on calcium sulfate and silicon compounds, aluminum and potassium, elements usually present in the volcanic soil of sedimentation and pollutants from the environment of the archaeological site of Pompeii (41).

Secondly, by optic microscopy, a study of the layers of paint was performed. It was determined that the thickness of the paint layers is not regular, it varies from a minimum of 10-20 microns to a maximum of approximately 110 microns. In the SEM-EDX study of the paint layers (Figure 6) was also detected the presence of calcium. Elements attributed to the use of lime (carbonation of fresh mortar or mixture of water lime with pigments) that appeared constantly in the samples.

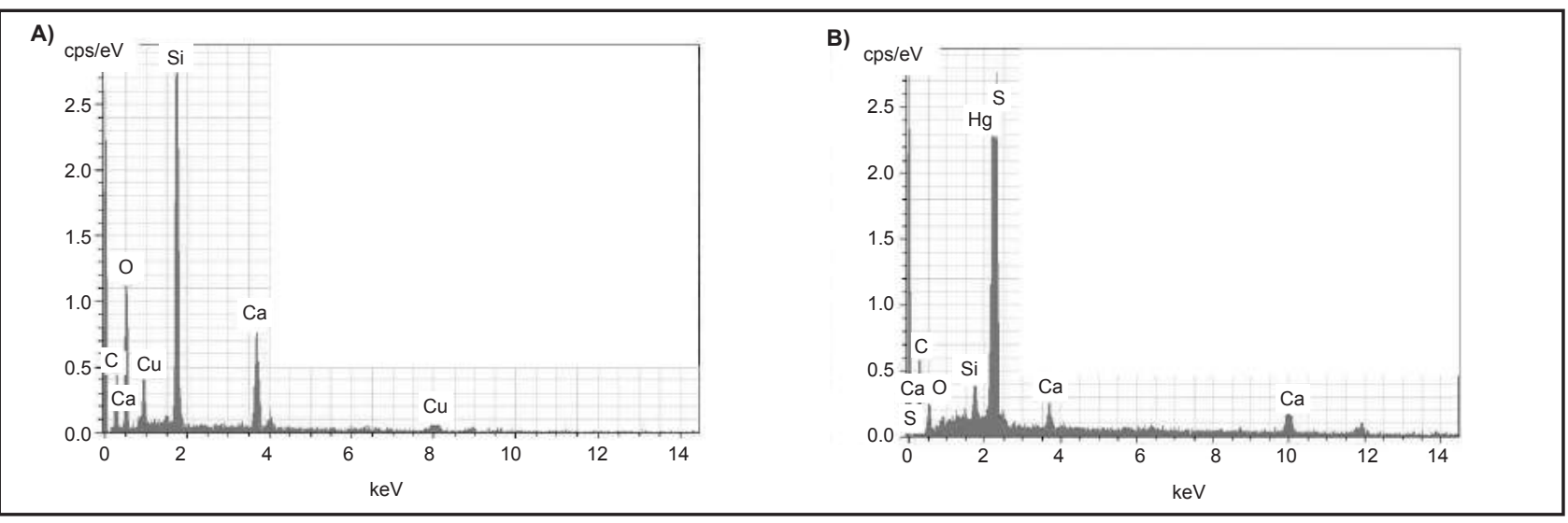

Figura 6. SEM-EDX estudio de las capas de pintura: a) Microanálisis donde se detecta la presencia de calcio, cobre y silicio, que sugieren la presencia de silicato de cobre y calcio (cuprorivaíta) (azul Egipcio o Caeruleum). b) Microanálisis donde se detecta la presencia de mercurio y azufre que sugieren la presencia de cinabrio (rojo Pompeyano o Minium).

Figure 6. SEM-EDX study of the paint layers: a) Microanalysis detecting the presence of calcium, copper and silicon, that suggest the presence of copper silicate (Blue Pompeii or Cearuleum). b) Microanalysis detecting the presence of mercury and sulfur that suggest the presence of cinnabar (Red Pompeii or minium).

Los estudios anteriormente descritos han permitido identificar las distintas capas de preparación de las pinturas, permitiendo demostrar que unas pinturas fueron ejecutadas con la técnica pictórica "al fresco" y otras con la técnica "al secco" (42). Los pigmentos identificados se muestran en la Tabla 1.
The studies described above have identified the various layers of preparation, allowing to demonstrate that some paintings were executed with the painting technique "al fresco" and others with the technique "al secco" (42). The identified pigments are shown in Table 1. 
Tabla 1 / Table 1

Pigmentos identificados en las pinturas murales de la Casa de Ariadna en Pompeya.

Pigments identified in the wall paintings of Ariadne's House in Pompeii.

\begin{tabular}{|c|c|c|}
\hline Color / Colors & Nombre antiguo / Old name & Composición / Composition \\
\hline Blanco / White & Creta calcárea / Creta calcarea & Carbonato de calcio / Calcium carbonate \\
\hline Amarillo / Yellow & Ochra & Ocre amarillo a base de hidróxido de hierro / Yellow ochre iron hydroxide base \\
\hline Rojo / Red & Rubricae & $\begin{array}{c}\text { Ocre roja a base de óxidos de hierro con Si, Al, Ca y Mg / } \\
\text { Red Ochre based on iron oxides with Si, Al, Ca and Mg } \\
\text { Cinabrio / Cinnabar }\end{array}$ \\
\hline Verde / Green & Minium & $\begin{array}{c}\text { Tierra verde a base de arcilla coloreada por silicatos de hierro / } \\
\text { Green earth from clay colored by iron silicates }\end{array}$ \\
\hline Azul / Blue & Creta viridis & $\begin{array}{c}\text { Azul Egipcio a base de silicato de cobre y calcio / } \\
\text { Egyptian blue based on copper and calcium silicate }\end{array}$ \\
\hline
\end{tabular}

En tercer lugar, los resultados de los estudios estratigráficos y de los morteros mediante las técnicas instrumentales como la microscopía óptica, la microscopia electrónica de barrido con microanálisis (SEM-EDX) y los análisis de difracción de rayos-X (DRX), muestran que las pinturas murales tienen una estratigrafía compuesta de, al menos, 3 capas de morteros de diferentes espesores (Figura 7), sobre los cuales se encuentran las capas de policromía.

La capa inferior de mortero gris (arriccio) identificado, está elaborado con un aglomerante blanco de carbonato de calcio, y un árido a base de silicatos de aluminio hidratados, sílice, óxidos de hierro, potasio, sodio y magnesio (pozzolana). Las capas sucesivas de mortero presentan color blanco (intonaco e intonachino), y están constituidos por un aglomerante de carbonato de calcio y árido formado por calcita, con cantidades menores de cuarzo, ferrocalcita, dolomita y compuestos de arcilla. El intonachino resulta ser más fino y tiene menos áridos que el intonaco.
Third, the results of stratigraphic and mortars studies using instrumental techniques such as optical microscopy, scanning electron microscopy analysis with microanalysis (SEM-EDX) and X-ray diffraction (XRD) show that the wall paintings have a stratigraphy composed of at least 3 layers of mortars of different thicknesses (Figure 7), on which lie the layers of polychromy.

The lower layer of gray mortar (arriccio) identified, is made with a white binder of calcium carbonate, and silicate-based aggregate of hydrates of aluminum, silica, iron oxide, potassium, sodium and magnesium (pozzolana). Successive layers of mortar are presented in white color (intonaco and intonachino), prepared with a calcium carbonate binder and arid formed by calcite, with minor amounts of quartz, ferrocalcita, dolomite calcite and clay compounds. Intonachino is thinner and has lower arids aggregated than intonaco.

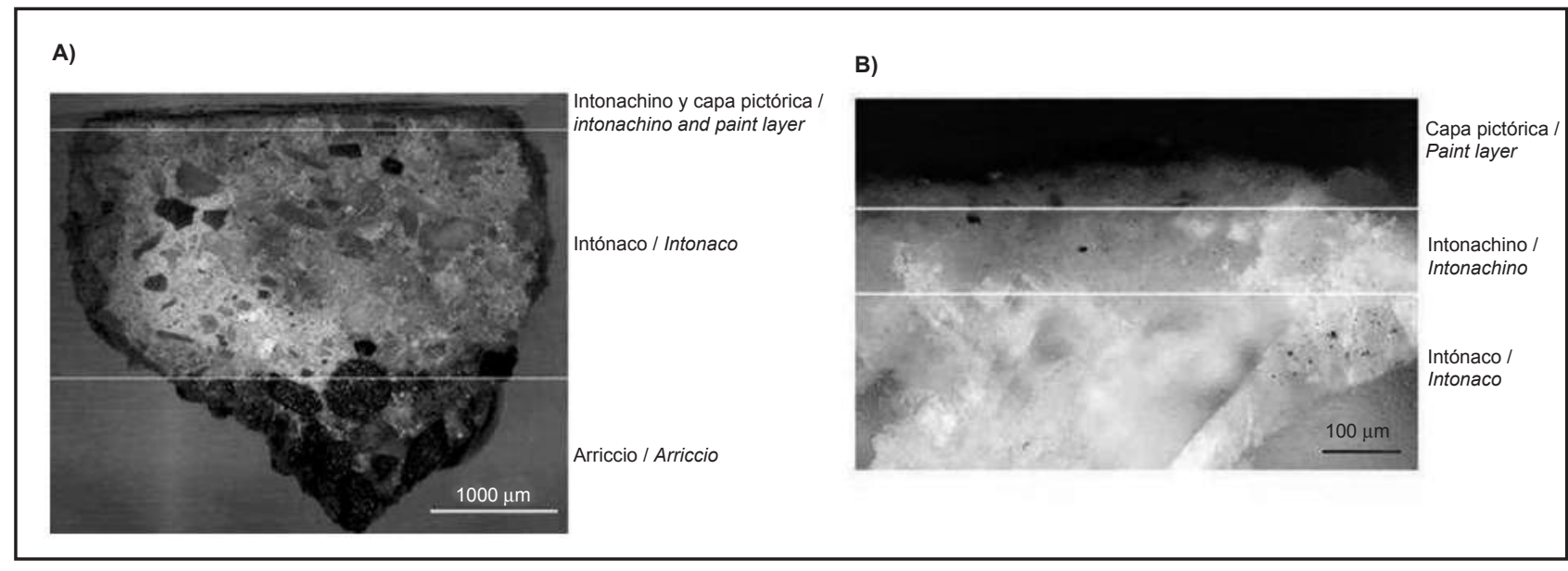

Figura 7. a) Sección transversal obtenida con microscopio estereoscópico (2x). b) Sección transversal obtenida con microscopia óptica (50x). Se observan las diferentes capas de mortero y el estrato pictórico amarillo. De arriba a abajo, capa pictórica, intonachino, intonaco y arriccio.

Figure 7. a) Cross-section obtained with optical microscopy (2x). b) Cross-section obtained with optical microscopy (50x). The different layers of mortar and the yellow paint layers are observed. From top to bottom, paint layer, intonachino, intonaco and arriccio. 
Por otro lado, las técnicas de difracción de rayos- $X$ y de espectroscopia infrarroja por transformada de Fourier (FTIR), se utilizaron para analizar muestras de morteros que se añadieron en anteriores intervenciones de restauración (43). Los resultados de estos estudios, muestran generalmente la presencia de estucados a base de morteros de cal, cal hidráulica o morteros de cementos. También se observa el uso de materiales del lugar de recuperación (material lávico, pómez, material refractario, etc.), creando estucados o materiales de rellenos de naturaleza cementicia con la presencia de áridos y otros componentes de diferente composición.

En último lugar, se detectó el fenómeno más preocupante para la conservación futura de las pinturas murales que es la cristalización de sales solubles por debajo del estrato de policromía. Este fenómeno afecta a todas las capas pictóricas y sus efectos visibles son la aparición de grandes áreas de policromía con un aspecto polvoriento (Figura 8 a) y el desprendimiento de las capas más superficiales de pintura. Mediante microscopía óptica se observó (Figura 8 b), que la cristalización se desarrollaba en el interior de la estructura del soporte, provocando, el desprendimiento de los estratos más superficiales (fenómenos de la sub-eflorescencia). Téngase en cuenta que tras poner de manifiesto la existencia de sales a la hora de una futura restauración será necesario realizar un mapeo muy completo de la zona para determinar las zonas concretas de afectación.
On the other hand, X-ray diffraction (XRD) and Fourier transform infrared spectroscopy (FTIR) was used to analyze samples of original mortars and those of mortars that have been added in previous building interventions (43). The results of these studies generally show the presence of coated based mortar of lime, hydraulic lime or cement mortar. Also show the use of materials of the archeological site (lava material, pumice, refractory material, etc.), creating coated or filled materials of cement nature with the presence of aggregates and other components of different composition.

Finally, the more worrying phenomenon for the future conservation of wall paintings was detected, that is the crystallization of soluble salts below the layer of polychrome. This phenomenon affects all paint layers and their visible effects are the appearance of large areas of polychrome with a dusty appearance (Figure 8 a) and detachment of the outermost layers of paint. By optic microscopy (Figure 8 b), it was observed that the crystallization was developed inside the supporting structure, causing the detachment of the more superficial layers (sub-efflorescence phenomenon). Note that after highlighting the existence of salts at the time of a future restoration will be required a comprehensive mapping of the area to determine specific areas of involvement.

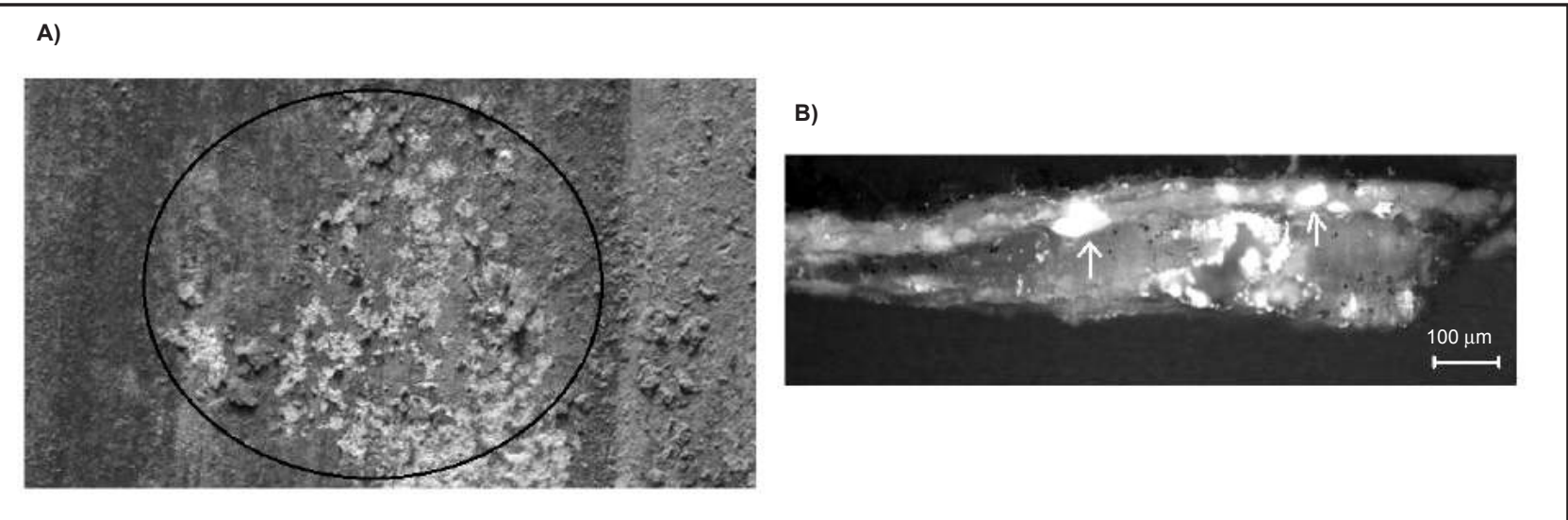

Figura 8. a) Detalle de la pintura mural presente en la casa de Ariadna en Pompeya. Se observa el fenómeno de alteración de la capa de policromía por cristalización de sales (círculo). b) Sección de una muestra de policromía roja por microscopía óptica (10x). Se observa la cristalización de sulfatos por debajo del estrato de policromía (flechas).

Figure 8. a) Detail of Ariadne's house mural painting in Pompeii. The alteration of the polychrome layer by crystallization of salts is observed (circle). b) Section of a sample of red polychromy by light microscope (10x). Crystallization of sulfates is observed below the stratum polychrome (arrows).

Las sales, que han sido caracterizadas mediante análisis XRD, están constituidas principalmente por sulfato de calcio hidratado (yeso), sulfato de sodio y sulfato de potasio, productos que suelen ser generados por la presencia de sulfatos de metales alcalinos $\left(\mathrm{Na}_{2} \mathrm{O}\right.$ y $\left.\mathrm{K}_{2} \mathrm{O}\right)$, presentes en los materiales de construcción y de restauración utilizados
The salts, which have been characterized by XRD analysis are mainly determined by the presence of calcium sulfate (gypsum), sodium sulfate and potassium sulfate, products that can be generated by the presence of alkaline salts $\left(\mathrm{Na}_{2} \mathrm{O}\right.$ and $\left.\mathrm{K}_{2} \mathrm{O}\right)$ in the building materials used in recent times (44) (gypsum, ettringite and thaumasite, which 
en los últimos tiempos (44) (yeso, ettringite y thaumasite, que se originan a través de la reacción del cemento Portland con los compuestos del azufre).

El deterioro que afecta a las pinturas murales de la casa de Ariadna, producido por la cristalización de sales, requiere la eliminación o la reducción de las contribuciones de estas soluciones salinas, es decir, la eliminación mecánica de los morteros utilizados en el pasado siglo para la consolidación estructural de las pinturas. Sin embargo, dado que estas pinturas murales se sitúan en su contexto original, en un sitio arqueológico al aire libre, las medidas para eliminar o reducir la concentración de contaminantes no son fáciles de aplicar ya que estos pueden provenir de las casas adyacentes o del suelo. Entre las soluciones que pueden retardar el proceso de deterioro se puede resaltar un control de los ciclos de cristalización y los mecanismos de evaporación de las soluciones salinas mediante el seguimiento de los parámetros ambientales y creación de barreras de humedad en las paredes de la casa para evitar la humectación por capilaridad.

Además resulta necesaria una intervención conservativa directa sobre las pinturas, para prevenir el desprendimiento de las capas de policromía mediante la aplicación de específicas metodologías de restauración, como pueden ser la pre-consolidación, los tratamientos de eliminación de sales y la consolidación de los estratos de color al soporte y su posterior protección.

En resumen, es importante destacar la necesidad de un seguimiento periódico de las intervenciones, a través de un control del estado de conservación de las pinturas (45, 46), el estudio del soporte (47) y la compatibilidad de los materiales de restauración con la obra y con los contaminantes del medioambiente.

\subsection{Fotografía}

Los resultados obtenidos con la fotografía de alta resolución digital, la fotografía de infrarrojos y la fotografía infrarroja de falso color, pueden ser muy útiles en la restauración. Con ellos se obtiene información que a menudo escapa a nuestra visión, especialmente si se complementa o combina con otras técnicas, como en este trabajo, como la reflectografía infrarroja, multiespectral, termografía, etc.

La fotografía Infrarroja en falso color es una técnica complementaria interesante para el estudio y caracterización de los objetos, en especial la identificación de pigmentos (35). La Figura 9 es útil para una explicación más detallada de esta técnica, donde se pueden ver más detalles y una mayor definición de las líneas y contornos que serían esenciales para una futura restauración. originate through the reaction of Portland cement with sulfur compounds).

The deterioration affecting Ariadne's house wall paintings, produced by salt crystallization, requires the elimination or reduction of the contributions of salt solutions, i.e. the mechanical removal of the mortars used in the past century for the structural consolidation of the paintings. However, since these wall paintings are placed at their original context, in an outdoor archaeological site, the measure to eliminate or reduce pollutant concentrations is not easy to apply as these can come from the adjacent houses or the floor. Among the solutions that can slow the deterioration process we may highlight a control of the evaporation-crystallization cycles through monitoring the environmental parameters and creating barriers to moisture in the walls of the house to prevent moisture by capillary.

Furthermore it is necessary a direct conservative intervention on frescoes, to prevent detachment of paint layers by applying specific restoration methodologies, such as pre-consolidation, salt elimination treatments and consolidation of the layers of color to its support and further protection.

Summarizing, it is important to emphasize the need for regular monitoring of interventions, through a control of the frescoes state of conservation $(45,46)$, the study of the support (47) and the compatibility of restoration materials with the work and environmental contaminants.

\subsection{Photography}

The results obtained with high resolution digital photography, IR photography and infrared false-color photography can be very useful in restoration. With them we get information that often eludes our vision especially if complemented or joined with other techniques like in this work, such as infrared reflectography, multispectral, thermography, etc.

Infrared false-color photography is a useful supplementary technique for the examination and characterization of objects, especially pigment identification (35). Figure 9 is useful for a more thorough explanation of this technique, where we can see more details and a greater definition of the lines and contours that would be essential in a future restoration. 


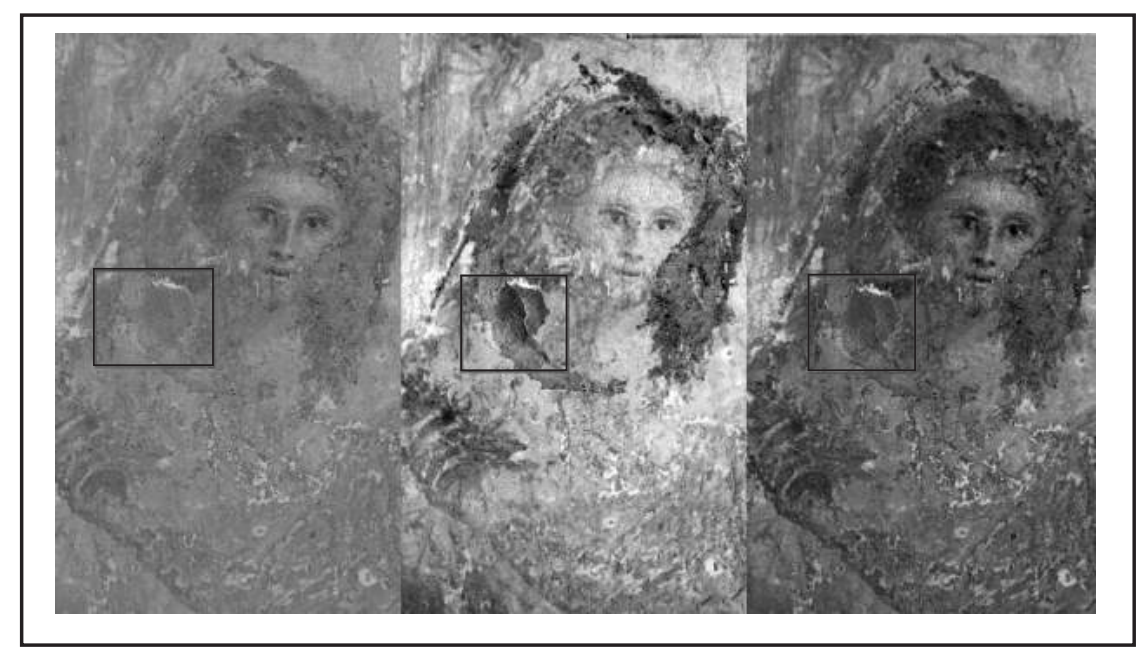

Figura 9. Comparación de reflectografía de infrarrojos. Esta figura nos permite apreciar sutilezas necesarias (por ejemplo, zona del cuadro negro) a fin de hacer juicios precisos sobre objetos arqueológicos. De izquierda a derecha: fotografía digital RGB, fotografía infrarroja (IR) y fotografía infrarroja de falso color (IR-RG).

Figure 9. Infrared reflectography comparison. This Fig. allows us to appreciate subtleties (e.g. the black square) needed in order to make accurate judgments about archeological objects. From left to right: digital RGB photography, infrared photography (IR) and false-color IR photography (IR-RG).

\section{CONCLUSIONES}

Los estudios desarrollados en este trabajo (estudios ambientales, las mediciones de radiación electromagnética, el estudio de los materiales y fotografía), permitió documentar el estado de conservación de la casa de Ariadna y la evaluación de los procedimientos más convenientes para una conservación preventiva, así como incrementar el conocimiento de los materiales utilizados en su construcción, su proceso pictórico y cuál ha sido el proceso de deterioro, para la discusión de una futura restauración.

Los estudios sugieren que el proceso de deterioro se ha acelerado debido a la cubierta transparente instalada. A continuación, se determinó que la cubierta óptima debe ser opaca y lo más aislada posible y, si es factible, que cubra las paredes y las puertas para impedir la entrada de agua de lluvia y la luz solar y elevar la cubierta un poco para lograr la ventilación de la habitación.

Así, la decisión sobre el cambio de los tejados fue tomada y en 2009-2010 fueron sustituidos. Como consecuencia, la variabilidad de las condiciones ambientales se ha reducido considerablemente y los valores se han aproximado a los óptimos.

El enfoque multidisciplinar ha sido fundamental para lograr el objetivo de este trabajo. El estudio de los materiales y el estudio fotográfico también han demostrado la importancia de controlar las condiciones ambientales a fin de detener el deterioro causado por la cristalización de sales, junto con la aplicación de técnicas específicas

\section{CONCLUSIONS}

The studies developed in this work (environmental study, electromagnetic radiation measurement, the study of materials and photography) allowed documenting the state of conservation of Ariadne's house and evaluating the most convenient procedures for a preventive conservation as well as increasing the knowledge about the materials used in its construction, its pictorial procedure and what has been the process of deterioration for the discussion of a future restoration.

The studies suggest that the deterioration process has been accelerated due to the transparent rooftop used. Then, it was determined that the optimal cover should be opaque and as isolated as possible and, if feasible, covering the walls and the doors to prevent the entry of rain water and sunlight and raising the deck a little to achieve the ventilation of the room.

Therefore the decision on changing the rooftops was taken and within 2009-2010 they were replaced. As consequence, the variability of the environmental conditions has been considerably reduced and the values have approximated to the optimal ones.

The multidisciplinary approach has been fundamental to achieve the goal of this work. The study of materials and the photographic study have also shown the relevance of monitoring the environmental conditions in order to stop the deterioration caused by salts crystallization, together with the application of specific techniques for fixing the 
para la fijación de la policromía, proporcionando conocimiento valioso para una posible restauración en el futuro. Además, estos estudios muestran el actual estado de las pinturas que posiblemente empeorará en el transcurso de los próximos años.

\section{AGRADECIMIENTOS}

Este trabajo fue parcialmente apoyado por el español "Ministerio de Ciencia e Innovación" en los proyectos HAR2010-21944-C02-01 y HAR2010-21944-C02-02. Los autores agradecen a J. Mínguez por sus correcciones gramaticales de inglés. polychrome, providing valuable knowledge for a possible restoration in the future. In addition, these studies reveal the current state of conservation of the frescoes that will get worse over the years.

\section{ACKNOWLEDGEMENTS}

This work was partially supported by the Spanish "Ministerio de Ciencia e Innovación" under projects HAR201021944-C02-01 and HAR2010-21944-C02-02. The authors are grateful to J. Mínguez for his English grammar corrections.

\section{BIBLIOGRAFÍA / BIBLIOGRAPHY}

(1) Pesando, F.: La Casa de Ariadna de Pompeya: redescubrimiento de una domus, in Ribera, A.; Olcina, M.; Ballester, C.; Pompeya bajo Pompeya, Las excavaciones en la Casa de Ariadna, Valencia, Spain (2007).

(2) Pesando, F.: Domus: edilizia privata e società pompeiana fra III e I secolo a.C. "L'Erma" di Bretschneider, Rome (1997).

(3) Kontozova-Deutsch, V.; Cardell, C.; Urosevic, M.; Ruiz-Agudo, E.; Deutsch, F.; Van Grieken, R.: "Characterization of indoor and outdoor atmospheric pollutants impacting architectural monuments: the case of San Jerónimo Monastery (Granada, Spain)", Environ Earth Sci, vol. 63 (2011) pp. 1433-1445, DOI: 10.1007/s12665-010-0657-5.

(4) Arnold, A.; Zehnder, K.: "Monitoring wall paintings affected by soluble salts". In The Conservation of Wall Paintings, 2nd ed.; Cather, S., Ed.; Courtauld Institute of Art and the Getty Conservation Institute: London, UK (1996); pp. 103-136.

(5) La Gennusa, M.; Rizzo, G.; Scaccianoce, G.; Nicoletti, F.: "Control of indoor environments in heritage buildings: Experimental measurements in an old Italian museum and proposal of a methodology", J. Cult. Herit., vol. 6 (2005) pp. 147-155, doi: 10.1016/j. culher.2005.03.001.

(6) Ariño, X.; Saiz-Jiménez, C.: "Deterioration of the Elephant Tomb (Necropolis of Carmona, Seville, Spain)", Int. Biodeter. Biodegr., Vol. 40 (1997) 233-239, doi: 10.1016/S0964-8305(97)00034-6.

(7) Miriello, D.; Barca, D.; Bloise, A.; Ciarallo, A.; Crisci, G.M.; De Rose, T.; Gattuso, C.; Gazineo, F.; La Russa, M.F.: "Characterisation of archaeological mortars from Pompeii (Campania, Italy) and identification of construction phases by compositional data analysis", J. Arch. Sci., vol. 37 (2010), pp. 2207-2223, doi: 10.1016/j.jas.2010.03.019.

(8) Volpin, S.; Appolonia. L.: Le analisi di laboratorio applicate ai beni artistici policromi. Collana i Talenti, Il Prato (1999).

(9) Creagh, D.; Bradley, D.: Radiation in Art and Archeometry. Elsevier, Amsterdam (2000).

(10) Van der Weerd, J.; Van Veen, M.K.; Heeren, R.M.A.; Boon, J.J.: "Identification of pigments in paint cross sections by reflection visible light imaging microspectroscopy". Analytical Chemistry 75 (4) (2003), pp. 716-722.

(11) Nevin, A.; Melia, J.L.; Osticioli, I.; Gautier, G.; Colombini, M.P.: "The identification of copper oxalates in a 16th century Cypriot exterior wall painting using micro FTIR, micro Raman spectroscopy and Gas Chromatography-Mass Spectrometry", J. Cult. Herit. , vol. 9 (2008), pp. 154-161, doi: 10.1016/j.culher.2007.10.002.

(12) Ferro, D.: La microscopia elettronica a scansione per la storia,per l'arte, per la conservazione. Istituto Centrale per la Patologia del Libro, Roma (2007).

(13) Botticelli. G.: Metodologia e Restauro delle Pitture Murali. Edizioni Centro Di, Firenze (1992).

(14) Mora, P.; Mora, L.; Philippot, P.: La conservazione delle pitture murali. Editrice Compositori, Bologna (2002).

(15) Martinez, M.C.I.; Seoane, A.N.; Romani, J.R.V.: "Study of the deterioration of the ancient stone walls of San Antolin de Toques in Gali$\mathrm{cia}$, Spain, and the influence of the substitution of traditional lime mortars", Proceedings of the 19975 th International Conference on Structural Studies, Repairs and Maintenance of Historical Buildings, STREMAH V; San Sebastian, Spain; Code46967. Vol. 3 (1997), pp 221-231.

(16) Augusti. S.: La tecnica del'antica pittura parietale pompeiana. Gaetana Macchiaroli Editore, Nápoles (1950).

(17) Plinio. C. S.: Historia Naturelle. Eds. Capps, E., Rouse, W. N. D., Post, L. A. y Warmington, E. H., in The Loeb Classical libraty. William Heinermann Ltd., Harvard University Press, Cambridge, Mass. (1958-1966).

(18) Vitruvio. M. L.: De Architectura Libri Decem. Edición crítica por S. Ferri. Fratelli Palombi. Roma (1960).

(19) Maltese. C.: Las técnicas artísticas. Ediciones Cátedra, S.A. Madrid (1985).

(20) Genestar, C.; Pons, C.; Más, A.: "Analytical characterisation of ancient mortars from the archaeological Roman city of Pollentia (Balearic Islands, Spain)". Analytica Chimica Acta 557 (2006), pp. 373-379. 
(21) Castriota, M.; Cosco, V.; Barone, T.; De Santo, G.; Carafa, P.; Cazzanelli, E.: "Micro-Raman characterizations of Pompei'smortars". Journal of Raman Spectroscopy 39 (2) (2008), pp. 295-301.

(22) Maguregui, M.; Knuutinen, U.; Castro, K.; Madariaga, J.M.: "Raman spectroscopy as a tool to diagnose the impact and conservation stateof Pompeian second and fourth style wall paintings exposed to diverseenvironments (House of Marcus Lucretius)". Journal of Raman Spectroscopy 41 (11) (2010), pp. 1400-1409.

(23) Durán, A.; Pérez-Maqueda, L.A.; Poyato, J.; Pérez-Rodríguez, J.L.: "A thermal study approach to roman age wall painting mortars". J Therm Anal Calorim 99 (3) (2010), pp. 803-809.

(24) Pérez, C.; Ferrazza, L.; Doménech, M.; Sarrió, F.; Ribera, A.: Las pinturas murales de la Casa de Ariadna en Pompeya: Un ejemplo de estudio e investigaciones científicas aplicados en el proyecto de conservación y restauración, La Ciencia y el Arte II, Ciencias experimentales y conservación del Patrimonio Histórico, Ministerio de Cultura, Madrid, Spain (2010).

(25) Andreas; Kon, Z.: "Monitoring wall paintings affected by soluble salts". The conservation of wall paintings: proceedings of a symposium organized by the Courtald Institute of Art and the Getty Conservation Institute, London, july 13-16 (1987).

(26) Peña-Poza, J., Conde, J.F., Palomar, T., Agua, F., García-Heras, M., Villegas, M.A.: "Environmental evaluation of the holdings at the CCHS-CSIC Tomás Navarro Tomás library", Revista Espanola de Documentacion Cientifica, vol. 34 (2011), pp. 65-78, doi: 10.3989/redc.2011.1.774.

(27) Zarzo, M.; Fernández-Navajas, A.; García-Diego, F.: "Long-term monitoring of fresco paintings in the cathedral of Valencia (Spain) through humidity and temperature sensors in various locations for preventive conservation", Sensors, vol. 9 (2011), pp. 8685-8710, doi: 10.3390/s110908685.

(28) Grinzato, E.; Bressan, C.; Marinetti, S.; Bison, P.G.; Bonacina, C.: "Monitoring of the Scrovegni Chapel by IR thermography: Giotto at infrared", Infr. Phys. Tech., vol. 43 (2002), pp. 165-169, doi: 10.1016/S1350-4495(02)00136-6.

(29) Palombi, L.; Cecchi, G.; Lognoli, D.; Raimondi, V.; Masotti, L.: "A fluorescence imaging lidar for the control of cultural heritage", Proceedings of SPIE - The International Society for Optical Engineering, vol. 6750 (2007), art. no. 675002, doi: 10.1117/12.739680.

(30) Bonizzoni, L.; Caglio, S.; Galli, A.; Poldi, G.: "Comparison of three portable EDXRF spectrometers for pigment characterization", X-Ray Spectrom., vol. 39 (2010) pp. 233-242, doi: 10.1002/xrs.1253.

(31) López, M.C.; Medina, V.J.; Adroher, A.M.; García, A.: "Estudio de materiales y técnica de ejecución de los restos de pintura mural romana hallados en una excavación arqueológica en Guadix (Granada)", Espacio, Tiempo y Forma, Serie I, Prehistoria y Arqueología, vol. 13 (2000), pp. 253-278.

(32) Edreira, M.C.; Feliu, M.J.; Fernández-Lorenzo, C.; Martín, J.: "Roman wall painting characterization from Cripta del Museo and Alcazaba in Mérida (Spain): chromatic, energy dispersive X-ray fluorescence spectroscopic, X-ray diffraction and Fourier transform infrared spectroscopic analysis", Analyt. Chim. Acta, vol. 434 Issue 2 (2001), pp. 331-345, doi: 10.1016/S00032670(01)00847-9.

(33) Schirripa, G.: "Virtual restoration: detection and removal of craquelure in digitized image of old paintings", Proceedings of SPIE - The International Society for Optical Engineering 8084, 2011, art. no. 80840B, doi: 10.1117/12.888299.

(34) Dellepiane, M.; Venturi, A.; Scopigno, R.: "Image guided reconstruction of un-sampled data: a filling technique for cultural Heritage models", Int. Journal of Computer Vision, Vol. 94 (2011) pp. 2-11, doi: 10.1007/s11263-010-0382-2.

(35) Moon, T.; Schilling, M.R.; Thirkettle, S.: "A note on the use of false-color infrared photography in conservation", Stud. Conservat., vol. 37 (1992), pp. 42-52.

(36) Klein, M.E.; Aalderink, B.J.; Padoan, R.; De Bruin, G.; Steemers, T.A.G.: "Quantitative hyperspectral reflectance imagining", Sensors, vol. 8 (2008) pp. 5576-5618, doi: 10.3390/s8095576.

(37) Veniale, F.; M.; Setti, M.; Lodola, S.: "Diagnosing stone decay in built heritage. Facts and perspectives" Mater. Constr., vol. 58, n0289 (2008), doi: 10.3989/mc.2008.v58.i289-290.85.

(38) Liu, B.; Chen, X.; Fang, D.; Perrone, A.; Pispas, A.; Vainos, N.A.: "Environmental monitoring by thin film nanocomposite sensors for cultural heritage preservation", Jour. Alloys Comp., vol. 504 (2010) S405-S409, doi: 10.1016/j.jallcom.2010.02.147.

(39) UNI 10829. Works of Art of Historical Importance. Ambient Conditions for the Conservation. Measurement and Analysis; UNI Ente Nazionale Italiano di Unificazione: Milano, Italy, 1999.

(40) ASMETEC. Meteolite UV 400 description of UV-filter-sleeves UV-400. www.asmetec.de (2011).

(41) Gurioli, L.; Cioni, R.; Sbrana, A.; Zanella, E.: "Transport and deposition of pyroclastic density currents over an inhabitated area: the deposits of the AD 79 eruption of Vesuvius at Herculaneum, Italy". Sedimentology, 49 (5) (2002), pp. 929-953.

(42) Selim, A.: I colori pompeiani, Rome, 1967.

(43) Corpora, H.; Quaresima, R.: Malte storiche e da restauro: stato dell 'arte, considerazioni e prospettive alla luce della normativa esistente. Edizioni Il prato, Padova (2007).

(44) Baglioni, P.; Bitossi, G.; Fratini, F.; Rescic, S.; Dei, L.: "Salt crystallization in porous materials: physicochemical aspects and effects of antiscaling additives". Proceedings: Science and technology for cultural heritage - Atti II Convegno naz. Chmica dei beni culturali della Società Chimica Italiana - Torino 23-26 giugno 2003- Istituti editoriali e poligrafici internazionali MMIV. 
(45) Castellano, A.; Cesareo, R.; Buccolieri, G.; Donativi, M.; Palama, F.; Quarta, S.; De Nunzio, G.; Brunetti, A.; Marabelli, M.; Santamaria, U.: "Detection of detachments and inhomogeneities in frescos by Compton scattering", Nucl Instrum Meth A, vol. 234 (2005), pp. 548-554, doi: 10.1016/j.nimb.2005.02.012.

(46) Zehnder. K.: "Long term monitoring of wall painting affected by soluble salts". Environmental Geology 52 (2) (2007), pp. 395-409.

(47) García-Diego, F. J.; María Bravo, J.; Pérez-Miralles, J.; Estrada, H.; Fernández-Navajas, A.: "Development of a low-cost airborne ultrasound sensor for the detection of brick joints behind a wall painting", Sensors, vol. 12 (2012), pp. 1299-1311, doi: $10.3390 /$ s120201299. 



\title{
Synthesis and Characterization of Nanostructured $\mathrm{BaO}$ Solutions: Application in Conservation of Wall Paintings
}

\author{
Elisa Cordoncillo ${ }^{1}$, T.R. Machado ${ }^{1}$, L. Ferrazza ${ }^{2}$, and David Juanes ${ }^{2}$ \\ ${ }^{1}$ Departamento de Química Inorgánica y Orgánica, Universitat Jaume I de Castellón, \\ Campus del Riu Sec, E-12071, Castellón de la Plana, Spain \\ (cordonci, machado) @qio.uji.es \\ ${ }^{2}$ Laboratorio Materiales, Instituto Valenciano de Conservación y Restauración de Bienes \\ Culturales, C/ Genaro Lahuerta $\mathrm{n}^{\circ} 25-3^{\circ}, 46010$, Valencia, Spain \\ (djuanes, lferrazza) @iver.es
}

\begin{abstract}
This paper shows a study about the preparation and characterization of nanostructured $\mathrm{BaO}$ suspensions and their evaluation as consolidant products for lime stone supports. Product preparation was made by chemical synthesis of coprecipitation in non-aqueous solutions of barium acetate $\left[\mathrm{Ba}\left(\mathrm{CH}_{3} \mathrm{CO}_{2}\right)_{2}\right]$ and sodium hydroxide $[\mathrm{NaOH}]$ reagents, with the use of ethylene glycol as a reaction medium. The nanoparticles were characterized by transmission electron microscopy (TEM) showing that all syntheses carried out with different experimental conditions gave a $20-50 \mathrm{~nm}$ particle size. This paper also evaluated the first results on the application of synthesized $\mathrm{BaO}$ on samples of wall paintings by optical microscopy (OM), scanning electron microscopy (SEM-EDX) and colorimetry. The results indicate that the nanostructurated $\mathrm{BaO}$ products may have a protection or pre-consolidation function on wall paint layers. The superficial application of the product forms a thin layer, compatible with the chemical nature of the wall painting and produces a consolidating action, on the surface.
\end{abstract}

Keywords: Colloidal suspensions, Nanoparticles, $\mathrm{BaO}$, Coprecipitation synthesis, Wall paintings, Consolidant.

\section{Introduction}

The materials used in architectural, sculptural or mural cultural heritage are subject to numerous causes of deterioration. An important aspect in the conservation of this cultural property is the consolidation treatment that restores and enhances the strength of the matter encountered. The ideal products should be physical-chemical compatible with the properties of the materials in the works of art where they are being applied.

Consolidant products based on inorganic elements such as aqueous solutions of calcium hydroxide or barium hydroxide, show high physical-mechanical compatibility with the stone supports, as in the case of mural paintings. These products produce carbonate precipitations inside the structure of the material, binding the particles or the different components of the support and creating a consolidating action. 
In recent years, the field of nanomaterials has focused its attention on the research of new inorganic consolidants based on dispersions of calcium hydroxide or barium hydroxide in nonaqueous solvents. The synthesis of new nanomaterials has enhanced possibilities in the consolidation of wall paintings using products with a high affinity with the material of the artwork [1].

Consolidation with barium hydroxide has the advantage of the great chemicalphysical compatibility of barium carbonate with the components of the mortar and stone supports, minimizing the degradation action by sulphates [2]. The aim of this study on the synthesis of nanostructured barium oxide is to develop a product with viable applications in the consolidation treatment of wall paintings. Initially, it reacts with water giving $\mathrm{Ba}(\mathrm{OH})_{2}$, an intermediate product, and a subsequent reaction with carbon dioxide produces the formation of $\mathrm{BaCO}_{3}$. The development of a consolidant product containing barium, allows us to evaluate the penetration in the mural support, usually consisting of $\mathrm{CaCO}_{3}$, by SEM-EDX. This last point is important for cultural heritage conservation since the knowledge of the amount of the consolidant's penetration inside the structure allows us to evaluate the effectiveness of the treatment and the appropriate conservation of the work in time.

\section{Experimental Section}

\subsection{Colloidal Suspensions of BaO}

The colloidal suspensions of $\mathrm{BaO}$ were obtained by coprecipitation synthesis [3], [4]. The research was focused on the study of the synthesis conditions in nonaqueous solvents, due to the high solubility of the hydroxide and barium oxide in water [5]. $\mathrm{BaO}$ colloidal particles were synthesized dissolving the precursor of barium, $\mathrm{Ba}\left(\mathrm{CH} 3 \mathrm{CO}_{2}\right)_{2}(\mathrm{ABCR} \mathrm{GmbH} \& \mathrm{Co} ., 99 \%$ purity) in ethylene glycol (Sigma-Aldrich, $99.5 \%$ purity) in soft shaking at $25^{\circ} \mathrm{C}$. Subsequently, sodium hydroxide $\mathrm{NaOH}$ (Baker, $98.6 \%$ purity) was added and dissolved in ethylene glycol to obtain a basic medium in the solution and to help the formation of nanometric particles in the system. The solvent used, also acts as a surfactant, preventing the agglomeration of the synthesized product. Different tests were made at different concentrations of the precursor (Table 1), to observe how they affected the concentrations of reactants in the particle size [6].

The characterization of crystalline phases and the morphological and dimensional particles was made by transmission electron microscopy (TEM) with a 2100 JOEL microscope equipped with EDX spectrometer INCA Energy TEM (Oxford). The images (Fig. 1) show the morphology of the nanoparticles of barium oxide. They have a spherical shape with a diameter of 20 to $50 \mathrm{~nm}$.

The identification of the crystalline phase was carried out with digital diffraction patterns (dap-D), and Digital Micrograph software. The real space was obtained from TEM images (Fig. 2) and by Fourier's transform, the reciprocal space was calculated. This provides the digital diffraction pattern of sample and the lattice parameters (angles and spacing) were obtained comparing with the theoretical crystal lattice 
parameters of barium oxide. We calculated the values of $\mathrm{d}_{\mathrm{hkl} 1}=2.79 \AA, \mathrm{d}_{\mathrm{hkl} 2}=3.08 \AA, \alpha$ $=52.12^{\circ} ; \mathrm{d}_{\mathrm{hk} 12}=3.08 \AA, \mathrm{d}_{\mathrm{hk} 13}=3.25 \AA, \alpha=71.56^{\circ}$. These experimental values were compared with theoretical crystal lattice parameters of $\mathrm{BaO}: \mathrm{d}_{\mathrm{hkl} 1}=2.76 \AA(200), \mathrm{d}_{\mathrm{hkl} 2}=$ $3.19 \AA$ (11-1), $\alpha=54.74^{\circ} ; \mathrm{d}_{\mathrm{hkl} 2}=3.19 \AA(11-1), \mathrm{d}_{\mathrm{hk} 13}=3.19 \AA$ ( -11 to 1$) \alpha=70.53^{\circ}$.

Table 1. Experimental conditions for the coprecipitation synthesis

\begin{tabular}{c|ccc}
\hline Synthesis & Precursors & Ethylene glycol & pH \\
\hline \multirow{6}{*}{ I } & $\mathrm{Ba}(\mathrm{ac})_{2} 1 \mathrm{~g}$ & $20 \mathrm{ml}$ & \multirow{6}{*}{ II } \\
& $\mathrm{NaOH} \mathrm{0,3} \mathrm{g}$ & $20 \mathrm{ml}$ & \\
& $\mathrm{Ba}(\mathrm{ac})_{2} 2 \mathrm{~g}$ & $20 \mathrm{ml}$ & 13,16 \\
& $\mathrm{NaOH} 1,2 \mathrm{~g}$ & $40 \mathrm{ml}$ & \\
III & $\mathrm{Ba}(\mathrm{ac})_{2} 4 \mathrm{~g}$ & $20 \mathrm{ml}$ & 13,36 \\
& $\mathrm{NaOH} \mathrm{1,2 \textrm {g }}$ & $20 \mathrm{ml}$ & \\
\hline
\end{tabular}
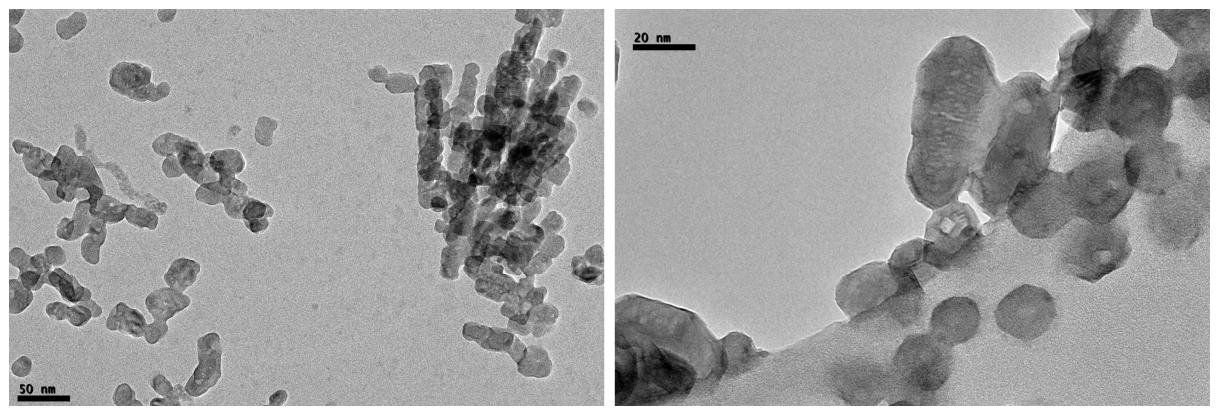

Fig. 1. Clusters of barium oxide nanoparticles prepared through a coprecipitation reaction in ethylene glycol, recorded by means of transmission electron microscopy (TEM)

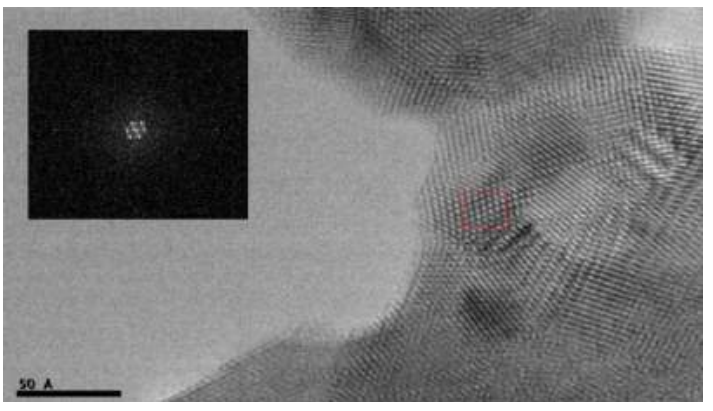

Fig. 2. TEM image of barium oxide nanoparticles and digital diffraction pattern corresponding to the selected area 


\section{Results and Discussion}

\subsection{Evaluation of the Treatment with $\mathrm{BaO}$ Nanoparticles on Wall Painting}

The evaluation of $\mathrm{BaO}$ synthesized as a consolidant product was studied on unrecovrable wall painting fragments containing different layers of colours on the lime support. We selected $1 \mathrm{~cm}^{2}$ areas of different colours and mortars to study the consolidation, fixation and the carbonation process of the $\mathrm{BaO}$ suspensions in ethylene glycol (Fig. 3).

These fragments are composed almost entirely of calcium carbonate, the material used in the pictorial arts of the ancient world. Based on the intrinsic characteristics of this material, calcium carbonate is susceptible to various agents of deterioration, with consequent loss of cohesion and adhesion of the material. One of the most evident deterioration processes of these paintings is the powdery appearance of the colors (Fig. 4).

These initial studies led us to verify the product distribution on the surface of the fragments and inside the structure of the mural painting, in order to evaluate the adhesive and cohesive action of the product and to analyze colour changes in the consolidated areas.

We used a scanning electron microscope of high resolution (HR-SEM) model JEOL $7001 \mathrm{~F}$ coupled to EDX OXFORD $\mathrm{Si}(\mathrm{Li})$ and variable pressure scanning electron microscope (VP-SEM) Hitachi S-3400N coupled to EDX BRUKER model with XFlash ${ }^{\circledR}$ Silicon drift detector (SDD). The study of the carbonation process was made by X-ray diffraction (XRD) with a powder diffractometer Bruker-AXS with D4 Endeavor. We used a Konica Minolta Spectrophotometer CM-700D for the colorimetric analysis.

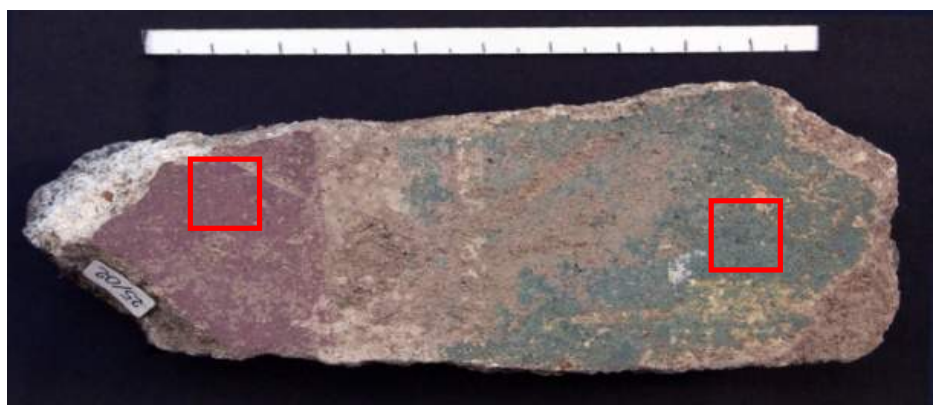

Fig. 3. One of the fragments of mural paintings used in the evaluation of the product. The fragments are from the House of Ariadne in Pompeii (Italy) (first century AD). Marked areas correspond to areas treated with the colloidal suspension based on barium oxide.

\subsection{Surface Wall Painting Evaluation}

Different painted surfaces were studied before and after application of the colloidal suspension by one brushstroke. We used the electron microscopy images (Fig. 5) to compare the areas before and after the consolidation process. We could observe a 


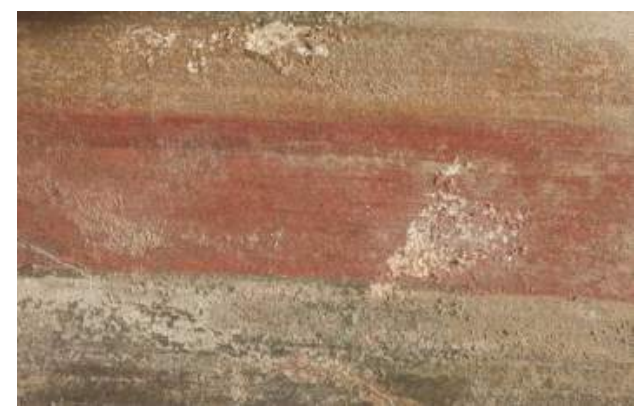

Fig. 4. Pompeian wall painting that presents the degradation phenomena of paints layers
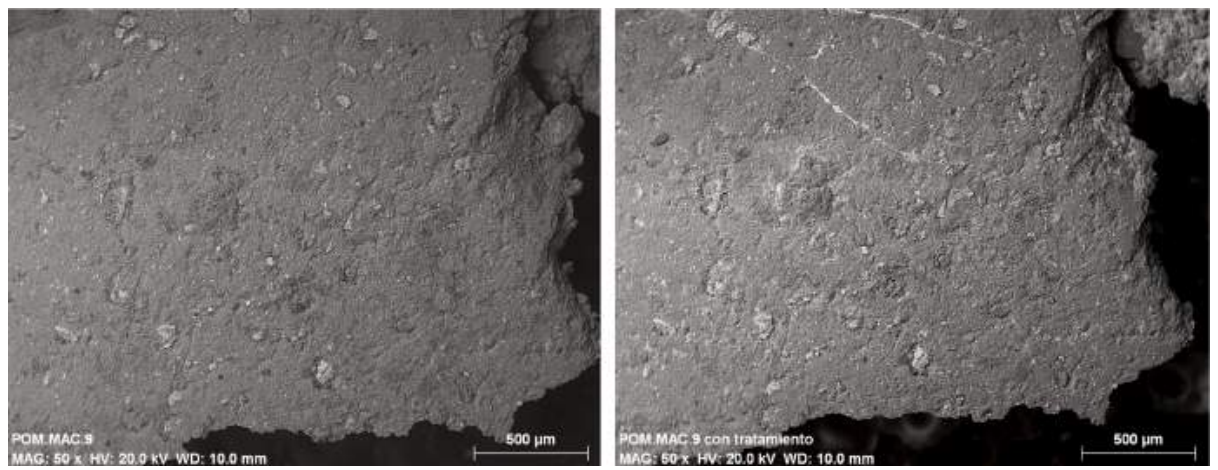

Fig. 5. SEM micrographs of the surface of wall painting specimens before the treatment and after the treatment

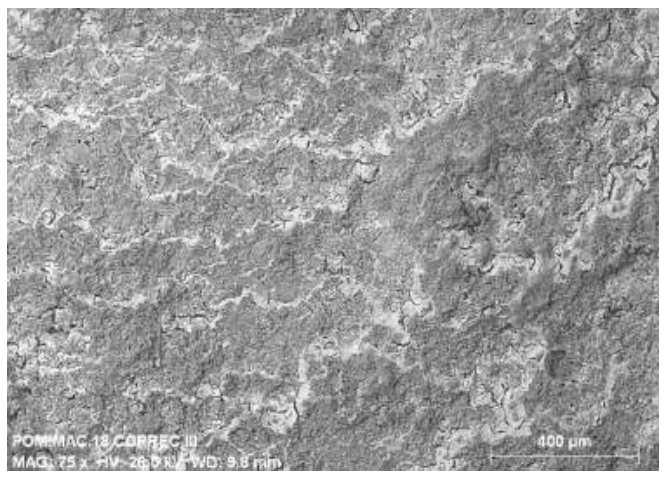

Fig. 6. SEM micrographs of the surface of wall painting with the treatment

homogeneous distribution of barium, without significant alterations of the surfaces. However, other areas showed some alterations of the painted surface (Fig. 6) where the product was not homogeneous on the surface and its thickness was larger. This problem is due to the morphological characteristics of the surface and to the viscosity of the ethylene glycol. This high viscosity limited the diffusion and penetration of the consolidant product within the mortar. 


\subsection{Evaluation of the Surface's Lime Mortar}

The product evenly coats the mortar's structure leaving the pores uncoated (Fig. 7, left), resulting in an appropriate treatment that strengthens the structure without turning the surface waterproof.

The cross-section study (Fig. 7, right) revealed a thin and uniform layer composed of barium on the painted surface and the outside of the mineralogical components of the mortar, probably making an adhesive, cohesive and protection layer. The penetration of barium oxide in the mortar is small, reaching $350-400 \mu \mathrm{m}$ approximately.
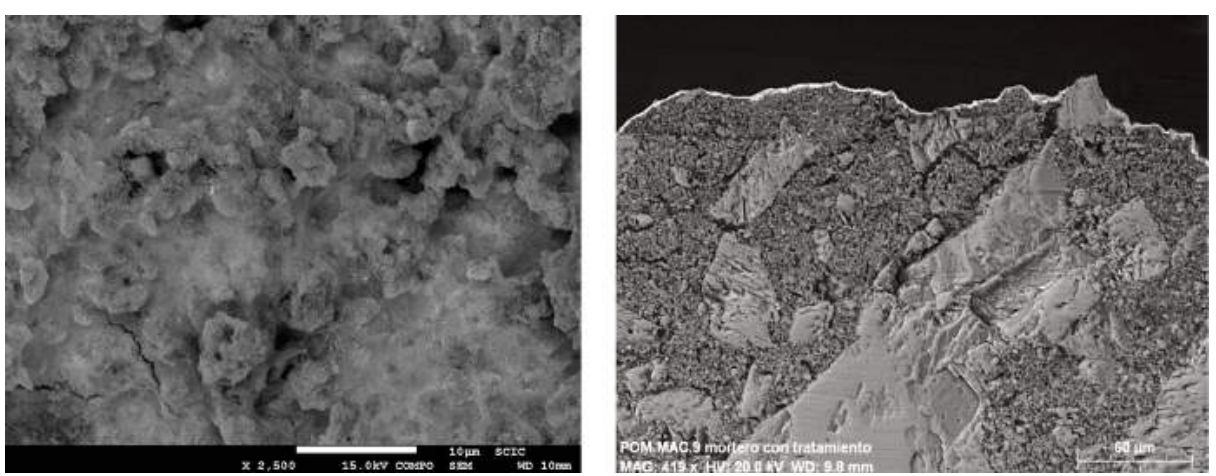

Fig. 7. (Left) SEM micrographs of the lime mortar with the treatment. (Right) SEM image in backscattered electron mode of the structure of the mortar after treatment.

\subsection{Colorimetric Study}

Colorimetric study was made before and after application of the dispersion of barium oxide. CIEL $* a * b *$ coordinates were obtained and the variations of the colour coordinates and colour difference were calculated (Table 2). There were small colour variations, except on red areas that present an increased depth and brightness of colour after the product application. The white painted areas show a negative value of the brightness $\left(\Delta \mathrm{L}^{*}\right)$ and a small increase of the parameters $\mathrm{a}^{*}$ and $\mathrm{b}^{*}$, generating a slight yellowing probably due to residues of the solvent or accumulation of barium.

Table 2. Variations of the colorimetric coordinates and change of colour after treatment

\begin{tabular}{|c|c|c|c|c|}
\hline Colour & $\boldsymbol{\Delta} \boldsymbol{L}^{*}$ & $\boldsymbol{\Delta} \boldsymbol{a}^{*}$ & $\boldsymbol{\Delta} \boldsymbol{b}^{*}$ & $\boldsymbol{\Delta \boldsymbol { E } ^ { * }}$ \\
\hline White & $-0,22$ & 0,26 & 0,31 & 0,46 \\
Light red & 3,38 & $-2,31$ & $-3,76$ & 5,56 \\
Dark red & 3,68 & $-4,96$ & $-5,48$ & 8,26 \\
Purple & $-0,83$ & 0,40 & $-2,53$ & 2,69 \\
Blue & 0,61 & 0,09 & $-1,13$ & 1,29 \\
Green & $-0,64$ & 0,36 & 5,73 & 1,68 \\
\hline
\end{tabular}


Restoration processes should not cause a colour difference $\Delta \mathrm{E}^{*}$ greater than 5 [7]. The different painted areas show $\Delta \mathrm{E}^{*}$ less than 3 , except in red, so that the tested product does not change significantly the colorimetric parameters [8], [9]. The red areas show an $\Delta \mathrm{E}^{*}$ value greater than 5 , so the treatment causes a colour parameter variation not acceptable from a conservation point of view for works of art.

\section{Conclusion}

This study shows that colloidal suspensions based on $\mathrm{BaO}$ nanoparticles can be obtained by coprecipitation synthesis in ethylene glycol. TEM characterization shows spherical shaped particles with dimensions between 20-50 nm.

The nanostructured $\mathrm{BaO}$ dispersed in ethylene glycol, has been applied as a fixative and a consolidating product on unrecoverable wall painting fragments, in order to evaluate the protective and consolidation treatment of materials during the process of carbonation and formation of $\mathrm{BaCO}_{3}$. The results have been quite positive. The product applied acts as a protector of the surface layers and has adhesive and cohesive functions in the constituents of the wall paint.

The application of this treatment has not produced any significant differences of the colour of the surfaces. Colorimetric parameter variations have been detected by the presence of residual products of the treatment. In this case the drawback may be due to the organic solvent employed in the synthesis and the accumulation on the polychrome surface irregularities of barium oxide. Based upon these initial results, it can be concluded that the treatment may be adequate for the protection or preconsolidation of the painted surfaces, and compatible with the chemical nature of the work of art.

It is an ongoing project. We are testing new less viscous solvents to allow greater penetration of nanostructured $\mathrm{BaO}$ in the interior of the wall paintings and stone supports.

Acknowledgments. Financial support is gratefully acknowledged form the Spanish "I+D+I MICINN" project HAR2010-21455.

The authors wish to thanks a Carmen Pérez García, Director Manager of the Instituto Valenciano de Conservación y Restauración de Bienes Culturales (Valencia, Spain), to the SIAM (Sección de Arqueología Municipal of the Valencia, Spain) and to the Servei Central d'Instrumentació Científica of the Universitat Jaime I de Castellón, Spain.

\section{References}

1. Giorgi, R., Baglioni, M., Berti, D., Baglioni, P.: New Methodologies for the Conservation of Cultural Heritage: Micellar Solutions, Microemulsions, and Hydroxide Nanoparticles. Accounts of Chemical Research 43, 695-704 (2010) 
2. Giorgi, R., Ambrosi, M., Toccafondi, N., Baglioni, P.: Nanoparticles for Cultural Heritage Conservation: Calcium and Barium Hydroxide Nanoparticles for Wall Painting Consolidation. Chemistry - A European Journal 16, 9374-9382 (2010)

3. Mahamuni, S., Bendre, B.S., Baruah, T., Kshirsagar, A., Joshi, S.S., Bedekar, A.G., Patil, S.F., Singh, P., Maiti, K., Sarma, D.D.: Studies on BaO particles in nanosize regime. Nanostructured Materials 7, 557-564 (1996)

4. Koch, U., Fojtik, A., Weller, H., Henglein, A.: Photochemistry of semiconductor colloids. Preparation of extremely small $\mathrm{ZnO}$ particles, fluorescence phenomena and size quantization effects. Chemical Physics Letters 122, 507-510 (1985)

5. Rodrigues, J.D., Grossi, A.: Indicators and ratings for the compatibility assessment of conservation actions. Journal of Cultural Heritage 8, 32-43 (2007)

6. Mahamuni, S., Khosravi, A.A., Kundu, M., Kshirsagar, A., Bedekar, A., Avasare, D.B., Singh, P., Kulkarni, S.K.: Thiophenol-capped ZnS quantum dots. Journal of Applied Phsics 73 (1993)

7. 20/85, N.: Interventi conservativi: progettazione esecuzione e valutazione preventive. CNR-ICR, Milan (1996)

8. Grossi, C.M., Brimblecombe, P., Esbert, R.M., Alonso, F.J.: Color changes in architectural limestones from pollution and cleaning. Color Research \& Application 32, 320-331 (2007)

9. Benavente, D., Martínez-Verdú, F., Bernabeu, A., Viqueira, V., Fort, R., García del Cura, M.A., Illueca, C., Ordóñez, S.: Influence of surface roughness on color changes in building stones. Color Research \& Application 28, 343-351 (2003) 
